\title{
Untersuchung der Querkrafttragfähigkeit von schlaff bewehrten und vorgespannten Mauerwerkbalken mittels Schubspannungsfeldmodellen
}

\author{
Von der \\ Fakultät Architektur, Bauingenieurwesen und Umweltwissenschaften \\ der Technischen Universität Carolo-Wilhelmina \\ zu Braunschweig
}

zur Erlangung des Grades eines

Doktor-Ingenieurs (Dr.-Ing.)

genehmigte

Dissertation

von

Johann Jakob Marx

geboren am 28.01.1988

aus Bielefeld

Eingereicht am

17. September 2019

Disputation am

28. Oktober 2020

Berichterstatter

Prof. Dr.-Ing. Harald Budelmann

Prof. Dr.-Ing. Erhard Gunkler 



\section{Vorwort}

Die vorliegende Arbeit entstand während meiner Tätigkeit als wissenschaftlicher Mitarbeiter im Lehrgebiet Baustoffe und Massivbau des Fachbereichs 3 „Bauingenieurwesen und Wirtschaftsingenieurwesen-Bau“ an der Hochschule Ostwestfalen-Lippe.

Die Fragestellung ergab sich durch wissenschaftliche Forschungsaktivitäten im Bereich des Mauerwerkbaus, die ich im Rahmen von Zulassungsentwürfen und Gutachten durchgeführt habe. Ergänzende experimentelle Untersuchungen wurden finanziell durch ein Forschungsförderungsprogramm der Hochschule Ostwestfalen-Lippe sowie durch geldwerte Leistungen verschiedener regionaler Unternehmen gefördert.

Die vorliegende Arbeit wurde durch Herrn Prof. Dr.-Ing. Harald Budelmann betreut. Ihm bin ich für seine fachliche Unterstützung und konstruktiven Gespräche sowie für die Übernahme des Hauptreferats zu besonderem Dank verpflichtet.

Im Besonderen danke ich Herrn Prof. Dr.-Ing. Erhard Gunkler, der das Korreferat übernommen hat. Seine fachlichen Anregungen, Hinweise, Diskussionsbereitschaft und sein stetiges Interesse an meiner Arbeit haben zu einem großen Teil zur Anfertigung der vorliegenden Arbeit beigetragen.

Darüber hinaus möchte ich mich bei dem Fachbereich 3 der Hochschule Ostwestfalen-Lippe sowie bei den Mitarbeitern für die stetige Unterstützung und gute Zusammenarbeit bedanken. Dieser Dank gilt ebenfalls den studentischen Hilfskräften, die mich im Rahmen meiner experimentellen Untersuchungen unterstützt haben.

Ein Blick in die Vergangenheit zeigt, dass bereits 1836 wissenschaftliches Interesse an der Tragfähigkeit bewehrter Mauerwerkbalken bestand.
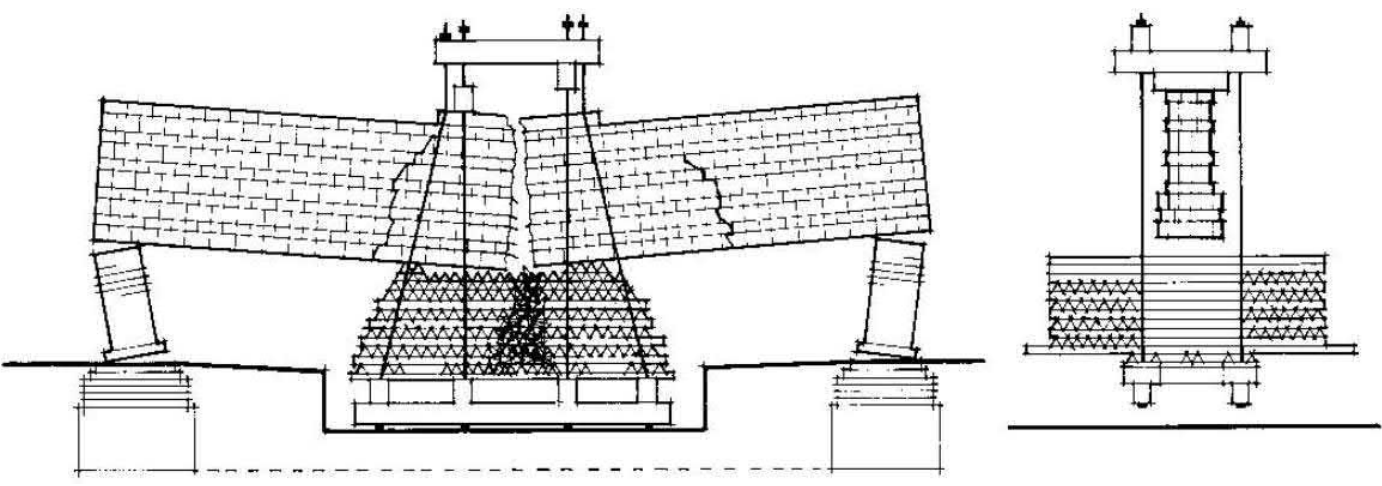

Nine Elms Reinforced Masonry Beam tested by Sir Marc Brunel in the period between 1836 - 1838

(Roberts et al. 1986) 



\section{Inhaltsverzeichnis}

1 Einleitung 1

1.1 Problemstellung und Zielsetzung 1

1.2 Gliederung der Arbeit 2

2 Grundlagen und „Stand der Forschung“ von Mauerwerkbalken 3

2.1 Unterscheidungsmerkmale 3

2.2 Bewehrungsanordnung und Konstruktionsarten 3

2.2.1 Flachsturz 4

2.2.2 Fertigteilsturz $\quad 5$

$\begin{array}{lll}\text { 2.2.3 Vorgespannte Mauerwerkbalken } & 6\end{array}$

2.2.4 Balkenkonstruktionen für Vormauerwerk und/ oder Verblendmauerwerk 7

2.3 Abgrenzung von Mauerwerkbalken gegenüber wandartigen Trägern aus Mauerwerk 7

2.4 Ergebnisse experimenteller Forschungsarbeiten 9

2.4.1 Schlaff bewehrte Mauerwerkbalken 9

2.4.2 Vorgespannte Mauerwerkbalken 22

2.5 Inhalte bauaufsichtlicher Regelwerke 23

2.5.1 DIN EN 1996-1-1:2013 24

2.5.2 DIN 1053-3:1990 27

2.5.3 E DIN 1053-3:2008 27

2.5.4 DIN EN 12602:2016 - Porenbeton 27

2.5.5 DIN EN 1520:2011 - Leichtbeton 27

2.5.6 DIN 1045-100:2017 - Ziegeldecken 27

2.5.7 Flachsturzrichtlinie (Entwurf 2005) - Flachsturz 27

2.5.8 Allgemein bauaufsichtliche Zulassung (abZ) - FertigteilsturZ 28

2.5.9 Zusammenfassung der in Regelwerken benannten Tragwiderstände 29

2.5.10 Kritik an aktueller Schubbemessung und verwendeter Werkstoffkenngrößen 30

2.5.10.1 Schubfestigkeit $(\boldsymbol{f} \mathbf{v d}) \quad 31$

2.5.10.2 Querkrafttragfähigkeit (VRd1) 31

2.6 Ausblick auf den Berechnungsansatz dieser Arbeit 33

2.7 Zusammenfassung, Bewertung und Schlussfolgerungen für diese Arbeit 35

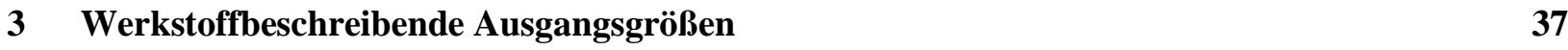

$\begin{array}{lll}3.1 & \text { Mauersteine } & 37\end{array}$

3.1.1 Geometrie und Lochanteil 37 
3.1.2 Druckfestigkeit senkrecht zur Lagerfuge 38

3.1.3 Zugfestigkeit parallel und senkrecht zur Lagerfuge 38

$\begin{array}{lll}3.2 & \text { Mauermörtel } & 38\end{array}$

$\begin{array}{lll}3.2 .1 & \text { Druckfestigkeit } & 38\end{array}$

3.2.2 Verbundeigenschaften zwischen Dünnbettmörtel und Mauersteinen 38

$\begin{array}{lll}3.3 & \text { Mauerwerk } & 38\end{array}$

3.3.1 Einaxiales Trag- und Verformungsverhalten 38

3.3.1.1 Druckfestigkeit senkrecht zur Lagerfuge 38

3.3.1.2 Druck-E-Modul senkrecht zur Lagerfuge 39

3.3.1.3 Druckfestigkeit parallel zur Lagerfuge 40

3.3.2 Zweiaxiales Trag- und Verformungsverhalten 42

3.3.2.1 Mann/ Müller 42

3.3.2.2 Ganz/ Thürlimann/ Mojsilović 43

$\begin{array}{lll}3.4 & \text { Injektionsmörtel } & 48\end{array}$

$\begin{array}{lll}3.5 & \text { Betonergänzung } & 49\end{array}$

$\begin{array}{lll}3.6 & \text { Bewehrung } & 49\end{array}$

$\begin{array}{lll}\text { 3.6.1 Betonstahl } & 49\end{array}$

$\begin{array}{lll}\text { 3.6.2 Spannstahl } & 49\end{array}$

$4 \quad$ Analytische Grundlagen zu Spannungsfeldern für bewehrtes Mauerwerk 51

4.1 Spannungsfelder $\quad 51$

4.1.1 Elastische, gerissene Spannungsfelder $\quad 52$

4.1.2 Starr-plastische Spannungsfelder (klassische Spannungsfelder) 52

4.1.3 Erweiterte starr-plastische Spannungsfelder (verallgemeinerte Spannungsfelder) 55

4.1.4 Elastisch-plastische Spannungsfelder (erweiterte Spannungsfelder) 57

4.1.5 Besonderheiten vorgespannten Mauerwerks in Spannungsfeldern 58

4.2 Schubübertragungsmechanismen innerhalb von Spannungsfeldern 59

$\begin{array}{lll}\text { 4.2.1 Ungerissene Biegedruckzone } & 60\end{array}$

$\begin{array}{lll}\text { 4.2.2 Rissuferverzahnung und Rissreibung } & 60\end{array}$

$\begin{array}{lll}\text { 4.2.3 Dübelwirkung der Biegezugbewehrung } & 62\end{array}$

4.2.4 Vertikalwiderstand der Betonzugfestigkeit in der Rissprozesszone 63

$\begin{array}{lll}\text { 4.2.5 Maßstabseffekt } & 63\end{array}$

$\begin{array}{lll}\text { 4.2.6 Schubschlankheit } & 64\end{array}$

4.3 Abgrenzung herkömmlicher Schubtragmodelle von der Spannungsfeldmethode 65

$\begin{array}{lll}\text { 4.3.1 Sprengwerk- und Bogenzugbandmodelle } & 65\end{array}$ 
4.3.2 Kamm- und Zahnmodelle $\quad 65$

4.3.3 Semi-Empirisches Schubmodell von EC2 66

4.4 Zusammenfassung und Beurteilung 68

5 Experimentelle Untersuchungen $\quad 69$

$5.1 \quad$ Vorbemerkungen $\quad 69$

$\begin{array}{lll}5.2 & \text { Flachstürze - Ia } & 70\end{array}$

$\begin{array}{lll}5.3 & \text { Scheitrechte Mauerwerkbalken - IIa } & 74\end{array}$

$\begin{array}{lll}\text { 5.3.1 Trag- und Verformungsverhalten } & 77\end{array}$

5.3.2 Einfluss der Schubschlankheit auf die Querkrafttragfähigkeit $\quad 80$

5.3.3 Einfluss des Bewehrungsgrades auf die Querkrafttragfähigkeit $\quad 82$

5.3.4 Ermittlung des Hebelarms der inneren Kräfte 83

5.3.5 Neigung des Druckstrebenwinkels innerhalb des Schubfeldes $\quad 84$

5.4 Scheitrechte Mauerwerkbalken mit Ergänzungsschicht aus Beton - IIa 86

5.5 Vorgespannte scheitrechte Mauerwerkbalken - IIb $\mathrm{III}_{\mathrm{II}} \quad 91$

5.6 Zusammenfassung der Ergebnisse $\quad 94$

$6 \quad$ Ergänzende FE-Untersuchung $\quad 96$

6.1 Verifikation des gewählten FE-Modells 96

6.2 Parameterstudie 100

$\begin{array}{lll}\text { 6.2.1 Schlaff bewehrte Balken } & 100\end{array}$

6.2.1.1 Bewehrungsgrad und Längsdehnungseinfluss 101

6.2.1.2 Schubschlankheit 103

$\begin{array}{lll}\text { 6.2.2 Vorgespannte Balken } & 106\end{array}$

6.2.2.1 Verformungsverhalten und Bruchzustand 107

6.2.2.2 Grad der Vorspannung 108

6.2.2.3 Schubschlankheit und zentrische Vorspannung 109

6.2.3 Abweichendes Tragverhalten wandartiger Träger 111

$\begin{array}{lll}6.3 & \text { Zusammenfassung } & 117\end{array}$

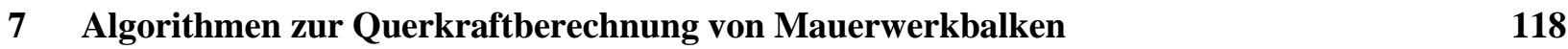

$\begin{array}{lll}7.1 & \text { Herleitung und Darstellung der SMCFT } & 118\end{array}$

7.1.1 Modified Compression Field Theory 118

7.1.2 Simplified Modified Compression Field Theory 123

7.2 Modellvorschlag und Berechnungsalgorithmen 126

7.3 Vergleichsrechnungen auf Basis experimenteller und numerischer Untersuchungen 131

$\begin{array}{lll}7.4 & \text { Vergleich mit bestehenden Regelwerken } & 137\end{array}$ 
7.5 Zusammenfassung mit Bewertung der Ergebnisse

8 Zusammenfassung 142

9 Literaturverzeichnis 


\section{Abkürzungsverzeichnis}

Im Folgenden werden die signifikanten Abkürzungen, die in der Arbeit verwendet werden, festgelegt. Hier nicht aufgeführte Abkürzungen werden im Text gesondert erläutert.

$\begin{array}{ll}\text { Gl. } & \text { Gleichung } \\ \text { bspw. } & \text { beispielsweise } \\ \text { exp. } & \text { experimentell /-en /-er } \\ \text { theor. } & \text { theoretisch /-en /-er } \\ \text { rechn. } & \text { rechnerisch /-en } \\ \text { i.d.R. } & \text { in der Regel } \\ \text { u.a. } & \text { unter anderem } \\ \text { Abschn. } & \text { Abschnitt } \\ \text { abZ } & \text { allgemeine bauaufsichtliche Zulassung } \\ \text { Bez. } & \text { Bezeichnung } \\ \text { DM } & \text { Dünnbettmörtel } \\ \text { SDL } & \text { Spannungs-Dehnungslinie }\end{array}$





\section{$1 \quad$ Einleitung}

\subsection{Problemstellung und Zielsetzung}

Die Beurteilung des Schubtragverhaltens von schlaff bewehrten Mauerwerkbalken basiert auf experimentellen und theoretischen Untersuchungen. Auf Basis dessen wurden verschiedene sowohl empirische als auch semiempirische Tragmodelle entwickelt, deren jeweilige Anwendbarkeit konstruktionsabhängig ist. Ein allgemein gültiges Schubkonzept existiert bislang nicht.

Die unterschiedlichen Tragmodelle aktueller Regelwerke zur Ermittlung des Querkraftwiderstandes $\left(V_{\mathrm{R}}\right)$ von bewehrten, balkenartigen Mauerwerkkonstruktionen sind überwiegend auf nicht mehr gültige Annahmen der Stahlbetontheorie zurückzuführen; siehe Abschnitt 2.5.10 (Graubner 2017, S. 7). Grundlage ist die Annahme eines klassischen Druckfeldmodells, welches durch ein in seiner Ebene homogen belastetes, gerissenes, orthogonal bewehrtes und isotropes Stahlbetonscheibenelement beschrieben wird (Weber und Stempfle 2013, S. 172). Die Schubtragfähigkeit wird dabei i.d.R. ausschließlich über die Druckzone bestimmt, was den tatsächlichen Lastabtrag nicht umfassend widerspiegelt (Gunkler und Marx 2018, S. 7).

Darüber hinaus bleiben bei den bisherigen Schubtragmodellen, die sich von dem Werkstoff „Beton“ unterscheidenden inhomogenen, anisotropen Werkstoffeigenschaften von Mauerwerk unberücksichtigt. Diese erscheinen vor allem von dem Lochbild und dem Überbindemaß der Mauersteine sowie der Ausbildung der Stoßfugen abhängig zu sein (Gunkler et al. 2017, S. 156). Diese Aspekte berücksichtigend müsste der Bemessungswert der Schubfestigkeit $\left(f_{\mathrm{vd}}\right)$ auf einem nichtlinearen Materialgesetz für Mauerwerk basieren, welches die obigen Einflüsse beinhaltet.

Der Anwendungsfall vorgespannter Mauerwerkbalken ist normativ in Deutschland ausgeschlossen, da hierzu keine umfassenden und veröffentlichten Forschungsergebnisse vorliegen. Lediglich einige wenige Konstruktionsarten vorgespannter Zugbänder mit nachträglicher Übermauerung sind über abZ in Deutschland anwendbar; siehe bspw. (Z-17.1-957 2017).

Die bisherigen Forschungsarbeiten, die im Zusammenhang mit der Untersuchung schlaff bewehrter als auch vorgespannter Mauerwerkbalken stehen, liefern Ergebnisse im Hinblick auf einzelne, das Tragverhalten beschreibende Einflussfaktoren. Für die hier $\mathrm{zu}$ bearbeitende Zielsetzung fehlen ganzheitliche Untersuchungen, bei denen verschiedene Konstruktionsarten systematisch einbezogen werden.

Ziel ist die Entwicklung eines von der Konstruktionsart unabhängigen Berechnungsvorschlages zur Bestimmung der Querkrafttragfähigkeit für sowohl schlaff bewehrte als auch vorgespannte Mauerwerkbalken. Schwerpunkt ist dabei die realistische Erfassung des mechanischen Schubtragverhaltens unter Anwendung von Schubspannungsfeldern sowie anisotropen Werkstoffeigenschaften bewehrten Mauerwerks. Dies ist die Vorrausetzung für eine zukünftige Implementierung in ein einheitliches normativ geregeltes Bemessungskonzept. Ein möglicher, hier zu entwickelnder Ansatz könnte aus der „Simplified Compression Field Theory“ (SMCFT), angewendet im ,fib Modelcode 2010", abgeleitet werden, in Kombination mit der Berücksichtigung der Anisotropie von Mauerwerk. Dabei würde der tatsächliche Verformungszustand des sowohl bewehrten als auch vorgespannten Mauerwerks über Längsdehnungen in die Definition der Schubfestigkeit einbezogen werden. 


\subsection{Gliederung der Arbeit}

Aufgrund der Vielfalt von Mauerwerkkonstruktionen wird in Abschnitt 2 für Mauerwerkbalken eine Kategorisierung (Bauteilkategorien) auf Basis zuvor definierter Unterscheidungsmerkmale vorgenommen. Die in der Arbeit behandelten Balkenkonstruktionen werden beschrieben; eine Abgrenzung zwischen Balkenmodell und wandartigen Trägern wird durchgeführt. Zur Beurteilung des Schubtragverhaltens von Mauerwerkbalken werden Forschungsergebnisse zitiert und hinsichtlich der Zielsetzung bewertet. Daran anschließend werden Inhalte von Schubbemessungsansätzen bauaufsichtlicher Regelwerke wiedergegeben und kritisch bewertet. Die bislang überwiegend angewendeten Schubbemessungsverfahren beschreiben Mauerwerkabschnitte realer Größe nicht ausreichend, weshalb auf die Anwendung von Schubspannungsfeldern verwiesen wird.

Im Hinblick auf den $\mathrm{zu}$ entwickelnden Berechnungsvorschlag sowie die hierfür erforderlichen experimentellen und theoretischen Untersuchungen sind in Abschnitt 3 Werkstoffeigenschaften verwendeter Materialien aufgeführt. Ergänzend wird auf Stoffgesetze eingegangen, welche die Anisotropie von Mauerwerk erfassen.

In Abschnitt 4 werden die Grundlagen von Schubspannungsfeldern mit Verweis auf die Anwendung bei bewehrtem Mauerwerk erläutert. Die in den Schubspannungsfeldern aus dem Stahlbetonbau bekannten Schubübertragungsmechanismen werden vorgestellt und deren Übertragbarkeit auf Mauerwerkbalken hypothetisch bewertet. Eine Abgrenzung der Spannungsfeldmethode zu herkömmlichen Schubtragmodellen wird ebenfalls dargestellt. Diesen Abschnitt vervollständigend werden die Besonderheiten einer Vorspannung im Mauerwerkbau erläutert.

Auf der Grundlage durchgeführter Bauteilprüfungen an Mauerwerkbalken unterschiedlicher Bauteilkategorien werden mechanische und geometrische Untersuchungsparameter analysiert, die einen Einfluss auf den Querkraftwiderstand haben; siehe Abschnitt 5. Die Ergebnisse liegen den Berechnungsalgorithmen nach Abschnitt 7 zugrunde und werden zu Vergleichsrechnungen herangezogen. Fehlende Parameterrechnungen werden in Abschnitt 6 mit Hilfe der Finite-Element-Methode durchgeführt. Die Berechnungen basieren auf einem zuvor gewählten und anhand experimenteller Untersuchungen verifiziertem FE-Modell.

Auf Basis verallgemeinerter Spannungsfelder werden Berechnungsalgorithmen zur Bestimmung der Querkrafttragfähigkeit von sowohl schlaff bewehrten als auch vorgespannten Mauerwerkbalken ohne Querkraftbewehrung unter Anwendung der SMCFT erarbeitet, in denen anisotropes Verhalten von Mauerwerk berücksichtigt wird. Die Anwendbarkeit wird mittels experimenteller und theoretischer Prüfergebnisse verifiziert; siehe Abschnitt 7.

In Abschnitt 8 werden die Ergebnisse dieser Arbeit zusammengefasst. 


\section{Grundlagen und „Stand der Forschung“ von Mauerwerkbalken}

\subsection{Unterscheidungsmerkmale}

Die Anwendung bewehrten Mauerwerks für die Herstellung von Mauerwerkbalken ist vielfältig. In der vorliegenden Arbeit wird eine Differenzierung nach Tabelle A 1.1 vorgenommen, welche die Anwendungsvielfalt verdeutlicht. Eine in Deutschland praxisübliche Anwendungsform ist der schlaff bewehrte Mauerwerksturz. Als Ergänzungsbauteil für Mauerwerk ist dieser nach DIN EN 845-2 geregelt. Der in dem Wort „Mauerwerksturz“ enthaltende Begriff „Sturz“ ist in DIN EN 845-2, Abschnitt 3.1.12, definiert: „Balken, der Lasten über einer Öffnung in einer Mauerwerkswand aufnimmt“ (DIN EN 845-2, S. 7). Nicht Gegenstand der Norm sind Balken, die eine Stützweite von 4,5 m überschreiten (DIN EN 845-2, S. 5). Unabhängig davon wird in der vorliegenden Arbeit der Begriff „Sturz“ für Balken und wandartige Träger verwendet.

Darüber hinaus bleibt der Begriff „Balken“ nach DIN EN 845-2 undefiniert, weshalb hier auf DIN EN 1992-1-1, Abschnitt 5.3.1 (3;4) verwiesen wird. Danach sind Balken und, zur Unterscheidung, wandartige Träger entsprechend dem Verhältnis von Stützweite $(l)$ zu Gesamtquerschnittshöhe $(h)$, nach Tabelle A 1.2 definiert; für Balken gilt die Definition $\frac{l_{\text {eff }}}{h} \geq 3$. Dieser Normenbezug scheint aus Gründen der Vergleichbarkeit vertretbar, da in DIN EN 845-2 auch die Anwendung von Betonstürzen geregelt ist, die aus Spannbeton oder Stahlbeton hergestellt werden.

\subsection{Bewehrungsanordnung und Konstruktionsarten}

Die Unterscheidungsmerkmale nach Tabelle A 1.1 enthalten Angaben über die Anordnung der Bewehrung in balkenartigen Mauerwerkkonstruktionen; siehe auch Bild 2.1. Die Bewehrung wird überwiegend in Lagerfugen oder Hohlräumen angeordnet. Eine Ausnahme können Zugbänder aus Porenbeton sein (Abschnitt 2.2.1). Zur Sicherstellung ausreichenden Verbundes werden die Hohlräume nach dem Einbau der Bewehrung mit Mörtel oder Beton verfüllt oder ausinjiziert.
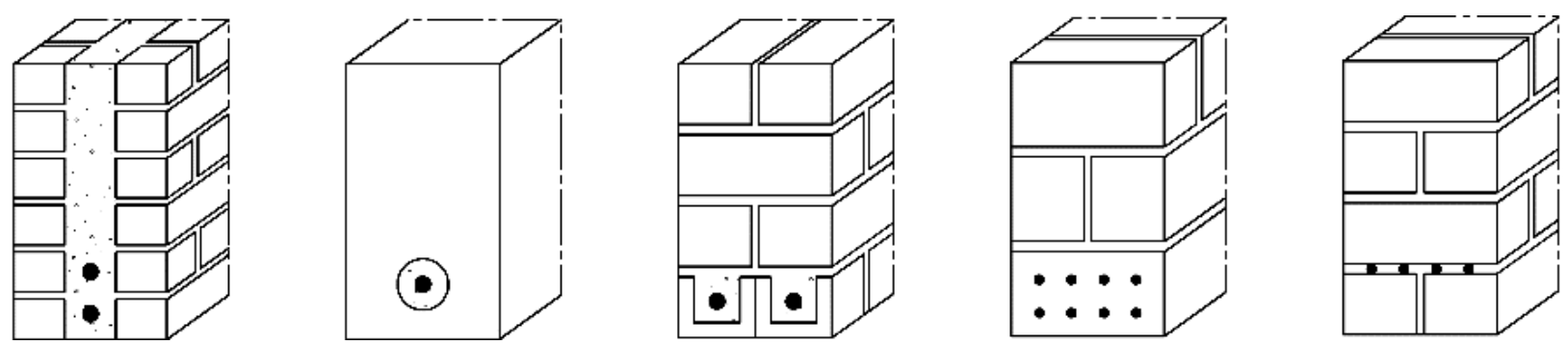

Bild 2.1 Unterschiedliche Bewehrungsanordnung von Mauerwerkbalken vgl. (Hendry et al. 2004, S. 181)

In dieser Arbeit werden Mauerwerkbalken nach ihrer Konstruktionsart in Anlehnung an DIN EN 845-2 unterschieden; siehe Tabelle 2.1. Die Konstruktionsarten des teilweise vorgefertigten, bauseits ergänzten Sturzes (Bauteilkategorie I), im Folgenden „Flachsturz“ genannt, und des vorgefertigten Sturzes (Bauteilkategorie II), im Folgenden „Fertigteilsturz“ genannt, sind in Bild 2.2 dargestellt. Darüber hinaus kann, entsprechend der Art der Längsbewehrung, in schlaff bewehrte und vorgespannte Balken (Bauteilkategorie III) unterschieden werden. Nichttragende balkenartige Konstruktionen werden der Bauteilkategorie IV zugeordnet. 
Tabelle 2.1 Einteilung balkenartiger Mauerwerkkonstruktionen in Bauteilkategorien

\begin{tabular}{|c|c|c|c|c|c|c|}
\hline Bauteilkategorie & \multicolumn{2}{|c|}{ I } & \multicolumn{2}{|c|}{ II } & III & IV \\
\hline Konstruktionsart & \multicolumn{2}{|c|}{ Flachsturz } & \multicolumn{2}{|c|}{ Fertigteilsturz } & $\begin{array}{l}\text { Vorgespannte } \\
\text { balkenartige } \\
\text { Konstruktion }\end{array}$ & $\begin{array}{l}\text { Nichttragende } \\
\text { balkenartige } \\
\text { Konstruktion }\end{array}$ \\
\hline $\begin{array}{l}\text { Abschnitt } \\
\text { vorliegender } \\
\text { Arbeit }\end{array}$ & \multicolumn{2}{|c|}{2.2 .1} & \multicolumn{2}{|c|}{2.2 .2} & 2.2 .3 & 2.2 .4 \\
\hline Beschreibung & \multicolumn{2}{|c|}{$\begin{array}{c}\text { Teilweise } \\
\text { vorgefertigter, bauseits } \\
\text { ergänzter Sturz DIN } \\
\text { EN 845-2, S. } 7\end{array}$} & \multicolumn{2}{|c|}{$\begin{array}{c}\text { Scheitrechter Sturz } \\
\text { oder vorgefertigter } \\
\text { Sturz DIN EN 845-2, } \\
\text { S. } 8\end{array}$} & $\begin{array}{l}\text { Vorgespannte } \\
\text { balkenartige } \\
\text { Konstruktion }\end{array}$ & $\begin{array}{l}\text { Nichttragende } \\
\text { balkenartige } \\
\text { Konstruktion für } \\
\text { Vormauer- oder } \\
\text { Verblendschale }\end{array}$ \\
\hline Subkategorie & $\begin{array}{c}\text { Ia } \\
\text { Schlaff } \\
\text { bewehrt }\end{array}$ & $\begin{array}{c}\text { Ib }_{\text {III }}^{1} \\
\text { Vor- } \\
\text { gespannt }\end{array}$ & $\begin{array}{c}\text { IIa } \\
\text { Schlaff } \\
\text { bewehrt }\end{array}$ & $\begin{array}{c}\text { IIb }_{\text {III }}^{1} \\
\text { Vor- } \\
\text { gespannt }\end{array}$ & - & - \\
\hline
\end{tabular}

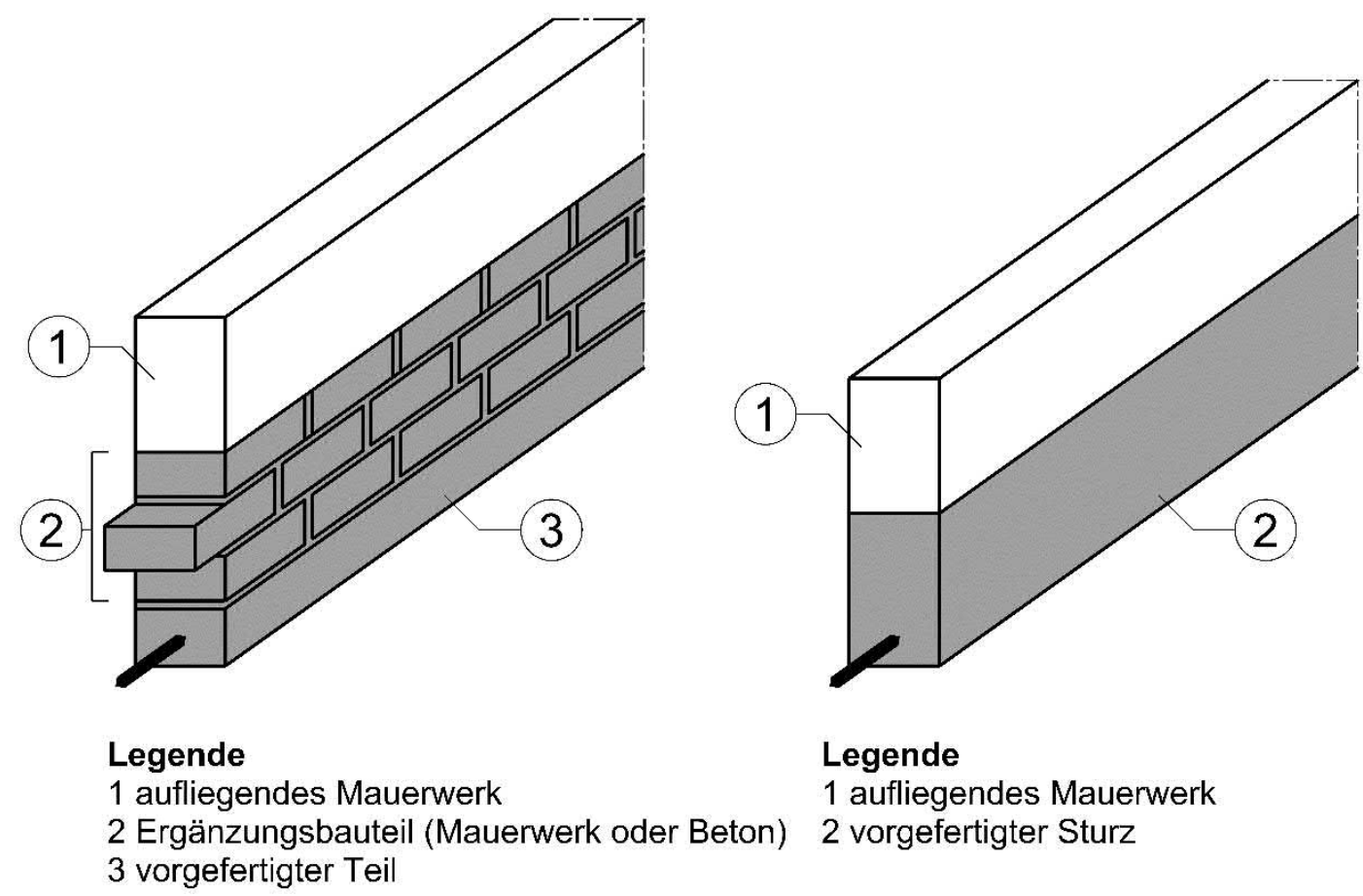

Bild 2.2 Flachsturz (links) und Fertigteilsturz (rechts) vgl. (DIN EN 845-2, S. 9)

Der Großteil internationaler Untersuchungen über bewehrte Mauerwerkbalken bezieht sich auf Konstruktionsarten, in denen die Bewehrung in Betonkernen, Hohlblocksteinen oder in verfüllten Aussparungen zwischen den einzelnen Mauersteinschichten angeordnet ist; siehe Bild 2.1. Es existieren vergleichsweise wenige Untersuchungen, in denen die Bewehrung in horizontalen Lagerfugen angeordnet ist.

\subsubsection{Flachsturz}

Ein Flachsturz ist eine zusammengesetzte Konstruktion aus Zugband mit einer sich darüber befindenden, bauseits ergänzenden Druckzone aus Mauerwerk und/ oder Beton. Das vorgefertigte Zugband besteht, je nach Bauart, aus Beton mit eingelegter Längsbewehrung oder einer vergossenen, bewehrten U-Schale; siehe Bild A 1.1. Bei Porenbetonflachstürzen ermöglicht der Herstellungsprozess eine direkte Ummantelung der Bewehrung mit Porenbeton, wodurch ein nahezu homogener Bauteilaufbau möglich ist. 
Das sich über dem Zugband befindende Mauerwerk bildet, ggf. mit der sich darüber befindenden Decke, die Druckzone; siehe Bild A 1.2.

Die Stoßfugen des sich über dem Zugband befindenden Mauerwerks werden in dieser Arbeit grundsätzlich als vermörtelt angenommen, sodass neben dem Eigengewicht des Mauerwerks auch die sich darüber befindenden Lasten bemessungstechnisch angerechnet werden dürfen; siehe (Z-17.1-981 2013; E DIN 1053-3:2008-03; Flachsturz-Richtlinie - Vorläufiger Schlussentwurf). Nichttragende Flachstürze (Bauteilkategorie IV nach Tabelle 2.1), bei denen die Stoßfugen unvermörtelt sind, werden hier nicht weiter behandelt.

\subsubsection{Fertigteilsturz}

Eine Alternative zum Flachsturz ist der Fertigteilsturz nach Bild 2.3. Hier besteht der Sturz aus einem oder mehreren zusammengesetzten Mauersteinelementen, häufig aus Kalksandsteinmaterial. Im Fall mehrerer Elemente wird Dünnbettmörtel für die Stoßfugen verwendet. Die Längsbewehrung ist in eigens dafür vorgesehenen Aussparungen der Vollsteinelemente angeordnet und zur Sicherstellung ausreichenden Verbundes mit Beton bzw. Mörtel ummantelt. Der wesentliche konstruktive Unterschied zu Flachstürzen besteht darin, dass sich der Zuggurt und die Druckzone im selben Mauerstein (Monolith) befinden. Die Anordnung der Mauersteine wird als ,scheitrecht“ bezeichnet (scheitrechter Fertigteilsturz), wenn wie hier, entgegen ihrer sonst üblichen Anordnung, die Mauersteine um $90^{\circ}$ gedreht sind und damit die Richtung ihrer Haupttragfähigkeit horizontal ausgerichtet ist. Das Bauteil wird werkseitig vorgefertigt und auf der Baustelle zur Überbrückung von Öffnungen eingesetzt. Diese Konstruktionsart implementiert die Vorteile eines Fertigteils in Bezug auf den nachfolgenden Bauablauf. Meist bedarf es keiner weiteren Übermauerung, da Fertigteilstürze mit unterschiedlichen Konstruktionshöhen $(h)$ verfügbar sind.

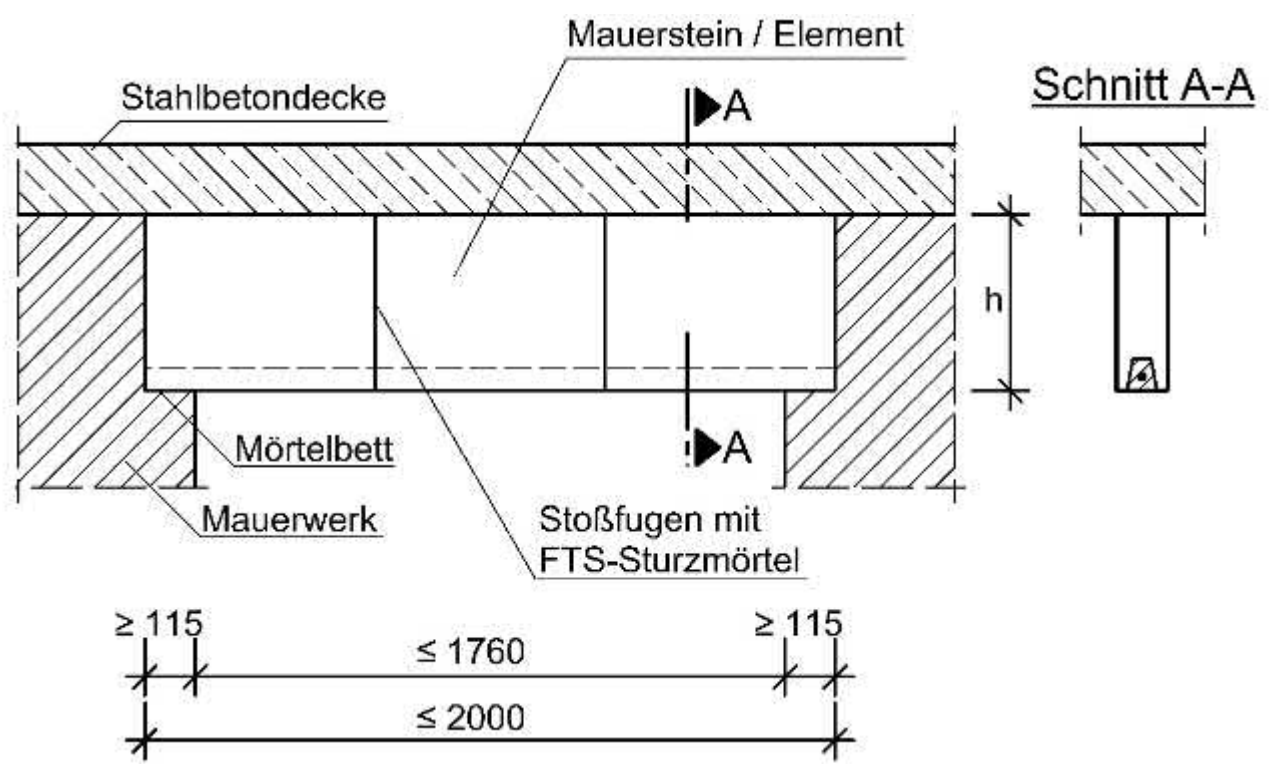

Bild 2.3 Darstellung eines bewehrten KS-Fertigteilsturzes; vgl. (Z-17.1-621 2005, A1)

Fertigteilstürze werden, wie Flachstürze, als Einfeldträger mit direkter Auflagerung eingesetzt. Bedingungsgemäß sind sie durch ihr Eigengewicht und durch vorwiegend ruhende gleichstrecken- oder trapezförmige Nutzlasten beansprucht (Z-17.1-621 2005, S. 3). Einwirkungen aus Einzellasten sind unzulässig.

Auf internationaler Ebene existieren artverwandte Konstruktionen, wie bspw. die in Österreich entwickelten Sturzsysteme mit einer lichten Spannweite von bis zu 3,5 m; siehe Bild 2.4. Dabei werden einzelne Mauerziegel „ohne Einsatz von Fugenbeton oder Mörtel, durch eine schnelle und sichere 
Klebeverbindung in der Fuge" (Leitl 2015, S. 16) miteinander verbunden. Die Eigenschaften des Werkstoffes der Klebeverbindung sind von dem Hersteller nicht angegeben.

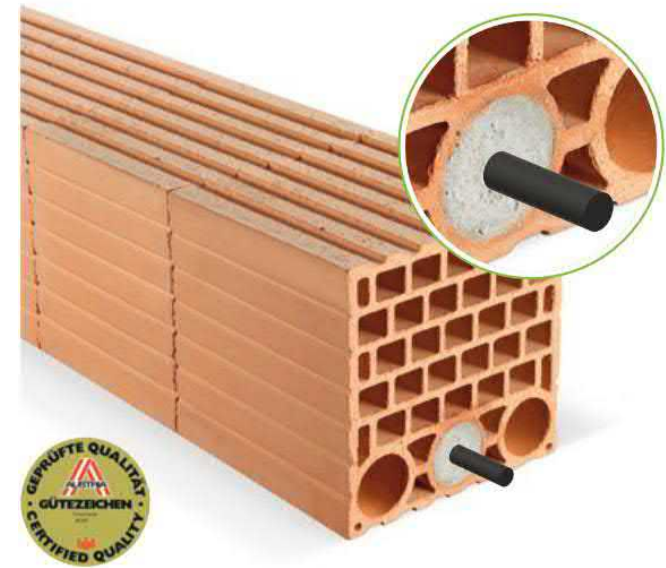

Bild 2.4 Isometrische Darstellung eines Fertigteilsturzes aus Mauerziegeln; vgl. (Leitl 2015, S. 16)

\subsubsection{Vorgespannte Mauerwerkbalken}

Neben Flachstürzen mit vorgespannten Zuggurten (Z-17.1-1065 2017; Z-17.1-957 2017) sind auch vorgespannte Fertigteilstürze verfügbar (Leitl 2008, S. 1). Sie entsprechen den Konstruktionsarten der

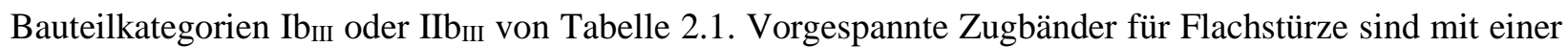
Übermauerung als Druckzone herzustellen. Bei vorgespannten scheitrechten Fertigteilstürzen entfällt eine Übermauerung.

Verglichen mit schlaff bewehrten Mauerwerkbalken lassen sich mit vorgespannten Mauerwerkbalken deutlich größere Öffnungen überbrücken; siehe Bild 2.5. Die Konstruktionsart entspricht der Bauteilkategorie III nach Tabelle 2.1.

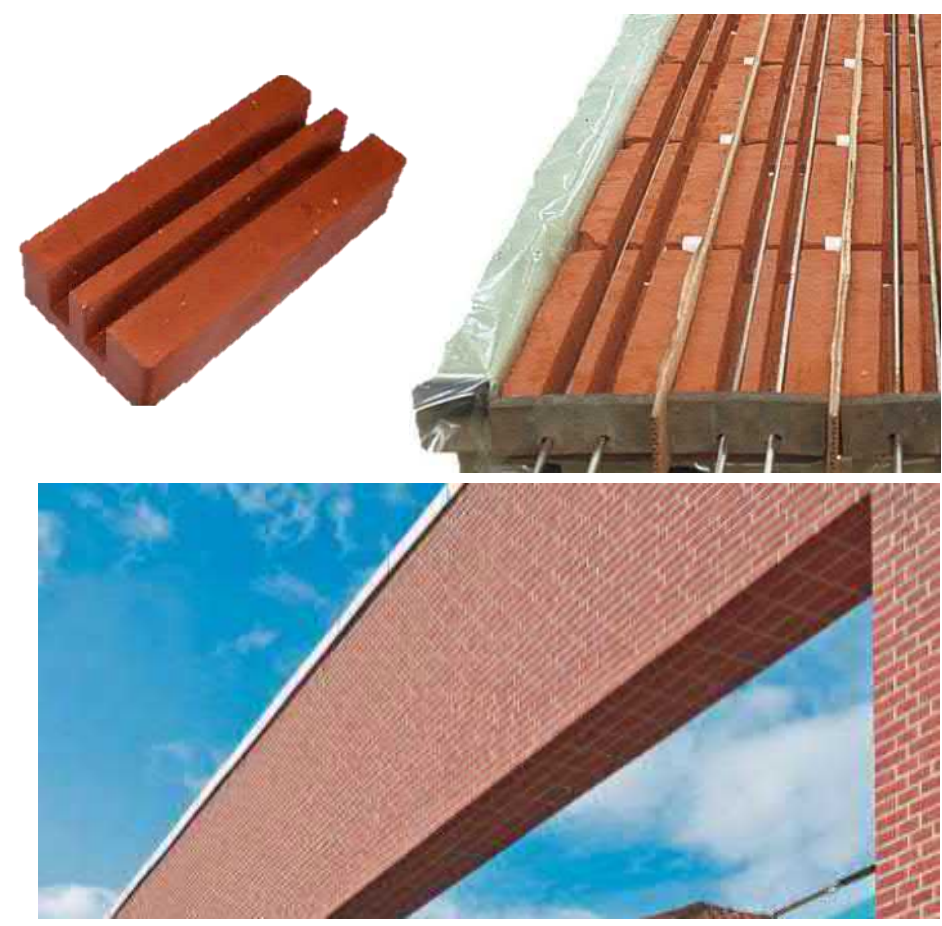

Bild 2.5 Mauerstein für Spannbett (oben links); Mauersteine und Spannstähle im Spannbett (oben rechts); vorgespannter Mauerwerkbalken: $b / \mathbf{l}=0,69 \mathrm{~m} / \mathbf{8 , 8 4} \mathrm{m}$ (unten) (Carlsberg Bjælker 2013) 
Balken des dänischen Herstellers „Carlsberg Bjælker“ werden im Spannbett vorgespannt. Dabei bestehen mindestens 65\% des Querschnitts aus Ziegelmauerwerk. Der Spannstahl wird in Formschlitze eigens hierfür hergestellter Mauersteine eingelegt, die mit einem speziellen Mörtel verfüllt sind.

\subsubsection{Balkenkonstruktionen für Vormauerwerk und/ oder Verblendmauerwerk}

Als Vormauerwerk wird bei zweischaligem Mauerwerk die äußere Schale der Wand bezeichnet, wobei die Mauersteine auf der Außenseite der Wand sichtbar bleiben. Es wird dem Verblendmauerwerk zugeordnet und oft als Sichtmauerwerk bezeichnet. Besteht der Wandquerschnitt aus zweischaligem Mauerwerk, gilt in Deutschland die Außenschale als nicht tragend. In Vormauerschalen angeordnete Balkenkonstruktionen werden daher ausschließlich durch ihr Eigengewicht beansprucht. Sie werden daher auch als nicht tragende Balken bezeichnet; siehe Bauteilkategorien IV nach Tabelle 2.1. Hierzu zählen bspw. Balken mit einer Grenadier- oder Rollschicht nach Tabelle A 1.1. In Bild A 1.3 ist das Konstruktionsbeispiel eines Balkens mit Grenadierschicht und fachwerkartigen Murfor®-Bewehrungselementen angegeben. Weitere Beispiele hierfür sind den abZ der Firma „Elmenhorst Bauspezialartikel GmbH \& Co. KG“ (Z-17.1-602 2012) für leiterartige Bewehrungselemente sowie der Firma „Wilhelm Modersohn GmbH \& Co. KG“ (Z-17.1-603 2012) für Lochbandstreifen zu entnehmen.

Für Verblendmauerwerk kommen auch Fertig-Verblendstürze zum Einsatz, die aus einem werkseitig mit Verblender-Riemchen beklebten, bewehrten Betonkern bestehen; siehe Bild A 1.4. Auflagerwinkel aus nichtrostendem Stahl mit angeschweißtem Rundstahl sichern die Auflagerung auf das angrenzende Verblendmauerwerk.

\subsection{Abgrenzung von Mauerwerkbalken gegenüber wandartigen Trägern aus Mauerwerk}

Für das in der vorliegenden Arbeit zu entwickelnde Schubtragmodell ist eine Abgrenzung von Balken gegenüber wandartigen Trägern erforderlich. Die Definition zur geometrischen Abgrenzung basiert auf einem Längen- zu Höhenverhältnis $\left(l_{\mathrm{eff}} / h\right)$; siehe Abschnitt 2.2.

Im Gegensatz zu balkenartigen Konstruktionen verläuft bei wandartigen Trägern die Verteilung der Längsdehnungen $\left(\varepsilon_{\mathrm{x}}\right)$ über die Querschnittshöhe nichtlinear (Leonhatdt und Mönnig 1986, S. 32); siehe Bild 2.6.
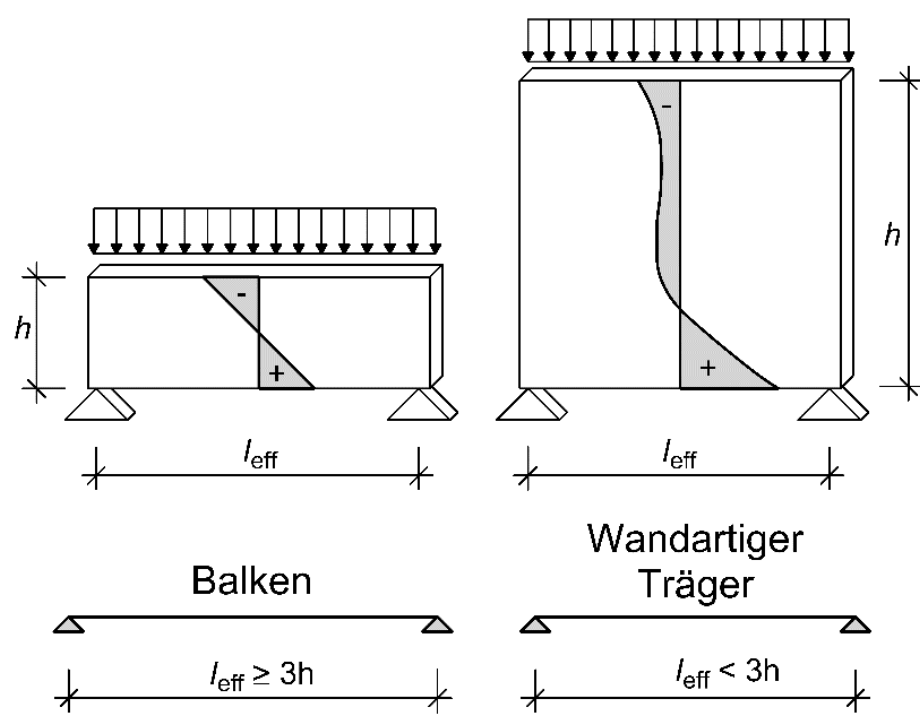

Bild 2.6 Verlauf der Längsdehnungen $\left(\varepsilon_{x}\right)$ : Balken (links); wandartiger Träger (rechts)

Entgegen dieser Erkenntnis wird in dem aktuellen Ansatz der DIN EN 1996-1-1:2013, Abschnitt 6.7.4 (DIN EN 1996-1-1:2013-02, S. 79) (Nachweis von Wandscheiben unter Schubbelastung) inhaltlich auf die Regelungen von Abschnitt 6.7.3 (DIN EN 1996-1-1:2013-02, S. 78) (Nachweis von bewehrten 
Mauerwerkbalken unter Schubbelastung) für Balken verwiesen. DIN EN 1996-1-1, Abschnitt 6.7.4, ergänzt, dass für die Bemessung wandartiger Träger die einwirkende Schubkraft am Auflagerrand und die statische Höhe mit $d=1,3 \cdot z$ anzunehmen sind; siehe Abschnitt 2.5.1.

Aufgrund des Längsdehnungsverlaufes von wandartigen Trägern in Bild 2.6 (rechts) ist ein Ebenbleiben der Querschnitte nicht gegeben. Die Bemessung von wandartigen Trägern auf Basis der Balkentheorie erscheint dabei, im Gegensatz zum Hinweis von DIN EN 1996-1-1, Abschnitt 6.7.4, als nicht gerechtfertigt.

Im Stahlbetonbau wird in DIN EN 1992-1-1 für wandartige Träger zum einen die Bemessung über Stabwerkmodelle vorgeschlagen. Dabei sollte sich das gewählte Scheibenmodell an den Spannungsverteilungen der linear-elastischen Elastizitätstheorie orientieren. Die Druckstrebenneigung wird dabei an dem Verlauf der Hauptspannungen orientiert (Bild 2.7). Dies verhindert eine übermäßige Rissbildung im Gegensatz zum Ansatz rein plastischen Tragverhaltens (Reineck 2005, S. 246).

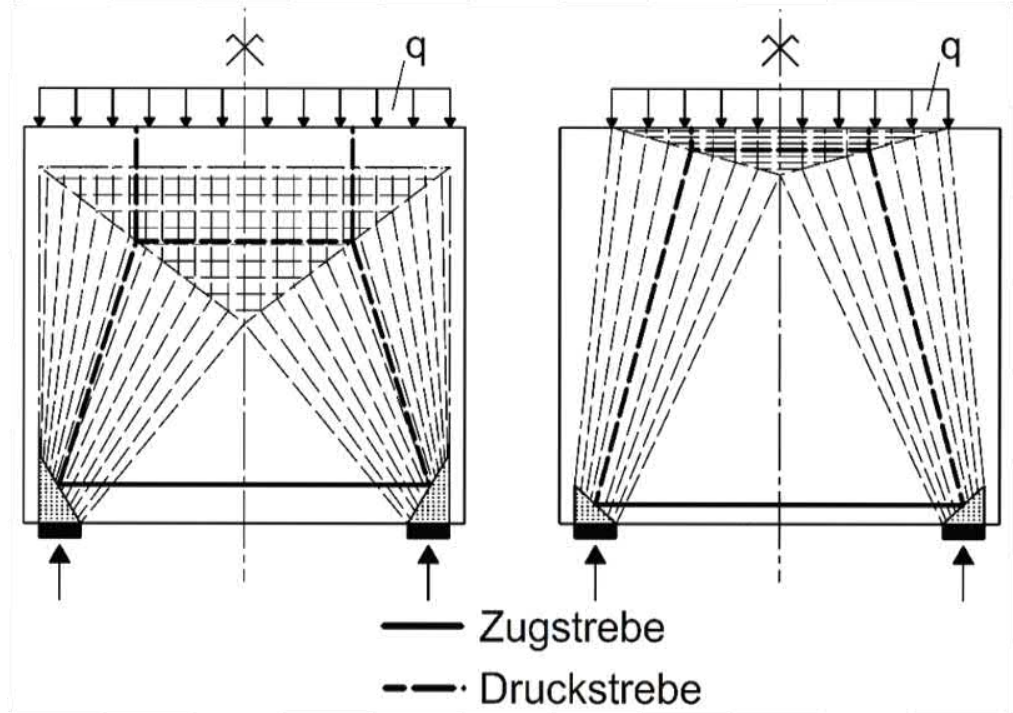

Bild 2.7 Verlauf von Spannungstrajektorien eines wandartigen Trägers unter Annahme linear-elastischen (links) und plastischen (rechts) Tragverhaltens

Zum anderen ist eine Bemessung über den Verlauf der Hauptzug- und Hauptdruckspannungen möglich; berechnet nach der Finite-Elemente-Methode oder nach Heft 631. Bei Anwendung der Ansätze nach Heft 631 ist ein gesonderter Schubnachweis nicht erforderlich (DAfStb Heft 631 2019, S. 73), da die Wirkung von Schubspannungen bei der Betrachtung der Hauptzug- und Hauptdruckspannungen für die Bemessung der Bewehrung implizit berücksichtigt ist.

Bacht und Stempniewski haben 2013 Forschungsergebnisse experimenteller Untersuchungen an wandartigen Trägern aus Mauerwerk veröffentlicht. Sie empfehlen für die Bemessung die Anwendung von Fachwerkmodellen (Bacht und Stempniewski 2013). In der für diese Arbeit erforderlichen Abgrenzung der Tragmodelle von Bild 2.6 wurden experimentelle Tastversuche an bewehrten wandartigen Trägern aus Mauerwerk durchgeführt und durch FE-Rechnungen ergänzt; siehe Abschnitt 6.2.3.

Vorteilhaft für scheibenartige Konstruktionen ist eine Verteilung der Bewehrung über die Querschnittshöhe. Dazu eignet sich insbesondere das von Bacht und Stempniewski untersuchte Mauerwerk aus Schalungssteinen, ggf. mit Netzbewehrung (Bacht und Stempniewski 2013) sowie Mauerwerk aus kleinformatigen Steinen bzw. geringen Steinhöhen mit der Möglichkeit der Einbringung einer Fugenbewehrung. Ein Anwendungsbeispiel hierfür sind Konstruktionen in Fassadenmauerwerk; siehe (Z17.1-602 2012; Z-17.1-603 2012). 


\subsection{Ergebnisse experimenteller Forschungsarbeiten}

Die Literaturauswertung zur Querkrafttragfähigkeit umfasst experimentell geprüfte, schlaff bewehrte oder vorgespannte Mauerwerkbalken, die den Bauteilkategorien I bis III nach Tabelle 2.1 entsprechen. Ergänzt wird diese durch Untersuchungsergebnisse indirekt vergleichbarer Konstruktionsarten, die einen Beitrag zur Erforschung des Trag- und Verformungsverhaltens von Mauerwerkbalken liefern.

\subsubsection{Schlaff bewehrte Mauerwerkbalken}

Bereits 1932 führten Parason et al. Bauteiluntersuchungen zum Schubtragverhalten an 18 schlaff bewehrten Mauerwerkbalken mit einer Länge von 4,28 m durch (Parason et al. 1932, S. 749-768). Die Balken unterschieden sich hinsichtlich der Anordnung der Mauersteine (Bild A 1.5). Die Steine wurden horizontal, scheitrecht (wie bei Fertigteilstürzen) oder aus einer Kombination beider Steinanordnungen vermauert. Die Bewehrung wurde in den Lagerfugen verlegt.

Die Mauerwerkbalken wurden im 4-Punkt-Biegeversuch geprüft. Ein Bauteilversagen setzte nach Auftreten eines diagonal verlaufenden Risses zwischen Auflager und einwirkender Einzellast ein; siehe Bild 2.8.

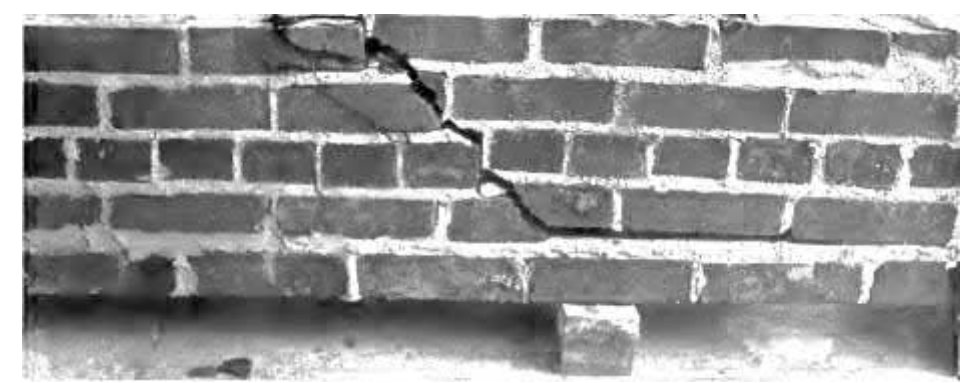

Bild 2.8 Typisches Rissbild eines auf Schub beanspruchten Mauerwerkbalkens (Parason et al. 1932, S. 755)

Die Untersuchungen ergaben, dass im Verband gemauerte Ziegelbalken (Bild A 1.5, Balken A und B) eine bis zu 60\% höhere Schubtragfähigkeit aufweisen als die mit nicht versetzter Mauersteinanordnung (Bild A 1.5, Balken C). Aus den Ergebnissen konnte keine direkte Abhängigkeit zwischen Druckfestigkeit der Steine und der Schubtragfähigkeit der Mauerwerkbalken abgeleitet werden.

Zelger und Daschner haben zwischen 1959 und 1963 umfangreiche Untersuchungen zum Trag- und Verformungsverhalten von Stahlsteindecken sowie von bewehrten Ziegelstürzen durchgeführt (Zelger und Daschner 1972). Stellvertretend für Stahlsteindecken wurden balkenartige Streifen mit einer Bruttoquerschnittsbreite zwischen 18,7 ..50,0 cm und einer Schubschlankheit $\left(\lambda=\frac{\max M}{\max Q \cdot d}\right)$ zwischen $\lambda=$ $1,08 \ldots 6,10$ geprüft. Hier wird zur Ermittlung der Schubschlankheit $(\lambda)$ die frühere Bezeichnung der statischen Höhe $(h)$ durch die heutige Bezeichnung $(d)$ ersetzt. Im Weiteren wurden folgende Parameter variiert: Die

- Ziegelform nach Bild 2.9,

- Prüfanordnung nach Bild 2.10,

- Nettoquerschnittsbreite (Mörtelrippe und Ziegelstege) der Ziegelbalken (7,8 .. 16,5 cm),

- Druckfestigkeit des Mörtels (11,5 .. 16,1 N/mm²) und der Ziegel $(18,2 \ldots 33,3$ N/mm²). 


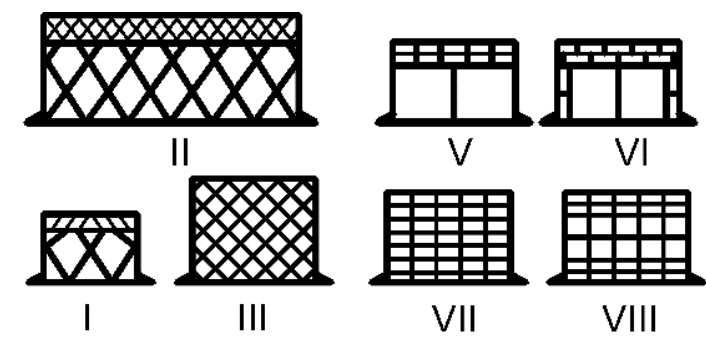

Bild 2.9 Querschnitte verwendeter Deckenziegel für balkenartige Prüfkörper; vgl. (Zelger und Daschner 1972, S. 5)

Die Balkenprüfungen wurden mit Laststellungen nach Bild 2.10 durchgeführt. Einige Prüfkörper, die unter Laststellung „,a von Bild 2.10 einseitiges Schubversagen aufwiesen, wurden in einer zweiten Prüfung mit geänderter Laststellung nach „, b“ untersucht.

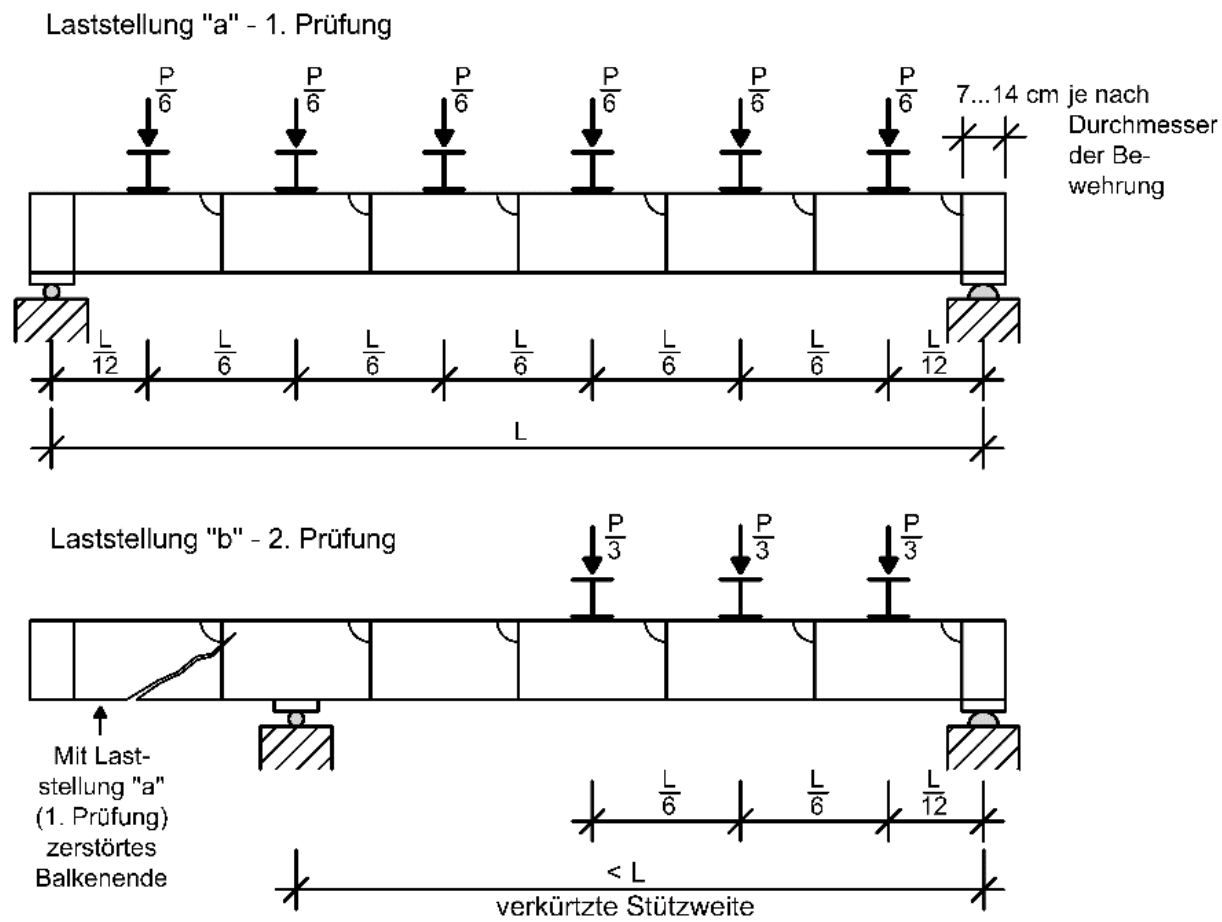

Bild 2.10 Versuchsanordnung zur Ermittlung des Querkraftwiderstandes balkenartiger Prüfkörper (Zelger und Daschner 1972, S. 23)

Aufgrund der unterschiedlichen Ziegelquerschnitte hat Zelger die Ergebnisse der Balkenversuche in Abhängigkeit einer ideellen Stegbreite $\left(b_{\mathrm{i}}\right)$ nach Gleichung (2.1) ausgewertet. Er wies nach, dass mit abnehmender Schubschlankheit die Querkrafttragfähigkeit ebenfalls abnimmt; siehe Bild 2.11.

$$
b_{\mathrm{i}}=\bar{b}_{\mathrm{o}} \cdot\left(\frac{\beta}{\bar{\beta}}\right)^{A}+\Delta \bar{b}_{\mathrm{oz}, \mathrm{R}} \cdot\left(\frac{\beta_{\mathrm{z}}}{\bar{\beta}_{\mathrm{Z}}}\right)^{A}
$$

Dabei sind:

$\bar{b}_{\mathrm{o}} \quad$ Die Breite einer Mörtelrippe,

$\beta \quad$ die Druckfestigkeit des verwendeten Mörtels oder Betons; geprüft am $20 \mathrm{~cm}$ Würfel,

$\bar{\beta} \quad$ die Bezugsfestigkeit der gängigen Kombination (Bn150/Deckenziegel) für Beton; hier 14,71 $\mathrm{N} / \mathrm{mm}^{2}$,

A die Konstante,

$\Delta \bar{b}_{\mathrm{oz}, \mathrm{R}} \quad$ die mitwirkende Stegbreite eines Deckenziegels,

$\beta_{\mathrm{Z}} \quad$ die Druckfestigkeit des verwendeten Deckenziegels,

$\overline{\beta_{\mathrm{Z}}} \quad$ die Bezugsfestigkeit der gängiger Kombination für Deckenziegel; hier 17,65 N/mm². 


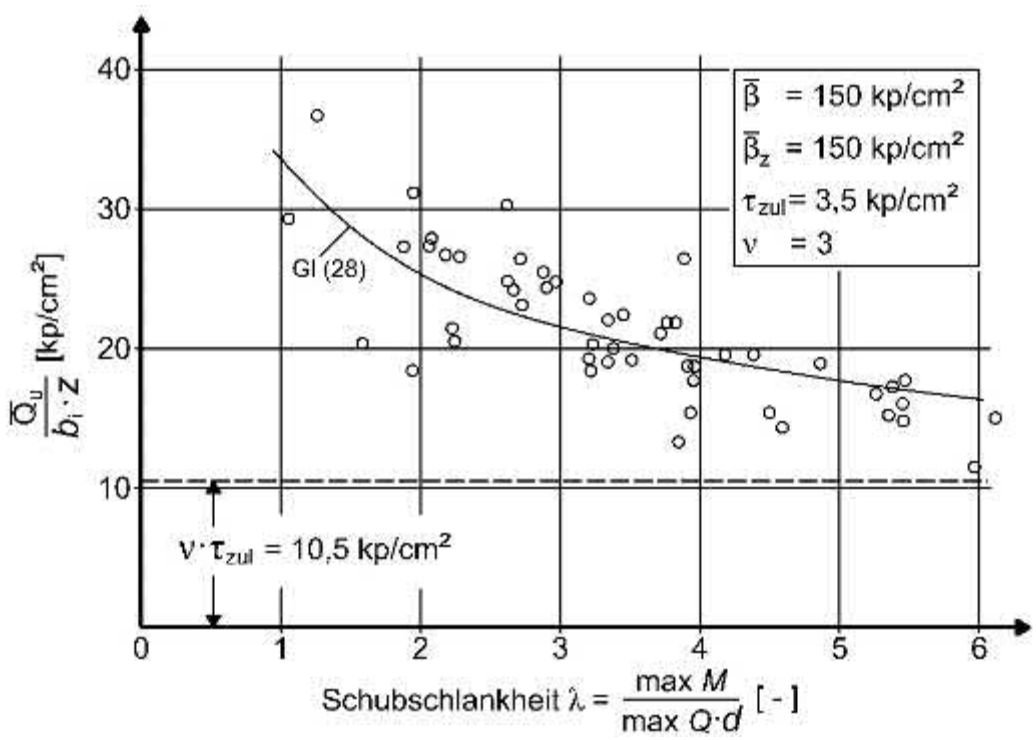

Bild 2.11 Ideelle, bezogene Schubspannung in Abhängigkeit zur Schubschlankheit $\lambda$. Prüfwerte und ausgleichende Hyperbel nach (Zelger und Daschner 1972, S. 25)

Zelger und Daschner errechneten die bezogene Querkrafttragfähigkeit $\left(\frac{\bar{Q}_{\mathrm{U}}}{b_{\mathrm{i} \cdot z} \cdot z}\right)$ mit Gleichung (2.2), die als Funktion mit asymptotischem Verlauf in Abhängigkeit variierender Schubschlankheiten in Bild 2.11 dargestellt und mit „, (G1 28)“ bezeichnet ist. Der darin enthaltene nichtlineare Anteil kann mit Gleichung (2.3) bestimmt werden.

$\frac{\bar{Q}_{\mathrm{U}}}{b_{\mathrm{i}} \cdot z}=v \cdot \tau_{\mathrm{zul}} \cdot \chi$

Dabei sind:

$\mathcal{V}$

Der Sicherheitsbeiwert,

$\tau_{\text {zul }} \quad$ die zulässige Schubspannung, mit $\tau_{\text {zul }}=0,34 \frac{\mathrm{N}}{\mathrm{mm}^{2}}$,

$\chi \quad$ der Einfluss durch die Schubschlankheit.

$\chi=\frac{\lambda+B}{\lambda-C}$

$\lambda=\frac{\max M}{\max Q \cdot d}$

Dabei sind:

$\lambda \quad$ Die Schubschlankheit,

$d \quad$ die statische Höhe,

$B, C \quad$ die Konstanten.

Ihre Ergebnisse zeigen, dass die Querkrafttragfähigkeit durch folgende Parameter beeinflusst wird: Die

- Querschnittsabmessungen,

- Materialeigenschaften,

- Ziegelformen und die

- Schubschlankheiten.

Zelger und Daschner weisen darauf hin, dass die Verwendung von Ziegeln mit schräg geneigter Steganordnung und gleicher Festigkeit zu kleineren Tragwiderständen geführt haben, als die Verwendung 
von Mauersteinen mit lot- und waagerechten Stegen. Schubbrüche hätten sich ausschließlich bei einer Schubschlankheit von $\lambda<6$ eingestellt.

Zelger hat von 1959 bis 1963 Untersuchungen an 11 flachsturzartigen Ziegelbalken (siehe Abschnitt 2.2.1) durchgeführt. Deren Stützweite variierte zwischen $l_{\mathrm{eff}}=0,5 \ldots 4,0 \mathrm{~m}$. Die Schubschlankheit der Balken betrug $\lambda=0,3 \ldots 2,49$. In Bild 2.12 ist exemplarisch ein Ziegelbalken mit einer mittleren Schubschlankheit von $\lambda=1,23$ dargestellt. Auch hier hat Zelger einen Zusammenhang zwischen der aufnehmbaren Schubspannung und der Schubschlankheit festgestellt; siehe Bild 2.13.

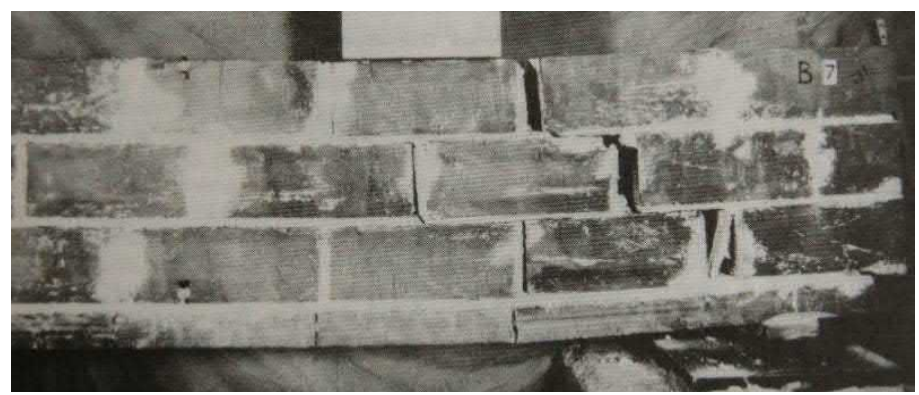

Bild 2.12 Ziegelbalken mit einer mittleren Schubschlankheit $\lambda=1,23$; Gleitversagen (Zelger und Daschner 1972, S. 69)

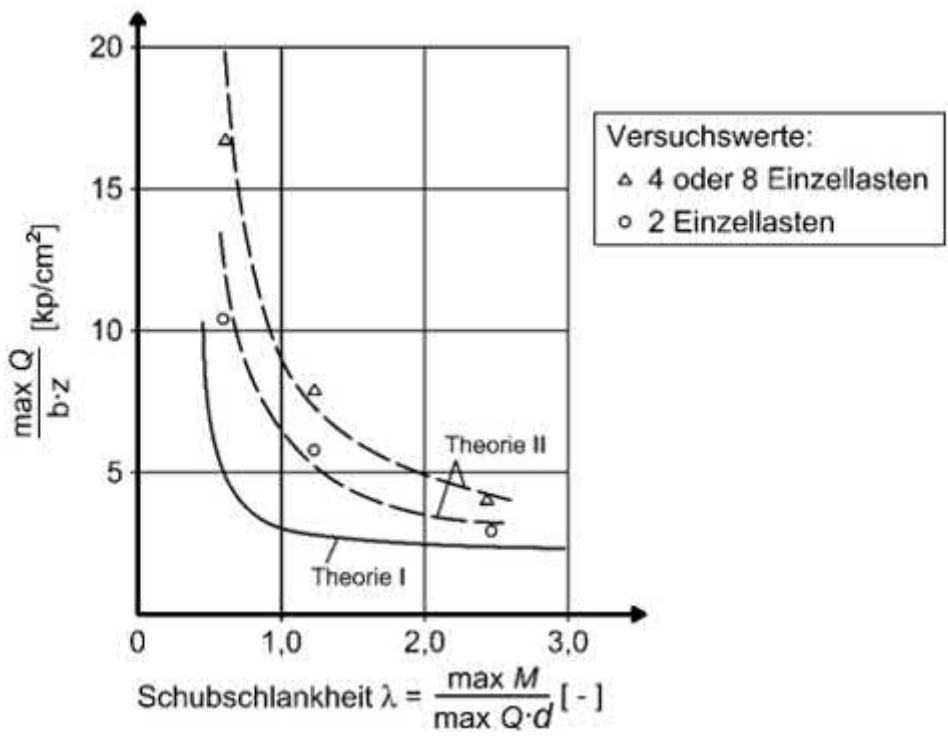

Bild 2.13 Darstellung der aufnehmbaren Schubspannung in Abhängigkeit der Schubschlankheit $\lambda$. Prüfwerte und Vergleich zwischen ausgleichenden Hyperbeln der Theorie I und II (Zelger und Daschner 1972, S. 71)

Im Rahmen seiner Untersuchungen hat er Gleichung (2.5) (Theorie I) zur rechnerischen Bestimmung der aufnehmbaren Querkraft von Flachstürzen entwickelt. Dabei wird der Widerstand aus der Reibung in der Lagerfuge bei lotrechter Auflastspannung in Anlehnung an das „Coulomb'sche Reibungsgesetz“ gebildet. Um eine befriedigende Übereinstimmung zwischen Versuch und Rechnung zu erlangen, hat er ein Korrekturglied zur Beschreibung der wirksamen Haftfläche eingeführt (Zelger und Daschner 1972, S. 7172). Die Erweiterung um den Korrekturfaktor enthält Gleichung (2.6) und wird als Theorie II bezeichnet. In Bild 2.13 ist ein Vergleich der Theorie I und Theorie II unter Bezug auf die Prüfwerte dargestellt.

Theorie I: $\frac{\max Q_{\mathrm{u}}}{b \cdot z}=\frac{\beta \tau}{1-\frac{\mu}{\lambda} \cdot k_{\mathrm{z}}}$

Dabei sind:

$\max Q_{\mathrm{u}} \quad$ Die maximal einwirkende Querkraft, 
$b \quad$ die Querschnittsbreite,

Z der Hebelarm der inneren Kräfte,

$\beta_{\tau} \quad$ die Festigkeitsgröße zur Beschreibung des Gleitwiderstandes zwischen aneinanderhaftenden Körpern (entspricht der Kohäsion); hier Schubfestigkeit genannt,

$\mu \quad$ der Reibungsbeiwert,

d die statische Höhe,

$\lambda \quad$ die Schubschlankheit; $\lambda=\frac{\max M}{\max Q \cdot d}$,

$k_{\mathrm{z}} \quad k_{\mathrm{z}}=\frac{z}{d}$.

Theorie II: $\frac{\max Q_{u}}{b \cdot z}=\beta \tau \cdot \frac{\lambda+\frac{t}{d}}{\lambda-\mu * k_{\mathrm{z}}}$

Im Weiteren ist:

$t \quad$ Korrekturglied zur Beschreibung der wirksamen Haftfläche.

Zelger hat unter Annahme eines definierten Bemessungswertes des Gleitwiderstandes Gleichung (2.6) zu Gleichung (2.7) vereinfacht (Zelger und Schellbach 1967, S. 768). Dieser Ansatz wird in der Flachsturzrichtlinie zur Bestimmung des Querkraftwiderstandes angewendet; siehe Gleichung (A 1.27) (Flachsturz-Richtlinie - Vorläufiger Schlussentwurf).

$$
Q_{\mathrm{zul}}=b \cdot z \cdot 0,9 \cdot \frac{\lambda+0,4}{\lambda-0,4}
$$

Im Weiteren ist:

Qul Querkraftwiderstand.

Sinha (Sinha 1982, S. 226-243) untersuchte das Schubtragverhalten von Balken und Platten aus 3schichtigem Ziegelmauerwerk mit bewehrter Mörtelfüllung im 4-Punkt-Biegeversuch; siehe Bild 2.14.

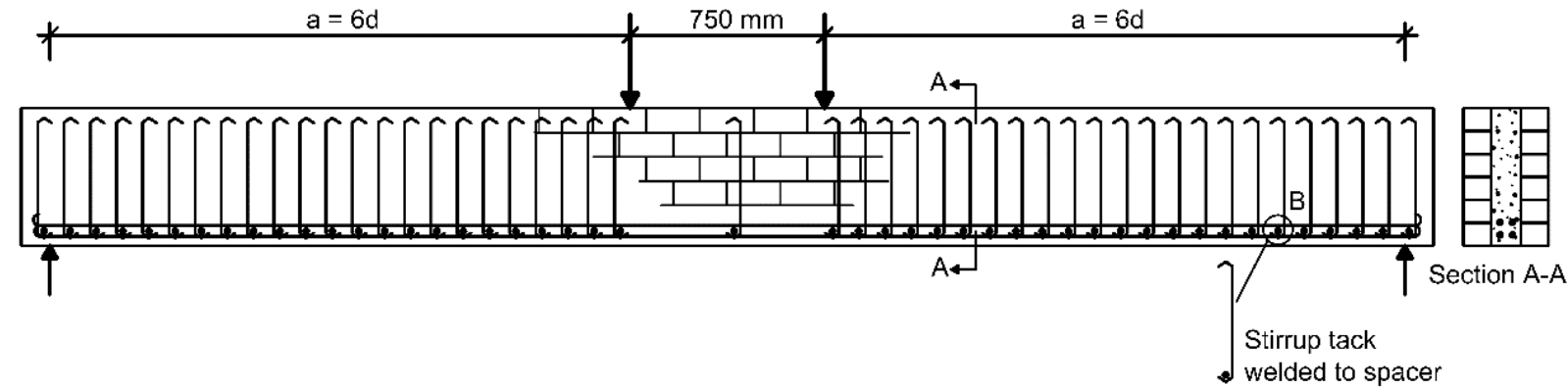

Bild 2.14 Exemplarisch dargestellter Versuchsaufbau eines untersuchten Mauerwerkbalkens mit bewehrtem Betonkern (Sinha 1982, 226, 228)

Folgende Parameter wurden berücksichtigt:

- Der Bewehrungsgrad (Schub- und Biegebewehrung),

- die Festigkeit der Beton- oder Mörtelfüllung,

- die Festigkeit des Ziegelmaterials sowie

- $\quad$ Schubschlankheit $\lambda$; siehe Gleichung (2.8) bzw. (2.9).

$\lambda=\frac{a}{d}$

$\lambda=\frac{\max M_{\mathrm{Ed}}}{\max V_{\mathrm{Ed}} \cdot d}$ 
Dabei sind:

a Der Abstand zwischen Auflager und einwirkender Einzellast,

$d \quad$ die effektive Höhe,

$\max M_{\mathrm{Ed}} \quad$ der Bemessungswert des größten einwirkenden Biegemoments,

$\max V_{\mathrm{Ed}} \quad$ der Bemessungswert der größten einwirkenden Querkraft im Bauteil.

Sinha wies nach, dass die Schubtragfähigkeit zunimmt, wenn

- die Schubschlankheit mit $\lambda<5$ abnimmt (Bild 2.15),

- die Biegezugbewehrung zunimmt (Bild 2.16) und

- die Querkraftbewehrung zunimmt; Voraussetzung: Mauersteine mit einer Druckfestigkeit $f_{\text {st }} \geq$ $12 \mathrm{~N} / \mathrm{mm}^{2}$

Keinen signifikanten Einfluss auf die Schubtragfähigkeit hatten

- die Druckfestigkeit der Mauersteine bei Nachweis von Mauerwerkbalken ohne Querkraftbewehrung und

- die Druckfestigkeit des Mauermörtels.

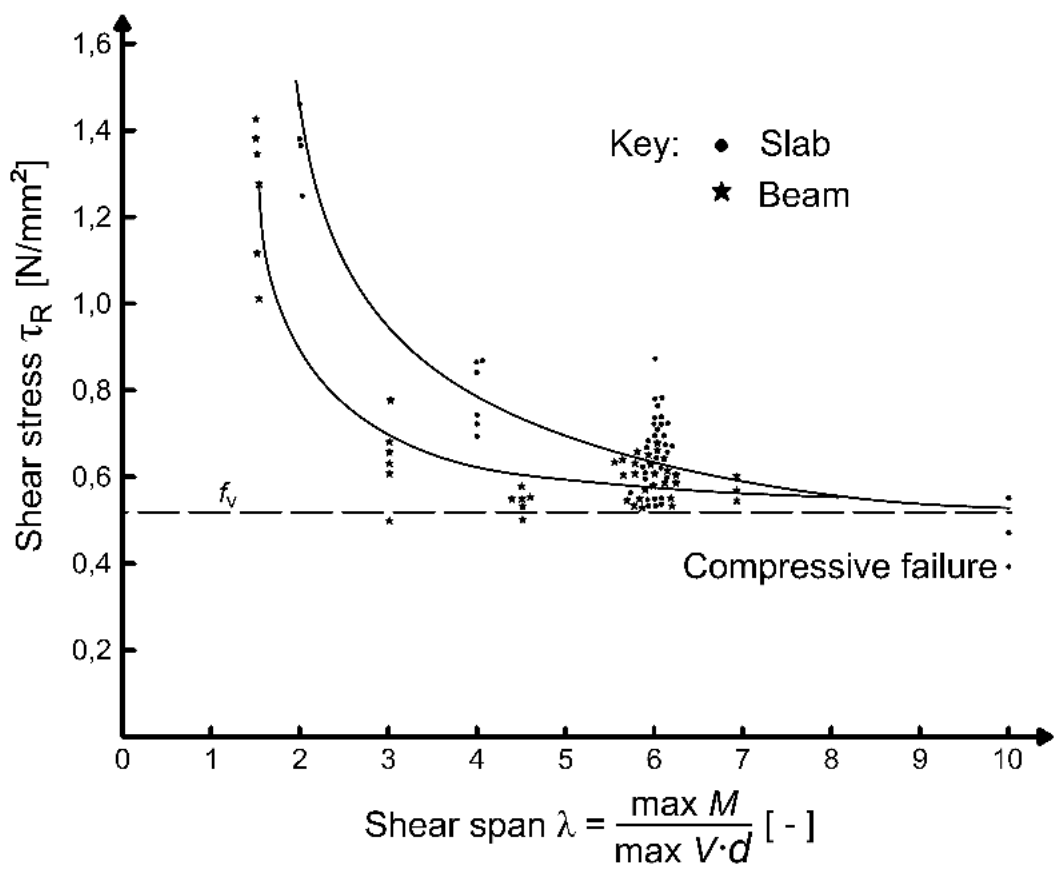

Bild 2.15 Schubschlankheit in Abhängigkeit zur Schubtragfähigkeit (Sinha 1982, S. 231)

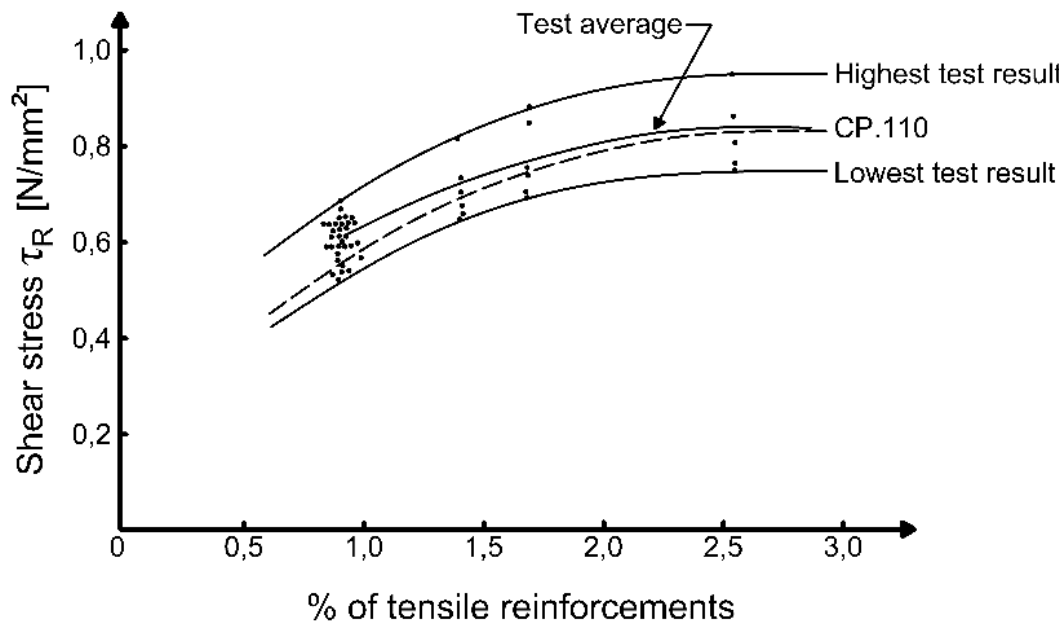

Bild 2.16 Schubtragfähigkeit in Abhängigkeit zur Größe der Biegebewehrung (Sinha 1982, S. 234) 
Sinha führt das Versagen von schlanken Balken auf eine Überschreitung der Druckzonentragfähigkeit zurück. Dabei verläuft die Rissbildung des Mauerwerks mäanderförmig in diagonaler Richtung zwischen dem Auflager und der einwirkenden Vertikalkraft; siehe Bild 2.17 (links) (Sinha 1982, S. 230). Durch diese Versagensform rechtfertigt er die Annahme eines Bogenzugbandmodells zur Erklärung dieses Tragverhaltens, siehe Abschnitt 4.3.1. Im Bereich gedrungener Balken wird ein Teil der einwirkenden Querkraft, abhängig von der Entfernung der Einzellast zum Auflager, direkt in das Auflager abgetragen, was zu einer Erhöhung der Schubtragfähigkeit führt (Hendry et al. 2004, S. 188). Im Bruchzustand stellt sich neben einem weitestgehend geradlinigen Rissverlauf ein Druckversagen im Auflagerbereich ein; siehe Bild 2.17 (rechts). Dieses Bruchverhalten erklärt er durch die Bildung eines Sprengwerkes.

schlanker Balken

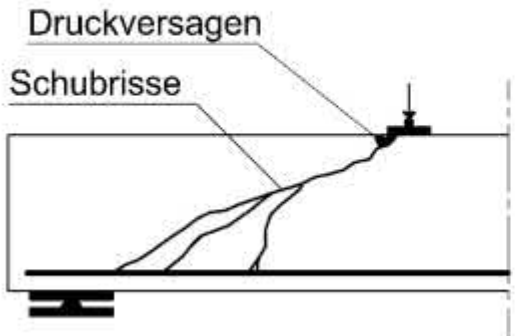

gedrungener Balken

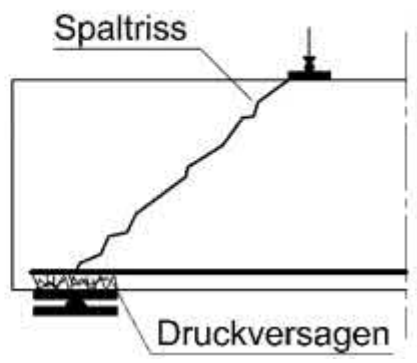

Bild 2.17 Typisiertes Rissmodell von querkraftbeanspruchten Mauerwerkbalken, abhängig von hoher (links) und niedriger (rechts) Schubschlankheit vgl. (A. Ghaffar et al. 2010, S. 2)

Hendry et al. beschreiben den Schubwiderstand von bewehrten Mauerwerkbalken ohne Schubbewehrung mit Hilfe folgender Tragwiderstände:

- Die ungerissene Biegedruckzone,

- die Rissuferverzahnung mit Reibungskräften entlang des Risses,

- die Dübelwirkung der Biegezugbewehrung und die

- Schubschlankheit des Balkens (Hendry et al. 2004, S. 188).

Die einzelnen Tragwiderstände können mit denen aus dem Stahlbetonbau für Balken ohne Querkraftbewehrung verglichen werden. Abhängig von der Konstruktionsart bewehrter Mauerwerkbalken treten diese einzeln oder in Kombination auf (Hendry et al. 2004, S. 181).

Die Rissuferverzahnung bei lagerfugenbewehrten Mauerwerkbalken ist wenig ausgeprägt, was auf die geringe Querzugfestigkeit des Mörtels zurückzuführen ist. Im Gegensatz dazu ist dieser Tragwiderstand bei Mauerwerkbalken mit bewehrten, verfüllten Hohlräumen bzw. mit Formsteinen deutlicher feststellbar (Hendry et al. 2004, S. 188).

Hendry et al. stellen in Bild 2.18 die Abhängigkeit der bezogenen Schubtragfähigkeit $\left(\tau_{\mathrm{R}}\right)$ von der Schubschlankheit $(\lambda=a / d)$ bewehrter Mauerwerkbalken, Mauerwerkbalken mit bewehrten Betonkernen und von vorgespannten Mauerwerkbalken dar. Im Vergleich zu fugenbewehrten Mauerwerkbalken ist bei Mauerwerkbalken mit bewehrtem Betonkern eine deutlich höhere Schubtragfähigkeit erkennbar. Die Anwendung der Vorspannung führt zu den höchsten beobachteten Schubtragfähigkeiten. 


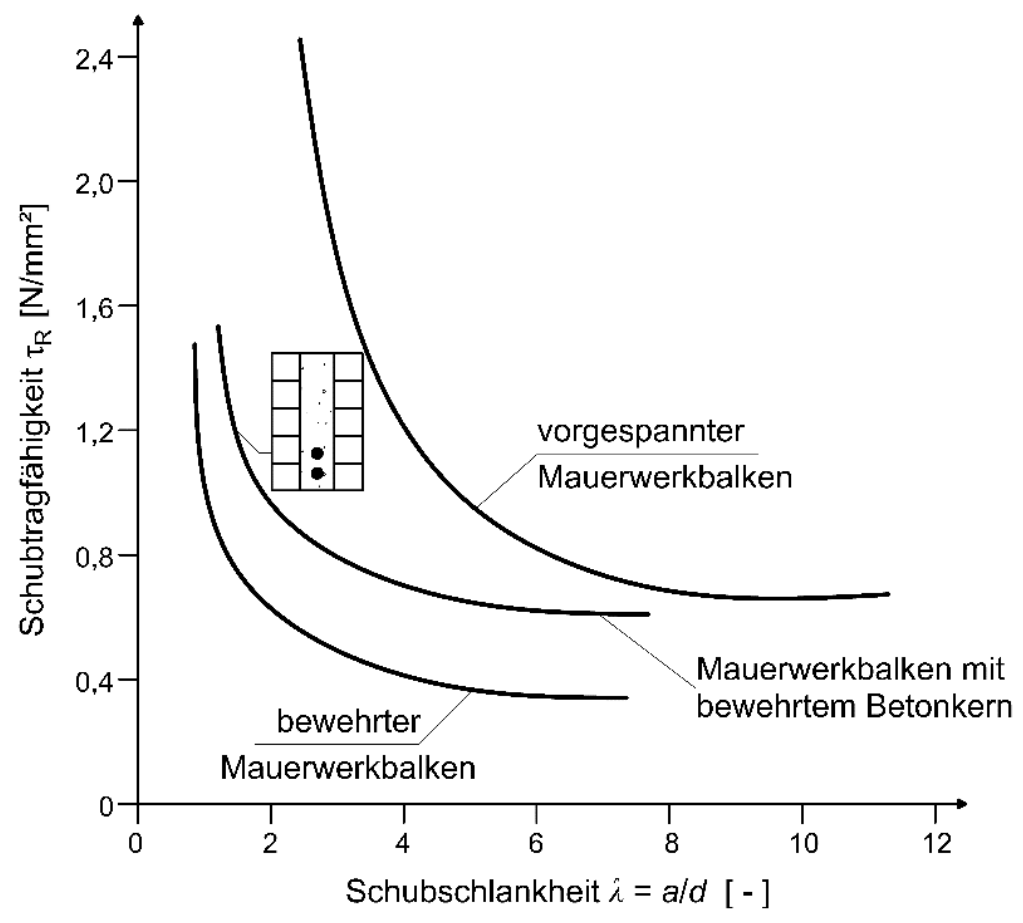

Bild 2.18 Schubtragfähigkeit in Abhängigkeit zur Schubschlankheit unterschiedlicher bewehrter bzw. vorgespannter Mauerwerkbalken vgl. (Hendry et al. 2004, S. 203)

Flohrer und Hilsdorf (Flohrer und Hilsdorf 1984) bestätigen den Einfluss der Schubschlankheit auf die Schubtragfähigkeit von bewehrten Mauerwerkbalken.

Martin und Sager haben 1986 Bauteilprüfungen zur spannungsbezogenen Querkrafttragfähigkeit von bewehrten Mauerwerkbalken der Schubschlankheit $(\lambda=a / d=2,63)$ durchgeführt (Martin und Sager 1986). Lagerfugenbewehrte Mauerwerkbalken wurden in ihren Drittelspunkten belastet; siehe Bild A 1.6.

1986 erfolgte der Querkraftnachweis durch einen Vergleich der Schubspannungen. Unter Gebrauchslasten zu bestimmende Schubspannungen $\left(\max \tau \cdot \gamma=\frac{V}{b \cdot z} \cdot \gamma\right)$ wurden mit zulässigen Schubspannungen $\left(\tau_{0.11}\right)$ nach DIN 1053-3:1990 verglichen; siehe Gleichung (A 1.1). Aufgrund ihrer Prüfergebnisse formulieren sie Werte zulässiger Schubspannungen $\left(\tau_{0.11}\right)$ zwischen $0,047 \ldots 0,167 \mathrm{~N} / \mathrm{mm}^{2}$, die unabhängig von der Schubschlankheit sind. Dies widerspricht den anderen bisher zitierten Forschungsarbeiten. Die Bestimmung der zulässigen Schubspannung ist nach Gleichung (A 1.4) mechanisch ausschließlich von dem Rechenwert der Mauerwerkdruckfestigkeit abhängig, welcher Mauerwerkfestigkeitsklassen (M) nach DIN 1053-2, Tabelle 6 (DIN 1053-2:1984-07) zugeordnet ist. Diese variieren bei heute anzunehmenden charakteristischen Mauerwerkdruckfestigkeiten $\left(f_{\mathrm{k}}\right)$ zwischen $5 \ldots 18 \mathrm{~N} / \mathrm{mm}^{2}$.

Mastumura (Mastumura 1988) führte 1988 experimentelle Untersuchungen zum Schubtragverhalten von bewehrten als „Wandstreifen“ berechneten Versuchskörpern aus Ziegel- und Betonsteinen durch; siehe Bild 2.19. 


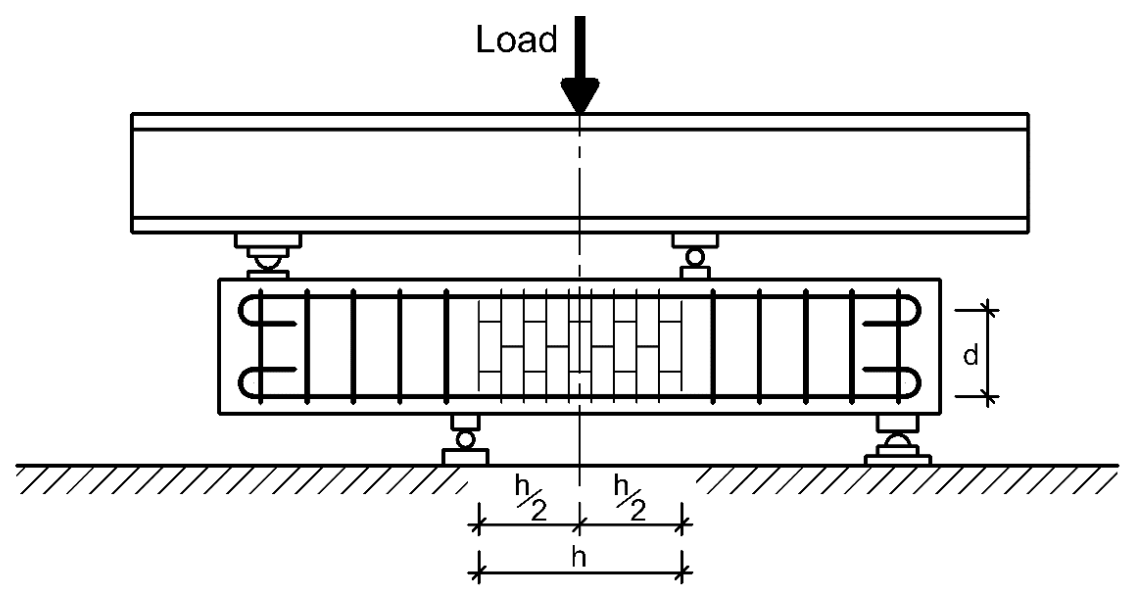

Bild 2.19 Versuchsaufbau (Mastumura 1988, VI-122)

Untersucht wurde der Einfluss der Schubschlankheit, der Mauerwerkdruckfestigkeit, der Längsbewehrung, der Konstruktionsart und der Art der Mörtelfüllung der Mauersteine auf die Schubtragfähigkeit.

Die Ergebnisse bestätigten die nichtlineare Zunahme der Schubtragfähigkeit von Balken bei Abnahme der Schubschlankheit $\lambda_{\mathrm{M}}$ (Gleichung (2.10)), was Mastumura mit dem mathematischen Algorithmus $(\chi)$ beschrieben hat; siehe Bild 2.20 und Gleichung (2.11).

$\lambda_{\mathrm{M}}=h / d$

Dabei sind:

$h \quad$ Der lichte Abstand zwischen Auflager und einwirkender Einzellast (Bild 2.19),

$d \quad$ die effektive Breite der liegend geprüften Wand (Bild 2.19); vom Schwerpunkt der Druckzone bis zum Schwerpunkt der Biegebewehrung (heute „ $z^{“}$ - innerer Hebelarm).

$\chi=\frac{0,76}{h / d+0,7}+0,012$

Bild 2.20 zeigt die Auswertung der Versuchsergebnisse, dargestellt im Verhältnis zwischen der Schubschlankheit und dem bezogenen Schubwiderstand $\left(v_{\mathrm{R}}\right)$; siehe Gleichung (2.12).

$v_{\mathrm{R}}=\frac{1}{k_{\mathrm{p}}} \cdot\left(\frac{\tau_{\mathrm{u}}}{\sqrt{f_{\mathrm{m}^{\prime}}}}-0,18 \cdot r \cdot \delta \cdot \sqrt{P_{\mathrm{h}} \cdot h \cdot \sigma_{\mathrm{y}}}-\frac{0,2 \cdot \sigma_{0}}{\sqrt{f_{\mathrm{m}}}}\right)$

Dabei sind:

$k_{\mathrm{p}} \quad$ Der Faktor zur Berücksichtigung des Längsbewehrungsgrades,

$\tau_{\mathrm{u}} \quad$ die Schubfestigkeit der Mauersteine,

$f_{\mathrm{m}}{ }^{\prime} \quad$ die Druckfestigkeit der Mauersteine,

der Faktor zur Berücksichtigung der Art der Bewehrung:

- 1,0 für vergossenen Bandstahl,

$r \quad \circ \quad 0,8$ für einen Bewehrungsstab mit aufgebogenen Haken an den Enden,

○ 0,6 für die gleiche Art der Bewehrung mit teilweiser Verfüllung der Hohlräume,

$\delta \quad$ der Faktor zur Berücksichtigung der Belastungsart (hier 1,0),

$P_{\mathrm{h}} \quad$ der Bewehrungsgrad horizontaler Schubbewehrung,

$h \quad$ der lichte Abstand zwischen Auflager und einwirkender Einzellast,

$\sigma_{\mathrm{y}} \quad$ die Streckgrenze der horizontalen Schubbewehrung,

$\sigma_{0} \quad$ die Axialspannung. 


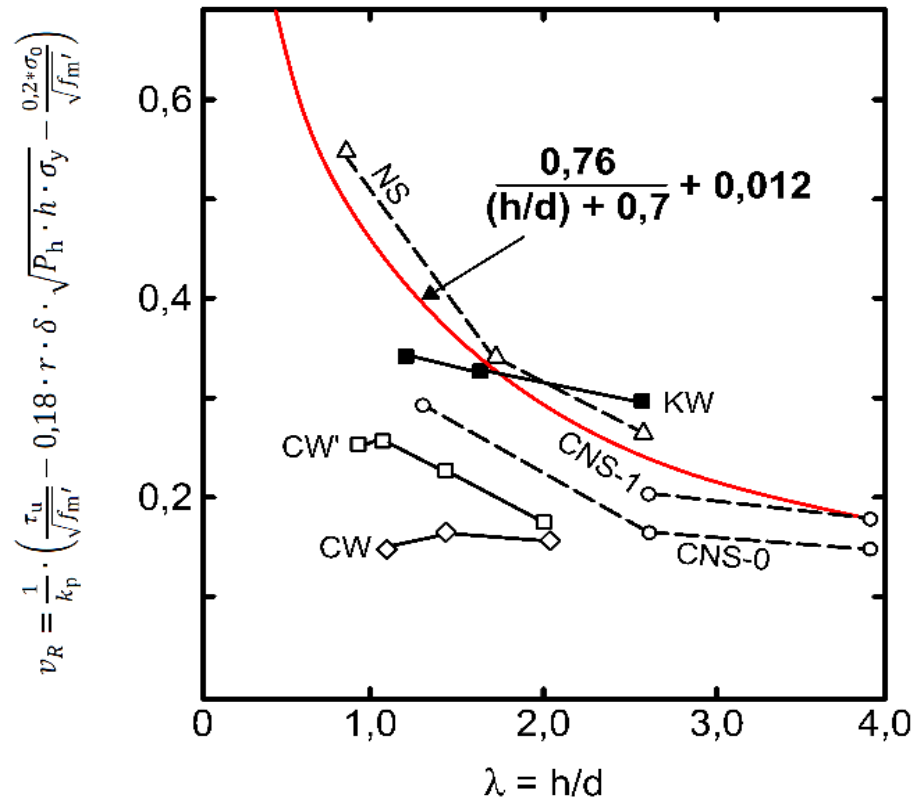

Bild 2.20 Verhältnis zwischen der Schubschlankheit und bezogener Schubtragfähigkeit (Mastumura 1988, VI-125)

Die Gleichung zur Ermittlung des Schubwiderstands $\left(V_{R}\right)$ lautet:

$$
V_{\mathrm{R}}=\left(k_{\mathrm{u}} \cdot k_{\mathrm{p}} \cdot\left(\frac{0,76}{\frac{h}{d}+0,7}+0,012\right) \cdot \sqrt{f_{\mathrm{m}}{ }^{\prime}}+0,18 \cdot r \cdot \delta \cdot \sqrt{P_{\mathrm{h}} \cdot h \cdot \sigma_{\mathrm{y}} \cdot f_{\mathrm{m}}{ }^{\prime}}+0,2 \cdot \sigma_{0}\right) \cdot t \cdot j \cdot 10^{3}
$$

Dabei sind im Weiteren zu Gleichung (2.12):

$$
\begin{aligned}
& \text { Der Faktor zur Berücksichtigung der Art der Verfüllung, } \\
& \circ \quad 1,0 \text { für vollständig verfülltes Mauerwerk, } \\
& k_{\mathrm{u}} \\
& \quad \circ \quad 0,8 \text { für teilweise verfülltes Mauerwerk, } \\
& \\
& \mathrm{j} \quad 0,64 \text { für teilweise verfülltes Betonsteinmauerwerk, } \\
& t \quad j=7 / 8 \cdot d, \\
& \quad \text { die Dicke der Wand. }
\end{aligned}
$$

Gleichung (2.13) berücksichtigt neben dem Einfluss der Schubschlankheit auch weitere Parameter wie: Die

- Art der Bewehrung,

- Druckfestigkeit und Schubfestigkeit der Mauersteine,

- Mauerwerkkonstruktion (fugenbewehrte Balken, bewehrte Balken mit verfülltem Hohlraum),

- Bewehrungsgrade (Biegebewehrung und Schubbewehrung).

Schubert, Schieß1 und Schmidt haben 1998...2003 Untersuchungen zum Tragverhalten von Ziegelflachstürzen mit und ohne Stoßfugenvermörtelung durchgeführt (Schieß1 und Schubert 1998; Schubert und Schmidt 2003). Zur Übermauerung der Zugbänder wurden Hochlochziegel mit einer Festigkeitsklasse zwischen 6 und 12 verwendet. Im Folgenden werden die Versuchsserien I, III und V angesprochen, bei denen eine Stoßfugenvermörtelung vorhanden war. Die Versuchsserie I sowie die Prüfanordnung ist exemplarisch in Bild 2.21 dargestellt. Die Versuchsserie III unterschied sich von Versuchsserie I durch eine geänderte Stützweite $l_{\text {eff }}=2,77 m$ und Laststellung. Bei Versuchsserie V wurden die Zugbänder durch eine zweilagige Übermauerung ergänzt. Die Stützweiten der Balken betrugen $l_{\mathrm{eff}}=1,65 \mathrm{~m}$. 


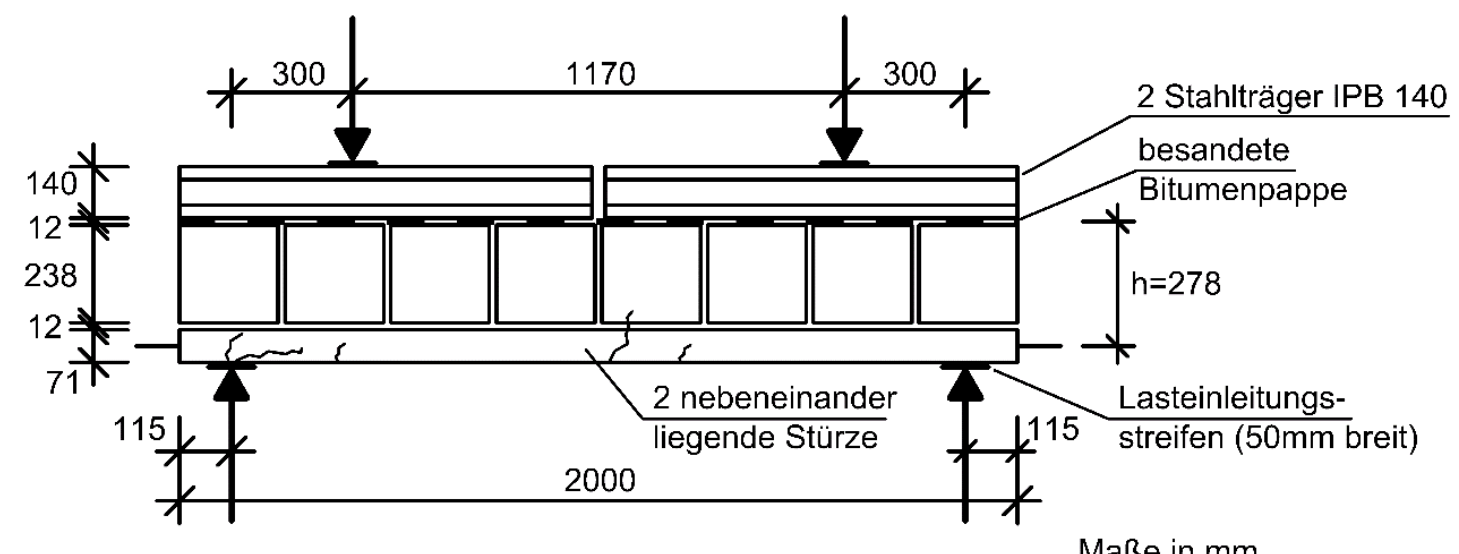

Maße in $\mathrm{mm}$

Bild 2.21 Prüfanordnung und Rissbild nach Belastungsende; Versuchsserie I - Prüfkörper 1 (Schießl und Schubert 1998, B5)

Schieß1 und Schubert führen das Bruchbild der Versuchsserie I auf ein Schubversagen infolge Reibung zwischen Zugband und Übermauerung zurück und begründen dies durch deren unterschiedliche Biegesteifigkeiten. Bei den Prüfkörpern der Versuchsserie III wurde stets Druckzonenversagen ohne typisches Schubversagen mit diagonaler Rissbildung festgestellt (Schieß1 und Schubert 1998, S. 23).

Auch die Bauteilprüfungen der Versuchsserie V wiesen Druckzonenversagen auf. Schubert und Schmidt führten dies auf die geringe Druckfestigkeit der Hochlochziegel parallel zur Lagerfuge zurück, bei denen die Stege in Längsrichtung des Balkens versetzt waren. In Bild 2.22 sind die Schubspannungen im Bruchzustand in Abhängigkeit der Schubschlankheit dargestellt. Dort ist ein Einfluss der Schubschlankheit nicht erkennbar, was auf die annähernd identisch gewählten Schubschlankheiten der Flachsturzkonstruktionen und die jeweiligen Versagensarten zurückgeführt wird. Die Untersuchungen lassen Rückschlüsse auf die Bedeutung der Druckfestigkeit der Mauersteine parallel zur Lagerfuge bzw. die Berücksichtigung anisotroper Werkstoffeigenschaften zu.

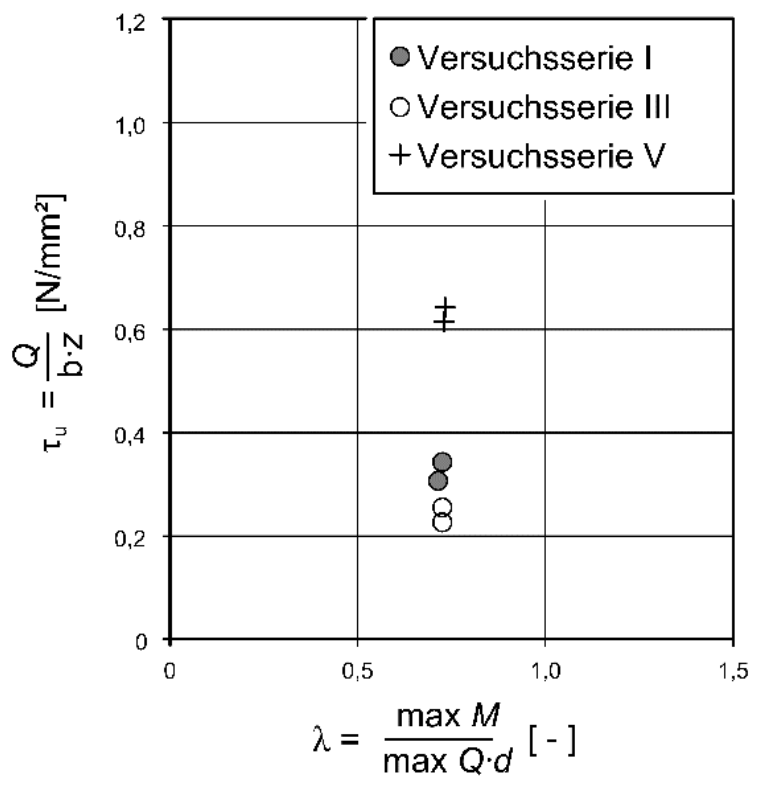

Bild 2.22 Schubspannungen im Bruchzustand und zulässige Schubspannungen nach „Richtlinie für die Bemessung und Ausführung von Flachstürzen“" in Abhängigkeit von der Schubschlankheit $\lambda$ (Schubert und Schmidt 2003, B8)

Schmidt, Fehling und Seim haben 2004 Untersuchungen an 30 Flachstürzen aus Kalksandsteinen durchgeführt. Dabei wurden die Stoß- und Lagerfugen im Dünnbettverfahren vermörtelt. Es wurden folgende Belastungsanordnungen unterschieden: 
- Belastung durch zwei Einzellasten; im Weiteren kurz mit „Biegung“ bezeichnet (DIN EN 8469:2016-08, 5; Bild 1a)).

- Prüfanordnung für Schub am Auflager; im Weiteren kurz mit „Schub am Auflager“ bezeichnet (DIN EN 846-9:2016-08, 5; Bild 1e)).

Die Ergebnisse der Untersuchungen sind in einem Gutachten von Klute zusammengestellt, auf dessen Inhalt in Abschnitt 7.3 Bezug genommen wird (Klute 2004). In Bild 2.23 sind Querkrafttragfähigkeiten untersuchter Balken in Abhängigkeit der Schubschlankheit dargestellt, bei denen Schubversagen maßgebendes Bruchkriterium ist. Eine Abhängigkeit der Querkrafttragfähigkeit von der Schubschlankheit ist erkennbar. Eine Erhöhung der Querschnittsbreite von $115 \mathrm{~mm}$ auf $175 \mathrm{~mm}$ führt zu größeren Querkrafttragfähigkeiten.
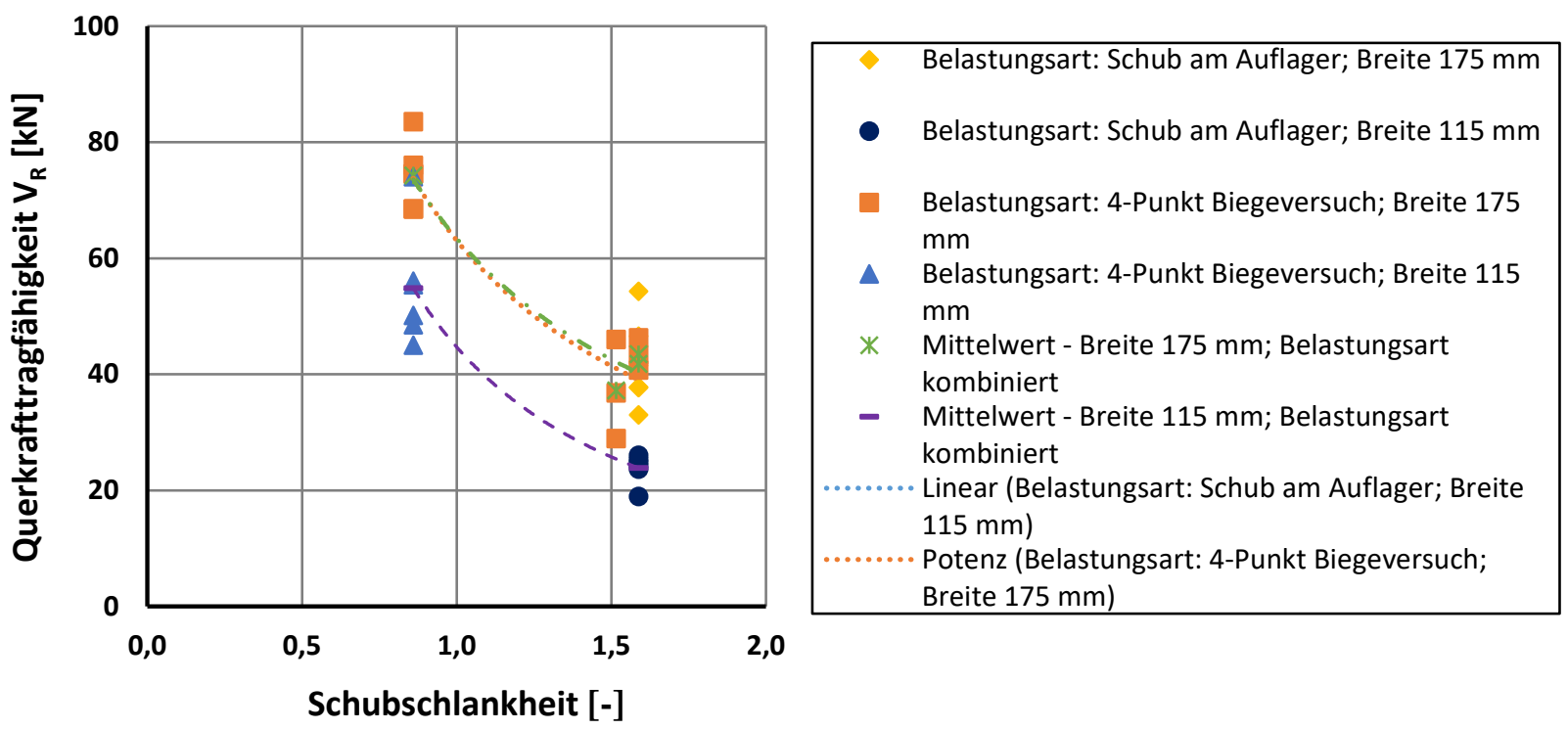

Bild 2.23 Querkrafttragfähigkeit von KS-Flachstürzen in Abhängigkeit der Schubschlankheit $\lambda$; vgl. (Klute 2004, A 1.1)

Schmidt et al. haben 2004 eine Zusammenstellung von eigenen und externen Untersuchungen an Flachstürzen mit vermörtelten und unvermörtelten Stoßfugen durchgeführt (Schmidt et al. 2004). Schmidt et al. haben den Einfluss der Schubschlankheit auf die Schubtragfähigkeit ausgewertet; siehe Bild 2.24. Die Ergebnisse zeigen, dass mit zunehmender Schubschlankheit die erreichten Schubspannungen abnehmen. Die Versuchsergebnisse mit sehr geringen, stark streuenden Schubwiderständen begründen Schmidt et al. durch die verwendeten Mauersteine mit geringer Drucktragfähigkeit. Damit bestätigen sie den Einfluss der Drucktragfähigkeit der Mauersteine auf den Schubwiderstand. 


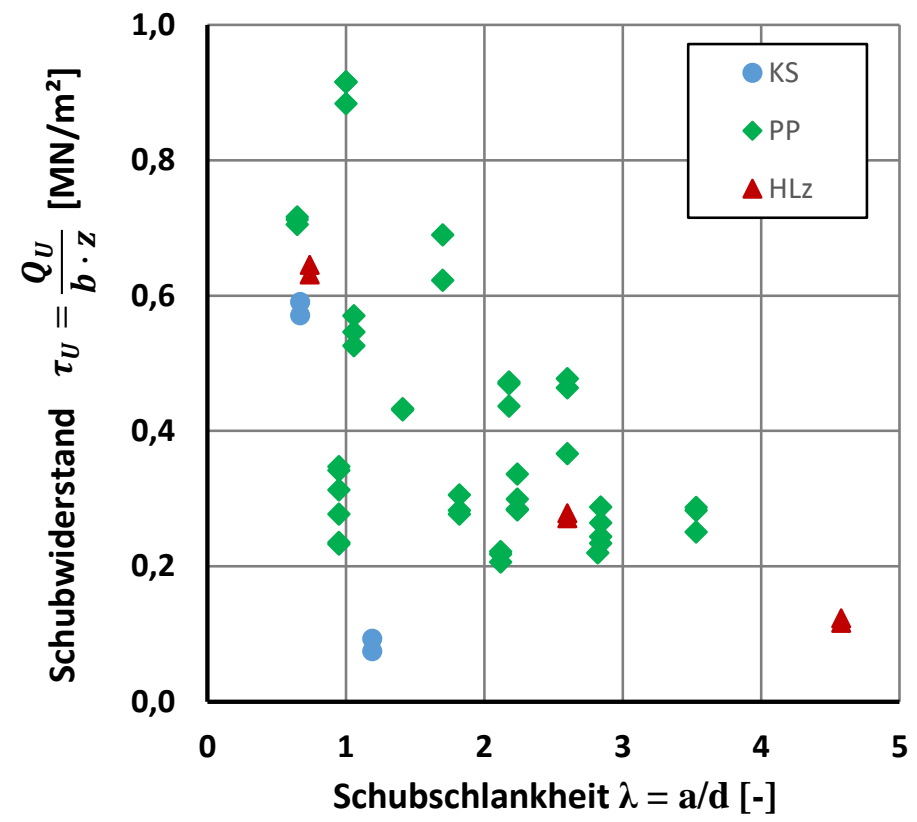

Bild 2.24 Querkrafttragfähigkeit von Flachstürzen in Abhängigkeit von der Schubschlankheit; vgl. (Schmidt et al. 2004, S. 302)

Die bisherigen Forschungsergebnisse belegen die grundsätzliche Abhängigkeit der Schubtragfähigkeit von der Schubschlankheit. Darüber hinaus sind in Tabelle 2.2 die zitierten Forschungsergebnisse hinsichtlich Einflussfaktoren und Tragmechanismen auf die Größe des Schubwiderstandes zusammengefasst.

Tabelle 2.2 Schubwiderstand: Einflussfaktoren und Tragmechanismen

\begin{tabular}{|c|c|}
\hline Literatur & $\begin{array}{l}\text { Schubwiderstand: } \\
\text { Einflussfaktoren und Tragmechanismen }\end{array}$ \\
\hline Parason et al. & - Mauerwerkverband. \\
\hline Sinha & $\begin{array}{l}\text { - } \quad \text { Schubschlankheit, } \\
\text { - } \quad \text { Längsbewehrung. }\end{array}$ \\
\hline Mastumura & $\begin{array}{ll}\text { - } & \text { Art der Bewehrung, } \\
\text { - } & \text { Druckfestigkeit der Mauersteine, } \\
\text { - } & \text { Schubfestigkeit der Mauersteine, } \\
\text { - } & \text { Mauerwerkkonstruktion (fugenbewehrte Balken, bewehrte Balken } \\
\text { mit verfülltem Hohlraum), } \\
\text { - } \quad \text { Bewehrungsgrad der Schubbewehrung, } \\
\text { - } \quad \text { Bewehrungsgrad der Biegebewehrung. }\end{array}$ \\
\hline Hendry et al. & $\begin{array}{ll}\text { - } & \text { Ungerissene Biegedruckzone, } \\
\text { - } & \text { Rissuferverzahnung, } \\
\text { - } & \text { Dübelwirkung der Längsbewehrung, } \\
\text { - } & \text { Schubschlankheit, } \\
\text { - } & \text { Mauerwerkkonstruktion (fugenbewehrte Balken, bewehrte Balken } \\
\text { mit verfülltem Hohlraum), } \\
\text { - } \quad \text { Vorspannung. }\end{array}$ \\
\hline Flohrer und Hilsdorf & - $\quad$ Schubschlankheit. \\
\hline Sager & - $\quad$ Mauerwerkfestigkeitsklassen. \\
\hline Zelger und Daschner & $\begin{array}{ll}\text { - } & \text { Schubschlankheit, } \\
\text { - } & \text { Lochbild der Mauersteine. }\end{array}$ \\
\hline Schieß1, Schubert und Schmidt & $\begin{array}{ll}\text { - } & \text { Druckfestigkeit der Mauersteine, } \\
\text { - } & \text { Vermörtelte und unvermörtelte Stoßfugen. }\end{array}$ \\
\hline Schmidt, Fehling und Seim & - $\quad$ Schubschlankheit. \\
\hline
\end{tabular}




\subsubsection{Vorgespannte Mauerwerkbalken}

Uduehi hat 1989 eine Literaturrecherche über experimentelle Untersuchungen an vorgespannten Mauerwerkbalken durchgeführt (Uduehi 1989): Es zeigte sich, dass der Ankerbereich von vorgespannten Mauerwerkbalken mehrfach zum Bauteilversagen geführt hat. Daher wurde vorgeschlagen, Mauersteine mit einem Zugwiderstand einzusetzen, der größer als die einwirkenden Querzugspannungen ist. Hinsichtlich der Spannstahlanordnung in der Konstruktion wurde empfohlen, Mauersteine mit Lochungen (Spannkanälen) herzustellen, durch die der Spannstahl geführt werden kann. Die Ergebnisse der Literaturrecherche belegen, dass mit abnehmender Schubschlankheit die Schubtragfähigkeit zunimmt. Uduehi begründet die Umlagerung vom Balken- zum Sprengwerkmodell durch das Einsetzen von Biegerissen (Uduehi 1989, S. 6-29).

Uduehi hat eigene experimentelle und theoretische Untersuchungen zur Vergleichbarkeit von vorgespannten Balken aus Mauerwerk mit solchen aus Beton durchgeführt. Die Untersuchungen ergaben, dass teilweise vorgespannte Mauerwerkbalken geringere Schubtragfähigkeiten aufweisen, als solche mit vollständig vorgespannten Querschnitten. Höhere Schubtragfähigkeiten von Betonbalken begründet Uduehi durch die von der Gesteinskörnung ausgehende Rissuferverzahnung (aggregate interlock) und dem Fehlen von Fugen wie bei Mauerwerkbalken. Eine Abhängigkeit der Schubtragfähigkeit vorgespannter und teilweise vorgespannter Mauerwerkbalken von der Schubschlankheit wurde nachgewiesen. Bild 2.25 zeigt, dass voll vorgespannte Mauerwerkbalken mit geringen Schubschlankheiten deutlich größere Schubwiderstände aufweisen, als solche mit teilweiser Vorspannung.

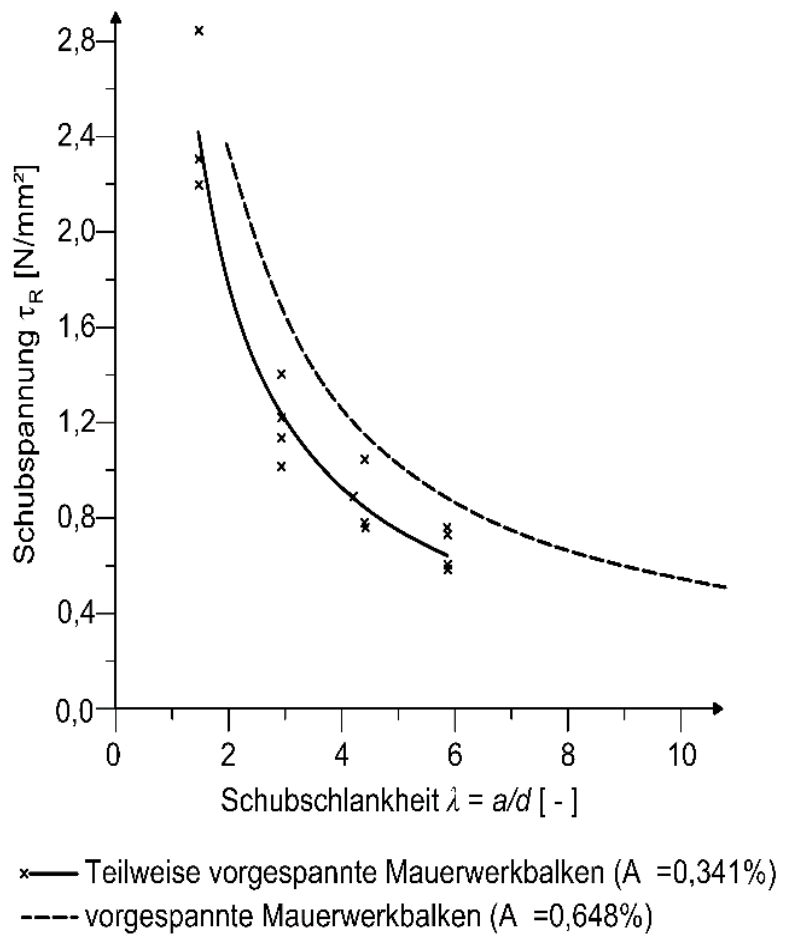

Bild 2.25 Verhältnis der bezogenen Schubtragfähigkeit zwischen vorgespannten und teilweise vorgespannten Mauerwerkbalken in Abhängigkeit zur Bauteilschlankheit vgl. (Uduehi 1989, S. 286)

Curtin et al. veröffentlichten 1988 einen Bemessungsvorschlag für vorgespannte Mauerwerkbalken unter Anwendung der Gleichung (2.18), wobei die bezogene Schubtragfähigkeit $\left(f_{\mathrm{v}}\right)$ nach Gleichung (2.14) zu bestimmen ist (Curtin et al. 1988, S. 117-141).

$f_{\mathrm{v}}=0,35+0,6 \cdot g_{\mathrm{B}}$ 
Dabei ist:

$g_{\mathrm{B}} \quad$ Die Bemessungsspannung in horizontaler Richtung inklusive der Vorspannung bei einer Beanspruchung senkrecht zu den Lagerfugen.

Bei einer Beanspruchung parallel zu den Lagerfugen ist $g_{\mathrm{B}}$ mit Null anzunehmen (Curtin et al. 1988, S. 138). Für vorgespannte Balken, Kragarme oder wandartige Träger, bei denen die Schubschlankheit zwischen $2>\lambda=\frac{\max M}{\max V \cdot d} \leq 6$ beträgt, kann $f_{\mathrm{v}}$ durch den Faktor $x$ nach Gleichung (2.15) erhöht werden (Curtin et al. 1988, S. 22). Dabei darf $f_{\mathrm{v}}$ einen Wert von 1,75 N/mm² nicht überschreiten (Curtin et al. 1988, S. 138). Curtin weist darauf hin, dass dieser Grenzwert für schlaff bewehrtes Mauerwerk sinnvoll erscheint, jedoch nicht zwangsläufig auch für vorgespannte Balkenkonstruktionen gilt (Curtin et al. 1988, S. 139).

$$
x=2,5-0,25 \cdot\left(\frac{a}{d}\right)
$$

Darüber hinaus geben Curtin et al. einen Zusammenhang zwischen Schub- und Zugfestigkeit von Mauerwerk an, wonach die Bruchschubspannung etwa doppelt so groß ist als die Mauerwerkszugfestigkeit (Curtin et al. 1988, S. 140).

In DIN EN 1996-1-1, Anhang J (DIN EN 1996-1-1:2013-02, S. 116), ist kein Hinweis auf die Bemessung von vorgespannten Mauerwerkbalken enthalten. In dem zugehörigen Normentext heißt es unter Abschnitt 6.8.2 „Nachweis von Bauteilen“ (2): „Die Tragfähigkeit vorgespannter Mauerwerksbauteile muss auf der Basis einer geeigneten Theorie, die sämtliche Parameter des Materialverhaltens und Effekte der Theorie II. Ordnung berücksichtigt, berechnet werden.“ sowie unter Abschnitt 6.8.2 (5): „Der Bemessungswert der aufnehmbaren Schubkraft muss größer als der Bemessungswert der einwirkenden Schubkraft sein." (DIN EN 1996-1-1:2013-02, S. 80).

Für vorgespannte Flachstürze (Z-17.1-1065 2017; Z-17.1-957 2017) der Bauteilkategorie $\mathrm{Ib}_{\text {III }}$ von Tabelle 2.1 erfolgt die Schubbemessung wie für schlaff bewehrte Flachstürze nach Abschnitt 2.5.7. Eine Erhöhung des Bemessungswertes der Schubfestigkeit durch die Vorspannung erfolgt nicht.

Im Ergebnis fehlt ein konsistentes Trag- und Handrechenmodell zur Querkraftbemessung vorgespannter Mauerwerkbalken, weshalb diese Konstruktionsart bislang wenig eingesetzt wird.

\subsection{Inhalte bauaufsichtlicher Regelwerke}

In bauaufsichtlichen Regelwerken erfolgt der Querkraftnachweis über einen Vergleich von einwirkenden und widerstehenden Querkräften $(V)$ oder Schubspannungen $(\tau)$.

Im Mauerwerkbau erfolgt der Nachweis heute üblicherweise kraftbezogen:

$$
V_{\mathrm{Ed}} \leq V_{\mathrm{Rd}}
$$

Dabei sind:

$\begin{array}{ll}V_{\text {Ed }} & \text { Der Bemessungswert der einwirkenden Querkraft, } \\ V_{\mathrm{Rd}} & \text { der Bemessungswert des Schubtragwiderstands. }\end{array}$

In spannungsbezogenen Nachweisen wird die einwirkende Schubspannung $\left(\tau_{0}\right)$ dem Grenzwert $\left(\tau_{011}\right)$ gegenübergestellt. Es ist: 
$\max \tau \leq \tau_{011}$

Dabei sind:

$\max \tau \quad$ Der unter Gebrauchslasten ermittelte Rechenwert einwirkender Schubspannungen $\max \tau=\frac{V_{\mathrm{E}}}{b_{\mathrm{w}} \cdot \mathrm{z}}$,

$b_{\mathrm{w}} \quad$ die kleinste wirksame Schubbreite,

$z \quad$ der Hebelarm der inneren Kräfte,

$\tau_{011} \quad$ der Grenzwert der aufnehmbaren Schubspannungen.

Bis auf die Inhalte von „DIN EN 1996-1-1“ (DIN EN 1996-1-1:2013-02) in Kombination mit dem nationalen Anwendungsdokument (DIN EN 1996-1-1:2012-01/NA) sind wegen der kompakten Darstellung die Bestimmungen weiterer Regelwerke detailliert in den Tabellen (Tabelle A 1.3 bis Tabelle A 1.9) aufgeführt.

\subsubsection{DIN EN 1996-1-1:2013}

Im Folgenden werden Inhalte von DIN EN 1996-1-1 (DIN EN 1996-1-1:2013-02) zitiert. Eine Bemessung von bewehrtem Mauerwerk nach nationalem Anwendungsdokument (DIN EN 1996-1-1:2012-01/NA) ist aufgrund vergleichsweise hoher Teilsicherheitsbeiwerte $\left(\gamma_{M}=10\right)$ wirtschaftlich nicht möglich.

Für bewehrte Mauerwerkbalken ohne Querkraftbewehrung ist, nach DIN EN 1996-1-1, Abschnitt 6.7.3, Gleichung (2.16) zu erfüllen (DIN EN 1996-1-1:2013-02, S. 78). Der Bemessungswert des Schubtragwiderstands $V_{\mathrm{Rd}}$, hier $V_{\mathrm{Rd} 1}$ genannt, ist für bewehrte Mauerwerkbalken ohne Querkraftbewehrung nach Gleichung (2.18) zu bestimmen und basiert auf den theoretischen Grundlagen von Abschnitt 2.5.10.2.

$$
V_{\mathrm{Rd} 1}=f_{\mathrm{vd}} \cdot b \cdot d
$$

Dabei sind:

$b \quad$ Die minimale Breite des Trägers an der Stelle der zur Berechnung verwendeten Nutzhöhe,

$d \quad$ die Nutzhöhe des Trägers,

$f_{\mathrm{vd}} \quad$ der Bemessungswert der Schubfestigkeit des unbewehrten Mauerwerks nach 2.4.1 und 3.6.2, DIN EN 1996-1-1 (DIN EN 1996-1-1:2013-02, 26, 36); siehe auch Gleichung (2.19).

$f_{\mathrm{vd}}=f_{\mathrm{vk}} / \gamma_{\mathrm{M}}$

Dabei sind:

$f_{\mathrm{vk}} \quad$ Die charakteristische Schubfestigkeit nach DIN EN 1996-1-1/NA (DIN EN 1996-1-1:2012-01/NA, S. 17), abhängig von der Lastrichtung und dem sich daraus ergebenden Mauerwerkverband nach Gleichung (2.20) bzw. Gleichung (2.21),

$\gamma_{\mathrm{M}} \quad$ der Teilsicherheitsbeiwert des Mauerwerks.

Die charakteristische Schubfestigkeit $\left(f_{\mathrm{vk}}\right)$ wird durch den Grenzwert $\left(f_{\mathrm{vlt}}\right)$ bestimmt. Für die Ermittlung von $\left(f_{\text {vlt }}\right)$ wird nach DIN EN 1996-1-1 auf das entsprechende nationale Anwendungsdokument verwiesen (DIN EN 1996-1-1:2013-02, S. 36). Nach DIN EN 1996-1-1/NA (DIN EN 1996-1-1:2012-01/NA) ist der $f_{\text {vlt }}$-Wert für bewehrtes Mauerwerk der gleiche wie für unbewehrtes Mauerwerk. $f_{\text {vlt }}$ ist in Abhängigkeit der Beanspruchungsart „Scheibenschub“ oder „Plattenschub“ zu bestimmen und basiert auf den theoretischen Grundlagen von Mann/ Müller nach Abschnitt 3.3.2.1 dieser Arbeit. Für eine Beanspruchung in Scheibenrichtung ergibt sich der Wert der charakteristischen Schubfestigkeit $\left(f_{\mathrm{vk}}\right)$ aus dem kleineren der beiden Grenzwerte $\left(f_{\mathrm{vlt}, 1}\right.$ und $\left.f_{\mathrm{vlt}, 2}\right)$ nach Gleichung (2.20). Für die Ermittlung der Grenzwerte unter einer Scheibenschubbeanspruchung wird auf Abschnitt 3.3.2.1 verwiesen. 
Scheibenschub:

$f_{\mathrm{vk}}=\min \left(f_{\mathrm{vlt} 1} ; f_{\mathrm{vlt} 2}\right)$

Dabei sind:

$f_{\text {vlt1 }} \quad$ Der Reibungsversagen nach Gleichung (A 3.1),

$f_{\text {vlt2 }} \quad$ die Steinzugversagen nach Gleichung (A 3.4);

bei Mauerwerk aus Porenbetonplansteinen mit glatten Stirnflächen und vollflächig vermörtelten Stoßfugen kann dieser Wert mit dem Faktor 1,2 erhöht werden.

Plattenschub:

$f_{\mathrm{vk}}=f_{\mathrm{vlt}}$

Der Bemessungswert der Mauerwerkschubfestigkeit unbewehrten Mauerwerks $\left(f_{\mathrm{vd}}\right)$ in Gleichung (2.18) darf nach DIN EN 1996-1-1 zur Bestimmung von $V_{\mathrm{Rd} 1}$ durch Multiplikation mit einem Zahlenwert nach Gleichung (2.22) erhöht werden, gleichwohl ein Grenzwert von $f_{\mathrm{vd}} \leq 0,3 \mathrm{~N} / \mathrm{mm}^{2}$ einzuhalten ist.

$$
1 \leq \frac{2 \cdot d \cdot \max V_{E d}}{\max M_{E d}}=\frac{2 \cdot d}{a} \leq 4
$$

Dabei ist:

$a$

$$
a=\max M_{\mathrm{Ed}} / \max V_{\mathrm{Ed}} .
$$

Wird die Gleichung (2.22) durch Einsetzen der Schubschlankheit $(\lambda)$ aus Gleichung (2.9) modifiziert, kann der Erhöhungsfaktor nach Gleichung (2.23) berechnet werden.

$$
1 \leq 2 / \lambda \leq 4
$$

Weiterhin verweist DIN EN 1996-1-1 unter Abschnitt 6.7.3 (DIN EN 1996-1-1:2013-02, S. 78) auf den als „informativ“ deklarierten Anhang J „Bewehrte Mauerwerkbauteile unter Querkraftbeanspruchung: Vergrößerungsfaktor $f_{\mathrm{vd}}$ ". Dort wird angegeben, dass bei Wänden oder Balken mit Hauptbewehrungen (longitudinal reinforcement) in Aussparungen, Kanälen oder Zwischenräumen der Wert $f_{\mathrm{vd}}$ für die Berechnung von $V_{\mathrm{Rd} 1}$ mit Gleichung (2.24) ermittelt werden darf.

$$
f_{\mathrm{vd}}=\frac{(0,35+17,5 \cdot \rho)}{\gamma_{\mathrm{M}}} \leq \frac{0,7}{\gamma_{\mathrm{M}}}
$$

Dabei sind:

$$
\begin{array}{ll}
\gamma_{\mathrm{M}} & \text { Der Teilsicherheitsbeiwert des Mauerwerks, } \\
\rho & \text { der geometrische Bewehrungsgrad nach Gleichung (2.25). }
\end{array}
$$

$\rho=A_{\mathrm{s}} /(b \cdot d)$

Dabei sind:

$A_{\mathrm{s}} \quad$ Die Querschnittsfläche der Hauptbewehrung,

$b \quad$ die Breite des Querschnitts,

d die Nutzhöhe.

Für gelenkig gelagerte, bewehrte Balken (oder eingespannte Stützwände) mit der Hauptbewehrung in Aussparungen, Kanälen oder Zwischenräumen, umgeben von Füllbeton (Druckfestigkeit des Füllmaterials $\geq 6 \mathrm{~N} / \mathrm{mm}^{2}$ ) bei denen das Verhältnis von $\alpha_{\mathrm{v}} / d \leq 6$ eingehalten wird, darf $f_{\mathrm{vd}}$ nach Absatz (2), Anhang J, DIN EN 1996-1-1 um den Faktor $(\chi)$ nach Gleichung (2.26) erhöht werden, wobei ein Grenzwert von $f_{\mathrm{vd}} \leq$ $1,75 / \gamma_{\mathrm{M}}$ einzuhalten ist. 
$\chi=(2,5-0,25 \cdot a / d)$

Gleichung (2.27) zeigt eine vereinfachte Darstellung der Gleichung (2.26) durch Einsetzen der Schubschlankheit $\lambda$.

$$
\chi=(2,5-0,25 \cdot \lambda)
$$

In Bild 2.26 ist der Einfluss der Erhöhungsfaktoren von DIN EN 1996-1-1, Abschnitt 6.7.3 (2) sowie von Anhang J (2) in Abhängigkeit zur Schubschlankheit dargestellt. Bei einer Schubschlankheit von $\lambda=0,89$ ergibt sich ein Schnittpunkt der Funktionen. Nicht nachvollziehbar erscheint, dass im Bereich bis zu einer Schubschlankheit von 2 keine eindeutige Vorgehensweise existiert. Wie bereits unter Abschnitt 2.4.2 (vorgespannte Mauerwerkbalken) beschrieben, hat Curtin auch für bewehrte Mauerwerkbalken Bemessungsgleichungen angegeben. Dabei hat er den Anwendungsbereich der Gleichung (2.26) auf einen Bereich von $2>\lambda \leq 6$ beschränkt (Curtin et al. 1988, S. 22).

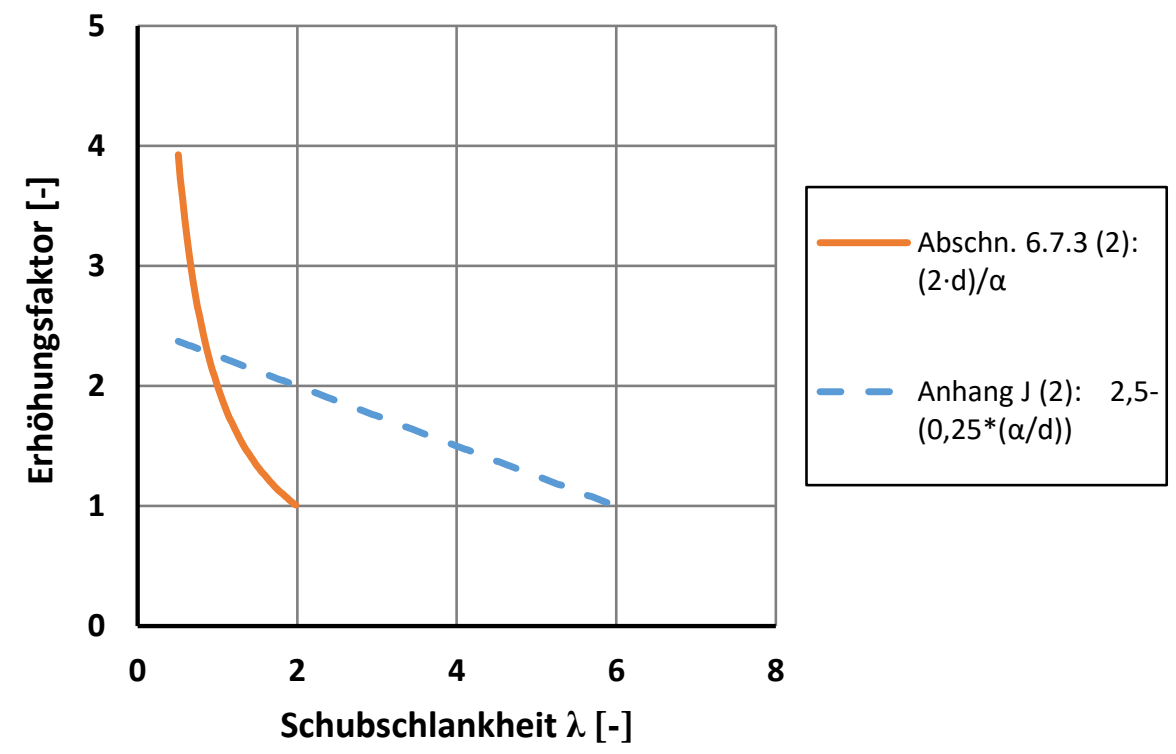

Bild 2.26 Erhöhungsfaktoren für den Bemessungswert der Schubfestigkeit in Abhängigkeit zur Schubschlankheit nach DIN EN 1996-1-1 (DIN EN 1996-1-1:2013-02, S. 116)

Werden Flachstürze nach DIN EN 1996-1-1, Abschnitt 6.6.5, bemessen, gilt, je nachdem ob es sich um einen Balken oder einen wandartigen Träger handelt, Abschnitt 6.7.3 (DIN EN 1996-1-1:2013-02, S. 78) (Nachweis von bewehrten Mauerwerkbalken unter Schubbelastung); siehe Gleichungen (2.18) bis (2.27) oder 6.7.4 (DIN EN 1996-1-1:2013-02, S. 79) (Nachweis von Wandscheiben unter Schubbelastung). Ist nach Abschnitt 6.7.4 zu bemessen, gilt weiterhin die Nachweisführung nach Abschnitt 6.7.3 unter der Bedingung, dass die einwirkende Schubkraft am Auflagerrand anzunehmen ist und die statische Nutzhöhe nach Gleichung (2.28) bestimmt wird.

$d=1,3 \cdot z$

Dabei sind:

$d \quad$ Die statische Nutzhöhe,

z $\quad$ der Hebelarm der inneren Kräfte. 


\subsubsection{DIN 1053-3:1990}

In der nicht mehr gültigen DIN 1053-3:1990 wurde bei der Querkraftbemessung nach Gleichung (A 1.1) zwischen einer Beanspruchung parallel zur Mauerwerkebene (Scheibenschub) und rechtwinklig dazu (Plattenschub) unterschieden (DIN 1053-3:1990-02, S. 3-4). Der Nachweis erfolgte spannungsbasiert; es war nachzuweisen, dass die unter Gebrauchslasten bestimmten Schubspannungen ( $\max \tau$ ) kleiner sind als die aufnehmbaren Schubspannungen ( $\left.\tau_{011}\right)$ nach DIN 1053-2:1984-07, Abschnitt 7.5 (DIN 1053-2:198407); siehe Gleichung (A 1.1). $\tau_{011}$ nach Gleichung (A 1.4) ist mechanisch ausschließlich von dem Rechenwert der jeweiligen Mauerwerkdruckfestigkeit bzw. von der Mauerwerkfestigkeitsklasse (M) nach DIN 1053-2, Tabelle 6 (DIN 1053-2:1984-07), abhängig.

\subsubsection{E DIN 1053-3:2008}

Nach dem Normenentwurf E DIN 1053-3 (E DIN 1053-3:2008-03) sind zur Schubbemessung bewehrter Mauerwerkbalken die Regelungen von DIN EN 1996-1-1 (DIN EN 1996-1-1:2013-02) bzw. DIN EN 19961-1/NA (DIN EN 1996-1-1:2012-01/NA) anzuwenden; siehe Tabelle A 1.4. Bei Balken mit einer Einzellast im Abstand vom Auflagerrand $\left(a_{\mathrm{v}}^{*}\right)$ nach Gleichung (A 1.5) darf bei direkter Auflagerung die einwirkende Querkraft am Auflager um den Beiwert nach (A 1.6) verringert werden, was als Äquivalent zu einer Erhöhung des Bemessungswertes der Schubfestigkeit um den Faktor nach Gleichung (2.22) anzusehen ist. Für die Ermittlung von $f_{\mathrm{vk}}$ wird die lotrechte Druckspannung in der Lagerfuge für direkt aufgelagerte Balken vereinfachend aus der Auflagerkraft $\left(F_{\mathrm{Ad}}\right)$ der Balken nach Gleichung (A 1.7) abgeschätzt.

\subsubsection{DIN EN 12602:2016 - Porenbeton}

DIN EN 12602:2016-12, Anhang A.4 (DIN EN 12602:2016-12, S. 76), enthält Gleichungen zur Schubbemessung von vorgefertigten bewehrten Balkenkonstruktionen aus dampfgehärtetem Porenbeton; siehe Tabelle A 1.5. Die Bemessungsgleichungen orientieren sich an der Schubbemessung für Stahlbetonbalken nach (DIN EN 1992-1-1:2011-01) in Verbindung mit (DIN EN 1992-1-1/NA:2013-04); siehe Abschnitt 4.3.3.

\subsubsection{DIN EN 1520:2011 - Leichtbeton}

Die Querkraftbemessung von Balken aus haufwerksporigem Leichtbeton erfolgt nach DIN EN 1520:201106, Anhang A.5 (DIN EN 1520:2011-06, S. 59). Der Bemessungswert der aufnehmbaren Querkraft für Bauteile ohne Schubbewehrung $\left(V_{\mathrm{Rd} 1}\right)$ ist nach Gleichung (A 1.13) oder Gleichung (A 1.18) und der Bemessungswert der Druckstrebentragfähigkeit $\left(V_{\mathrm{Rd} 2}\right)$ nach Gleichung (A 1.23) zu berechnen; siehe Tabelle A 1.6.

\subsubsection{DIN 1045-100:2017 - Ziegeldecken}

Nach DIN 1045-100 (DIN 1045-100:2017-09) wird ein Deckenstreifen mit geometrischen Eigenschaften nach Abschnitt 2.2 betrachtet. Der Bemessungswert der aufnehmbaren Querkrafttragfähigkeit wird nach Gleichung (A 1.26) bestimmt; siehe Tabelle A 1.7. Darin enthaltener Wert der aufnehmbaren Schubspannungen wird, je nach Druckfestigkeitsklasse der Deckenziegel, mit einem konstanten Wert von $\tau_{\mathrm{Rd}}=0,53$ oder $0,63 \mathrm{~N} / \mathrm{mm}^{2}$ angenommen.

\subsubsection{Flachsturzrichtlinie (Entwurf 2005) - Flachsturz}

Die in der abZ zur Schubbemessung von Flachstürzen verwendeten Gleichungen basieren auf der Flachsturzrichtlinie (Flachsturz-Richtlinie - Vorläufiger Schlussentwurf). Der Querkraftwiderstand ist nach Gleichung (A 1.27) zu ermitteln, siehe Tabelle A 1.8. Der lineare Anteil der Gleichung basiert auf den theoretischen Zusammenhängen nach Gleichung (2.36) und Bild 2.30; siehe auch Gunkler (Gunkler 1992, S. 101). Die Bemessungsgleichung berücksichtigt den Einfluss der Schubschlankheit sowie den Reibungswiderstand der Lagerfugen. Als einwirkende Querkraft wird die Höhe der Auflagerlinie 
angenommen. Im Gutachten Nr. GA 02/09 hat Gunkler einen Vergleich zwischen der Querkrafttragfähigkeit von Fertigteilstürzen (Abschnitt 2.5.7) und Flachstürzen durchgeführt; siehe Bild 2.27 (Gutachten Nr. GA 02/09 2009, S. 24). Die Gleichungen zur Bestimmung des Schubwiderstandes von Fertigteilstürzen enthält Abschnitt 2.5.7.

Bild 2.27 sind folgende Materialparameter zugrunde gelegt (Gutachten Nr. GA 02/09 2009, S. 22):

$$
\begin{aligned}
& \gamma_{\mathrm{M}}=1,5 \quad \text { Teilsicherheitsbeiwert für das Material, } \\
& f_{\mathrm{vk} 0}=0,50 \mathrm{MN} / \mathrm{m}^{2} \quad \text { charakteristische Haftscherfestigkeit für Dünnbettmörtel, } \\
& \mu=0,6 \quad \text { der Reibungskoeffizient, } \\
& f_{\mathrm{bz}}=0,66 \mathrm{MN} / \mathrm{m}^{2} \quad \begin{array}{l}
\text { Steinzugfestigkeit von Hochlochste } \\
f_{\mathrm{bk}}, \text {, der Steinfestigkeitsklasse } 20 .
\end{array}
\end{aligned}
$$

Querkraftwiderstand bei DM nach Zulassung $\left(f_{\mathrm{vk} 0}=0,5 \mathrm{~N} / \mathrm{mm}^{2}\right)$

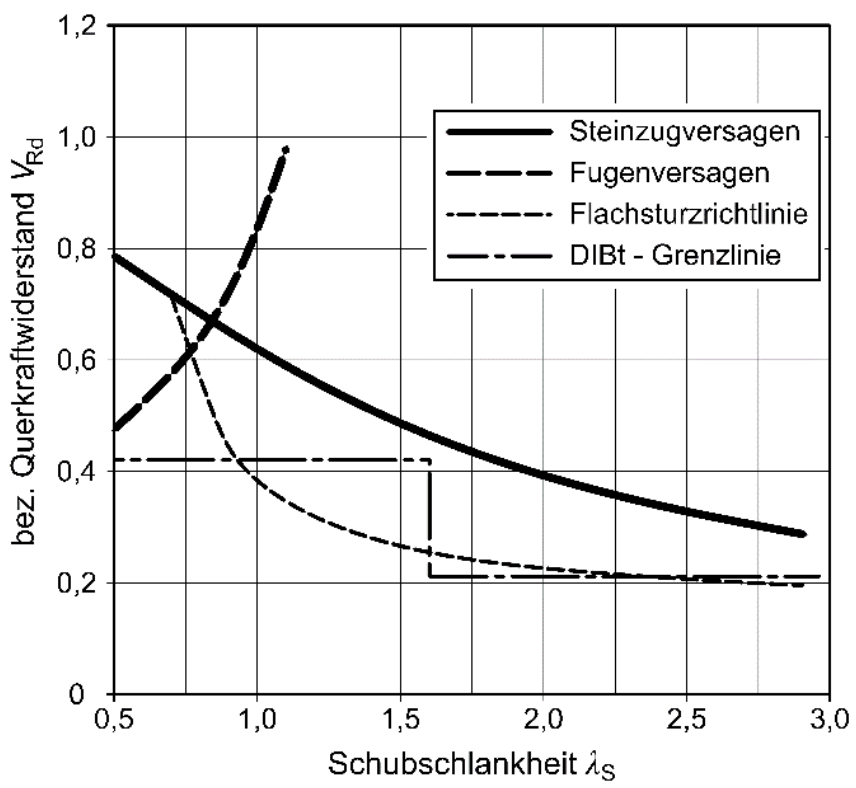

Bild 2.27 Vergleich von bezogenen Schubtragfähigkeiten $v_{\mathrm{Rd}}$ von Flachstürzen und Fertigteilstürzen (Gutachten Nr. GA 02/09 2009, S. 24)

Bild 2.27 zeigt, dass Flachstürze rechnerisch eine geringere Schubtragfähigkeit aufweisen als scheitrechte Fertigteilstürze. Das Bruchkriterium der Flachstürze ist neben dem Einfluss der Schubschlankheit von dem Reibungswiderstand in der Lagerfuge abhängig. Ein Zugversagen der Mauersteine bleibt unberücksichtigt, wobei für die Anwendung der Flachsturzrichtlinie eine Mindestdruckfestigkeitsklasse der Mauersteine von 12 gefordert ist.

\subsubsection{Allgemein bauaufsichtliche Zulassung (abZ) - Fertigteilsturz}

Im Gegensatz zu Flachstürzen wird bei der Bemessung des Schubwiderstandes von Fertigteilstürzen ein Nachweis der Vertikalfuge sowie ein Nachweis auf Zugversagen der Mauersteine geführt; der kleinere Wert ist maßgebend (Gutachten Nr. GA 02/09 2009, S. 9-15). Die hier genannten Bemessungsgleichungen basieren auf Inhalten von abZ, wie Z-17.1-621 (Z-17.1-621 2005) bzw. den zugrunde liegenden Gutachten (Gutachten Nr. GA 02/09 2009; Gutachten Nr. G971318 1999) und sind in Gleichungen (A 1.28) bis (A $1.30)$ angegeben.

\section{Widerstand der Vertikalfuge - Reibung:}

Die Tragfähigkeit der Vertikalfuge ( $V_{\text {Rd,Fuge }}$ ) nach Gleichung (A 1.28) hängt von der Haftscherfestigkeit $\left(f_{\text {vk0 }}\right)$ des Fugenmörtels und dem Reibungskoeffizienten $(\mu)$ der Stein-Mörtelkombination ab (Bild 2.28). 


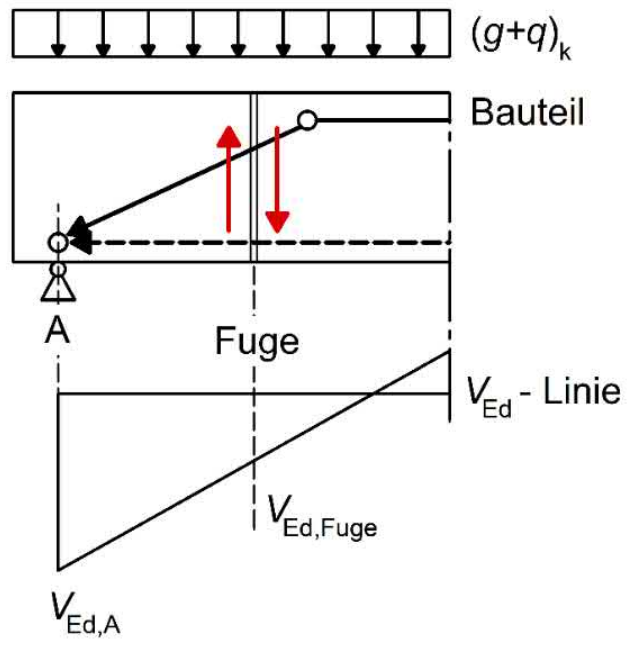

Bild 2.28 Darstellung der einwirkenden Schubkraft in Vertikalfuge

Bei der Annahme eines Druckbogens bleibt in der Gleichung (A 1.28) der Einfluss der mit größer werdendem Abstand zwischen Auflager und Vertikalfuge abnehmenden Druckzonenhöhe unberücksichtigt; siehe Bild A 1.7. Dieser Effekt kann auf der sicheren Seite liegend vernachlässigt werden, da sich eine Abnahme der Querkraft in Richtung des maximalen Moments einstellt.

\section{Widerstand gegen Steinzugversagen:}

Der Tragwiderstand gegen Steinzugversagen $\left(V_{\mathrm{Rd} \text {,Stein }}\right)$ nach Gleichung (A 1.30) basiert auf der Annahme eines Sprengwerkmodells. Durch die 2-dimensionale Lastausbreitung der Druckstrebe $\left(D_{1}\right)$ in die Druckkräfte $\left(D_{\mathrm{s}}\right)$ entstehen Querzugkräfte $\left(Z_{\mathrm{s}}\right)$ rechtwinklig zur Achse der Druckstrebe, die Steinzugversagen verursachen können; siehe Bild 2.29.
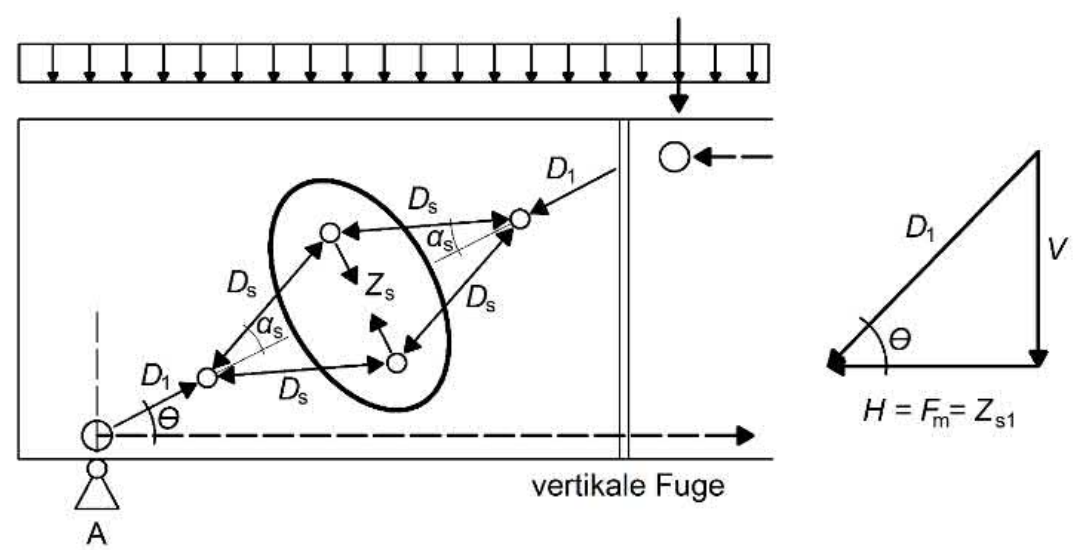

Bild 2.29 Sprengwerkmodell für die 2-dimensionale Verteilung der Druckstrebe D1; vgl. (Gutachten Nr. GA 02/09 2009, S. 21; CIB Commission W023 - State of Art Report 2013, S. 34)

Für die Berechnung von $Z_{\mathrm{s}}$ wird ein Lastausbreitungswinkel $\left(\alpha_{\mathrm{s}}\right)$ der Druckkräfte verwendet; nach Gunkler kann dieser mit $\alpha_{s}=25^{\circ}$ angenommen werden (Gutachten Nr. GA 02/09 2009, S. 21).

\subsubsection{Zusammenfassung der in Regelwerken benannten Tragwiderstände}

Tabelle 2.3 enthält eine Zusammenfassung der im Bemessungswert des Querkraftwiderstandes normativ berücksichtigten Einflussfaktoren und Tragmechanismen. Der Vergleich der Regelwerke zeigt, dass der Bemessungsansatz zur Ermittlung des Querkraftwiderstandes nach DIN EN 1520:2011 (Leichtbeton) die in experimentellen Untersuchungen ermittelten Einflussfaktoren (siehe Abschnitt 2.4) am umfassendsten berücksichtigt. DIN EN 1996-1-1 basiert hingegen auf nicht mehr aktuellen Ansätzen der Stahlbetontheorie, deren theoretische Grundlagen nachfolgend in Abschnitt 2.5.10 aufgeführt und kritisch bewertet werden. 
Tabelle 2.3 Bemessungswert der Schubfestigkeit: Einflussfaktoren und Tragwiderstände

\begin{tabular}{|c|c|c|}
\hline \multicolumn{2}{|c|}{ Regelwerke } & \multirow{2}{*}{ 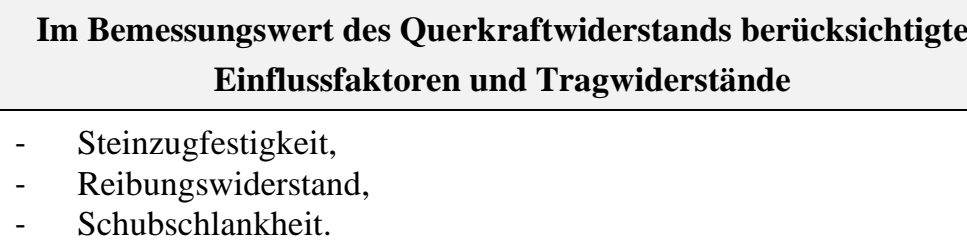 } \\
\hline $\begin{array}{l}\text { DIN EN 1996-1- } \\
1: 2013 \\
\text { Mauerwerk }\end{array}$ & $\begin{array}{l}\text { Abschnitt } \\
6.7 .3(2)\end{array}$ & \\
\hline & Anhang J & $\begin{array}{ll}\text { - } & \text { konstanter Grundwert der Schubfestigkeit, } \\
\text { - } & \text { Längsbewehrung, } \\
\text { - } & \text { Schubschlankheit. }\end{array}$ \\
\hline \multicolumn{2}{|c|}{$\begin{array}{l}\text { DIN 1053-3:1990- } \\
\text { Bewehrtes Mauerwerk }\end{array}$} & $\begin{array}{ll}\text { - } & \text { Steinzugfestigkeit, } \\
\text { - } & \text { Reibungswiderstand. }\end{array}$ \\
\hline \multicolumn{2}{|c|}{$\begin{array}{l}\text { E DIN 1053-3:2008 - } \\
\text { Bewehrtes Mauerwerk }\end{array}$} & $\begin{array}{ll}\text { - } & \text { Steinzugfestigkeit, } \\
\text { - } & \text { Reibungswiderstand, } \\
\text { - } & \text { Schubschlankheit. }\end{array}$ \\
\hline \multicolumn{2}{|c|}{$\begin{array}{l}\text { DIN EN 12602:2016- } \\
\text { Porenbeton }\end{array}$} & $\begin{array}{ll}\text { - } & \text { Schubschlankheit, } \\
\text { - } & \text { Längsbewehrung, } \\
\text { - } & \text { Zugfestigkeit implizit erfasst. }\end{array}$ \\
\hline \multicolumn{2}{|l|}{$\begin{array}{l}\text { DIN EN 1520:2011 - } \\
\text { Leichtbeton }\end{array}$} & $\begin{array}{ll}\text { - } & \text { Maßstabsfaktor, } \\
\text { - } & \text { ungerissene Biegedruckzone, } \\
\text { - } & \text { Längsbewehrung, } \\
\text { - } & \text { Zugfestigkeit implizit erfasst, } \\
\text { - } & \text { Schubschlankheit. }\end{array}$ \\
\hline \multicolumn{2}{|c|}{$\begin{array}{l}\text { DIN 1045-100:2017- } \\
\text { Ziegel-Elementdecken }\end{array}$} & - $\quad$ Tragwiderstand der Druckzone. \\
\hline \multicolumn{2}{|c|}{$\begin{array}{l}\text { Flachsturzrichtlinie (E):2005 - } \\
\text { Flachstürze }\end{array}$} & $\begin{array}{ll}\text { - } & \text { Schubschlankheit, } \\
\text { - } & \text { Reibungswiderstand, } \\
\text { - } & \text { Tragwiderstand der Druckzone. }\end{array}$ \\
\hline \multicolumn{2}{|c|}{$\begin{array}{lc}\text { Allgemein } & \text { bauaufsichtliche } \\
\text { Zulassungen } & (\text { abZ }) \quad \text { für } \\
\text { Fertigteilstürze } & \end{array}$} & $\begin{array}{ll}\text { - } & \text { Steinzugfestigkeit, } \\
\text { - } & \text { Reibungswiderstand, } \\
\text { - } & \text { Schubschlankheit. }\end{array}$ \\
\hline
\end{tabular}

\subsubsection{Kritik an aktueller Schubbemessung und verwendeter Werkstoffkenngrößen}

Die Beurteilung des Schubtragverhaltens von schlaff bewehrten Mauerwerkbalken basiert auf empirischen und theoretischen Untersuchungen. Es wurden zahlreiche empirische und semiempirische Tragmodelle entwickelt, die ursprünglich für Massivbaukonstruktionen aufgestellt wurden und auf den Baustoff „Beton“ zugeschnitten sind. Eine Vielzahl der in Abschnitt 2.5 aufgeführten Bemessungsansätze zur Ermittlung des Querkraftwiderstandes von bewehrten Mauerwerkbalken basieren auf der Annahme eines klassischen Druckfeldmodells (auch „,compression field model“ genannt). Dies wird durch ein in seiner Ebene homogen belastetes, gerissenes, orthogonal bewehrtes und isotropes Stahlbetonscheibenelement beschrieben (Weber und Stempfle 2013, S. 172). Der daraus abgeleitete Querkraftwiderstand $\left(V_{\mathrm{Rd} 1}\right)$ von Gleichung (2.18), von bewehrten Mauerwerkbalken, in Gleichung (2.36) als $\left(V_{\mathrm{R}}\right)$ bezeichnet, basiert auf eben diesen nicht mehr aktuellen Annahmen der Stahlbetontheorie. Im Folgenden wird die Kritik an diesem Vorgehen am Beispiel der Bemessungsgleichung nach DIN EN 1996-1-1, Abschnitt 2.5.1, unter Bezug auf Bild 2.30 erläutert und im Rahmen dieser Literaturrecherche kritisch bewertet. 


\subsubsection{Schubfestigkeit $\left(f_{\mathrm{vd}}\right)$}

Für Mauerwerk wird isotropes Werkstoffverhalten unterstellt, was durch die Annahme eines von der Richtung unabhängigen Schubfestigkeitswertes $f_{\mathrm{vd}}$ in Gleichung (2.18) für horizontale Lasteinwirkungen hervorgeht. Mauerwerk weist jedoch inhomogene, anisotrope Werkstoffeigenschaften auf, die u.a. von dem Lochbild, dem Überbindemaß der Mauersteine sowie von der Ausbildung der Stoßfugen abhängig sind. Diese Merkmale werden von den obigen Annahmen nicht abgebildet. Die Anisotropie der Druck-, Zugund Scherfestigkeit sowie die Verformungseigenschaften des Mauerwerks werden vernachlässigt. Ein Beispiel ist die Druckfestigkeit parallel zur Lagerfuge, bei der die Druckspannung nur über die Längsstege der Mauersteine übertragen werden können, wohingegen bei der Druckfestigkeit senkrecht zur Lagerfuge der gesamte Querschnitt zur Übertragung von Druckspannungen angesetzt werden kann. Graubner schlägt daher vor, anstelle eines pauschalen Wertes eine insbesondere vom Lochbild der Mauersteine abhängige, diagonale Mauerwerkfestigkeit als Widerstandsgröße einzuführen (Graubner 2017, S. 14).

Darüber hinaus gilt für bewehrte Mauerwerkbalken derselbe Wert der Bemessungsschubfestigkeit $f_{\mathrm{vd}}$ nach Gleichung (2.18) wie für unbewehrtes Mauerwerk. Graubner führt an, dass der Ansatz der Haftscherfestigkeit $f_{\mathrm{vk} 0}$, in Gleichung (A 3.1), zur Ermittlung der Schubfestigkeit $f_{\mathrm{vk}}$, nach Gleichung (2.20) bzw. Gleichung (2.21) zu hinterfragen ist. Dies begründet er damit, dass bei unbewehrtem Mauerwerk zu prüfen sei, ob der Tragquerschnitt durch Rissbildung begrenzt ist. Bei bewehrtem Mauerwerk ist dies oft der Fall, weil die Biegezugbewehrung erst nach Überschreitung der Zugfestigkeit des Mauerwerks aktiviert wird. Der Ansatz der Haftscherfestigkeit ist nur dann gerechtfertigt, wenn Bauteile überwiegend auf Druck beansprucht sind und keine wechselnde Biegebeanspruchung erfahren (Graubner 2017, S. 11). Damit bleibt die Druckzonenhöhe über die Zeit konstant. Mauerwerkbalken unterliegen hingegen einer überwiegenden Biegebeanspruchung. Die möglicherweise auftretende, tragfähigkeitssteigernde Verdübelungswirkung der Längsbewehrung, die national bei Stahlbetonbauteilen erfasst wird, bleibt in DIN EN 1996-1-1 namentlich unbenannt. Stattdessen wird in einer Note auf Annex $\mathrm{J}$ verwiesen, wo der geometrische Bewehrungsgrad erfasst wird (siehe auch Abschnitt 2.5.1). International ist die Berücksichtigung dieses Einflusses jedoch auch im Stahlbetonbau umstritten, da die Größe des Tragwiderstands bisher nicht eindeutig quantifizierbar ist.

\subsubsection{Querkrafttragfähigkeit $\left(V_{\mathrm{Rd} 1}\right)$}

Die Ermittlung des Querkraftwiderstandes $\left(V_{\mathrm{Rd} 1}\right)$ aus Gleichung (2.18) - in Gleichung (2.36) als $\left(V_{\mathrm{R}}\right)$ bezeichnet - von bewehrten Mauerwerkbalken ist auf frühere, nicht mehr aktuelle Annahmen der Stahlbetontheorie zurückzuführen. Diese sind in Bild 2.30 dargestellt. Der hiermit berechnete Querkraftwiderstand ist die Resultierende der Schubspannungen $\left(\tau_{\mathrm{m}} \cdot b_{\mathrm{w}}\right)$ in der ungerissenen Biegedruckzone. Durch Überschreiten der Biegezugfestigkeit wachsen Biegerisse in Richtung der Druckzone, was zu einer Verschiebung der Spannungsnullinie und damit zur Einschnürung der Druckzone führt. In Bild 2.30 ist die Ermittlung der Querkrafttragfähigkeit durch den Ansatz der Gleichgewichtsbeziehungen der inneren Kräfte an einem durch Risse begrenzten Balkenabschnitt der Länge $(\Delta x)$ dargestellt (Gunkler 1992, S. 101). Für die Ermittlung von $\tau_{\mathrm{m}}$ wird eine Rissbildung mit unendlich kleinen Rissabständen unterstellt, die sich ausschließlich senkrecht zur Längsbewehrung öffnen. Eine Rissuferverzahnung wird ausgeschlossen. 


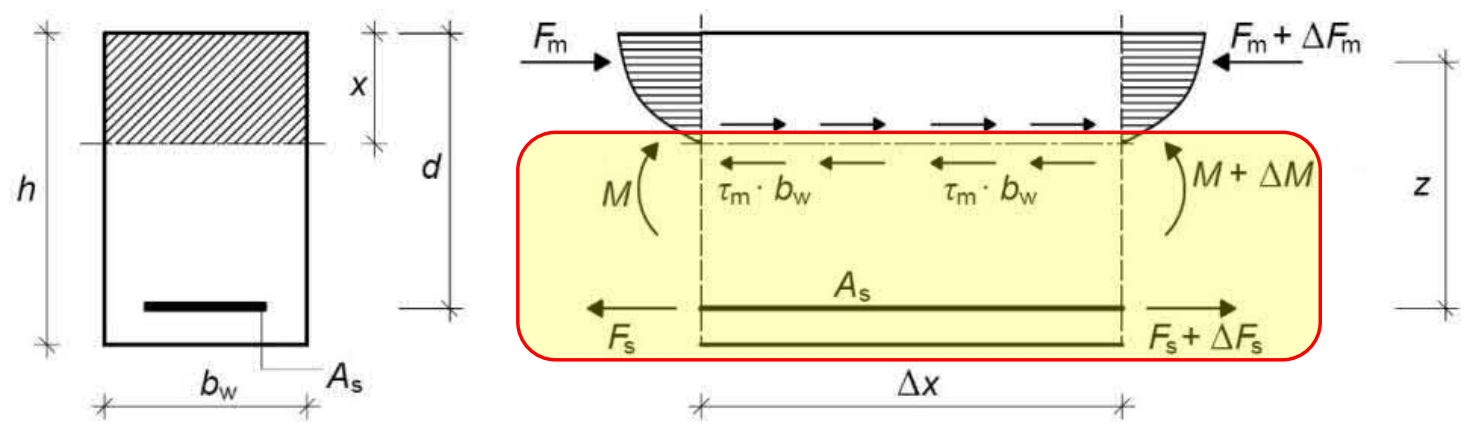

Bild 2.30 Einwirkendes Biegemoment $(M)$ und innere Kräfte an einem Balkenelement der Länge $(\Delta x)$

Gleichgewicht der inneren Kräfte im markierten Bereich von Bild 2.30:

$$
\begin{aligned}
& \sum H=0 \rightarrow \Delta F_{\mathrm{s}}-\tau_{\mathrm{m}} \cdot b_{\mathrm{w}} \cdot \Delta x=0 ; \\
& \Delta F_{\mathrm{s}}=\frac{\Delta M}{z} \\
& \tau_{\mathrm{m}}=\frac{\Delta M}{\Delta x} \cdot \frac{1}{b_{\mathrm{w}} \cdot z}
\end{aligned}
$$

Grenzübergang bei Annahme infinitesimal kleiner Rissabstände:

$$
\begin{aligned}
& \Delta x \rightarrow 0: \Delta x=d x ; \Delta M=d M ; z \rightarrow \text { konstant } \\
& \tau_{\mathrm{m}}=\frac{d M}{d x} \cdot \frac{1}{b_{\mathrm{w}} \cdot z} \\
& V=\frac{d M}{d x} \\
& \tau_{\mathrm{m}}=\frac{V}{b_{\mathrm{w}} \cdot z}
\end{aligned}
$$

Übertragen auf den Grenzzustand der Tragfähigkeit entspricht die Schubspannung $\left(\tau_{\mathrm{m}}\right)$ der Schubfestigkeit $\left(f_{\mathrm{v}}\right)$; die Querkraft $(\mathrm{V})$ bildet den Querkraftwiderstand $\left(V_{\mathrm{R}}\right)$ :

$$
\tau_{\mathrm{m}} \rightarrow f_{\mathrm{v}} ; \mathrm{V} \rightarrow V_{\mathrm{R}}
$$

Aus Gleichung (2.33) ergibt sich der Querkraftwiderstand $\left(V_{\mathrm{R}}\right)$ zu:

$$
V_{\mathrm{R}}=f_{\mathrm{v}} \cdot b_{\mathrm{w}} \cdot z
$$

Dabei sind:

$$
\begin{array}{ll}
V_{\mathrm{R}} & \text { Der Querkraftwiderstand, } \\
f_{\mathrm{v}} & \text { die Schubfestigkeit des Mauerwerks, } \\
b_{\mathrm{w}} & \text { die kleinste wirksame Schubbreite, } \\
\mathrm{z} & \text { der Hebelarm der inneren Kräfte. }
\end{array}
$$

Gleichung (2.36) hat die gleiche Struktur wie Gleichung (2.18) zur Berechnung von $\mathrm{V}_{\mathrm{Rd} 1}$, wenn dort die Balkendicke $(b)$ durch die Schubbreite $\left(b_{\mathrm{w}}\right)$ und die statische Höhe $(d)$ durch den Hebelarm der inneren Kräfte (z) ersetzt wird. Konsequenter müsste Gleichung (2.18) mit $z \cong 0,9 \cdot d$ daher lauten:

$$
V_{\mathrm{R}}=f_{\mathrm{v}} \cdot b_{\mathrm{w}} \cdot 0,9 \cdot d
$$


Die Gleichung (2.18) wurde aus mittlerweile nicht mehr aktuellen Vorstellungen des Tragverhaltens von bewehrten Betonbauteilen abgeleitet. Sie basiert auf der Annahme, dass für den Zustand II die Bernoulli Hypothese zu unterstellen ist und die Querkräfte aus den Biegemomenten abgeleitet werden können. Ferner wird von vollständigem Verbund zwischen Bewehrung und umgebendem Mauerwerk ausgegangen und isotropes Werkstoffverhalten des Mauerwerks unterstellt. Vor dem Hintergrund der Lochungen in Mauersteinen und dem Unterschied der Druckfestigkeit des Mauerwerks senkrecht und parallel zu den Lagerfugen erscheint dies nichtzutreffend.

Die Schubtragfähigkeit wird im Zusammenhang mit Gleichung (2.18) ausschließlich über die Druckzone bestimmt. Für Betonquerschnitte liegt der Anteil aus der Druckzone an der Gesamtschubtragfähigkeit zwischen ca. 15\% bis 30\% (Tue et al. 2014, S. 667). Um trotzdem ein Kräftegleichgewicht zu erzeugen, müssen weitere Traglastwiderstände aktiviert werden, wie bspw. die Rissuferverzahnung; siehe Abschnitt 4.2.2. Darüber hinaus entstehen Biegerisse nicht nur in einem spezifischen Querschnitt, sondern in entsprechenden Balkenabschnitten der Größe $\Delta x$. Mit $\Delta x=0$ wird jedoch die Annahme der theoretischen, im Zugbereich konstant verlaufenden Schubspannung begründet, was sich in der Praxis nicht einstellen kann. Dem entgegen wird heute im Massivbau das Rissverhalten ganzer Bauteilabschnitte betrachtet (,Betonzahn“) und lokale Einflüsse, wie z. B. Rissreibung und Dübelwirkung der Bewehrung erfasst.

\subsection{Ausblick auf den Berechnungsansatz dieser Arbeit}

Viele Berechnungsansätze bauaufsichtlicher Regelwerke nehmen die Bestimmung des Querkraftwiderstandes $\left(V_{\mathrm{R}}\right)$ bewehrten Mauerwerks auf der Grundlage der Theorie infinitesimal kleiner Rissabstände vor. Diese Vorgehensweise erfasst das tatsächliche Tragverhalten für einen diskreten Mauerwerkausschnitt realer Abmessungen nicht ausreichend.

Stattdessen erscheint es notwendig, ganze, auflagernahe Mauerwerkbereiche zu betrachten, die durch schräge Druckstreben als resultierende Größe feldartiger Druckspannungsverteilungen beansprucht werden. Dabei sind vom Material abhängige Randbedingungen zu berücksichtigen, wie die Anisotropie von unter Druck beanspruchtem Mauerwerk mit Ansatz einer variablen Druckstrebenneigung.

Zimmerli et al. berichten über die Anwendung von Druckspannungsfeldern für Mauerwerkkonstruktionen in Form von unbewehrten oder bewehrten

- horizontal beanspruchten Schubwänden sowie von

- vertikal beanspruchten Wänden mit Trägerwirkung (wandartige Träger).

In Bild 2.31 ist die Querkraftbeanspruchung einer bewehrten Mauerwerkwand mit Hilfe eines unter dem Winkel $\alpha \leq \varphi$ geneigten Spannungsfeldes dargestellt - mit $\varphi$ als Grenzwert der inneren Reibung. Wird $\varphi$ überschritten, tritt Reibungsversagen auf. 


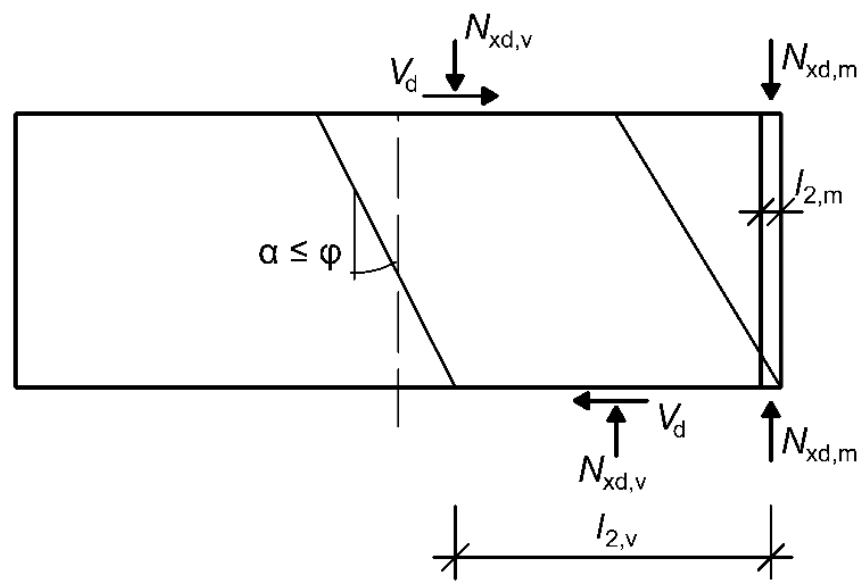

Bild 2.31 Bewehrte, in Wandebene querkraftbeanspruchte Mauerwerkwand mit erweitertem Spannungsfeld (Zimmerli et al. 1999, S. 129)

Diese Herangehensweise basiert auf dem statischen Grenzwertsatz der Plastizitätstheorie; siehe Abschnitt 4.1.2. Die Querkraftbeanspruchung des Mauerwerks wird durch die geneigte Druckstrebe aufgenommen, in der die richtungsabhängigen Mauerwerkeigenschaften wirken. Der Druckkraftverlauf entspricht dem eines fächerförmigen Druckspannungsfeldes, welches im Rahmen der Bemessung durch ein parallel verlaufendes ersetzt wird. Die Größe des Beanspruchungswinkels $(\alpha)$ ist geometrie- oder lastabhängig.

Diese Vorgehensweise wird in (Zimmerli et al. 1999, S. 101) auch für „Wände mit Trägerwirkung“ (wandartige Träger) beschrieben, die auf bewehrten Betondecken aufstehen (Bild 2.32 (a) und (b)). Auch bei nicht vorhandenen Decken wird dieser Bemessungsweg beschrieben, wenn im Zugbereich der Mauerwerkwand eine entsprechende Bewehrung eingebaut ist (Bild 2.32 (c)).

(a)

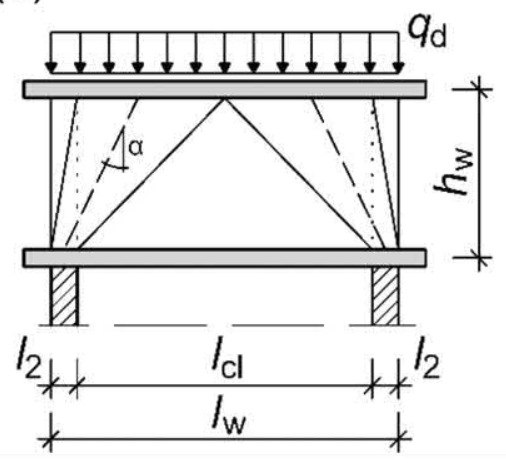

(b)

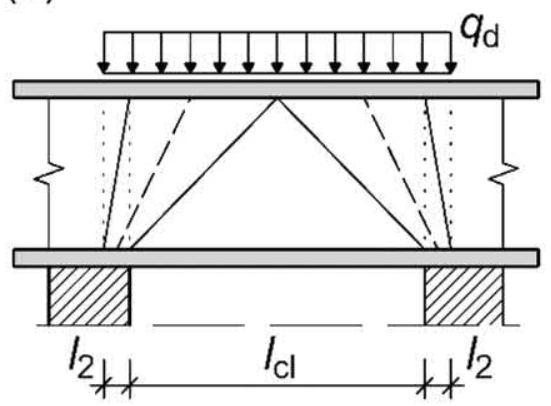

(c)

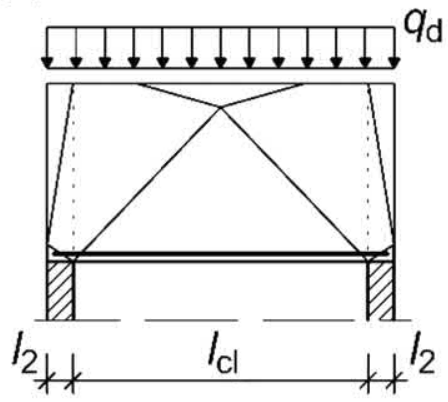

Bild 2.32 Randbedingungen für vertikal beanspruchte Wände mit Trägerwirkung nach Spannungsfeld (Zimmerli et al. 1999, S. 102); a) Einzelwand, oben und unten begrenzt durch bewehrte Stahlbetondecken; b) durchlaufende Wand; c) Biegewand ohne Betonplatten, jedoch mit unten eingebauter Biegebewehrung

Als Druckfestigkeit des durch die Neigung der Druckstrebe unter dem Winkel $\alpha$ beanspruchten Mauerwerks wird angenommen:

$$
f_{\mathrm{y}}=\delta \cdot f_{\mathrm{x}}
$$

Dabei sind:

$f_{\mathrm{y}} \quad$ Die Druckfestigkeit des Mauerwerks parallel zu den Lagerfugen,

$f_{\mathrm{x}} \quad$ die Druckfestigkeit des Mauerwerks senkrecht zu den Lagerfugen, 
der Umrechnungsfaktor (Zimmerli et al. 1999, S. 101), z. B.

$\boldsymbol{\delta}=0,5$ Backstein-Mauerwerk, Stoßfugen vermörtelt,

$\boldsymbol{\delta}=0,3$ Kalksandstein-Mauerwerk, Stoßfugen unvermörtelt.

Weitere Werkstoffkenngrößen des Mauerwerks gehen nicht in die Berechnung ein.

Die Bemessung von bewehrten Betonbalken mit Spannungsfeldern wird durch Muttoni et al. erläutert (Muttoni et al. 1997, S. 17-48); siehe auch Bild 2.33.

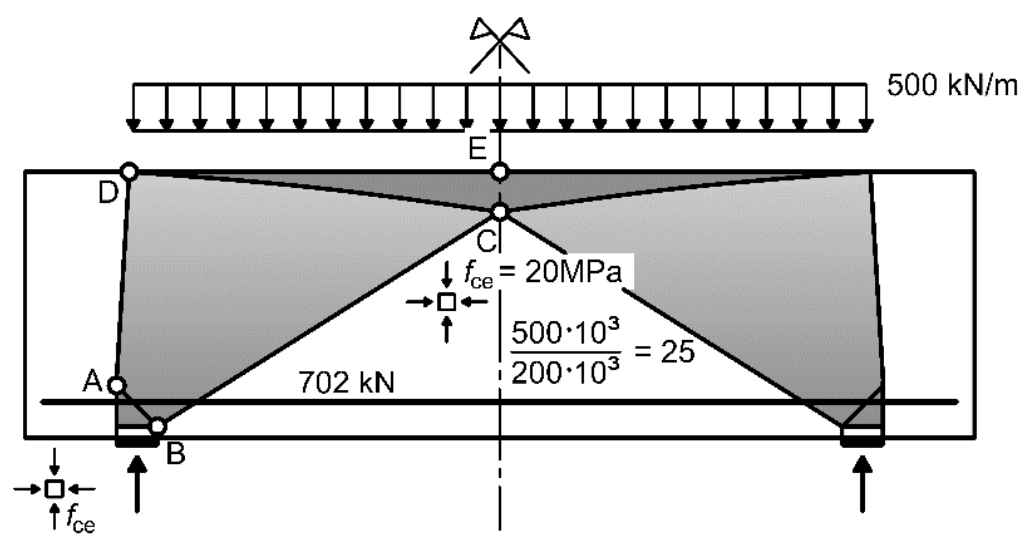

Bild 2.33 Spannungsfelder in einem durch eine Gleichstreckenlast beanspruchten Betonbalken (Muttoni et al. 1997, S. 26)

Die maximale Spannung im Bereich der Linie AB des Spannungsfeldes (Bild 2.33) wird der Betondruckfestigkeit gleichgesetzt. Die Druckspannung nimmt mit zunehmender Entfernung vom Balkenauflager ab. Im Bereich CDE herrscht ein zweiachsiger Spannungszustand.

In dieser Arbeit wird die Methode der Spannungsfelder für schlaff bewehrte und vorgespannte Mauerwerkbalken auf Basis der für bewehrte Betonbauteile entwickelten Theorie „Simplified compression field theory (SCFT)“ angewendet und für Mauerwerk verifiziert. Die theoretischen Grundlagen hierfür werden in Abschnitt 4 beschrieben.

\subsection{Zusammenfassung, Bewertung und Schlussfolgerungen für diese Arbeit}

International werden unterschiedlichste Konstruktionsformen schlaff bewehrter Mauerwerkbalken eingesetzt. In Deutschland beschränkt sich die Anwendung i.d.R. auf:

- Flachstürze (teilweise vorgefertigter, bauseits ergänzter Sturz DIN EN 845-2, S. 7),

- Fertigteilstürze (scheitrechter Sturz oder vorgefertigter Sturz DIN EN 845-2, S. 8) sowie

- spezielle Balkenkonstruktionen für Vormauer- bzw. Verblendschalen.

Vorgespannte Mauerwerkbalken kommen in Deutschland kaum zur Anwendung.

In der vorliegenden Arbeit wird die Querkrafttragfähigkeit von Fertigteilstürzen und Flachstürzen mit vermörtelten Stoßfugen untersucht, die neben ihrem Eigengewicht auch noch durch sich darüber befindende Lasten beansprucht werden können. Eine mögliche Vorspannung von Mauerwerkbalken soll erfasst werden.

Bisherige Untersuchungen an schlaff bewehrten oder vorgespannten Mauerwerkkonstruktionen liefern Ergebnisse für einzelne, das Tragverhalten bestimmende Einflussfaktoren. Gleichwohl fehlen ganzheitliche Untersuchungen, bei denen unterschiedliche Konstruktionsarten systematisch einbezogen wurden. Die Ergebnisse zeigen Parallelen mit aus dem Stahlbetonbau bekannten Querkraftwiderständen:

- Der Widerstand der ungerissenen Biegedruckzone,

- die Rissuferverzahnung sowie 
- das Mitwirken des Materials zwischen den Rissen,

- ggf. die Dübelwirkung der Biegezugbewehrung.

Die o.g. Tragwiderstände bleiben in den Regelwerken meist unberücksichtigt.

Einen hier für Mauerwerk weiter zu entwickelnden Ansatz liefert die „SMCFT“, angewendet im ,fib Modelcode 2010“ zur Ermittlung des Querkraftwiderstandes für Balken ohne Querkraftbewehrung. Hierbei ist der Verformungszustand über Längsdehnungen in die Definition des Querkraftwiderstandes mit einbezogen. Dieser Ansatz in Kombination mit einem nichtlinearen Werkstoffgesetz, das die Anisotropie von Mauerwerk erfasst, liefert eine realistische Einschätzung des tatsächlichen Querkraftwiderstandes.

Eine Verifizierung eines neuen Berechnungsvorschlages setzt entsprechende experimentelle Untersuchungen voraus. Daher sind im Rahmen dieser Arbeit eigene experimentelle Bauteiluntersuchungen durchgeführt worden (Abschnitt 5). Externe Prüfwerte von Klute (Klute 2004) werden zur Verifikation des Bemessungsvorschlages in Abschnitt 7 einbezogen. 


\section{Werkstoffbeschreibende Ausgangsgrößen}

\subsection{Mauersteine}

\subsubsection{Geometrie und Lochanteil}

Für die experimentellen Bauteilprüfungen von Abschnitt 5 wurden Ziegel-, Kalksand- und Porenbetonsteine nach Tabelle 3.1 verwendet. Ziel ist es, Einflüsse durch unterschiedliche Steinfestigkeiten und Lochgeometrien auf die Tragwiderstände zu berücksichtigen. Im Folgenden werden ausschließlich werkstoffbeschreibende Ausgangsgrößen angegeben, die im Zusammenhang mit der weiteren Bearbeitung erforderlich sind. Dabei werden Mittelwerte aus Materialprüfungen in Anlehnung an den Mauerwerkkalender (Brameshuber und Jäger 2015) mit $\beta$ bezeichnet.

Tabelle 3.1 Kennzeichnung, Geometrie und Lochanteil verwendeter Mauersteine

\begin{tabular}{|c|c|c|c|c|}
\hline Kennzeichnung & Maße & Photographie & Lochanteil & Prüfköper ${ }^{1}$ \\
\hline $\begin{array}{c}\text { HLZ B }-8 \text { DF }-12-0,8 \\
\text { (Planstein) }\end{array}$ & $497 \times 115 \times 249$ & & $48 \%^{2}$ & $\mathrm{ZI}-01^{1}$ \\
\hline $\begin{array}{c}\text { HLZ B - } 6 \text { DF }-12-0,8 \\
\text { (Planstein) }\end{array}$ & $365 \times 115 \times 238$ & & $48 \%^{2}$ & $\mathrm{ZI}-02-\mathrm{ZI}-10^{1}$ \\
\hline $\begin{array}{c}\text { HLZ B - } 5 \text { DF }-12-0,8 \\
\text { (Planstein) }\end{array}$ & $300 \times 115 \times 238$ & & $47 \%^{2}$ & ZI-11 - ZI-13 \\
\hline $\begin{array}{c}\text { KS - } 6 \text { DF }-12-1,4 \\
\text { (Planstein) }\end{array}$ & $373 \times 115 \times 248$ & & $<15 \%$ & KS-00 \\
\hline $\begin{array}{c}\text { KS XL-QU } 20-2,0 \\
\text { (Ergänzungselement) }\end{array}$ & $373 \times 240 \times 498$ & & $<15 \%$ & $\mathrm{KS}-01-\mathrm{KS}-15$ \\
\hline $\begin{array}{l}\text { KS 6DF 20-2,0 } \\
\text { (Planstein) }\end{array}$ & $248 \times 175 \times 248$ & & $<15 \%$ & $\mathrm{KS}-16-\mathrm{KS}-18$ \\
\hline $\begin{array}{c}\mathrm{PPW}-4-0,5 \\
\text { (Planstein) }\end{array}$ & $624 \times 249 \times 240$ & & $<15 \%$ & PP-01 - PP-02 \\
\hline & -1 & & & \\
\hline
\end{tabular}




\subsubsection{Druckfestigkeit senkrecht zur Lagerfuge}

Die Druckfestigkeiten der Mauersteine senkrecht zur Lagerfuge wurden nach DIN EN 772-1 (DIN EN 7721:2011+A1:2015) bestimmt. Sie variieren zwischen $\beta_{\mathrm{b}, \perp}=3,9 \ldots 27,2 \frac{\mathrm{N}}{\mathrm{mm}^{2}}$; siehe Tabelle A 3.1.

\subsubsection{Zugfestigkeit parallel und senkrecht zur Lagerfuge}

Die Ermittlung der Steinzugfestigkeit verwendeter Mauersteine wurde mit Umrechenfaktoren der Literatur (Brameshuber und Jäger 2015, S. 5) vorgenommen, die das Verhältnis zwischen der zentrischen Zugfestigkeit in Steinlängsrichtung $\beta_{\mathrm{z}, \mathrm{l}}$ und der Festigkeit senkrecht zu den Lagerfugen $\beta_{\mathrm{b}, \perp}$ beschreiben. Die ermittelten Steinzugfestigkeiten betragen zwischen $\beta_{\mathrm{z}, \mathrm{l}}=0,163 \ldots 2,851 \mathrm{~N} / \mathrm{mm}^{2}$; siehe Tabelle A 3.2.

\subsection{Mauermörtel}

\subsubsection{Druckfestigkeit}

Die in den experimentellen Bauteilprüfungen ausschließlich verwendeten Dünnbettmörtel wurden auf ihre Drucktragfähigkeit nach DIN EN 196-1 (DIN EN 196-1:2005-05) hin untersucht; die Werte variieren zwischen $\beta_{\mathrm{m}}=9,9 \ldots 12,4\left[\frac{\mathrm{N}}{\mathrm{mm}^{2}}\right]$; siehe Tabelle A 3.3 .

\subsubsection{Verbundeigenschaften zwischen Dünnbettmörtel und Mauersteinen}

Eine Kraftübertragung zwischen Mauermörtel und Mauersteinen basiert auf den Verbundeigenschaften der Stein-Mörtelkombination. Diese lassen sich durch die Haftscherfestigkeit $\left(\beta_{\mathrm{HS}}\right)$, den Reibungsbeiwert $(\mu)$ und die Haftzugfestigkeit $\left(\beta_{\mathrm{HZ}}\right)$ beschreiben. Die Werte variieren zwischen:

- Haftscherfestigkeit $(\bar{x}): \beta_{\mathrm{HS}}=0,43 \ldots 0,94\left[\mathrm{~N} / \mathrm{mm}^{2}\right]$,

- Haftzugfestigkeit $(\bar{x}): \beta_{\mathrm{HZ}}=0,19 \ldots 0,42\left[\mathrm{~N} / \mathrm{mm}^{2}\right]$,

- Reibungsbeiwert: $\mu=0,4 \ldots 0,6[-]$.

Einzelwerte können Tabelle A 3.4 (Haftscherfestigkeit und Reibungsbeiwert) und Tabelle A 3.5 (Haftzugfestigkeit) entnommen werden.

\subsection{Mauerwerk}

\subsubsection{Einaxiales Trag- und Verformungsverhalten}

\subsubsection{Druckfestigkeit senkrecht zur Lagerfuge}

Werden die Lagerfugen durch senkrecht wirkende, axiale Druckkräfte beansprucht, zeigt sich je nach SteinMörtelkombination ein unterschiedliches Querdehnungsverhalten des Mauerwerks. Dabei unterscheidet sich der Mörtel von dem Mauerstein i.d.R. durch eine erhöhte Querdehnung (Simon 2002, S. 7). Hierdurch entsteht in den Steinen und im Mörtel ein mehraxialer Spannungszustand; siehe Bild 3.1. Je größer der Wert für die Querverformbarkeit des Mauermörtels ist, desto geringer ist die Mauerwerkdruckfestigkeit (Brameshuber und Jäger 2015, S. 7). Die Bruchlast wird erreicht, wenn die in den Mauersteinen entstehende Querzugspannung die horizontale Steinzugfestigkeit überschreitet. Im Fall der Anwendung von Dünnbettmauerwerk wird dieser Effekt durch die geringe Fugendicke minimiert. Dementsprechend werden durch die Anwendung von Dünnbettmauerwerk vergleichsweise hohe Druckfestigkeiten des Mauerwerks erreicht. 


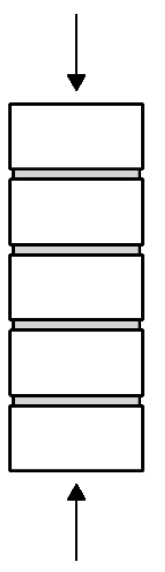

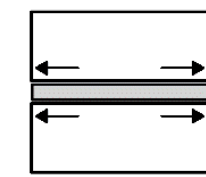

Zugspannungen im Stein durch behinderte Querverformung des Mörtels

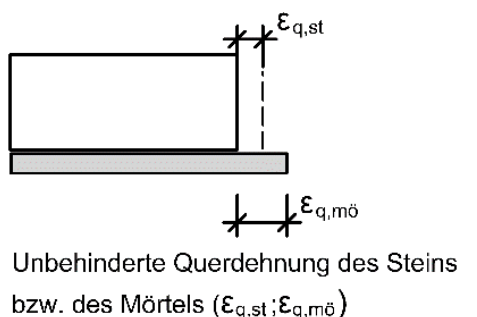

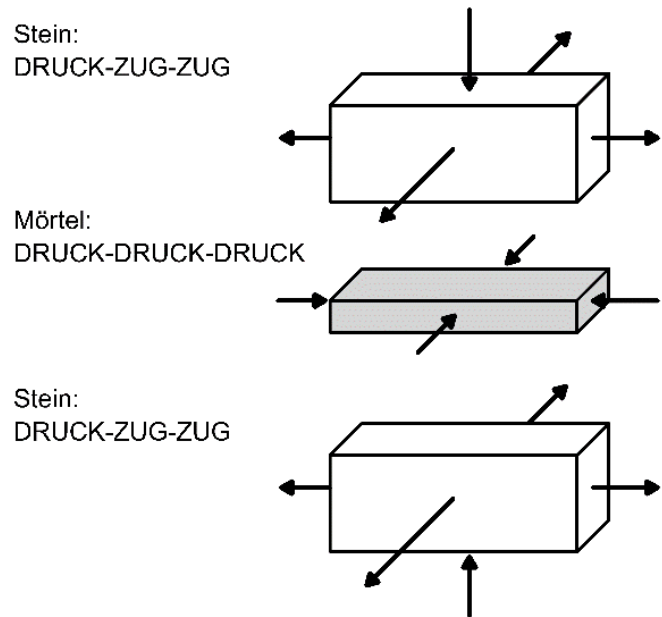

Bild 3.1 Dreiaxialer Spannungszustand einer Stein- Mörtelkombination

Die Druckfestigkeit des Mauerwerks senkrecht zur Lagerfuge kann nach DIN EN 1996-1-1 (DIN EN 19961-1:2013-02) aus dem Produkt von Mörteldruckfestigkeit und Druckfestigkeit der Mauersteine in Lastrichtung nach Gleichung (3.1) berechnet werden. Die Parameter $K, \alpha, \beta$ in Gleichung (3.1) basieren auf in Datenbanken hinterlegten Prüfwerten. Sie sind den jeweiligen nationalen Anwendungsdokumenten zu entnehmen.

$$
f_{k}=K \cdot f_{\mathrm{b}}^{\alpha} \cdot f_{\mathrm{m}}^{\beta}
$$

Dabei sind:

$f_{\mathrm{k}} \quad$ Die charakteristische Druckfestigkeit von Mauerwerk in $\left[\mathrm{N} / \mathrm{mm}^{2}\right]$,

$K, \alpha, \beta \quad$ die über die Auswertung (mittels Regression) von Versuchen bestimmten Faktoren nach DIN EN 1996-1-1/NA, Tabelle NA4 bis NA10,

$f_{\mathrm{b}} \quad$ die normierte oder in Zulassung festgesetzte Mauersteindruckfestigkeit in Lastrichtung $\left[\mathrm{N} / \mathrm{mm}^{2}\right]$,

$f_{\mathrm{m}} \quad$ die Druckfestigkeit des Mauermörtels $\left[\mathrm{N} / \mathrm{mm}^{2}\right]$.

Die Bestimmung von Mittelwerten erfolgte hier durch eine Umrechnung über das Verhältnis charakteristischer Festigkeiten zu Mittelwerten mit $\frac{f_{\mathrm{k}}}{\beta_{\mathrm{D}, \mathrm{m} w, \perp}}=0$,8. Für die Stein-Mörtelkombination - Ziegel in Verbindung mit Dünnbettmörtel - existieren in DIN EN 1996-1-1/NA keine Konstanten. Kranzler et al. geben für das hier verwendete Ziegelmauerwerk eine charakteristische Druckfestigkeit von $f_{\mathrm{k}}=$ $4,2\left[\mathrm{~N} / \mathrm{mm}^{2}\right]$ an, wonach sich durch Umrechnung ein Mittelwert von $\beta_{\mathrm{D}, \mathrm{mw}, \perp}=5,25\left[\mathrm{~N} / \mathrm{mm}^{2}\right]$ ergibt; siehe Tabelle A 3.6.

Für KS-Mauerwerk wurden die Mauerwerkdruckfestigkeiten nach Gleichung (3.1) bestimmt und ebenfalls auf Mittelwerte umgerechnet. Sie variieren zwischen $\beta_{\mathrm{D}, \mathrm{mw}, \perp}=7,01 \ldots 17,23\left[\mathrm{~N} / \mathrm{mm}^{2}\right]$; siehe Tabelle A 3.7.

Für Porenbeton beträgt der Wert $\beta_{\mathrm{D}, \mathrm{mw}, \perp}=3,16\left[\mathrm{~N} / \mathrm{mm}^{2}\right]$; siehe Tabelle A 3.8.

\subsubsection{Druck-E-Modul senkrecht zur Lagerfuge}

Das Verformungsverhalten von Mauerwerk kann u.a. durch den E-Modul sowie den Querdehnungsmodul beschrieben werden. Der E-Modul ist als Sekantenmodul bei $\frac{1}{3}$ der Höchstspannungen bei einmaliger Lastaufbringung definiert. In der vorliegenden Arbeit wurden die Druck-Elastizitätsmodule der verwendeten Mauerwerke mit Gleichung (3.2) nach (Alfes 2013, S. 43) ermittelt. 
$E_{\mathrm{D}}=K_{\mathrm{E}} \cdot f_{\mathrm{k}}$

Dabei sind:

$E_{\mathrm{D}} \quad$ Der Druck-Elastizitätsmodul des Mauerwerks,

$K_{\mathrm{E}} \quad$ die Kennzahl in Abhängigkeit der verwendeten Mauersteinart,

$f_{\mathrm{k}} \quad$ die charakteristische Druckfestigkeit von Mauerwerk in $\left[\mathrm{N} / \mathrm{mm}^{2}\right]$.

Sie betragen zwischen $E=1392 \ldots 13215\left[\mathrm{~N} / \mathrm{mm}^{2}\right]$; siehe Tabelle A 3.9.

In DIN EN 1996-1-1 wird für das Lastverformungsverhalten von Druck beanspruchtem Mauerwerk eine nichtlineare Spannungs-Dehnungsverteilung unterstellt. Im Hinblick auf die Bemessung kann diese vereinfachend als linear, parabelförmig, parabel-rechteckförmig oder in Form eines rechteckigen Spannungsblockes angenommen werden (DIN EN 1996-1-1:2017 (E), S. 39); siehe Bild 3.2.

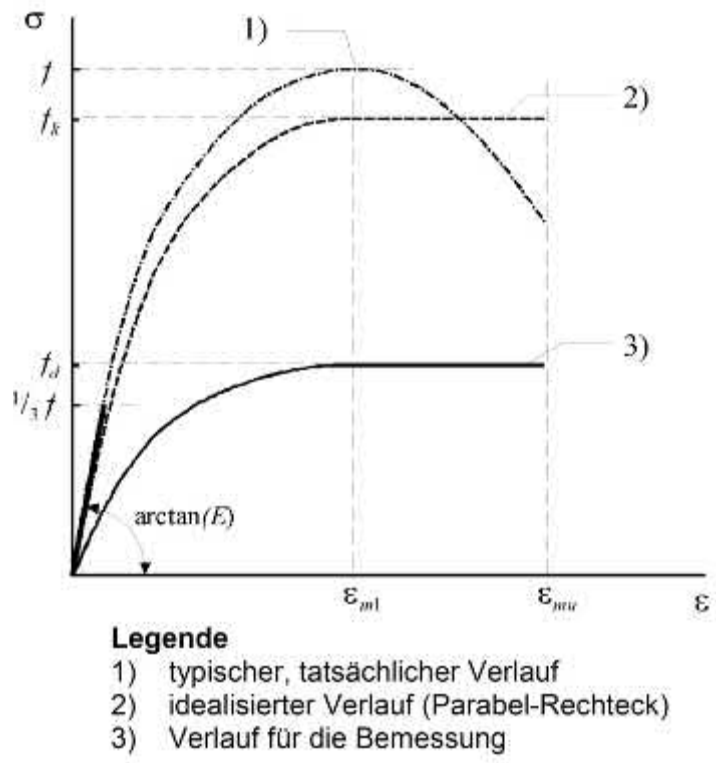

Bild 3.2 Spannungs-Dehnungslinie für Mauerwerk unter Druckbeanspruchung; vgl. (DIN EN 1996-11:2017 (E), S. 39)

Die Querdehnungszahl $\left(\mu_{\mathrm{D}}\right)$ und die Dehnung bei Höchstspannung $\left(\varepsilon_{\mathrm{u}, \mathrm{D}}\right)$ des hier verwendeten Mauerwerks sind Tabelle A 3.10 zu entnehmen. Die Werte für die Querdehnungszahl betragen zwischen $\mu_{\mathrm{D}}=0,05 \ldots 0,32$ [-]. Die Dehnwerte bei Höchstspannung variieren zwischen $\varepsilon_{\mathrm{u}, \mathrm{D}}=1,0 \ldots 3,9[\mathrm{~mm} / \mathrm{m}]$.

\subsubsection{Druckfestigkeit parallel zur Lagerfuge}

Für die Beanspruchung parallel zur Lagerfuge liegen vergleichsweise wenig Druckfestigkeitswerte vor. Im Falle einer zweiaxialen Beanspruchung, wie bei Balkenkonstruktionen, ist die Kenntnis dieser Werkstoffgröße jedoch von besonderer Bedeutung. Sie ist Bestandteil für das Materialgesetz von Ganz/Thürlimann/Mojsilović, welches in dieser Arbeit angewandt wird; siehe Abschnitt 3.3.2.2. Durch die Anisotropie des Mauerwerks weicht die Druckfestigkeit parallel von der Festigkeit senkrecht zur Lagerfuge ab. Verstärkt wird dies durch den Einfluss der vermörtelten oder unvermörtelten Stoßfugen. Im Folgenden wird ausschließlich Mauerwerk mit vermörtelten Stoßfugen behandelt.

Die Bestimmung der Druckfestigkeit parallel zur Lagerfuge kann auf Grundlage folgender Quellen durchgeführt werden:

- $\quad$ DIN EN 1996-1-1 (NA), Abschnitt 3.6.1.2 (1), (DIN EN 1996-1-1:2012-01/NA, S. 16), 
- Schubert und Graubohm (Schubert und Graubohm 2004, S. 207),

- $\quad$ E DIN 1053-3 (E DIN 1053-3:2008-03, S. 9),

- $\quad$ Brameshuber und Saenger (Brameshuber 2016; Saenger und Brameshuber 2016).

In der vorliegenden Arbeit erfolgt die Berechnung der Druckfestigkeit von Mauerwerk mit einer Beanspruchung parallel zur Lagerfuge nach Brameshuber und Saenger.

Brameshuber und Saenger entwickelten 2016 die Gleichung (3.3) zur Bestimmung der Mauerwerkdruckfestigkeit parallel zur Lagerfuge $\left(\min f_{\mathrm{k}, \mathrm{I}}\right)$. Sie differenzieren dabei zwischen Fugen- und Steinzugversagen des Mauerwerks (Brameshuber 2016; Saenger und Brameshuber 2016). Mechanisch wird das Fugenversagen durch den Ansatz des Maximalwertes zwischen Versagen in der Lagerfuge, durch den Ansatz der Haftscherfestigkeit $\left(f_{\mathrm{vk} 0}\right)$, oder in der Stoßfuge nach Gleichung (3.3) berücksichtigt. Ersteres ist durch folgenden mechanischen Zusammenhang zu erklären: $\left(f_{\mathrm{vk} 0}+\mu \cdot \sigma_{\mathrm{D}}\right) \cdot l_{\mathrm{ol}} / h_{\mathrm{u}}$. Dabei ist die Gleichung auf der sicheren Seite liegend, durch Vernachlässigung einer laststeigernden Auflastspannung $\left(\sigma_{\mathrm{D}}\right)$, auf $\left(f_{\mathrm{vk} 0} \cdot 0,4\right)$ zu reduzieren. Der Wert 0,4 beschreibt dabei das nach EC6 einzuhaltende auf die Steinhöhe $\left(h_{\mathrm{u}}\right)$ bezogene Überbindemaß von $l_{\mathrm{ol}} / h_{\mathrm{u}}=0,4$. Für das in dieser Arbeit untersuchte Mauerwerk mit vermörtelten Stoßfugen ist die Mörteldruckfestigkeit in der Stoßfuge entscheidendes Kriterium, da die Haftscherfestigkeit in der Lagerfuge bereits als überschritten gilt. Damit ist das Fugenversagen ausschließlich auf die Fugendrucktragfähigkeit $\left(f_{\mathrm{m}, \mathrm{joint}}\right)$ zurückzuführen, welches als Kriterium für die Mindestlängsdrucktragfähigkeit in der Stoßfuge gilt.

$$
\min f_{\mathrm{k}, \| l}=\min \left\{\begin{array}{c}
\max \left\{\begin{array}{c}
f_{\mathrm{vk} 0} \cdot 0,4 \\
\alpha \cdot f_{\mathrm{m}, \text { joint }} \\
\alpha_{\mathrm{b}} \cdot f_{\mathrm{b}}
\end{array}\right.
\end{array}\right.
$$

Dabei sind:

$\begin{array}{ll}\alpha & \begin{array}{l}\text { Der Abminderungsfaktor infolge erschwerter Ausführungsbedingungen für vermörtelte Stoßfugen: } \\ \text { bei Stoßfugen } \alpha=0,6,\end{array} \\ f_{\mathrm{m}, \text { joint }} & \text { die Fugendruckfestigkeit des Mörtels nach Gleichung (3.4) bzw. Tabelle A 3.11, } \\ f_{\mathrm{b}} & \text { die Steindruckfestigkeit senkrecht zur Lagerfuge, } \\ \alpha_{\mathrm{b}} & \text { der empirische Verhältnisfaktor; mit min } \alpha_{\mathrm{b}}=0,1 \text { bzw. nach Tabelle A 3.12, } \\ f_{\mathrm{m}, \text { oint }}=0,7 \cdot f_{\mathrm{m}} \ldots 1,3 \cdot f_{\mathrm{m}} \\ f_{\mathrm{m}}\end{array}$

Die Erhöhung der Fugendruckfestigkeit des Mörtels in Gleichung (3.4) um 30\% resultiert aus empirischen Untersuchungen an Mauerziegeln und ist auf den Kontakt des Mörtels mit den Mauersteinen zurückzuführen. Untersuchungen an anderen Mauersteinarten ergaben eine Abminderung auf $70 \%$ der Mörteldruckfestigkeit. Dies gilt beispielsweise für Kalksandsteine, bei denen dem Frischmörtel das zur Erhärtung notwendige Wasser entzogen wird. Die Abminderung durch den Faktor $\alpha=0,6$ in Gleichung (3.3) ist abhängig von den erschwerten Bedingungen bei der Ausführung einer Stoßfugenvermörtelung.

Die in Tabelle A 3.12. angegebenen $\alpha_{\mathrm{b}}$-Werte haben Brameshuber und Saenger auf Grundlage der im MWKalender (Brameshuber und Jäger 2015) angegeben Verhältniswerte von Steindruckfestigkeit senkrecht zur Lagerfuge zu Steindruckfestigkeit parallel zur Lagerfuge ermittelt. Für Hochlochziegel mit einer Lochfläche $\leq 50 \%$ und unterschiedlicher Loch-/ Steganordnung ließ sich kein Zusammenhang zwischen Normdruckfestigkeit der Mauersteine und Steinlängsdruckfestigkeit ableiten (Saenger und Brameshuber 2016, S. 375). Für diese Mauersteinart wird daher auf einen Umrechenfaktor in Anlehnung an (Ganz 1985) verwiesen; siehe Tabelle A 3.13. 
Werden in Gleichung (3.3) für die Festigkeitskennwerte Mittelwerte eingesetzt, variiert die Mauerwerkdruckfestigkeit parallel zur Lagerfuge zwischen $\beta_{\mathrm{D}, \mathrm{mw}, \|}=2,63 \ldots 7,44\left[\mathrm{~N} / \mathrm{mm}^{2}\right]$; siehe Tabelle A 3.13 .

\subsubsection{Zweiaxiales Trag- und Verformungsverhalten}

Bei druckbeanspruchtem Mauerwerk erfolgt die Ausbreitung von Einzellasten unter einem Winkel $(\alpha)$, was zu einem zweiaxialen Trag- und Verformungsverhalten der Konstruktion führt. Bei einer Vielzahl der bisherigen Schubbemessungsansätze ist die Bestimmung des $f_{\mathrm{vd}}$-Wertes nach Gleichung (2.19) auf die Versagensfälle nach Mann/ Müller (Reibungs- oder Steinzugversagen) zurückzuführen. Zum besseren Verständnis der an diesem Vorgehen geäußerten Kritik aus Abschnitt 2.5.10.1 wird die Theorie in Abschnitt 3.3.2.1 erläutert.

Die Notwendigkeit für bewehrte Mauerwerkbalken einen neuen Schubbemessungsansatz zu formulieren, der auf Grundlage von Spannungsfeldern und der Berïcksichtigung anisotropen Werkstoffverhaltens von Mauerwerk basiert, wurde bereits begründet. Einen Vorschlag liefern hierzu Ganz/ Thürlimann und Mojsilović durch Angabe eines Werkstoffgesetzes für druckbeanspruchtes Mauerwerk unter einem Belastungswinkel $\alpha$, was bei der Bemessung von Mauerwerkwänden mit Spannungsfeldern in der SIA 2661 (SIA 266-1:2003, S. 15) Anwendung findet. Das entsprechende Werkstoffgesetz ist in Abschnitt 3.3.2.2 erläutert.

\subsubsection{Mann/ Müller}

Mauerwerk kann, abhängig von der Belastungssituation, in seiner Ebene (in Scheibenrichtung) oder senkrecht dazu (in Plattenrichtung) auf Schub beansprucht werden.

Wird eine Wandscheibe durch eine am Wandkopf angreifende Vertikal- und Horizontallast belastet, führt dies zu einer in Wandebene wirkenden, zweiachsigen Scheibenschubbeanspruchung.

Mann/ Müller haben hierzu eine Bruchtheorie entwickelt, bei der die aufnehmbaren Schubspannungen $(\tau)$ in Abhängigkeit von der einwirkenden Drucknormalspannung $(-\sigma)$ durch vier Versagensfälle begrenzt sind:

a. Klaffende Lagerfugen (Haftzugversagen),

b. Abscherende Lagerfugen (Haftscherversagen bzw. Reibungsversagen),

c. Überschreiten der Steinzugfestigkeit (Steinzugversagen),

d. Überschreiten der Mauerwerkdruckfestigkeit (Druckversagen).

Aus diesen Kriterien lassen sich Grenzwerte ableiten, welche durch eine Brucheinhüllende beschrieben werden können; siehe Bild 3.3. Eine Überschreitung dieser Hüllfläche führt zu Schubversagen.

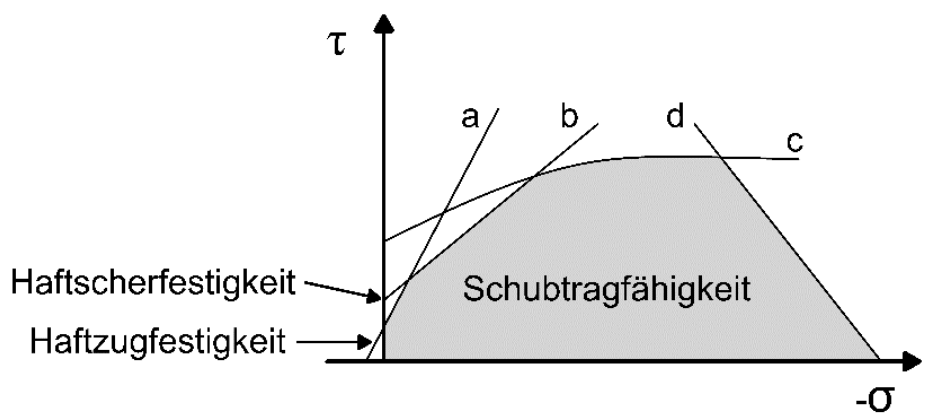

Bild 3.3 Brucheinhüllende nach Mann und Müller (Jäger und Marzahn 2010, S. 166)

Das Verformungsverhalten der Mauerwerkkonstruktion hängt von vier unterschiedlich verursachten Versagensfällen ab (Bild 3.4). Daraus geht hervor, dass neben Materialparametern der Mauersteine und des 
Mauermörtels auch geometrische Parameter wie Steinformat, das Überbindemaß und die Fugendicke einen entscheidenden Einfluss auf den Schubtragwiderstand haben.

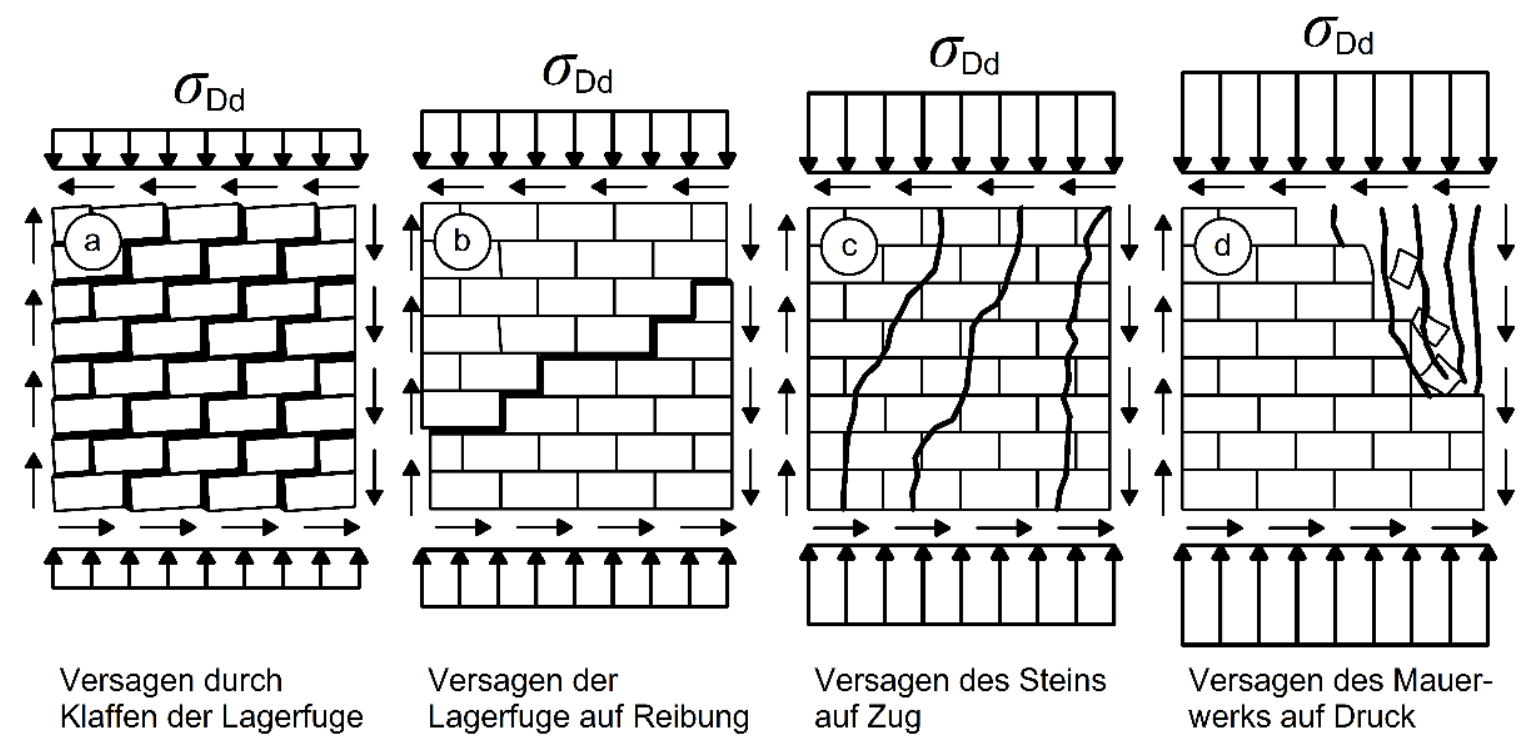

Bild 3.4 Bruchbilder durch Scheibenschubbeanspruchung (Jäger und Marzahn 2010, S. 166)

Unter Bezug auf DIN EN 1996-1-1/NA (DIN EN 1996-1-1:2012-01/NA, S. 17) werden die o.g. Versagenskriterien von Mann/ Müller infolge Scheibenschubbeanspruchung in Tabelle A 3.14 erläutert.

\subsubsection{Ganz/ Thürlimann/ Mojsilović}

Ganz (Ganz 1985) hat Untersuchungen zum Tragverhalten von Mauerwerk unter kombinierter Beanspruchung durchgeführt. Darin wird die Drucktragfähigkeit von Mauerwerk in Abhängigkeit der unten aufgeführten fünf verschiedenen Bruchbedingungen (I bis IVb) beschrieben, die in Bild 3.6 durch eine Hüllfläche (siehe Bild 3.6 a)) dargestellt sind. Für die Materialien wird ein Werkstoffverhalten nach Bild 3.5 unterstellt. Dabei wird die Zugfestigkeit des Steinmaterials vernachlässigt.

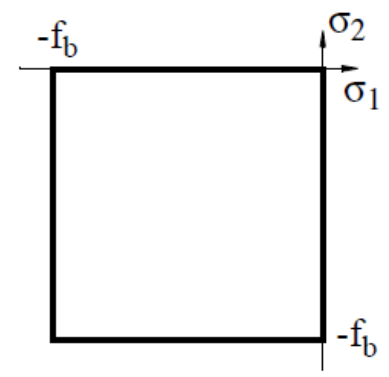

Stein

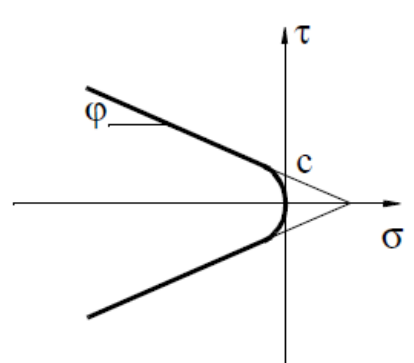

Lagerfuge

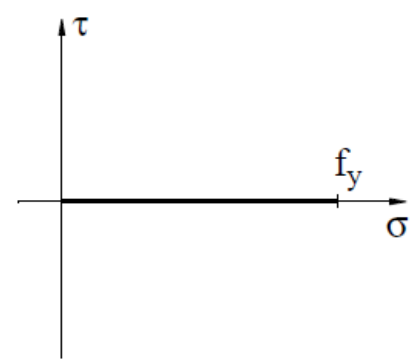

Bewehrung

Bild 3.5 Werkstoffverhalten verwendeter Materialien (Ganz 1985, S. 8; Mojsilović 1995, S. 6)

Das Werkstoffmodell gilt für die Bemessung von vertikal und horizontal bzw. unter einem Belastungswinkel $(\alpha)$ in Wandebene belasteten Mauerwerkwänden. Es stellt die Beziehung der Spannungen $\sigma_{\mathrm{x}}, \sigma_{\mathrm{y}}$ und $\tau_{\mathrm{xy}}$ unmittelbar vor dem Versagen des Mauerwerks dar. Damit gelten für Mauerwerk folgende fünf Bruchbedingungen:

- $\quad$ Steinzugversagen (I),

$$
\tau_{\mathrm{xy}}^{2}-\sigma_{\mathrm{x}} \cdot \sigma_{\mathrm{y}} \leq 0
$$


- Druckversagen der Steine (II) bei zweiachsig beanspruchtem Mauerwerk durch $\sigma_{1}$ und $\sigma_{2}$,

$$
\tau_{\mathrm{xy}}^{2}-\left(\sigma_{\mathrm{x}}+f_{\mathrm{Mx}}\right) \cdot\left(\sigma_{\mathrm{y}}+f_{\mathrm{My}}\right) \leq 0
$$

- Schubdruckversagen des Steins (III) bei einachsig beanspruchtem Mauerwerk durch $\sigma_{2}$,

$$
\tau_{\mathrm{xy}}^{2}-\sigma_{\mathrm{y}} \cdot\left(\sigma_{\mathrm{y}}+f_{\mathrm{My}}\right) \leq 0
$$

- Gleiten entlang der Lagerfuge (IVa),

$$
\tau_{\mathrm{xy}}^{2}-\left(c-\sigma_{\mathrm{x}} \cdot \tan \varphi\right)^{2} \leq 0
$$

- Zugversagen (Trennbruch der Lagerfuge (IVb).

$$
\tau_{\mathrm{xy}}^{2}+\sigma_{\mathrm{x}} \cdot\left(\sigma_{\mathrm{x}}+2 \cdot c \cdot \tan \left(\frac{\pi}{4}+\frac{\varphi}{2}\right)\right) \leq 0 \quad ; \sigma_{\mathrm{x}} \geq-c \cdot \cos \varphi
$$

Transformiert auf Hauptspannungen nach Gleichungen (3.10) und (3.11) lassen sich die Versagensarten auch in zweidimensionaler Diagrammform darstellen (siehe Bild 3.6 b)).

$$
\begin{aligned}
& \sigma_{1}=0 \\
& \sigma_{2}=F_{\mathrm{u}} / A
\end{aligned}
$$

Dabei sind:

$$
\begin{array}{ll}
F_{\mathrm{u}} & \text { Die Bruchlast, } \\
A & \text { die Bruttoquerschnittsfläche. }
\end{array}
$$

Die Transformation erfolgt auf Grundlage der Gleichungen (3.12) bis (3.15) (Guggisberg und Thürlimann 1987, S. 24-25).

$$
\begin{aligned}
& F_{\mathrm{x}}=F_{\mathrm{u}} \cdot \cos \alpha ; F_{\mathrm{y}}=F_{\mathrm{u}} \cdot \sin \alpha \\
& \sigma_{\mathrm{x}}=\frac{F_{\mathrm{u}} \cdot \cos \alpha}{A / \cos \alpha}=\sigma_{2} \cdot \cos \alpha^{2} \\
& \sigma_{\mathrm{y}}=\frac{F_{\mathrm{u}} \cdot \sin \alpha}{A / \sin \alpha}=\sigma_{2} \cdot \sin \alpha^{2} \\
& \tau_{\mathrm{xy}}=-\frac{F_{\mathrm{y}}}{A}=-\frac{F_{\mathrm{u}} \cdot \sin \alpha}{\frac{A}{\cos \alpha}}=-\sigma_{2} \cdot \sin \alpha \cdot \cos \alpha
\end{aligned}
$$

Dabei ist:

$\alpha$

Der Winkel der x-Achse zur Wirkungsrichtung der Hauptspannung $\sigma_{2}$.

Auf Basis der oben genannten Bruchbedingungen resultiert ein Linienverlauf der einachsigen Druckspannung A bis E aus Bild 3.6 b) nach Gleichung (3.16) bis (3.19). Dabei beschreibt der Winkel $\varphi$ die Neigung von $\sigma_{2}$, ab der bei einem einachsigen Druckversuch ein Fugenversagen auftritt. Dieser ergibt sich durch Gleichsetzen der Bruchbedingung B - C und C - D. (Ganz 1985, S. 13)

$$
\begin{array}{ll}
\text { A: } & \sigma_{2}=-f_{\mathrm{Mx}} \\
\text { B - C: } & \sigma_{2}=-f_{\mathrm{My}} \\
\text { C - D: } & \sigma_{2}=-\frac{c}{\cos \alpha^{2} \cdot(\tan \alpha-\tan \varphi)} \\
\text { D - E: } & \sigma_{2}=-2 \cdot c \cdot \tan \left(\frac{\pi}{4}+\frac{\varphi}{2}\right)
\end{array}
$$


Dabei sind:

$\varphi \quad$ Der Winkel der inneren Reibung,

c die Kohäsion oder die Haftscherfestigkeit der Lagerfuge.

In Bezug auf den Kurvenverlauf „C - D“ - Gleiten entlang der Lagerfuge - ergibt sich eine Druckspannung in x-Richtung nach Gleichung (3.20) und eine Schubspannung $\tau_{\mathrm{xy}}$ nach Gleichung (3.21). Wird Gleichung (3.20) in Gleichung (3.21) eingesetzt, wird deutlich, dass im Vergleich zu den Regelungen nach DIN EN 1996-1-1 (Gleichung (3.23)), Gleichung (3.22) von der Auflastspannung unabhängig ist.

$$
\begin{aligned}
& \sigma_{\mathrm{x}}=-\frac{c}{\tan \alpha-\tan \varphi} \\
& \tau_{\mathrm{xy}}=c-\sigma_{\mathrm{x}} \cdot \tan \varphi \\
& \tau_{\mathrm{xy}}=c+\frac{c}{\tan \alpha-\tan \varphi} \cdot \tan \varphi=c+\frac{c \cdot \tan \varphi}{\tan \alpha-\tan \varphi} \\
& \tau=f_{\mathrm{vk} 0}+0,4 \cdot \sigma_{\mathrm{Dd}}
\end{aligned}
$$

Damit verdeutlicht Gleichung (3.22) die Abhängigkeit der ertragbaren Hauptdruckspannung $\left(\sigma_{2}\right)$ von dem Belastungswinkel $(\alpha)$ und der Höhe der Hauptzugspannung $\sigma_{1}$.

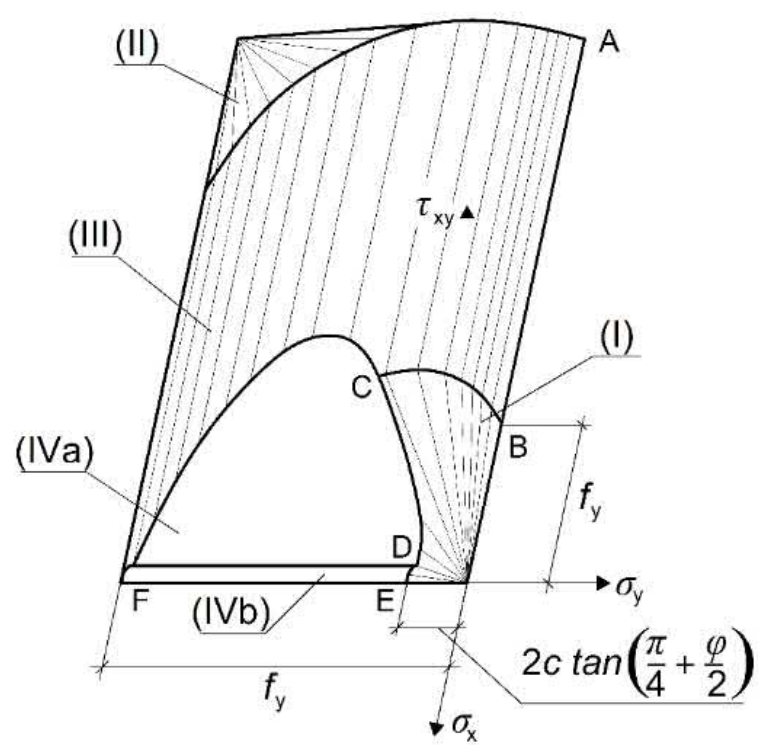

a)

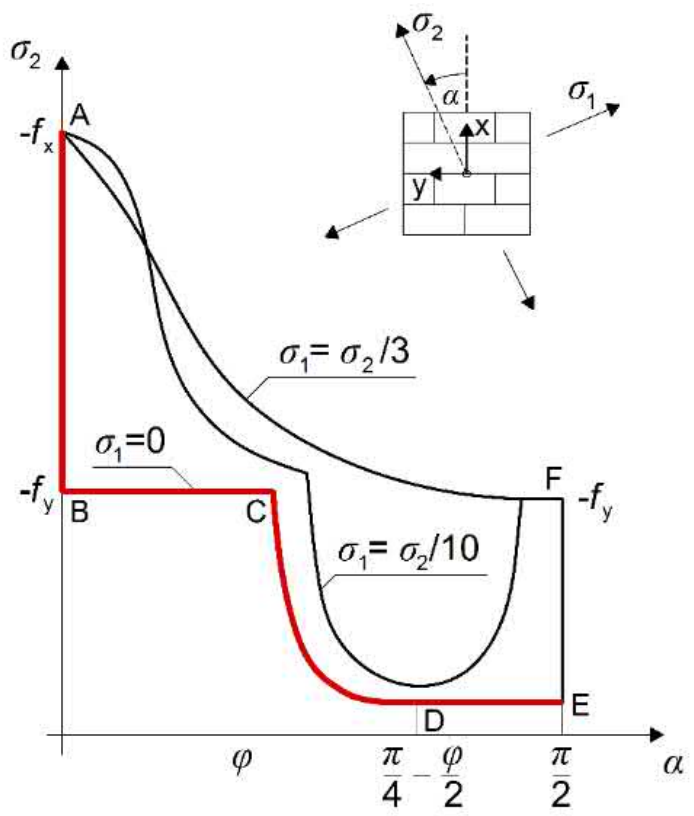

b)

Bild 3.6 Richtungsabhängiges Bruchverhalten von Mauerwerk; zweiachsig beanspruchtes Mauerwerk a), einachsig beanspruchtes Mauerwerk b); vgl. (Ganz 1985, S. 13)

Für einachsig beanspruchtes Mauerwerk, wie bei Balkenkonstruktionen aus bewehrtem Mauerwerk, ist der Kurvenverlauf von Bild 3.6 b) für den Fall $\sigma_{1}=0$ von Bedeutung.

Mögliches Reibungs- oder Schub-Zug-Versagen des Mauerwerks ist also in der Richtungsabhängigkeit der Größe der Mauerwerkdruckfestigkeit $\left(f_{\alpha}\right)$ bereits vorteilhaft implementiert. Die für die Bemessung der Druckspannungsfelder maßgebende Druckfestigkeit des Mauerwerks $\left(f_{\alpha}\right)$ wird als Werkstoffgesetz in Abhängigkeit von dem Belastungswinkel $(\alpha)$ eingesetzt. Weicht die Belastungsrichtung im Bauteil von der maßgebenden Richtung für die einachsige Druckfestigkeit des Mauerwerks $\left(f_{\mathrm{x}}\right)$ (Punkt A in Bild $3.6 \mathrm{~b}$ )) 
nur geringfügig ab, hat dies eine Reduzierung der Drucktragfähigkeit von Mauerwerk auf den Wert der Druckfestigkeit des Mauerwerks parallel zu der Lagerfuge $\left(f_{\mathrm{y}}\right)$ zur Folge (Punkt B in Bild 3.6 b)). Wird von $(\alpha)$ der Winkel der inneren Reibung $(\varphi)$ überschritten (Punkt C in Bild 3.6 b)), setzt Gleiten ein und die Mauerwerkfestigkeit nimmt weiter ab (Punkte D - E in Bild 3.6 b)). Dabei basieren die Bruchbedingungen auf folgenden Materialparametern: Der Mauerwerkfestigkeit senkrecht und parallel zur Lagerfuge $\left(f_{\mathrm{x}}\right.$ und $\left.f_{\mathrm{y}}\right)$ sowie dem Reibungswinkel $(\phi)$ und der Haftscherfestigkeit bzw. Kohäsion $(c)$.

Mechanisch ist das Bruchkriterium D - E für die Druckfestigkeit des Mauerwerks unterschiedlicher Balkentypen aus bewehrtem Mauerwerk von großer Bedeutung. So wird der Druckstrebenwinkel $\theta$ bei schlanken, langen Flachstürzen den Winkel der inneren Reibung $(\varphi)$ oftmals überschreiten, was Reibungsversagen auslösen würde. Bei scheitrechten Fertigteilstürzen ist dies bei gedrungenen, kurzen Balken der Fall. Unter Annahme eines Reibungswinkels $\varphi=\arctan (0,75)$ und einem Verhältnis von Kohäsion zur Drucktragfähigkeit parallel zur Lagerfuge $\frac{c}{f_{\mathrm{my}}} \geq 0,25$ existiert kein Einfluss der Lagerfuge (Ganz 1985, S. 14).

Darüber hinaus soll auch der Einfluss vermörtelter Stoßfugen, wie bei Flachstürzen, in dem zukünftigen Bemessungskonzept berücksichtigt werden.

Aufbauend auf den Untersuchungen von Ganz hat Mojsilović in seiner Arbeit (Mojsilović 1995) Untersuchungen zum Tragverhalten von Mauerwerk mit kombinierter Beanspruchung unter Berücksichtigung der Stoßfugen veröffentlicht. Er stellt einen maßgebenden Versagenseinfluss der Stoßfugen entlang einer Gleitlinie fest; siehe Bild 3.7.

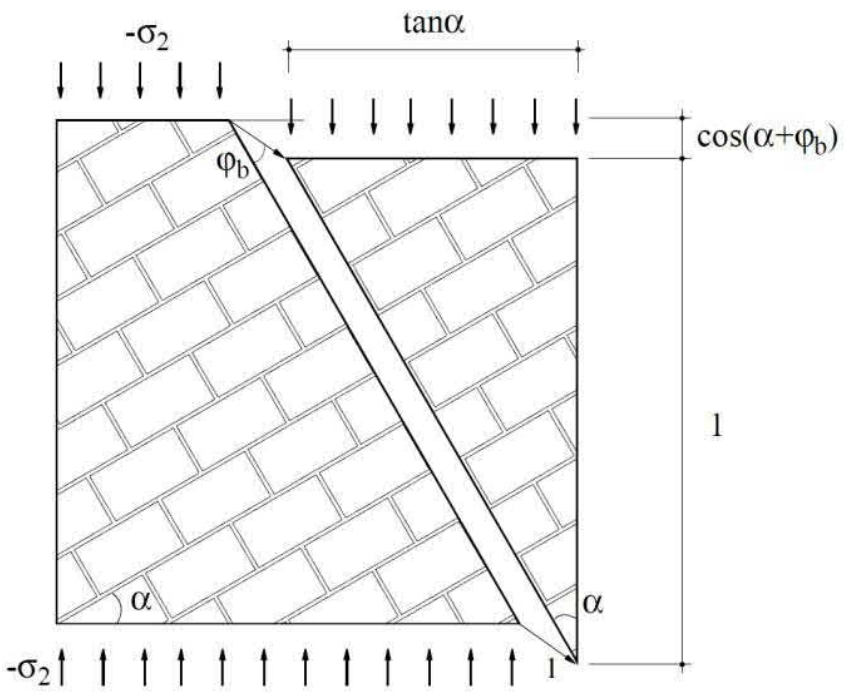

Bild 3.7 Bruchkriterium: Gleiten entlang der Stoßfugenflucht (Mojsilović 1995, S. 94)

Diese Versagensart bindet er als ein weiteres Bruchregime nach Gleichung (3.24) in die Theorie von Ganz ein; siehe Bruchregime V in Bild 3.8. Der in Gleichung (3.24) enthaltene Faktor von 0,5 entspricht der Tatsache, dass die Stoßfugenflucht mit jeder zweiten Steinreihe unterbrochen ist. Der Linienverlauf des Versagenskriteriums nach Bild 3.8 V ergibt sich nach Gleichung (3.25) bzw. aus einem Mindestwert nach Gleichung (3.26) (Mojsilović 1995, S. 92-96).

$$
\begin{aligned}
& \tau_{\mathrm{xy}}^{2}-\left(\frac{c_{\mathrm{b}}}{2}-\sigma_{\mathrm{y}} \cdot \tan \varphi_{\mathrm{b}}\right)^{2} \leq 0 \\
& \sigma_{2}=\frac{c_{\mathrm{b}}}{2 \cdot \sin ^{2} \alpha \cdot\left(\tan \varphi_{\mathrm{b}}-\cot \alpha\right)}
\end{aligned}
$$


$\sigma_{2, \min }=\frac{-c_{\mathrm{b}} \cdot \cos \varphi_{\mathrm{b}}}{1-\sin \varphi_{\mathrm{b}}}$

Dabei sind:

$c_{\mathrm{b}}$

Die Kohäsion der Mauersteine,

$\varphi_{\mathrm{b}}$ der Winkel der inneren Reibung der Mauersteine.

Mojsilović schlägt für die Annahme der Kohäsion und des inneren Reibungswinkels der Mauersteine eine praktische Näherung nach Gleichung (3.27) und (3.28) vor (Mojsilović 1995, S. 95).

$\tan \varphi_{\mathrm{b}}=\frac{3}{4}$

$c_{\mathrm{b}}=\frac{f_{\mathrm{y}}}{4}$

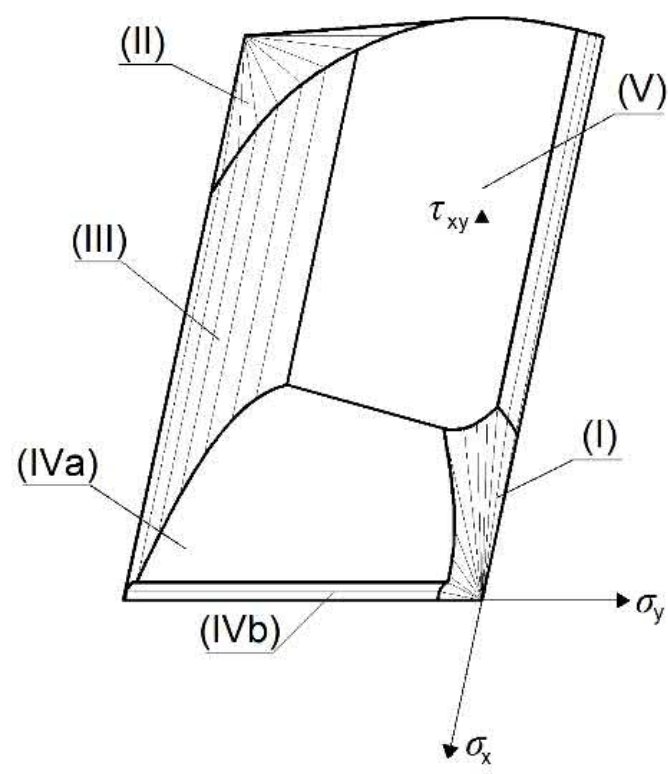

a)

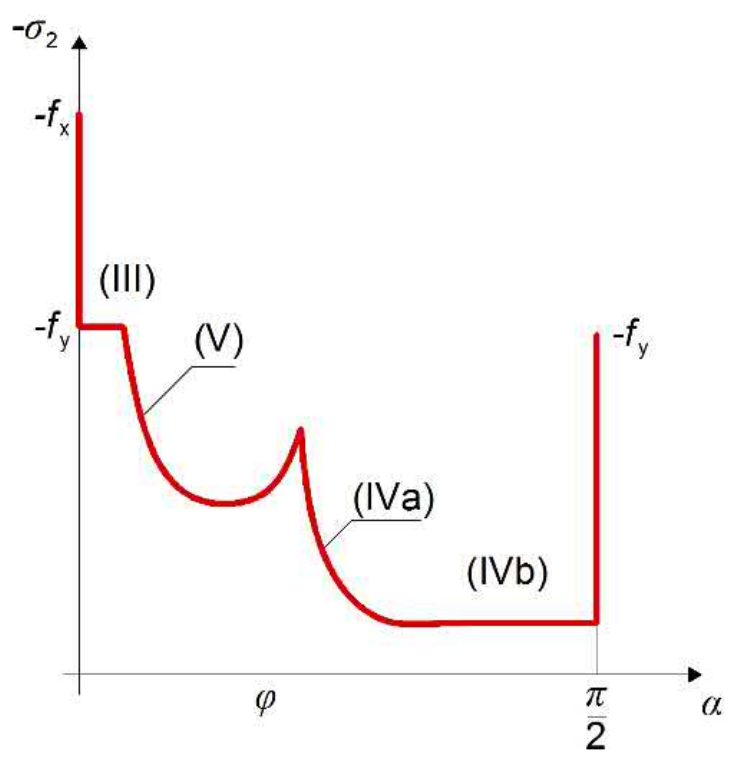

b)

Bild 3.8 Richtungsabhängiges Bruchverhalten von Mauerwerk unter Berücksichtigung der Wirkung der Stoßfugen; zweiachsig beanspruchtes Mauerwerk (a), einachsig beanspruchtes Mauerwerk (b); vgl. (Mojsilović 1995, S. 96) 


\section{Normative Regelungen nach SIA 266-1 (SIA 266-1:2003)}

Bild 3.9 zeigt eine Vereinfachung der Zusammenhänge von Bild 3.6, rechts, wie sie in der Schweizer Mauerwerknorm SIA 266-1 angegeben sind.

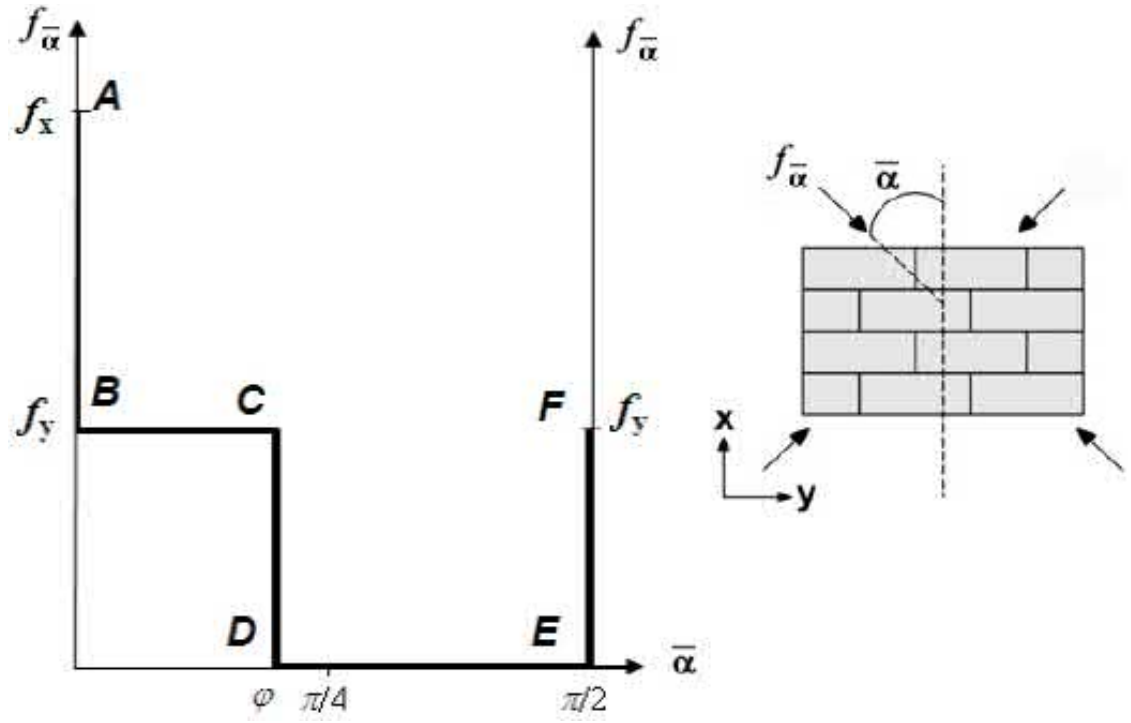

Bild 3.9 Rechnerische Druckfestigkeit $f_{\bar{\alpha}}$ in Abhängigkeit des Beanspruchungswinkels $\bar{\alpha}$; vgl. SIA 266-1 (SIA 266-1:2003, S. 15)

Die Mauerwerkdruckfestigkeit $f_{\bar{\alpha}}$ nimmt mit zunehmendem Winkel $\bar{\alpha}$ stark ab. Überschreitet der Neigungswinkel $\bar{\alpha}$ den Winkel der inneren Reibung $\varphi$, entsteht Reibungsversagen. Für diesen Fall ist $f_{\bar{\alpha}}$ in Bild 3.9 mit $f_{\bar{\alpha}}=0$ angegeben. Ausgehend von dem Reibungsbeiwert $\mu=0,6$ beträgt $\varphi=30^{\circ}$ gegenüber der $x$-Achse, die senkrecht zu den Lagerfugen definiert ist (Gunkler und Marx 2016, S. 213-231).

Widerstände, die sich im Bereich $\varphi \leq \bar{\alpha} \leq \pi / 2$ unmittelbar vor dem Bruch durch Gleiten der Mauersteine oder Zugversagen des Mörtels in der Lagerfuge ergeben (Bereich um D - E), sind in SIA 266 nicht berücksichtigt; s. auch Bild 3.9.

Im Bereich $0 \leq \bar{\alpha} \leq \varphi$ werden in Bild 3.9, Bild 3.8 und Bild 3.6 übereinstimmend die Mauerwerkdruckfestigkeit mit $f_{\bar{\alpha}}=f_{\mathrm{y}}$ angegeben, was der Mauerwerkdruckfestigkeit parallel zu den Lagerfugen $f_{\|}$entspricht.

Für den Nachweis der schrägen Druckstrebe eines Fachwerkmodells in Bezug auf die Querkrafttragfähigkeit bedeutet dies, dass im Bereich $\bar{\alpha}<\varphi=30^{\circ}$ gegenüber der $x$-Achse senkrecht zu den Lagerfugen die Druckfestigkeit des Mauerwerks parallel zu den Lagerfugen $f_{\|}$als maßgebend anzunehmen ist.

Im Vergleich zum Ansatz von Mann/ Müller wird beim Ansatz nach Ganz/ Thürlimann/ Mojsilović die Neigung, unter der die Beanspruchung auf das Mauerwerk einwirkt, berücksichtigt. Der Einfluss durch Lager- und Stoßfugen ist in der Definition des Materialgesetzes ebenfalls berücksichtigt. Die Größe des Materialwiderstandes in den Beanspruchungsfeldern ist abhängig von den unter einem Neigungswinkel verlaufenden Hauptspannungen.

\subsection{Injektionsmörtel}

Die zur Verfüllung des Bewehrungskanals scheitrechter Mauerwerkbalken verwendeten Injektionsmörtel wurden auf ihre Drucktragfähigkeit nach DIN EN 196-1 (DIN EN 196-1:2005-05) hin untersucht; die Werte variieren zwischen $\beta_{\mathrm{m}}=39,5 \ldots 50,3\left[\mathrm{~N} / \mathrm{mm}^{2}\right]$; siehe Tabelle A 3.15 . 


\subsection{Betonergänzung}

Der für die scheitrechten Mauerwerkbalken mit Ergänzungsschicht verwendete Beton wurde auf seine Drucktragfähigkeit nach DIN EN 12390-3 (DIN EN 12390-3:2009-06) untersucht; sie beträgt $\beta_{\mathrm{cm}, \mathrm{dry}}=$ $39,1\left[\mathrm{~N} / \mathrm{mm}^{2}\right]$; Tabelle A 3.16 .

\subsection{Bewehrung}

\subsubsection{Betonstahl}

Als Längsbewehrungsstahl sollten aus Gründen ausreichenden Verbundes nur gerippte Stäbe eingesetzt werden. Bei Korrosionsschutz durch ausreichende Betondeckung nach (Gunkler und Budelmann 2019, Abschn. 6.1.5.3) oder in trockener Umgebung (MX1) nach DIN EN 1996-2, Abschnitt 2.1.2 (DIN EN 1996-2:2010-12, S. 10), bietet sich die Verwendung von geripptem Betonstahl B500 nach DIN 488-1 (DIN 488-1:2009-08) mit einer charakteristischen Steckgrenze von $f_{\mathrm{yk}}=500 \mathrm{~N} / \mathrm{mm}^{2}$ an, wie er auch im Stahlbetonbau eingesetzt wird.

Wird von der o.g. Mikroumweltbedingung abgewichen und ausreichende Betondeckung unterschritten, sind die Auswahlbedingungen für Bewehrungsstähle zur Sicherstellung der Dauerhaftigkeit nach Expositionsklassen der Tabelle 6.5 in (Gunkler und Budelmann 2019) zu entnehmen. Daraus folgend ist eine korrosionsbeständige Bewehrung, z.B. aus austenitischem nichtrostendem Stahl (z. B. X10CrNi18-8, Werkstoff-Nr. 1.4310) oder feuerverzinktem und/ oder Kunststoff beschichtetem Bewehrungsstahl zu verwenden. Korrosionsbeständige Bewehrung wird in dieser Arbeit nicht weiter behandelt. Tabelle A 3.17 enthält Angaben zu mechanischen Eigenschaftswerten des verwendeten Längsbewehrungsstahls.

In E DIN 1053-3 (E DIN 1053-3:2008-03) wird die Spannungs-Dehnungs-Linie ( $\sigma-\varepsilon-L i n i e)$ von Bild 3.10 angegeben. Dabei wird für den Verlauf der Spannungs-Dehnungs-Linie (SDL) der Ansatz ohne Verfestigung unterstellt. Dies entspricht auch dem Vorgehen der aktuell gültigen DIN EN 1992-1-1 (DIN EN 1992-1-1:2011-01).

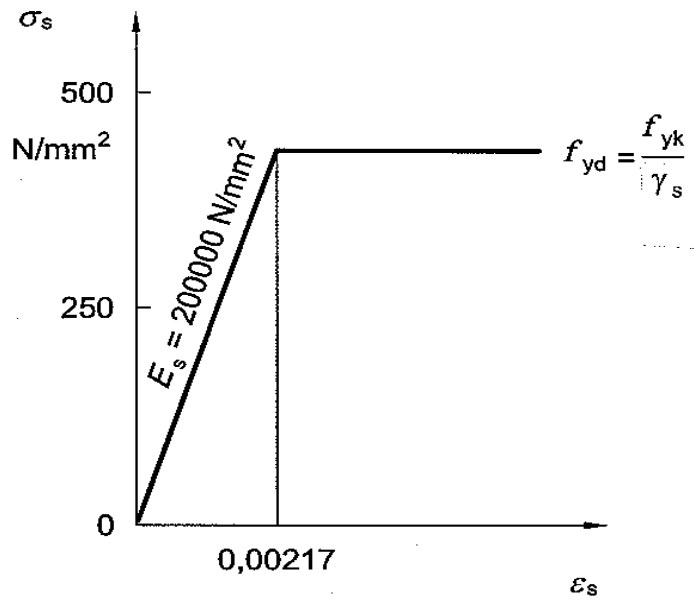

Bild 3.10 Rechnerische Spannungs-Dehnungs-Linie des Betonstahls für die Bemessung; vgl. (E DIN 10533:2008-03, S. 12)

\subsubsection{Spannstahl}

Das Werkstoffgesetz des verwendeten Spannstahls wird durch die Angabe der rechnerischen SDL in Bild 3.11 nach DIN EN 1996-1-1 (DIN EN 1996-1-1:2013-02), basierend auf den Grundlagen nach DIN EN 1992-1-1 (DIN EN 1992-1-1:2011-01), beschrieben. 


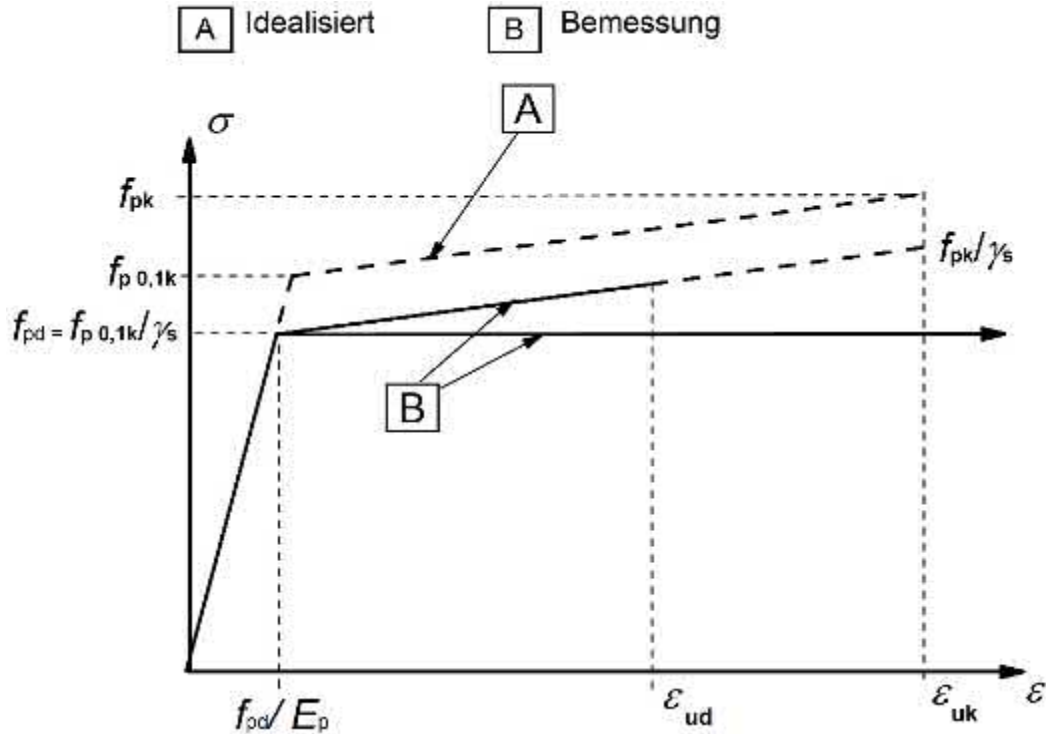

Bild 3.11 Rechnerische Spannungs-Dehnungs-Linien des Spannstahls für die Bemessung; vgl. (DIN EN 1992-1-1:2011-01, S. 46)

Für den in den experimentellen Untersuchungen an vorgespannten Mauerwerkbalken verwendeten Spannstahl wurden die Materialeigenschaften in einem Zugversuch nach DIN EN ISO 6892-1 ermittelt. Die Ergebnisse sind in Tabelle A 3.18 angegeben. 


\section{Analytische Grundlagen zu Spannungsfeldern für bewehrtes Mauerwerk}

Bislang existieren keine Tragmodelle für unterschiedliche Konstruktionsarten von Mauerwerkbalken, welche das Bauteilverhalten realitätsnah abbilden; siehe Abschnitt 2. Die Schubbemessungsgleichungen zur Berechnung bewehrten Mauerwerkbaus wurden überwiegend aus Modellen des Stahlbetonbaus abgeleitet. Dies gilt sowohl für das Druckzonenmodell als auch für das semi-empirische Schubmodell des EC2; vergleiche Abschnitt 2.5. Da sich das Tragverhalten von bewehrtem Mauerwerk bis auf dessen anisotrope Eigenschaften oftmals an dem von Stahlbeton annähert, ist es naheliegend, die Erkenntnisse aus der Forschung des Stahlbetonbaus auf die Anwendbarkeit für bewehrtes Mauerwerk hin zu überprüfen. Vorausgesetzt wird in dieser Arbeit die Implementierung richtungsabhängiger Materialeigenschaften in ein entsprechendes Schubmodell.

Das in dieser Arbeit entwickelte Schubtragmodell für Mauerwerkbalken ohne Querkraftbewehrung basiert auf Annahmen des fib Model Codes (MC) 2010 und damit der SMCFT; siehe Abschnitt 7.1.2. Dieses Schubmodell berücksichtigt die Längsdehnungen $\left(\varepsilon_{\mathrm{x}}\right)$ in Abhängigkeit der Einwirkungen (Berücksichtigung des Verformungszustandes); gute Ergebnisse bei der Querkraftbemessung wurden durch aktuelle Forschungsarbeiten bestätigt; siehe (Walraven 2016, S. 987) und (Yang 2014). Abschnitt 4.2 enthält Angaben zu Schubübertragungsmechanismen in Spannungsfeldern, deren Wirkungsweisen hinsichtlich der Übertragbarkeit auf bewehrte Mauerwerkbalken bewertet werden.

$\mathrm{Zu}$ Vergleichszwecken ist mit Hilfe der Ausführungen von Abschnitt 4.3 ein Überblick bisheriger Schubtragmodelle möglich. In dieser Arbeit wird der Schwerpunkt auf die Herleitung des analytisch lösbaren Schubbemessungsansatzes der „SMCFT“ gelegt, der auf einer Vereinfachung der ausschließlich numerisch lösbaren MCFT basiert; siehe Abschnitt 7.1. Die „SMCFT“ basiert auf der Anwendung von Spannungsfeldern, deren Grundlagen daher in Abschnitt 4.1 erläutert werden.

\subsection{Spannungsfelder}

Spannungsfelder fanden in den 60er Jahren durch Drucker erstmals Anwendung für die Bemessung von Stahlbetonkonstruktionen und wurden u.a. durch Thürlimann, Nielsen, Chen, Müller, Martin, Collins und Michell weiterentwickelt (Muttoni et al. 1997, S. 17). Zur Erläuterung werden daher im Folgenden häufiger Forschungsarbeiten aus dem Stahlbetonbau zitiert. Die Anwendung auf bewehrtes Mauerwerk wird fortlaufend kommentiert.

Spannungsfelder stellen, wie auch die von diesen abgeleitete Fachwerkmodelle, eine Idealisierung des Lastabtrages von Bauteilen dar. Bestimmte Bereiche der Konstruktion liefern einen zu differenzierenden Anteil am Lastabtrag. In Fachwerkmodellen beschreiben die Zug- und Druckstreben die Resultierenden von Zugspannungs- bzw. Druckspannungsfeldern. Spannungsfelder lassen sich im weitesten Sinne in Modelle mit variabler Druckstrebenneigung und in elastisch-plastische Spannungsfelder einteilen. Ersteres basiert auf der Plastizitätstheorie mit variabler Druckstrebenneigung und dem Gleichgewicht zwischen Druck- und Zugspannungsfeld; siehe Bild 4.1. Dabei wird die Querkrafttragfähigkeit durch das Stegbruchkriterium begrenzt. Die Druckfeldneigung beträgt dabei nach DIN EN 1992-1-1 zwischen 18,4 und $45^{\circ}$. Elastisch-plastische Spannungsfelder implementieren einen Widerstand aus der Druck- und Zugfestigkeit des Betons sowie der Schubbewehrung. Der Betontraganteil basiert auf dem Mechanismus der Rissuferverzahnung (siehe Abschnitt 4.2.2) entlang einer konstanten Rissneigung. Diese kann durch einen festen Wert vorgegeben werden, der in Abhängigkeit der Trägerlängsdehnung ermittelt wird (Rupf 2014, S. 11-12). 


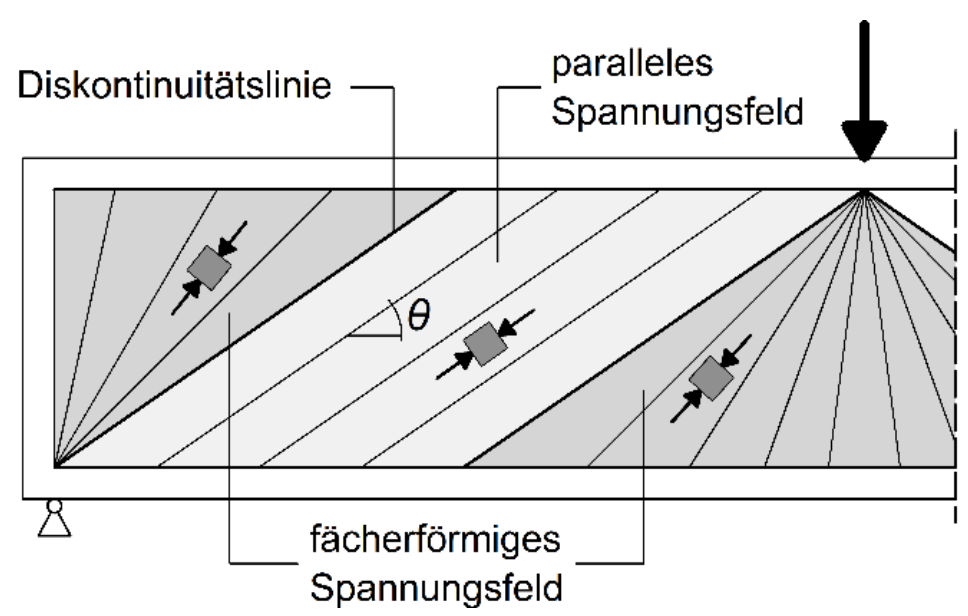

Bild 4.1 Starr-plastisches Spannungsfeld vgl. (Rupf 2014, S. 13)

\subsubsection{Elastische, gerissene Spannungsfelder}

Elastische, gerissene Spannungsfelder können unter Verwendung eines komplett elastischen und damit linearen Werkstoffverhaltens des entsprechenden Werkstoffes formuliert werden. Spannungen ergeben sich durch Multiplikation der Dehnungen mit dem jeweiligen Elastizitätsmodul des Materials und sind nicht durch einen Maximalwert limitiert (Rupf 2014, S. 16). Sie werden daher hier für Mauerwerk nicht weiter diskutiert, weil bei Mauerwerk nach Erreichen aufnehmbarer Schubspannungen Querkraftversagen einsetzt.

\subsubsection{Starr-plastische Spannungsfelder (klassische Spannungsfelder)}

Das Tragverhalten von Balken- und Scheibentragwerken kann nach der klassischen Spannungsfeldmethode mit streben- und fächerartigen Spannungsfeldern erfasst werden; siehe Bild 4.1. Bei Balken gilt dies im Bereich von Einzellasten sowie im auflagernahen Bereich (Schlaich und Schäfer 2001, S. 342). Für das in Bild 4.1 dargestellte Spannungsfeld wird hier starr-plastisches Materialverhalten unterstellt. Diese Vereinfachung kann vorgenommen werden, wenn im Wesentlichen plastische Verformungen das Tragverhalten bestimmen. Für die Anwendung von Fachwerkmodellen und Spannungsfeldern wird vorwiegend der untere Grenzwertsatz der Plastizitätstheorie verwendet (Kaufmann 2018, S. 6); der Vollständigkeit halber wird hier auch der obere Grenzwertsatz genannt (Jäger 2007, S. 18):

- Unterer statischer Grenzwertsatz:

Jede Belastung, zu der sich ein statisch zulässiger Spannungszustand angeben lässt, der die Fließbedingung nirgends verletzt, liegt nicht höher als die Traglast.

- Oberer kinematischer Grenzwertsatz:

Jede Belastung, zu welcher ein instabiler kinematisch zulässiger Verschiebungszustand angegeben werden kann, liegt nicht tiefer als die Traglast.

Dabei werden durch das Spannungsfeld ausschließlich Druckkräfte und über die unterstellte vertikale Schubbewehrung (falls vorhanden) Zugkräfte übertragen. Für die mit diesem Verfahren unterstellte variable Druckstrebenneigung kann aus Gründen der Wirtschaftlichkeit, wie im EC2, ein unterer Grenzwert von $18,4^{\circ}$ sowie ein oberer Grenzwert von $45^{\circ}$ vorgegeben werden.

Durch den rein plastischen Zustand des Spannungsfeldes können Diskontinuitätslinien zwischen den einzelnen Feldern angenommen werden. Die Spannungen parallel zur Grenzlinie können dabei unterschiedlich groß sein. Dahingegen müssen senkrecht zur Grenzlinie verlaufende Spannungen sowie Schubspannungen die Gleichgewichtsbedingungen erfüllen. In Bild 4.2 sind die Grundlagen der unterstellten Werkstoffgesetze für den druckübertragenden Werkstoff (Beton) und Stahl angegeben. 
(a)

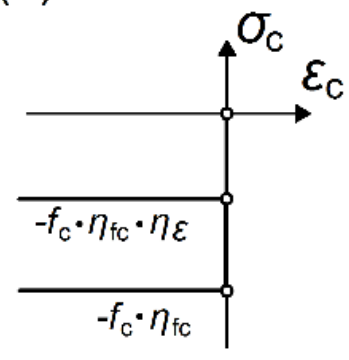

(b)

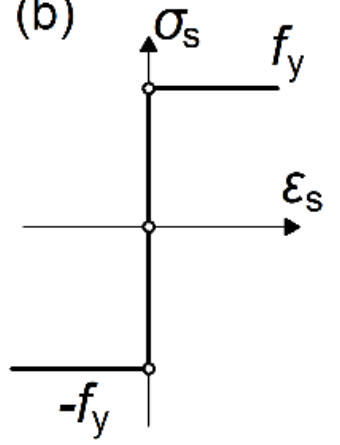

(c)

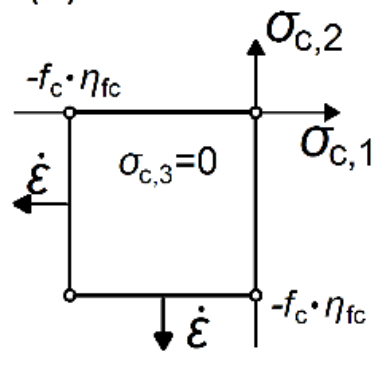

Bild 4.2 Starr-plastisches Materialgesetz: (a) Beton ohne Ansatz einer Zugfestigkeit (b) Bewehrungsstahl (c) Fließbedingung von Beton im ebenen Spannungszustand vgl. (Rupf 2014, S. 19)

Muttoni et al. stellen die Entwicklung eines Spannungsfeldes auf Basis eines Stabwerkmodells dar. Sie geben an, dass für übliche Bewehrungsgehalte des Stahlbetonbaus die Wahl der Spannungsverteilung keinen großen Einfluss auf die Lage der resultierenden Druckkraft $\left(f_{\text {ce }}\right)$ hat, wodurch vereinfachend eine konstante Spannungsverteilung in der Druckstrebe angenommen werden kann. Dies ist solange möglich, wie die Höhe des Druckgurtes im Verhältnis zur Trägerhöhe klein bleibt. Dies erscheint für schlaff bewehrte Mauerwerkbalken aufgrund vergleichsweise geringer Längsbewehrungsgrade in gleicher Weise anwendbar und wird in DIN EN 1996-1-1 und DIN EN 1996-1-1/NA bemessungstechnisch umgesetzt. Andernfalls ist für Träger mit starker Längsbewehrung und/oder mit großer Normalkraft eine nicht konstante Spannungsverteilung zu unterstellen; siehe Bild 4.3 (a) (Muttoni et al. 1997, S. 20). Unter Umständen könnte dies für vorgespanntes Mauerwerk mit hohen Festigkeitsklassen zutreffen.

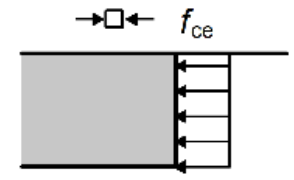

(a) gewählte Lösung
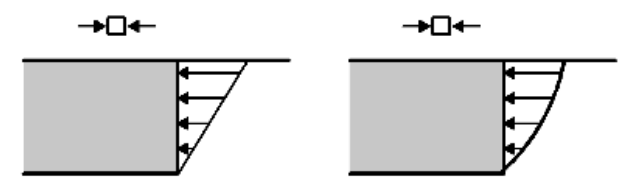

(b) alternative Lösungen ohne Diskontinuität

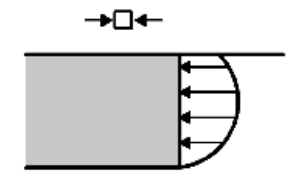

Bild 4.3 Spannungsverteilungen im Druckgurt; vgl. (Muttoni et al. 1997, S. 20)

Im Bereich der Knotenausbildung am Auflagerbereich ist zu unterscheiden, ob die Zugkraft in der Bewehrung bis zum Ende voll wirksam ist (Bild 4.4 (a)) oder diese durch Verbundspannungen im Bereich des Knotens kontinuierlich auf den Werkstoff (z.B. Beton, Mauerwerk) übertragen wird (Bild 4.4 (b, c)). Für letzteren Fall wird die Aufstandsfläche größer, womit die Spannungen des vertikalen Druckfeldes unterhalb der Bewehrung reduziert werden. Dies beugt einem Druckversagen im Auflagerbereich vor. Insbesondere bei Mauerwerk aus Steinen mit hohem Lochanteil besteht die Gefahr des Druckversagens im Auflagerbereich bzw. im Bereich der Lasteinleitung; siehe Tabelle A 4.1 (ZI-12 und ZI-13).

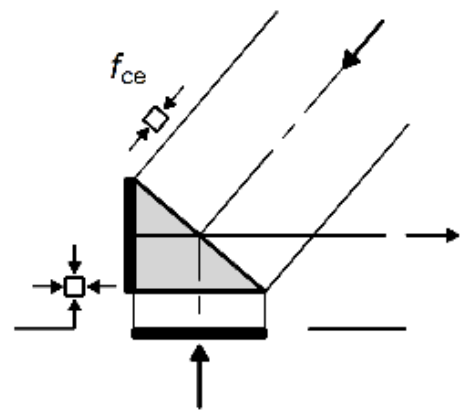

(a)

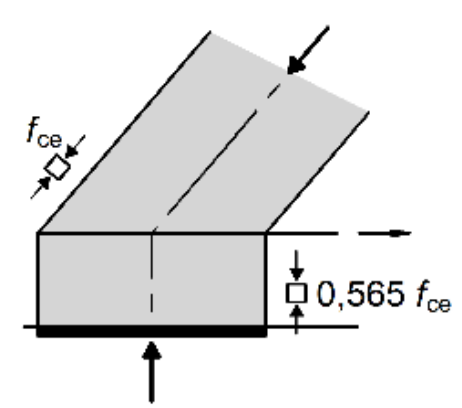

(b)

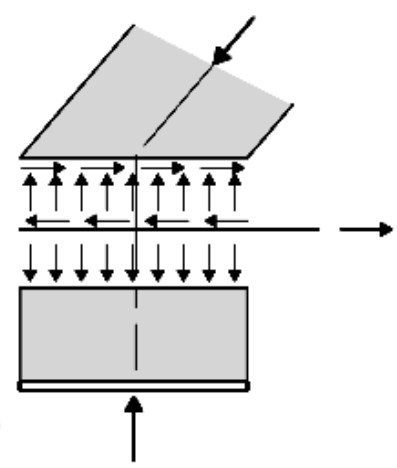

Bild 4.4 Ausbildung des Knotenbereiches; vgl. (Muttoni et al. 1997, S. 22) 
Schlaich und Schäfer (Schlaich und Schäfer 2001, S. 311-492) haben insbesondere für Stahlbetonbalken eine vereinfachte, fächerförmige Darstellung der Verteilung der Druckspannungsfelder entwickelt; siehe Bild 4.5. Dabei beschreiben sie eine Differenzierung zwischen B-Bereichen - parallel verlaufenden Spannungsfeldern - (B: äquivalent für Bernoulli-Hypothese bzw. Balkentheorie) und D-Bereichen fächerförmig verlaufenden Spannungsfeldern - (D: äquivalent für statische oder geometrische Diskontinuität) innerhalb eines Tragwerkes; siehe Bild 4.5. Statische Diskontinuität tritt dort auf, wo konzentrierte Lasten wirken; siehe auch Bild 4.1. Geometrische Diskontinuität wird durch Änderung der Tragwerksform hervorgerufen (Schlaich und Schäfer 2001, S. 342). Die Überführung von Spannungsfeldern in Stabwerkmodelle kann bspw. durch die Lastpfadmethode oder durch die Orientierung an linear-elastischen FE-Berechnungen erfolgen. Schlaich/ Schäfer schlagen für die Bemessung der DBereiche folgendes Vorgehen vor (Schlaich und Schäfer 2001, S. 393):

- Bemessung der Zugstreben mittels Stabwerkmodell und Verteilung der Bewehrung in den Zugbereichen.

- Bemessung der Druckstäbe bzw. Knotenbereiche mit Berücksichtigung der Druckfestigkeit sowie der Querzugtragfähigkeit des druckkraftübertragenden Materials.

- Besonderheit der Knotenbereiche:

a. Entwurf des Knotens auch unter Berücksichtigung ausreichender Verankerung.

b. Der Nachweis erfolgt über die mittleren Druckspannungen der Druckstrebe in den Knotenrändern bzw. Auflagern.

c. Nachweis ausreichender Verankerung unter Berücksichtigung von Krümmungsradien und Querzugtragfähigkeit.

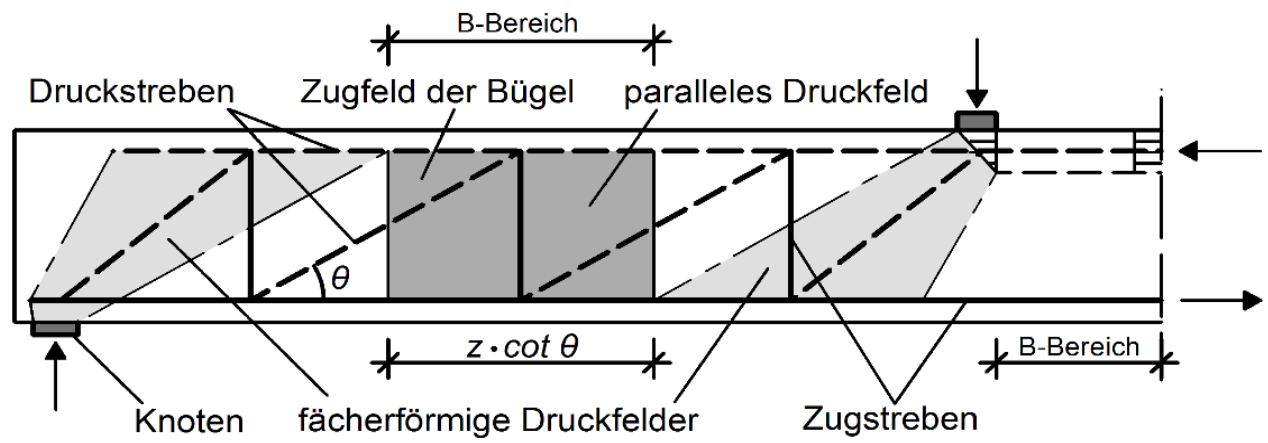

Bild 4.5 B- und D-Bereiche eines Stahlbetonbalkens unter Einzellast und Ansatz eines Stabwerkmodells; vgl. (Reineck 2005, S. 244)

Weist der Träger eine gedrungene Geometrie auf, sodass kein paralleles Spannungsfeld (B-Bereich) zwischen Lasteinleitung und Auflager existiert, ergibt sich nach Schlaich und Schäfer das Tragmodell eines wandartigen Trägers nach Abschnitt 2.3 (Reineck 2005, S. 256). Damit definieren sie ein Grenzkriterium zur Unterscheidung von Tragmodellen für Balken und für wandartige Träger, dessen Anwendbarkeit für Konstruktionen aus Mauerwerk in Abschnitt 7.3 (Bild 7.19) verifiziert wird. 


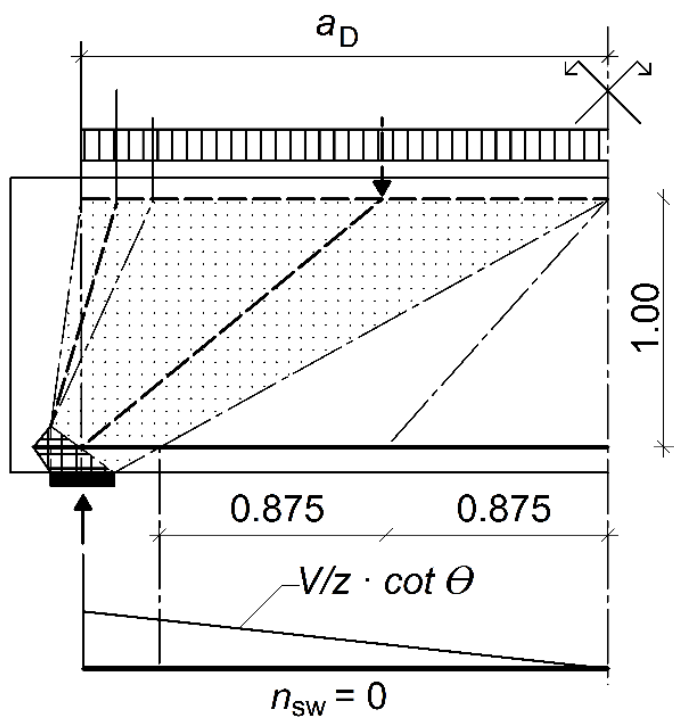

Bild 4.6 Druckfeld infolge einer resultierenden, auflagernahen Einzellast bei einem schlanken, wandartigen Träger; vgl. (Reineck 2005, S. 256)

Infolge einer vertikalen Belastung aus einer auflagernahen Einzellast definiert Reineck (Reineck 2005, S. 256) einen Bereich, in dem ein Teil der Last direkt in das Auflager eingeleitet wird; siehe Bild 4.6. Je weiter die Last vom Auflager entfernt ist, desto geringer wird der Anteil des direkten Lastabtrages und desto kleiner wird die Breite der Druckstrebe. Im EC2 wird bei Massivbauteilen aus Beton dieser Einfluss in einem Abstand von 0,5 $\cdot d \leq a_{\mathrm{v}}<2 \cdot d$ durch eine Abminderung der einwirkenden Querkraft durch den Faktor $\beta=\frac{a_{\mathrm{v}}}{2} \cdot d$ berücksichtigt; vergleiche Gleichung (4.16). Dasselbe gilt auch für Mauerwerk nach EC6, wobei hier der Bemessungswert der Schubfestigkeit durch Multiplikation mit dem Faktor nach Gleichung (2.23) erhöht wird.

Auf Basis o.g. Grundlagen wurde von Hegger - IV 1-5-876/98 (Hegger et al. 1999, S. 6) - für Bauteile ohne Querkraftbewehrung eine Bemessungsgleichung zur Ermittlung des Widerstands des Betontraganteils ermittelt. Dieser Gleichungsansatz bildet in Deutschland bis heute die Grundlage der Schubbemessung im EC2 für Stahlbetonbauteile ohne Querkraftbewehrung; siehe Gleichung (4.8).

\subsubsection{Erweiterte starr-plastische Spannungsfelder (verallgemeinerte Spannungsfelder)}

Die verallgemeinerten Spannungsfelder auf Basis der Compression Field Theory (CFT) ermöglichen für Betontragwerke unter Annahme gleicher Randbedingungen wie bei den klassischen Spannungsfeldern, die Berücksichtigung der Spannungsfeldneigung sowie der Verformungsverträglichkeit. Grundlage zur Ermittlung der Verformungsverträglichkeit ist die Längsdehnung unter Annahme einer Kontrollhöhe in halber Höhe des Hebelarms der inneren Kräfte; siehe Bild 7.8. Die Längsdehnung wird anhand der Druckstauchung und Zugdehnung unter Annahme der Bernoulli-Hypothese berechnet. Die Stauchung $\left(\varepsilon_{2}\right)$ hat dabei die gleiche Ausrichtung wie die Hauptdruckspannung $\left(f_{\mathrm{c} 2}\right)$, womit auch deren Neigungswinkel $\left(\Theta=\Theta_{c}\right)$ kongruent sind; siehe auch Bild 4.7. 

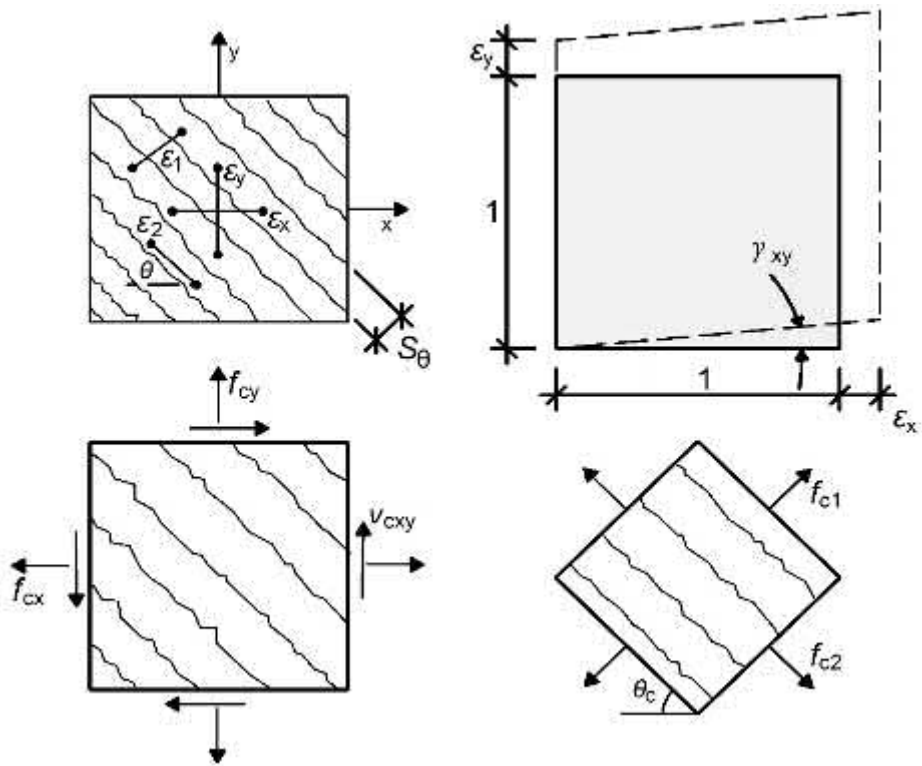

Bild 4.7 Dehnungsbeziehung (oben links), Schwerwinkel (oben rechts), mittlere Spannungen im Beton Schubspannungen $v_{c x y}$ (unten links) und Hauptspannungen im Beton - Hauptdruckspannungen $f_{c x / y}$ (unten rechts); vgl. (Vecchio, Frank, J. und Collins, Michael, P 1986, S. 221)

Entsprechend den Annahmen des Mohr'schen Spannungskreises (Bild 4.8) kann die Hauptzugdehnung $\left(\varepsilon_{1}\right)$ nach Gleichung (4.1) berechnet werden. Der Scherwinkel $\left(\gamma_{\mathrm{xy}}\right)$ ergibt sich nach Gleichung (4.2).

$\varepsilon_{1}=\varepsilon_{\mathrm{x}}+\frac{\varepsilon_{\mathrm{x}}-\varepsilon_{2}}{\tan ^{2} \theta_{\varepsilon}}$

Dabei sind:

$\varepsilon_{\mathrm{x}} \quad$ Die mittlere Längsdehnung,

$\varepsilon_{2} \quad$ die Hauptdruckstauchung,

$\theta_{\varepsilon} \quad$ die Druckfeldneigung in Abhängigkeit der Dehnungen.

$\gamma_{\mathrm{xy}}=\frac{2 \cdot\left(\varepsilon_{\mathrm{x}}-\varepsilon_{2}\right)}{\tan \theta_{\varepsilon}}$

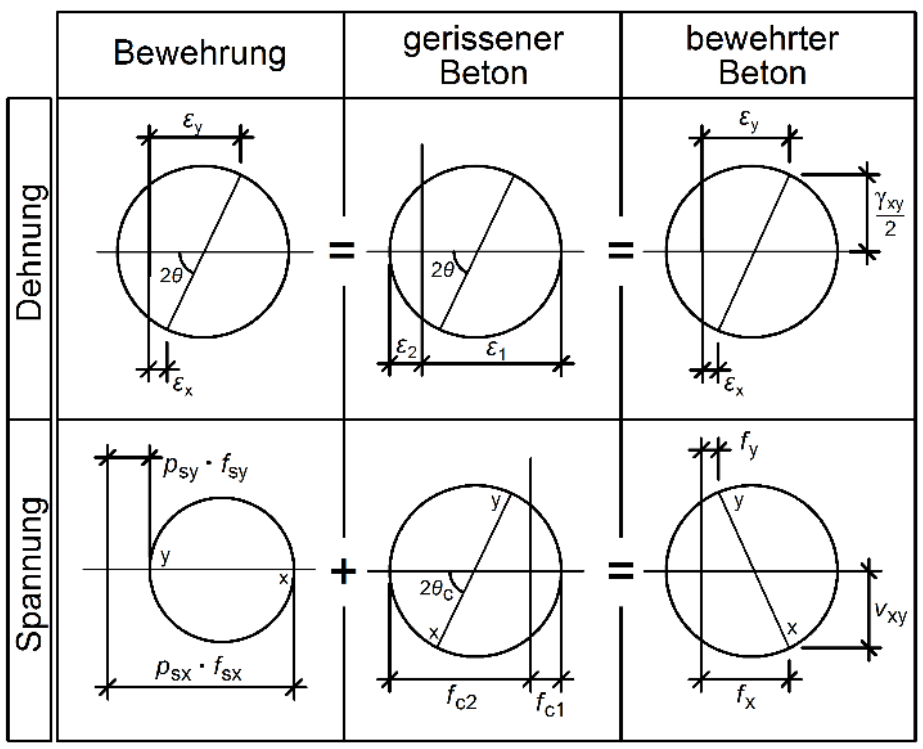

Bild 4.8 Mohr'scher Spannungskreis in Abhängigkeit von Spannungen und Dehnungen für Beton unter Annahme der modifizierten Druckfeldmethode; vgl. (Vecchio, Frank, J. und Collins, Michael, P 1986, S. 229) 
Wird die daraus abgeleitete Bedingung nach Gleichung (4.3) (Michael P. Collins, Denis Mitchell 1980, S. 39) weiter vereinfacht, ergibt sich die Druckfeldneigung in Abhängigkeit der Spannung nach Gleichung (4.4) (Sigrist und Hackbarth 2010, S. 688).

$$
\tan ^{2} \theta_{\sigma}=\frac{\varepsilon_{\mathrm{x}}-\varepsilon_{2}}{\varepsilon_{\mathrm{y}}-\varepsilon_{2}}
$$

Dabei ist:

$\varepsilon_{\mathrm{X}} \quad$ Die mittlere Vertikaldehnung.

$$
\theta_{\sigma}=\arctan \left(\frac{\varepsilon_{\mathrm{x}}-\varepsilon_{2}}{\varepsilon_{\mathrm{y}}-\varepsilon_{2}}\right)^{\frac{1}{2}}
$$

Durch die Annahme einer Materialstauchung von $\varepsilon_{2}=-2 \%$ und einer mittleren Dehnung der Schubbewehrung zum Zeitpunkt des Fließbeginns (Erreichen der Zugfestigkeit) leiten Sigrist et al. einen minimalen und maximalen Neigungswinkel für unterschiedliche Duktilitätsklassen ab. Dabei implementieren sie Verbundbeiwerte $(\kappa)$ für den Fließbeginn von $\kappa=0,8$ und für das Erreichen der Streckgrenze von $\kappa=0,25$. Daraus ergibt sich für normal duktilen Stahl in einem praktischen Anwendungsbereich von $-0,2 \% 0 \leq \varepsilon_{\mathrm{x}} \leq 1,2 \%$ durch Linearisierung der Gleichung (4.4) eine Näherung nach Gleichung (4.5).

$$
20^{\circ}+5000 \cdot \varepsilon_{\mathrm{x}} \leq \theta \leq 35^{\circ}+5000 \cdot \varepsilon_{\mathrm{x}}
$$

Sigrist gibt die zur Ermittlung der Neigungswinkel erforderlichen Längsdehnungen für unterschiedliche Laststellungen sowie für vorgespannte Konstruktionen in (Sigrist und Hackbarth 2010, S. 688) an. Die verallgemeinerten Spannungsfelder bilden die Grundlage verschiedener Bemessungsnormen. Gleichwohl ist dies ein Näherungsverfahren, welches Querkraftwiderstände aus der Betonzugfestigkeit und der Dübelwirkung der Bewehrung vernachlässigt. Auch unterstellt das Modell, dass beim Erreichen des Querkraftwiderstands die maximale Stauchung des Betons erreicht wird (Rupf 2014, S. 22). Für Mauerwerk ist eine Übertragung dieser Annahmen grundsätzlich vorstellbar, da auch hier eine mögliche Dübelwirkung erst nach bereits einsetzender Rissbildung erfolgt. Eine Modifikation erscheint jedoch notwendig, um ein Mitwirken des Mauerwerks zwischen den Rissen zu berücksichtigen.

\subsubsection{Elastisch-plastische Spannungsfelder (erweiterte Spannungsfelder)}

Eine Weiterentwicklung des verallgemeinerten Spannungsfeldes stellt das elastisch-plastische Spannungsfeld dar. Dabei wird das Materialverhalten elastisch-plastisch bzw. bilinear abgebildet. Bild 4.9 zeigt dies beispielhaft für Beton und Stahl. Weiterhin gelten die zuvor genannten Grundlagen. Betonzugspannungen sowie eine von der Längsbewehrung ausgehende Dübelwirkung werden vernachlässigt. Diese Art der Spannungsfelder ist häufig die Grundlage von FE-Berechnungsprogrammen (Rupf 2014, S. 22-23). Für FE-Berechnungen von Mauerwerk wurden mit dem bilinearen Ansatz von Bild 4.9 bislang gute Erfahrungen gemacht; siehe (Dashkhuu 2013). 

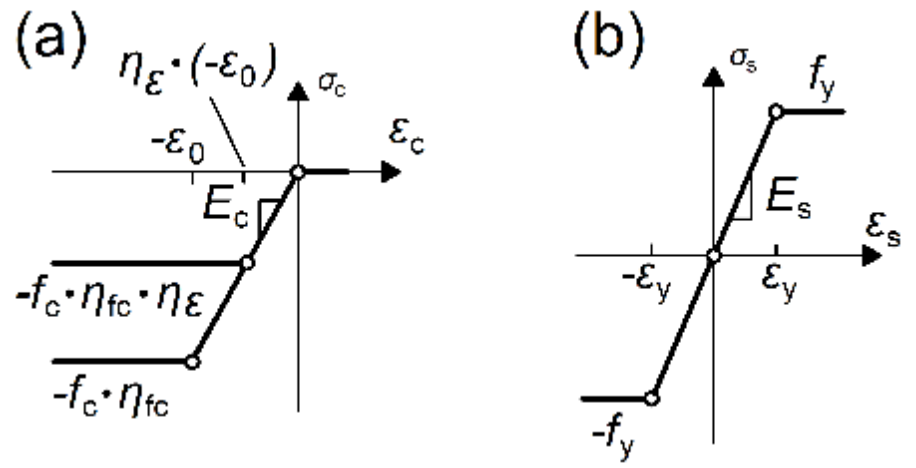

Bild 4.9 Bilineares Materialgesetz: Beton (a), Betonstahl (b); vgl. (Rupf 2014, S. 22)

\subsubsection{Besonderheiten vorgespannten Mauerwerks in Spannungsfeldern}

Grundsätzlich ist, wie im Stahlbetonbau, eine Vorspannung mit und ohne Verbund auch in Mauerwerk anwendbar. Dabei liegt der Verankerungsbereich der Vorspannkraft i.d.R. innerhalb des Schubspannungsfeldes. Die lokale Einleitung einer Vorspannung in eine Mauerwerkkonstruktion, z.B. über eine Ankerplatte, führt zu Querzugbeanspruchungen im Bauteil; siehe (Dashkhuu 2013, S. 74). Anders als im Stahlbetonbau, wo spezielle Bewehrungselemente zum Einsatz kommen (z.B. Wendelbewehrung), darf bei Spanngliedern in Lagerfugenrichtung, z.B. bei zu konsolidierendem historischen Mauerwerk, die Querzugbeanspruchung gerade nur so groß sein, dass kein Zugversagen des Mauerwerks senkrecht zu den Lagerfugen eintreten kann. Die durch die Vorspannung hervorgerufenen Querzugspannungen infolge Vorspannung können in Anlehnung an Heft 631 (DAfStb Heft 631 2019, S. 90) sowohl für zentrische als auch für exzentrische Beanspruchungen bestimmt werden. In Bild 4.10 sind qualitativ Spaltzugkräfte und Randzugkräfte angegeben, wie sie z.B. bei einer einwirkenden, exzentrisch wirkenden Vorspannkraft vorkommen (Korjenic und Kolbitsch 2012, S. 224). Einzelkräfte $\left(F_{\mathrm{S}}, F_{\mathrm{R}}\right)$ können mit Gleichungen aus Tabelle A 2.2 ermittelt werden.

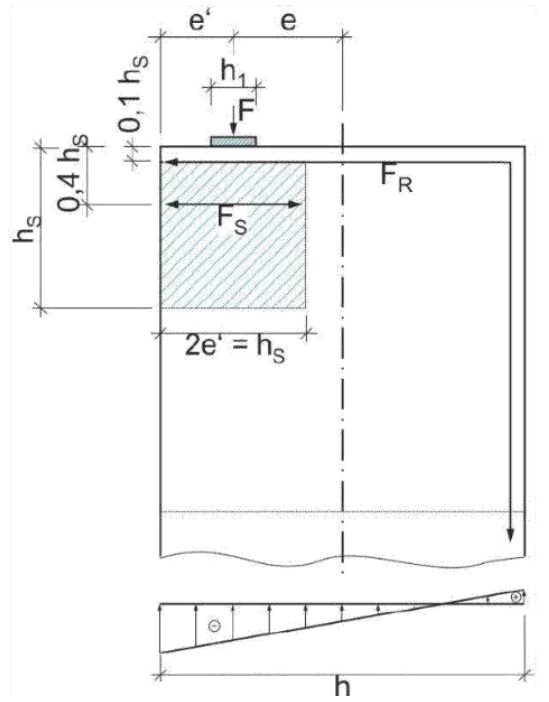

Bild 4.10 Spaltzug- und Randzugkräfte bei exzentrisch einwirkender Vorspannkraft (DAfStb Heft 631 2019, S. 90)

Auf Kriterien, die im Zusammenhang mit der Dauerhaftigkeit und Gebrauchstauglichkeit von Konstruktionen stehen, wie beispielweise Korrosionsschutz oder Langzeitverhalten (z.B. Kriechen und Relaxation), wird in der vorliegenden Arbeit nicht weiter eingegangen.

Unterschiedliche Vorgehensweisen für die Einleitung einer Drucknormalkraft werden in Curtin et al. (Curtin et al. 1988, S. 117-120), Gunkler (Irmschler und Schubert 2000, S. 334-343) sowie von Dashkhuu (Dashkhuu 2013, S. 7-12) dargestellt. 
Für auf Plattenbiegung beanspruchtes Mauerwerk beschreibt Zimmerli für die Einwirkung einer exzentrischen Drucknormalkraft den Einfluss eines mehraxialen Spannungszustandes der Stein-MörtelKombination auf das Verformungs- und Bruchverhalten. Eine schematische Darstellung zeigt Bild 4.11. Dabei weist Zimmerli darauf hin, dass allgemein ein Kräfteverlauf mit entsprechender Rissbildung nach dem Bruchregime II vorliegt. Durch die unterschiedlichen Werte zwischen Stein mit geringerer und Fugenmaterial mit höherer Querdehnungszahl dehnt sich die Fuge in Querrichtung, welches eine Druckbelastung hervorruft. Hierdurch erfährt das Steinmaterial eine Zugbeanspruchung, wodurch es dort zu einer Aufspaltung nach Bild 4.11 kommen kann. Regime I beschreibt einen Zustand, bei dem unter kleiner Normalkraft und gerissenem Mauerwerk die Steinzugbeanspruchungen klein sind. Regime III tritt vorzugsweise bei zentrischer Normalkraftbeanspruchung ein. Das entsprechende Regime ist abhängig von der Stein-Lochgeometrie sowie von den Materialeigenschaften der Steine und des Mörtels. Weiterführende Erläuterungen sind Zimmerli et al. zu entnehmen (Zimmerli et al. 1999, S. 50).
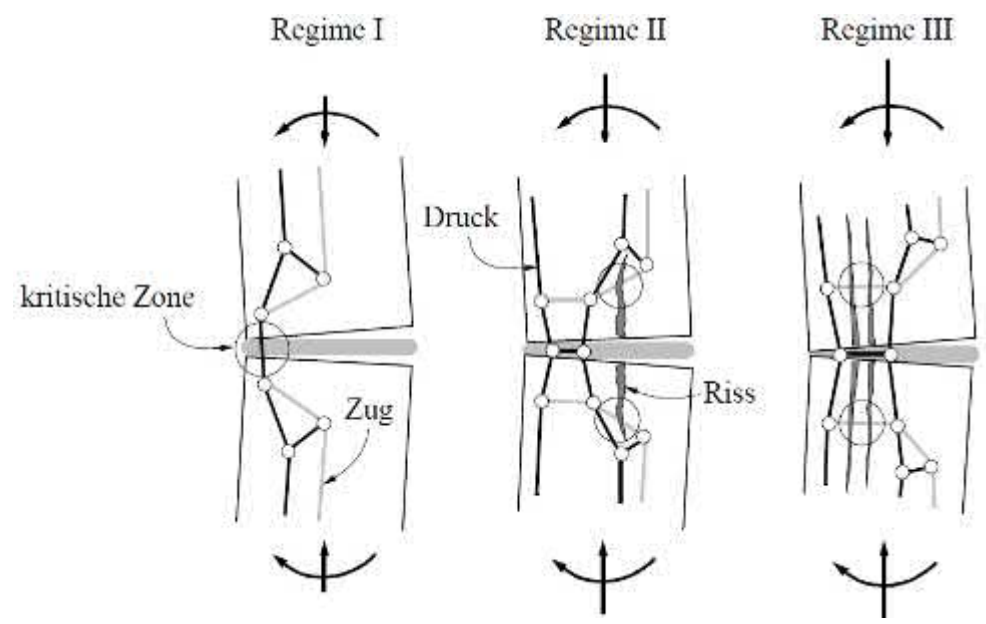

Bild 4.11 Kräfteverlauf in den Fugen infolge unterschiedlich hoher Momenten-NormalkraftBeanspruchung; vgl. (Zimmerli et al. 1999, S. 50; Schwartz 1989, 141 ff)

Für Bauteile im sofortigen oder nachträglichen Verbund ist eine Eintragungslänge für die im Spannstahl wirkende Kraft zu bestimmen, die über Verbundspannungen auf das Mauerwerk übertragen wird. Anders ist dies bei Vorspannung ohne Verbund; hier wird die Vorspannkraft direkt über Ankerkörper in die Konstruktion eingeleitet, wodurch es keine Eintragungslänge infolge Verbundwirkung gibt. Diese Art der Vorspannung wird für die experimentell untersuchten Mauerwerkbalken verwendet, da hier die Vorspannkraft über die Balkenlänge konstant ist. Anstelle eines Schubzugrisses kann eine Rissbildung nach Bild 4.11 nicht vollständig ausgeschlossen werden.

\subsection{Schubübertragungsmechanismen innerhalb von Spannungsfeldern}

Für Balken aus bewehrtem Mauerwerk oder Stahlbeton sind folgende Mechanismen der Schubübertragung zu unterscheiden; vgl. Hendry et al. (Hendry et al. 2004, S. 188): Der Schubwiderstand resultiert aus der

- $\quad$ ungerissenen Biegedruckzone,

- Rissuferverzahnung (Interaktion mit Nachbarzahn),

- Dübelwirkung der Biegezugbewehrung (teilweise umstritten),

- Materialzugfestigkeit an schräg aufgehender Rissspitze; siehe Bild 4.12.

Sie sollen hier in qualitativer Hinsicht berücksichtigt und beschrieben werden. 


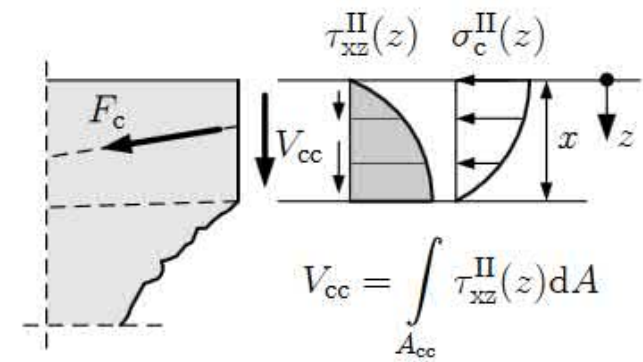

Traganteil der Druckzone
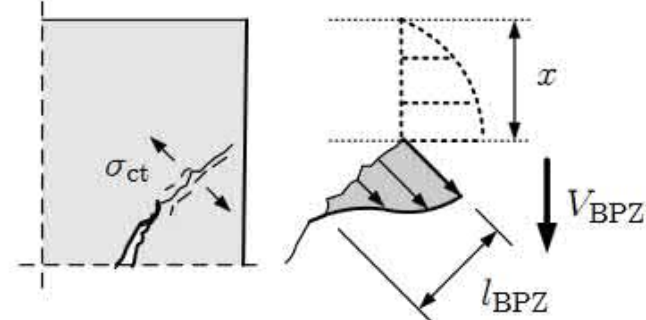

Traganteil der Bruchprozesszone

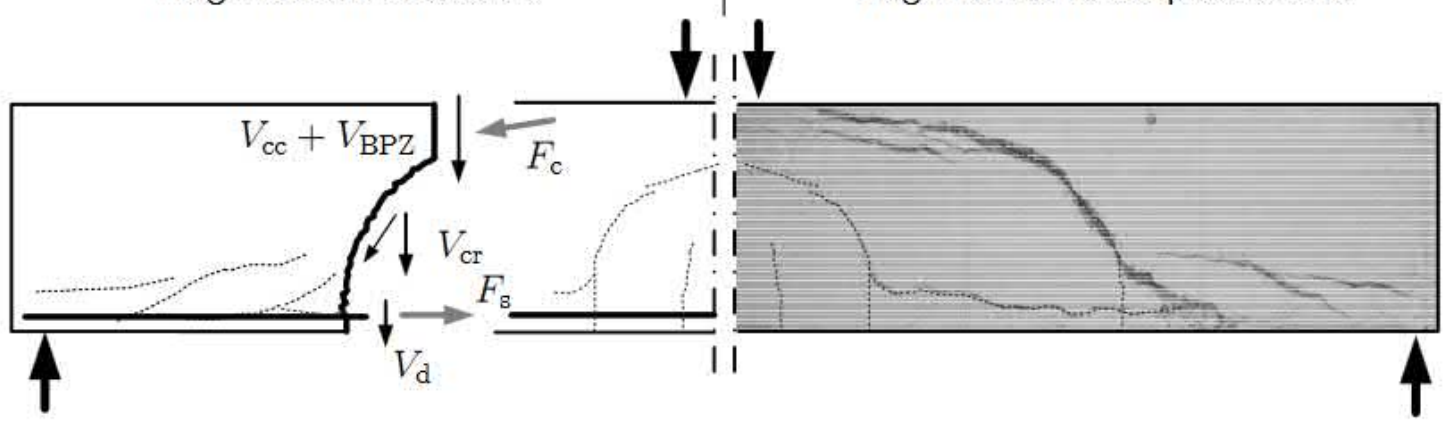

Rissverzahnung und Reibung
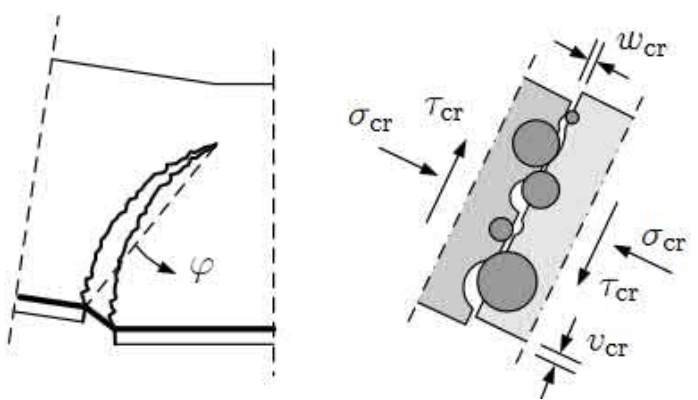

Dübelwirkung der Längsbewehrung
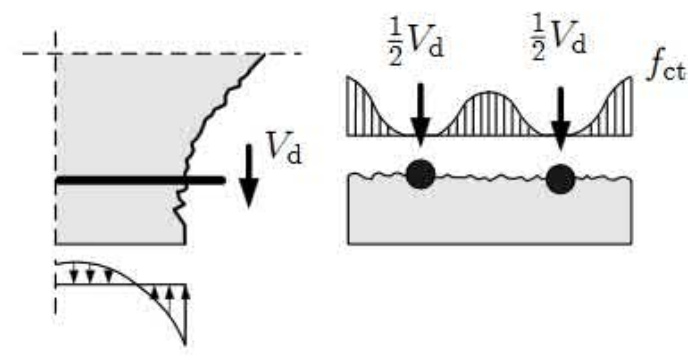

Bild 4.12 Tragwiderstände eines Bauteils ohne zusätzliche Schubbewehrung (Bender 2019, S. 10)

\subsubsection{Ungerissene Biegedruckzone}

Hinsichtlich der Ermittlung des Querkraftanteils der ungerissenen Biegedruckzone an der Gesamtschubtragfähigkeit wird auf Abschnitt 2.5.10.2 verwiesen.

\subsubsection{Rissuferverzahnung und Rissreibung}

Um den sich entwickelnden kritischen Schubriss erfolgt eine Rotation um die Rissspitze; siehe Bild 4.12. Dadurch wird eine Relativverschiebung bzw. Rissgleitung $(v)$ zwischen den Rissufern hervorgerufen. Durch die Topographie bzw. durch lokale und globale Rauigkeiten der Rissoberfläche werden Rissverzahnungskräfte aktiviert, wodurch Schub- $\left(\tau_{\mathrm{i}}\right)$ und Normalspannungen $(\sigma)$ übertragen werden können (Bild 4.13). Nach Zedler (Zedler 2011, S. 97-99) bleibt die globale Rissrauigkeit, bedingt durch die Streuung der Zugfestigkeit des Materials unberücksichtigt. Dies ist auf die Aktivierung von Kräften erst bei großen Verzerrungen zurückzuführen. Dahingegen sind die infolge lokaler Rissrauigkeit anzusetzenden, übertragbaren Spannungen in Untersuchungen an Stahlbetonbauteilen durch Walraven (Walraven 1980, S. 197 ff.) abhängig von: Der

- $\quad$ Rissgleitung $(v)$,

- Rissweite $(w)$,

- Druckfestigkeit $\left(f_{\mathrm{c}}\right)$,

- $\quad$ und von dem Größtkorndurchmesser $\left(D_{\max }\right)$. 


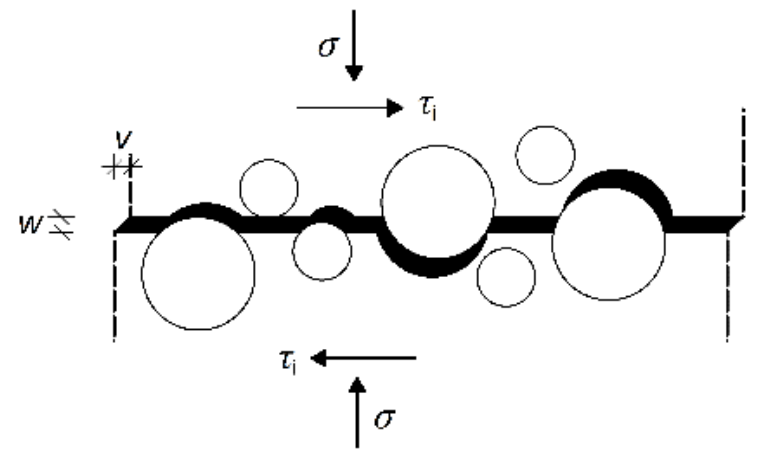

Bild 4.13 Kinematik der Rissverzahnung bei Stahlbeton; vgl. (Zink 2000, S. 64)

Darüber hinaus ist die Rissverzahnung bzw. die Größe der aufnehmbaren Schubspannungen abhängig von dem Material. Bei Normalbeton verläuft der Riss überwiegend in dem Zementstein und umwandert dabei die einzelnen Gesteinskörner. Dies könnte auch auf Rissverläufe in Mauersteinen angewendet werden, die Gesteinskörnung enthalten (z.B. Mauersteine aus Kalksandstein oder aus Beton). Die von der Gesteinskörnung abhängige Topographie der Rissoberfläche kann zu einer Verzahnung der Rissflanken führen; siehe Bild 4.14 (links). Im Gegensatz dazu durchtrennt der Riss bei Leichtbeton das Gesteinskorn, was zu einer deutlichen Reduktion der im Riss übertragbaren Spannungen führt; siehe Bild 4.14 (rechts). Dies könnte ebenfalls bei Mauerwerk aus Leichtbetonsteinen oder solchen Mauersteinen mit geringer Korngröße der Fall sein. Gleichwohl findet auch hier eine Kraftübertragung statt, wobei dann häufig der Begriff der Rissreibung anstelle der Rissverzahnung verwendet wird (Kohl 2014, S. 14). Tritt bei Mauerwerk unabhängig vom Steinmaterial ein Riss in den Mauerwerkfugen auf, ist eine Kraftübertragung in Form von Rissreibung wie bei Leichtbeton zu erwarten.
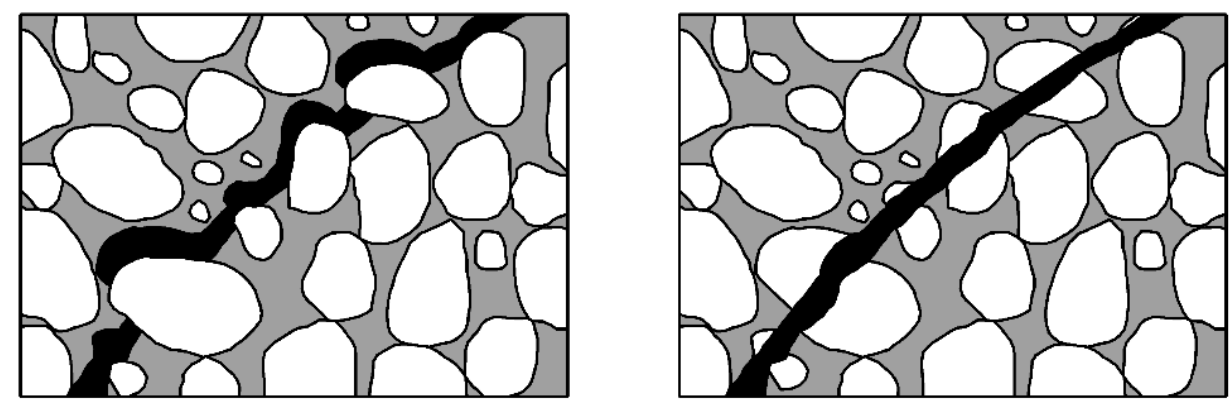

Bild 4.14 Schematische Darstellungen der Rissoberfläche: Normalbeton (links), Leichtbeton / hochfester Beton (rechts); vgl. (König et al. 2000, S. 587)

Walraven zeigt für Beton, dass parallel zu dem Rissverlauf eine Kraftübertragung auch ohne den Ansatz einer Rissnormalspannung stattfinden kann. Diese Erkenntnis wurde bei der Modifizierung der CFT zur MCFT durch Vecchio und Collins berücksichtigt (Vecchio, Frank, J. und Collins, Michael, P 1986, S. 219 231).

Der abhängig von der Gesteinskörnung hervorgerufene Einfluss auf die Schubtragfähigkeit wurde durch Walraven untersucht. Bild 4.15 zeigt die schematische Darstellung der Spannungsverteilung in der durch einsetzende Rissgleitung hervorgerufenen Kontaktfläche bei Normalbeton. 

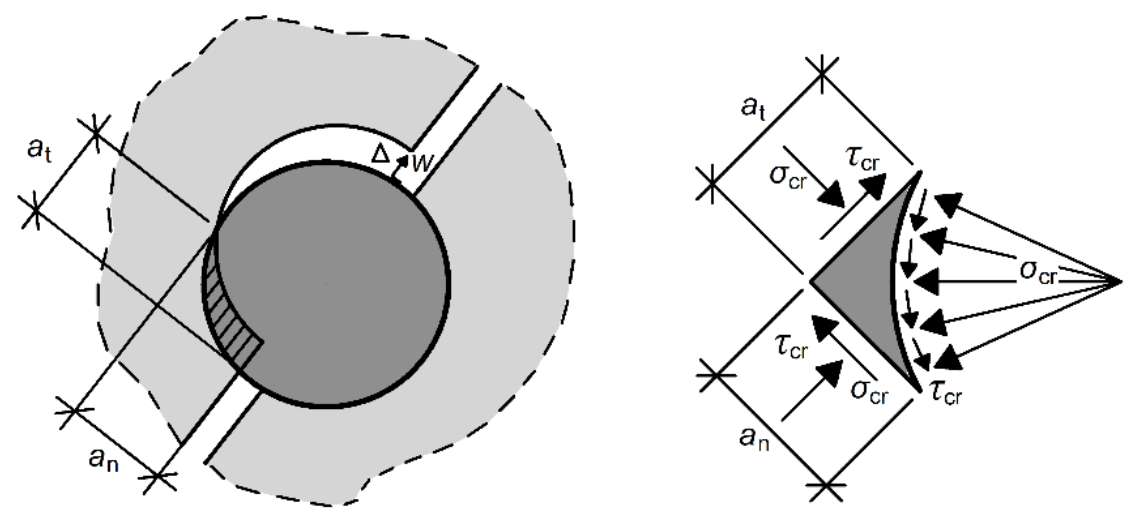

Bild 4.15 Spannungsverteilung in der Kontaktfläche vgl. (Walraven 1980, S. 59)

Aus seinen Untersuchungen schlussfolgerte Walraven, dass der Größtkorndurchmesser der Gesteinskörnung zwischen $16 \mathrm{~mm}$ und $32 \mathrm{~mm}$ mit zunehmender Rissgröße einen erheblichen Einfluss auf die Rissschubspannung $\left(\tau_{\mathrm{cr}}\right)$ ausübt. Demgegenüber wird die Rissnormalspannung $\left(\sigma_{\mathrm{cr}}\right)$ nur marginal beeinflusst. Weiterführende Untersuchungen, u.a. durch Sherwood, zeigen, dass ab einer Korngröße von $25 \mathrm{~mm}$ die maximale, durch den Korndurchmesser hervorgerufene, Querkraftzunahme erreicht ist (Edward G. Sherwood 2007). Der Tragmechanismus wird u.a. in Kamm- und Zahnmodellen berücksichtigt; siehe Abschnitt 4.3.2. In der SMCFT ist dieser Einfluss durch die Erfassung des Größtkorns enthalten. In Kalksandsteinen werden Gesteinskörnungen zwischen $2 \ldots 8 \mathrm{~mm}$ verwendet, wodurch der Effekt der Rissverzahnung für KS-Mauerwerk vorläufig vernachlässigbar erscheint.

Für Mauerwerk ist daher vorläufig eine Berücksichtigung der Rissreibung bzw. Rissverzahnung wie für Leichtbeton bzw. hochfesten Beton empfehlenswert.

\subsubsection{Dübelwirkung der Biegezugbewehrung}

Die Rissuferverzahnung verursacht einen vertikalen Relativversatz der benachbarten Rissflanken. Hierdurch werden in der Biegezugbewehrung Dübelkräfte senkrecht zur Bauteilachse aktiviert. Das Herunterdrücken der Bewehrung am Übergang zur benachbarten Rissflanke beansprucht die Überdeckung der Bewehrung durch Querzugkräfte.

Fischer hat in FE-Rechnungen die Dübelwirkung in schubschlanken Stahlbetonbauteilen untersucht. Dabei beschreibt er den Dübelriss als notwendige Voraussetzung zur Entwicklung des zum Versagen in Richtung der Lasteinleitung führenden Schrägrisses (Fischer und König 1997b, S. 220). Er gibt das Versagen durch die Dübelwirkung als maßgebendes Gesamtversagen an (Fischer und König 1997a, S. 175). Mit Überschreiten der Betonzugfestigkeit infolge zunehmender Dübelkraft entsteht ein längs der Bewehrung entlang verlaufender Dübelriss in Richtung des Auflagers. Dieser kann zu einem Absprengen des Betons im Bereich der Überdeckung führen; siehe Bild 4.16.
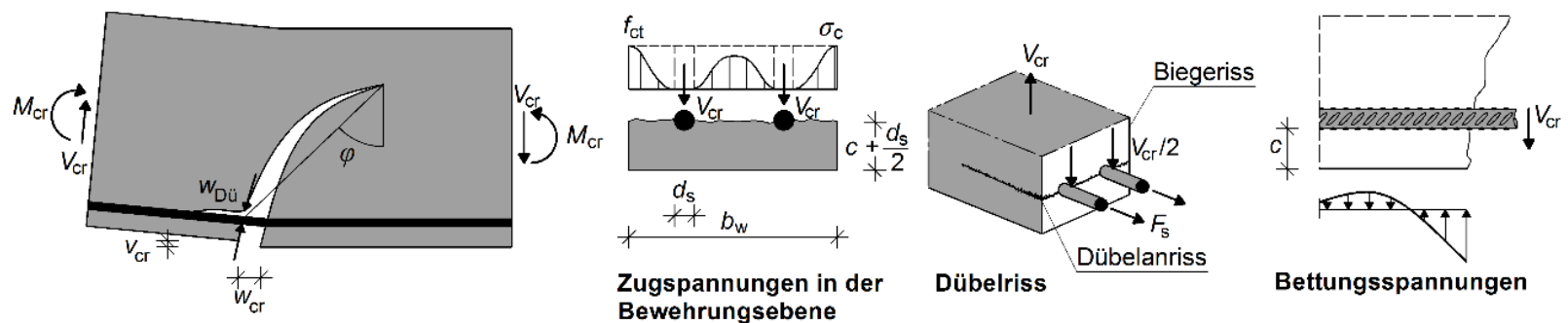

Bild 4.16 Dübelwirkung bzw. Dübelriss; vgl. (Zink 2000, S. 61; König et al. 2008, S. 242)

Ein stabiler Tragzustand hängt von der Biegesteifigkeit der Bewehrung und der Tragfähigkeit der zwischen der Bewehrung verbleibenden Betonfläche ab, über welche die Dübelkraft in die Betondruckzone zurückgehängt wird. Es folgt ein Risswachstum entlang der Bewehrung. Nach Zink hängt der Anteil der 
Dübelwirkung an der Gesamttragfähigkeit davon ab, zu welchem Zeitpunkt des Versagens der Dübelwiderstand überschritten wird (Zink 2000, S. 124).

Umstritten ist der Ansatz der Dübelwirkung für Stahlbetonbauteile, da dieser erst sekundär, nach Einsetzen des kritischen Schubrisses aktiviert wird und sich kein stabiler Tragzustand mehr einstellt. Die Folge ist ein Querkraftversagen. Ergänzt wird diese Hypothese durch den Einfluss der Zugfestigkeit des Betons. Die Zugfestigkeit beeinflusst den Widerstand maßgeblich, unterliegt jedoch hohen Streuungen, was somit auch für den Tagwiderstand aus der Dübelwirkung gilt. Dies ist auch bei Balken aus bewehrtem Mauerwerk zu erwarten. Darüber hinaus ist der Querkraftmechanismus aus der Dübelwirkung durch die praxisüblichen Längsbewehrungsgrade von untergeordneter Bedeutung (Huber et al. 2014, S. 17). Bei der Entwicklung der SMCFT wurde daher auf eine Berücksichtigung der Dübelwirkung verzichtet, was deren Anwendbarkeit auf Mauerwerk erleichtert.

\subsubsection{Vertikalwiderstand der Betonzugfestigkeit in der Rissprozesszone}

Im Bereich der Rissprozesszone können dort wirkende Zugspannungen aufgenommen werden. Die resultierende Vertikalkomponente der Zugspannungen in der Rissspitze bildet bei Stahlbetonbauteilen einen Anteil am Gesamtschubwiderstand; siehe Bild 4.17.

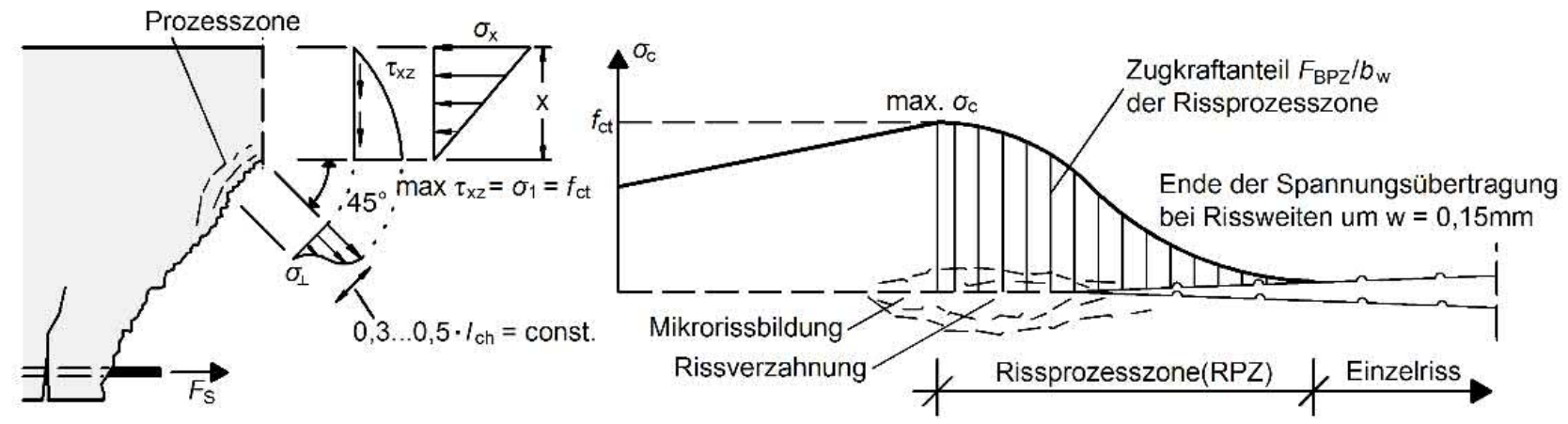

Bild 4.17 Spannungsverteilung in der Bruchprozesszone sowie in der Druckzone (links); Spannungsübertragung über einen Riss hinweg (rechts); vgl. (Zink 2000, S. 121-122)

Die Größe des durch die Rissprozesszone anrechenbaren Anteils an der Gesamtschubtragfähigkeit ist aufgrund der geringen Länge der Rissprozesszone so klein, dass dieser hier vernachlässigt werden kann (Huber et al. 2014, S. 18). Dies ist insbesondere bei Mauerwerk zu erwarten, weil auch die Größe der Steinzugfestigkeit im Vergleich zu Beton deutlich geringer ist.

\subsubsection{Maßstabseffekt}

Der Maßstabseffekt bildet ein Phänomen ab, bei dem, unter sonst gleichen Bedingungen, ein größeres Bauteil im Vergleich zu einem identischen, aber geometrisch kleineren Bauteil eine geringere Schubtragfähigkeit aufweist. Dieser Effekt wird durch den Maßstabsfaktor $(\kappa)$ beschrieben.

Im Vergleich zwischen Bauteilen verschiedener Größe resultiert dies bei größeren Bauteilen zum einen aus der statistisch größeren Wahrscheinlichkeit von Inhomogenitäten oder Fehlstellen entlang der Querschnittshöhe. Zum anderen kann der Effekt durch die Bruchmechanik beschrieben werden, wonach er auf eine höhere Dehnungsenergie bei gleichbleibender Nennspannung zurückzuführen ist.

Hegger weist dieses Phänomen durch eine Auswertung experimentell untersuchter Stahlbetonbalken nach (Hegger et al. 1999, S. 7). Dabei zeigt sich eine Abhängigkeit zwischen der Schubtragfähigkeit und der statischen Höhe untersuchter Probekörper. Mit kleiner werdender statischer Höhe ergibt sich eine Zunahme der auf die Querschnittshöhe bezogenen Schubtragfähigkeit. 
In der SMCFT, die im fib MC 2010 für Stahlbetonbauteile Anwendung findet, ist der Maßstabsfaktor von der Rissverzahnung (Rissreibung) abhängig und damit auch von dem Größtkorn und dem Hebelarm der inneren Kräfte; vgl. Gleichung (4.6) und (4.7).

Kanadische Norm:

CSA A23.3:

$1300 /\left(1000+s_{\mathrm{xe}}\right)$

fib Model Code 2010:

Level II:

$1300 /\left(1000+k_{\mathrm{dg}} \cdot z\right)$

Dabei ist:

$s_{\mathrm{xe}} \quad$ Die geometrische Größe zur Berücksichtigung der Rissverzahnung (Rissreibung) bzw. des Rissabstandes; ergibt sich in Abhängigkeit vom Hebelarm der inneren Kräfte und dem Durchmesser des Größtkorns $\left(s_{\mathrm{xe}}=k_{\mathrm{dg}} \cdot z\right)$.

Da der Maßstabseffekt weitestgehend geometrieabhängig bzw. auch von im Mauerwerk vorkommenden Tragmechanismen (Rissuferverzahnung und Rissreibung) abhängig ist, erscheint eine Übertragung dieses Ansatzes auf bewehrte Mauerwerkbalken zweckmäßig.

\subsubsection{Schubschlankheit}

Die Schubschlankheit $\left(\lambda=\frac{\max M_{\mathrm{Ed}}}{\max V_{\mathrm{Ed}} \cdot d}\right)$ ist entsprechend Gleichung (2.9) als Momenten-Schubkraftverhältnis definiert. Die ursprünglich für Stahlbetonbalken ermittelte Abhängigkeit der Schubtragfähigkeit von der Schubschlankheit gilt qualitativ sowohl für schlaff bewehrte als auch für vorgespannte Mauerwerkbalken; siehe Abschnitt 2.4. Ein Nachweis der Übertragbarkeit dieses Ansatzes erfolgt hier in Abschnitt 5.3.2 anhand experimenteller Untersuchungen.

Leonhardt und Walther bestätigten 1962 durch experimentelle Untersuchungen an Stahlbetonbalken die Abhängigkeit der Rissgeometrie von der Schubschlankheit. Dabei untersuchten sie fünf Stahlbetonbalken ohne Querkraftbewehrung im Hinblick auf variierende Schubschlankheiten und damit einhergehenden Rissverläufen; siehe Bild 4.18. Werden diese Ergebnisse mit denen experimenteller Untersuchungen an Mauerwerkbalken nach Abschnitt 2.4 verglichen, zeigen sich auch hier deutliche Parallelen zwischen den Rissverläufen bewehrter Mauerwerk- und Stahlbetonbalken, siehe auch Bild 2.8.

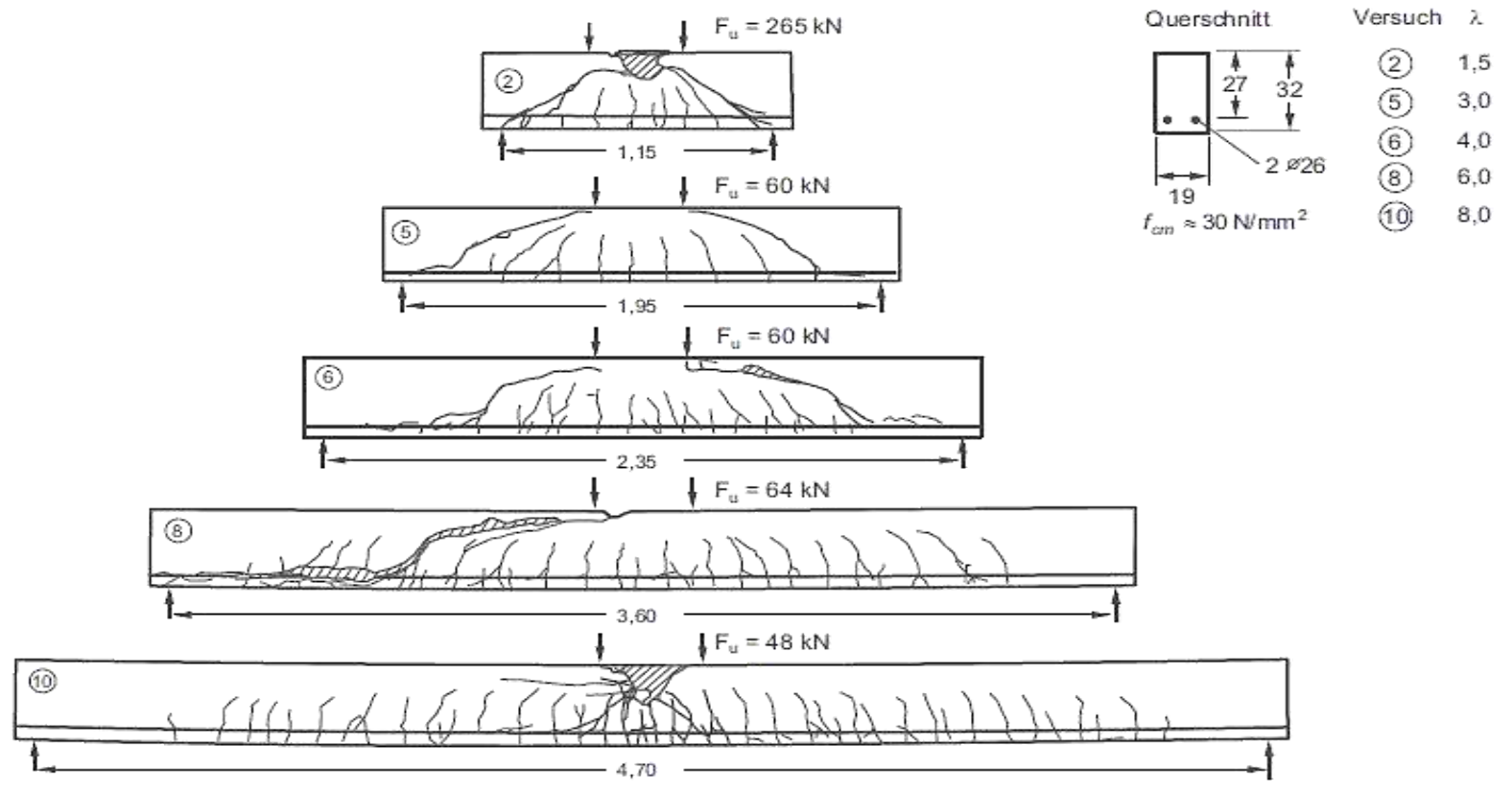

Bild 4.18 Rissgeometrie von Stahlbetonbalken ohne Querkraftbewehrung (Leonhardt und Walther 1962) 


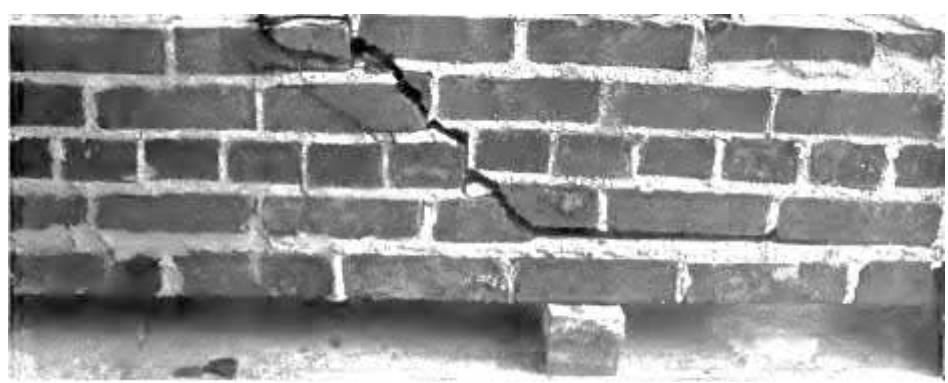

Bild 2.8 Typisches Rissbild eines auf Schub beanspruchten Mauerwerkbalkens (Parason et al. 1932, S. 755) (Wiederholung; vgl. Bild 2.8)

Wie auch Untersuchungen an bewehrten Mauerwerkbalken ergaben (Bild 2.18) hat die Schubschlankheit auf vorgespannte Konstruktionen einen deutlich größeren Einfluss als solche ohne Vorspannung (Zink 2000, S. 150). Zink erklärt dies durch die Sprengwerkwirkung, welche entscheidend für die Schubrissbildung der vorgespannten Konstruktion und für die stark schrumpfende Druckzonenhöhe im Bereich des größer werdenden Momentes ist.

\subsection{Abgrenzung herkömmlicher Schubtragmodelle von der Spannungsfeldmethode}

Zink (Zink 2000, S. 75-85), Bender (Bender 2019, S. 14) und Wehr (Wehr 2001, S. 6-12) geben einen umfassenden Überblick über im Stahlbetonbau angewendete Schubtragmodelle; vgl. Tabelle A 2.1. Um eine Abgrenzung der in Abschnitt 7.1 hergeleiteten, auf Mauerwerk angewendeten Spannungsfeldmethode (SMCFT) von den herkömmlichen Schubtragmodellen $\mathrm{zu}$ verdeutlichen, werden diese hier der Vollständigkeit halber angesprochen.

\subsubsection{Sprengwerk- und Bogenzugbandmodelle}

Sprengwerk- und Bogenzugbandmodelle resultieren aus einer Vereinfachung des klassischen Fachwerkmodells, welches auf Basis von in Spannungsfeldern unterstellten Druck- und Zugresultierenden entwickelt wurde. Die Grundlagen des Sprengwerkmodells werden für die Bemessung von Flachsturzkonstruktionen angewendet; vgl. (Flachsturz-Richtlinie - Vorläufiger Schlussentwurf; Gutachten Nr. GA 02/09 2009). Die Kritik an diesem Modell, auch im Zusammenhang mit der Anwendung für Mauerwerk, wurde in Abschnitt 2.5.7 ausführlich beschrieben.

\subsubsection{Kamm- und Zahnmodelle}

Anders als Sprengwerk- und Bogenzugbandmodelle orientieren sich die Kamm- und Zahnmodelle an der Rissgeometrie der Bauteile; siehe Tabelle A 2.1. Dabei hat Kani für Stahlbetonbalken eines der ersten Kamm- und Zahnmodelle entwickelt. Er interpretiert den auftretenden diagonalen Schubbruch als ein Versagen der Einspannung der Betonzähne in die ungerissene Betondruckzone. Darauf aufbauend wurden weitere Kamm- bzw. Zahnmodelle entwickelt, die auf einer idealisierten Rissgeometrie basieren; siehe Tabelle A 2.1 sowie die Arbeiten von Bender (Bender 2019, S. 14-20) und Zink (Zink 2000, S. 75-85).

Das Kamm- und Zahnmodell liefert für Mauerwerk mit scheitrecht angeordneten Mauersteinen einen guten Ansatz, da vertikal angeordnete Mauersteine (Zähne) Biegekräfte aufnehmen können. Während mit dem bisherigen Schubmodell für Mauerwerkbalken ausschließlich die Druckzonentragfähigkeit erfasst wird, werden hier weitere Tragmechanismen einbezogen. Diese sind: Wiederstände aus der Rissreibung, der Rissprozesszone und der Dübelwirkung der Bewehrung. Gleichwohl ist die qualitative Größe der einzelnen Tragmechanismen schwierig zu bestimmen, weshalb eine Anwendung auf Mauerwerk nicht geprüft wird. Weiterhin offen bleibt auch die Frage nach dem Ansatz eines geeigneten Schubfestigkeitswertes in Abhängigkeit des Neigungswinkels der schrägen Druckstrebe. 


\subsubsection{Semi-Empirisches Schubmodell von EC2}

Die theoretischen Grundlagen des semi-empirischen Schubmodells von DIN EN 1992-1-1 (DIN EN 19921-1:2011-01) bzw. DIN EN 1992-1-1/NA (DIN EN 1992-1-1/NA:2013-04) basieren auf experimentellen Untersuchungen an Stahlbetonbalken. Es werden mechanische Einflüsse aus dem Längsbewehrungsgrad, der Betonfestigkeitsklasse bzw. der Betonzugfestigkeit sowie dem Maßstabsfaktor berücksichtigt. Der Schubwiderstand $\left(V_{\mathrm{Rd}, \mathrm{c}}\right)$ wird mit Gleichung (4.8) berechnet.

$$
V_{\mathrm{Rd}, \mathrm{c}}=\left[C_{\mathrm{Rd}, \mathrm{c}} \cdot \kappa \cdot\left(100 \cdot \rho_{\mathrm{l}} \cdot f_{\mathrm{ck}}\right)^{\frac{1}{3}}+k_{1} \cdot \sigma_{\mathrm{cp}}\right] \cdot b_{\mathrm{w}} \cdot d \geq V_{\mathrm{Rd}, \mathrm{c}, \min }
$$

Dabei sind:

$C_{\mathrm{Rd}, \mathrm{c}} \quad$ der Vorfaktor nach Gleichung (4.9),

$C_{\mathrm{Rd}, \mathrm{c}}=\frac{0,15}{\gamma_{c}}$

$\kappa$

der Maßstabsfaktor nach Gleichung,

$\kappa=1+\sqrt{\frac{200}{d}} \leq 2,0$

$f_{\text {ck }} \quad$ die Druckfestigkeit des Materials,

$\rho_{\mathrm{l}} \quad$ der Bewehrungsgrad nach Gleichung (A 1.10), wobei $\rho_{\mathrm{l}} \leq 0,02$,

$\sigma_{\mathrm{cp}} \quad$ die Betonspannung nach Gleichung (4.11), wobei $\sigma_{\mathrm{cp}}<0,2 \cdot f_{\mathrm{cd}}$,

$\sigma_{\mathrm{cp}}=N_{\mathrm{Ed}} / A_{\mathrm{c}}$

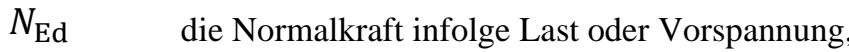

$A_{\mathrm{c}} \quad$ die Gesamtfläche des Betonquerschnitts,

$V_{\mathrm{Rd}, \mathrm{c}, \text { min }}=\left(v_{\min }+k_{1} \cdot \sigma_{\mathrm{cp}}\right) \cdot b_{\mathrm{w}} \cdot d$

$k_{1} \quad$ der Vorfaktor nach Gleichung (4.13),

$k_{1}=0,12$

$v_{\min } \quad$ für $d \leq 600 \mathrm{~mm}$, nach Gleichung (4.14),

für $d>800 \mathrm{~mm}$, nach Gleichung (4.15),

dazwischen darf interpoliert werden.

$$
\begin{aligned}
& v_{\text {min }}=\left(0,0525 / \gamma_{\mathrm{c}}\right) \cdot \kappa^{\frac{3}{2}} \cdot f_{\mathrm{ck}}^{1 / 2} \\
& v_{\min }=\left(0,0375 / \gamma_{\mathrm{c}}\right) \cdot \kappa^{\frac{3}{2}} \cdot f_{\mathrm{ck}}^{1 / 2}
\end{aligned}
$$

Der Vorfaktor $\left(C_{R d, c}\right)$ von Gleichung (4.8) ist ein empirisches Maß zur Anpassung von Versuchsergebnissen und berechneten Werten. Ebenso implementiert er ein Sicherheitsniveau für einen Bezugszeitraum von 50 Jahren. Der ebenfalls in Gleichung (4.8) enthaltene Maßstabsfaktor kann in Abhängigkeit der statischen Höhe nach Gleichung (4.10) bestimmt werden. Für statische Höhen zwischen $d=200 \ldots 1400 \mathrm{~mm}$ ist der Einfluss in Bild 4.19 dargestellt. 


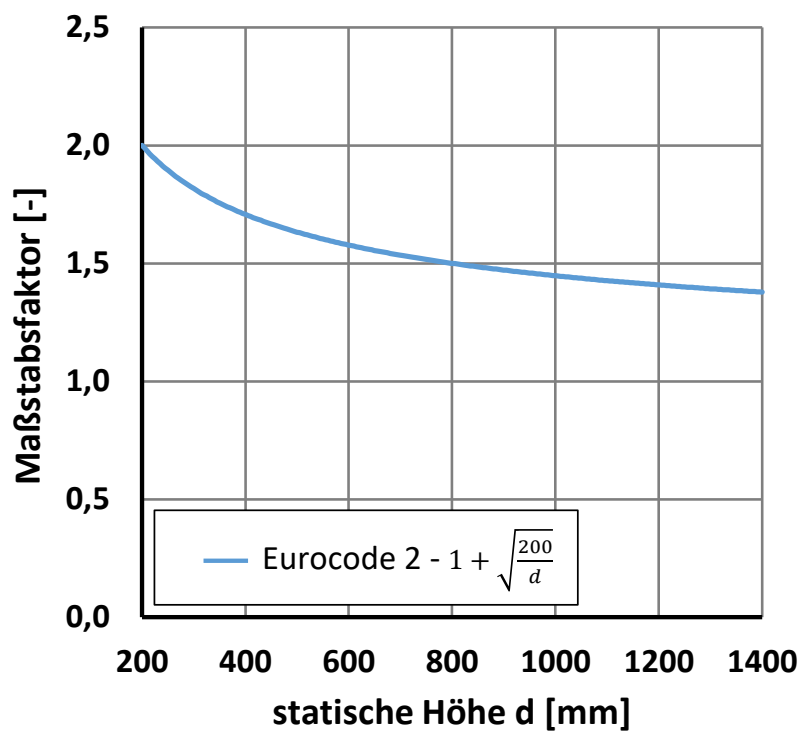

Bild 4.19 Maßstabsfaktor in Abhängigkeit der statischen Höhe nach Gleichung (4.10)

Die Auswertungen empirischer Untersuchungen an bewehrten und vorgespannten Betonkonstruktionen durch Hegger zeigen eine Abhängigkeit der Schubtragfähigkeit von der Schubschlankheit; siehe auch Abschnitt 2.5.1. Dabei nimmt die experimentell ermittelte Schubtragfähigkeit mit abnehmender Schubschlankheit deutlich zu; siehe Bild A 2.1.

Um den Effekt der erhöhten Tragfähigkeit in der Bemessung zu berücksichtigen, wird für Bauteile mit auflagernahen Einzellasten bzw. kleinen Schubschlankheiten die einwirkende Querkraft durch Multiplikation mit dem Faktor $\beta$ nach Gleichung (A 1.6) abgemindert, wobei $a_{\mathrm{v}}^{*}$ hier durch $a_{\mathrm{v}}$ ersetzt wird. Für die Anwendbarkeit von $\beta$ zur Abminderung der einwirkenden Last $V_{\mathrm{Ed}}$ gelten Grenzbereiche nach Gleichung (4.16).

$0,5 \cdot d \leq a_{v}<2 \cdot d$

Dabei sind:

$d \quad$ Die statische Höhe,

$a_{\mathrm{v}} \quad$ der Abstand zwischen Auflagerrand und Rand der Lasteinleitung.

Grundsätzlich ist der zuletzt genannte Effekt mit einer Erhöhung der Querkrafttragfähigkeit nach Gleichung (2.22) gleichzusetzen, wie dies für Mauerwerkkonstruktionen nach DIN EN 1996-1-1, Abschnitt 6.7.3 (2) (DIN EN 1996-1-1:2013-02, S. 78) vorgenommen wird. Im Bereich $a_{\mathrm{v}}<0,5 \cdot \mathrm{d}$ verhindert die Berücksichtigung des in Gleichung (4.16) angegebenen Grenzwertes ein Spalten der Druckstrebe.

Der Längsbewehrungsgrad ist nach EC2 auf den Grenzwert von $\rho_{1} \leq 2 \%$ beschränkt. Diese Vorgabe beugt der Planung überbewehrter Bauteile vor, wodurch ein sprödes Bruchversagen ohne vorherige Versagensankündigung vermieden wird. Dies gilt insbesondere für spröde Materialien wie Beton und kann auf verschiedene Mauerwerke, z.B. Ziegelmauerwerk übertragen werden.

Die Berücksichtigung von Längsspannungen $\left(\sigma_{\mathrm{cp}}\right)$ erfasst die Wirkung einer äußeren Normalkraft und/ oder einer Vorspannung. Der dazugehörige Vorfaktor $\left(k_{1}\right)$ nach Gleichung (4.13) wurde anhand von Versuchsauswertungen statistisch ermittelt (Hegger et al. 1999, S. 38 ff.).

Wird der Bewehrungsgrad der Längsbewehrung nach Gleichung (A 1.10) stark reduziert, tendiert die Querkrafttragfähigkeit gegen Null. Um diesen Effekt $\mathrm{zu}$ kompensieren, wurde eine Mindestquerkrafttragfähigkeit $\left(V_{\mathrm{Rd}, \mathrm{c}, \mathrm{min}}\right)$ nach Gleichung (4.12) eingeführt. Diese Konstante liefert 
insbesondere in Bereichen sehr geringer Längsbewehrung deutlich höhere Querkrafttragfähigkeiten als Gleichung (4.8).

Für Bauteile ohne Schubbewehrung ist die Zugfestigkeit des die Balkengeometrie bildenden Materials von entscheidender Größe. Da die Zugfestigkeit des Bauteils häufig wegen lokaler Gefügeschäden starken Schwankungen unterliegt, kann nicht ausgeschlossen werden, dass sich der kritische Schubriss deutlich früher als der rechnerische Schubriss einstellt. Da die Rissbildung bei dem jeweiligen Bauteil direkt zu einem Schubversagen führen kann, ist im Stahlbetonbau eine Mindestquerkraftbewehrung vorzusehen.

Die Bemessungsgleichung (4.8) zur Ermittlung des Schubwiderstandes liefert eine gute Grundlage für eine Übertragbarkeit auf Mauerwerk. Der Ansatz hat aber den entscheidenden Nachteil, dass der Schubwiderstand nicht auf Basis des tatsächlichen Verformungszustands bestimmt wird, wonach Längsdehnungen nicht in die Definition der Schubfestigkeit einbezogen werden. Anders ist dies bei den Bemessungsansätzen der Spannungsfeldmethode nach fib MC 2010, wonach die Schubbemessung auf Grundlage der „Simplified Modified Compression Field Theory“ (SMCFT) erfolgt. In Abschnitt 7.1 wird die Schubtheorie der SMCFT vorgestellt und im Hinblick auf eine Übertragbarkeit auf Mauerwerk bewertet.

\subsection{Zusammenfassung und Beurteilung}

In diesem Kapitel wurden die analytischen Grundlagen des Schubtragverhaltens von Balkenkonstruktionen aus bewehrtem Mauerwerk in Anlehnung an die von bewehrten Betonkonstruktionen erarbeitet. Dies erscheint zweckmäßig, weil zu überprüfen ist, ob bewehrtes Mauerwerk sich lediglich durch dessen Anisotropie von Stahlbeton unterscheidet. Es wurden Schubübertragungsmechanismen aufgezeigt, die auch bei Verwendung von Mauerwerk anstelle von Beton relevant erscheinen. Aus mechanischer Sicht bildet der Ansatz der Spannungsfeldtheorie eine gute Grundlage für die Beschreibung der Schubtragfähigkeit von bewehrten Mauerwerkbalken. Dies betrifft zunächst hypothetisch die SMCFT, weil diese auf der Theorie der verallgemeinerten Spannungsfelder basiert. Deren Herleitung erfolgt in Abschnitt 7.1. Die SMCFT ist Bestandteil der Schubbemessung von Betonbalken im fib MC 2010 (Volume 3). Dabei wird neben den Schubwiderständen mechanischen und geometrischen Ursprungs, im Gegensatz zu bisherigen Modellen, auch der tatsächliche Verformungszustand über Längsdehnungen in die Definition der Schubfestigkeit einbezogen. Die Anisotropie des Mauerwerks bleibt in der klassischen SMCFT zunächst unberücksichtigt, weil sie für Konstruktionen aus dem vergleichsweise isotropen Werkstoff „Beton“ entwickelt wurde. Die SMCFT soll über die Implementierung eines von der Beanspruchungsrichtung abhängigen Werkstoffgesetzes für den Baustoff „Mauerwerk“ - entwickelt durch Ganz und Thürlimann berücksichtigt werden. Zur entsprechenden Verifikation dieser Vorgehensweise wird auf Abschnitt 7 hingewiesen. 
Experimentelle Untersuchungen

\subsection{Vorbemerkungen}

Dieser Abschnitt beschreibt an der Hochschule Ostwestfalen-Lippe - Labor für Baustoffe und Massivbau - durchgeführten experimentellen Bauteiluntersuchungen bewehrter Mauerwerkbalken mit und ohne Aufbeton oder Vorspannung. Das Ziel ist es, Kenntnis über das Trag- und Verformungsverhalten im Bereich der Schubspannungsfelder von Mauerwerkbalken zu erhalten. Es wurden konstruktions- und materialspezifische Einflüsse auf die Querkrafttragfähigkeit erforscht. Untersucht wurden bewehrte Mauerwerkbalken mit vermörtelten Stoßfugen nach Tabelle 5.1, in Anlehnung an die Bauteilkategorien der Tabelle 2.1. Für den Begriff „Fertigteilsturz“ (II) wird im Folgenden „Fertigteilbalken“ verwendet, da dies aufgrund der gewählten Schubschlankheiten zutreffender erscheint.

Tabelle 5.1 Kombinationsformen untersuchter Bauteilkategorien

\begin{tabular}{|c|c|c|c|}
\hline Bauteilkategorie & Schlaffe Bewehrung & Spannbewehrung & $\begin{array}{c}\text { Ergänzungsschicht aus } \\
\text { Beton }\end{array}$ \\
\hline Ia - Flachsturz & $\mathrm{x}$ & - & - \\
\hline \multirow{2}{*}{ IIa - scheitrechter Fertigteilbalken } & $\mathrm{x}$ & - & - \\
\hline & $\mathrm{x}$ & - & $\mathrm{x}$ \\
\hline IIbIII - vorgespannter Balken & - & $\mathrm{x}$ & - \\
\hline
\end{tabular}

Ein wesentlicher Einfluss auf den Querkraftwiderstand resultiert aus der Geometrie und der Belastungssituation der Mauerwerkbalken innerhalb der Schubspannungsfelder, was u.a. durch den Parameter „Schubschlankheit“ erfasst wird. Der Einfluss wurde für entsprechende Konstruktionsformen untersucht. Im Weiteren wurden Auswirkungen auf die Querkrafttragfähigkeit durch die Mauerwerkdruckfestigkeit, die Verbundfuge zwischen Balken und Ergänzungsschicht aus Beton, den Bewehrungsgrad und den Druckstrebenwinkel innerhalb des Schubfeldes untersucht.

Bei der Herstellung von scheitrechten Fertigteilstürzen erfolgt die Anordnung der Mauersteine entgegen ihrer üblichen Ausrichtung (wie bei Wänden) um 90 Grad gedreht, wodurch die Druckfestigkeit senkrecht zur Lagerfuge, längs des Balkens, in Biegedruckrichtung anzunehmen ist. In Bild 5.6 und Bild 5.7 ist ein solcher Probekörper exemplarisch dargestellt. Die Längsbewehrung wurde in einem, zuvor durch Kernbohrung hergestellten, durchgehenden Kanal zentrisch angeordnet. Für die schlaff bewehrten Mauerwerkbalken nach Abschnitt 5.2 und 5.4 wurde der Verbund über Injektionsmörtel hergestellt. Bei Mauerwerkbalken mit Vorspannung ohne Verbund nach Abschnitt 5.5, wurde die Vorspannkraft durch stirnseitig angeordnete Ankerplatten in das System eingeleitet (Bild 5.25). Die in Abschnitt 5.2 beschriebenen Flachstürze aus Porenbeton wurden durch Übermauerung der Zugbänder mit bereits eingeschäumter, schlaffer Bewehrung hergestellt; siehe Bild 5.1.

Nach ihrer Herstellung wurden die Mauerwerkbalken 28 Tage bei einer Raumtemperatur zwischen 18 und $22^{\circ} \mathrm{C}$ und einer relativen Luftfeuchtigkeit zwischen ca. $40 \%$ und 65\% RH gelagert. Die Mauerwerkbalken wurden in Anlehnung an DIN EN 846-9 (DIN EN 846-9:2016-08) geprüft. Für die nach Abschnitt 5.2 geprüften Flachstürze wurde eine Belastungsanordnung nach Bild 2 (d) (DIN EN 846-9:2016-08, S. 10) vorgenommen. Die Fertigteilstürze nach Abschnitt 5.3 bis 5.5 wurden entsprechend einer Belastungsanordnung von Bild 2 (a) (DIN EN 846-9:2016-08, S. 10) geprüft.

Zur Ermittlung des Lastabtrages und des Verformungsverhaltens wurden die Prüfkörper mit spezifischen Messstellen versehen. Die Anordnung der Wegaufnehmer wurde in Messstellenplänen dokumentiert; siehe Bild 5.7. In Einzelfällen wurde zusätzlich ein optisches 3D-Verformungsmesssystem (Aramis der Firma GOM) eingesetzt. Die Verformungen wurden graphisch dargestellt und ermöglichten eine flächenhafte 
Auswertung des Trag- und Verformungsverhaltens der Mauerwerkbalken. Als Messgrößen wurden die Riss- und die Bruchlast sowie Verformungen an definierten Stellen und in einigen Fällen flächenbezogen dokumentiert.

Der besseren Übersicht wegen sind die experimentellen Bauteilprüfungen entsprechend den Bauteilkategorien nach Tabelle 5.1 in einzelne Abschnitte gegliedert.

\subsection{Flachstürze - Ia}

Die experimentellen Untersuchungen an Flachstürzen wurden nach den Versuchsprogrammen von Tabelle 5.2 und Tabelle 5.3 durchgeführt. Die Prüfkörper wurden aus durchgehenden Porenbetonzugbändern mit darüber angeordneten Übermauerungen aus Porenbeton hergestellt. In den Zugbändern ist die Biegebewehrung werkseitig eingeschäumt. Ziel der Untersuchungen war es, den Einfluss nicht vorgenommener Stoßfugenvermörtelung zu ermitteln, weshalb die Druckzone zum einen mit vermörtelten (vm) und zum anderen mit unvermörtelten (um) Stoßfugen ausgeführt wurde. Die Horizontalfuge oberhalb des Zugbandes wurde auf mögliches frühzeitiges Reibungsversagen hin geprüft. Bild 5.1 zeigt den schematischen Aufbau untersuchter Flachstürze.

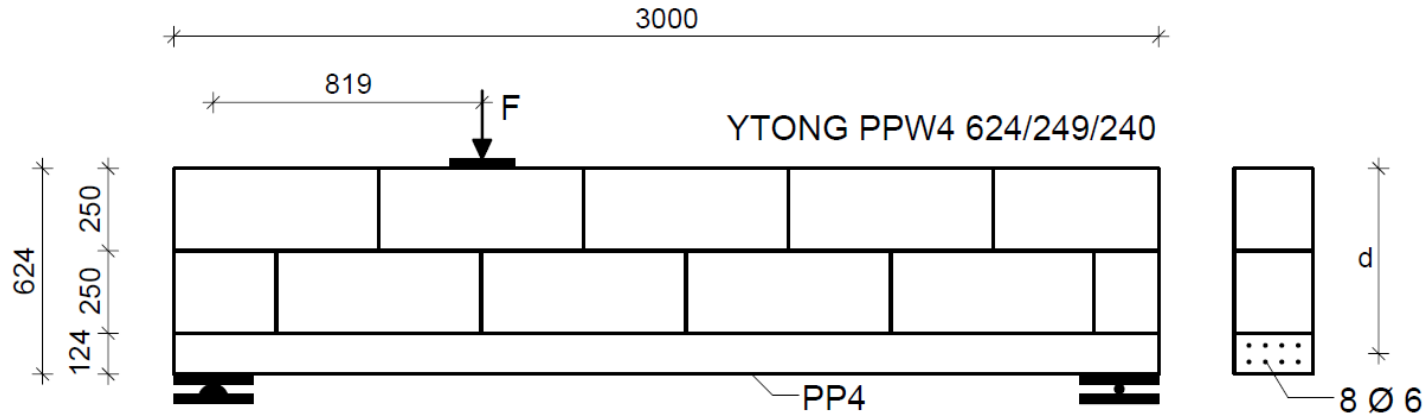

\section{Bild 5.1 Systemskizze untersuchter Flachstürze}

Tabelle 5.2 enthält Angaben über Geometrie und Eigenschaften der untersuchten Flachstürze. Tabelle 5.3 ist die Art und Menge der in den Zugbändern angeordneten Bewehrung zu entnehmen.

Tabelle 5.2 Versuchsprogramm: Geometrie und Eigenschaften der Probekörper

\begin{tabular}{|c|c|c|c|c|c|c|c|c|c|c|c|c|}
\hline \multirow{2}{*}{\multicolumn{2}{|c|}{\begin{tabular}{|c|} 
Versuchs- \\
Bez./ Anzahl \\
n
\end{tabular}}} & \multirow[t]{2}{*}{$\begin{array}{l}\text { Steinart/ } \\
\text { Festig- } \\
\text { keits- } \\
\text { klasse }\end{array}$} & \multirow[t]{2}{*}{$\begin{array}{c}\text { Mörtel- } \\
\text { art/ } \\
\text { Stoß- } \\
\text { fuge }^{2}\end{array}$} & \multicolumn{3}{|c|}{$\begin{array}{l}\text { Querschnittswerte } \\
{[\mathrm{mm}]}\end{array}$} & \multicolumn{2}{|c|}{$\begin{array}{l}\text { Prüfkörper- } \\
\text { länge } \\
\text { [m] }\end{array}$} & \multicolumn{2}{|c|}{\begin{tabular}{|c|} 
Abstand zwischen: \\
Achse Auflager - Achse F / \\
Abstand zwischen: \\
Auflager - F \\
[mm]
\end{tabular}} & \multirow{2}{*}{\begin{tabular}{|c|}
$\begin{array}{c}\text { Auflager- } \\
\text { länge } \\
{[\mathrm{mm}]}\end{array}$ \\
$a_{1}$ \\
\end{tabular}} & \multirow[t]{2}{*}{$\begin{array}{c}\begin{array}{c}\text { Schlank- } \\
\text { heit }^{1} \\
{[-]}\end{array} \\
\lambda\end{array}$} \\
\hline & & & & $h$ & $d$ & $t$ & $l$ & $l_{\text {eff }}$ & $a$ & $a_{\mathrm{v}}$ & & \\
\hline PP-01 & 1 & $\begin{array}{c}\text { PPW }-4 \\
-0,5\end{array}$ & $\begin{array}{l}\mathrm{DM} / \\
\mathrm{um}\end{array}$ & 624 & 562 & 240 & 3,00 & 2,76 & 819 & 599 & 240 & 1,5 \\
\hline PP-02 & 1 & $\begin{array}{c}\text { PPW }-4 \\
-0,5 \\
\end{array}$ & $\begin{array}{c}\mathrm{DM} / \\
\mathrm{vm}\end{array}$ & 624 & 562 & 240 & 3,00 & 2,76 & 819 & 599 & 240 & 1,5 \\
\hline PP-03 & 1 & $\begin{array}{c}\mathrm{PPW}-4 \\
-0,5\end{array}$ & $\begin{array}{l}\mathrm{DM} / \\
\mathrm{vm}\end{array}$ & 624 & 562 & 240 & 3,00 & 2,76 & 819 & 599 & 240 & 1,5 \\
\hline PP-04 & 1 & $\begin{array}{c}\mathrm{PPW}-4 \\
-0,5\end{array}$ & $\begin{array}{c}\mathrm{DM} / \\
\mathrm{um}\end{array}$ & 624 & 562 & 240 & 3,00 & 2,76 & 819 & 599 & 240 & 1,5 \\
\hline
\end{tabular}


Tabelle 5.3 Versuchsprogramm: Art und Menge der Bewehrung

\begin{tabular}{|c|c|c|}
\hline Versuchsbezeichnung & Art der Bewehrung & $\begin{array}{c}\text { Durchmesser Bewehrung } \\
{[\mathbf{m m}]}\end{array}$ \\
\hline PP-01 & B500A & $8 \times 6$ \\
\hline PP-02 & B500A & $8 \times 6$ \\
\hline PP-03 & B500A & $8 \times 6$ \\
\hline PP-04 & B500A & $8 \times 6$ \\
\hline
\end{tabular}

Zur Erfassung eines möglichen Lagerfugenversagens zwischen Zugband und Übermauerungsschicht wurde an den jeweiligen Enden der Prüfkörper die Horizontalverschiebung gemessen; siehe Bild 5.2.

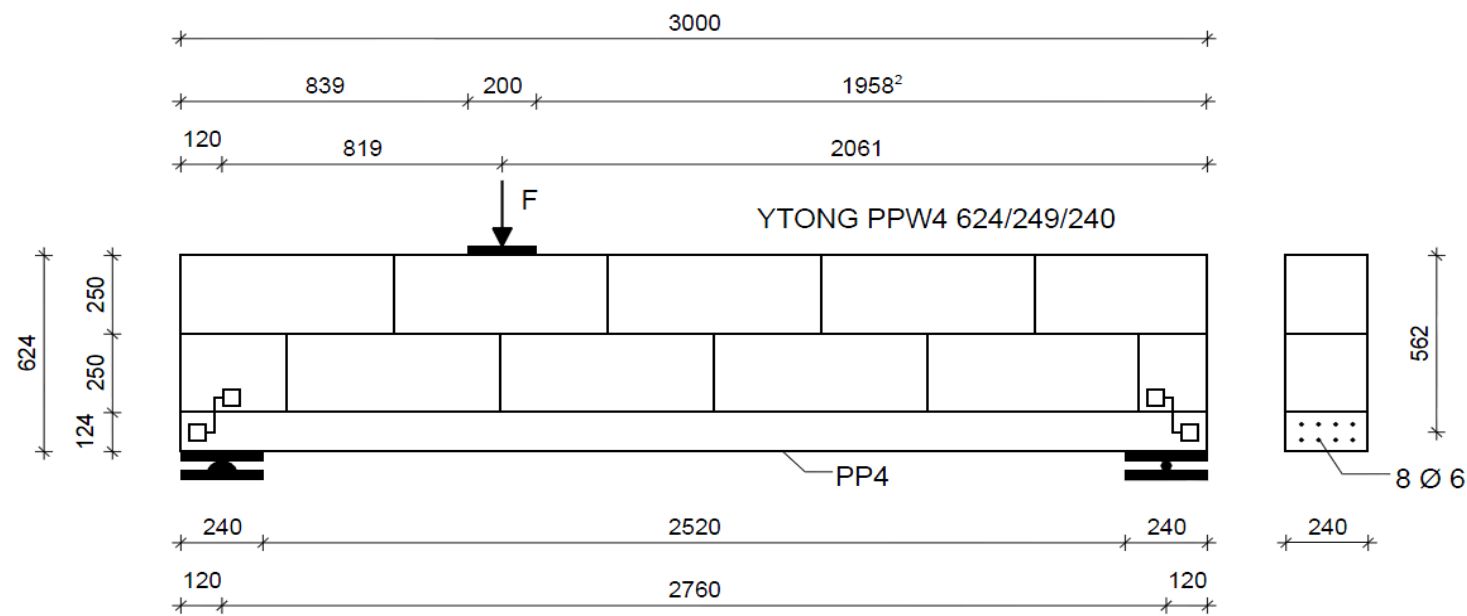

Bild 5.2 Messstellenplan untersuchter Flachstürze

In Tabelle 5.4 sind die Risslasten $\left(F_{\text {exp,cr }}\right)$ und die Bruchlasten inkl. Eigengewicht $\left(F_{\text {exp,u }}\right)$ der Versuchskörper sowie die Versagensart angegeben.

Tabelle 5.4 Riss- und Bruchlasten untersuchter Flachstürze

\begin{tabular}{|c|c|c|c|}
\hline $\begin{array}{c}\text { Versuchs- } \\
\text { bezeichnung }\end{array}$ & $\begin{array}{c}\text { Risslast }\left(\boldsymbol{F}_{\text {exp,cr }}\right) \\
{[\mathbf{k N}]}\end{array}$ & $\begin{array}{c}\text { Bruchlast }\left(\boldsymbol{F}_{\text {exp, u }}\right) \\
{[\mathbf{k N}]}\end{array}$ & Versagensart $^{\mathbf{1}}$ \\
\hline PP-01 & 17,3 & 21,6 & $\mathrm{R}$ \\
\hline PP-02 & 36,3 & 36,3 & $\mathrm{Z}$ \\
\hline PP-03 & 35,3 & 35,3 & $\mathrm{Z}$ \\
\hline PP-04 & 12,3 & 15,3 & $\mathrm{R}$ \\
\hline${ }^{1}$ Versagensart: Z - Schubzugversagen; R - Reibungsversagen \\
\hline
\end{tabular}

Die Rissbilder der Prüfkörper PP-01 mit unvermörtelten Stoßfugen und PP-02 mit vermörtelten Stoßfugen sind beispielhaft in Bild 5.3 dargestellt. Zu erkennen ist ein Rissverlauf im Bereich des Schubfeldes. Das Primärversagen ist auf das Einsetzen eines Schubzugbruches zurückzuführen. Dieser verläuft bei unvermörtelten Stoßfugen treppenförmig im Bereich der Fugen (Reibungsversagen; siehe Bild 5.3 oben) und bei vermörtelten Stoßfugen diagonal (Bild 5.3 unten), wodurch Steinzugversagen maßgebend wird. Nachweislich setzt sich damit der Schubwiderstand aus einem Anteil aus Reibung und aus Steinzugfestigkeit zusammen. Das Reibungsversagen der Horizontalfugen ist bei vermörtelten Stoßfugen als Sekundärversagen einzustufen. 


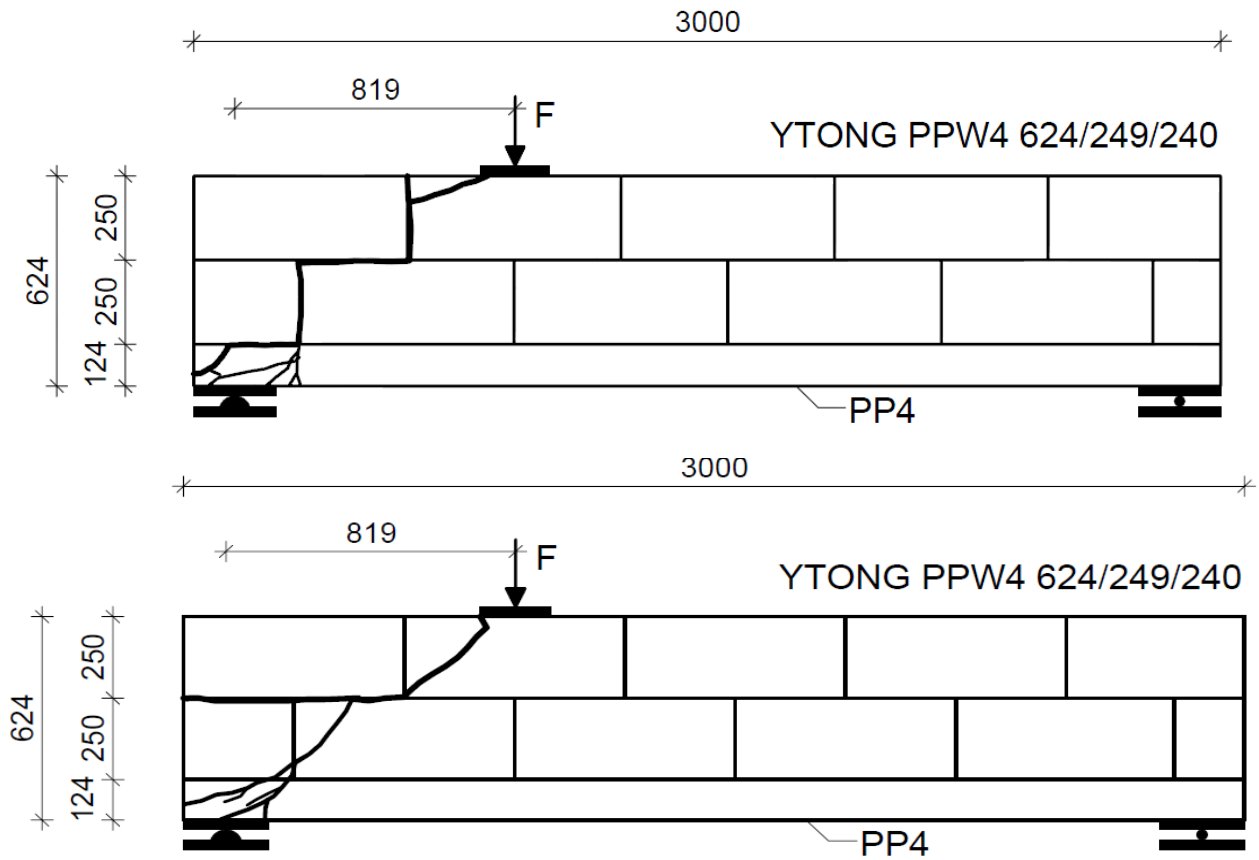

Bild 5.3 PP-01-um (oben) und PP-02-vm (unten): Rissbild untersuchter Flachstürze ohne (um) und mit Stoßfugenvermörtelung (vm)

Die experimentellen Untersuchungen zeigen bei Flachstürzen aus Porenbeton mit einer Stoßfugenvermörtelung, im Vergleich zu solchen ohne Stoßfugenvermörtelung, ein deutlich homogeneres Bauteilverhalten. In Bild 5.4 sind Ergebnisse flächenbezogener Verformungsmessungen des Prüfkörpers PP-01 mit unvermörtelten und in Bild 5.5 des Prüfkörpers PP-02 mit vermörtelten Stoßfugen dargestellt. Ein Vergleich der Last-Durchbiegungslinien zeigt, dass die Unterschiede hinsichtlich der Homogenität der Mauerwerkstrukturen deutliche Auswirkungen auf die Traglasten und die Mittendurchbiegungen haben. Die Traglast kann anhand des Vergleiches der Prüfkörper PP-01 und PP-02 durch eine Stoßfugenvermörtelung um 67,5\% gesteigert werden. Die Mittendurchbiegung beträgt bei dem Prüfkörper PP-01, mit unvermörtelten Stoßfugen, $w=2,8 \mathrm{~mm}$ und bei PP-02, mit vermörtelten Stoßfugen, $w=$ 0,9 $\mathrm{mm}$. Den Bildern kann ferner entnommen werden, dass bei vermörtelten Stoßfugen die Durchbiegung unter Laststeigerung linear zunimmt; bei Balken ohne Stoßfugenvermörtelung ist der Verlauf degressiv. Letzterer zeigt Sprünge im Verlauf, die auf einen Lastabfall infolge Rissbildung hindeuten. Hier kam es vor Bauteilversagen bei ca. 19,5 kN zur Rissbildung in den Stoßfugen. Neben den Steinen hat auch die von Lager- und Stoßfugen gebildete Mauerwerksstruktur einen Einfluss auf die Querkrafttragfähigkeit. Für Mauerwerk erscheint es daher wesentlich, die Berücksichtigung der Anisotropie des Mauerwerks über ein zweiaxiales Materialmodell im Bereich von Schubspannungsfeldern zu simulieren. So können Reibungswiderstände über Bruchregime in der Beschreibung des Tragwiderstandes berücksichtigt werden. 


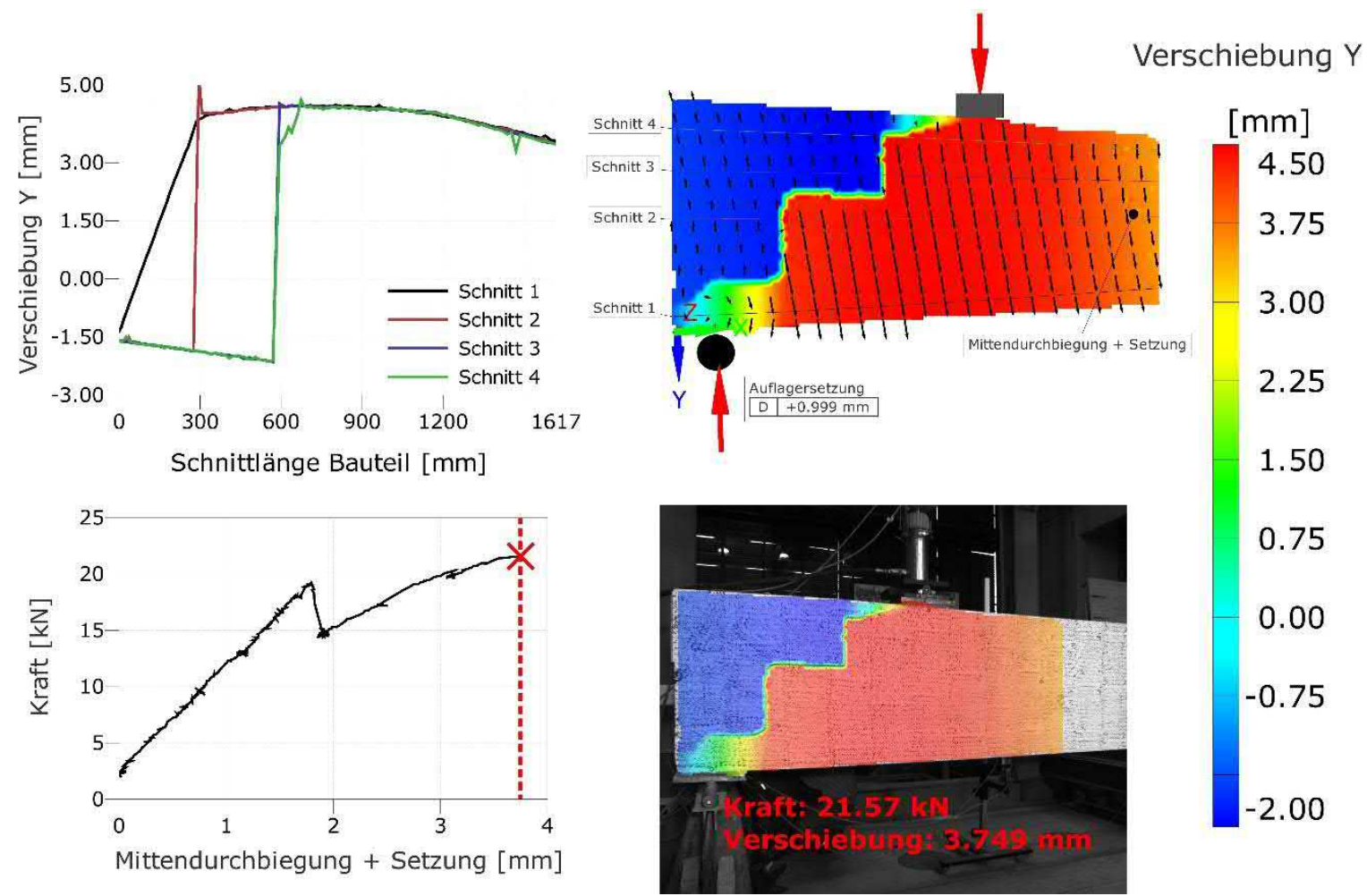

Bild 5.4 Flächenhafte Darstellung der Vertikalverformung (Y-Richtung) des Prüfkörpers „PP-01“ mit unvermörtelten Stoßfugen
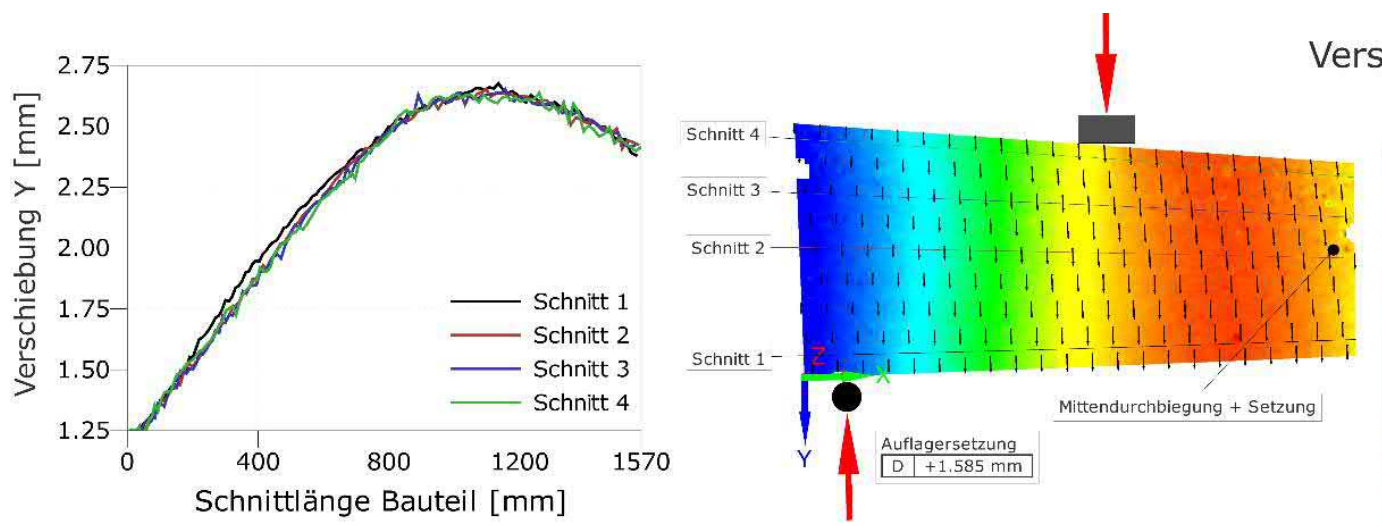

erschiebung $Y$

[mm]

2.75

2.60

2.40

2.20
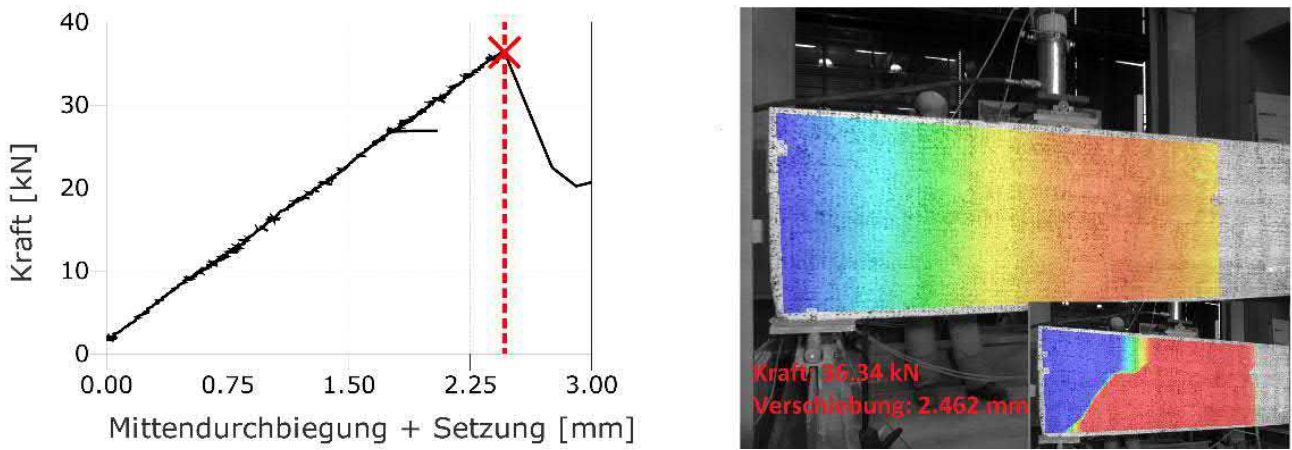

2.00

1.80

1.60

1.40

1.25

Bild 5.5 Flächenhafte Darstellung der Vertikalverformung (Y-Richtung) des Prüfkörpers „PP-02“ mit vermörtelten Stoßfugen

Diese Erkenntnisse aus den experimentellen Untersuchungen an Flachstürzen bestätigen die Vorgabe der abZ (bspw. Z-17.1-1051). Hier heißt es: „Die Lager- und Stoßfugen sind vollfugig mit Dünnbettmörtel [...] zu vermörteln [...]“" (Z-17.1-1051 2014, S. 18). Daher werden für die in Abschnitt 7.3 durchgeführten Vergleichsrechnungen nur Untersuchungsergebnisse von Flachstürzen mit vermörtelten Stoßfugen herangezogen. 


\subsection{Scheitrechte Mauerwerkbalken - IIa}

Den experimentellen Untersuchungen an scheitrechten Mauerwerkbalken wurde das Versuchsprogramm von Tabelle 5.5 und Tabelle 5.6 zugrunde gelegt. Die Prüfkörper wurden aus Hochlochziegeln mittlerer Festigkeit (HLZ 12) sowie Kalksandsteinen hoher Festigkeit (KS XL 20) hergestellt, um Unterschiede im Tragverhalten aufgrund der Mauerwerksdruckfestigkeit zu prüfen. Ebenso wurden Einflüsse aus der Schubschlankheit und des Bewehrungsgrades auf die Querkrafttragfähigkeit untersucht. Auch die Verifikation des rechnerisch ermittelten inneren Hebelarms sowie die Bestimmung des globalen Druckstrebenwinkels innerhalb des Schubfeldes war Gegenstand der experimentellen Untersuchungen.

In Bild 5.6 ist der Aufbau der Prüfkörper anhand von Systemskizzen für die Balken ZI-01 (oben) und KS07 (unten) dargestellt.
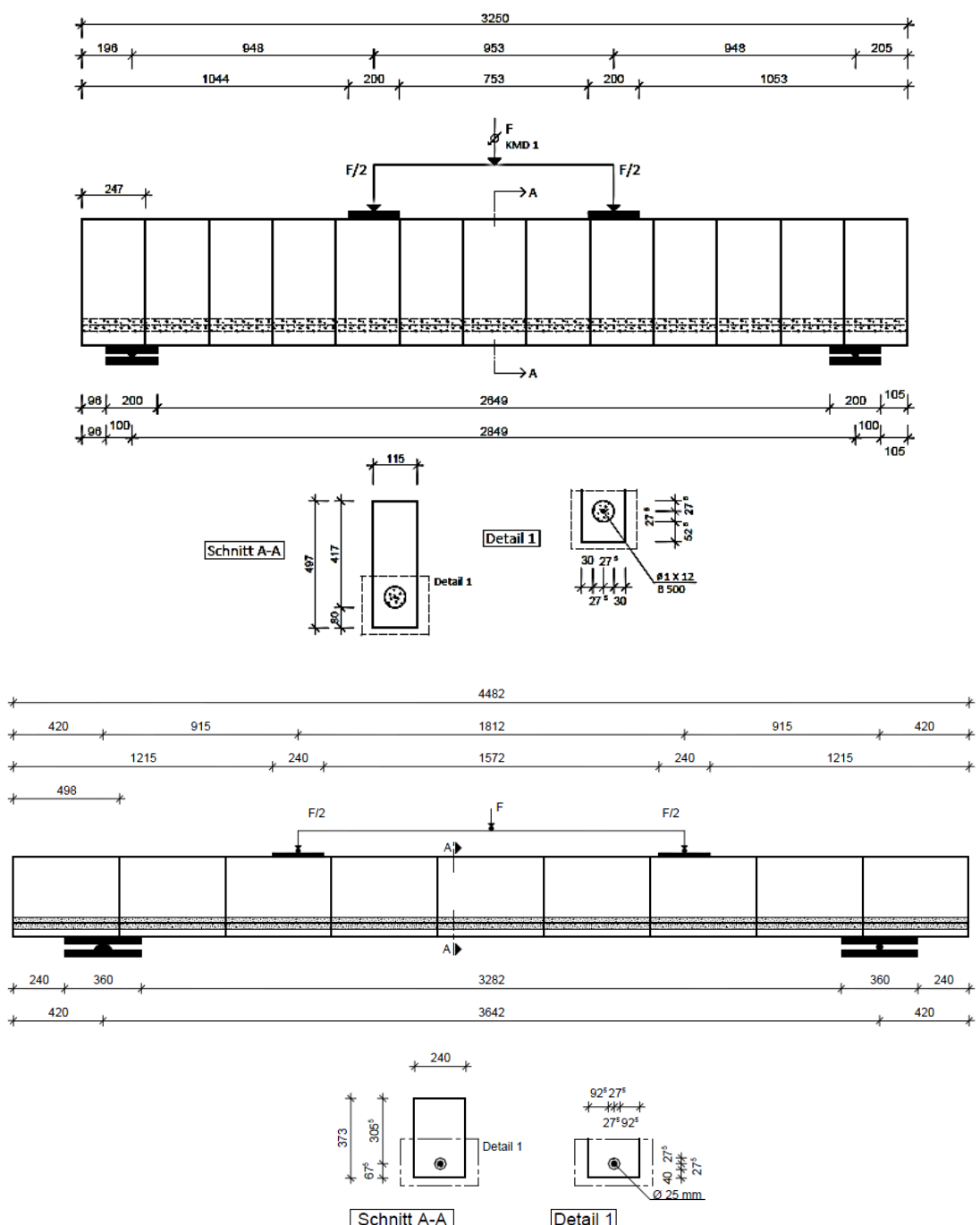

Bild 5.6 Systemskizzen bewehrter, scheitrechter Mauerwerkbalken - ZI-01 (oben) und KS-07 (unten)

Tabelle 5.5 enthält Angaben über Geometrien und Eigenschaften der untersuchten scheitrechten Mauerwerkbalken; in Tabelle 5.6 sind Art und Durchmesser der verwendeten Bewehrung angegeben. 
Tabelle 5.5 Versuchsprogramm: Geometrie und Eigenschaften der Probekörper

\begin{tabular}{|c|c|c|c|c|c|c|c|c|c|c|c|}
\hline \multirow{2}{*}{\multicolumn{2}{|c|}{\begin{tabular}{|c|} 
Versuchs- \\
Bez./ Anzahl \\
n
\end{tabular}}} & \multirow{3}{*}{$\begin{array}{c}\begin{array}{c}\text { Steinart/ } \\
\text { Festigkeitsklasse/ } \\
\text { Mörtelart }\end{array} \\
\\
\text { HLZ B - 8 DF - } \\
12-0,8(\mathrm{DM})\end{array}$} & \multicolumn{3}{|c|}{$\begin{array}{c}\text { Querschnittswerte } \\
{[\mathrm{mm}]}\end{array}$} & \multicolumn{2}{|c|}{$\begin{array}{l}\text { Prüfkörper- } \\
\text { länge } \\
\text { [m] }\end{array}$} & \multicolumn{2}{|c|}{\begin{tabular}{|c|} 
Abstand zwischen: \\
Achse Auflager - Achse F \\
/ Abstand zwischen: \\
Auflager - F \\
[mm]
\end{tabular}} & \multirow{2}{*}{\begin{tabular}{|c|}
$\begin{array}{c}\text { Auflager- } \\
\text { länge } \\
{[\mathrm{mm}]}\end{array}$ \\
$a_{1}$ \\
\end{tabular}} & \multirow{2}{*}{$\begin{array}{c}\begin{array}{c}\text { Schub- } \\
\text { schlank } \\
\text { heit }^{1} \\
{[-]}\end{array} \\
\lambda \\
\end{array}$} \\
\hline & & & $h$ & $d$ & $t$ & $l$ & $l_{\text {eff }}$ & $a$ & $a_{\mathrm{v}}$ & & \\
\hline ZI-01 & 1 & & 497 & 447 & 115 & 3,25 & 2,85 & 948 & 748 & 200 & 2,1 \\
\hline ZI-02 & 1 & $\begin{array}{c}\text { HLZ B - 6 DF - } \\
12-0,8(\mathrm{DM})\end{array}$ & 365 & 285 & 115 & 2,14 & 1,60 & 533 & 333 & 200 & 1,9 \\
\hline ZI-03 & 1 & $\begin{array}{c}\text { HLZ B - } 6 \text { DF - } \\
12-0,8(\mathrm{DM})\end{array}$ & 365 & 285 & 115 & 1,67 & 1,52 & 436 & 261 & 150 & 1,5 \\
\hline ZI-04 & 1 & $\begin{array}{l}\text { HLZ B - } 6 \text { DF - } \\
12-0,8(\mathrm{DM})\end{array}$ & 365 & 285 & 115 & 1,67 & 1,52 & 436 & 261 & 150 & 1,5 \\
\hline ZI-05 & 1 & $\begin{array}{c}\text { HLZ B - } 6 \text { DF - } \\
12-0,8(\mathrm{DM})\end{array}$ & 365 & 285 & 115 & 1,67 & 1,52 & 436 & 261 & 150 & 1,5 \\
\hline ZI-06 & 1 & $\begin{array}{c}\text { HLZ B - } 6 \text { DF - } \\
12-0,8(\mathrm{DM})\end{array}$ & 365 & 285 & 115 & 1,67 & 1,52 & 436 & 261 & 150 & 1,5 \\
\hline ZI-07 & 1 & $\begin{array}{c}\text { HLZ B - } 6 \text { DF - } \\
12-0,8(\mathrm{DM})\end{array}$ & 365 & 285 & 115 & 1,67 & 1,52 & 436 & 261 & 150 & 1,5 \\
\hline ZI-10 & 1 & $\begin{array}{c}\text { HLZ B - } 6 \text { DF - } \\
12-0,8 \text { (DM) }\end{array}$ & 365 & 285 & 115 & 1,43 & 1,28 & 339 & 264 & 150 & 1,2 \\
\hline ZI-11 & 1 & $\begin{array}{c}\text { HLZ B - } 5 \text { DF - } \\
12-0,8 \text { (DM) }\end{array}$ & 300 & 220 & 115 & 1,43 & 1,08 & 340 & 140 & 200 & 1,5 \\
\hline ZI-12 & 1 & $\begin{array}{c}\text { HLZ B - } 5 \text { DF - } \\
12-0,8(\mathrm{DM})\end{array}$ & 300 & 220 & 115 & 0,72 & 0,48 & 243 & 43 & 200 & 1,1 \\
\hline ZI-13 & 1 & $\begin{array}{c}\text { HLZ B - } 5 \text { DF - } \\
12-0,8(\mathrm{DM})\end{array}$ & 300 & 220 & 115 & 0,72 & 0,48 & 243 & 43 & 200 & 1,1 \\
\hline $\mathrm{KS}-00$ & 1 & $\begin{array}{c}\text { KS - } 6 \text { DF - } 12- \\
1,4(\mathrm{DM})\end{array}$ & 373 & 313 & 115 & 2,75 & 2,40 & 805 & 605 & 200 & 2,1 \\
\hline KS-01 & 1 & $\begin{array}{c}\text { KS XL-QU - } 20 \text { - } \\
2,0(\mathrm{DM})\end{array}$ & 373 & 306 & 240 & 0,37 & 0,26 & 129,3 & 22 & 115 & 0,4 \\
\hline KS-02 & 1 & $\begin{array}{c}\text { KS XL-QU - } 20 \text { - } \\
2,0(\mathrm{DM})\end{array}$ & 373 & 306 & 240 & 0,50 & 0,38 & 191,5 & 84 & 115 & 0,6 \\
\hline KS-03 & 1 & $\begin{array}{c}\text { KS XL-QU - } 20 \text { - } \\
2,0 \text { (DM) }\end{array}$ & 373 & 306 & 240 & 0,99 & 0,87 & 216 & 109 & 115 & 0,7 \\
\hline $\begin{array}{l}\text { KS- } \\
05.1 \\
\end{array}$ & 1 & $\begin{array}{c}\text { KS XL-QU - } 20 \text { - } \\
2,0(\mathrm{DM})\end{array}$ & 373 & 306 & 240 & 1,50 & 1,29 & 324 & 174 & 200 & 1,1 \\
\hline $\begin{array}{l}\mathrm{KS}- \\
05.2 \\
\end{array}$ & 1 & $\begin{array}{c}\text { KS XL-QU -20 - } \\
2,0(\mathrm{DM})\end{array}$ & 373 & 306 & 240 & 1,49 & 1,25 & 314 & 164 & 240 & 1,0 \\
\hline $\begin{array}{l}\text { KS- } \\
06.1 \\
\end{array}$ & 1 & $\begin{array}{c}\text { KS XL-QU - } 20 \text { - } \\
2,0(\mathrm{DM}) \\
\end{array}$ & 373 & 306 & 240 & 3,24 & 2,40 & 598 & 398 & 360 & 2,0 \\
\hline KS-07 & 1 & $\begin{array}{c}\text { KS XL-QU - } 20 \text { - } \\
2,0 \text { (DM) }\end{array}$ & 373 & 306 & 240 & 4,48 & 3,64 & 915 & 715 & 360 & 3,0 \\
\hline
\end{tabular}


Tabelle 5.6 Versuchsprogramm: Art und Menge der Bewehrung

\begin{tabular}{|c|c|c|}
\hline Versuchsbezeichnung & Art der Bewehrung & $\begin{array}{c}\text { Durchmesser Bewehrung } \\
{[\mathrm{mm}]}\end{array}$ \\
\hline ZI-01 & B500A & $1 \times 12$ \\
\hline ZI-02 & B500A & $1 \times 12$ \\
\hline ZI-03 & B500A & $1 \times 12$ \\
\hline ZI-04 & B500A & $2 \times 8$ \\
\hline ZI-05 & B500A & $2 \times 10$ \\
\hline ZI-06 & B500A & $2 \times 12$ \\
\hline ZI-07 & B500A & $1 \times 14$ \\
\hline ZI-10 & B500A & $1 \times 12$ \\
\hline ZI-11 & B500A & $1 \times 12$ \\
\hline ZI-12 & B500A & $1 \times 12$ \\
\hline ZI-13 & B500A & $1 \times 12$ \\
\hline KS-00 & B500A & $1 \times 12$ \\
\hline KS-01 & B500A & $1 \times 14$ \\
\hline KS-02 & B500A & $1 \times 14$ \\
\hline KS-03 & B500A & $1 \times 14$ \\
\hline KS-05.1 & B500A & $1 \times 20$ \\
\hline KS-05.2 & B500A & $1 \times 20$ \\
\hline KS-06.1 & B500A & $1 \times 20$ \\
\hline KS-07 & B500A & $1 \times 25$ \\
\hline
\end{tabular}

Beispielhaft sind in Bild 5.7 die Messstellenpläne für die Versuchskörper ZI-01 und KS-07 dargestellt. Die Messstellenpläne weiterer Prüfkörper sind dem Anhang zu entnehmen; siehe Abschnitt A 4.2.3 und Abschnitt A 4.3.2.
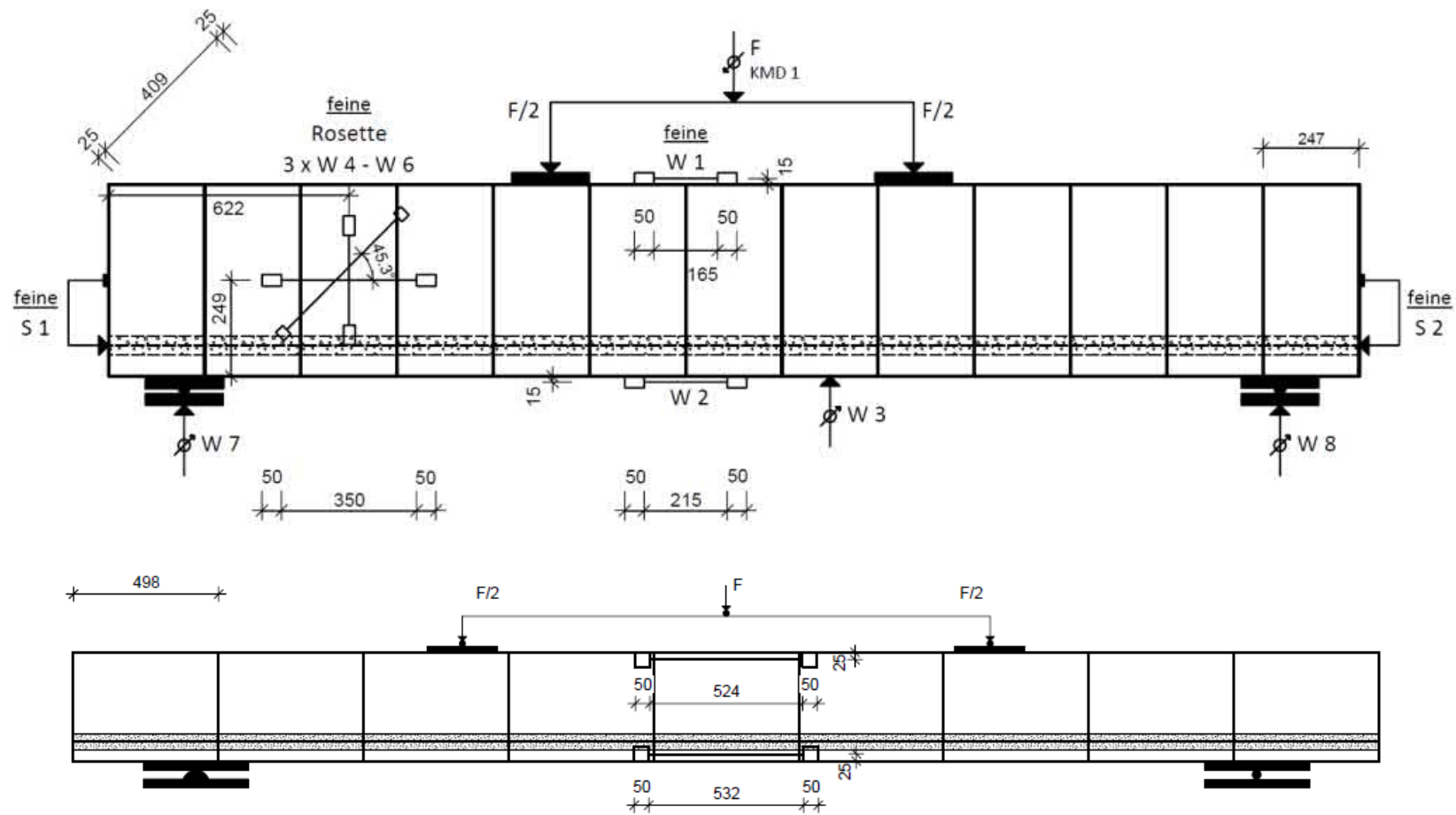

Bild 5.7 Messstellenpläne bewehrter, scheitrechter Mauerwerkbalken - ZI-01 (oben) und KS-07 (unten) 
Die Auswertung und Interpretation der Versuchsergebnisse sind in folgende Abschnitte gegliedert:

- Trag- und Verformungsverhalten,

- Einfluss der Schubschlankheit auf die Querkrafttragfähigkeit,

- Einfluss des Bewehrungsgrades auf die Querkrafttragfähigkeit,

- Verifikation des rechnerischen Ansatzes zur Ermittlung des Hebelarms der inneren Kräfte,

- Größe des Druckstrebenwinkels innerhalb des Schubfeldes.

\subsubsection{Trag- und Verformungsverhalten}

Während der Prüfungen wurden die Verformungen an den in Bild 5.7 dargestellten Messstellen und die jeweilige zugehörige Lastbeanspruchung aufgezeichnet. In Tabelle 5.7 sind sowohl die Risslasten $\left(F_{\text {exp,cr }}\right)$ und die Bruchlasten inkl. Eigengewicht $\left(F_{\text {exp,u }}\right)$ als auch die jeweilige Versagensart der Mauerwerkbalken angegeben.

Tabelle 5.7 Riss- und Bruchlasten der betonstahlbewehrten, scheitrechten Mauerwerkbalken

\begin{tabular}{|c|c|c|c|}
\hline $\begin{array}{c}\text { Versuchs- } \\
\text { bezeichnung }\end{array}$ & $\begin{array}{c}\text { Risslast }\left(F_{\text {exp,cr }}\right) \\
{[k N]}\end{array}$ & $\begin{array}{c}\text { Bruchlast }\left(F_{\text {exp,u }}\right) \\
{[\mathbf{k N}]}\end{array}$ & Versagensart $^{1)}$ \\
\hline ZI-01 & 12,0 & 37,2 & $\mathrm{Z}$ \\
\hline $\mathrm{Zi}-02$ & 4,0 & 36,2 & $\mathrm{Z}$ \\
\hline $\mathrm{Zi}-03$ & 9,0 & 25,4 & $\mathrm{Z}$ \\
\hline $\mathrm{Zi}-04$ & 16,0 & 27,8 & $\mathrm{Z}$ \\
\hline $\mathrm{Zi}-05$ & 15,0 & 22,0 & $\mathrm{Z}$ \\
\hline Zi-06 & 14,0 & 25,2 & $\mathrm{Z}$ \\
\hline $\mathrm{Zi}-07$ & 11,0 & 32,8 & A \\
\hline $\mathrm{Zi}-10$ & 16,0 & 36,6 & $\mathrm{Z}$ \\
\hline $\mathrm{Zi}-11$ & 15,0 & 55,0 & $\mathrm{Z}$ \\
\hline $\mathrm{Zi}-12$ & 12,0 & 21,0 & Q \\
\hline ZI-13 & 3,0 & 52,5 & Q \\
\hline KS-00 & 5,0 & 26,0 & $\mathrm{Z}$ \\
\hline KS-01 & 46,8 & 58,5 & $\mathrm{R}$ \\
\hline KS-02 & 47,3 & 57,2 & $\mathrm{R}$ \\
\hline KS-03 & 43,7 & 50,3 & $\mathrm{R}$ \\
\hline KS-05.1 & 86,3 & 86,5 & $\mathrm{R}$ \\
\hline KS-05.2 & 18,6 & 103,8 & $\mathrm{R}$ \\
\hline KS-06.1 & 20,0 & 112,0 & $\mathrm{Z}$ \\
\hline KS-07 & 15,0 & 92,7 & $\mathrm{Z}$ \\
\hline
\end{tabular}

Die Tragfähigkeiten der Mauerwerkbalken ZI-12 und ZI-13 waren aufgrund partieller Fehlstellen in Randbereichen der Mörtelausgleichsschicht stark vermindert. Dies hat zu Spannungsspitzen geführt, wodurch die Querdruckfestigkeit in den Mauerziegeln nahe der Auflager überschritten wurde. Die Ergebnisse der Bruchlasten sind nicht repräsentativ und werden daher für weitere Auswertungen ausgeschlossen. 
Bild 5.8 enthält eine exemplarische Darstellung der Rissbilder von den Prüfkörpern ZI-01 und KS-07 mit einer Schubschlankheit $\lambda>1,1$. Die Rissverläufe der bewehrten Mauerwerkbalken sind mit Schubzugrissen von Stahlbetonbalken vergleichbar (siehe Abschnitt 4.2.6), mit dem Unterschied von Rissversätzen im Bereich der Vertikalfugen. Das Risswachstum entwickelte sich zwischen Auflager- und Lasteinleitungsplatte, i.d.R. ausgehend von einer sich öffnenden Vertikalfuge. Dann verlief der Schubriss diagonal nach oben in Richtung der Lasteinleitung, wodurch die Druckzone stark eingeschnürt wurde. Gleichzeitig entwickelte sich der Riss schräg nach unten zum Auflager. Ab Höhe des Bewehrungskanals verlief der Riss bis zum Auflager annähernd horizontal, was auf ein sekundäres Verbundversagen hindeutet. Gekennzeichnet wurde dieser Rissverlauf durch einen Versatz der Rissufer in der vom Auflager ausgehenden, nächstgelegenen Vertikalfuge bis auf die Höhe des Injektionskanals. Bei Mauerwerkbalken mit einer Schubschlankheit $\lambda \leq 1,1$ hat sich überwiegend ein Reibungsversagen in den auflagernahen Vertikalfugen eingestellt.

Der globale Verlauf des diagonalen Schubzugrisses lässt sich aus der Verbindung der Rissspitzen zwischen Einzellast und Auflager innerhalb des Schubfeldes $(a / d)$ ableiten; siehe Abschnitt 5.3.5. Der Winkel des Schubzugrisses kann über dessen Neigung gegen die Schwerachse beschrieben werden. Der jeweilige, sich daraus ergebende Neigungswinkel entspricht dem unter Abschnitt 5.3.5 beschriebenen und anhand von Prüfungen verifizierten Druckstrebenwinkel $\Theta$.
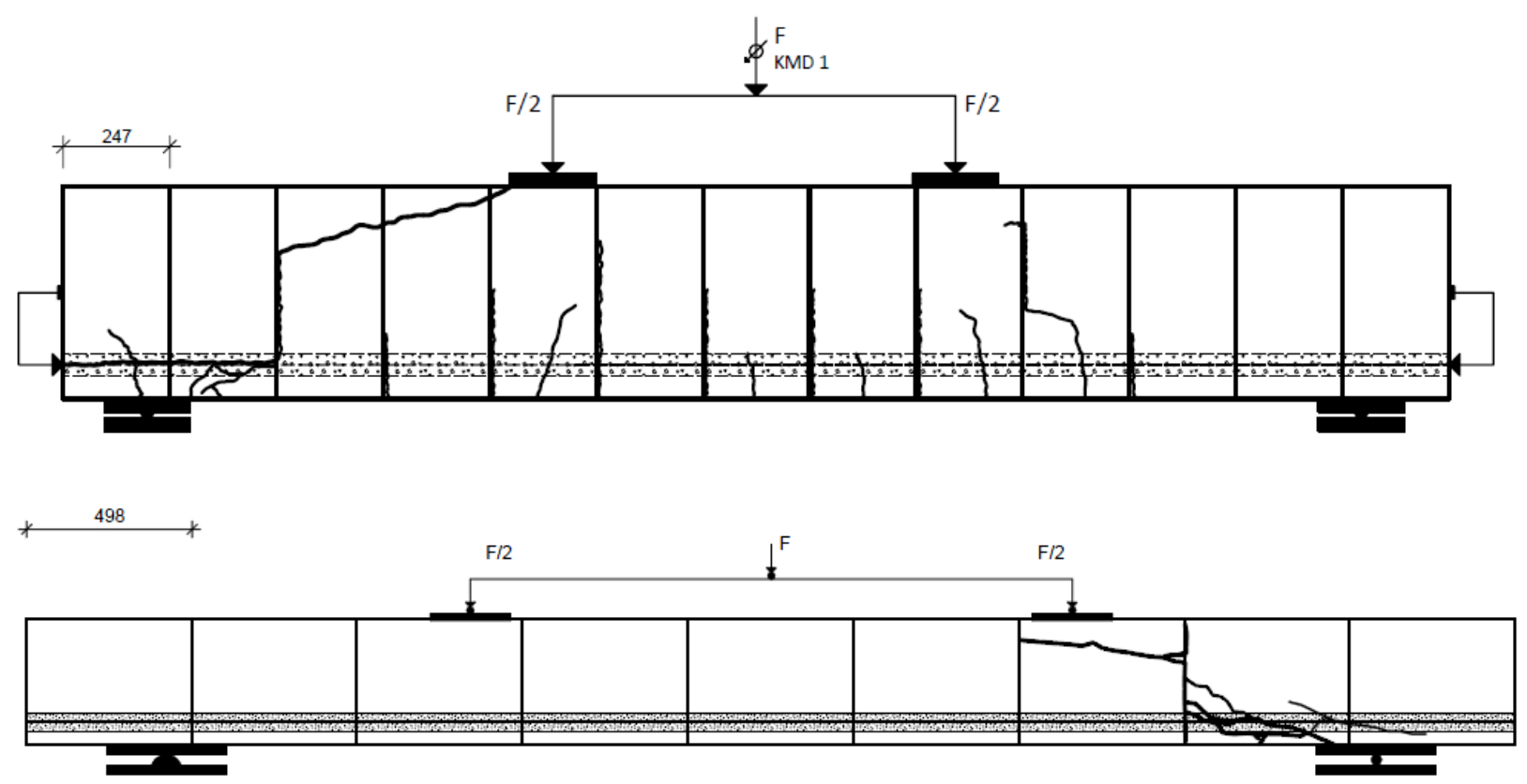

Bild 5.8 Rissbilder bewehrter, scheitrechter Mauerwerkbalken - ZI-01 (oben) und KS-07 (unten)

Die jeweiligen Durchbiegungen der Versuchskörper wurden in Balkenmitte gemessen. Für ZI-01 ist die Auswertung der Last-Durchbiegung in Bild 5.9 dargestellt. Weitere Last-Durchbiegungslinien sind den Anlagen A 4.2.5 und A 4.3.4 zu entnehmen. 


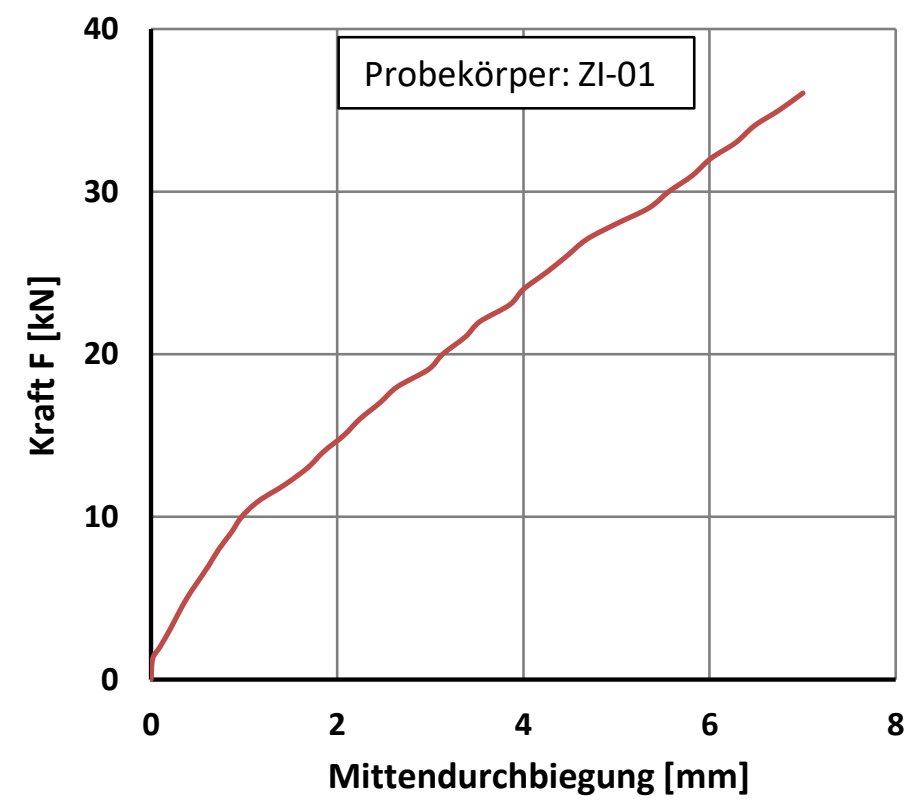

Bild 5.9

Last-Durchbiegungslinie exemplarisch für ZI-01

Bild 5.10 zeigt die Mittendurchbiegung ( $w$ ) der schlaff bewehrten Mauerwerkbalken in Abhängigkeit der Schubschlankheit $(\lambda)$. Zu erkennen ist ein progressiver Verlauf der Mittendurchbiegung bei zunehmender Schubschlankheit. Der Schlankheitsbereich $\lambda \leq 1,5 \ldots 2$ mit vergleichsweise geringen Mittendurchbiegungen deutet darauf hin, dass ein Großteil der Auflast direkt in das Auflager abgetragen wird. Dies kann auf das Vorliegen eines Sprengwerkmodells nach Abschnitt 4.3.1 zurückgeführt werden. Anders ist dies im Bereich von Schubschlankheiten $\lambda>1,5 \ldots 2$. Hier wird aufgrund der progressiven Zunahme der Mittendurchbiegungswerte von einem Balkenmodell ausgegangen. Aufgrund der großen Verformungszunahmen erscheint die Aktivierung weiterer Tragmechanismen gegeben, wie bspw. die Rissuferverzahnung.

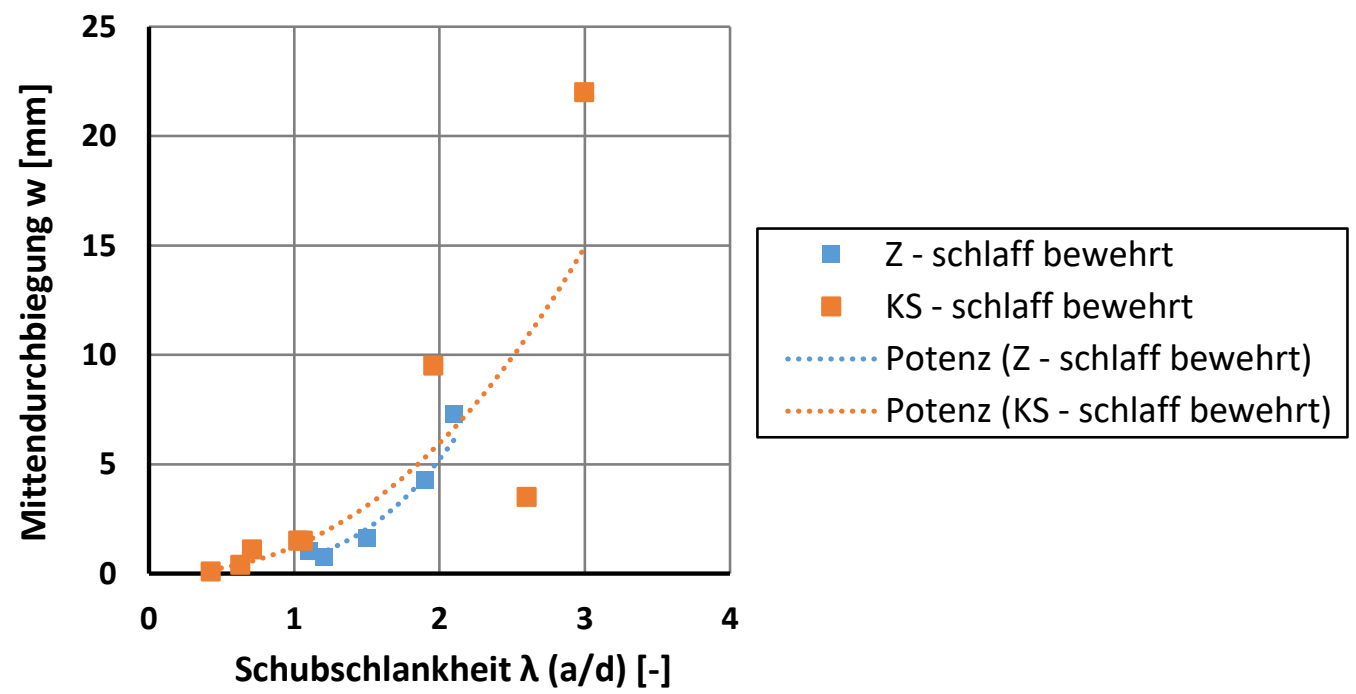

Bild 5.10 Durchbiegung der Mauerwerkbalken in Abhängigkeit zur Schubschlankheit

Darüber hinaus wurden während der Prüfung in Feldmitte an der Ober- und Unterseite des Querschnitts Längenänderungen in Längsrichtung des Mauerwerkbalkens gemessen. Die daraus ermittelten Stauchungen an der Balkenoberseite und die Dehnungen in Querschnittshöhe der Zugbewehrung sind in Bild 5.11 in Abhängigkeit von der äußeren Belastung beispielhaft für den Prüfkörper KS-07 dargestellt. Der im Diagramm gezeigte Knick (bei ca. $12 \mathrm{kN}$ ) deutet auf das Einsetzen einer frühzeitigen Erstrissbildung hin. Vermutet wird ein Zusammenhang mit dem hohen Eigengewicht der Kalksandsteinbalken. Die Ziegelbalken zeigten bis zur Erstrissbildung nur eine geringe Zunahme der Dehnung auf Höhe der 
Längsbewehrung. Nach Einsetzen erster Biegerisse in den Vertikalfugen der Zugzone wurde ein Zuwachs der Längsdehnungen auf Höhe der Bewehrungslage gemessen. Dies ist auf die Übertragung der zuvor durch das Mauerwerk aufgenommenen Zugkräfte auf die Bewehrung zurückzuführen.

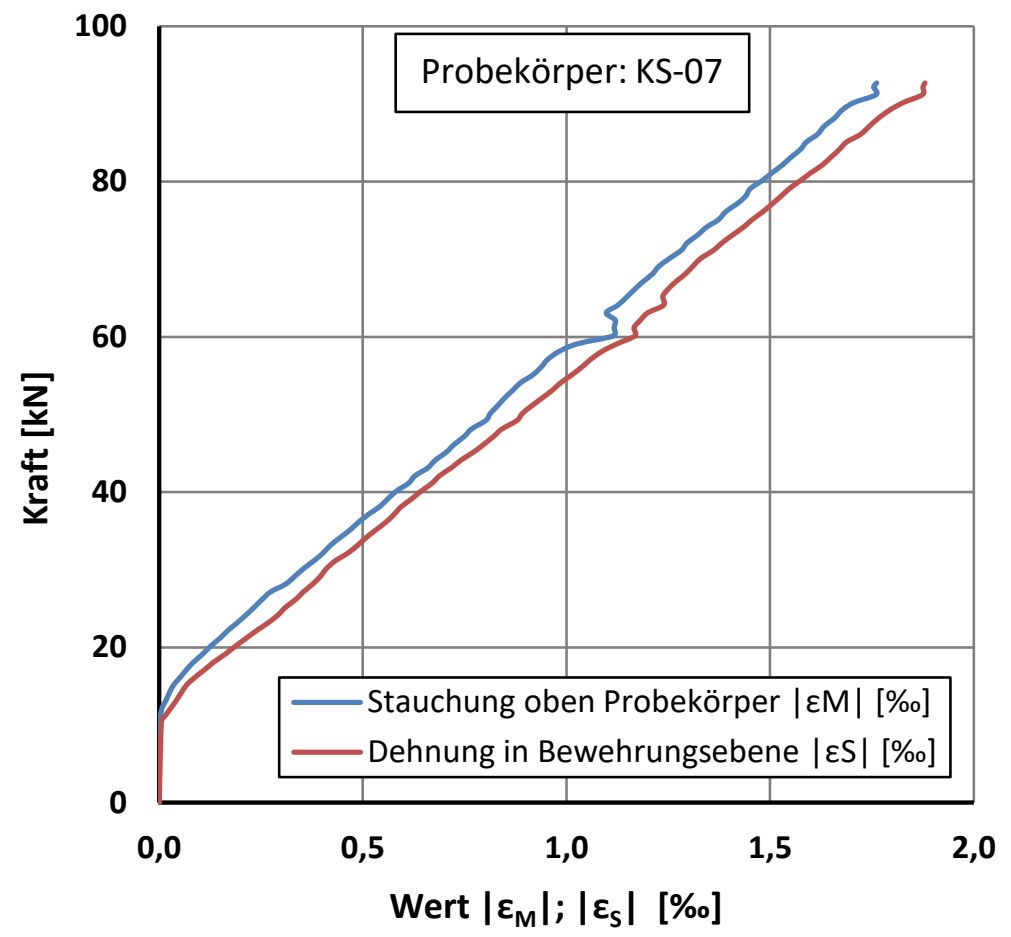

Bild 5.11 Stauchung und Dehnung in Abhängigkeit der Kraft exemplarisch für KS-07

\subsubsection{Einfluss der Schubschlankheit auf die Querkrafttragfähigkeit}

Bei den experimentellen Untersuchungen wurde auch der Einfluss der Schubschlankheit auf die Querkrafttragfähigkeit bzw. auf die bezogene Querkrafttragfähigkeit $\left(v_{\mathrm{R}}=\frac{V_{\mathrm{R}}}{b \cdot d}\right)$ bewehrter, scheitrechter Mauerwerkbalken quantifiziert. In Bild 5.12 ist das Ergebnis der Auswertung am Beispiel untersuchter Ziegelbalken dargestellt. Erkennbar ist ein signifikanter Einfluss der Schubschlankheit bewehrter Mauerwerkbalken auf die Größe der Schubtragfähigkeit. Dieser nimmt mit kleiner werdenden Schubschlankheiten deutlich zu. Die gezeigte Trendlinie wurde mit dem Ansatz zur Berücksichtigung des Schubschlankheitseinflusses nach DIN EN 1996-1-1 (Gleichung (2.22)) verglichen.

$$
1 \leq \frac{2 \cdot d \cdot \max V_{\mathrm{Ed}}}{\max M_{\mathrm{Ed}}}=\frac{2 \cdot d}{a}=\frac{1}{\frac{a}{2 \cdot d}} \leq 4
$$

Dabei ist:

$a$

$$
a=\max M_{\mathrm{Ed}} / \max V_{\mathrm{Ed}} .
$$

Das obere bzw. untere Grenzkriterium der zuvor genannten Funktionen ist berücksichtigt. Zu erkennen ist, dass der durch die Schubschlankheit hervorgerufene Einfluss auf die bezogene Querkrafttragfähigkeit durch den Ansatz ausreichend gut beschrieben wird. 


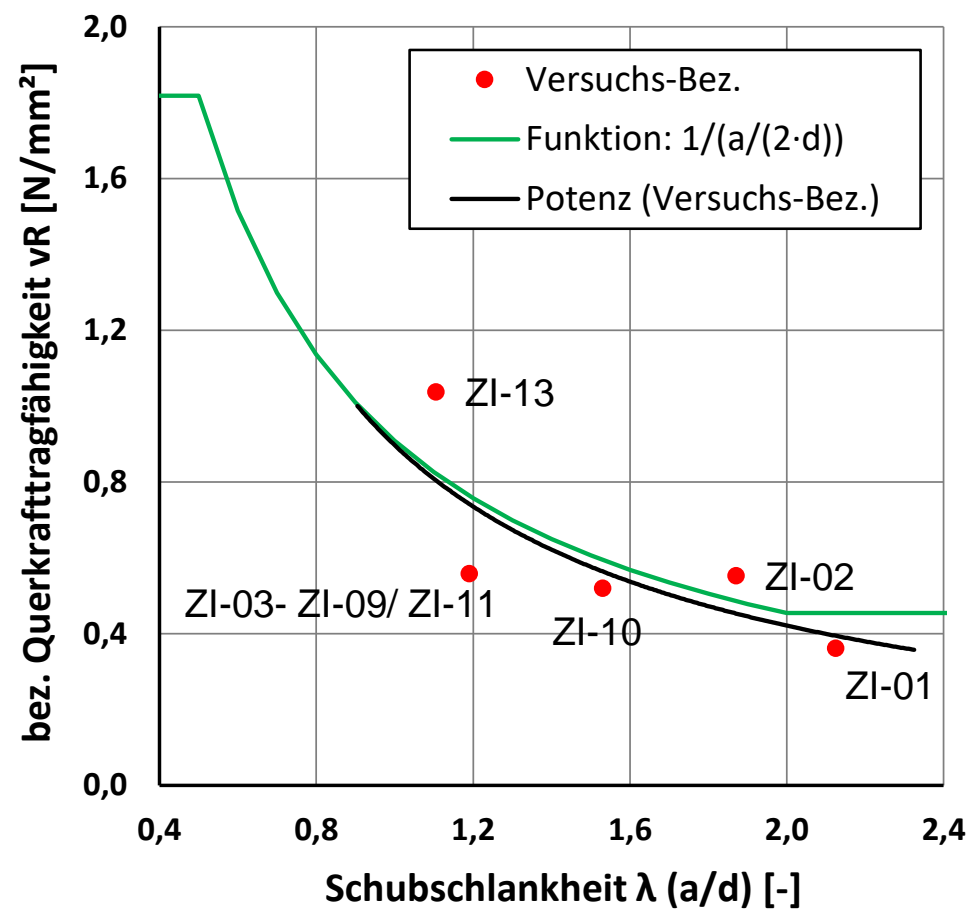

Bild 5.12 Schubschlankheit in Abhängigkeit zur bez. Querkrafttragfähigkeit schlaff bewehrter Ziegelbalken

Die Untersuchungen an gedrungenen Kalksandsteinbalken mit kleiner Schubschlankheit und Mauerwerk hoher Druckfestigkeit wurden im Hinblick auf mögliches Reibungsversagen durchgeführt. Ergänzend wurden zwei Prüfkörper (KS-06.1 und KS-07) im Schlankheitsbereich $(\lambda=2 \ldots 3)$ eines typischen Schubzugversagens getestet. Die Ergebnisse sind in Bild 5.13 zusammengefasst. Der Darstellung ist ebenfalls, vergleichbar mit Bild 5.12, der Funktionsverlauf zur Berücksichtigung des Schlankheitseinflusses nach DIN EN 1996-1-1, Abschn. 6.7.3, zu entnehmen.

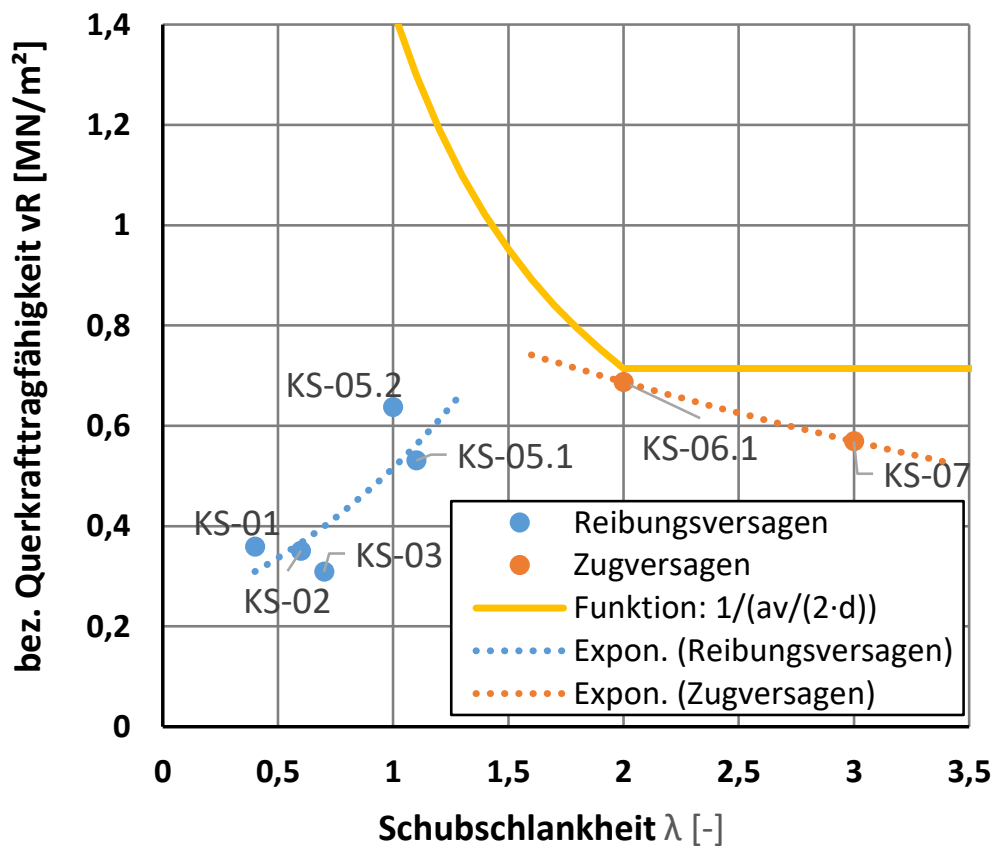

Bild 5.13 Schubschlankheit in Abhängigkeit zur bez. Querkrafttragfähigkeit schlaff bewehrter Kalksandsteinbalken

Bei Prüfkörpern kleiner Schubschlankheiten hat sich ein Reibungsversagen in den Vertikalfugen eingestellt. Der Darstellung in Bild 5.13 ist zu entnehmen, dass die Prüfkörper mit dieser Versagensart nicht 
mit der Funktion zur Beschreibung des Schlankheitseinflusses berücksichtigt werden können, wie dies bei Prüfkörpern mit einem Versagenskriterium infolge Schubzugversagen möglich ist. Daher wird für das Reibungsversagen der Einfluss aus der Schubschlankheit auf die Querkrafttragfähigkeit auf den Mauerwerkverband zurückgeführt. Dies könnte über die Berücksichtigung der Mauerwerkdruckfestigkeit unter einem Beanspruchungswinkel kompensiert werden. Je kleiner die Schubschlankheit bei scheitrecht beanspruchten Mauerwerkbalken wird, desto bedeutender ist die Berücksichtigung einer Druckfestigkeit unter einem Beanspruchungswinkel (Bild 7.9); siehe Abschnitt 3.3.2.2.

\subsubsection{Einfluss des Bewehrungsgrades auf die Querkrafttragfähigkeit}

Mit den Ergebnissen geprüfter Mauerwerkbalken wurde der Einfluss des Längsbewehrungsgrades $(\rho)$ auf die Schubtragfähigkeit analysiert. Die Auswertung für die Ziegelbalken zeigt Bild 5.14. Der Einfluss der Schubschlankheit auf die Querkrafttragfähigkeiten untersuchter Prüfkörper wurde durch den obig verifizierten Ansatz berücksichtigt, wodurch sich die reduziert bezogene Querkrafttragfähigkeit nach Gleichung (5.1) ergibt.

$$
v_{\mathrm{R}, \mathrm{red}}=\frac{V_{\mathrm{R}} \cdot a_{\mathrm{V}}}{2 \cdot b \cdot d^{2}}
$$

Erkennbar ist, dass trotz steigendem Längsbewehrungsgrad die Schubtragfähigkeit der Balken nur geringfügig zunimmt und somit als vernachlässigbar eingestuft werden kann. Die geringe Zunahme wird auf die niedrigen Steindruckfestigkeiten verwendeter Mauersteine zurückgeführt, sodass der Bewehrungsquerschnitt nicht vollständig ausgenutzt wird.

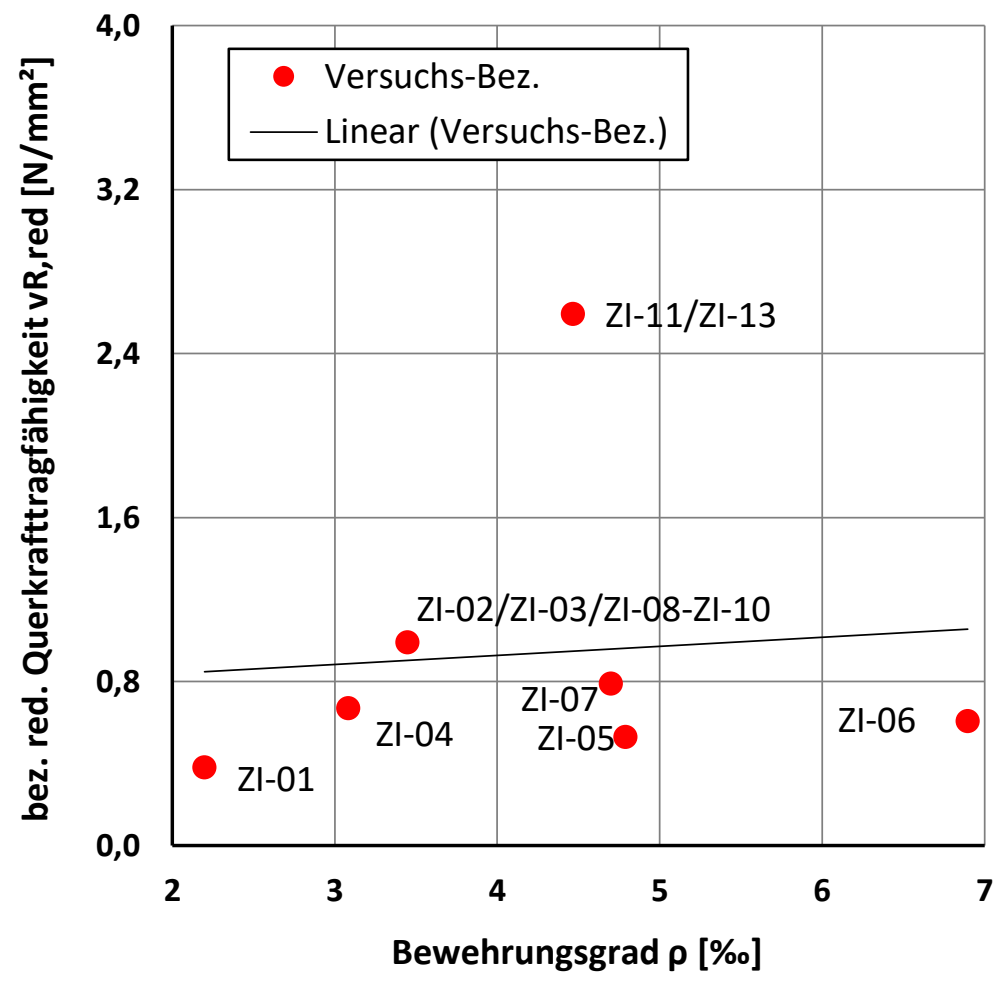

Bild 5.14 Einfluss der Längsbewehrung auf die Schubtragfähigkeit schlaff bewehrter Ziegelbalken

Anders ist dies bei Mauersteinen höherer Druckfestigkeit. Hier zeigt die Auswertung, dargestellt in Bild 5.15, eine deutliche Abhängigkeit der Querkrafttragfähigkeit von der Größe des Bewehrungsgrades. Die Darstellung der Trendlinien erfolgte zum einen unter Einbeziehung der Prüfkörper KS-01 ... KS-07 und zum anderen ausschließlich für die Prüfkörper KS-06 und KS-07. Dieses Vorgehen wurde gewählt, da bei den Prüfkörpern KS-01 ... KS-5.2 die Reibung in der Vertikalfuge maßgebendes Versagenskriterium war. 
Bestätigt wird die Annahme, dass der Einfluss des Bewehrungsgrades auf die Querkrafttragfähigkeit mit höherer Mauerwerkdruckfestigkeit zunimmt.

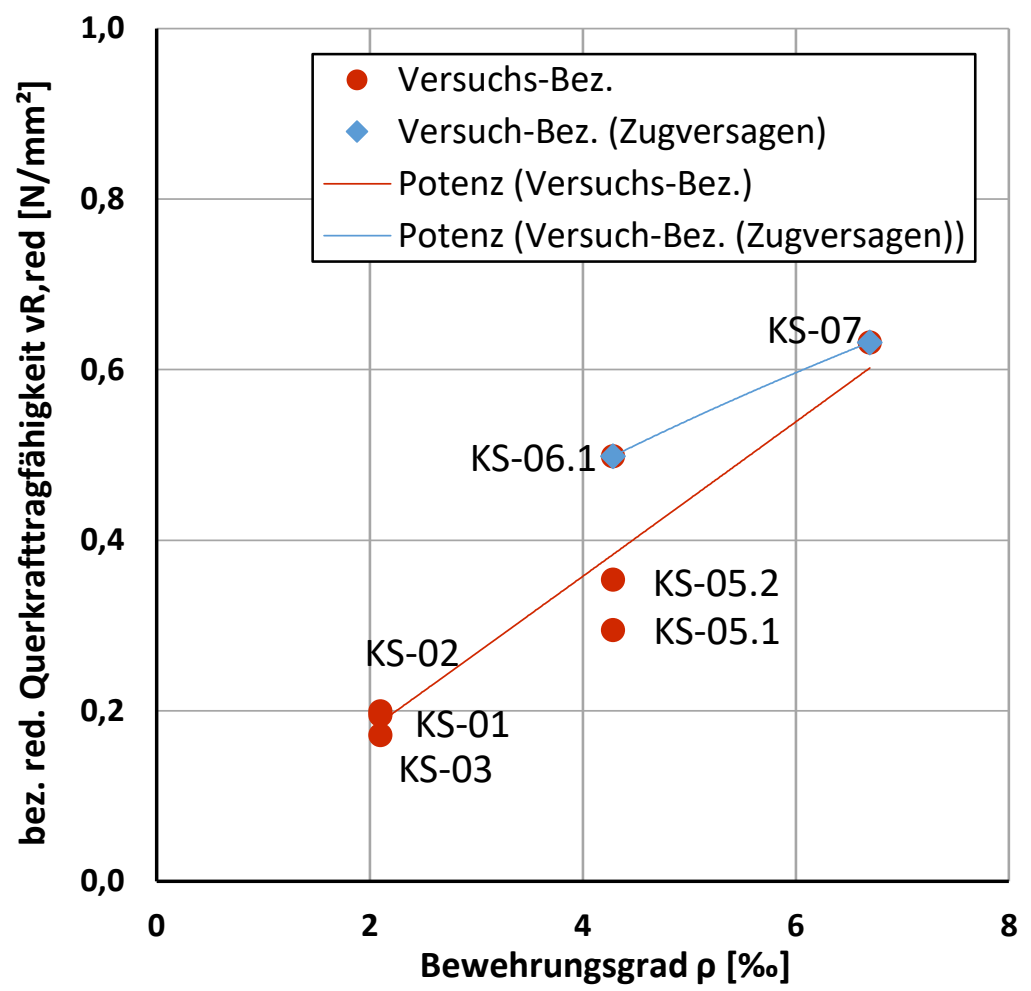

Bild 5.15 Einfluss der Längsbewehrung auf die Schubtragfähigkeit schlaff bewehrter Ziegelbalken

\subsubsection{Ermittlung des Hebelarms der inneren Kräfte}

Für die Entwicklung eines Berechnungsvorschlages ist es erforderlich, zuvor den Hebelarm der inneren Kräfte (z) rechnerisch abzuschätzen. Anhand der Dehnungen und Stauchungen an der Unter- und Oberseite der geprüften Balken war es möglich, die Druckzonenhöhen $(x)$ sowie die Hebelarme der inneren Kräfte $\left(z_{\text {exp. }}\right)$ zu bestimmen. Am Beispiel des Prüfkörpers ZI-01 zeigt ein Vergleich des experimentell ermittelten Hebelarms $\left(z_{\text {exp. }}\right)$ mit dem rechnerisch angenommenen Hebelarm $\left(z_{\text {rechn. }}=0,85 \cdot d\right)$ eine gute Übereinstimmung; siehe Bild 5.16. Die weiteren Prüfkörper weisen ähnlich gute Übereinstimmungen auf, was auch für Mauerwerkbalken aus Kalksandsteinen gilt; siehe Bild 5.17. 


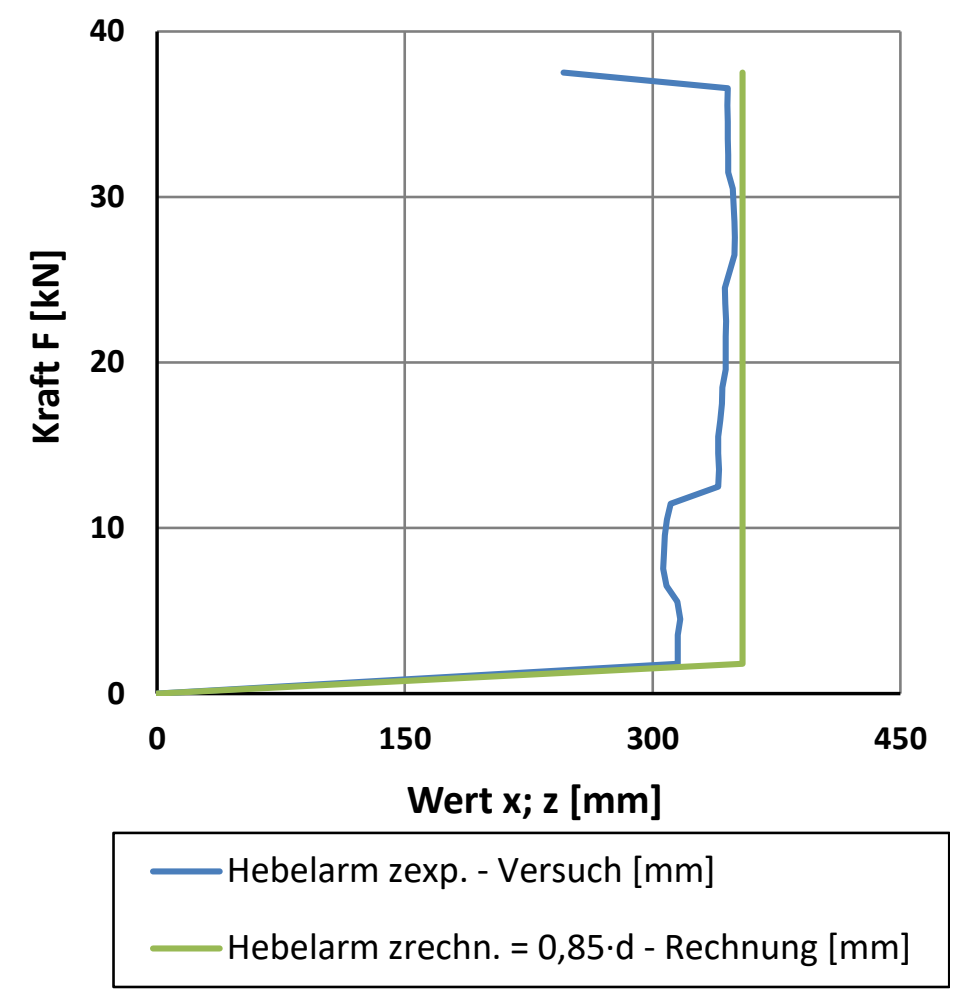

Bild 5.16 Vergleich von $z_{\text {rechn. }}$ ermitteltem zu $z_{\text {exp. }}$ bestimmtem Hebelarm der inneren Kräfte am Beispiel von ZI-01

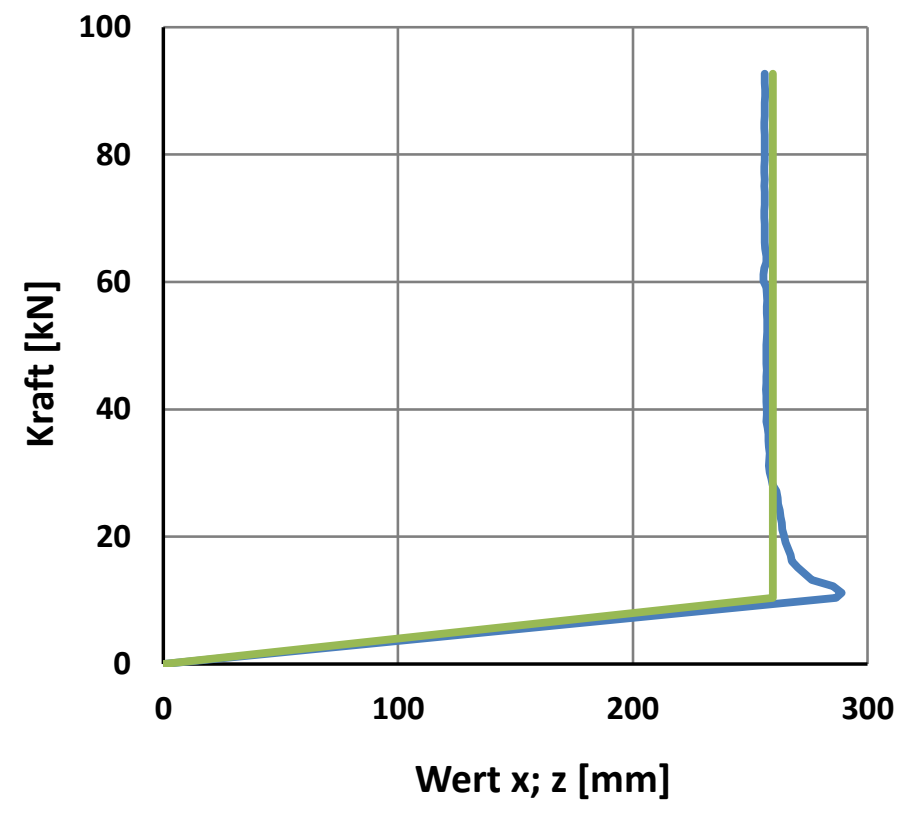

Hebelarm zexp. - Versuch [mm]

Hebelarm zrechn. $=0,85 \cdot \mathrm{d}-$ Rechnung $[\mathrm{mm}]$

Bild 5.17 Vergleich von $z_{\text {rechn. }}$ ermitteltem zu $z_{\text {exp. }}$ bestimmtem Hebelarm der inneren Kräfte am Beispiel von KS-07

\subsubsection{Neigung des Druckstrebenwinkels innerhalb des Schubfeldes}

Im Hinblick auf die Ermittlung der Mauerwerkfestigkeit und das nach Abschnitt 3.3.2.2 unterstellte Materialmodell ist der Druckstrebenwinkel $(\Theta)$ als resultierende Druckbeanspruchung innerhalb des Schubfeldes $(a / d)$ ein wesentlicher Modellparameter. Dieser ist unterhalb der Druckstrebe gegen die 
horizontale Systemachse des Mauerwerkbalkens definiert. Die Auswertung der an den Ziegelbalken instrumentierten Messrosetten hat ergeben, dass aufgrund der Anisotropie und Inhomogenität scheitrechter Mauerwerkbalken nur ein lokal existierender Druckstrebenwinkel bestimmt werden kann, der nicht für das gesamte Schubfeld repräsentativ erscheint. Zu erkennen ist dies insbesondere anhand der Versprünge des Diagonalrisses im Bereich des Mauerwerks. Daher wird eine Auswertung über den globalen Rissverlauf innerhalb des Schubfeldes durchgeführt; siehe Bild 5.18. Vereinfachend kann dabei „a“ als Abstand zwischen Auflager und einwirkender Einzellast und „d“ als statische Höhe angenommen werden.

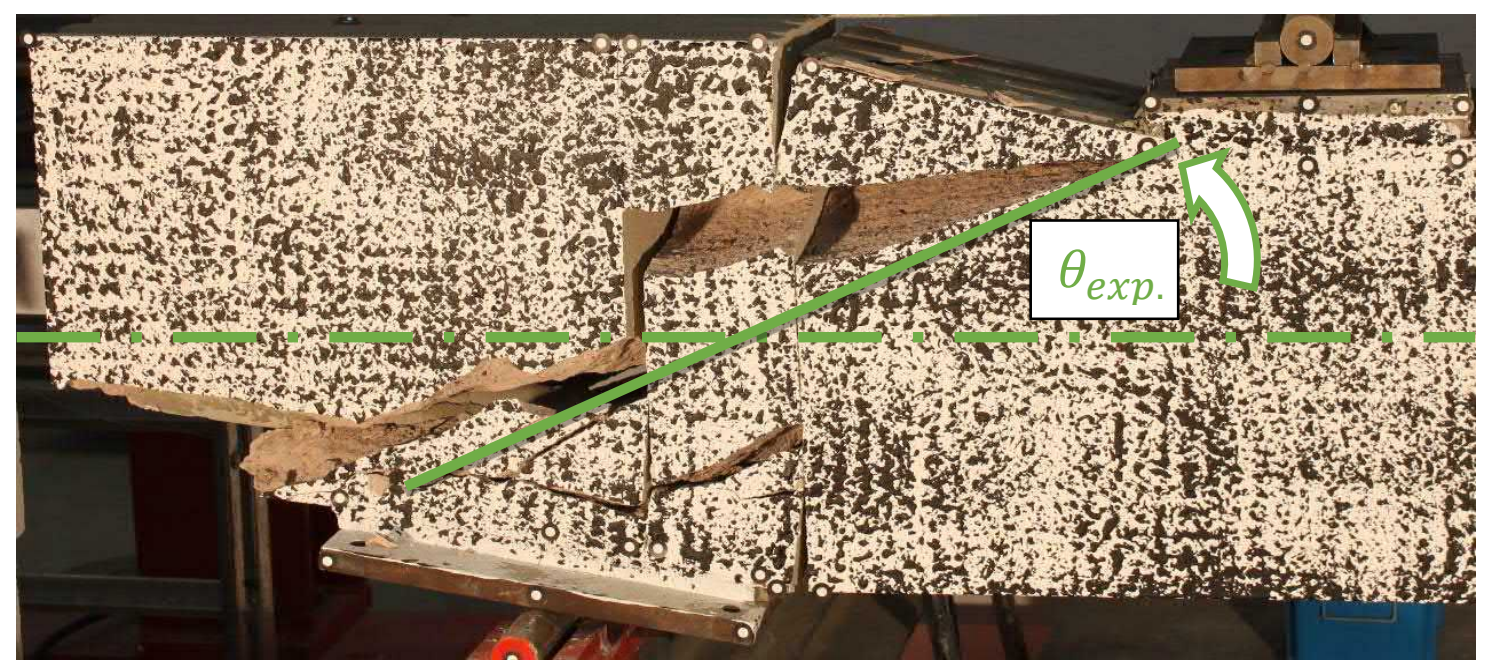

Bild 5.18 Auswertung und Definition des Druckstrebenwinkels ( $\Theta$ )

Die Rissspitzen des Primärrisses wurden durch eine globale Druckresultierende miteinander verbunden und mit der rechnerischen Annahme des Druckstrebenwinkels über die Beziehung nach Gleichung (5.2) miteinander verglichen.

$$
\theta_{\text {rechn. }}=\arctan \left(\frac{d}{a}\right)=\arctan \left(\frac{1}{\lambda}\right)=\arctan \left(\frac{\max V_{\mathrm{Ed}} \cdot d}{\max M_{\mathrm{Ed}}}\right)
$$

Dabei sind:

$$
\begin{array}{ll}
a & \text { Der Abstand zwischen Auflager und einwirkender Einzellast, } \\
d & \text { die effektive Höhe, } \\
\max M_{\mathrm{Ed}} & \text { der Bemessungswert des größten einwirkenden Biegemoments, } \\
\max V_{\mathrm{Ed}} & \text { der Bemessungswert der größten einwirkenden Querkraft im Bauteil. }
\end{array}
$$

Eine Auswertung zwischen experimentell und rechnerisch ermitteltem Druckstrebenwinkel ist Bild $5.19 \mathrm{zu}$ entnehmen. Ein Vergleich mit einer Abweichung von $\pm 15 \%\left(38,25^{\circ}\right.$ bzw. $\left.51,75^{\circ}\right)$ von einer unter $45^{\circ}$ laufenden Ideallinie zeigt eine gute Annäherung zwischen empirisch und nach Gleichung (5.2) bestimmtem Druckstrebenwinkel. Die Wertepaare unterschreiten die Grenzabweichung von der Ideallinie in überwiegender Anzahl deutlich. 


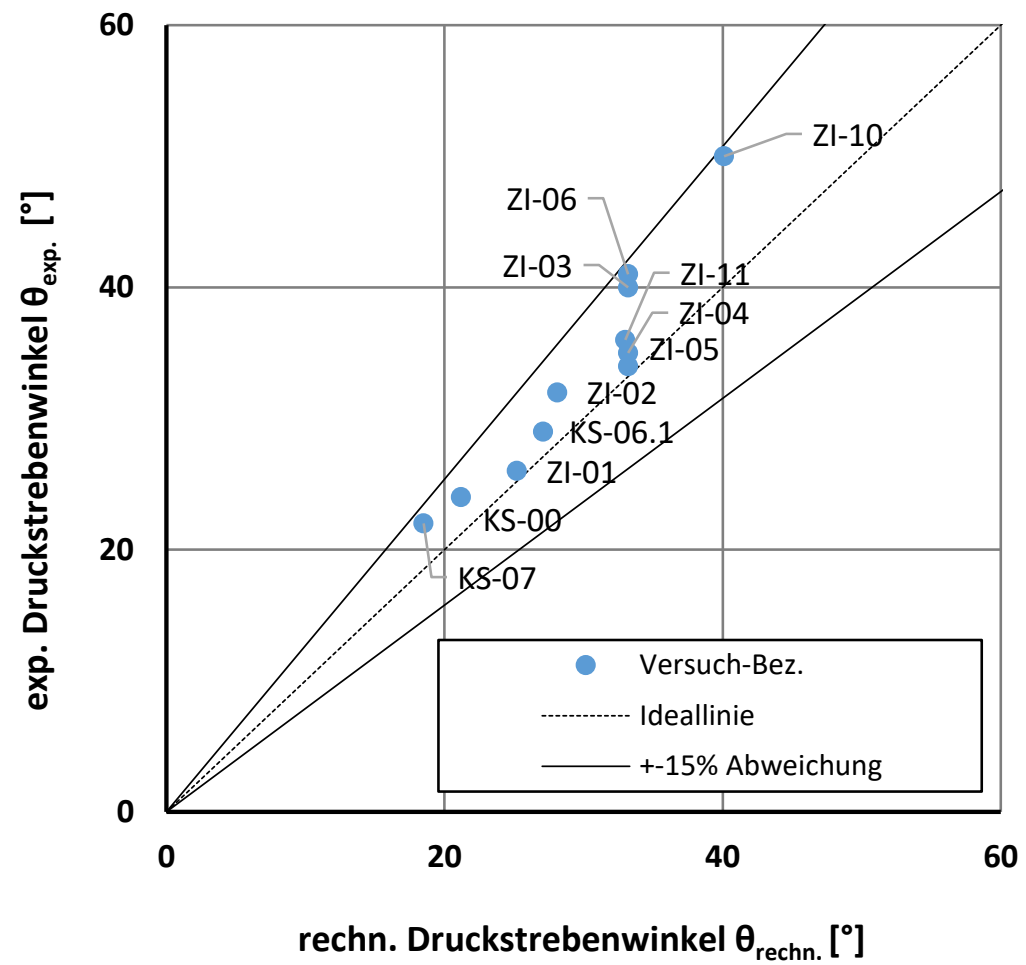

Bild 5.19 Vergleich der rechn. und exp. ermittelten Druckstrebenwinkel ( $\Theta$ )

\subsection{Scheitrechte Mauerwerkbalken mit Ergänzungsschicht aus Beton - IIa}

Die experimentellen Untersuchungen an scheitrechten Mauerwerkbalken mit Ergänzungsschicht aus Beton wurden entsprechend dem Versuchsprogramm nach Tabelle 5.8 durchgeführt. Dabei wurden die scheitrechten Kalksandsteinbalken nach Abschnitt 5.2 jeweils durch eine Aufbetonschicht ergänzt. Die Breite der sich zwischen Mauerwerk und Beton befindenden Verbundfuge wurde entsprechend Tabelle 5.8 vorgegeben. Die Ergänzungsschicht aus Beton repräsentiert hierbei die Tragwirkung einer beidseitig aufliegenden Gitterträgerelementdecke mit Ortbetonergänzung (Verbundbereich). Eine definierte Verbundfugenbreite infolge der aufliegenden Gitterträgerelementdecke wurde durch beidseitiges Einlegen einer zweilagigen Folie sichergestellt. Ziel der Untersuchungen war es zu überprüfen, ob und unter welchen Umständen ein monolithisches Bauteilverhalten der Balkenschichten unterstellt werden kann. Bild 5.20 zeigt exemplarisch den schematischen Aufbau der Prüfkörper anhand der Systemskizze des Balkens KS11. 

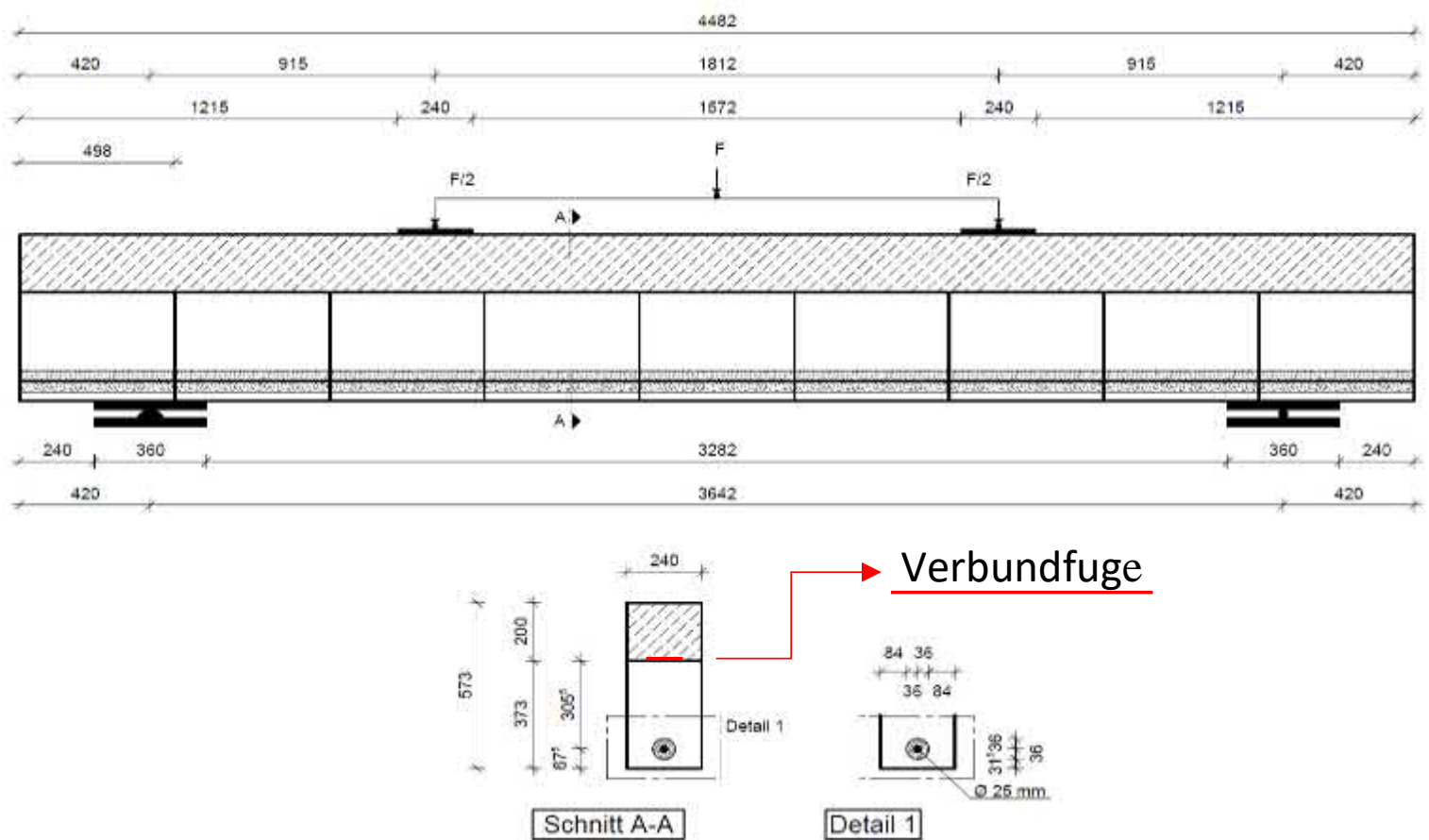

Bild 5.20 Systemskizze eines Mauerwerkbalkens mit Ergänzungsschicht aus Beton am Beispiel von KS-11

Das Versuchsprogramm ist Tabelle 5.8 und Tabelle 5.9 zu entnehmen. In Tabelle 5.8 sind Geometrien und Eigenschaften der untersuchten Mauerwerkbalken mit Ergänzungsschicht aus Beton angegeben. Tabelle 5.9 beinhaltet Angaben zur verwendeten Bewehrung.

Tabelle 5.8 Versuchsprogramm: Geometrie und Eigenschaften der Probekörper

\begin{tabular}{|c|c|c|c|c|c|c|c|c|c|c|c|c|}
\hline \multirow{2}{*}{\multicolumn{2}{|c|}{$\begin{array}{l}\text { Versuchs-Bez./ } \\
\text { Anzahl n }\end{array}$}} & \multirow{3}{*}{$\begin{array}{c}\text { Steinart/ } \\
\text { Festigkeits- } \\
\text { klasse/ } \\
\text { Mörtelart } \\
\\
\text { KS XL-QU } \\
20-2,0 \text { (DM) }\end{array}$} & \multicolumn{3}{|c|}{$\begin{array}{c}\text { Querschnittswerte } \\
{[\mathrm{mm}]}\end{array}$} & \multicolumn{2}{|c|}{$\begin{array}{c}\text { Prüfkörperlänge } \\
{[\mathrm{m}]}\end{array}$} & \multicolumn{2}{|c|}{\begin{tabular}{|c|} 
Abstand zwischen: \\
Achse Auflager - Achse \\
F / Abstand zwischen: \\
Auflager - F \\
[mm]
\end{tabular}} & \multirow{2}{*}{$\begin{array}{c}\begin{array}{c}\text { Auflager- } \\
\text { länge } \\
\text { [mm] }\end{array} \\
a_{1}\end{array}$} & \multirow{2}{*}{\begin{tabular}{|c}
$\begin{array}{c}\text { Schub- } \\
\text { schlankheit } \\
{[-]}\end{array}$ \\
$\lambda$
\end{tabular}} & \multirow{2}{*}{\begin{tabular}{|c}
$\begin{array}{c}\text { Verbund- } \\
\text { fugenbreite } \\
\text { [mm] }\end{array}$ \\
$F$
\end{tabular}} \\
\hline & & & $\boldsymbol{h}$ & $d$ & $t$ & $l$ & $l_{\text {eff }}$ & $\mathbf{a}$ & $a_{\mathrm{v}}$ & & & \\
\hline KS-08.1 & 1 & & 573 & 505,5 & 240 & 1,245 & 1,045 & 522,5 & 323,0 & 200 & 1,0 & 50 \\
\hline KS-08.2 & 1 & $\begin{array}{c}\text { KS XL-QU } \\
20-2,0 \text { (DM) }\end{array}$ & 573 & 505,5 & 240 & 1,245 & 1,045 & 522,5 & 323,0 & 200 & 1,0 & 80 \\
\hline KS-09.1 & 1 & $\begin{array}{c}\text { KS XL-QU } \\
20-2,0(\mathrm{DM}) \\
\end{array}$ & 573 & 505,5 & 240 & 1,494 & 1,154 & 263,5 & 190,0 & 240 & 0,5 & 50 \\
\hline KS-09.2 & 1 & $\begin{array}{c}\text { KS XL-QU } \\
20-2,0 \text { (DM) }\end{array}$ & 573 & 505,5 & 240 & 1,494 & 1,254 & 340,0 & 190,0 & 240 & 0,7 & 80 \\
\hline KS-10.1 & 1 & $\begin{array}{c}\text { KS XL-QU } \\
20-2,0(\mathrm{DM}) \\
\end{array}$ & 573 & 505,5 & 240 & 1,992 & 1,752 & 439,5 & 290,0 & 240 & 0,9 & 80 \\
\hline KS-10.2 & 1 & $\begin{array}{c}\text { KS XL-QU } \\
20-2,0(\mathrm{DM}) \\
\end{array}$ & 573 & 505,5 & 240 & 1,992 & 1,752 & 440,0 & 290,0 & 240 & 0,9 & 80 \\
\hline KS-11 & 1 & $\begin{array}{c}\text { KS XL-QU } \\
20-2,0(\mathrm{DM}) \\
\end{array}$ & 573 & 505,5 & 240 & 4,482 & 3,642 & 915,0 & 715,0 & 360 & 1,8 & 160 \\
\hline KS-16 F.1 & 1 & $\begin{array}{l}\text { KS 6DF } 20 \text { - } \\
2,0 \text { (DM) } \\
\end{array}$ & 434 & 382,0 & 175 & 1,500 & 1,300 & 325,0 & 175,0 & 200 & 0,9 & 50 \\
\hline KS-17 F & 1 & $\begin{array}{c}\text { KS 6DF } 20- \\
2,0 \text { (DM) }\end{array}$ & 434 & 382,0 & 175 & 1,250 & 1,050 & 262,5 & 112,5 & 200 & 0,7 & 50 \\
\hline KS-18 F.1 & 1 & $\begin{array}{c}\text { KS 6DF } 20 \text { - } \\
2,0(\mathrm{DM})\end{array}$ & 434 & 382,0 & 175 & 1,500 & 1,300 & 325,0 & 175,0 & 200 & 0,9 & 80 \\
\hline
\end{tabular}


Tabelle 5.9 Versuchsprogramm: Art und Menge der Bewehrung

\begin{tabular}{|c|c|c|}
\hline Versuchsbezeichnung & Art der Bewehrung & $\begin{array}{c}\text { Durchmesser Bewehrung } \\
{[\mathbf{m m}]}\end{array}$ \\
\hline KS-08.1 & B500A & $1 \times 20$ \\
\hline KS-08.2 & B500A & $1 \times 20$ \\
\hline KS-09.1 & B500A & $1 \times 20$ \\
\hline KS-09.2 & B500A & $1 \times 20$ \\
\hline KS-10.1 & B500A & $1 \times 20$ \\
\hline KS-10.2 & B500A & $1 \times 25$ \\
\hline KS-11 & B500A & $1 \times 25$ \\
\hline KS-16 F.1 & B500A & $1 \times 16$ \\
\hline KS-17 F & B500A & $1 \times 16$ \\
\hline KS-18 F.1 & B500A & $1 \times 16$ \\
\hline
\end{tabular}

Exemplarisch wird in Bild 5.21 der Messstellenplan des Prüfkörpers KS-11 dargestellt. Die Messstellenpläne der weiteren Prüfkörper sind dem Anhang zu entnehmen; siehe Abschnitt A 4.4.2.

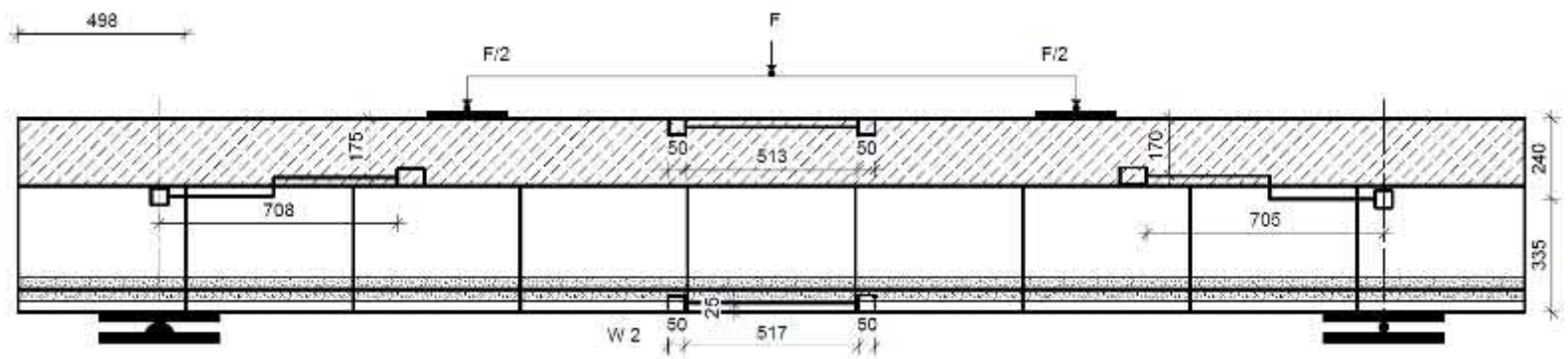

Bild 5.21 Messstellenplan eines Mauerwerkbalkens mit Ergänzungsschicht aus Beton - KS-11

Während der Prüfungen wurden Verformungen an den in Bild 5.21 dargestellten Messstellen in Abhängigkeit der jeweiligen Belastungsstufen aufgezeichnet. In Tabelle 5.10 sind sowohl die Risslasten $\left(F_{\text {exp,cr }}\right)$ und die Bruchlasten inkl. Eigengewicht $\left(F_{\text {exp,u }}\right)$ als auch die jeweilige Versagensart der Mauerwerkbalken angegeben. Das Primärversagen des Mauerwerkbalkens (KS-11) war auf einen diagonal verlaufenden Schubzugbruch in Kombination mit einem Reibungsversagen der Vertikalfuge (Vertikalversatz) zurückzuführen; siehe Bild 5.22. Dem Reibungsversagen in der Vertikalfuge folgte in den meisten Fällen ein Sekundärbruch, der zu einem Versagen der horizontalen Verbundfuge zwischen Kalksandsteinbalken und der Ergänzungsschicht aus Beton geführt hat. 
Tabelle 5.10 Riss- und Bruchlasten der betonstahlbewehrten, scheitrechten Mauerwerkbalken

\begin{tabular}{|c|c|c|c|}
\hline $\begin{array}{c}\text { Versuchs- } \\
\text { bezeichnung }\end{array}$ & $\begin{array}{c}\text { Risslast }\left(\boldsymbol{F}_{\text {exp,cr }}\right) \\
{[\mathbf{k N}]}\end{array}$ & $\begin{array}{c}\text { Bruchlast }\left(\boldsymbol{F}_{\text {exp,u }}\right) \\
{[\mathbf{k N}]}\end{array}$ & Versagensart $^{\mathbf{1})}$ \\
\hline KS-08.1 & 114,00 & 141,78 & $\mathrm{R}, \mathrm{V}$ \\
\hline KS-08.2 & 140,00 & 140,00 & $\mathrm{R}, \mathrm{V}$ \\
\hline KS-09.1 & 135,30 & 142,60 & $\mathrm{R}, \mathrm{V}$ \\
\hline KS-09.2 & 166,24 & 166,24 & $\mathrm{R}$ \\
\hline KS-10.1 & 78,20 & 127,82 & $\mathrm{R}, \mathrm{V}, \mathrm{V}$ \\
\hline KS-10.2 & 168,10 & 169,50 & $\mathrm{Z}$ \\
\hline KS-11 & 103,16 & 187,00 & $\mathrm{R}, \mathrm{V}$ \\
\hline KS-16 F.1 & 124,00 & 95,34 & $\mathrm{R}, \mathrm{V}$ \\
\hline KS-17 F & 127,69 & 118,00 & $\mathrm{R}, \mathrm{V}$ \\
\hline KS-18 F.1 & 108,30 & 95,00 & \\
\hline 1$)$ V - Verbundversagen Horizontalfuge; Z - Schubzugversagen; R - Reibungsversagen Vertikalfuge
\end{tabular}

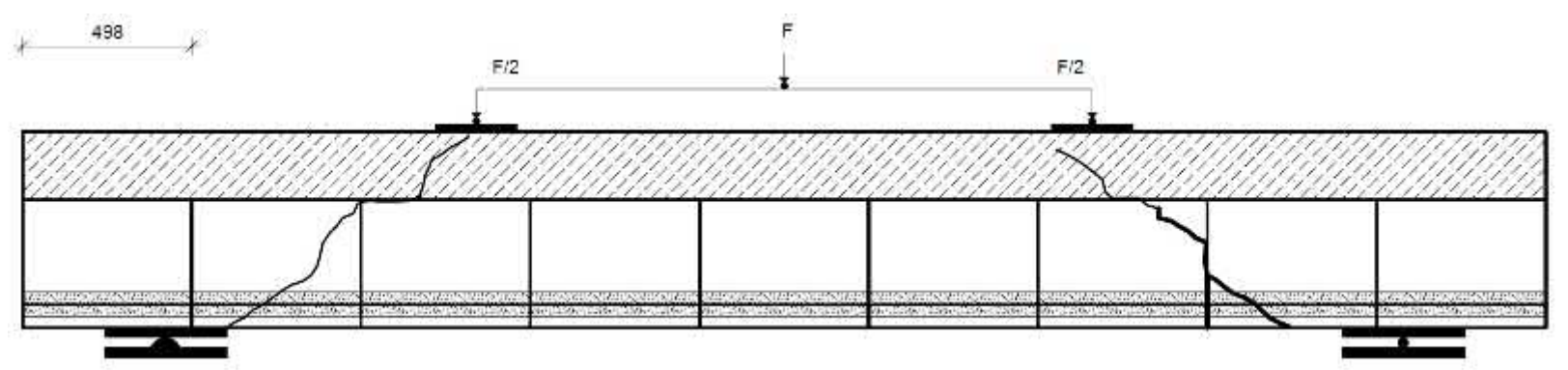

Bild 5.22 Rissbild eines Mauerwerkbalkens mit Ergänzungsschicht aus Beton - KS-11

Die Annahme eines monolithischen Bauteilverhaltens wird durch eine flächenhafte Auswertung der Verformung bestätigt; siehe Bild 5.23. Dargestellt ist zum einen die Horizontalverformung, die der Verschiebung in X-Richtung entspricht (Bild 5.23, links); zum anderen die Vertikalverformung, die der Verschiebung in Y-Richtung gleichzusetzen ist (Bild 5.23, rechts). Darüber hinaus ist eine KraftVerformungslinie dargestellt, welche den Verlauf der Mittendurchbiegung in Abhängigkeit zur aufgebrachten Last beschreibt. Infolge der flächenhaften Verformungsaufnahme ist es gelungen, das Schubfeld mit dem kreuzenden Schubzugriss genau zu analysieren. Die Ergebnisse zur Beschreibung des Rissverlaufes und der Verformung in X-als auch in Y-Richtung in Abhängigkeit der Längsschnitte (1 bis 4) sind den Diagrammen von Bild 5.23 zu entnehmen. Die flächenhafte, farbliche Darstellung der horizontalen und vertikalen Verformung auf der Bauteiloberfläche zeigt, dass im Bereich der Verbundfuge kein Reibungsversagen eingetreten ist. Dies entspricht dem Ergebnis der Auswertung rückseitig angebrachter Wegsensoren (Bild 5.21). Somit kann von einem intakten Verbund ausgegangen und ein monolithisches Bauteilverhalten unterstellt werden. Äquivalent gilt dies für die Prüfkörper nach Tabelle 5.10 . 


\section{Prüfkörper: KS-11}
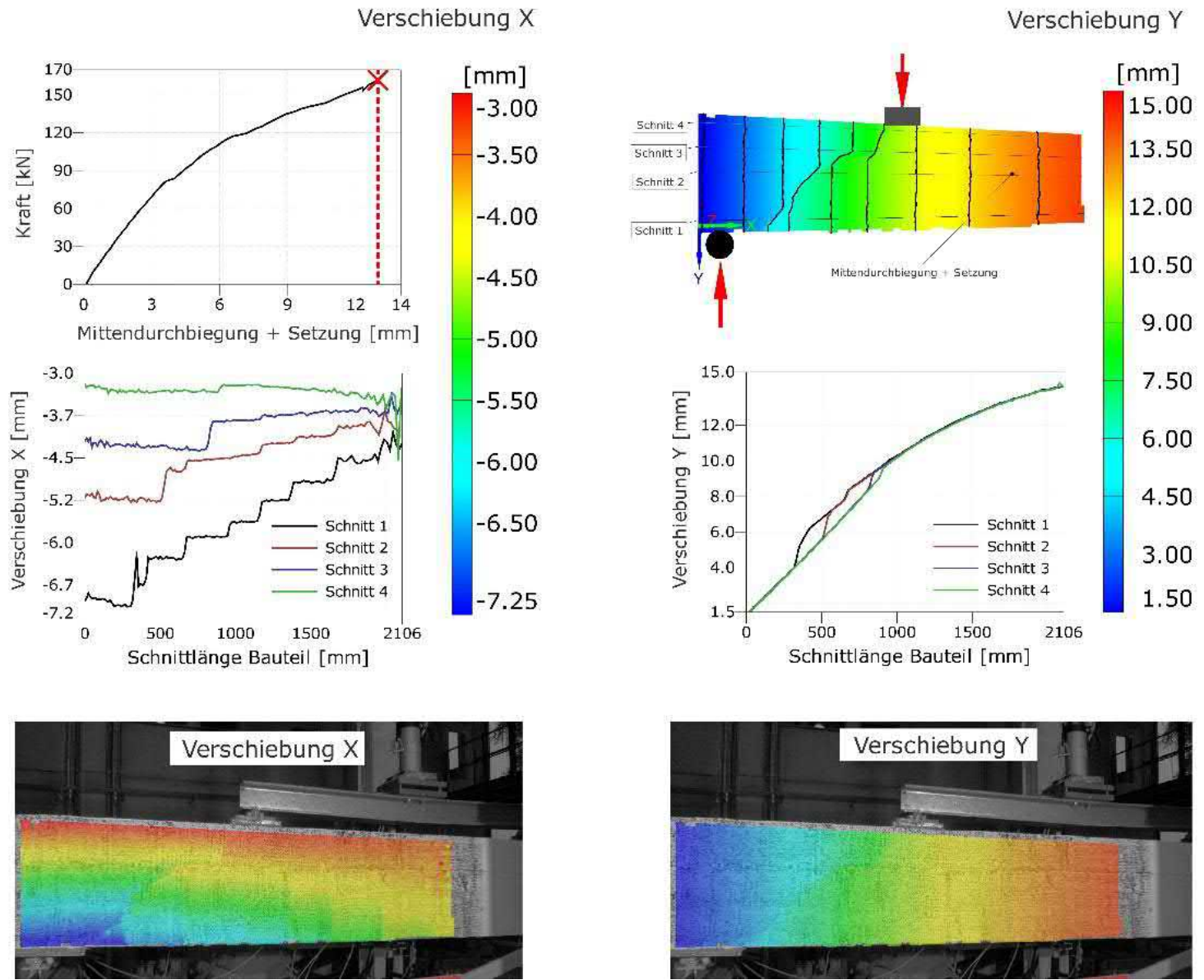

Bild 5.23

Darstellung einer flächenhaften Verformungsmessung am Beispiel von KS-11: Horizontalverformung in X-Richtung (links); Vertikalverformung in Y-Richtung (rechts)

Neben dem Verformungsverhalten der horizontalen Verbundfuge wurde für die Konstruktionsart mit Ergänzungsschicht aus Beton der Hebelarm der inneren Kräfte (z) untersucht. Die in Bild 5.24 exemplarisch dargestellte Auswertung für den Prüfkörper KS-11 ist repräsentativ für die Versuchsreihe. Ersichtlich ist, dass sich bei vorliegender Konstruktionsart der Hebelarm der inneren Kräfte mit einer rechnerischen Annahme von $z_{\text {rechn. }}=0,9 \cdot d$ dem im Experiment bestimmten Hebelarm der inneren Kräfte $\left(z_{\text {exp. }}\right)$ gut annähern lässt. 


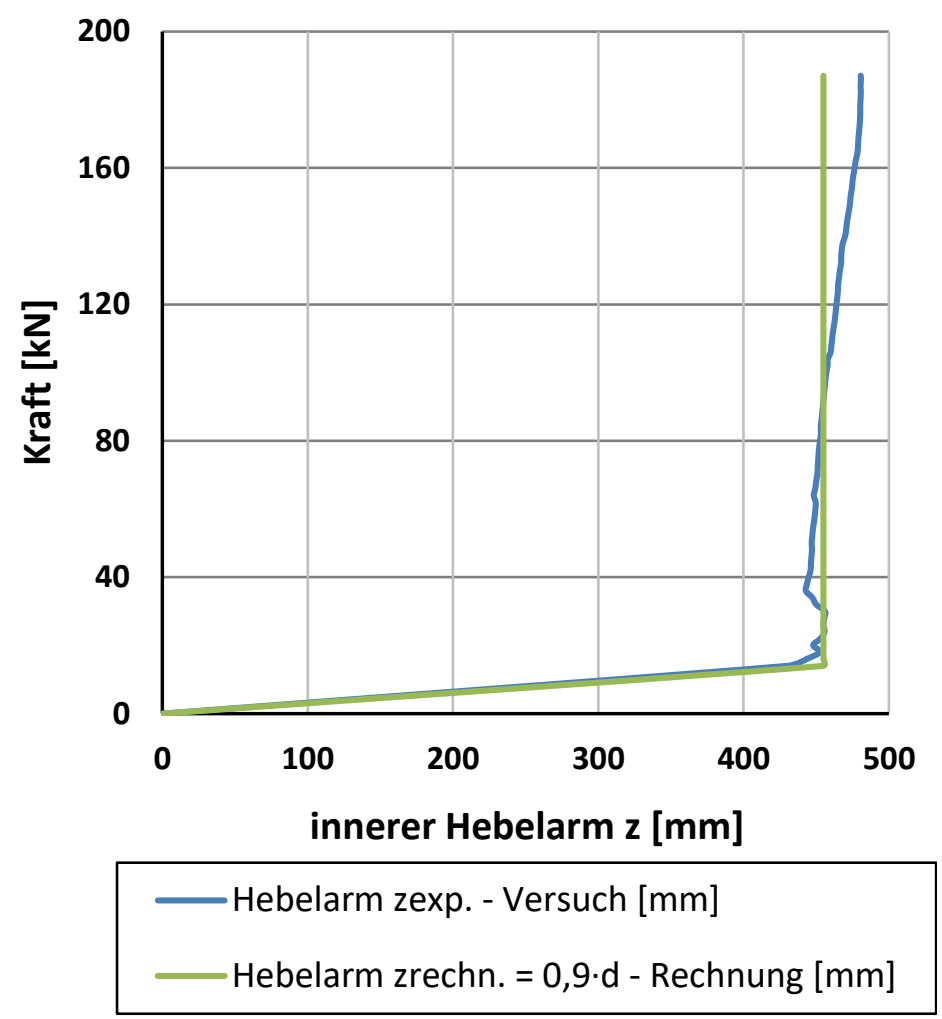

Bild 5.24 Vergleich von $z_{\text {rechn. }}$ ermitteltem zu $z_{\text {exp. }}$ bestimmtem Hebelarm der inneren Kräfte am Beispiel von KS-11

\subsection{Vorgespannte scheitrechte Mauerwerkbalken - IIbIII}

Die experimentellen Untersuchungen an vorgespannten, scheitrechten Mauerwerkbalken wurden entsprechend dem Versuchsprogramm nach Tabelle 5.11 durchgeführt. Dabei wurde die auf die exzentrisch und nicht im Verbund liegende stabförmige Spannbewehrung aufgebrachte Vorspannkraft über stirnseitig angeordnete Ankerplatten auf den Prüfköper übertragen. Mit einer Kraftmessdose zwischen Ankerplatte und Prüfkörper wurde die Vorspannkraft zu Beginn und während der laufenden Prüfung gemessen; siehe Bild 5.25. Darüber hinaus konnte hierdurch eine über die Balkenlänge konstant wirkende Vorspannkraft sichergestellt werden.

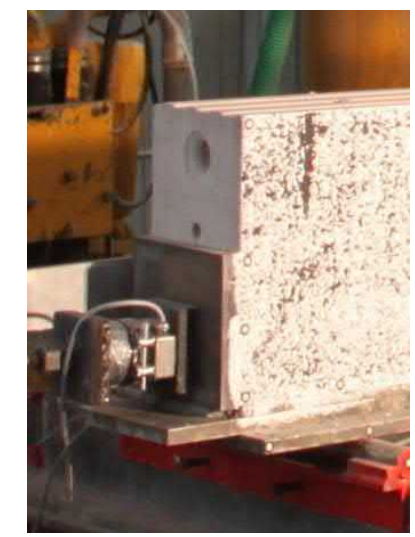

Bild 5.25 Ankerpunkt - Einleitung der Vorspannkraft

Ziel der Untersuchungen war es, den Normalkrafteinfluss aus einer Vorspannung auf die Querkrafttragfähigkeit scheitrecht bewehrter Mauerwerkbalken unterschiedlicher Schubschlankheit zu prüfen. Dabei erscheint die Art der Vorspannung von sekundärer Bedeutung zu sein. Der schematische Aufbau der Prüfkörper sowie die Anordnung der Messstellen folgen dem aus Abschnitt 5.2. 
Das Versuchsprogramm ist Tabelle 5.11 und Tabelle 5.12 zu entnehmen. In Tabelle 5.11 sind Geometrien und Eigenschaften der vorgespannten Mauerwerkbalken angegeben. Tabelle 5.12 beinhaltet Angaben zur verwendeten Bewehrung und Vorspannkraft. Die Größe der Vorspannkraft wurde so gewählt, dass die Vertikalfugen am oberen Rand gerade nicht dekompremieren.

Tabelle 5.11 Versuchsprogramm: Geometrie und Eigenschaften der Probekörper

\begin{tabular}{|c|c|c|c|c|c|c|c|c|c|c|c|}
\hline \multirow{2}{*}{\multicolumn{2}{|c|}{\begin{tabular}{|c} 
Versuchs- \\
Bez./ Anzahl \\
n
\end{tabular}}} & \multirow{3}{*}{\begin{tabular}{|c|} 
Steinart/ \\
Festigkeitsklasse/ \\
Mörtelart \\
\\
\\
KS XL-QU \\
$20-2,0(\mathrm{DM})$ \\
\end{tabular}} & \multicolumn{3}{|c|}{$\begin{array}{l}\text { Querschnittswerte } \\
{[\mathrm{mm}]}\end{array}$} & \multicolumn{2}{|c|}{$\begin{array}{c}\text { Prüfkörperlänge } \\
{[\mathrm{m}]}\end{array}$} & \multicolumn{2}{|c|}{\begin{tabular}{|c|} 
Abstand zwischen: \\
Achse Auflager - Achse \\
F / Abstand zwischen: \\
Auflager - F \\
[mm] \\
\end{tabular}} & \multirow{2}{*}{$\begin{array}{c}\text { Auf- } \\
\text { lager- } \\
\text { länge } \\
{[\mathrm{mm}]}\end{array}$} & \multirow{2}{*}{$\begin{array}{c}\begin{array}{c}\text { Schub- } \\
\text { schlank- } \\
\text { heit }^{1} \\
{[-]}\end{array} \\
\lambda\end{array}$} \\
\hline & & & $\boldsymbol{h}$ & $d$ & $t$ & $l$ & $l_{\text {eff }}$ & $a$ & $a_{\mathrm{v}}$ & & \\
\hline KS-12 & 1 & & 373 & 305,5 & 240 & 0,996 & 0,881 & 220,3 & 113 & 115 & 0,7 \\
\hline $\begin{array}{l}\text { KS- } \\
13.1 \\
\end{array}$ & 1 & $\begin{array}{c}\text { KS XL-QU } \\
20-2,0(\mathrm{DM})\end{array}$ & 373 & 305,5 & 240 & 1,245 & 1,005 & 250,0 & 80 & 240 & 0,8 \\
\hline $\begin{array}{l}\text { KS- } \\
13.2\end{array}$ & 1 & $\begin{array}{c}\text { KS XL-QU } \\
20-2,0(\mathrm{DM})\end{array}$ & 373 & 305,5 & 240 & 1,245 & 1,005 & 250,0 & 80 & 240 & 0,8 \\
\hline KS-14 & 1 & $\begin{array}{c}\text { KS XL-QU } \\
20-2,0 \text { (DM) }\end{array}$ & 373 & 305,5 & 240 & 3,237 & 2,937 & 719,3 & 519 & 360 & 2,4 \\
\hline KS-15 & 1 & $\begin{array}{c}\text { KS XL-QU } \\
20-2,0(\mathrm{DM})\end{array}$ & 373 & 305,5 & 240 & 4,482 & 3,642 & 915,0 & 715 & 360 & 3,0 \\
\hline
\end{tabular}

Tabelle 5.12 Versuchsprogramm: Art und Menge der Bewehrung sowie Höhe der Vorspannkraft

\begin{tabular}{|c|c|c|c|}
\hline Versuchsbezeichnung & Art der Bewehrung & $\begin{array}{c}\text { Durchmesser Bewehrung } \\
{[\mathbf{m m}]}\end{array}$ & $\begin{array}{c}\text { Vorspannkraft } \\
{[\mathbf{k N}]}\end{array}$ \\
\hline KS-12 & S 670/800 & $1 \times 22,14$ & 76,5 \\
\hline KS-13.1 & S 670/800 & $1 \times 22,14$ & 81,3 \\
\hline KS-13.2 & S 670/800 & $1 \times 22,14$ & 67,3 \\
\hline KS-14 & S 670/800 & $1 \times 22,14$ & 77,4 \\
\hline KS-15 & S 670/800 & $1 \times 22,14$ & 80,9 \\
\hline
\end{tabular}

In Tabelle 5.13 sind die Risslasten $\left(F_{\text {exp,cr }}\right)$ und die Bruchlasten inkl. Eigengewicht $\left(F_{\text {exp,u }}\right)$ der Versuchskörper sowie die Versagensart angegeben.

Tabelle 5.13 Riss- und Bruchlasten der scheitrechten Mauerwerkbalken unter Vorspannung

\begin{tabular}{|c|c|c|c|}
\hline $\begin{array}{c}\text { Versuchs- } \\
\text { bezeichnung }\end{array}$ & $\begin{array}{c}\text { Risslast }\left(\boldsymbol{F}_{\text {exp,cr }}\right) \\
{[\mathbf{k N}]}\end{array}$ & $\begin{array}{c}\text { Bruchlast }\left(\boldsymbol{F}_{\text {exp,u }}\right) \\
{[\mathbf{k N}]}\end{array}$ & Versagensart $^{\mathbf{1})}$ \\
\hline KS-12 & 130,10 & 130,10 & $\mathrm{R}$ \\
\hline KS-13.1 & 102,40 & 174,90 & $\mathrm{R}$ \\
\hline KS-13.2 & 213,40 & 213,40 & $\mathrm{k} . \mathrm{V}$. \\
\hline KS-14 & 138,70 & 167,10 & $\mathrm{Z}, \mathrm{A}$ \\
\hline KS-15 & 118,00 & 128,67 & \\
\hline 1) Versagensart: Z - Zugversagen; $\mathrm{R}-$ Reibungsversagen; A - Auflagerversagen; k.V. - kein Versagen \\
\hline
\end{tabular}

Auch bei den gedrungenen, vorgespannten Prüfkörpern geringer Schubschlankheit (KS-12, KS-13.1 und 13.2) wird im Wesentlichen die Vertikalfuge auf Reibung beansprucht, was durch die Versagensart der Untersuchungsergebnisse bestätigt wird.

In Bezug auf die vorgespannten Mauerwerkbalken großer Schubschlankheiten (KS-14 und KS-15) hat sich, entgegen den Versuchen ohne Vorspannung, ein Spaltriss zwischen der Druckzone und der Zugzone 
zwischen den Lasteinleitungsplatten (im Bereich des maximalen Moments) eingestellt. Dies entspricht dem klassischen Rissverlauf eines Stahlbetonbalkens mit einer Vorspannung ohne Verbund. Das Trag- und Verformungsverhalten von Stahlbetonbalken wird entscheidend von der Art der Vorspannung Vorspannung mit oder ohne Verbund - beeinflusst. Dabei kommt es bei vorgespannten Balken ohne Verbund im Vergleich zu solchen mit Verbund zu vergleichsweise weniger, aber größeren Rissen, welche die Druckzone einschnüren und letztlich zu einem Druckversagen führen können; siehe auch Rombach (Rombach 2010, S. 54). Dies scheint auch für vorgespannte Mauerwerkbalken zu gelten, bei denen eine Vorspannung ohne Verbund gewählt wurde. Im Fall der KS-Balken ist die aufgehende Vertikalfuge ein potenzieller Riss und führt somit zu einer Biegebeanspruchung am Einzelstein; siehe Bild 5.26 (links). Dies ist Ursache für die Rissbildung zwischen Druck- und Zuggurt und kann durch den Einfluss unterschiedlichen Querdehnungsverhaltens zwischen Mauerstein und Mauermörtel (Bild 4.11; Regime II) verstärkt werden. Letzteres ist bei vorliegender Kombination aus Mauersteinen und Dünnbettmauerwerk zu vernachlässigen. In Bild 5.26 (rechts) ist der Verformungszustand des vorgespannten Mauerwerkbalkens KS-15 zum Zeitpunkt der Versuchsdurchführung dargestellt. Das Rissbild des entsprechenden Balkens ist in Bild 5.27 angegeben.
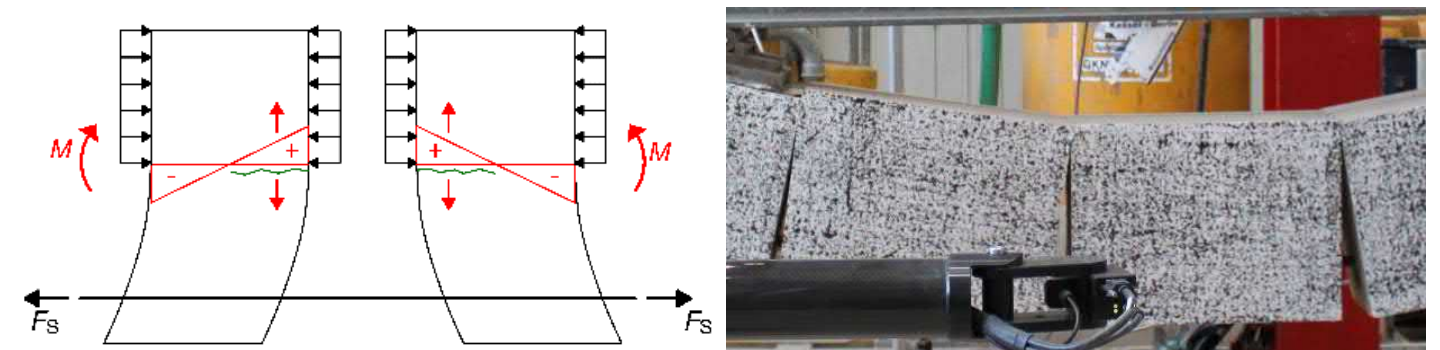

Bild 5.26 Trag- und Rissmodell eines scheitrechten Mauerwerkbalkens unter Vorspannung ohne Verbund im Bereich des maximalen Momentes (links); Verformung eines vorgespannten Mauerwerkbalkens ohne Verbund im Experiment (rechts)

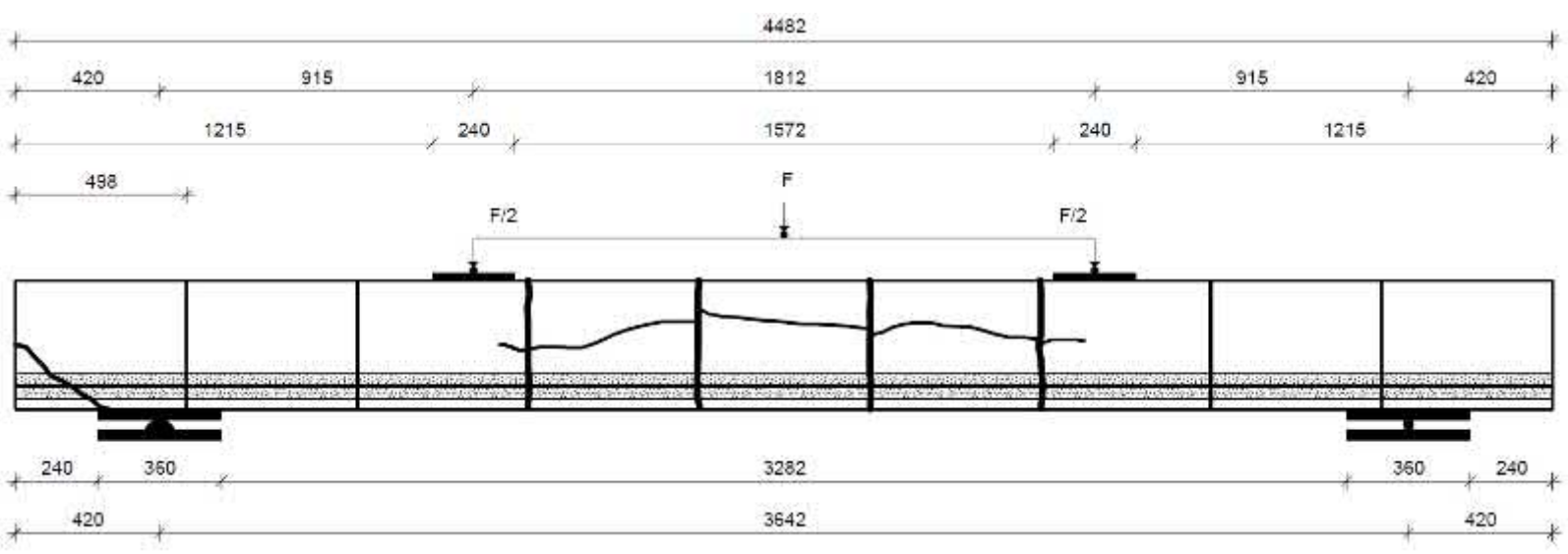

Bild 5.27 Rissbild des vorgespannten scheitrechten Mauerwerkbalkens am Beispiel von KS-15 


\subsection{Zusammenfassung der Ergebnisse}

In den experimentellen Untersuchungen wurden Mauerwerkbalken verschiedener Bauteilkategorien nach Tabelle 2.1 auf ihr Trag- und Verformungsverhalten untersucht. Die unterschiedlichen Varianten sind in Tabelle 5.14 dargestellt.

Tabelle 5.14 Zusammenfassung untersuchter Mauerwerkbalken nach Bauteilkategorien

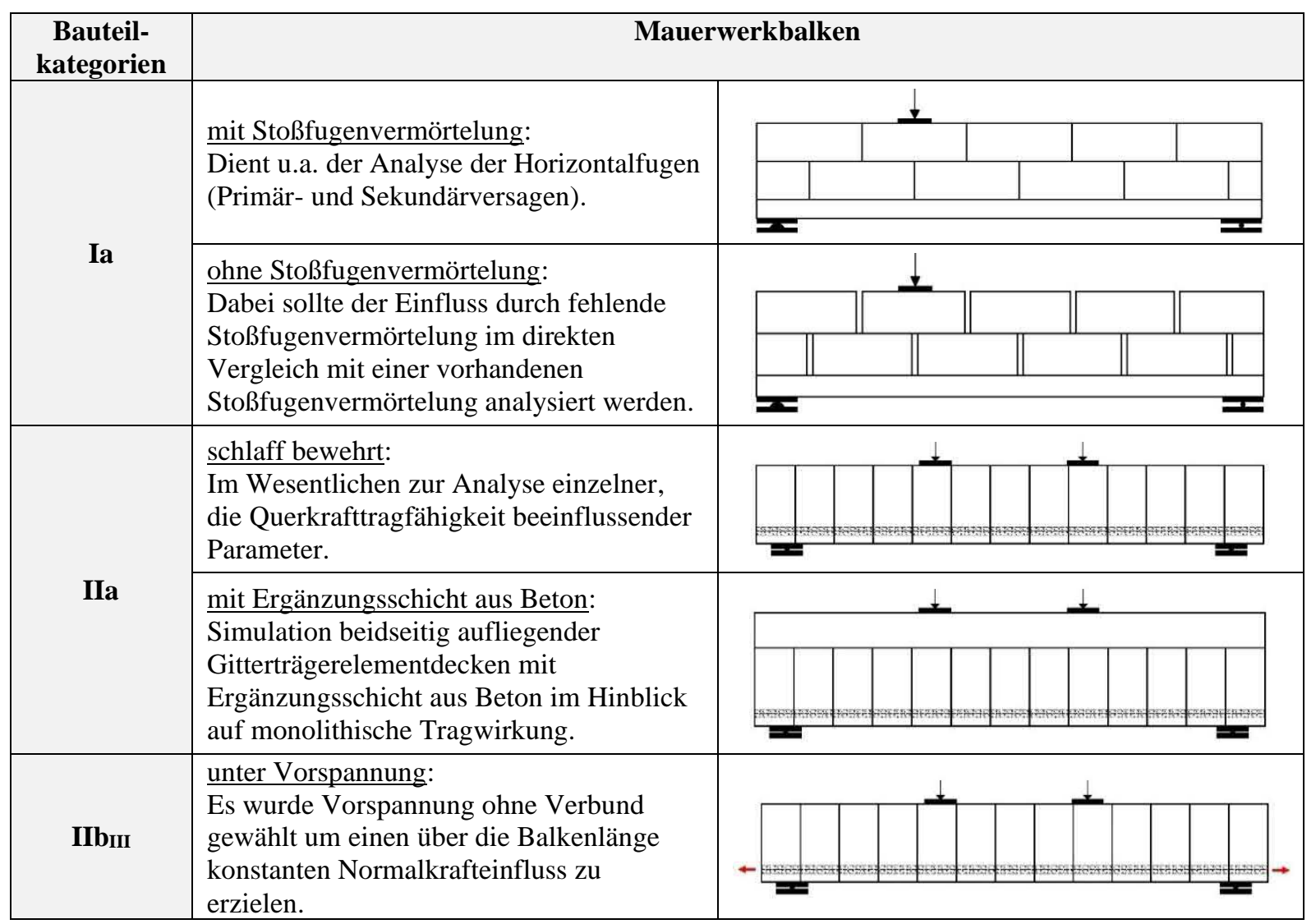

Neben den verschiedenen Bauteilgeometrien wurden folgende, den Querkraftwiderstand beeinflussende Faktoren und Einflüsse im Bereich von Schubfeldern untersucht:

- Die Rissgeometrie zur Analyse der Tragwirkung in Schubspannungsfeldern,

- der Einfluss der Schubschlankheit $(\lambda)$ auf die Querkrafttragfähigkeit,

- die Ermittlung des Hebelarms der inneren $\operatorname{Kräfte~}(z)$,

- der Druckstrebenwinkel $(\theta)$ in Abhängigkeit zur Schubschlankheit,

- der Einfluss des Bewehrungsgrades ( $\rho$ ) auf die Querkrafttragfähigkeit.

Der im Experiment ermittelte Hebelarm der inneren Kräfte $\left(z_{\text {exp. }}\right)$ stimmt für Balkenkonstruktionen aus Mauerwerk mit den Zahlenwerten der rechnerischen Annäherung nach Gleichung (5.3) überein. Für Balken mit einer Ergänzungsschicht aus Beton ist der rechnerische Hebelarm ( $z_{\text {rechn. }}$ ) nach Gleichung (5.4) anzunähern.

MW-Balken

MW-Balken mit einer Ergänzungsschicht aus Beton

$$
\begin{aligned}
& z_{\text {rechn. }}=0,85 \cdot d \\
& z_{\text {rechn. }}=0,9 \cdot d
\end{aligned}
$$

Dabei ist:

$d \quad$ Die statische Nutzhöhe.

Die Auswirkung variierender Schubschlankheiten auf die Querkrafttragfähigkeit von Mauerwerkbalken wurde experimentell ermittelt und mit einem rechnerischen Ansatz verglichen; siehe Abschnitt 5.3.2. 
Dieser Vergleich zeigt eine gute Übereinstimmung für Mauerwerkbalken mit Schubzugversagen. Unter der Annahme kleiner Schubschlankheiten und damit im Bereich möglichen Reibungsversagens in den Vertikalfugen der Mauerwerkbalken lässt sich der Einfluss mit dem rechnerischen Ansatz (Gleichung (2.22)) bzw. DIN EN 1992-1-1/NA (Gleichung (4.16)) nicht erfassen. Vielmehr ist dieser auf den Mauerwerkverband zurückzuführen und soll zukünftig über die von dem Belastungswinkel (Druckstrebenwinkel) abhängige Mauerwerkdruckfestigkeit berücksichtigt werden. Hierzu wird auf das Materialmodell von Ganz/Thürlimann/Mojsilović nach Abschnitt 3.3.2.2 hingewiesen, mit dem die Druckfestigkeit von Mauerwerk in Abhängigkeit eines Beanspruchungswinkels bestimmt werden kann.

In Bild 5.28 sind die Last-Durchbiegungslinien der Mauerwerkbalken KS-07 (schlaff bewehrt), KS-11 (schlaff bewehrt mit Ergänzungsschicht aus Beton) und KS-15 (mit Vorspannung ohne Verbund) gleicher Bauteillängen dargestellt. Es ist zu erkennen, dass der Mauerwerkbalken KS-11, mit Ergänzungsschicht aus Beton und somit größerem anrechenbarem Querschnitt, ein deutlich steiferes Verformungsverhalten zeigt als die Mauerwerkbalken KS-07 und KS-15 ohne Ergänzungsschichten. Dekomprimiert der zuvor vorgespannte Mauerwerksquerschnitt, nähert sich nach Überschreitung der Risslast der vorgespannte Balken (KS-15) hinsichtlich seines Verformungsverhalten dem des schlaff bewehrten Mauerwerkbalkens (KS-07) an. Die Last-Durchbiegungslinie des schlaff bewehrten Mauerwerkbalkens (KS-07) zeigt bereits frühzeitig hohe Verformungen infolge einsetzender Biegerisse; primär in den Vertikalfugen.

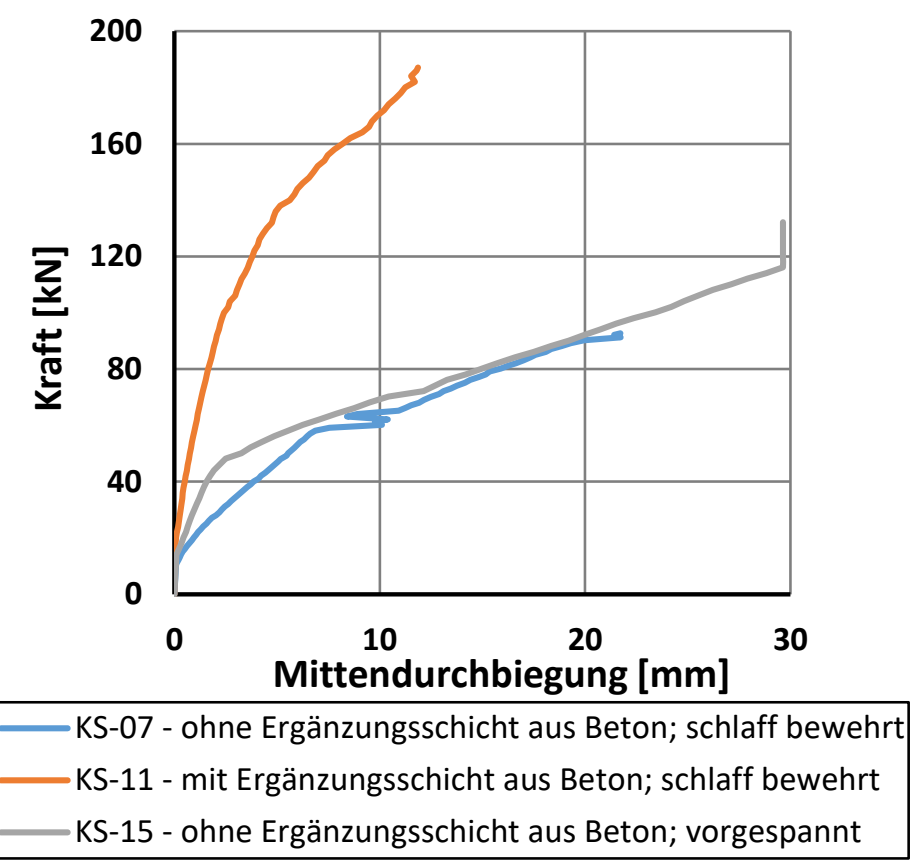

Bild 5.28 Last-Verformungslinie - Vergleichsdarstellung

Die experimentellen Untersuchungen an Mauerwerkbalken mit Ergänzungsschicht aus Beton haben gezeigt, dass bis zum Einsetzen des Schubzugbruches von einer quasi monolithischen Konstruktion ausgegangen werden kann. Die horizontale Schubfuge zwischen Mauerwerkbalken und der Ergänzungsschicht aus Beton hat trotz beidseitiger Einschnürung mittels zweilagiger Folie in keinem Fall zu einem Primärversagen geführt.

Die Untersuchungen ergaben, dass der Einfluss des Längsbewehrungsgrades auf die Querkrafttragfähigkeit mit steigender Mauerwerkdruckfestigkeit zunimmt. Bei Mauerwerk geringer Festigkeit ist dieser Einfluss von untergeordneter Bedeutung.

Im Weiteren wurde der global im Schubspannungsfeld sich einstellende Winkel der Druckstrebe ermittelt. Dieser wurde mit dem Ansatz nach Gleichung (5.2) verglichen. Eine gute Übereinstimmung mit dem im Versuch bestimmten Winkel der globalen Druckstrebe wurde festgestellt. 


\section{Ergänzende FE-Untersuchung}

In diesem Abschnitt werden die Ergebnisse von Parameteruntersuchungen vorgestellt, die unter Anwendung der Finite-Element-Methode durchgeführt wurden und die experimentellen Untersuchungen nach Abschnitten 5.3 und 5.5 ergänzen. Es werden tragfähigkeitsbestimmende Einflussgrößen quantifiziert und Ergebniswerte zur Verifizierung des Berechnungsvorschlages nach Abschnitt 7.3 verwendet.

Einflüsse auf den Querkraftwiderstand wurden in Abhängigkeit folgender Parameter untersucht:

- Längsbewehrungsgrad,

- Grad der Vorspannung,

- $\quad$ Art der Vorspannung (exzentrisch und zentrisch) und

- Schubschlankheiten von bis zu $\lambda=4,2$.

Die experimentellen Untersuchungen an vorgespannten Mauerwerkbalken nach Abschnitt 5.5 haben gezeigt, dass eine Vorspannung ohne Verbund bei einem vorwiegend auf Biegung beanspruchten Balken zu großen Durchbiegungen und Biegebeanspruchungen am Einzelstein führt; siehe Bild 5.26. Ein klassisches Schubzugversagen wurde nicht beobachtet. Um einen Schubzugbruch herbeizuführen, wird bei den FE-Berechnungen vorgespannter Mauerwerkbalken eine im Verbund liegende Spannbewehrung angenommen. Darüber hinaus wird, im Hinblick auf die Anwendung vorgespannter Balkenkonstruktionen in der Praxis, das Tragverhalten einer zentrischen Vorspannung im Vergleich zur experimentell geprüften, exzentrischen Vorspannung untersucht.

Ergänzt werden diese Untersuchungen durch die Analyse des Trag- und Verformungsverhaltens wandartiger Träger. Dabei soll der Unterschied im Tragverhalten im Vergleich zu balkenartigen Konstruktionen herausgestellt werden. Die Ergebnisse werden unter Bezugnahme auf die theoretischen Grundlagen aus Abschnitt 4.3 interpretiert.

Die Verifizierung der nichtlinearen FE- Berechnungen mit dem Programmsystem „SBETA-AT“ erfolgt für schlaff bewehrte KS-Balken an ausgewählten Prüfkörpern nach Abschnitt 5.3 und für vorgespannte KSBalken nach Abschnitt 5.5. Diese basiert auf einem Vergleich der Kraft- und Verformungswerte. SBETAAT dient ursprünglich der Berechnung von Konstruktionen aus Beton. Gleichwohl wurde es in den letzten Jahren für die Berechnung von Mauerwerk eingesetzt und deren Ergebnisse erfolgreich verifiziert (Budelmann et al. 2004; Dashkhuu 2013; Movila 2012), was dessen Anwendung in dieser Arbeit rechtfertigt.

\subsection{Verifikation des gewählten FE-Modells}

Die Voraussetzung zur Durchführung einer rechnerischen Simulation ist die Wahl einer geeigneten Modellierungsstrategie. Bei der Wahl der Modellierungsstrategie wird wie folgt unterschieden:

1. Homogene Modellierung (Makromodell),

2. Diskrete Modellierung (Mikromodell); siehe Bild 6.1.

Bezogen auf Mauerwerk beschreibt das Makromodell ein verschmiertes Ersatzkontinuum aus makroskopischen Eigenschaften des Mauerwerks. Demgegenüber werden bei der Mikromodellierung die einzelnen Mauersteine und die Fugen modelliert, was zu einer Berücksichtigung der exakten Struktur des Mauerwerkverbands führt (Schlegel 2004, S. 48).

Der Detaillierungsgrad des Mikromodells ist durch eine Unterscheidung zwischen dem vereinfachten Mikromodell und dem detaillierten Mikromodell gekennzeichnet. Bei Ersterem wird der Stein um die Fugendicke vergrößert, sodass einzelne Elemente (Blöcke) modelliert werden. Zwischen den Elementen werden Kontaktelemente (Interface) erzeugt, denen die Materialeigenschaften des verwendeten Mörtels 
zugewiesen werden. Infolge dieser Modellierungsstrategie bleiben Wechselwirkungen zwischen Mörtel und Stein unberücksichtigt. Dies führt dazu, dass den Blöcken i.d.R. nicht die Steinfestigkeit, sondern die Mauerwerkfestigkeit zugewiesen wird. Dies setzt eine Eingabe der Steine und Fugen in ihren tatsächlichen geometrischen Abmessungen voraus. Die so erzeugten Elemente werden mit den jeweiligen Materialeigenschaften versehen, sodass auch die Interaktion zwischen Steinen und Mörtel simuliert wird.

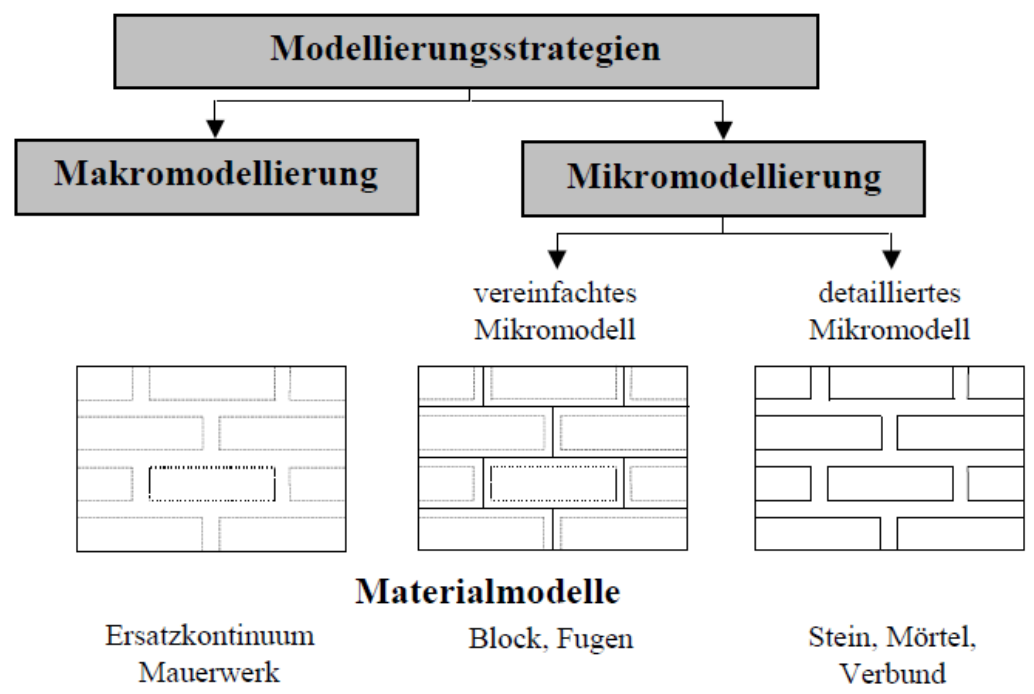

Bild 6.1 Modellierungsstrategien für FE-Berechnungen von Mauerwerk (Schlegel 2004, S. 49)

Für die hier durchgeführten Untersuchungen wurde die Strategie der vereinfachten Mikromodellierung verwendet. Den Makroelementen (Blöcken) wurden die Mauerwerkeigenschaften zugewiesen. Hierfür wurde das für die 2D-Analyse von ebenen Spannungen geeignete Materialmodell „SBETA Material“ verwendet, welches ein orthotropes, verschmiertes Rissmodell beschreibt. Für die anzugebende einaxiale Zugfestigkeit (Červenka et al. 2016, S. 26) wurde die zentrische Zugfestigkeit des Mauerwerks angesetzt.

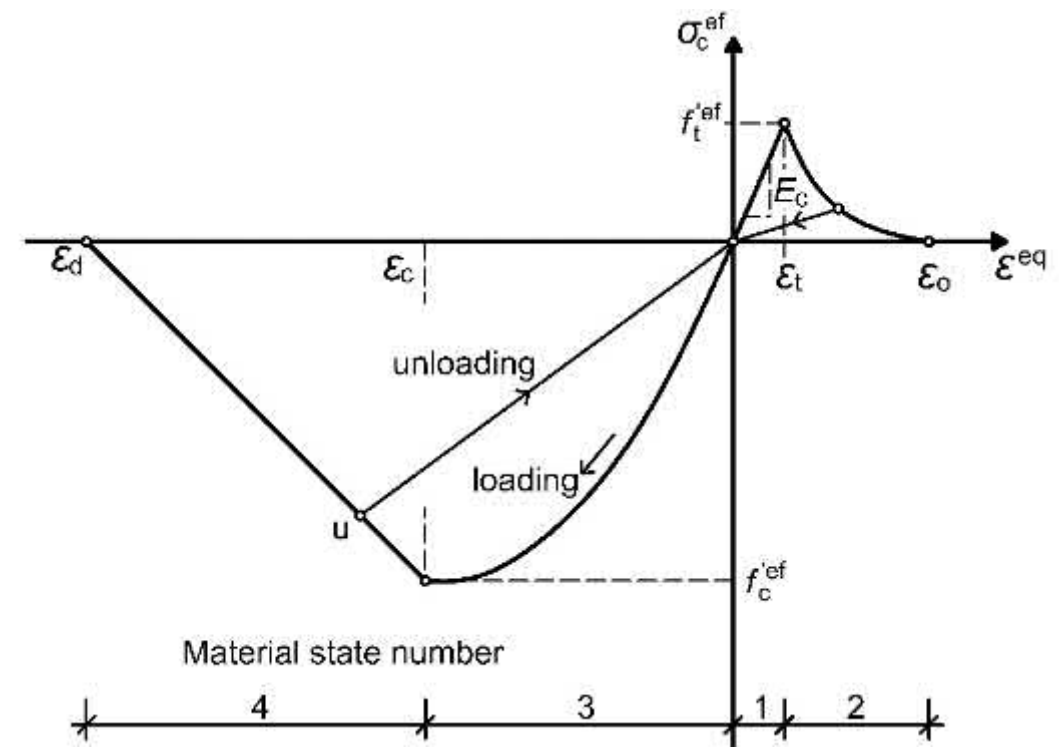

Bild 6.2 Spannungs-Dehnungslinie des verwendeten Materialmodells (Červenka et al. 2016, S. 18)

Die den FE-Rechnungen zu Grunde gelegten Materialparameter enthält Tabelle 6.1. Diese liegen in den entsprechenden Wertebereichen von Schubert (Brameshuber und Jäger 2015); siehe Abschnitt 3. 
Tabelle 6.1 FE-Rechnungen: Mauerwerkeigenschaften

\begin{tabular}{|c|c|c|c|c|c|}
\hline $\begin{array}{c}\text { Kenn- } \\
\text { zeichnung }\end{array}$ & $\begin{array}{c}\text { Druck- } \\
\text { festigkeit }^{1} \\
\boldsymbol{\beta}_{\mathrm{D}, \mathrm{mw}} \\
{\left[\mathrm{N} / \mathrm{mm}^{2}\right]}\end{array}$ & $\begin{array}{c}\text { Zugfestigkeit }{ }^{1,2} \\
\boldsymbol{\beta}_{\mathrm{z}, \mathbf{I}} \\
{\left[\mathrm{N} / \mathbf{m m}^{2}\right]}\end{array}$ & $\begin{array}{c}\text { E-Modul }^{1} \\
\text { E } \\
{\left[\mathrm{N} / \mathbf{m m}^{2}\right]}\end{array}$ & $\begin{array}{c}\text { Querdehnungszahl }{ }^{1} \\
\text { (Rechenwert) }^{1} \\
\mu_{\mathrm{D}} \\
{[-]}\end{array}$ & $\begin{array}{c}\text { Dehnung bei } \\
\text { Höchstspannung } \\
\text { (Rechenwert) } \\
\varepsilon_{\mathrm{u}, \mathrm{D}} \\
{[\mathrm{mm} / \mathrm{m}]}\end{array}$ \\
\hline $\begin{array}{c}\text { KS XL-QU } \\
20-2,0\end{array}$ & 13,1 & 0,75 & 8000 & 0,1 & 1,3 \\
\hline
\end{tabular}

Zwischen den Kontaktflächen der Makroelemente wurde jeweils ein Interface erzeugt, welches die Verbundbedingungen des Mauermörtels zwischen den Mauersteinen bzw. Makroelementen simuliert. Dieses Interface basiert auf dem Mohr-Coulomb'schen Reibungsgesetz (Bild 6.3) und lässt sich wie folgt beschreiben: Überschreiten die Schubkräfte die Hüllfläche (Bild 3.3) bzw. den Haftverbund (Haftscherfestigkeit), sind Schubkräfte nur noch über Gleitverbund übertragbar, wodurch es zu einem Kollaps des Systems kommt. Die Wertebereiche verwendeter Verbundeigenschaften sind in Abschnitt 3.2.2 angegeben. Für die FE-Rechnungen wurden Verbundeigenschaften nach Tabelle 6.2 verwendet, die iterativ durch Vergleich experimenteller Ergebnisse und solcher aus FE-Rechnungen bestimmt wurden. Der darin angegebene Reibungsbeiwert von $\mu=0,45$ wird durch das Vorliegen einer überwiegend scheibenschubartigen Beanspruchung begründet. Berücksichtigt wird die ungleichmäßige Spannungsverteilung in den Lagerfugen (Brameshuber und Jäger 2015).

Tabelle 6.2 FE-Rechnungen: Verbundeigenschaften

\begin{tabular}{|c|c|c|c|}
\hline Kennzeichnung & $\begin{array}{c}\text { Haftscherfestigkeit }^{1} \\
\boldsymbol{\beta}_{\mathbf{H S}} \\
{\left[\mathbf{N} / \mathbf{m m}^{\mathbf{2}}\right]}\end{array}$ & $\begin{array}{c}\text { Zugfestigkeit }^{1} \\
\boldsymbol{\beta}_{\mathbf{H Z}} \\
{\left[\mathbf{N} / \mathbf{m m}^{\mathbf{2}}\right]}\end{array}$ & $\begin{array}{c}\text { Reibungskoeffizient }^{\mathbf{1}} \\
\boldsymbol{\mu} \\
{[-]}\end{array}$ \\
\hline DM & 0,5 & 0,28 & 0,45 \\
\hline \multicolumn{2}{|c|}{ vgl. Wertebereiche (Brameshuber und Jäger 2015) } \\
\hline
\end{tabular}

Dem Interface sind neben den Eigenschaften des Dünnbettmörtels und den zuvor genannten Verbundeigenschaften auch die Steifigkeiten der Last-Verformungsbeziehung $K_{\mathrm{tt}}$ und $K_{\mathrm{nn}}$ zuzuweisen; siehe Bild 6.3.

Mit den folgenden Parametergrößen können die Steifigkeiten nach Gleichung (6.1) und Gleichung (6.2) ermittelt werden (Schlegel 2004, S. 129):

- Der Schubmodul der Mauersteine $G_{\mathrm{St}}$ sowie des Mauerwerkverbandes $G_{\mathrm{MW}}$,

- der Zugelastizitätsmodul der Mauersteine $E_{\mathrm{st}}$ sowie des Mauerwerkverbandes $E_{\mathrm{MW}}$ und

- die Dicke der Mauerwerkfuge $h_{\mathrm{F}}$.
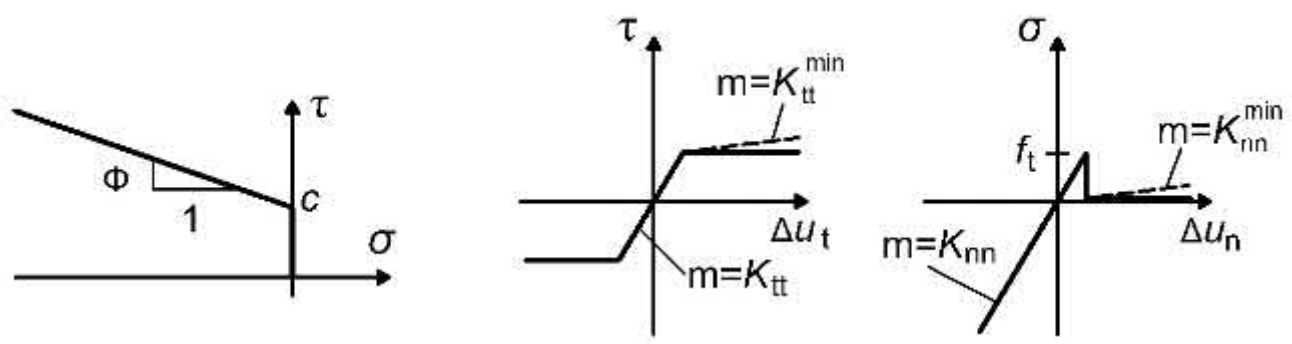

Bild 6.3 Steifigkeiten der Last-Verformungsbeziehung sowie Schub- / Zug-Verformungsverhalten des Kontaktelements; vgl. (Červenka et al. 2012, S. 55)

Die Steifigkeit $\left(k_{\mathrm{tt}}\right)$ dient der Simulation des Schubspannungs-Verformungsverhaltens der Mörtelfugen. 


$$
k_{\mathrm{tt}}=\frac{G_{\mathrm{St}} \cdot G_{\mathrm{MW}}}{h_{\mathrm{F}} \cdot\left(G_{\mathrm{St}}-G_{\mathrm{MW}}\right)}
$$

Die Steifigkeit $\left(k_{\mathrm{nn}}\right)$ dient der Simulation des Normalspannungs-Verformungsverhaltens der Mörtelfugen.

$$
k_{\mathrm{nn}}=\frac{E_{\mathrm{st}} \cdot E_{\mathrm{m}}}{h_{\mathrm{F}} \cdot\left(E_{\mathrm{St}}-E_{\mathrm{MW}}\right)}
$$

Nach Červenka (Červenka et al. 2016, S. 64) können die Steifigkeiten auch vereinfachend nach Gleichung (6.3) und (6.4) ermittelt werden. Dabei bestimmt das umgebende Material in der Kontaktfuge die Zahlenwerte des E-Moduls $(E)$ und Schubmoduls $(G)$. Untersuchungen mit dem Programmsystem SBETAAT (Movila 2012) haben gezeigt, dass für das umgebende Material die Annahme der Eigenschaften des Steinmaterials zu guten Ergebnissen führen.

$$
\begin{aligned}
& k_{\mathrm{tt}}=\frac{G}{h_{\mathrm{F}}} \\
& k_{\mathrm{nn}}=\frac{E}{h_{\mathrm{F}}}
\end{aligned}
$$

Für die hier durchgeführten FE-Rechnungen wurden Steifigkeitskennwerte nach Tabelle 6.3 verwendet, die in Anlehnung an das vereinfachte Verfahren bestimmt wurden.

Tabelle 6.3 Interface: Parameter und Steifigkeiten

\begin{tabular}{|c|c|c|c|c|c|}
\hline $\begin{array}{c}\text { Art der } \\
\text { Mauersteine }\end{array}$ & $\begin{array}{c}\boldsymbol{h}_{\mathbf{f}} \\
{[\mathbf{m}]}\end{array}$ & $\begin{array}{c}\boldsymbol{k}_{\mathrm{tt}} \\
{\left[\mathbf{M N} / \mathbf{m}^{3}\right]}\end{array}$ & $\begin{array}{c}\boldsymbol{k}_{\mathbf{t t}}^{\min } \\
{\left[\mathbf{M N} / \mathbf{m}^{3}\right]}\end{array}$ & $\begin{array}{c}\boldsymbol{k}_{\mathbf{n n}} \\
{\left[\mathbf{M N} / \mathbf{m}^{3}\right]}\end{array}$ & $\begin{array}{c}\boldsymbol{k}_{\mathbf{n n}}^{\min } \\
{\left[\mathbf{M N} / \mathbf{m}^{3}\right]}\end{array}$ \\
\hline $\mathrm{KS}$ & 0,00267 & $0,3 \times 10^{6}$ & $0,2 \times 10^{6}$ & $3 \times 10^{6}$ & $0,2 \times 10^{6}$ \\
\hline
\end{tabular}

Zur Verifikation der eingegebenen Materialparameter und der verwendeten Modellierungsstrategie wurden Vergleichsrechnungen mit Abmessungen und Materialkennwerten der experimentell untersuchten Mauerwerkbalken nach Abschnitt 5.2 und 5.5 durchgeführt. Bild 6.4 zeigt das in SBETA-AT erzeugte FEModell beispielhaft für den Mauerwerkbalken KS-07.

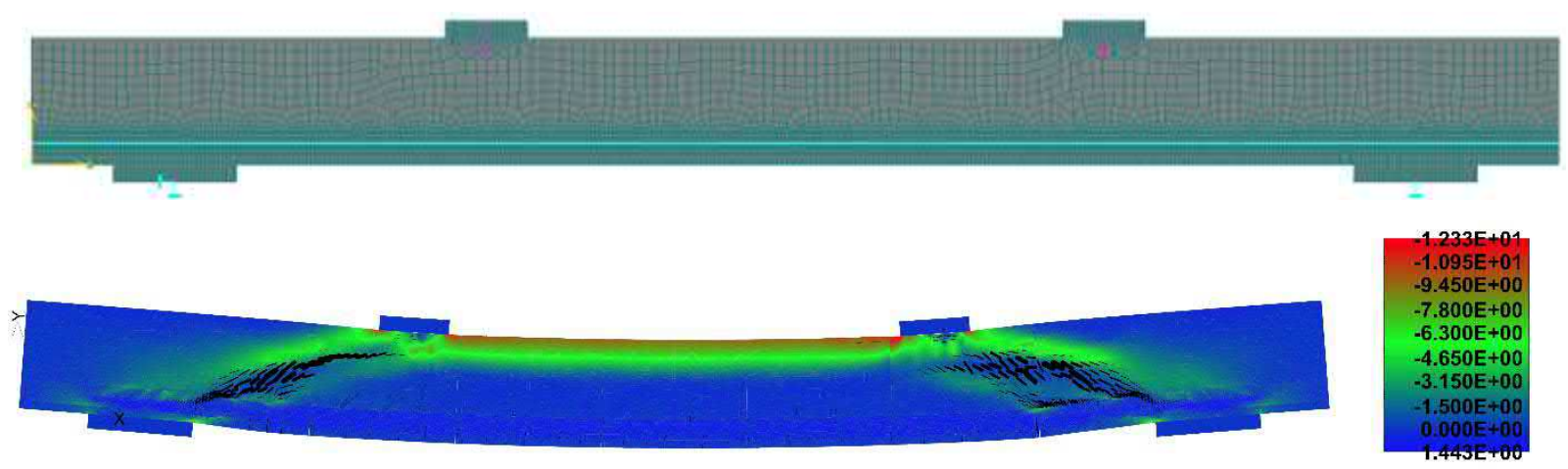

Bild 6.4 Mauerwerkbalken KS-07: FE-Netz (oben); Längsspannungen $\sigma_{\mathrm{x}}$ im Zustand II (unten)

Die durch Vergleichsrechnungen ermittelten Last-Durchbiegungslinien sind in Bild 6.5 dargestellt. Durchgezogene Linien sind Ergebnisse experimenteller Untersuchungen, gestrichelte Kurvenzüge sind Resultat durchgeführter FE-Berechnungen. Die Gegenüberstellung zeigt für Mauerwerkbalken unterschiedlicher Geometrieabmessungen gute Übereinstimmung. Dies gilt sowohl für schlaff bewehrte (KS-06 und KS-07) als auch vorgespannte Balken (KS-14 und KS-15). Sowohl Durchbiegungen als auch Traglasten weichen nur geringfügig voneinander ab. Das Ergebnis der FE-Simulationen rechtfertigt eine weitere Verwendung des FE-Modells im Rahmen der in dieser Arbeit durchgeführten Parameterstudie. 


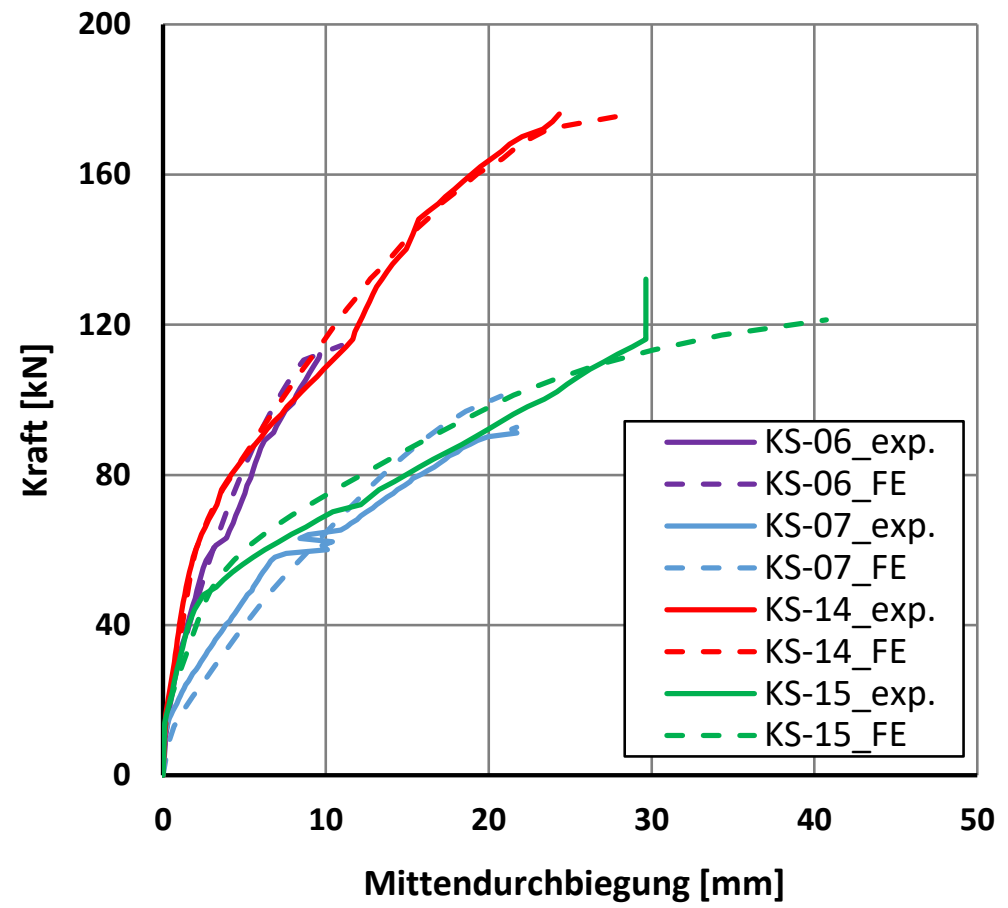

Bild 6.5 Vergleichsdarstellung zwischen exp. und theor. ermittelten Last-Durchbiegungslinien schlaff bewehrter (KS-06 und KS-07) und vorgespannter (KS-14 und KS-15) Mauerwerkbalken

\subsection{Parameterstudie}

Dieser Abschnitt enthält Ergebnisse durchgeführter FE-Parameterrechnungen, die aufgrund des begrenzten Umfangs an Einzelversuchen im Rahmen experimenteller Untersuchungen nach Abschnitt 5 nicht durchgeführt wurden. In Tabelle 6.4 ist eine Zusammenfassung untersuchter Parameter und deren Wertebereiche dargestellt.

Tabelle 6.4 Untersuchungsprogramm durchgeführter Parameterrechnungen

\begin{tabular}{|l|ll|}
\hline \multirow{4}{*}{ Schlaff bewehrte MW-Balken } & Bewehrungsgrad $\rho=\frac{A_{\mathrm{s}} \cdot 1000}{b \cdot d}:$ & $1,5 \ldots 6,7[\% \mathrm{o}]$ \\
& Bewehrungsdurchmesser: & $12 \ldots 25[\mathrm{~mm}]$ \\
\cline { 2 - 3 } & Schubschlankheit: & bis $4,2[-]$ \\
\hline \multirow{3}{*}{ Vorgespannte MW-Balken } & Höhe exzentrischer Vorspannung: & $0 \ldots 80[\mathrm{KN}]$ \\
\cline { 2 - 3 } & Höhe zentrischer Vorspannung: & $0 \ldots 80[\mathrm{KN}]$ \\
\cline { 2 - 3 } & Schubschlankheit: & bis 4,2 [-] \\
\hline
\end{tabular}

Die untersuchten Parameter sind Einflussgrößen der in Abschnitt 7.1 vorgestellten Schubtheorie „SMCFT“, deren Adaption auf Mauerwerk es zu prüfen gilt; siehe Abschnitt 7.2. Das Spektrum des untersuchten Stabstahldurchmessers der Spannbewehrung liegt zwischen 12 und 25 mm. Auch im Fall vorgespannter Mauerwerkbalken mit Schubschlankheiten von bis zu 4,2 wird dies als ausreichend angesehen. Größere Bewehrungsdurchmesser und damit verbundene Bewehrungsgrade sind nicht wirtschaftlich und baupraktisch von Nachteil. Die Schubschlankheit wurde bis auf einen Wert von $\lambda \leq 4,2$ begrenzt, sodass sich mindestens zwei Vertikalfugen im Bereich des Schubfeldes befinden. Im Hinblick auf die Höhe der Vorspannkraft wurde eine Grenzvorspannung von $80 \mathrm{kN}$ gewählt, bei der die Oberseite des Balkenquerschnittes gerade nicht dekomprimiert. Detaillierte Angaben und Erläuterungen sind den folgenden Abschnitten zu entnehmen.

\subsubsection{Schlaff bewehrte Balken}

Die Ergebnisse der FE-Untersuchungen an schlaff bewehrten Mauerwerkbalken sind Gegenstand dieses Abschnittes. Die Geometrien untersuchter Mauerwerkbalken sind in Tabelle 6.5 angegeben. Dabei 
entsprechen die Abmessungen der Prüfkörper KS-05, KS-06 und KS-07 den in Abschnitt 5.2 experimentell untersuchten Konstruktionen. KS-4,1 und KS-5,1 wurden mit dem Ziel modelliert, auch für Mauerwerkbalken großer Schubschlankheiten eine Aussage über die Querkrafttragfähigkeit treffen zu können.

Tabelle 6.5 Abmessungen untersuchter Balkenkonstruktionen

\begin{tabular}{|c|c|c|c|c|c|c|}
\hline \multirow{2}{*}{ Versuchs-Bez. } & \multicolumn{3}{|c|}{ Querschnittswerte [mm] } & \multicolumn{2}{|c|}{$\begin{array}{c}\text { Prüfkörperlänge } \\
\text { [m] }\end{array}$} & \multirow{2}{*}{$\begin{array}{c}\begin{array}{c}\text { Schubschlankheit } \\
{[-]}\end{array} \\
\lambda\end{array}$} \\
\hline & $h$ & $d$ & $t$ & $l$ & $l_{\text {eff }}$ & \\
\hline KS-05 & \multirow{5}{*}{373} & \multirow{5}{*}{306} & \multirow{5}{*}{240} & 3,24 & 2,40 & 2,0 \\
\hline KS-06 & & & & 3,24 & 2,40 & 2,0 \\
\hline KS-07 & & & & 4,48 & 3,64 & 3,0 \\
\hline KS-4,1 & & & & 4,14 & 3,78 & 3,4 \\
\hline KS-5,1 & & & & 5,14 & 4,78 & 4,2 \\
\hline
\end{tabular}

In Bild 6.6 ist das FE-Modell eines schlaff bewehrten Mauerwerkbalkens am Beispiel des Versuchskörpers KS-5,1 dargestellt.

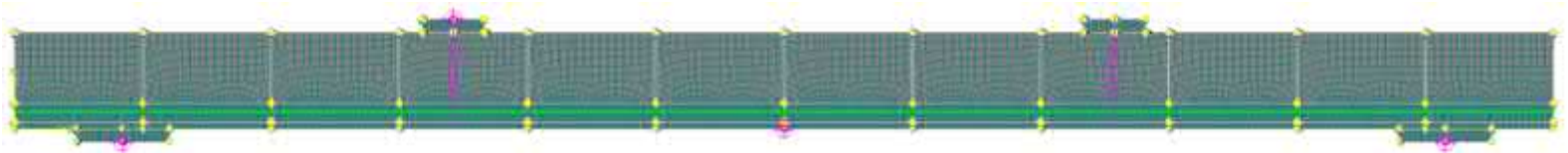

Bild 6.6 FE-Modell des Mauerwerkbalkens KS-5,1; erstellt mittels Programmsystem SBETA-AT

\subsubsection{Bewehrungsgrad und Längsdehnungseinfluss}

Die Höhe des Längsbewehrungsgrades beeinflusst die Querkrafttragfähigkeit von Mauerwerkbalken; siehe Abschnitt 5.3.3. In der SMCFT wird dieser Einfluss über Längsdehnungen berücksichtigt; siehe Abschnitt 7.1.2 (Gleichung (7.29) bzw. (7.30)). Hierdurch wird der Verformungszustand der Konstruktionsarten wirklichkeitsnah erfasst. Für Mauerwerkbalken ist zu prüfen, ob dieser Einfluss in vergleichbarer Weise anzunähern ist. Daher wurden zur Quantifizierung FE-Berechnungen an Mauerwerkbalken mit Geometrien nach Tabelle 6.5 durchgeführt. Der Bewehrungsgrad der Mauerwerkbalken lag dabei zwischen $\rho=$ 1,7 ... 6,7 [\%o] und ist in Form von Stabdurchmessern in Tabelle 6.6 angegeben. Es wurden ausschließlich Balkenprüfungen ausgewertet, bei denen ein Schubzugversagen innerhalb des Schubspannungsfeldes aufgetreten ist; Ergebnisse infolge Biegeversagen wurden nicht in die Auswertung einbezogen; Erläuterungen siehe Tabelle 6.5.

Tabelle 6.6 Untersuchungsprogramm: Verwendete Stabdurchmesser

\begin{tabular}{|c|c|c|c|}
\hline $\begin{array}{c}\text { Stabdurchmesser } \\
{[\mathrm{mm}]}\end{array}$ & KS-05 & KS-06 & KS-07 \\
\hline 12 & $X^{2)}$ & -1) & -1) \\
\hline 14 & $\mathrm{X}^{2)}$ & _1) & _1) \\
\hline 16 & $X^{2)}$ & $\mathrm{X}^{2)}$ & -1) \\
\hline 20 & $X^{2)}$ & $\mathrm{X}^{2)}$ & $X^{2)}$ \\
\hline 25 & $\mathrm{X}^{2)}$ & $\mathrm{X}^{2)}$ & $\mathrm{X}^{2)}$ \\
\hline
\end{tabular}

In Bild 6.7 ist der Einfluss zunehmenden Bewehrungsgrades auf die Querkrafttragfähigkeit dargestellt. Mit größer werdendem Bewehrungsgrad nimmt die Querkrafttragfähigkeit zu. Der Einfluss ist annähernd 
linear. Dieses Verhalten wird in dem Berechnungsvorschlag rechnerisch über den Dehnungseinfluss der Bewehrung, bezogen auf die halbe Querschnittshöhe der Konstruktion, berücksichtigt; siehe Gleichung (7.29). Im Weiteren enthält das Diagramm Einzelwerte bezogener Querkrafttragfähigkeiten experimentell untersuchter Mauerwerkbalken (rote Punkte), die in Abhängigkeit des jeweiligen Bewehrungsgrades dargestellt sind. Ein Vergleich mit den Ergebnissen der Parameteruntersuchungen zeigt eine gute Übereinstimmung. Die FE-Untersuchungen an dem Mauerwerkbalken KS-07 mit Bewehrungsdurchmessern $\leq 20 \mathrm{~mm}(\rho=4,28[\%])$ haben zu einem Biegeversagen geführt. Dies gilt ebenfalls für den Prüfkörper KS-06 mit einem Durchmesser $\leq 16 \mathrm{~mm}(\rho=2,74$ [\%o]). Die daraus erhaltenden Ergebnisse sind nicht dargestellt, da diese für die vorliegende Aufgabenstellung keine Aussagekraft haben.

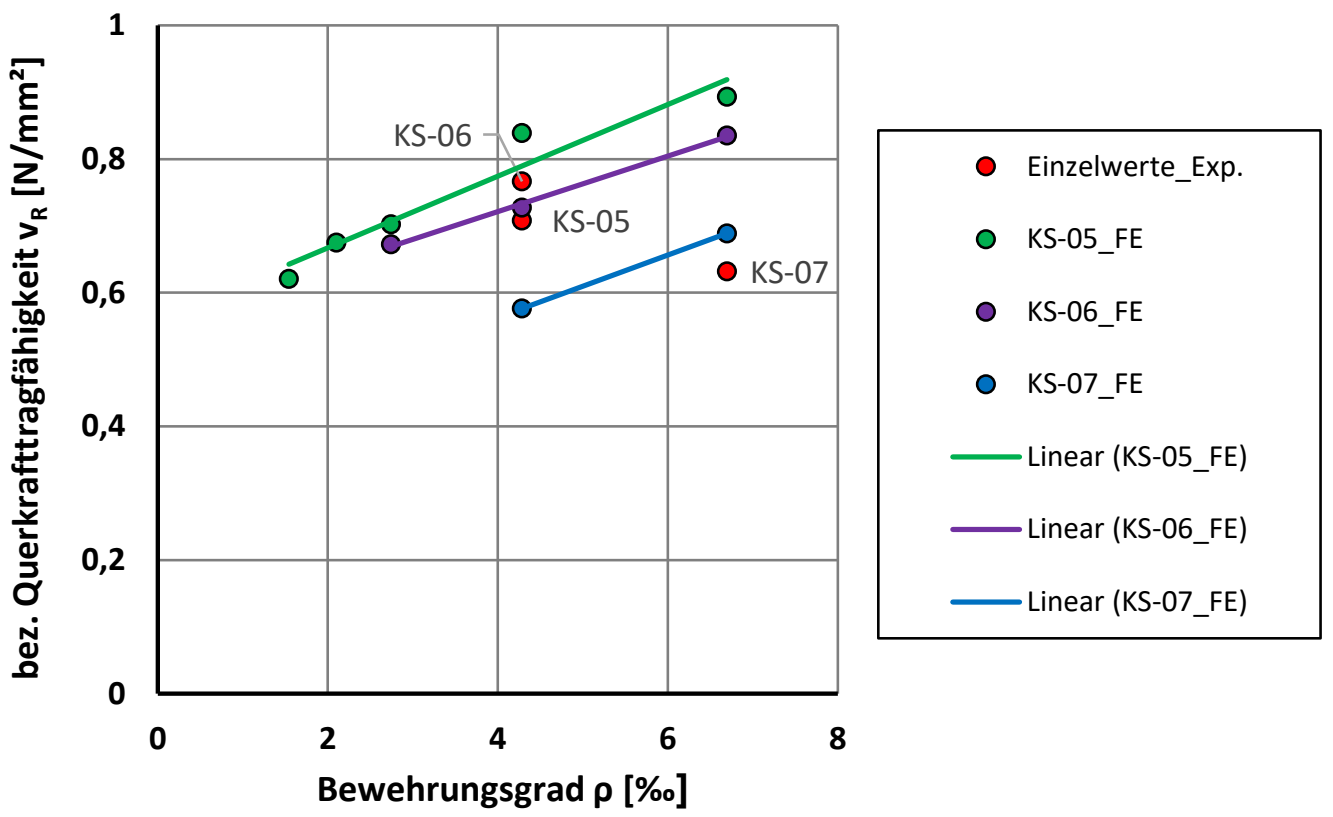

\section{Bild 6.7 Bewehrungsgrad in Abhängigkeit zur bez. Querkrafttragfähigkeit}

In Bild 6.8 ist der rechnerische Dehnungseinfluss $\left(\varepsilon_{\mathrm{x}}\right)$ nach Gleichungen von (7.29) bzw. (7.30) in Abhängigkeit zur bezogenen Querkrafttragfähigkeit dargestellt. Die rechnerische Dehnung $\left(\varepsilon_{\mathrm{x}}\right)$ ist dabei die Längsdehnung in halber Querschnittshöhe des Balkens. Gezeigt ist eine Zunahme der rechnerisch ermittelten Dehnung bei abnehmendem Bewehrungsgrad. Dies hat zur Folge, dass die bezogene Querkrafttragfähigkeit bei zunehmender Dehnung abnimmt. Die Analyse verdeutlicht die indirekte Erfassung des Bewehrungsgrades über den rechnerischen Ansatz von Gleichung (7.29) bzw. (7.30). Ein Vergleich zwischen Bild 6.7 und Bild 6.8 zeigt, dass die ursprünglich für Stahlbeton entwickelten Algorithmen auch auf Mauerwerk übertragbar sind. Der Bewehrungsgrad kann über die Berücksichtigung der rechnerischen Dehnung erfasst werden. Mit der Kenntnis über die Auswirkung dieses Einflusses auf das Tragverhalten bzw. die Tragfähigkeit wächst die Bedeutung einer möglichen Vorspannung nach Abschnitt 6.2.2, die zu einer Reduzierung der Längsdehnungen führt. In Bild 6.8 bleiben Ergebniswerte infolge Biegeversagen ebenfalls unberücksichtigt. 


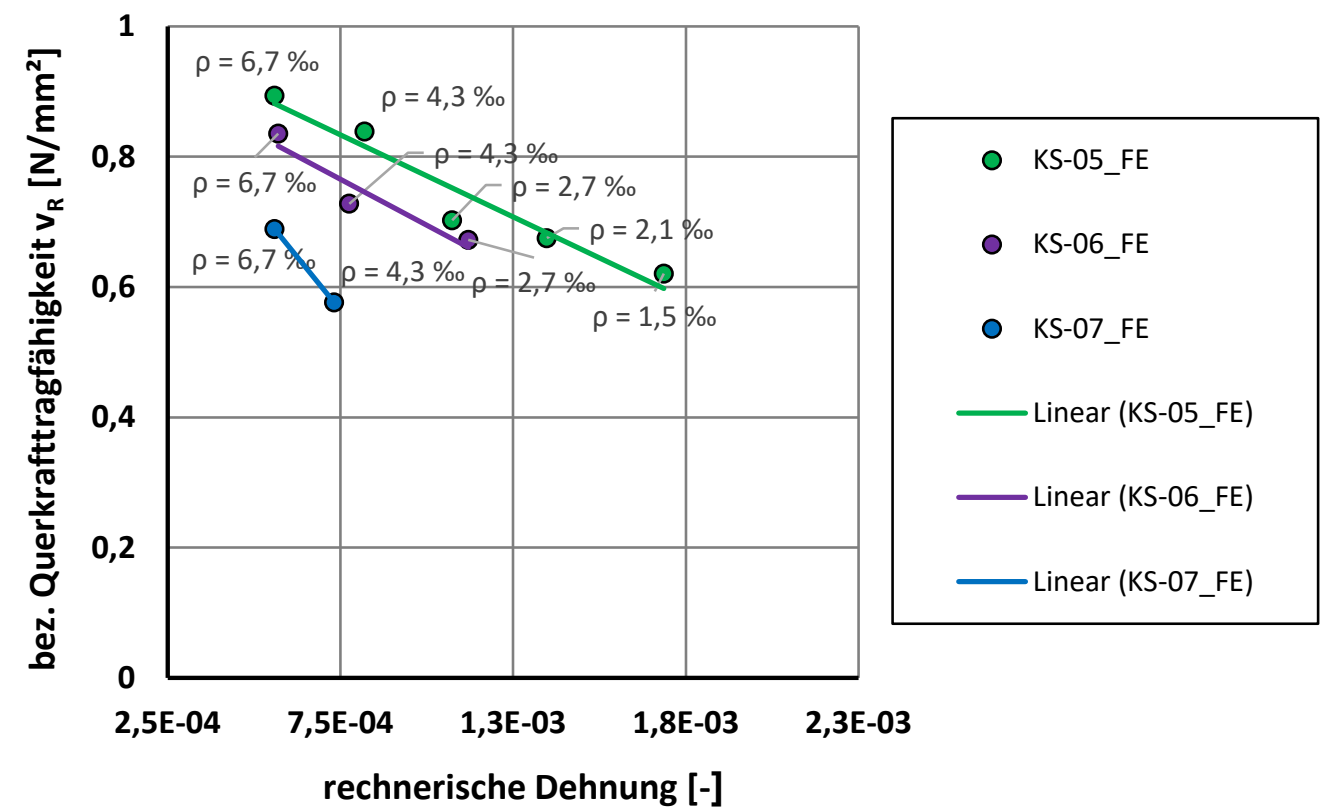

Bild 6.8 Rechnerische Dehnung in Abhängigkeit zur bez. Querkrafttragfähigkeit

\subsubsection{Schubschlankheit}

Die Schubschlankheit hat einen erheblichen Einfluss auf die Größe des Querkraftwiderstandes. Bis zu einer Schubschlankheit von $\lambda \approx 3$ kann dieser Einfluss durch die Gleichung (4.16), zur Berücksichtigung auflagernaher Einzellasten, ausreichend gut erfasst werden; siehe Abschnitt 5.3.2. Um darüber hinaus das Anwendungsfeld von Mauerwerkbalken zu erweitern, wurde in den FE-Berechnungen die Schubschlankheit auf bis zu $\lambda=4,2$ erweitert und die Auswirkungen auf das Tragverhalten analysiert. Diesen Aspekt begleitend wurde der bisher ausschließlich über die Rissneigung bestimmte globale Druckstrebenwinkel mit Erkenntnissen aus den FE-Rechnungen verglichen. Die Ergebnisse werden nachfolgend vorgestellt.

In Tabelle 6.7 sind die Ergebnisse der numerischen Untersuchungen durch flächenhafte Darstellung der Spannungen in horizontaler $\left(\sigma_{\mathrm{x}}\right)$ und vertikaler $\left(\sigma_{\mathrm{y}}\right)$ Richtung der Balkenkonstruktionen dargestellt. Das entscheidende Versagenskriterium wird in sämtlichen untersuchten Fällen durch einen eintretenden Schubzugbruch bestimmt. Die Schubrisse verlaufen diagonal und kreuzen das jeweilige Schubspannungsfeld zwischen dem Auflager- und Lasteinleitungspunkt. 
Tabelle 6.7 Flächenhafte, qualitative Darstellung der Spannungen in horizontaler $\sigma_{\mathrm{x}}$ und vertikaler $\sigma_{\mathrm{y}}$ Richtung numerisch untersuchter, schlaff bewehrter Balkenkonstruktionen nach Tabelle 6.5

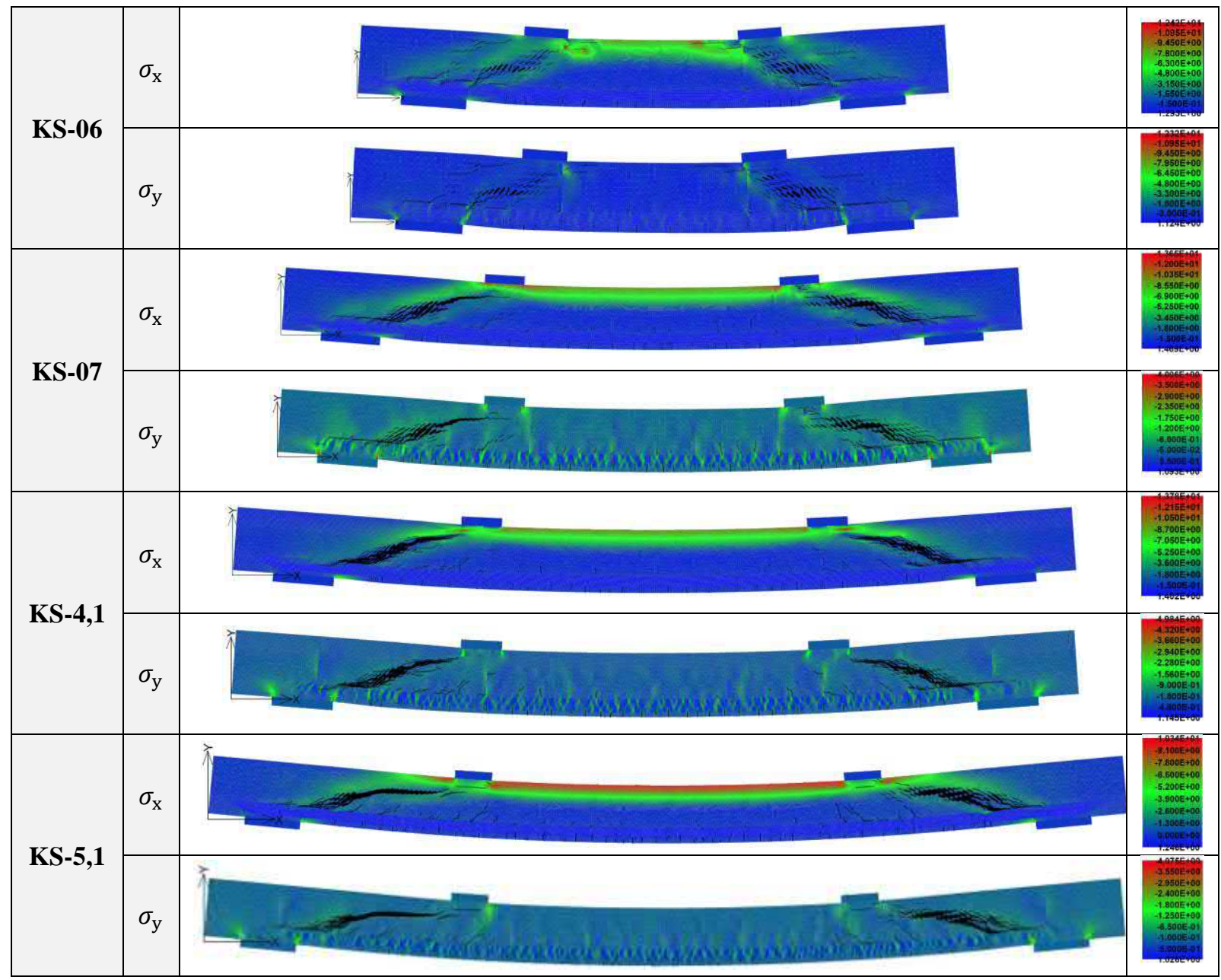

In Bild 6.9 ist die Querkrafttragfähigkeit in Abhängigkeit zur Schubschlankheit numerisch untersuchter, schlaff bewehrter Balkenkonstruktionen nach Tabelle 6.5 dargestellt. Ergänzend dazu ist der Funktionsverlauf zur Berücksichtigung auflagernaher Einzellasten nach Gleichung (4.16) angegeben. Mit zunehmender Schubschlankheit tendiert die Querkrafttragfähigkeit der untersuchten Mauerwerkbalken gegen einen konstanten Wert; siehe Bild 6.9. Dies entspricht den theoretischen Überlegungen aus Abschnitt 2.4 und 4.2.6 sowie den experimentellen Untersuchungen aus Abschnitt 5.3.2, wonach der Einfluss der Schubschlankheit mit zunehmender Balkenlänge abnimmt. 


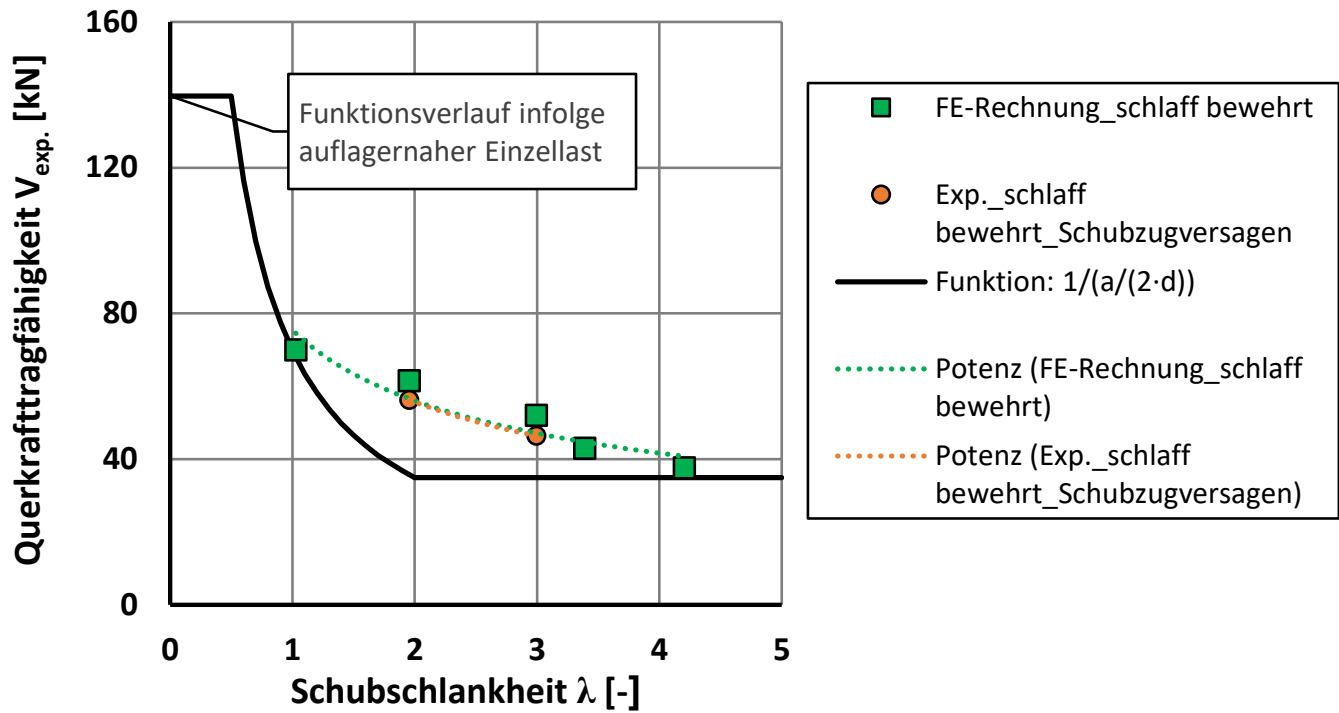

Bild 6.9 Schubschlankheit in Abhängigkeit zur Querkrafttragfähigkeit numerisch untersuchter, schlaff bewehrter Balkenkonstruktionen mit Angabe der Funktion ,auflagernaher Einzellasten“"

Das Ergebnis theoretischer Überlegungen zur Berücksichtigung der Schubschlankheit über die Wirkungsweise einer auflagernahen Einzellast im Bereich 0,5 $\cdot \mathrm{d} \leq a<2 \cdot \mathrm{d}$ (Gleichung (4.16)) ist in Bild 6.10 dargestellt. Dabei sind die nach Gleichung (4.16) reduzierten Querkrafttragfähigkeiten numerisch untersuchter, schlaff bewehrter Balkenkonstruktionen aus Kalksandsteinmauerwerk nach Tabelle 6.5 in Abhängigkeit zur Schubschlankheit dargestellt. Die Querkrafttragfähigkeit der Balkenkonstruktionen unterschiedlicher Schubschlankheit weist dabei einen nahezu konstanten Wert auf, was die rechnerische Annahme bestätigt.

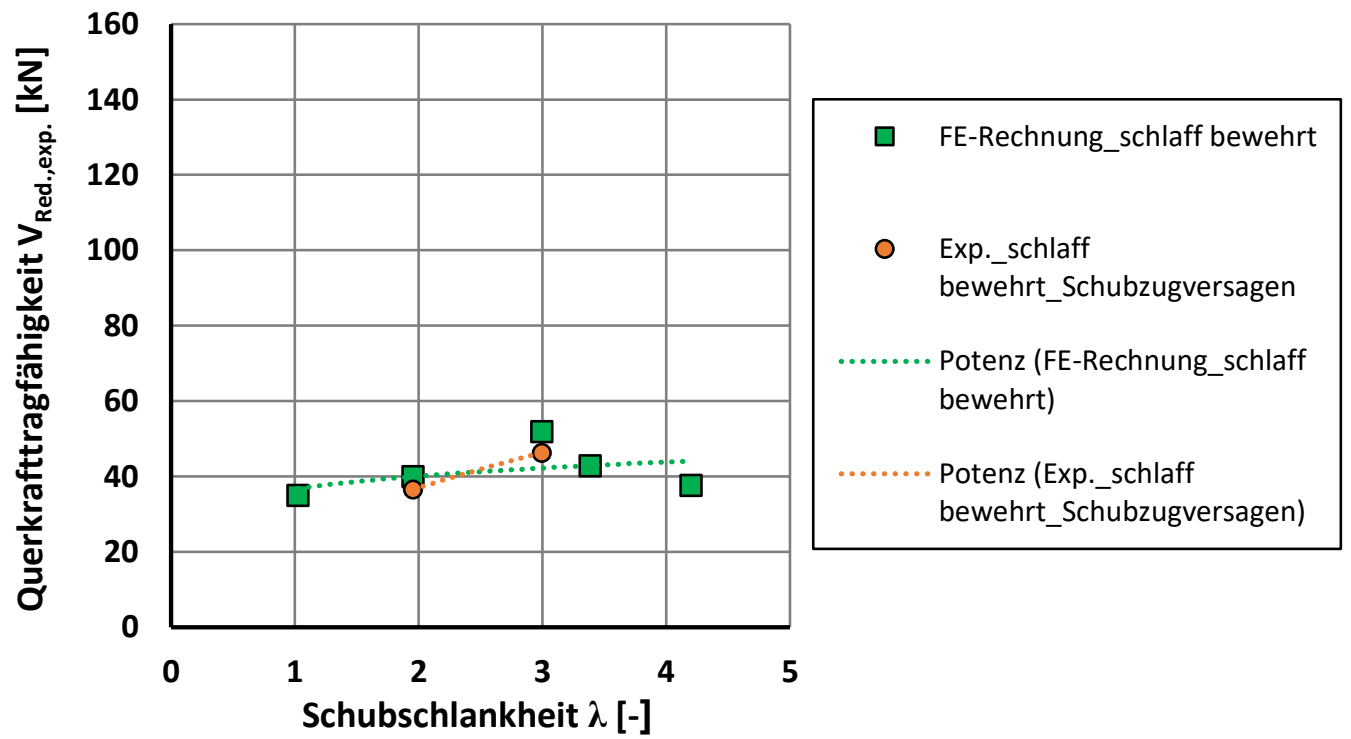

Bild 6.10 Darstellung der Schubschlankheit in Abhängigkeit zur reduzierten Querkrafttragfähigkeit unter Berücksichtigung des Schubschlankheitseinflusses

Der jeweilige, innerhalb der Schubfelder global verlaufende Druckstrebenwinkel, wurde nach Verifikation mit den experimentellen Untersuchungen mit Gleichung (5.2) bestimmt; siehe Abschnitt 5.3.5. Dabei wurde der Verlauf der Druckstrebe an den Verlauf des Schubrisses orientiert. Zur weiteren Verifikation dieses Vorgehens werden die in Tabelle 6.8 dargestellten Schubfelder untersuchter Mauerwerkbalken mit Darstellung der Längsdruckspannungen und der Schubrissbildung interpretiert. Es hat sich in allen Fällen ein Druckspannungsfeld ausbildet, bei dem die Rissneigung tangential zur Druckstrebe verläuft. Dies bestätigt die aus den experimentellen Untersuchungen gewonnenen Erkenntnisse. Der Verlauf der globalen Druckstrebe wird somit vereinfachend über die Rissneigung ausreichend gut beschrieben. 
Tabelle 6.8 Flächenhafte, qualitative Darstellung der Längsdruckspannungen numerisch untersuchter, schlaff bewehrter Balkenkonstruktionen nach Tabelle 6.5

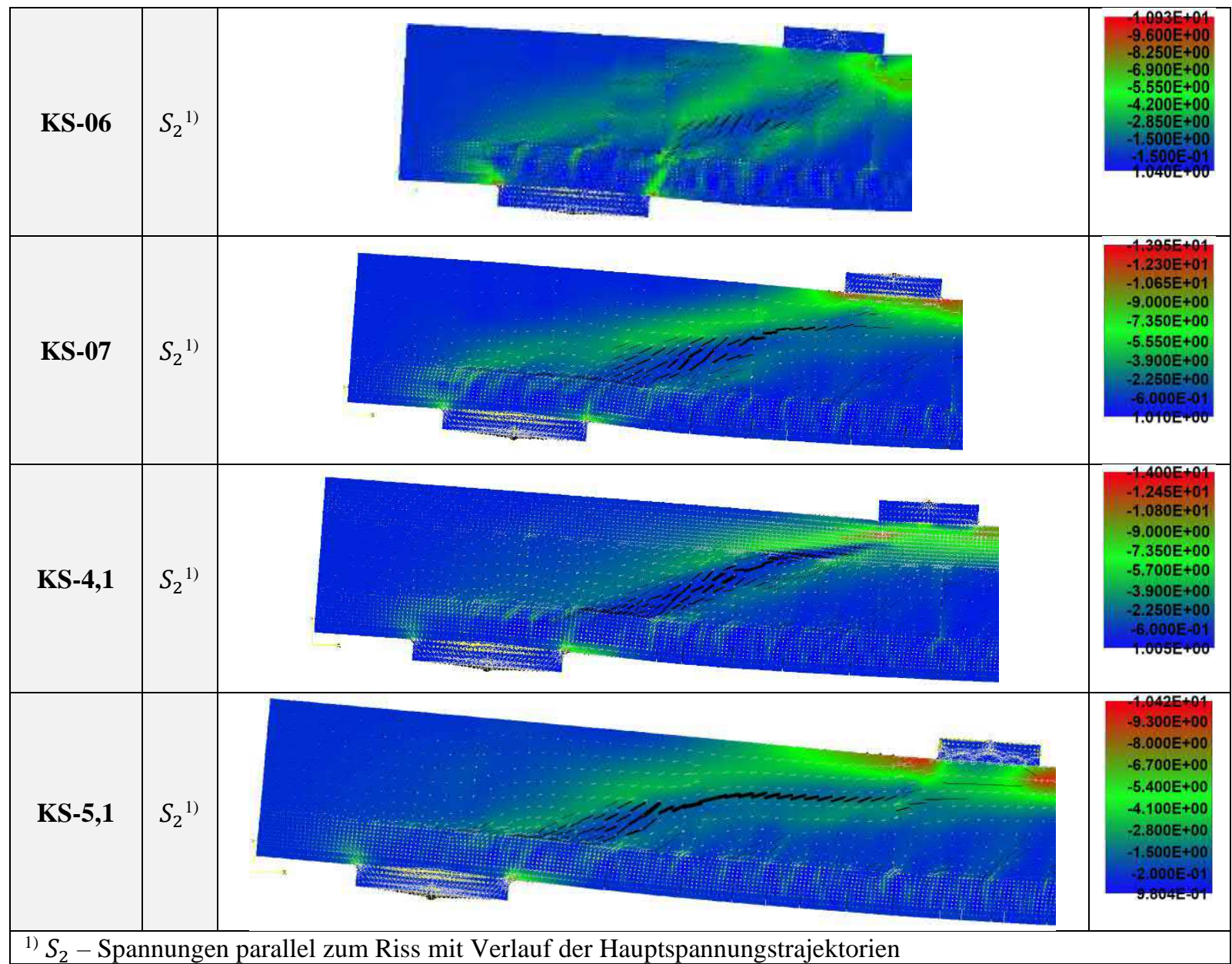

Gleichwohl trifft die bisherige Annahme zur Ermittlung des Druckstrebenwinkels nach Gleichung (5.2) nicht für den gesamten Schubschlankheitsbereich zu. Vielmehr ist Tabelle $6.8 \mathrm{zu}$ entnehmen, dass der jeweilige Schubriss der Prüfkörper KS-4.1 und KS-5.1 von Vorderkante der Lasteinleitung bis zur Vorderkante des Auflagers verläuft und nicht, wie bei den Prüfkörpern KS-06 und KS-07 im Mittel vom Zentrum des Auflagers bis zur Mitte der Lasteinleitung. Dieser Einfluss ist wesentlich für den in Abschnitt 7 entwickelten Berechnungsansatz. Dabei wird für die Ermittlung des Querkraftwiderstandes die Drucktragfähigkeit des anisotropen Mauerwerks unter einem Neigungswinkel $\alpha$, der im vorliegenden Fall dem Druckstrebenwinkel $\Theta$ entspricht, ermittelt. Für die rechnerische Berücksichtigung in dem Berechnungsvorschlag wird auf Abschnitt 7.3 bzw. Gleichung (7.44) verwiesen.

\subsubsection{Vorgespannte Balken}

Die in Abschnitt 5.5 durchgeführten experimentellen Untersuchungen an exzentrisch vorgespannten Mauerwerkbalken ergänzend, wurde im Folgenden der Einfluss durch die Größe der Vorspannkraft auf die Querkrafttragfähigkeit von Balkenkonstruktionen variierender Schubschlankheiten untersucht. Die unterschiedlichen Varianten sind dem Untersuchungsprogramm nach Tabelle 6.9 zu entnehmen. 
Tabelle 6.9 Untersuchungsprogramm: Einfluss exzentrischer Vorspannkraft

\begin{tabular}{|c|c|c|c|c|c|c|c|}
\hline $\begin{array}{c}\text { Vorspannkraft } \\
{[\mathrm{kN}]}\end{array}$ & $\begin{array}{c}\text { Durchmesser } \\
\text { Bewehrung } \\
{[\mathrm{mm}]}\end{array}$ & $\begin{array}{c}\text { Art der } \\
\text { Vorspannung }\end{array}$ & KS-05 & KS-06 & KS-07 & KS-4,1 & KS-5,1 \\
\hline 5 & $1 \times 25$ & exzentrisch & $\mathrm{X}^{1)}$ & $\mathrm{X}$ & $\mathrm{X}$ & $\mathrm{X}$ & $\mathrm{X}$ \\
\hline 10 & $1 \times 25$ & exzentrisch & $\mathrm{X}$ & $\mathrm{X}$ & $\mathrm{X}$ & $\mathrm{X}$ & $\mathrm{X}$ \\
\hline 20 & $1 \times 25$ & exzentrisch & $\mathrm{X}$ & $\mathrm{X}$ & $\mathrm{X}$ & $\mathrm{X}$ & $\mathrm{X}$ \\
\hline 60 & $1 \times 25$ & exzentrisch & $\mathrm{X}$ & $\mathrm{X}$ & $\mathrm{X}$ & $\mathrm{X}$ & $\mathrm{X}$ \\
\hline 80 & $1 \times 25$ & exzentrisch & $\mathrm{X}$ & $\mathrm{X}$ & $\mathrm{X}$ & $\mathrm{X}$ & $\mathrm{X}$ \\
\hline
\end{tabular}

Die experimentell durchgeführten Untersuchungen nach Abschnitt 5 haben gezeigt, dass es bei Vorspannung ohne Verbund ( VoV) und Verzicht auf schlaffe Bewehrung zu einem frühzeitigen, starken Aufklaffen der Vertikalfugen kommt, welche die Druckzone einschnüren. Eine durch Rombach gezeigte Gegenüberstellung zwischen Vorspannung mit und ohne Verbund bestätigt dies; siehe Bild 6.11. Anders ist dies bei Vorspannung mit Verbund $(\mathrm{VmV})$; hier wird ein weiteres Aufreißen durch die Bewehrung verhindert. Für die in diesem Abschnitt untersuchten Balken wird daher eine im Verbund liegende Vorspannung gewählt. Die Lage der Spannglieder im Querschnitt ist äquivalent zu den Untersuchungen aus Abschnitt 5.5.

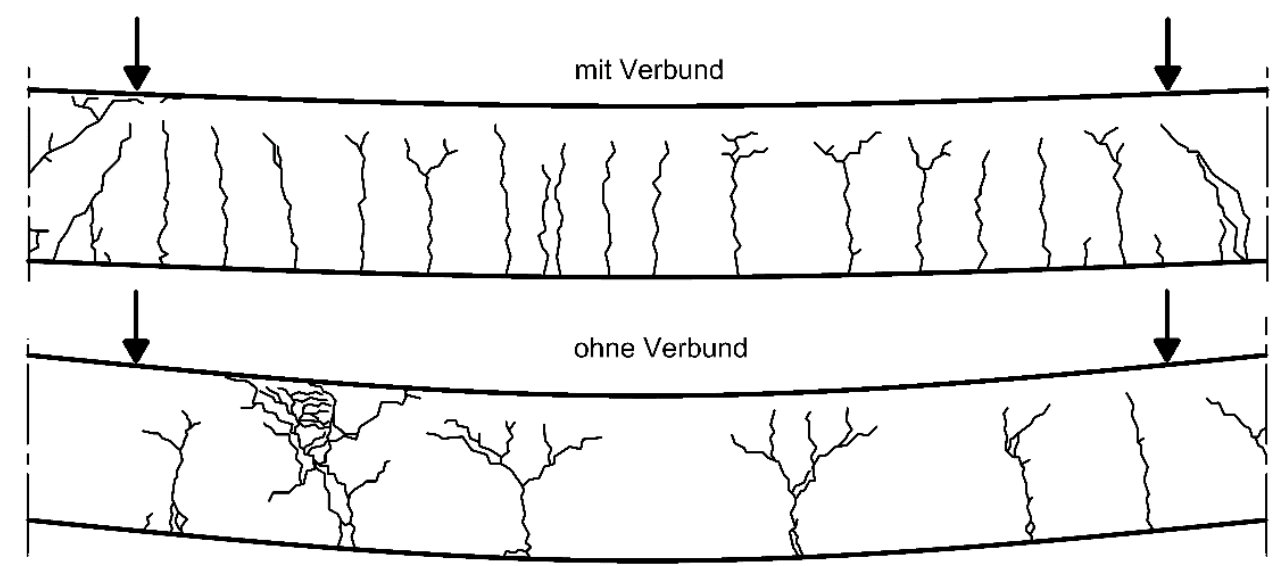

Bild 6.11 Rissbildung biegebeanspruchter Balken unter Vorspannung mit Verbund (oben) und Vorspannung ohne Verbund (unten); siehe (Rombach 2010, S. 54)

\subsubsection{Verformungsverhalten und Bruchzustand}

Das Last-Verformungsverhalten der experimentell untersuchten, ohne Verbund vorgespannten Mauerwerkbalken wurde u.a. in Bild 6.5 mit einem solchen schlaff bewehrten Mauerwerkbalkens verglichen. Die Abweichungen im Verformungsverhalten zwischen VoV (exp. und FE) und VmV (FE) zeigen sich neben der oben beschriebenen unterschiedlichen Rissbildung auch in unterschiedlich steifen Durchbiegungsverläufen; siehe Bild 6.12. Mauerwerkbalken mit Vorspannung mit Verbund zeigen geringere Durchbiegungen als solche mit Vorspannung ohne Verbund. 


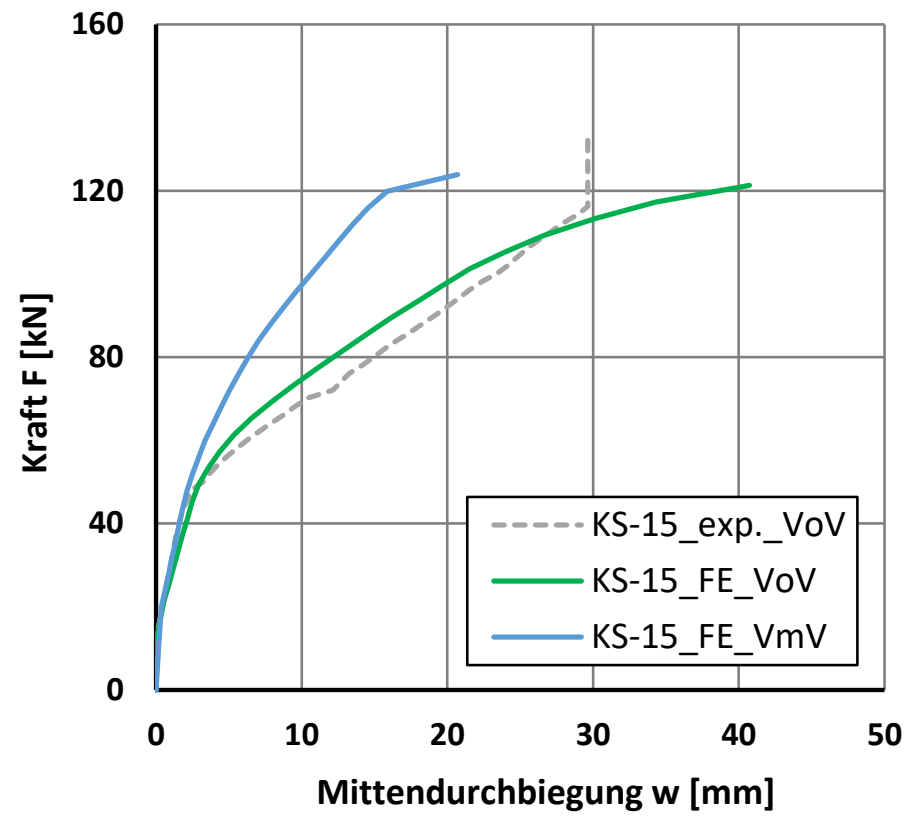

Bild 6.12 Vergleichsdarstellung der Last-Verformungslinien geometrisch gleichartiger Prüfkörper „KS15“ unter Vorspannung ohne Verbund (VoV) und Vorspannung mit Verbund (VmV)

Die geringere Durchbiegung verhindert damit auch ein Aufreißen des Querschnittes in Längsrichtung in Höhe der Spannungsnulllinie im Bereich des maximalen Momentes. Das Rissbild des Mauerwerkbalkens unter Vorspannung mit Verbund ist in Bild 6.13 dargestellt. Es hat sich ein typischer Schubzugbruch eingestellt, der diagonal zwischen Lasteinleitung und Auflager verläuft. Darüber hinaus sind viele kleine, eng gestaffelte Biegerisse erkennbar. Diese Rissverformung ist vergleichbar mit den Erkenntnissen von Rombach in (Rombach 2010, S. 54). Für eine spätere Anwendung vorgespannter Mauerwerkbalken in der Praxis erscheint es aus Gründen der Gebrauchstauglichkeit sinnvoll, Vorspannung im Verbund einzusetzen. Die Tragfähigkeit als solche wird so gut wie nicht beeinflusst; siehe Bild 6.12.

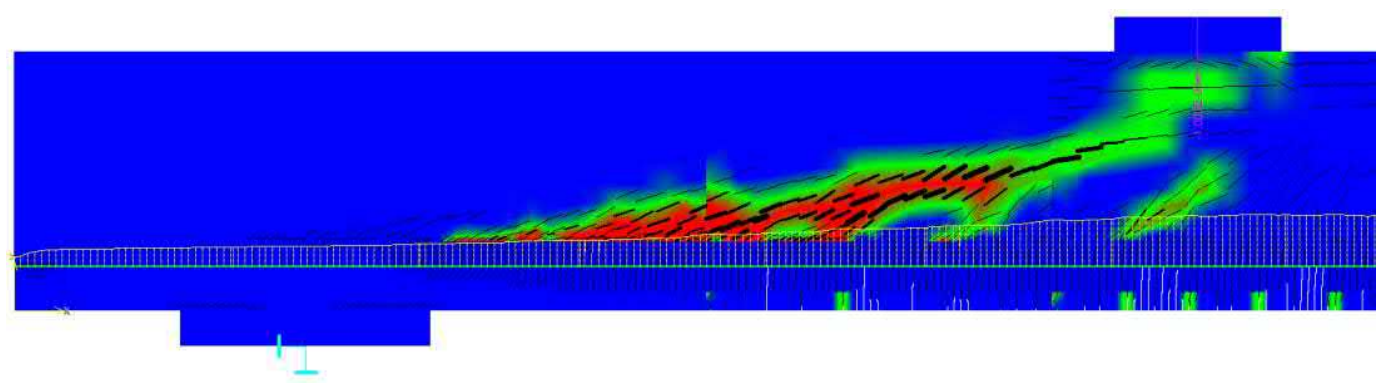

Bild 6.13 Qualitative Darstellung der Rissbildung und der Hauptdehnungen eines im Verbund vorgespannten Mauerwerkbalkens KS-15_FE_VmV

\subsubsection{Grad der Vorspannung}

Bild 6.14 zeigt die Querkrafttragfähigkeit numerisch untersuchter Mauerwerkbalken nach Tabelle 6.9 in Abhängigkeit zum Grad der Vorspannung. Dabei steigt die Querkrafttragfähigkeit mit Erhöhung der Vorspannkraft. 


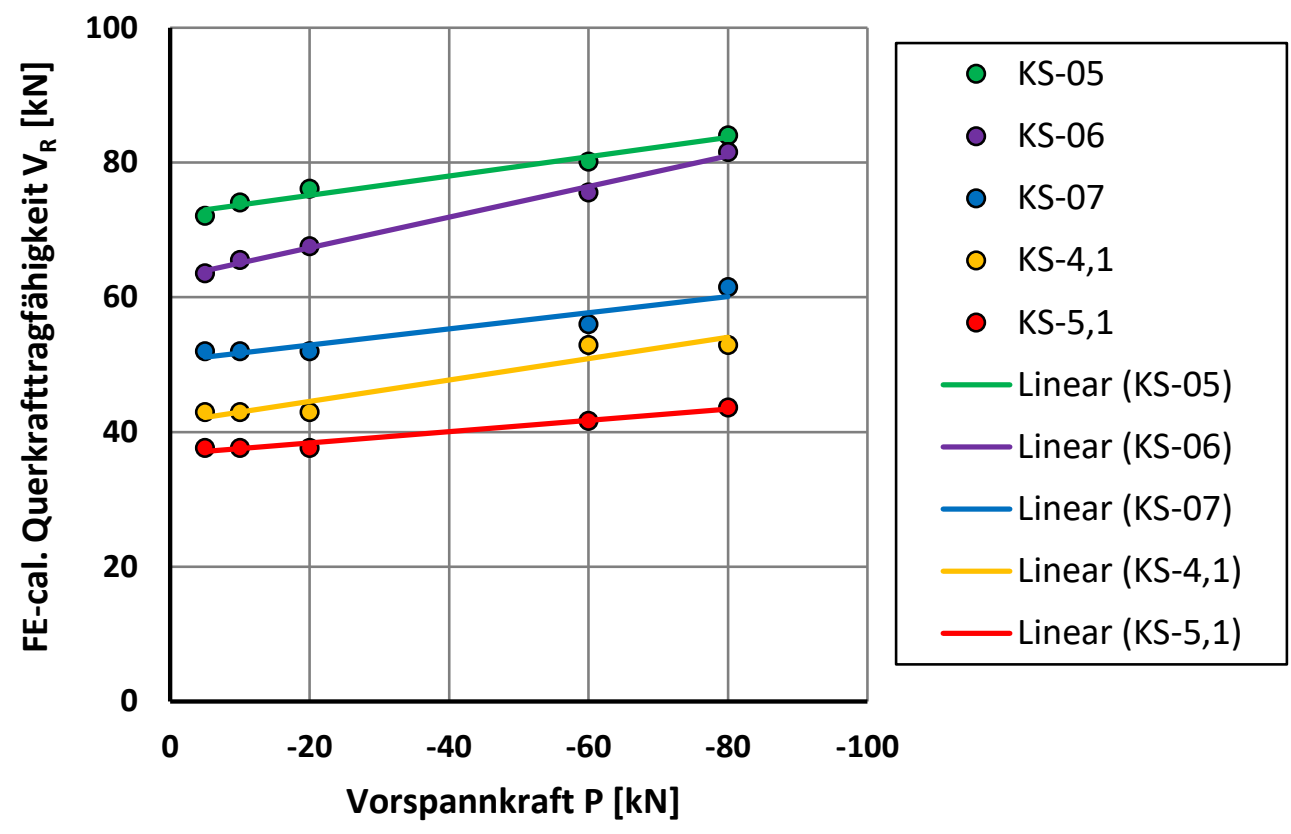

Bild 6.14 Grad der Vorspannung in Abhängigkeit zu numerisch ermittelten Querkrafttragfähigkeiten

\subsubsection{Schubschlankheit und zentrische Vorspannung}

Der durch die Schubschlankheit auf die Querkraft hervorgerufene Einfluss existiert auch bei vorgespannten Mauerwerkbalken; siehe Abschnitt 2.4.2. Nicht zweifelsfrei war bislang, ob auch für scheitrechte Mauerwerkbalken der Einfluss der Vorspannung auf die Größe der Querkraft mit zunehmender Schubschlankheit abnimmt.

Zur Klärung wurde daher der Einfluss der Schubschlankheit auf die Querkrafttragfähigkeit

- $\quad$ schlaff bewehrter und

- exzentrisch vorgespannter

Mauerwerkbalken miteinander verglichen. Im Bereich großer Schubschlankheiten von bis zu $\lambda=4,2$ weichen die Querkrafttragfähigkeiten nur geringfügig voneinander ab; siehe (Bild 6.15). Dies gilt sowohl für schlaff bewehrte als auch für Mauerwerkbalken mit unterschiedlich hoher Vorspannkraft. Gleichwohl nimmt der Unterschied mit kleiner werdender Schubschlankheit zu. Die in diesem Diagramm dargestellte Auswertung basiert auf Ergebnissen von Mauerwerkbalken, bei denen ein Schubzugbruch maßgebendes Versagenskriterium war. Der Einsatz einer Vorspannung für die Erweiterung des Anwendungsbereiches von Mauerwerkbalken mit großen Konstruktionslängen ist im Hinblick auf die Tragfähigkeit nahezu vernachlässigbar. Vergleichbare Ergebnisse wurden in früheren experimentellen Untersuchungen an vorgespannten balkenartigen Konstruktionen ermittelt; vergleiche hierzu Bild 2.18 nach Abschnitt 2.4.2. 

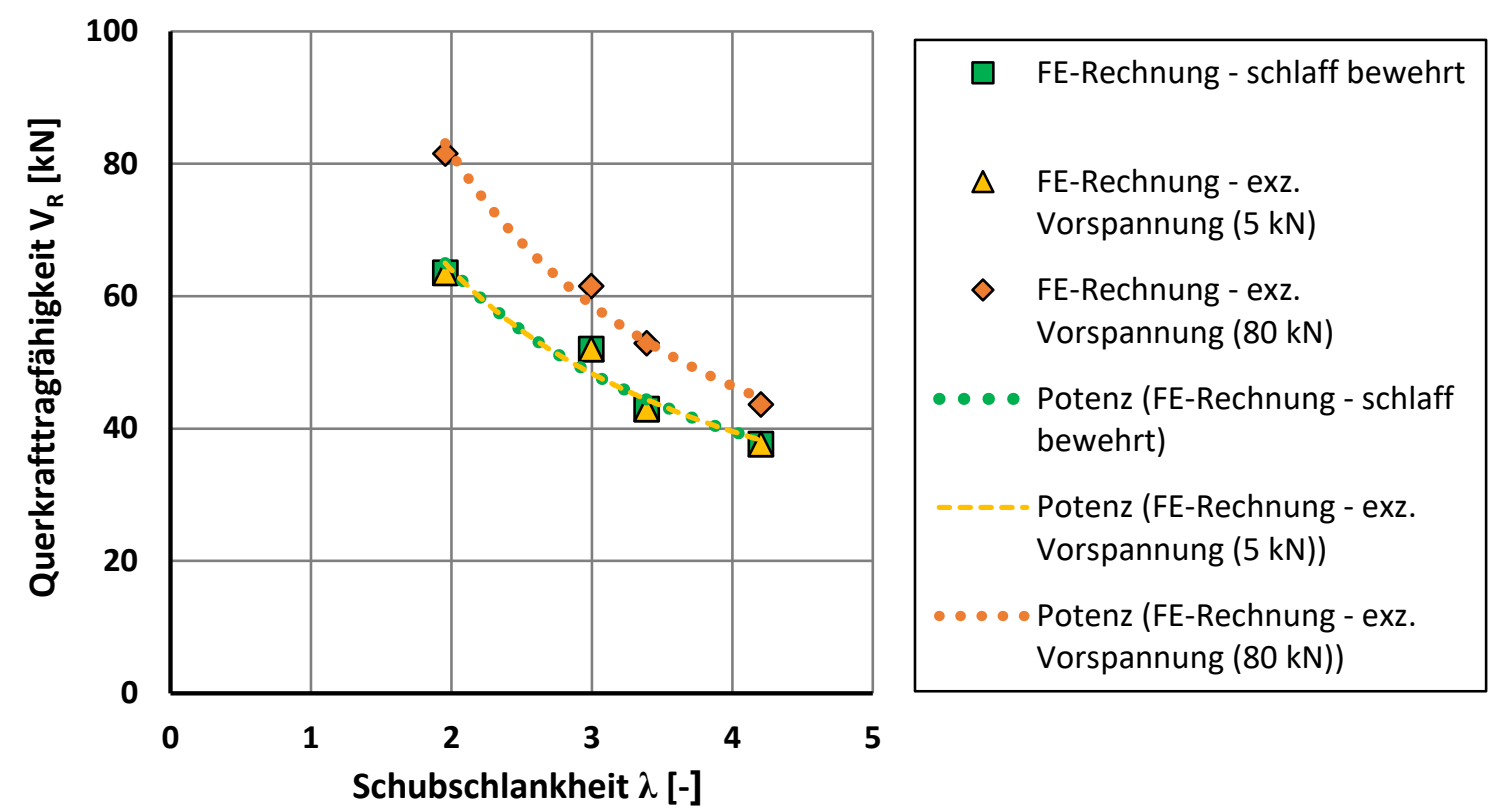

Bild 6.15 Darstellung der Schubschlankheit in Abhängigkeit zur Querkrafttragfähigkeit untersuchter, exzentrisch vorgespannter und schlaff bewehrter Mauerwerkbalken

Aufbauend auf obigen Ergebnissen wurde, insbesondere für den anwendungsbezogenen Einsatz der Balkenkonstruktionen als Fertigteil, der Einfluss durch eine zentrische Vorspannkraft untersucht. Bild 6.16 zeigt eine exemplarische Darstellung des FE-Modells anhand des Prüfkörpers KS-5,1.

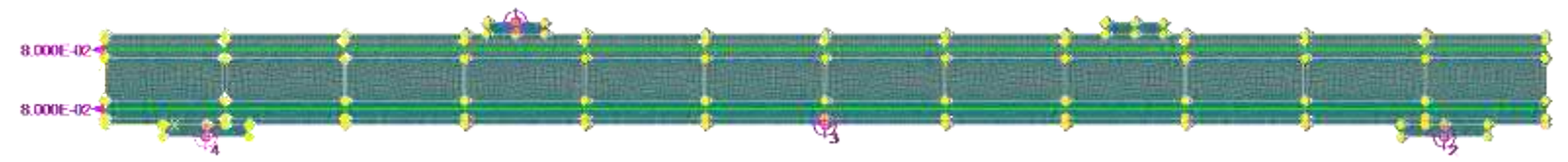

Bild 6.16 Exemplarische Darstellung des FE-Modells eines zentrisch vorgespannten Mauerwerkbalkens am Beispiel des Prüfkörpers KS-5,1

Tabelle 6.10 enthält Angaben zum Untersuchungsprogramm zentrisch vorgespannter Mauerwerkbalken mit Vorspannung mit Verbund.

Tabelle 6.10 Untersuchungsprogramm zum Einfluss zentrischer Vorspannkraft

\begin{tabular}{|c|c|c|c|c|c|c|c|}
\hline $\begin{array}{c}\text { Vorspannkraft } \\
{[\mathrm{kN}]}\end{array}$ & $\begin{array}{c}\text { Durchmesser } \\
\text { Bewehrung } \\
{[\mathrm{mm}]}\end{array}$ & Art der Vorspannung & KS-05 & KS-06 & KS-07 & KS-4,1 & KS-5,1 \\
\hline 10 & $2 \times 20$ & zentrisch, VmV & $X$ & $X$ & $X$ & $X$ & $X$ \\
\hline 60 & $2 \times 20$ & zentrisch, VmV & $X$ & $X$ & $X$ & $X$ & $X$ \\
\hline 80 & $2 \times 20$ & zentrisch, VmV & $X$ & $X$ & $X$ & $X$ & $X$ \\
\hline
\end{tabular}

Die Daten wurden in Anlehnung an Bild 6.15 ausgewertet. Die Ergebnisse sind in Bild 6.17 dargestellt. Die zentrische Vorspannung verstärkt den positiven Einfluss auf die Querkrafttragfähigkeit bei abnehmender Schubschlankheit. Von der Art der Vorspannung, hier zentrisch und im Verbund liegend, geht bei Anwendung größerer Schubschlankheiten sowie bei exzentrischer Vorspannung keine signifikante tragfähigkeitssteigernde Wirkung aus. 


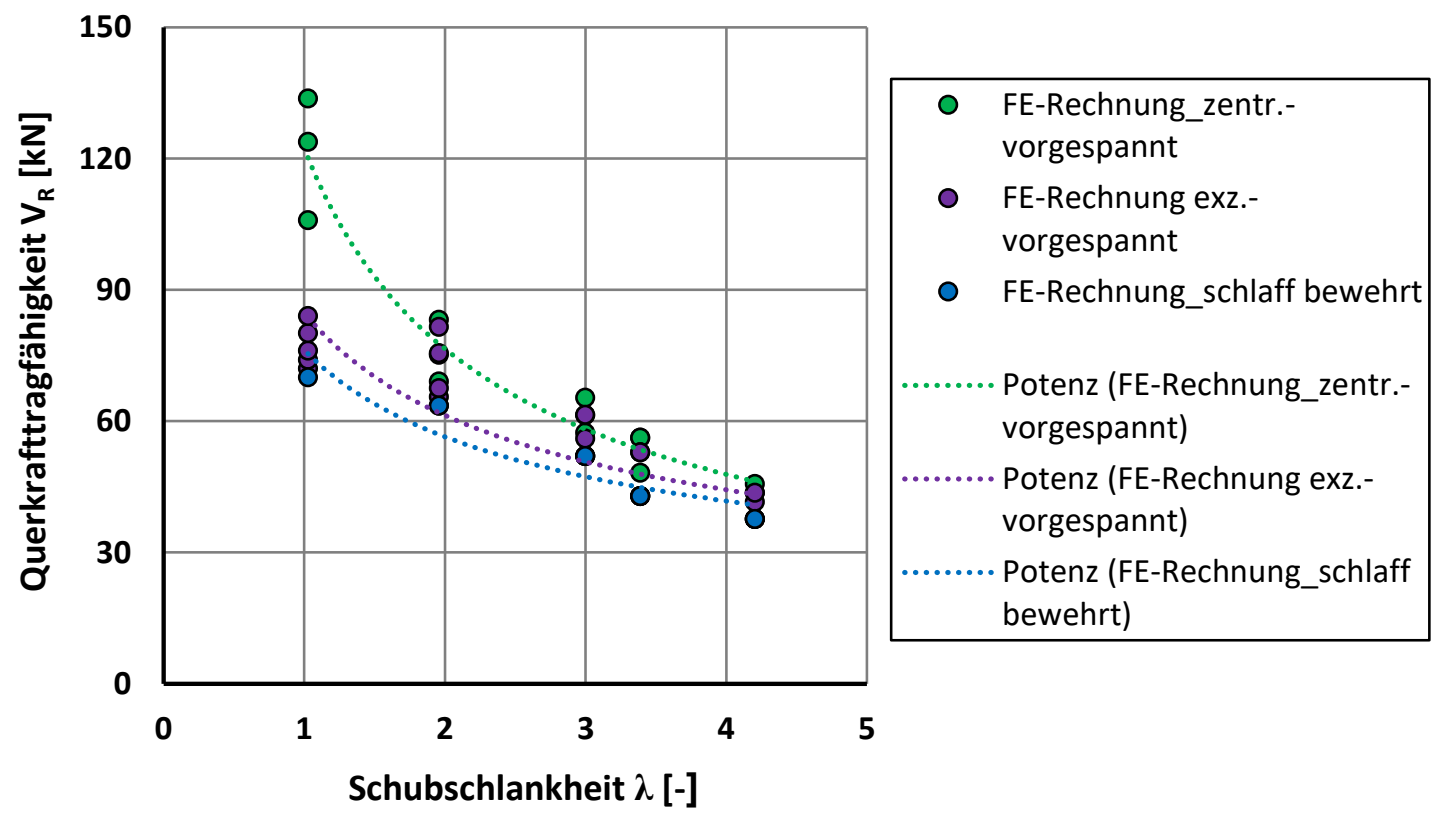

Bild 6.17 Darstellung der Schubschlankheit in Abhängigkeit zur Querkrafttragfähigkeit untersuchter, exzentrisch und zentrisch vorgespannter sowie schlaff bewehrter Mauerwerkbalken

\subsubsection{Abweichendes Tragverhalten wandartiger Träger}

In diesem Abschnitt wird das abweichende Tragverhalten von wandartigen Trägern im Vergleich zu den zuvor vorgestellten Mauerwerkbalken herausgearbeitet. Die typische Konstruktionsart eines wandartigen Trägers aus Mauerwerk kann durch die Anzahl der Mauersteinschichten in vertikaler Richtung beschrieben werden und erfüllt die Bedingung $l_{\text {eff }} / h<3$ von EC2; siehe Abschnitt 2.2.

Bild 6.18 zeigt die Geometrie eines experimentell geprüften wandartigen Trägers aus Porenbetonmauerwerk mit Lagerfugenbewehrung aus Moso-Lochband (Z-17.1-603 2012). Dabei ist die Bewehrung in den oberen beiden, auf Zug beanspruchten Lagerfugen angeordnet worden (Bild 6.18 (links): Als rote Linie dargestellt). Aus versuchstechnischen Gründen wurde das statische System des wandartigen Trägers um $180^{\circ}$ gedreht untersucht. Dabei wurde die Konstruktion an den Trägerenden durch eine synchron gesteuerte Lasteinleitung beansprucht. Die Aufstandsfläche simulierte dabei, durch die gleichstreckenförmige Druckspannungsverteilung infolge Kontaktpressung (nachgewiesen anhand der Mauerwerkstauchung im Bereich kurz oberhalb der Kontaktfläche „Aufspannfeld“), eine gleichstreckenartige Lasteinleitung. 


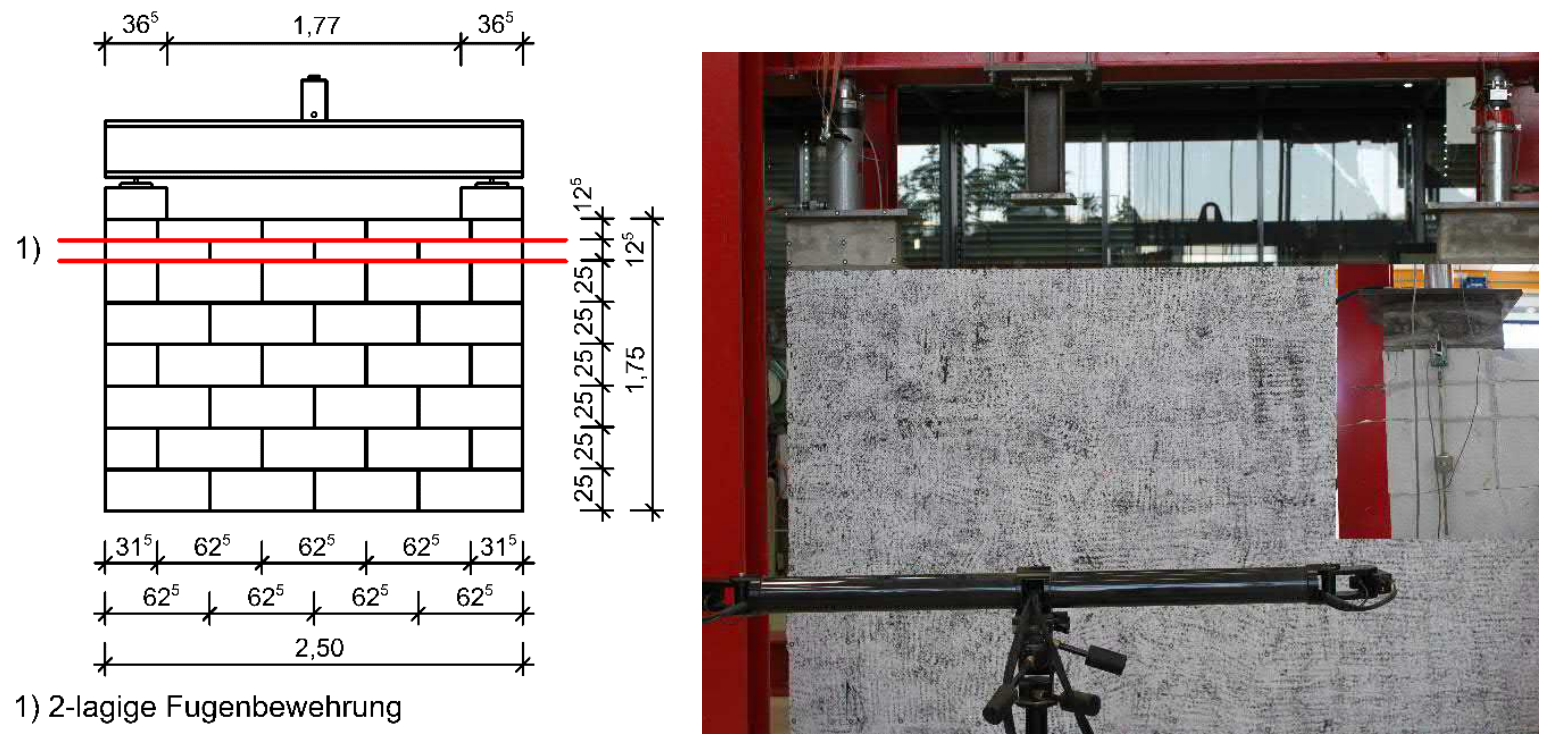

Bild 6.18 Systemskizze Prüfaufbau (links); exp. untersuchter wandartiger Träger im Prüfrahmen (rechts)

Bild 6.19 (links) zeigt das theoretisch unterstellte Sprengwerkmodell eines wandartigen Trägers im Vergleich zu einer Vertikalverformung eines im Experiment untersuchten wandartigen Trägers (rechts). Der Vergleich zwischen theoretischer Modellvorstellung und den Untersuchungsergebnissen zeigt bis zu einem Erreichen des Zustandes II ein linear elastisches Tragverhalten. Damit sind vorläufig auch die Annahmen von Reineck für wandartige Träger aus Beton (Reineck 2005, S. 246) auf Mauerwerk übertragbar. Im Weiteren zeigt das Verformungsbild eine Aufwölbung bzw. bei umgedrehtem System eine Durchbiegung des Querschnittes zwischen den Lasteinleitungspunkten.

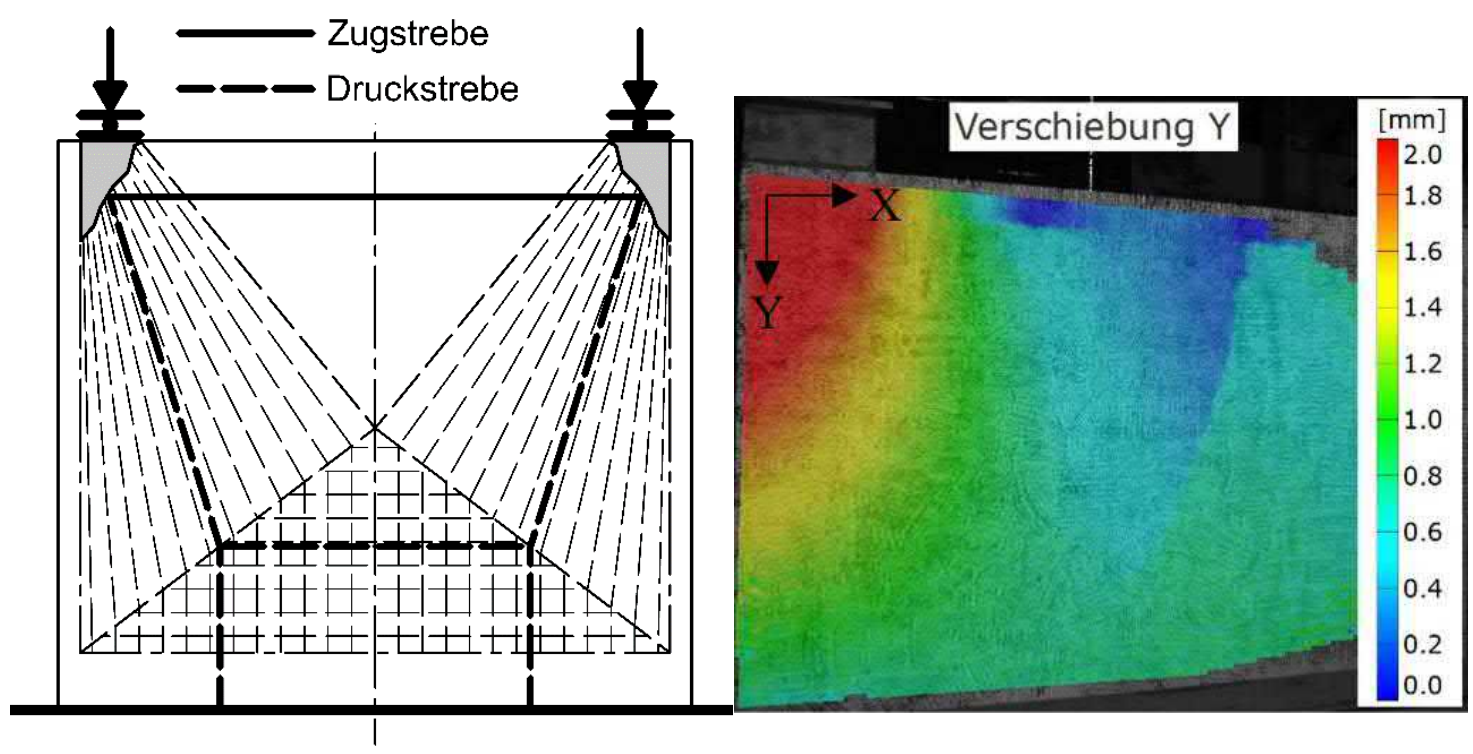

Bild 6.19 Wandartiger Träger im Übergang vom elastischen zum plastischen Verformungszustand: Theorie (links); exp. Prüfung (rechts)

Der Übergang der gesamten Konstruktion von Zustand I in Zustand II wird eingeleitet durch zwei zueinander gerichtete, diagonal verlaufende Risse; siehe Bild 6.20 (links). Daran anschließend findet eine Lastumlagerung statt, sodass ein Lastabtrag nur noch durch eine direkte, vertikale Druckstrebe erfolgt. Die maximale Tragfähigkeit wird letztlich durch ein Versagen der Druckstrebe begrenzt; siehe Bild 6.20 (rechts). 

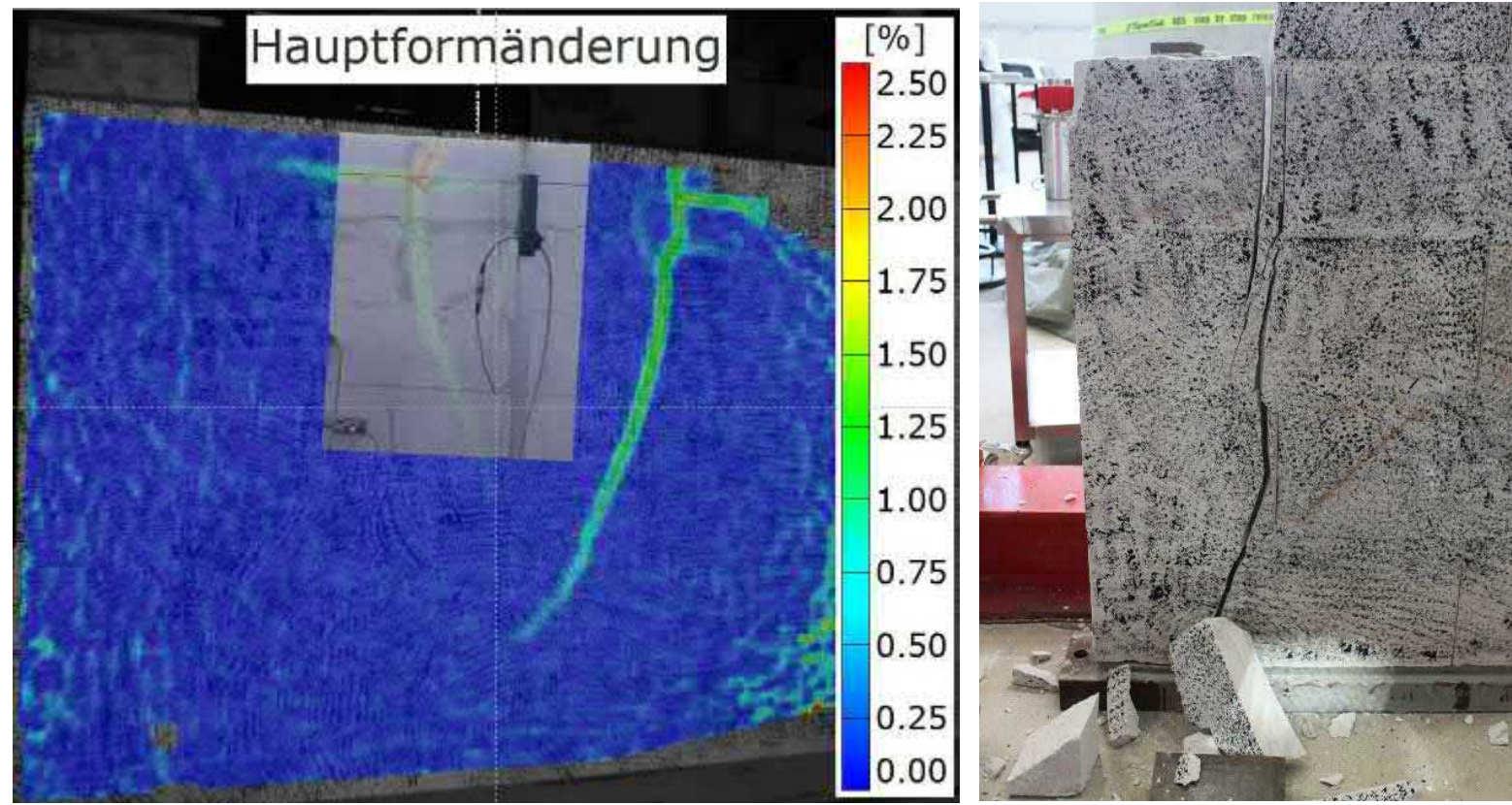

Bild 6.20 Wandartiger Träger im Zustand II (links); Kollaps der Konstruktion (rechts)

Aufgrund der wenigen vorliegenden experimentellen Untersuchungen an wandartigen Trägern wurden numerische Untersuchungen durchgeführt, die im Folgenden vorgestellt und bewertet werden. Für die rechnerischen Untersuchungen wurden Mauerwerkkörper mit gleichen Materialparametern wie zuvor, jedoch mit Geometrien nach Tabelle 6.11 modelliert.

Tabelle 6.11 Untersuchungsprogramm: Wandartige Träger

\begin{tabular}{|c|c|c|c|c|c|c|c|c|}
\hline \multirow[t]{2}{*}{$\begin{array}{l}\text { Versuchs- } \\
\text { Bez. }\end{array}$} & \multirow{2}{*}{$\begin{array}{c}\text { Anzahl der } \\
\text { Schichten [Stk.] / } \\
\text { Schichthöhe } \\
\text { [mm] }\end{array}$} & \multicolumn{3}{|c|}{$\begin{array}{c}\text { Querschnittswerte } \\
{[\mathrm{mm}]}\end{array}$} & \multicolumn{2}{|c|}{$\begin{array}{c}\text { Prüfkörperlänge } \\
{[\mathrm{m}]}\end{array}$} & \multirow{2}{*}{$\begin{array}{c}\text { Biegeschlankheit }^{1} \\
{[-]}\end{array}$} & \multirow[t]{2}{*}{ Tragform } \\
\hline & & $h$ & $d$ & $t$ & $l$ & $\boldsymbol{l}_{\text {eff }}$ & & \\
\hline KS-W-01 & $2 / 373$ & 746 & 683 & 240 & 3,47 & 3,13 & 4,19 & Balken \\
\hline KS-W-02 & $3 / 373$ & 1119 & 1056 & 240 & 3,47 & 3,13 & 2,80 & wand. Träger \\
\hline KS-W-03 & $5 / 373$ & 1865 & 1802 & 240 & 3,47 & 3,13 & 1,68 & wand. Träger \\
\hline KS-W-04 & $7 / 373$ & 2611 & 2548 & 240 & 3,47 & 3,13 & 1,20 & wand. Träger \\
\hline
\end{tabular}

Die Lage der Längsbewehrung wurde im Vergleich zu den untersuchten Mauerwerkbalken nicht verändert. Damit liegt die Längsbewehrung (Feldbewehrung) bei kleiner werdendem Verhältnis von $\frac{l_{\text {eff }}}{h}$ nicht, wie für wandartige Träger üblich, in einem Bereich nach Gleichung (6.5). Dies kann dazu führen, dass ein Teil der sonst über die Bewehrung aufgenommenen Zugspannungen im Mauerwerk umgelagert werden muss.

$$
\min \left\{\begin{array}{c}
0,1 \cdot h \\
0,1 \cdot l_{\text {eff }}
\end{array}\right.
$$

Dabei sind:

$h$

Die Querschnittshöhe,

$l_{\text {eff }}$

Die effektive Länge.

Weiterhin unterscheidet sich die Bewehrungsanordnung der untersuchten Konstruktionsarten von typischen wandartigen Trägern (Bild 6.21) durch den Verzicht auf eine Querzugbewehrung im Bereich zwischen den Lasteinleitungspunkten. 


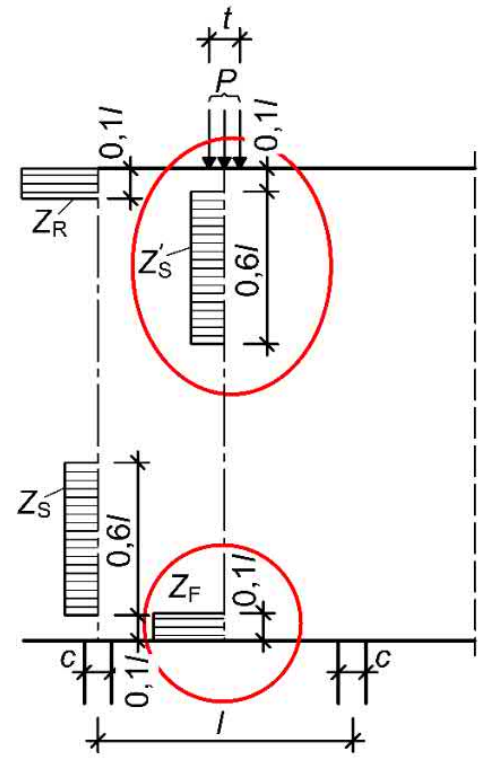

Bild 6.21 Wandartiger Träger: Verteilung der Hauptbewehrung nach Heft 240 (DAfStb Heft 240 1991, S. 61) bzw. Heft 631 (DAfStb Heft 631 2019, S. 86)

In Bild 6.22 ist exemplarisch das FE-Modell von KS-W-04 für die untersuchten Konstruktionsarten dargestellt.

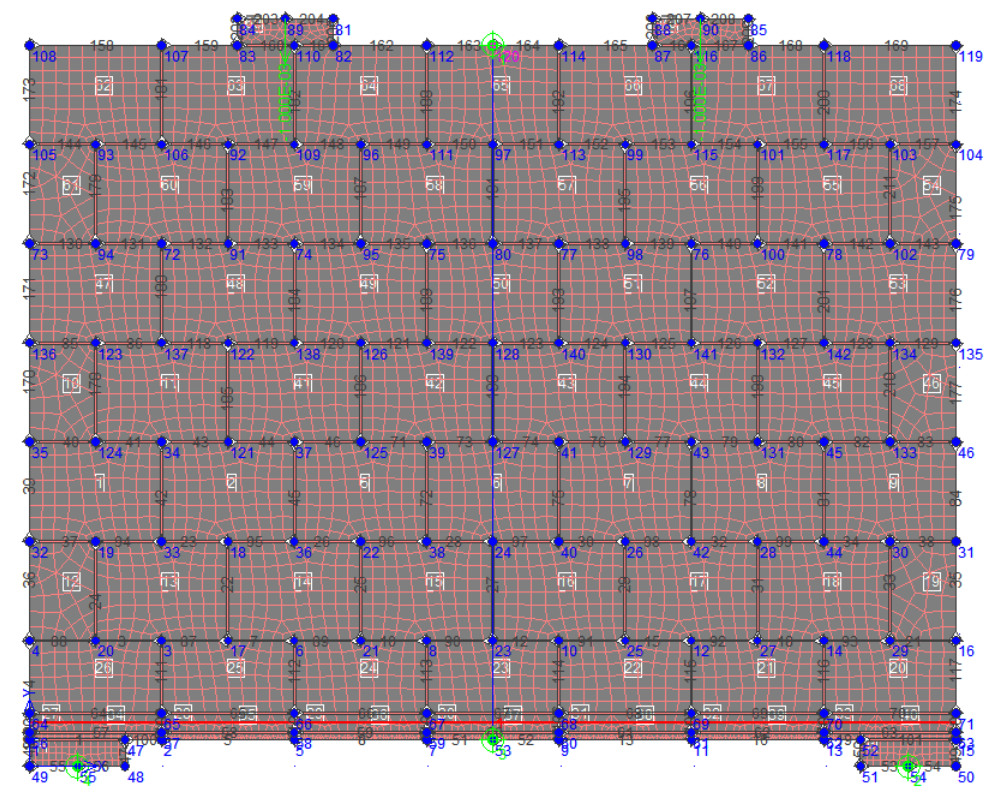

\section{Bild 6.22 Wandartiger Träger: KS-W-04 - FE-Modell}

Die Auswertung der Berechnung zeigt, dass wie bei den experimentellen Untersuchungen bereits ermittelt, die Anwendbarkeit der durch Reineck beschriebenen Grundlagen im Zustand I und II gerechtfertigt ist. Den Beweis hierfür liefert die Darstellung der Hauptzug- und Hauptdruckspannungsverteilung; auch hier ist innerhalb der Spannungsfelder ein Fachwerk- bzw. Sprengwerkmodell nach zuvor beschriebenen Grundsätzen vorstellbar; siehe Bild 6.23. 

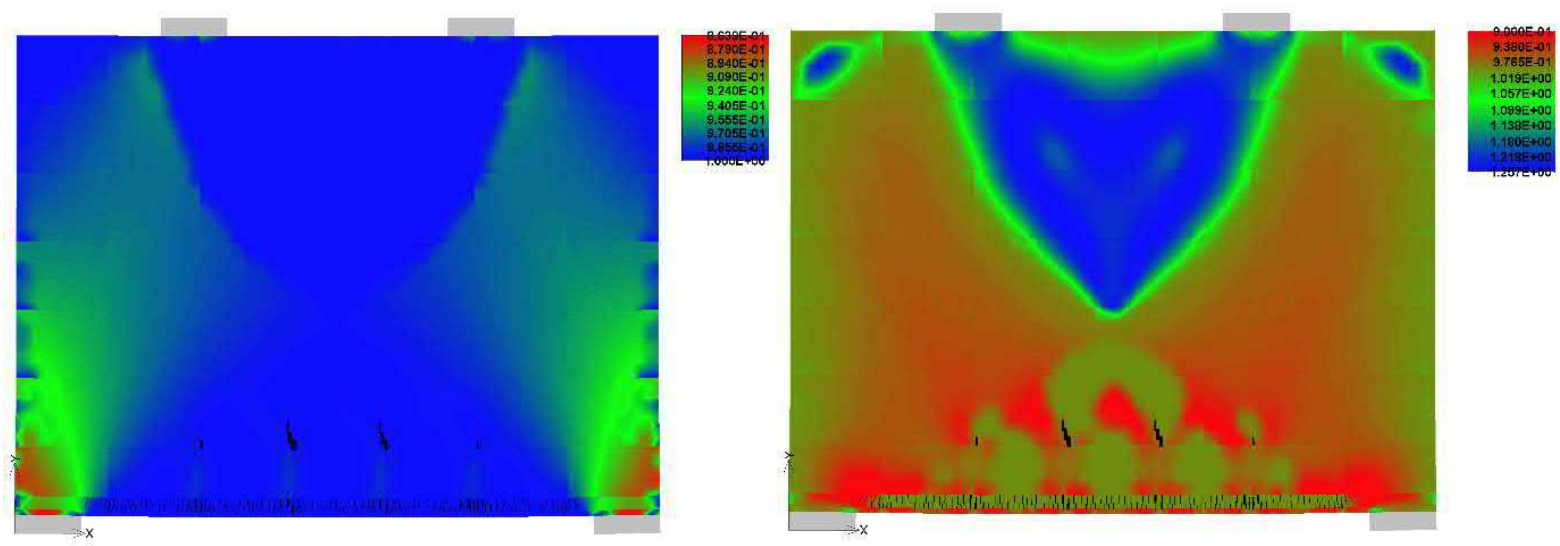

\section{Bild 6.23 Qualitative Darstellung - KS-W-04 - Zustand I: Hauptzugspannungen (links); Hauptdruckspannungen (rechts);}

Bei zunehmender Rissbildung und damit beim Wechsel in den Zustand II setzt ein plastisches Tragverhalten ein. In Bild 6.24 ist die Verteilung der Hauptzug- und Hauptdruckspannungsverteilung im Zustand II angegeben. Gezeigt ist, dass die Tragfähigkeit, wie auch experimentell ermittelt, durch das Versagen der Druckstrebe nach Rissbildung begrenzt wird.
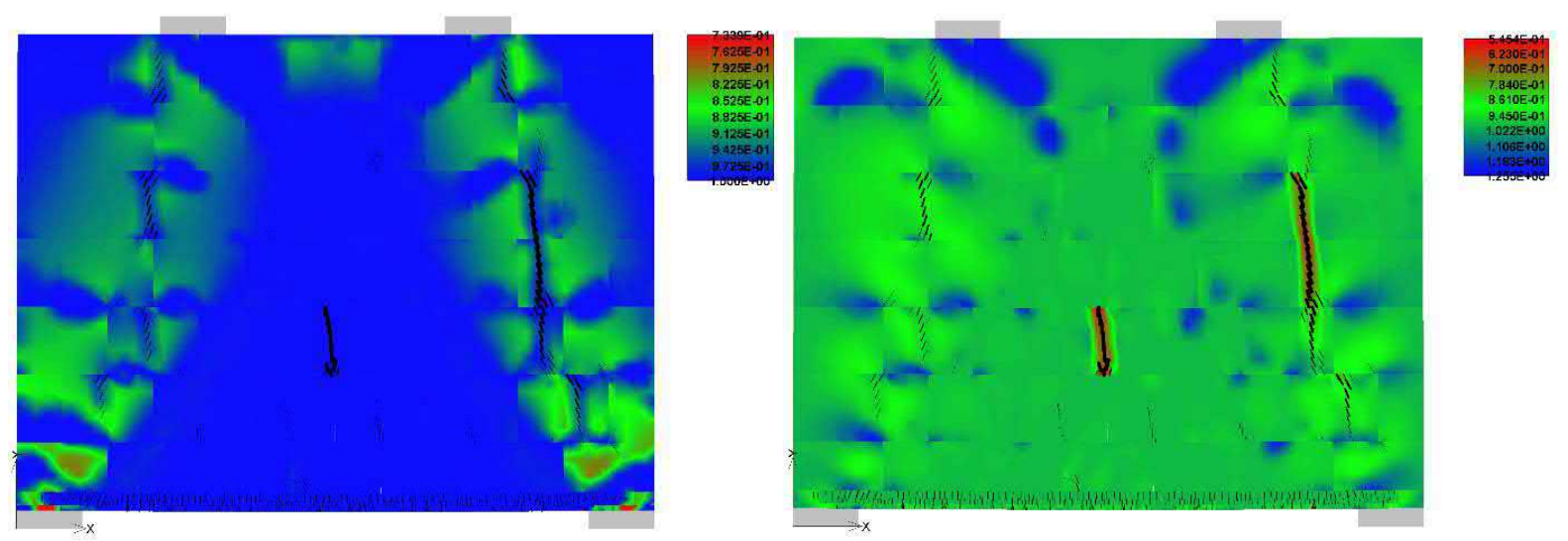

Bild 6.24 Qualitative Darstellung - KS-W-04 - Zustand II: Hauptzugspannungen (links); zweiaxiale Hauptdruckspannungen (rechts)

Auch hier lässt sich anhand der Hauptzug- und Hauptdruckspannungsverteilung im Zustand II (Bild 6.24) näherungsweise ein Sprengwerkmodell ableiten. Ein Vergleich mit dem Sprengwerk von wandartigen Trägern im plastischen Zustand nach der Theorie von Reineck zeigt ebenfalls eine gute Übereinstimmung; siehe Bild 2.7. Er empfiehlt jedoch die für die Bemessung vorzunehmende Modellfindung an der Spannungsverteilung der linear-elastischen Elastizitätstheorie zu orientieren (Reineck 2005, S. 246). 


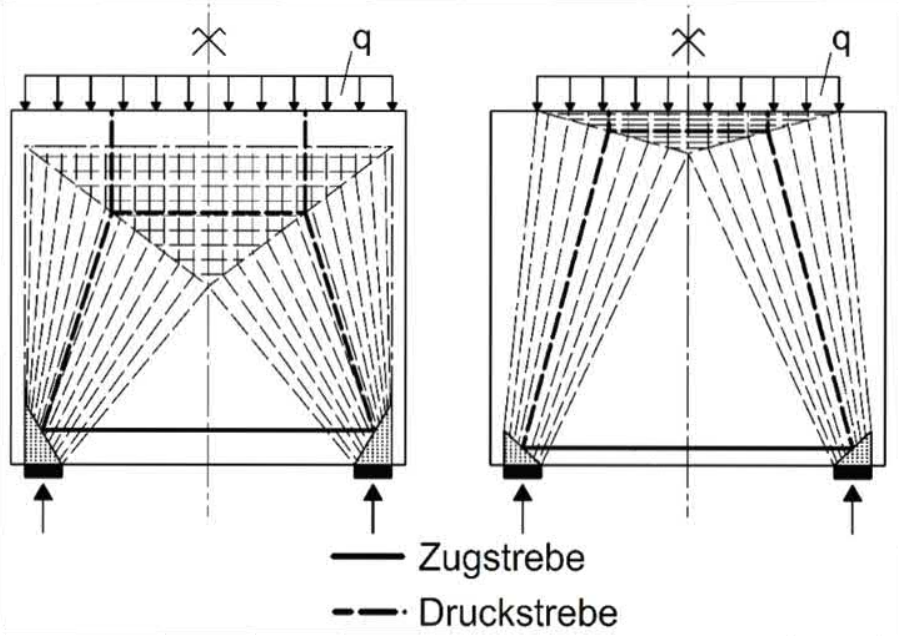

Bild 2.7 Verlauf von Spannungstrajektorien eines wandartigen Trägers unter Annahme linearelastischen (links) und plastischen (rechts) Tragverhaltens (Wiederholung; vgl. Bild 2.7)

Die Bemessung solcher Konstruktionsarten sollte daher durch den Ansatz eines Fachwerkmodells bzw. Sprengwerkmodells erfolgen, bspw. nach Heft 631 (DAfStb Heft 631 2019, S. 73-87), Abschnitt 4 (Schnittgrößen in wandartigen Trägern). Dabei wird die Bewehrung über die Ermittlung von Hauptzugspannungen, umgerechnet in Zugspannungen, bestimmt.

Die Auswertung der Ergebnisse der FE-Berechnungen zeigen bei einer Darstellung der Schubschlankheit in Abhängigkeit zur Gesamtlast einen annähernd linearen Zusammenhang; siehe Bild 6.25. Mit abnehmender Schubschlankheit ist eine deutliche Laststeigerung zu erkennen. Im Bereich $\lambda \leq 0,5$ scheint die Tragfähigkeit der Konstruktion einen konstanten Wert anzunehmen. Im Rahmen der Arbeit nicht abschließend zu klären, wird angenommen, dass in diesem Bereich die Grenzdrucktragfähigkeit des Mauerwerks erreicht ist.

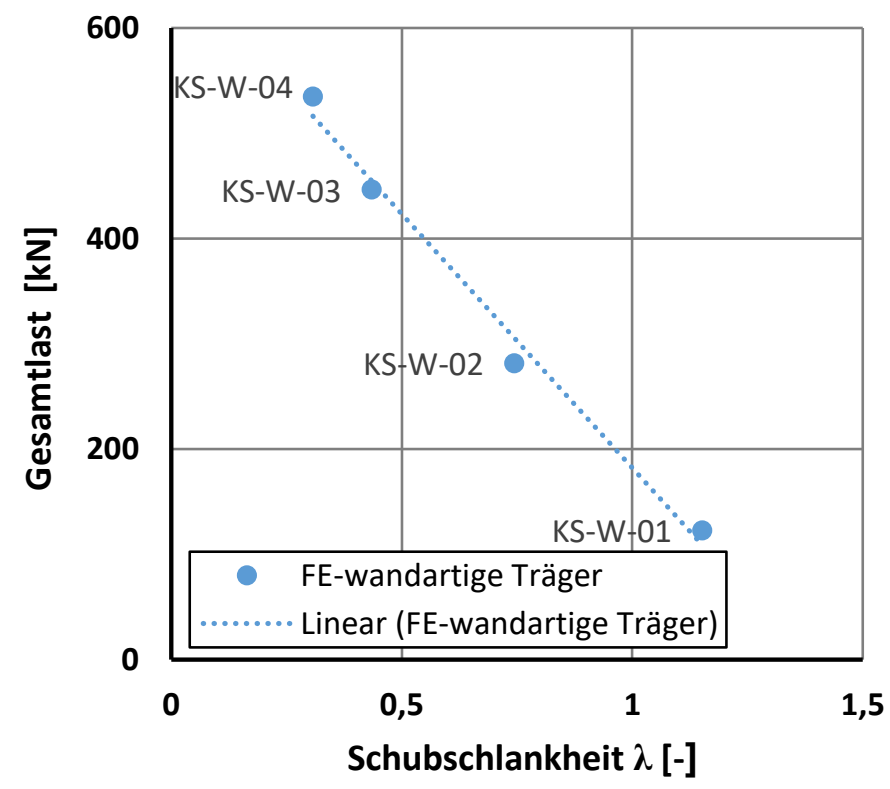

Bild 6.25 Wandartige Träger: Schubschlankheit in Abhängigkeit zur Gesamtlast 


\subsection{Zusammenfassung}

In diesem Abschnitt wurden numerische Untersuchungen zum Tragverhalten von Mauerwerkbalken durchgeführt. Diese beziehen sich auf Parameter, die aufgrund des erheblichen Prüfaufwandes nicht durch experimentelle Untersuchungen nach Abschnitt 5 erforscht wurden. Die mit dem Programmsystem „SBETA“ durchgeführten Berechnungen basieren auf der Modellierungsstrategie eines vereinfachten Mikromodells, welches anhand der exp. Prüfergebnisse nach Abschnitt 5 verifiziert wurde.

Untersucht wurden: Einflüsse aus

- variierenden Längsbewehrungsgraden,

- großen Schubschlankheiten,

- Höhe und Art der Vorspannung auf die Querkrafttragfähigkeit.

Die Auswertung zeigt eine Zunahme der Querkrafttragfähigkeit mit steigendem Längsbewehrungsgrad. Dies wird über einen rechnerischen Ansatz zur Erfassung der Längsdehnungen in dem Berechnungsvorschlag in Abschnitt 7 einbezogen; vgl. Bild 6.8.

Die Untersuchung schubschlanker Mauerwerkbalken ergab, dass ab einer Schubschlankheit von ca. $\lambda=4$ die Querkrafttragfähigkeit gegen einen konstanten Wert (ca. $40 \mathrm{kN}$ ) tendiert. Der rechnerische Ansatz zur Berücksichtigung auflagernaher Einzellasten erfasst diesen Einfluss zufriedenstellend; vgl. Bild 6.10. Bestätigt wurde das Vorgehen zur Ermittlung des global wirkenden Druckstrebenwinkels, der über die Rissneigung im Bereich des Schubfeldes bestimmt werden kann. Die Darstellung des rechnerischen Ansatzes erfolgt in Abschnitt 7.

Im Zusammenhang mit der Untersuchung vorgespannter Mauerwerkbalken wurde das unterschiedliche Last-Verformungsverhalten von Vorspannung mit Verbund und Vorspannung ohne Verbund dargestellt. Die Auswertungen zeigen einen annähernd gleichen Tragwiderstand, wohingegen die Durchbiegungen der Prüfkörper mit im Verbund liegender Spannbewehrung im gerissenen Zustand deutlich geringer sind.

Ein Vergleich von Mauerwerkbalken mit variierender Vorspannkraft hat mit größer werdender Normalkraft zu einer Zunahme der Querkrafttragfähigkeit geführt. Bei Schubschlankheiten $\lambda>4$ nimmt der positive Einfluss einer Vorspannung auf die Querkrafttragfähigkeit deutlich ab. Dies gilt sowohl für exzentrisch vorgespannte Mauerwerkbalken als auch für solche mit zentrischer Vorspannung. Bei zentrischer Vorspannung im Vergleich zu exzentrischer Vorspannung nimmt der Schlankheitseinfluss geringfügig zu, wodurch sich mit kleiner werdender Schubschlankheit größere Querkrafttragfähigkeiten ergeben.

In dieser Arbeit wurde das Tragverhalten von Mauerwerkbalken untersucht. Es unterscheidet sich stark vom Tragverhalten wandartiger Träger. Zur Darstellung dieser Abweichung wurde das jeweilige Tragverhalten analysiert. Die Auswertungen stützen die Theorie von Reineck, wonach die Spannungsverteilung an der linear-elastischen Elastizitätstheorie zu orientieren ist. Zur Vermeidung großer Rissweiten gilt dies insbesondere für Mauerwerkscheiben ohne flächenhafte Bewehrung. Für die Definition einer Anwendungsgrenze des in dieser Arbeit für Mauerwerkbalken $\mathrm{zu}$ entwickelnden Berechnungsverfahrens wird auf Abschnitt 7.3 bzw. Bild 7.19 verwiesen. 


\section{Algorithmen zur Querkraftberechnung von Mauerwerkbalken}

Dieser Abschnitt enthält die Herleitung und Verifikation des Berechnungsvorschlages zur Bestimmung der Querkrafttragfähigkeit von sowohl schlaff bewehrten als auch vorgespannten Mauerwerkbalken ohne Querkraftbewehrung. Die experimentellen und numerischen Untersuchungsergebnisse zum Trag- und Verformungsverhalten von Schubfeldern bewehrter Mauerwerkbalken zeigen Parallelen zu solchen von Stahlbetonbalken. Daher erscheint es zweckmäßig, den für Mauerwerkbalken zu entwickelnden Berechnungsvorschlag an die aus dem Stahlbetonbau bekannte Theorie der SMCFT anzugliedern, die auf der Grundlage von Spannungsfeldern basiert.

\subsection{Herleitung und Darstellung der SMCFT}

\subsubsection{Modified Compression Field Theory}

Auf Grundlage der in Abschnitt 4.1.3 beschriebenen verallgemeinerten Charakteristika der Spannungsfelder wurde durch Vecchio und Collins (Vecchio, Frank, J. und Collins, Michael, P 1986, S. 219-231) die Modified Compression Field Theory (MCFT) für Stahlbetonbalken entwickelt. Diese wird durch Sigrist auch als Modell der gerissenen Scheibe (Cracked Membrane) bezeichnet (Sigrist und Hackbarth 2010, S. 690). Sie unterscheidet sich von den verallgemeinerten Spannungsfeldern durch die Berücksichtigung der Mitwirkung des Betons zwischen den Rissen (Rupf 2014, S. 12-13). Daher wird an dieser Stelle auf den Querkraftwiderstand infolge Rissverzahnung bzw. Rissreibung und den Einfluss durch die Größe des Gesteinskorns auch für bewehrte Mauerwerkbalken hingewiesen; siehe Abschnitt 4.2.2. Eine Dübelwirkung der Bewehrung bleibt bei Anwendung dieses Modells hier weiterhin unberücksichtigt (Huber et al. 2014, S. 21). Die in dem Riss übertragenen Schubspannungen sind damit abhängig von der Rissweite, dem Größtkorn der Gesteinskörnung und der Betonfestigkeit (Mutsuyoshi 2013, S. 50). Dies könnte auch für Mauerwerk gelten, da es sich im Vergleich zu hochfestem Beton oder Leichtbeton im Weitesten durch dessen Anisotropie unterscheidet. Bild 7.1 liefert einen Überblick über die für Stahlbetonkonstruktionen unterstellten Gleichgewichtsbedingungen, geometrische Beziehungen sowie verwendete Materialmodelle. Dabei gelten für die Betondruckspannungen in Bezug auf die Gleichgewichtsbedingungen nach Bild 7.1 die Grundlagen nach Gleichung (7.1) bis (7.3).

$$
\begin{aligned}
& f_{\mathrm{z}}=v \cdot \tan \theta \\
& f_{\mathrm{x}}=v \cdot \cot \theta \\
& v=\frac{f_{\mathrm{z}}+f_{\mathrm{x}}}{\tan \theta+\cot \theta}
\end{aligned}
$$

Dabei sind:
$f_{\mathrm{x}}, f_{\mathrm{y}}$ die richtungsabhängigen Betonspannungen,
$v \quad$ die Schubspannungen entlang des Elements,
$\theta \quad$ der Neigungswinkel. 


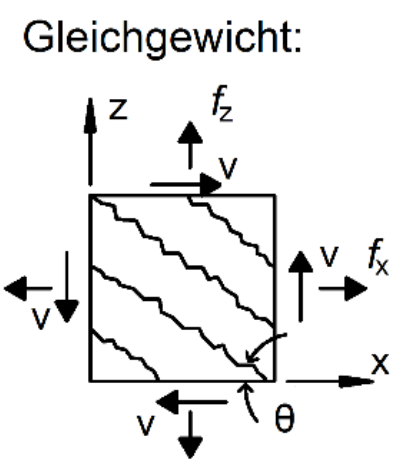

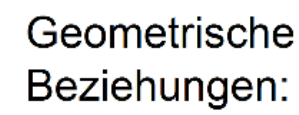

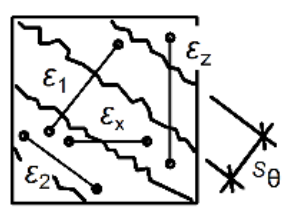

Spannungs-DehnungsDiagramm:

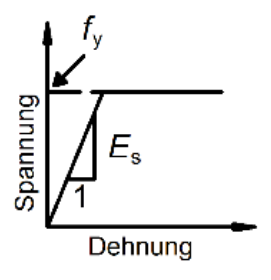

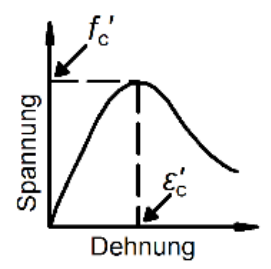

Bild 7.1 Gleichgewichtsbedingungen, geometrische Beziehungen sowie verwendete Materialmodelle der MCFT (Bentz, Evan, C. et al. 2006, S. 615; Vecchio, Frank, J. 2000, S. 13)

Auf Grundlage des Materialverhaltens, hier am Beispiel „Beton“ (Bild 7.2), ermittelt sich der Maximalwert der Hauptzugspannung $\left(f_{\text {cr }}\right)$ nach Gleichung (7.4). Durch eintretende Rissbildung nimmt die Hauptzugspannung $\left(f_{1}\right)$ in Abhängigkeit der Zugdehnung entsprechend Gleichung (7.5) ab. Mit zunehmender Rissgröße können nur noch Schubspannungen $\left(v_{c i}\right)$ nach Gleichung (7.7) übertragen werden, wodurch sich eine Reduzierung der Zugspannungen ( $\left.f_{1, \text { red }}\right)$ nach Gleichung (7.6) ergibt.

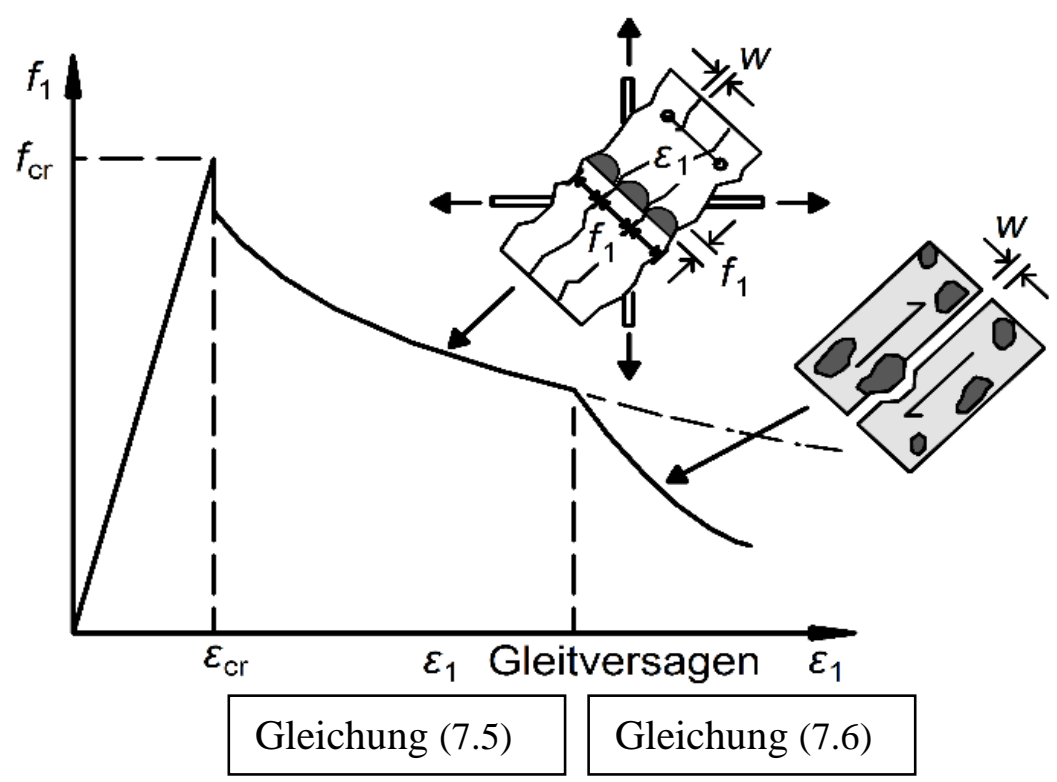

Bild 7.2 Mittlere Zugspannung im gerissenen Beton (Michael P. Collins 1996, S. 39)

$$
\begin{gathered}
f_{\mathrm{cr}}=0,33 \cdot \sqrt{f_{\mathrm{c}}^{\prime}} \\
f_{1}=\frac{f_{c r}}{1+\sqrt{500 \cdot \varepsilon_{1}}} \\
f_{1, \mathrm{red}}=v_{\mathrm{ci}} \cdot \tan \theta \\
v_{\mathrm{ci}}=\frac{0,18 \cdot \sqrt{f_{\mathrm{c}}^{\prime}}}{0,31+\frac{24 \cdot\left(\varepsilon_{1} \cdot S_{0}\right)}{a_{\mathrm{g}}+16}}=\frac{0,18 \cdot \sqrt{f_{\mathrm{c}}^{\prime}}}{0,31+\frac{24 \cdot w}{a_{\mathrm{g}}+16}}
\end{gathered}
$$

Dabei sind:

$f_{\text {cr }} \quad$ Die Betonzugspannung,

$\varepsilon_{1} \quad$ die Hauptzugdehnung senkrecht zu den Rissen nach Gleichung (4.1), 
$f_{\mathrm{c}}^{\prime} \quad$ die Zylinderdruckfestigkeit des Betons,

$b_{\mathrm{v}} \quad$ die kleinste Breite innerhalb des Schubfeldes,

$d_{\mathrm{v}} \quad$ die effektive schubübertragende Höhe, entspricht $z$ (innerer Hebelarm),

$a_{\mathrm{g}}$ das Größtkorn der Gesteinskörnung,

w die Rissweite nach Gleichung (7.8),

$w=\varepsilon_{1} \cdot s_{\theta}$

$s_{\theta} \quad$ die Rissweite unter dem Winkel $\theta$ nach Gleichung (7.9),

$s_{\theta}=\frac{1}{\frac{\sin \theta}{s_{\mathrm{mx}}}+\frac{\cos \theta}{s_{\mathrm{my}}}}$

$S_{\mathrm{mx}} \quad$ die durchschnittliche Rissweite in x-Richtung,

$S_{\mathrm{my}} \quad$ die durchschnittliche Rissweite in y-Richtung.

Die Hauptdruckspannungen des Betons $\left(f_{2}\right)$ sind in Abhängigkeit von den Hauptzug- $\left(\varepsilon_{1}\right)$ und Hauptdruckdehnungen $\left(\varepsilon_{2}\right)$ des Betons nach Gleichung (7.10) zu ermitteln. Beschränkt werden diese in Gleichung (7.10) durch die Berücksichtigung des Einflusses des gerissenen Betons und der damit reduzierten Druckfestigkeit $\left(f_{2 \max }\right)$ nach Gleichung (7.11). Bild 7.3 zeigt das Werkstoffverhalten von Beton eines auf Druck beanspruchten Zylinders und einer gerissenen bewehrten Druckstrebe. Dabei wird die Druckdehnung $\left(\varepsilon_{\mathrm{c}}^{\prime}\right)$ stets konstant nach Gleichung (7.12) mit $2 \%$ angenommen.

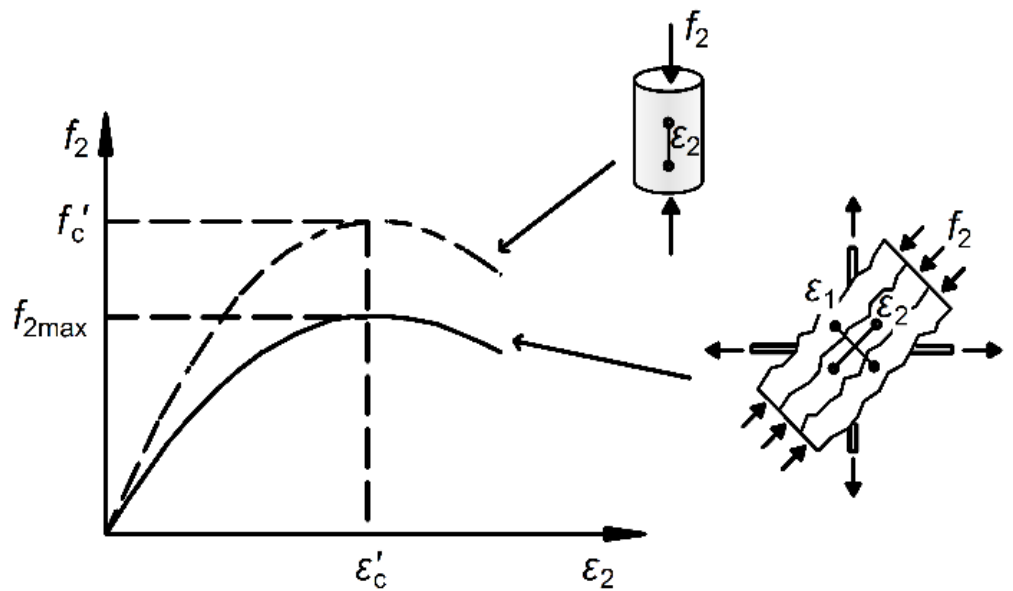

Bild 7.3 Spannungs-Dehnungslinie Beton (Michael P. Collins 1996, S. 39)

$$
\begin{aligned}
& f_{2}=f_{2 \max } \cdot\left(\frac{2 \cdot \varepsilon_{2}}{\varepsilon_{\mathrm{c}}^{\prime}}-\left(\frac{\varepsilon_{2}}{\varepsilon_{\mathrm{c}}^{\prime}}\right)^{2}\right) \\
& f_{2 \max }=\frac{f_{\mathrm{c}}^{\prime}}{0,8+170 \cdot \varepsilon_{1}} \leq f_{\mathrm{c}}^{\prime} \\
& \varepsilon_{\mathrm{c}}^{\prime}=0,002
\end{aligned}
$$

Für die Übertragung dieses Modells auf Balkenkonstruktionen aus Beton sind nach Collins bestimmte Annahmen erforderlich. Dabei wird die Schubspannungsverteilung im Schubfeld als konstant angenommen. Über die maximale Längsdehnung $\left(\varepsilon_{\mathrm{x}}\right)$ in Höhe der Biegezugbewehrung nach Gleichung (7.13) kann die Hauptdehnung des Querschnittes bestimmt werden (Michael P. Collins 1996, S. 39). 
$\varepsilon_{\mathrm{X}}=\frac{\left(\frac{M}{d_{\mathrm{v}}}\right)+0,5 \cdot N+0,5 \cdot V \cdot \cot \theta-A_{\mathrm{ps}} \cdot f_{\mathrm{p} 0}}{E_{\mathrm{s}} \cdot A_{\mathrm{S}}+E_{\mathrm{p}} \cdot A_{\mathrm{ps}}} \geq 0$

Dabei sind:

$A_{\mathrm{ps}} \quad$ Die Querschnittsfläche der Spannstahlbewehrung in Längsachse des Bauteils,

$A_{\mathrm{S}}$ die Querschnittsfläche der Bewehrung in Längsachse des Bauteils,

$f_{\mathrm{p} 0} \quad$ die Spannstahlspannung,

$E_{\mathrm{s}} ; E_{\mathrm{p}} \quad$ die Elastizitätsmodule der Bewehrung und des Spannstahls.

Der Querkraftwiderstand des Betons ohne Ansatz einer Schubbewehrung ergibt sich nach Gleichung (7.14), die zur Anwendung im Berechnungsverfahren in Gleichung (7.15) überführt wurde (Michael P. Collins 1996, S. 37).

$V_{\mathrm{c}}=f_{1} \cdot \cot \theta \cdot b_{\mathrm{v}} \cdot d_{\mathrm{v}}$

$V_{\mathrm{c}}=\beta \cdot \sqrt{f_{\mathrm{c}}^{\prime}} \cdot b_{\mathrm{v}} \cdot d_{\mathrm{v}}$

Dabei sind:

$\beta$

Der Parameter zur Berücksichtigung mittlerer Zugdehnung im gerissenen Beton nach Gleichung (7.16),

$f_{\mathrm{c}}^{\prime} \quad$ die Zylinderdruckfestigkeit des Betons,

$b_{\mathrm{v}} \quad$ die kleinste Breite innerhalb des Schubfeldes,

$d_{\mathrm{v}} \quad$ die effektive schubübertragende Höhe, entspricht $z$ (innerer Hebelarm).

Werden Gleichung (7.5) und Gleichung (7.6) unabhängig von den Zugspannungen, bezogen auf die Richtung der Schubspannungen dargestellt, ergeben sich der Parameter $\beta$ zur Berücksichtigung mittlerer Zugdehnung bzw. als Indikator zur Schubübertragung im gerissenen Beton nach Gleichung (7.16) sowie sein Grenzwert zu Gleichung (7.17). Für Bauteile ohne Schubbewehrung ist der Querkraftwiderstand in erster Linie von der Rissweite abhängig, welche vereinfachend aus dem Produkt der Hauptzugdehnung und dem Rissabstand berechnet werden kann. Für Balkenkonstruktionen aus Beton entspricht der Rissabstand in etwa der statischen Höhe bzw. dem Längsbewehrungsabstand. Unter Anwendung dieser Grundlagen kann der $\beta$-Faktor als Funktion aus der Druckstrebenneigung $(\theta)$, der Längsdehnung $\left(\varepsilon_{1} / \sin \theta\right)$ und dem Rissabstand $\left(s_{\mathrm{X}}\right)$ berechnet werden. Dabei tabelliert Collins $\beta$-Werte, die in Abhängigkeit einer vorgegeben Rissweite sowie einem vorgegebenen Druckstrebenwinkel ermittelt und auf ein Größtkorn von 19 mm bezogen wurden. Unter Verwendung eines abweichenden Größtkorns erfolgt die Umrechnung nach Gleichung (7.18). Durch Gleichung (7.17) und Gleichung (7.19) sowie der Annahme für die Rissweite nach Gleichung (7.20) kann der Grenzwert für $\beta_{\text {Grenz }}$ vereinfacht durch Gleichung (7.21) dargestellt werden (Michael P. Collins 1996, S. 41).

$$
\begin{aligned}
& \beta=\frac{0,33 \cdot \cot \theta}{\left(1+\sqrt{500 \cdot \varepsilon_{1}}\right)} ; \operatorname{vgl} . \text { (7.5) } \\
& \beta_{\text {Grenz }} \leq \frac{0,18}{0,31+\frac{24 \cdot w}{a g+16}} ; \operatorname{vgl} \text {. (7.6) und (7.7) }
\end{aligned}
$$


$s_{\mathrm{xe}}=s_{\mathrm{X}} \cdot \frac{35}{a_{\mathrm{g}}+16}$

$S_{\mathrm{X}}=\frac{S_{\mathrm{xe}} \cdot\left(a_{\mathrm{g}}+16\right)}{35}$

$w \triangleq S_{\mathrm{X}} \cdot \frac{\varepsilon_{1}}{\sin \theta}$

$\beta_{\text {Grenz }} \leq \frac{0,18}{0,31+\frac{24 \cdot \varepsilon_{1} \cdot s_{\mathrm{Xe}} \cdot\left(a_{\mathrm{g}}+16\right)}{\left(a_{\mathrm{g}}+16\right) \cdot \sin \theta \cdot 35}}=\frac{0,18}{0,31+\frac{0,686 \cdot \varepsilon_{1} \cdot s_{\mathrm{Xe}}}{\sin \theta}}$

Dabei ist:

$S_{\mathrm{xe}} \quad$ Der effektive Rissabstand in Abhängigkeit des Größtkorns nach Gleichung (7.18).

Für Leichtbetone sowie hochfeste Betone, bei denen die Risse durch die Gesteinskörnung verlaufen, ist der Faktor zur Berücksichtigung des Größtkorns $\left(a_{\mathrm{g}}\right)$ mit Null anzunehmen. Für Mauersteine des üblichen Hochbaus erscheint dieses Vorgehen ebenfalls zweckmäßig. Gleichwohl ist in zukünftigen Untersuchungen zu prüfen, ob dies auch in vollem Umfang für Kalksandsteine zutreffend ist, da bei diesen, je nach Hersteller, eine maximale Korngröße von bis zu 8 mm verwendet wird; siehe Abschnitt 4.2.2.

Der Druckstrebenwinkel zum Zeitpunkt des maximalen Schubwiderstandes nach Gleichung (7.22) ergibt sich für Bauteile aus Beton ohne Schubbewehrung unter der Vorrausetzung, dass Gleichung (7.16) und Gleichung (7.21) denselben Wert aufweisen (Adebar und Collins 1996, S. 35).

$$
\begin{aligned}
& \theta=\tan ^{-1}\left(\frac{0,568+\frac{1,258 \cdot s_{\mathrm{x}} \cdot \varepsilon_{1}}{\sin \theta}}{1+\sqrt{500 \varepsilon_{1}}}\right) \\
& \theta=\left(29 \mathrm{deg}+7000 \varepsilon_{\mathrm{x}}\right)\left(0,88+\frac{s_{\mathrm{xe}}}{2500}\right) \leq 75 \mathrm{deg}
\end{aligned}
$$

Auf Basis der Gleichungen (7.21) und (7.22) sind in Bild 7.4 $\beta$ - und $\theta$-Werte angegeben, die in Abhängigkeit verschiedener Werte für $\varepsilon_{1}$ und $s_{\mathrm{xe}}$ ermittelt wurden. Darüber hinaus kann die Umrechnung zwischen der Hauptzugdehnung und der Längsdehnung durch Gleichung (7.24) erfolgen. Die Schnittpunkte geben $\beta$-Werte an, bei denen Gleichung (7.22) und Gleichung (7.24) beiderseits erfüllt werden (Bentz, Evan, C. et al. 2006, S. 618). 


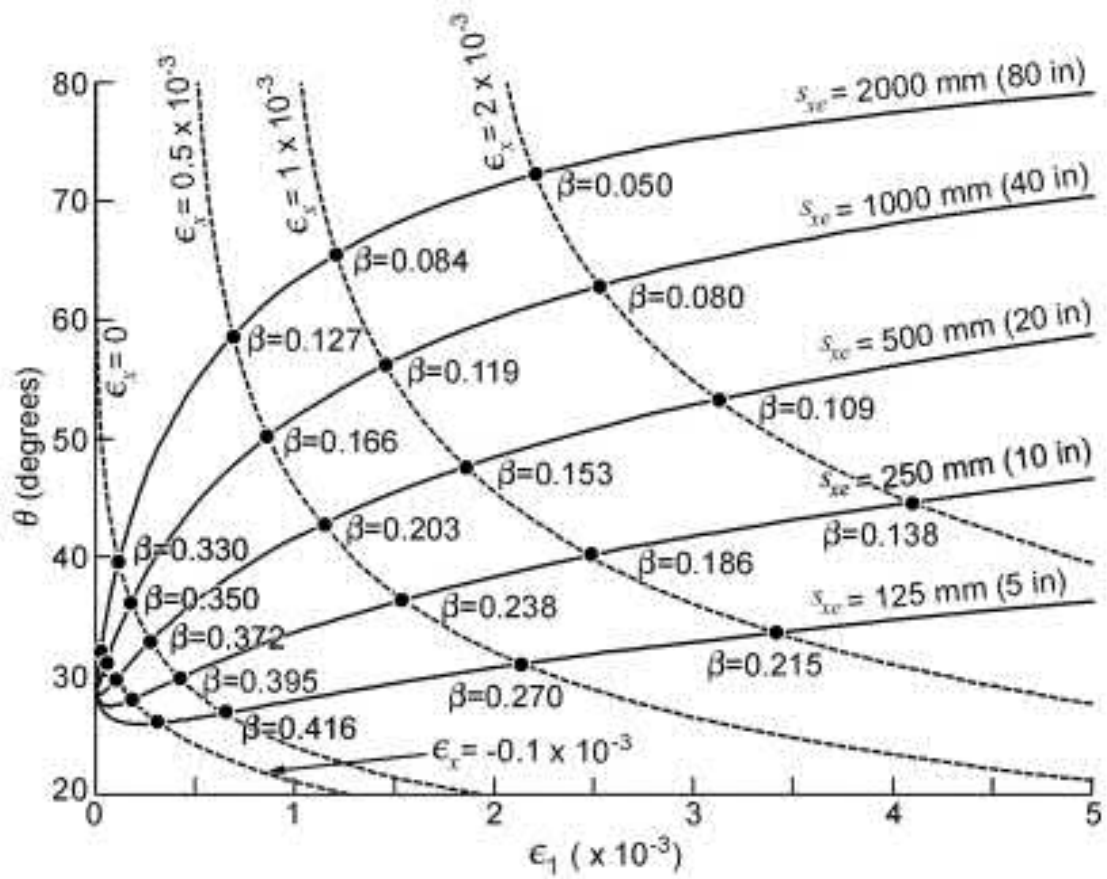

Bild 7.4 Werteermittlung von $\beta$ - und $\theta$-Werten für Bauteile ohne Schubbewehrung (Bentz, Evan, C. et al. 2006, S. 617)

$$
\varepsilon_{1}=\varepsilon_{\mathrm{x}} \cdot\left(1+\cot ^{2} \theta\right)+\frac{\cot ^{4} \theta}{15000 \cdot\left(1+\sqrt{500 \cdot \varepsilon_{1}}\right)}
$$

Berechnungen nach der Modified Compression Field Theory (MCFT) sind mit analytischen Mitteln nicht lösbar. Sie werden daher überwiegend in FE-Rechnungen vorgenommen. Um dieses Modell jedoch auch für einfache Bemessungsaufgaben zu verwenden, haben Bentz et al. diese Methode zur „Simplified Modified Compression Field Theory“" (SMCFT) vereinfacht (Huber et al. 2014, S. 22).

\subsubsection{Simplified Modified Compression Field Theory}

Die Anwendung der SMCFT basiert auf den Merkmalen der verallgemeinerten Spannungsfelder und wird im fib Model Code (MC) 2010 (Volume 3) zur Bemessung von Stahlbetonbalken erläutert. Dabei resultiert diese Methode aus einer durch Bentz et al. getroffenen Vereinfachung der zuvor erläuterten MCFT (Vecchio, Frank, J. und Collins, Michael, P 1986). Bild 7.5 zeigt den Unterschied des Maßstabs- und Längsdehnungseinflusses, ausgedrückt durch Gleichung (7.28), im Vergleich zur MCFT.
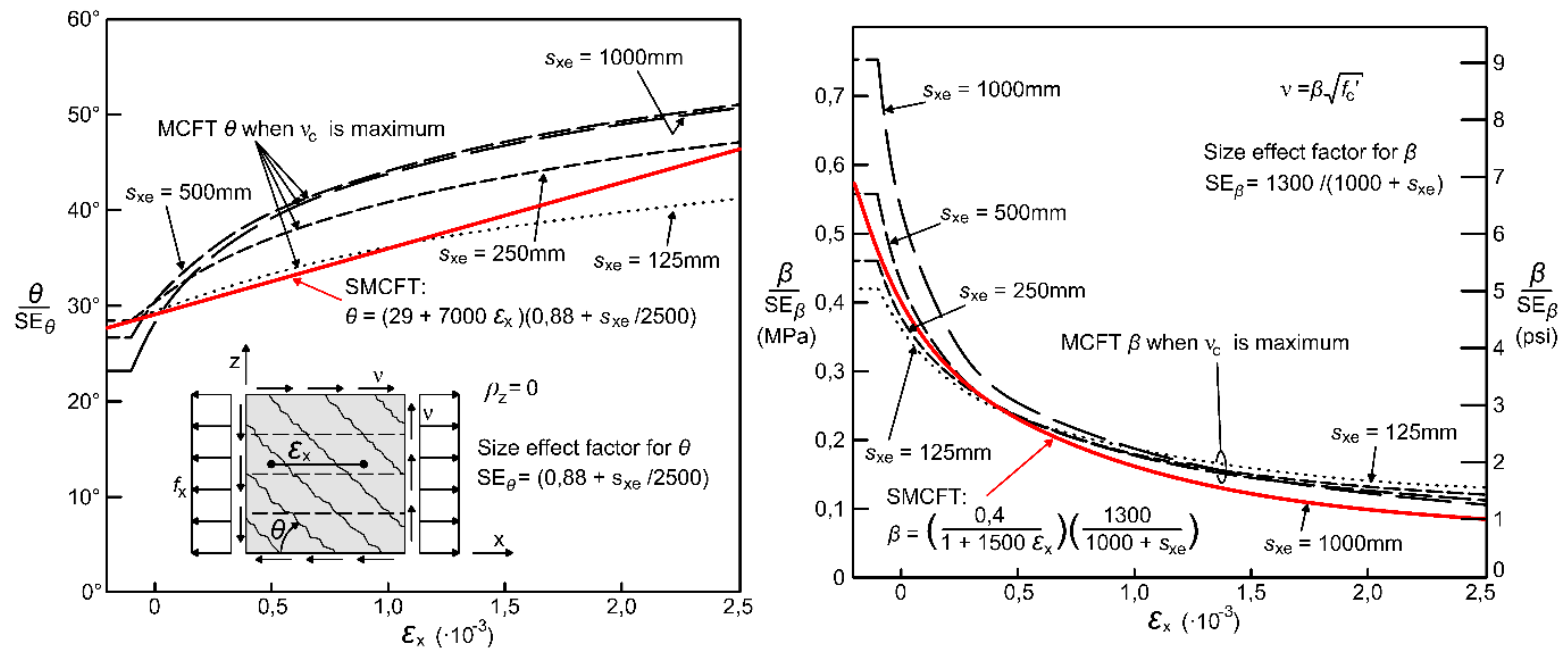

Bild 7.5 Vergleich von $\theta$ - und $\beta$-Werten in Abhängigkeit der MCFT und der SMCFT; vgl. (Bentz, Evan, C. et al. 2006, S. 618) 
In den Gleichungen der MCFT sind der Maßstabsfaktor und der Spannungsfaktor nicht völlig unabhängig voneinander. Diese Abhängigkeit wurde in der SMCFT vernachlässigt, wodurch $\beta$ aus dem Produkt der beiden Faktoren hervorgeht. Der Spannungsfaktor steht für die Berücksichtigung des Momenten-QuerkraftEinflusses auf die Längsdehnung. Der Maßstabsfaktor wurde von Bentz et al. auf den Rissabstand zurückgeführt, der direkt proportional zum inneren Hebelarm ist und als Produkt aus dem Größtkorn und der Schubfeldhöhe hervorgeht. Der Rissabstand wird über den Einfluss der Rissverzahnung bzw. dem davon maßgebenden Parameter, dem Größtkorndurchmesser, berücksichtigt. Wie schon bei der MCFT ist der Größtkorndurchmesser bei der Verwendung von Leichtbetonen und hochfesten Betonen infolge Rissbildung durch die Gesteinskörner zu Null zu setzen. Der Winkel der Druckstrebe wird in der SMCFT vereinfachend nach Gleichung (7.25) bestimmt; siehe auch Bild 7.5.

$$
\theta=\left(29 \mathrm{deg}+7000 \cdot \varepsilon_{\mathrm{x}}\right)
$$

Der fib MC 2010 unterscheidet für sogenannte „Level of Approximation“ (LOA), die für die Schubbemessung in Abhängigkeit der Rechengenauigkeit in drei Stufen (I...III) eingeteilt werden (Huber et al. 2012, S. 451). An dieser Stelle erfolgt eine Erläuterung des Berechnungsablaufes anhand der LOA II, bei welcher der Einfluss der Längsdehnungen berücksichtigt ist. Neben dem Gleichgewicht, welches an einem Bauteil im Zustand II mit Berücksichtigung eines mehraxialen Werkstoffverhaltens formuliert wird, werden auch die Verträglichkeitsbedingungen des Druckfeldes in Bezug auf die Druckstrebenneigung berücksichtigt. Dabei ist die Neigung des Druckspannungsfeldes abhängig von der Längsdehnung $\left(\varepsilon_{\mathrm{x}}\right)$ nach Gleichung (7.29) bzw. Gleichung (7.30), die auf einer Kontrollebene in halber Schubfeldhöhe bestimmt wird. Grundsätzlich setzt sich der Querkraftwiderstand bei Stahlbetonbalken aus einem Betontraganteil und einem Anteil der Querkraftbewehrung zusammen. Bei der Berechnung der Querkrafttragfähigkeit wird davon ausgegangen, dass der Schubwiderstand allein von dem Stegquerschnitt gebildet wird. Dabei wird die effektive Steglänge zwischen dem Schwerpunkt der Biegebewehrung und dem Schwerpunkt der Druckzone nach Bild 7.6 angenommen.

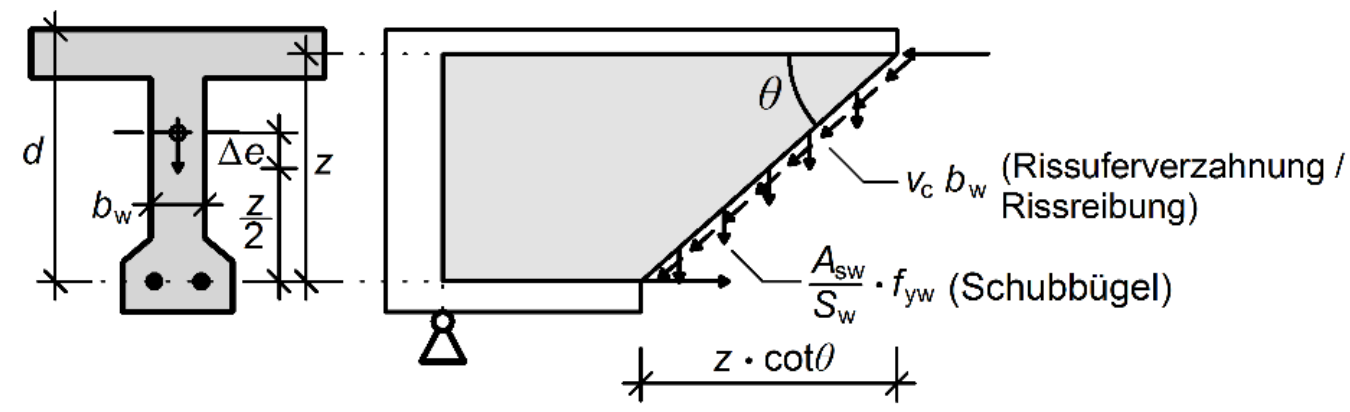

Bild 7.6 Effektive Schublänge biegeschlanker Bauteile; vgl. (Beverly 2013, S. 218)

Für Bauteile ohne Querkraftbewehrung ergibt sich der Querkraftwiderstand im Wesentlichen aus der Rissuferverzahnung, also der im Riss übertragbaren Schubspannung, die in Abhängigkeit der Rissöffnungen begrenzt ist (Huber et al. 2014, S. 21). Die in die Gleichung (7.26) eingehende axiale Längsdehnung $\left(\varepsilon_{\mathrm{x}}\right)$ berücksichtigt dabei den negativen Einfluss aus dem Biegemoment und der Querkraft auf den Schubwiderstand (Tue et al. 2014, S. 669). Dabei muss die Bewehrung eine aus der Querkraft zusätzlich resultierende Zugkraft aufnehmen können, wobei die Zugkraft an keiner Stelle des Balkens größer ist als das Verhältnis von maximalem Moment zu innerem Hebelarm (Bild 7.7). Dies führt zu einer zusätzlichen Dehnung , , $\varepsilon_{\mathrm{X}}$ “ in Balkenmitte (Bild 7.8) und damit einer Berücksichtigung in Gleichung (7.26). 

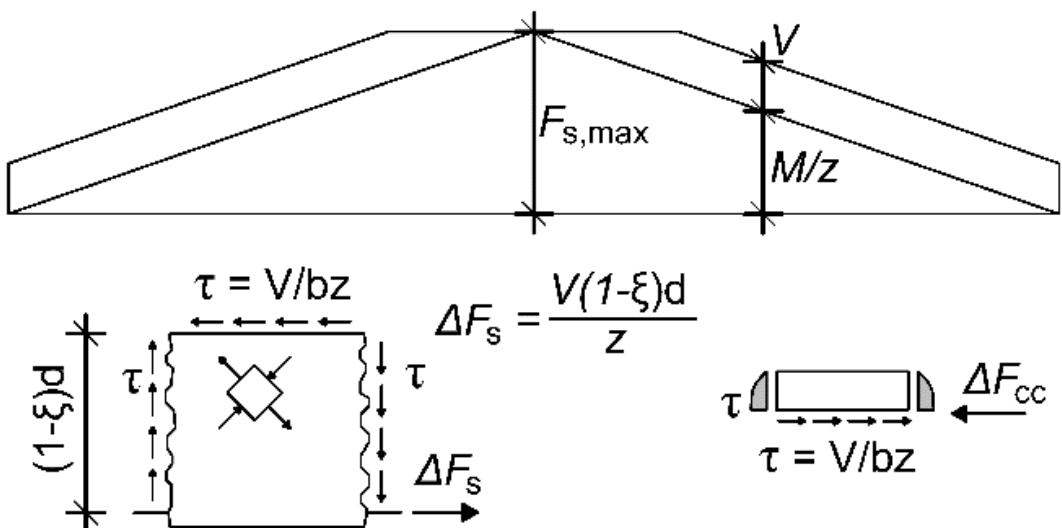

a)

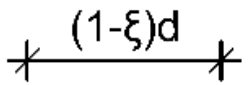

b)

Bild 7.7 Zusammengesetzte Zugkraft in der Bewehrungsebene (oben); Schubfeld (unten links); Druckspannung (unten rechts); vgl. (Herbrand und Hegger 2017, S. 705)
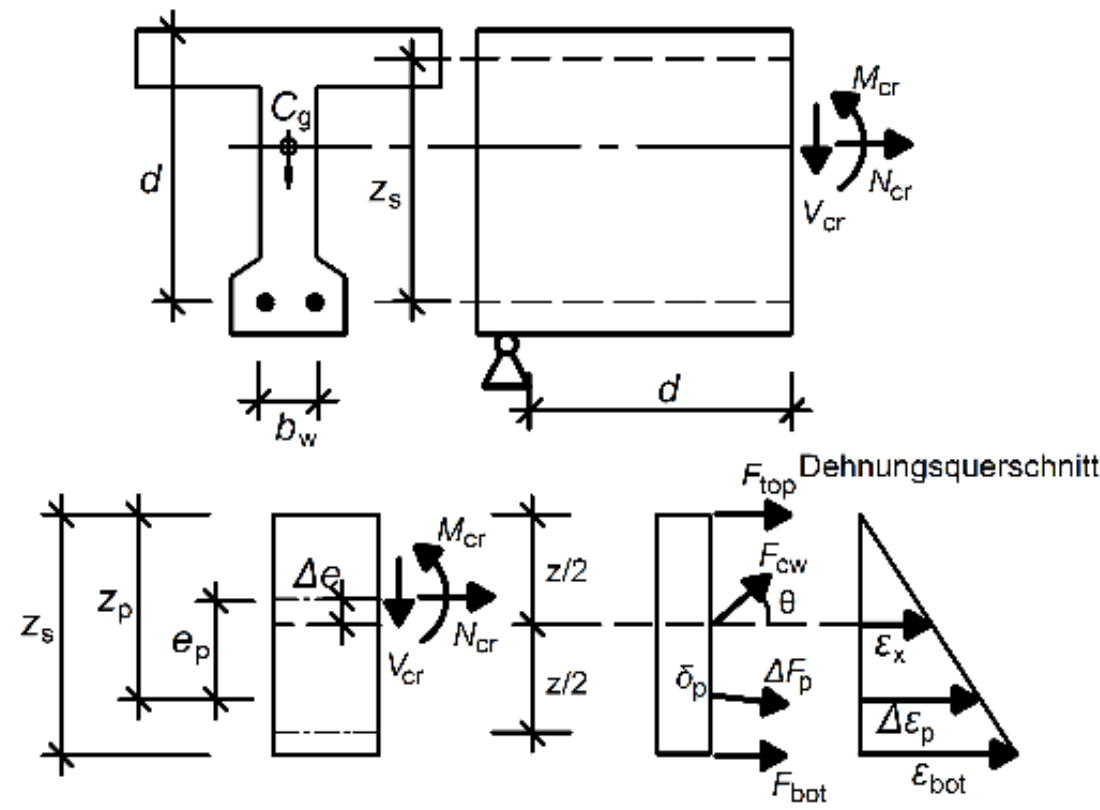

Bild 7.8 Berechnungsquerschnitt: Definition der Längsdehnung $\left(\varepsilon_{\mathrm{x}}\right)$; vgl. (Beverly 2013, S. 219)

Für Balken ohne Schubbewehrung ermittelt sich der Querkraftwiderstand aus dem Betontraganteil nach Gleichung (7.26). Zur Berücksichtigung auflagernaher Einzellasten kann die einwirkende Querkraft durch Multiplikation mit dem Faktor $\beta$ nach Gleichung (7.27) abgemindert werden. Die angegebenen Grenzwerte sind zu beachten.

$$
\begin{aligned}
& V_{\mathrm{R}, \mathrm{c}}=k_{\mathrm{v}} \cdot \sqrt{f_{\mathrm{ck}}} \cdot z \cdot b_{\mathrm{w}} \\
& \beta=\left\{\begin{array}{c}
d<a_{\mathrm{v}} \leq 2 \cdot d \rightarrow \beta=\frac{a_{\mathrm{v}}}{2 \cdot d} \\
a_{\mathrm{v}}<d \rightarrow \beta=0,5
\end{array}\right.
\end{aligned}
$$

Dabei sind:

$k_{\mathrm{v}} \quad$ Der Parameter: Dehnungszustand und Maßstabseinfluss nach Gleichung (7.28),

$a_{\mathrm{v}} \quad$ der Abstand zwischen Auflagerrand und Rand der Lasteinleitung.

$k_{\mathrm{v}}=\frac{0,4}{1+1500 \cdot \varepsilon_{\mathrm{x}}} \cdot \frac{1300}{1000+k_{\mathrm{dg}} \cdot z}$. 
Dabei sind:

$\varepsilon_{\mathrm{x}} \quad$ Die Längendehnung in halber Querschnittshöhe bei Spannbetonbauteilen und zugehörigem einwirkenden Moment nach Gleichung (7.29) bzw. (7.30),

ohne Vorspannung $\quad \varepsilon_{\mathrm{x}}=\frac{1}{2 \cdot E_{\mathrm{S}} \cdot A_{\mathrm{S}}} \cdot\left(\frac{M_{\mathrm{Ed}}}{z}+V_{\mathrm{Ed}}+N_{\mathrm{Ed}} \cdot\left(\frac{1}{2} \pm \frac{\Delta e}{z}\right)\right)$,

$\varepsilon_{\mathrm{x}}$

mit Vorspannung $\quad \varepsilon_{\mathrm{X}}=\frac{\left(\frac{M_{\mathrm{Ed}}}{z}\right)+V_{\mathrm{Ed}}+N_{\mathrm{Ed}} \cdot\left(\frac{z_{\mathrm{p}}-e_{\mathrm{p}}}{z}\right)}{\left(\frac{z_{\mathrm{S}}}{z} \cdot E_{\mathrm{S}} \cdot A_{\mathrm{s}}+\frac{z_{\mathrm{p}}}{z} \cdot E_{\mathrm{p}} \cdot A_{\mathrm{p}}\right)}$,

$f_{\mathrm{ck}} \quad$ die Betondruckfestigkeit; in Funktion $\sqrt{f_{\mathrm{ck}}} \leq 8 \frac{\mathrm{N}}{\mathrm{mm}^{2}}($ in N/mm²),

z die Schubfeldhöhe bzw. innerer Hebelarm nach Gleichung (7.31),

$z=0,9 \cdot d$

$k_{\mathrm{dg}} \quad$ der Parameter in Abhängigkeit des Größtkorns nach Gleichung (7.32),

$k_{\mathrm{dg}}=\frac{32}{d_{g}+16} \geq 0,75$

$d_{\mathrm{g}}$

der Größtkorndurchmesser der Gesteinskörnung; für Leichtbeton oder hochfesten Beton, bei dem die Risse durch das Gesteinskorn verlaufen, ist $d_{\mathrm{g}}=0$ zu setzen.

\subsection{Modellvorschlag und Berechnungsalgorithmen}

Die Ermittlung des Querkraftwiderstandes von Mauerwerkbalken ohne Querkraftbewehrung soll hier in Anlehnung an die Berechnungsgleichung (Gleichung (7.26)) nach fib MC 2010 erfolgen, welche auf den Grundlagen der „SMCFT“ basiert.

$$
V_{\mathrm{R}}=\sqrt{f_{\mathrm{ck}}} \cdot k_{\mathrm{v}} \cdot z \cdot b_{\mathrm{w}}
$$

Bei Mauerwerkbalken entstehen durch den Lastabtrag im Bereich zwischen Lasteinleitung und Auflager ebenfalls Druckspannungsfelder. Die unter einem Neigungswinkel $(\theta)$ verlaufenden resultierenden Druckstreben bewehrter Mauerwerkbalken weichen sowohl von der vertikalen als auch horizontalen Richtung des Mauerwerks ab. Für Betonkonstruktionen ist dies nahezu bedeutungslos, weil dort von annähernd isotropem Werkstoffverhalten des Betons ausgegangen wird. Anders ist dies im Mauerwerkbau; hier herrschen, je nach Mauerwerksstein und Stein-Mörtelkombination, unterschiedlich intensiv ausgeprägte anisotrope Werkstoffverhältnisse im Mauerwerk vor. Infolge dessen ist die Größe der Mauerwerkdruckfestigkeit von der Beanspruchungsrichtung unter einem Belastungswinkel $(\alpha)$ abhängig und von elementarer Bedeutung.

In Bild 7.9 ist die klassische Definition der Lagerfuge und der Stoßfuge bezogen auf die Richtung der Druckfestigkeit in $f_{\mathrm{x}}$ - und $f_{\mathrm{y}}$-Richtung für in üblicherweise hergestelltes Mauerwerk angegeben.

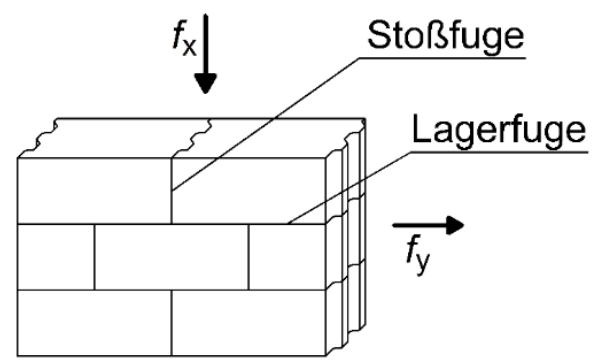

Bild 7.9 Definition Lagerfuge ( $f_{\mathrm{x}}$-Richtung) und Stoßfuge $\left(f_{\mathrm{y}}\right.$-Richtung) bezogen auf die Anordnung der Steine in Wänden für üblicherweise hergestelltes Mauerwerk 
Für die Übertragung der für Beton entwickelten Gleichung (7.26) auf Mauerwerk ist daher eine Anpassung der Festigkeitsgröße $f_{\text {ck }}$ erforderlich, die in eben diese Gleichung über einen vereinfachten Wurzel-Ansatz $\sqrt{f_{\text {ck }}}$ zur Erfassung der Betonzugfestigkeit eingeht. Für Mauerwerkbalken soll hier die Druckfestigkeit des anisotropen Mauerwerks unter Berücksichtigung eines Belastungswinkels $(\alpha)$ eingesetzt werden. Hierzu dienen die in Bild 7.10 und Bild 7.11 dargestellten Angaben. Dort werden Richtungsangaben für die Druckfestigkeit $\left(f_{\mathrm{x}}\right)$ senkrecht zu den Lagerfugen und $\left(f_{\mathrm{y}}\right)$ parallel zu den Lagerfugen für in üblicher Weise hergestelltes Mauerwerks gemacht. Der Unterschied in der Betrachtungsweise des Mauerwerkes von Flachstürzen und scheitrechten gemauerten Fertigteilstürzen besteht darin, dass bei Letzteren die als Bezugsebene dienende Lagerfuge um $90^{\circ}$ gedreht ist. Je nach Einbausituation des Mauerwerks bzw. der Mauersteine entspricht der Neigungswinkel $(\alpha)$ also der Rissneigung $(\theta)$ oder dem Ergänzungswinkel von ( $\theta$ ) zu $90^{\circ}$ (Bild 7.10). Aufgrund der o.g. Drehung der Mauersteine ist bei scheitrechten Mauerwerkbalken die Druckfestigkeit senkrecht zur Lagerfuge $\left(f_{\mathrm{x}}\right)$ mit der Druckfestigkeit in horizontaler Richtung gleichzusetzen; diese bestimmt somit die Tragfähigkeit der Biegedruckzone; siehe Bild 7.10.

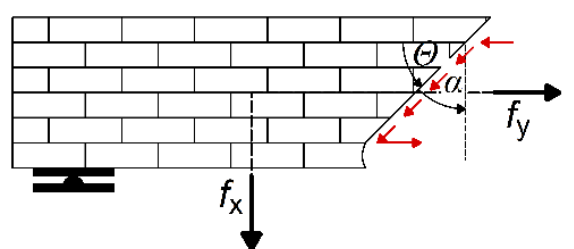

Flachsturz

Druckstrebenwinkel $\theta=90^{\circ}-\alpha$
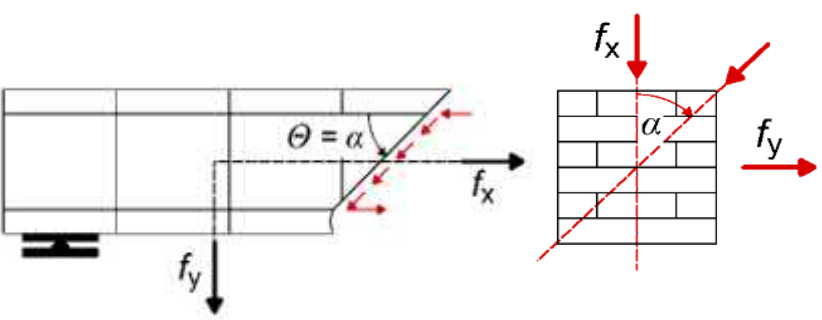

scheitrechter Fertigteilsturz

Druckstrebenwinkel $\theta=\alpha$

Bild 7.10 Einbau- und Belastungssituation von Mauerwerk für die Richtung der Mauerwerkdruckfestigkeiten $\left(f_{\mathrm{x}}\right)$ und $\left(f_{\mathrm{y}}\right)$

In diesem Sinne haben Ganz und Mojsilović Untersuchungen zum Tragverhalten von druckbeanspruchtem Mauerwerk unter einem Neigungswinkel $(\alpha)$ durchgeführt; siehe Abschnitt 3.3.2.2. Darin wird die Tragfähigkeit von Mauerwerk in Abhängigkeit verschiedener Bruchbedingungen beschrieben. Folgende durch sie entwickelte Bruchbedingungen (B - F; Bild 7.11) für einen Neigungswinkel $0^{\circ}<\alpha<90^{\circ}$ sind auf ein Schubzugversagen des Mauerwerks bzw. ein Reibungsversagen der Mauerwerkfugen zurückzuführen:

1. Druckfestigkeit parallel zur Lagerfuge $(\mathrm{B}-\mathrm{C})$,

2. Gleiten entlang der Stoßfuge $(\mathrm{C}-\mathrm{D})$,

3. Gleiten entlang der Lagerfuge $(\mathrm{D}-\mathrm{E})$,

4. Trennbruch in der Lagerfuge $(\mathrm{E}-\mathrm{F})$.

Über diese Bruchmechanismen sind in dem Materialmodell für druckbeanspruchtes Mauerwerk Reibungsbzw. Schubzugversagen des Mauerwerks berücksichtigt. Dieser Ansatz ermöglicht eine Bestimmung der Mauerwerkdruckfestigkeit $\left(f_{\alpha}\right)$ für einen Neigungswinkel zwischen $0^{\circ}<\alpha<90^{\circ}$. Bild 7.11 zeigt eine Abhängigkeit des Bruchkriteriums vom Neigungswinkel und der vorhandenen Konstruktionsart scheitrechter Mauerwerkbalken und Flachstürze. Bezogen auf die Definition der Beanspruchungsrichtung $f_{\mathrm{x}}$ bzw. $f_{\mathrm{y}}$ nach Bild 7.9 werden gedrungene Flachstürze sowie schlanke, scheitrechte Mauerwerkbalken überwiegend in den Stoßfugen beansprucht. Umgekehrt erfahren sowohl schlanke Flachstürze als auch gedrungene scheitrechte Mauerwerkbalken im Wesentlichen eine Beanspruchung in den Lagerfugen. 


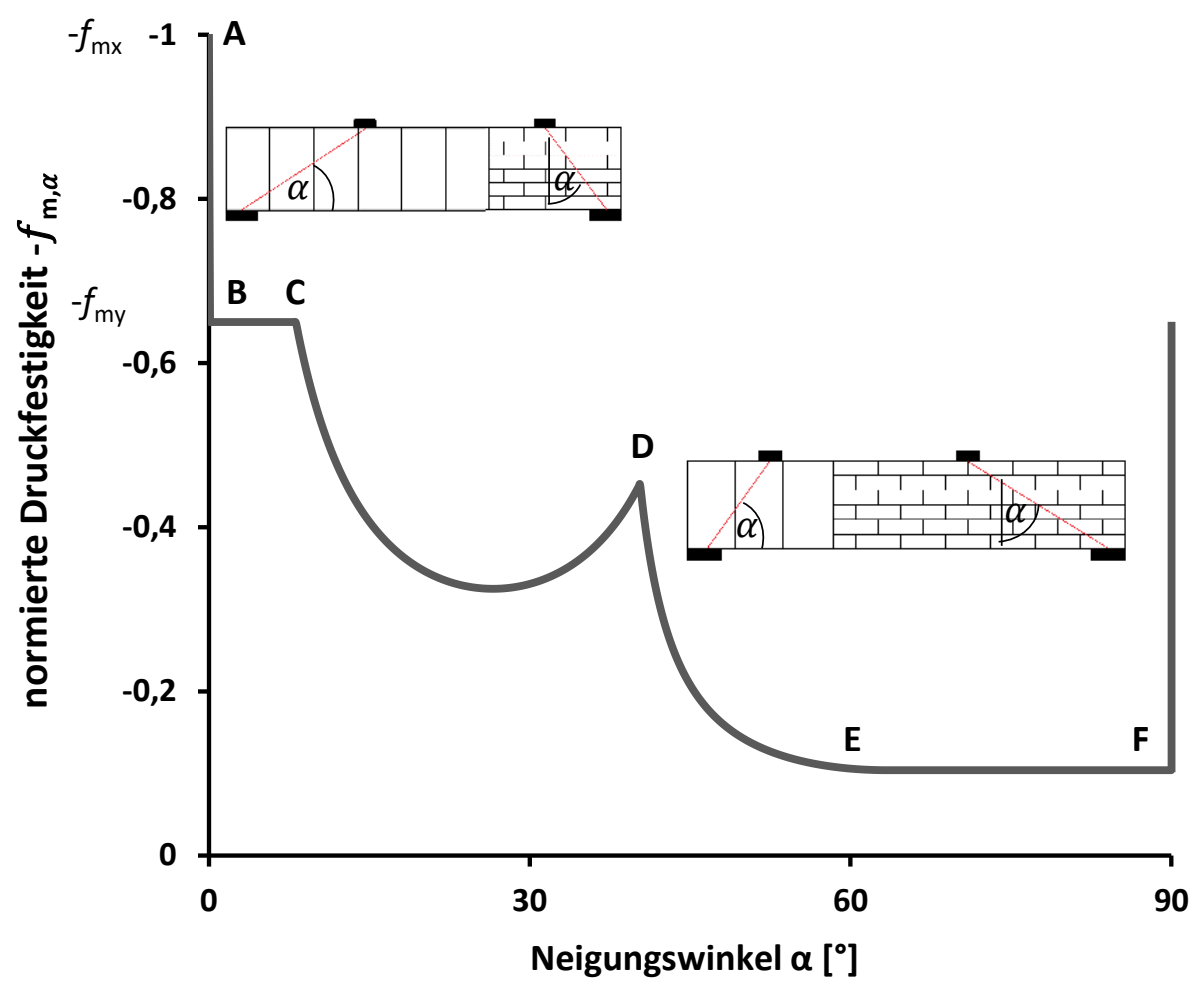

Bild 7.11 Werkstoffmodell druckbeanspruchten Mauerwerks: Abhängigkeit des Bruchkriteriums vom Neigungswinkel und der Konstruktionsart; hier scheitrechter Balken (links); Flachsturz (rechts)

Durch diesen Zusammenhang kann der Wurzel-Ansatz ursprünglich zur Berücksichtigung der Zugfestigkeit des Betons für die Übertragung auf Mauerwerk durch die richtungsabhängige Mauerwerkfestigkeit $\left(f_{\alpha}\right)$ ersetzt werden, wodurch sich Gleichung (7.33) ergibt. Der im Schubfeld wirkende globale Druckstrebenwinkel $(\theta)$ kann dabei über das Verhältnis nach Gleichung (5.2) bestimmt werden; was in Abschnitt 5.3.5 bereits empirisch verifiziert wurde. Beim scheitrechten Fertigteilbalken entspricht dieser, wie oben beschrieben, dem Neigungswinkel $(\alpha)$; siehe auch Bild 7.10.

$$
V_{\mathrm{R}}=f_{\alpha} \cdot k_{\mathrm{v}} \cdot z \cdot b_{\mathrm{w}}
$$

Dabei ist:

$f_{\alpha}$

Die richtungs- und vom Belastungswinkel $(\alpha)$ abhängige Mauerwerkdruckfestigkeit.

- Scheitrechter Balken: $\quad \alpha=\theta_{\text {rechn. }}=\arctan \left(\frac{1}{\lambda}\right)=\arctan \left(\frac{\max V_{\mathrm{Ed}} \cdot d}{\max M_{\mathrm{Ed}}}\right)=\arctan \left(\frac{d}{a}\right)$

- Flachsturz:

$$
\alpha=\arctan \left(\frac{a}{d}\right)
$$

Nach fib MC 2010 berücksichtigt der Parameter $k_{\mathrm{v}}$ (Gleichung (7.28)) den Dehnungszustand sowie den Maßstabseinfluss; siehe Abschnitt 7.1.2.

$$
k_{\mathrm{v}}=\frac{0,4}{1+1500 \cdot \varepsilon_{\mathrm{x}}} \cdot \frac{1300}{1000+k_{\mathrm{dg}} \cdot z}
$$

Die Abminderung der Betonzugfestigkeit $\sqrt{f_{\text {ck }}}$ nach der SMCFT über den Dehnungszustand ist auf die abfallende Zugfestigkeit durch einsetzende Rissbildung bis hin zum Gleitversagen im Riss zurückzuführen; siehe Abschnitt 7.1.1 (Bild 7.2). Im Mauerwerkbau stellen die Fugen potenzielle Risse dar, wodurch davon ausgegangen wird, dass ein vergleichbarer Effekt auftritt. Hier ist die Abminderung der Mauerwerkfestigkeit $f_{\alpha}$ auf die abfallende Zugfestigkeit, ebenfalls infolge Reibungsversagen der 
Mauerwerkfugen, zurückzuführen. Bild 7.12 zeigt eine typische Spannungs-Verschiebungslinie zugbeanspruchten Mauerwerks parallel zur Lagerfuge infolge Fugenversagen, bei der dieser Effekt dokumentiert wurde. Für den hier vorzustellenden Berechnungsvorschlag wird daher der gleiche Ansatz, wie im ersten Faktor der Gleichung (7.28) enthalten, verwendet. Da diese Annahme nicht uneingeschränkt auf jedes Mauerwerk übertragbar ist, sind zukünftig in diesem Bereich weitere Untersuchungen notwendig.

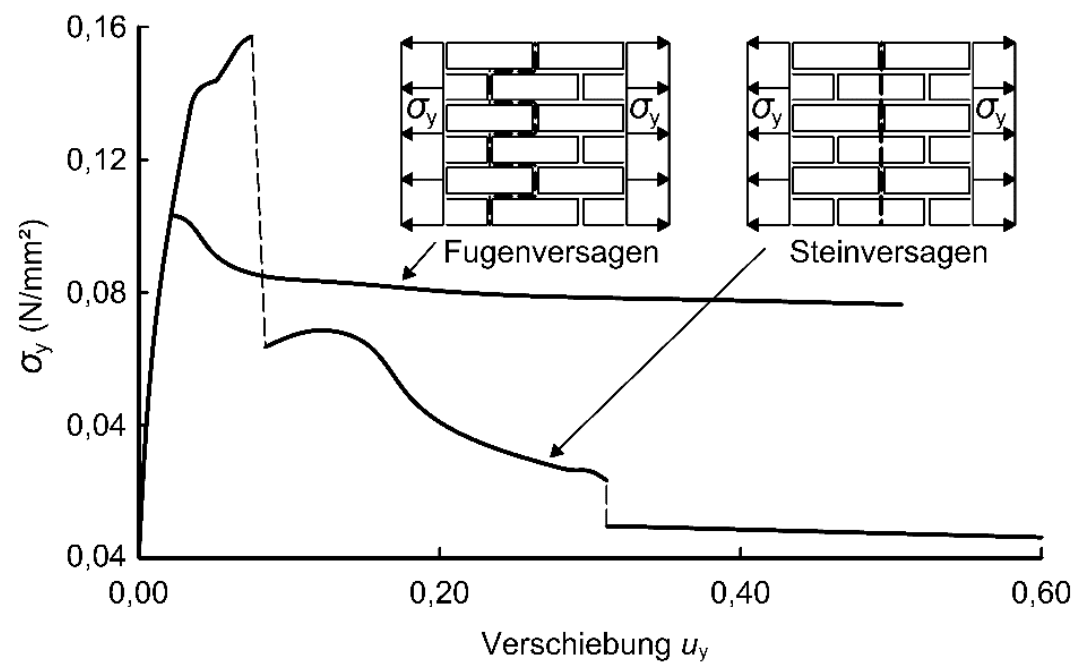

Bild 7.12 Mauerwerkzugfestigkeit parallel zur Lagerfuge für den Versagensfall Fugenversagen und Steinzugversagen (Schlegel 2004, S. 26; Backes 1985, B 54 - B 56)

In der dem fib MC 2010 zugrunde liegenden Theorie ist der Maßstabsfaktor (s.a. Abschnitt 4.2.5) sowohl abhängig von der statischen Höhe des Bauteils als auch vom Größtkorndurchmesser des Materials; siehe Abschn. 7.1.1 und Abschn. 7.1.2. Für Leichtbetone und hochfeste Betone ist der Größtkorndurchmesser $\left(d_{\mathrm{g}}\right)$ zu Null zu setzen, da die Rissbildung durch die Aggregate verläuft. Dies gilt auch für Mauersteine mit einem Größtkorndurchmesser $D_{\max } \leq 16 \mathrm{~mm}$. Dies trifft für die hier verwendeten und die überwiegende Anzahl bekannter Mauersteine zu. Für $k_{\mathrm{dg}}$ nach Gleichung (7.32) ergibt sich hierfür ein konstanter Faktor zu $k_{\mathrm{dg}}=2$, wodurch der Maßstabsfaktor nur noch von dem Hebelarm der inneren Kräfte $(z)$ abhängt. Ein Vergleich der Ansätze zur Ermittlung des Maßstabeffektes nach Eurocode 2 und fib MC 2010 zeigt einen nahezu identischen Verlauf der nichtlinearen Gleichungsanteile; siehe Bild 7.13. 


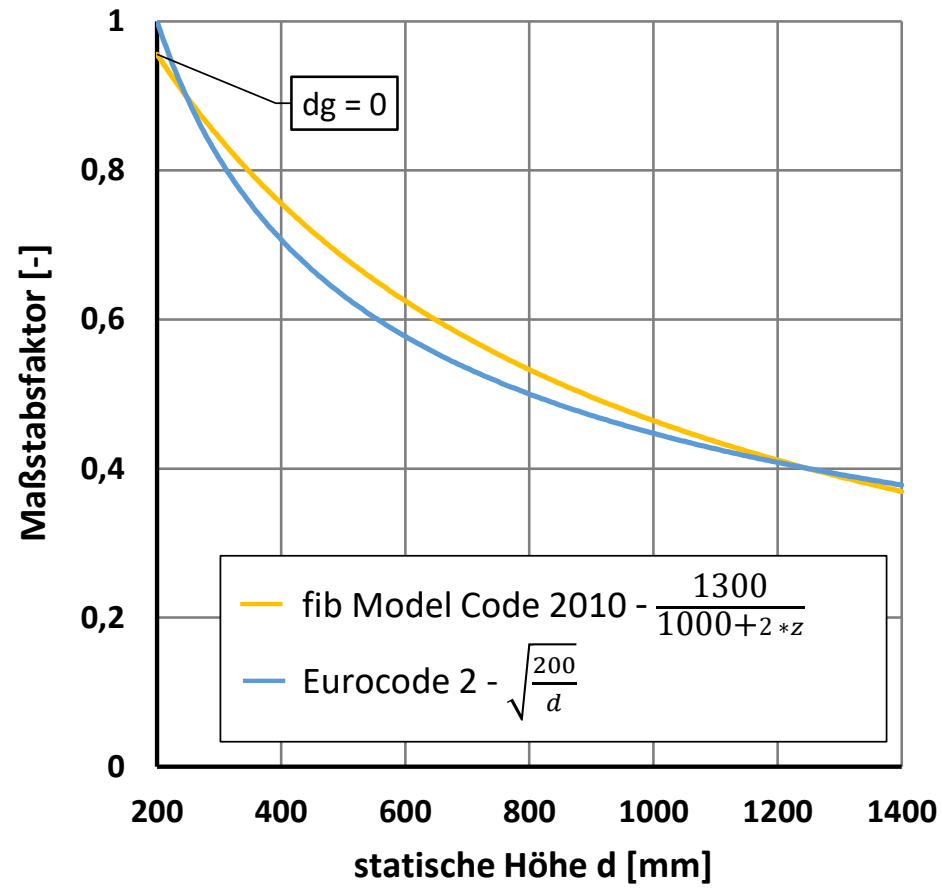

Bild 7.13 Vergleich zur Berücksichtigung des Maßstabseinflusses zwischen fib MC 2010 und Eurocode 2

Die experimentellen Untersuchungen haben gezeigt, dass für reine Mauerwerkbalken im Gegensatz zum Stahlbetonbau der Hebelarm der inneren Kräfte vereinfacht nach Gleichung (7.35) angenähert werden kann. Im Fall einer aufliegenden, rechnerisch zu berücksichtigenden Stahlbetondecke, ist der Hebelarm nach Gleichung (7.36) anzunehmen; siehe hierzu Abschnitt 5.3.4.

$$
\begin{aligned}
& z_{\mathrm{MW}}=0,85 \cdot d \\
& z_{\mathrm{MW}+\mathrm{C}}=0,9 \cdot d
\end{aligned}
$$

Dabei ist:

$d \quad$ Die statische Höhe.

Ist zusätzlich zu dem Mauerwerkbalken eine aufliegende Betondecke in der Berechnung zu berücksichtigen, wird der die Tragfähigkeit erhöhende Einfluss mittels geometrischer Interaktion zwischen Beton und Mauerwerk nach Gleichung (7.37) beschrieben.

$$
V_{\mathrm{R}}=k_{\mathrm{v}} \cdot\left(f_{\alpha} \cdot \frac{d-h_{\mathrm{c}}}{d}+\sqrt[3]{f_{\mathrm{cm}}} \cdot \frac{h_{\mathrm{c}}}{d}\right) \cdot z \cdot b_{\mathrm{w}}
$$

Dabei sind:

$$
\begin{aligned}
& h_{\mathrm{c}} \quad \text { Die Höhe der Ergänzungsschicht aus Beton, } \\
& f_{\mathrm{cm}} \quad \text { die mittlere Druckfestigkeit der Ergänzungsschicht aus Beton. }
\end{aligned}
$$

Die Festigkeiten der Baustoffe - Beton und Mauerwerk - wird gemäß ihrem Anteil an der statischen Höhe angesetzt. Abweichend von der Gleichung (7.33) geht in (7.37) die Betonzugfestigkeit als dritte Wurzel der Druckfestigkeit in die Berechnung ein; siehe hierzu Abschnitt 4.3.3.

Durch diese mechanisch begründeten Anpassungen ist die theoretische Anwendbarkeit der dem fib MC 2010 zugrunde liegenden Theorie „SMCFT“ auf Mauerwerk gegeben. 


\subsection{Vergleichsrechnungen auf Basis experimenteller und numerischer Untersuchungen}

Im Folgenden wird die Anwendbarkeit des Berechnungsvorschlages von Abschnitt 7.2 für Mauerwerkbalken anhand empirischer und numerischer Untersuchungsergebnisse nach Abschnitt 6 und Abschnitt 7 verifiziert. Hierzu erfolgten Vergleichsrechnungen zwischen theoretisch und experimentell ermittelten Schubtragfähigkeiten der in den Abschnitten 5.2, 5.4 und 5.5 beschriebenen scheitrechten, sowohl schlaff bewehrten als auch vorgespannten Balkenkonstruktionen aus Kalksandstein- und Ziegelmauerwerk. Für Flachstürze lagen bereits empirische, gut dokumentierte Untersuchungsergebnisse vor (Klute 2004), sodass für diese Konstruktionsart, neben den in Abschnitt 5.2 durchgeführten Untersuchungen, keine weiteren Prüfungen notwendig waren. Die Vergleichsrechnungen basieren auf entsprechenden Untersuchungsergebnissen.

Ein signifikanter Parameter für die Berechnung der Schubtragfähigkeit ist die Drucktragfähigkeit von Mauerwerk unter einem Winkel $\alpha>0^{\circ}$. Bild 7.14 zeigt das Materialmodell für Mauerwerk unter einachsiger Druckbeanspruchung in Anlehnung an die durch Ganz und Mojsilović vorgeschlagene praktische Näherung der zur Festlegung des Materialmodells notwendigen Materialparameter. Dabei sind:

1. Mauerwerkdruckfestigkeit senkrecht zur Lagerfuge $f_{\mathrm{mx}}$,

2. Mauerwerkdruckfestigkeit parallel zur Lagerfuge $f_{\mathrm{my}}=0,6 \cdot f_{\mathrm{mx}}$,

3. Kohäsion (Haftscherfestigkeit) der Lagerfuge $c=0,04 \cdot f_{\mathrm{my}}$,

4. Kohäsion (Haftscherfestigkeit) des Steinmaterials $c_{b}=0,25 \cdot f_{\mathrm{my}}$,

5. innerer Reibungswinkel der Lagerfuge $\varphi$ bzw. des Steinmaterials $\varphi_{\mathrm{b}}\left(\varphi=\varphi_{\mathrm{b}}=\tan ^{-1}(0,75)\right)$.

Diese können für eine Vorberechnung verwendet werden, solange keine weiteren Materialparameter bekannt sind. Für die in diesem Abschnitt durchgeführten Vergleichsrechnungen werden, entsprechend des vorliegenden Mauerwerks, sowohl für die Mauerwerkdruckfestigkeit parallel zur Lagerfuge als auch für die Haftscherfestigkeit des Mörtels, materialspezifische Parameter verwendet. Dabei wurde die Mauerwerkdruckfestigkeit parallel zur Lagerfuge in Anlehnung an einen Vorschlag von Brameshuber (Brameshuber 2016) bestimmt; siehe Gleichung (7.38).

$$
f_{\mathrm{my}}=\min \left\{\begin{array}{c}
0,6 \cdot f_{\mathrm{m}, \mathrm{joint}} \\
\alpha_{\mathrm{b}} \cdot f_{\mathrm{b}}
\end{array}\right.
$$

Dabei sind:

$$
\begin{array}{ll}
f_{\text {m,joint }} & \text { Die Mörtel-Fugendruckfestigkeit, empirischer Ansatz nach Brameshuber, } \\
\alpha_{\mathrm{b}} & \text { der empirische Verhältniswert }(\min \alpha=0,1) \text { nach Brameshuber, } \\
f_{\mathrm{b}} & \text { die Steindruckfestigkeit senkrecht zur Lagerfuge. }
\end{array}
$$

Unter Zuhilfenahme dieses Ansatzes kann ein Verhältnisfaktor $\eta_{\mathrm{fmx}}$ nach Gleichung (7.39) bestimmt werden, durch welchen mit Gleichung (7.40) die normierte Druckfestigkeit des einachsig beanspruchten Mauerwerks unter einem Neigungswinkel $(\alpha)$ bestimmt werden kann.

$$
\eta_{\mathrm{fmy}}=\frac{f_{\mathrm{mx}}}{f_{\mathrm{my}}}
$$

Die Größen der anzusetzenden Haftscherfestigkeiten $\left(\beta_{\mathrm{HS}}\right)$ wurden, entsprechend des spezifischen Mauerwerks, nach Abschnitt 3.2.2 gewählt. Dabei wurde der Wert der minimalen Haftscherfestigkeit angesetzt. Für die untersuchten Balken aus Kalksandsteinmauerwerk nach Abschnitt 5 wurde der Wert der Haftscherfestigkeit infolge teilweise fehlender Stoßfugenvermörtelung um 20\% verringert. Die effektive 
Stoßfugenvermörtelung wurde stichprobenartig ausplanimitriert, woraus sich eine effektive Fläche von ca. $80 \%$ ergab.

Die in Bild 7.14 dargestellten Grenzlinien der Mauerwerkdruckfestigkeit unter einem Winkel werden unter Anwendung der in Tabelle 7.1 enthaltenden Gleichungen bestimmt.

Tabelle 7.1 Gleichungen zur Bestimmung des Druckfestigkeitsverlaufes von einachsig beanspruchtem Mauerwerk unter einem Neigungswinkel $(\alpha)$

\begin{tabular}{|ll|l|l|}
\cline { 3 - 4 } \multicolumn{1}{l|}{} & \multicolumn{2}{l|}{ Scheitrechte Balken / Flachstürze } \\
\hline 1. & $\mathrm{A}-\mathrm{B}:$ & $f_{\alpha}=f_{\mathrm{my}}=\eta_{\mathrm{fmy}} \cdot f_{\mathrm{mx}}$ & $(7.40)$ \\
\hline 2. & $\mathrm{B}-\mathrm{C}:$ & $f_{\alpha}=\frac{c_{\mathrm{b}}}{2 \cdot \sin ^{2} \alpha \cdot\left(\tan \varphi_{\mathrm{b}}-\cot \alpha\right)}$ & $(7.41)$ \\
\hline 3. & $\mathrm{C}-\mathrm{D}:$ & $f_{\alpha}=\frac{c}{\cos ^{2} \alpha \cdot(\tan \varphi-\tan \alpha)}$ & \\
\hline 4. & $\mathrm{D}-\mathrm{E}:$ & $f_{\alpha}=\frac{2 \cdot c \cdot \cos \varphi}{1-\sin \varphi}$ & \\
\hline
\end{tabular}

Tatsächlich liegt für die Konstruktionsart des scheitrechten Mauerwerkbalkens keine unmittelbare Beanspruchung durch das zweite Bruchkriterium (Tabelle 7.1; 2.) vor. Gleichwohl kann von einer Übertragbarkeit ausgegangen werden, da sich im Verbundbereich der Längsbewehrung, zwischen Mörtel und Mauerwerk, eine Gleitlinie ausbilden könnte.

Darüber hinaus sind in Bild 7.14 die Versuchsbezeichnungen rechnerisch überprüfter, scheitrechter Mauerwerkbalken, entsprechend ihres mit Gleichung (5.2) bestimmten Druckstreben- bzw. Neigungswinkels $\left(0^{\circ}<\alpha>90^{\circ}\right)$, entlang des Festigkeitsverlaufes abgetragen (Gleichungen $\mathrm{A}-\mathrm{E}$ ). Bei vorgespannten Mauerwerkbalken wurde der Neigungswinkel durch Multiplikation mit dem Faktor 0,95 infolge der einwirkenden Drucknormalkraft verringert. Dies hat, unter Annahme variierender Schubschlankheiten, zu insgesamt höheren Übereinstimmungen zwischen Experiment und hier dargestellter Nachrechnung geführt. 


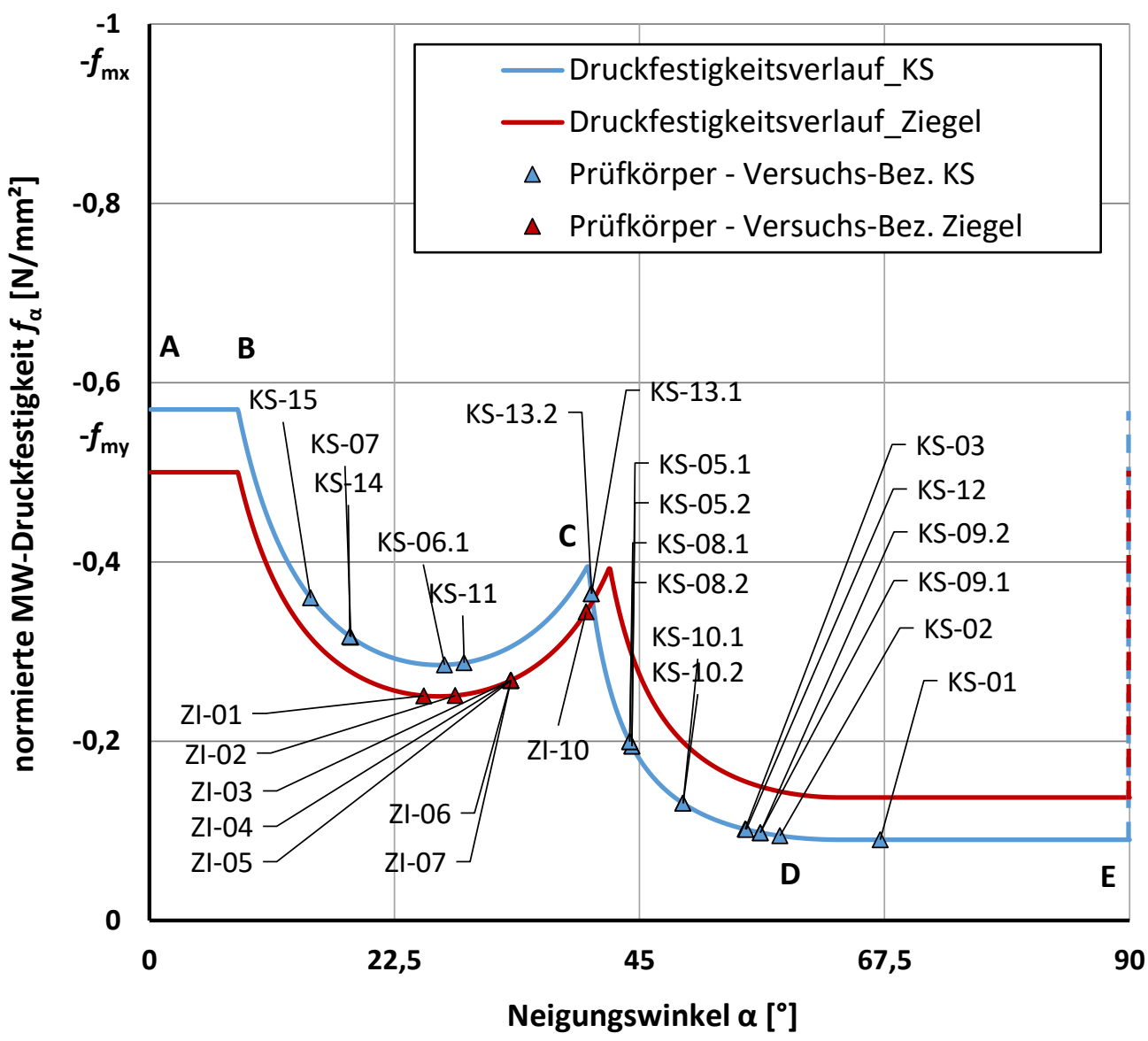

Bild 7.14 Materialmodell für Mauerwerk mit einachsigem Druckfestigkeitsverlauf unter einem Neigungswinkel $0^{\circ}<\alpha>90^{\circ}$

In Bild 7.15 und Bild 7.18 sind als Einzelpunkte die Wertepaare experimentell erhaltener Querkrafttragfähigkeiten $\left(V_{\text {exp. }}\right)$ und rechnerisch erhaltener Querkraftwiderstände $\left(V_{\text {rechn. }}\right)$ angegeben. $V_{\text {exp. }}$ entspricht der im Experiment einwirkenden Querkraft unter Berücksichtigung möglicher Abminderungen infolge auflagernaher Einzellasten; siehe Gleichung (7.27). Bei Übereinstimmung beider Werte würden sämtliche Punkte auf einer unter $45^{\circ}$ verlaufenden Ideallinie liegen. Die gestrichelten Grenzlinien zeigen Abweichungen der Werte von $\pm 15 \%$ an.

In Bild 7.15 sind Wertepaare von scheitrechten, schlaff bewehrten Mauerwerkbalken aus Kalksandsteinund Ziegelmauerwerk $(\mathrm{KS}, \mathrm{Z})$, sowie mit Ergänzungsschicht aus Beton $(\mathrm{KS}+\mathrm{C})$ und scheitrechten vorgespannten Mauerwerkbalken (KS-V) dargestellt. Es wird deutlich, dass vor dem Hintergrund der getroffenen Annahmen nahezu alle Wertepaare der geprüften Mauerwerkbalken um nicht mehr als $\pm 15 \%$ von der Ideallinie abweichen. Die überwiegenden Einzelpunkte liegen unterhalb der $45^{\circ}$-Linie. Die berechneten Querkraftwiderstände sind also geringfügig kleiner als die im Experiment ermittelte Querkrafttragfähigkeit und liegen somit auf der sicheren Seite. 


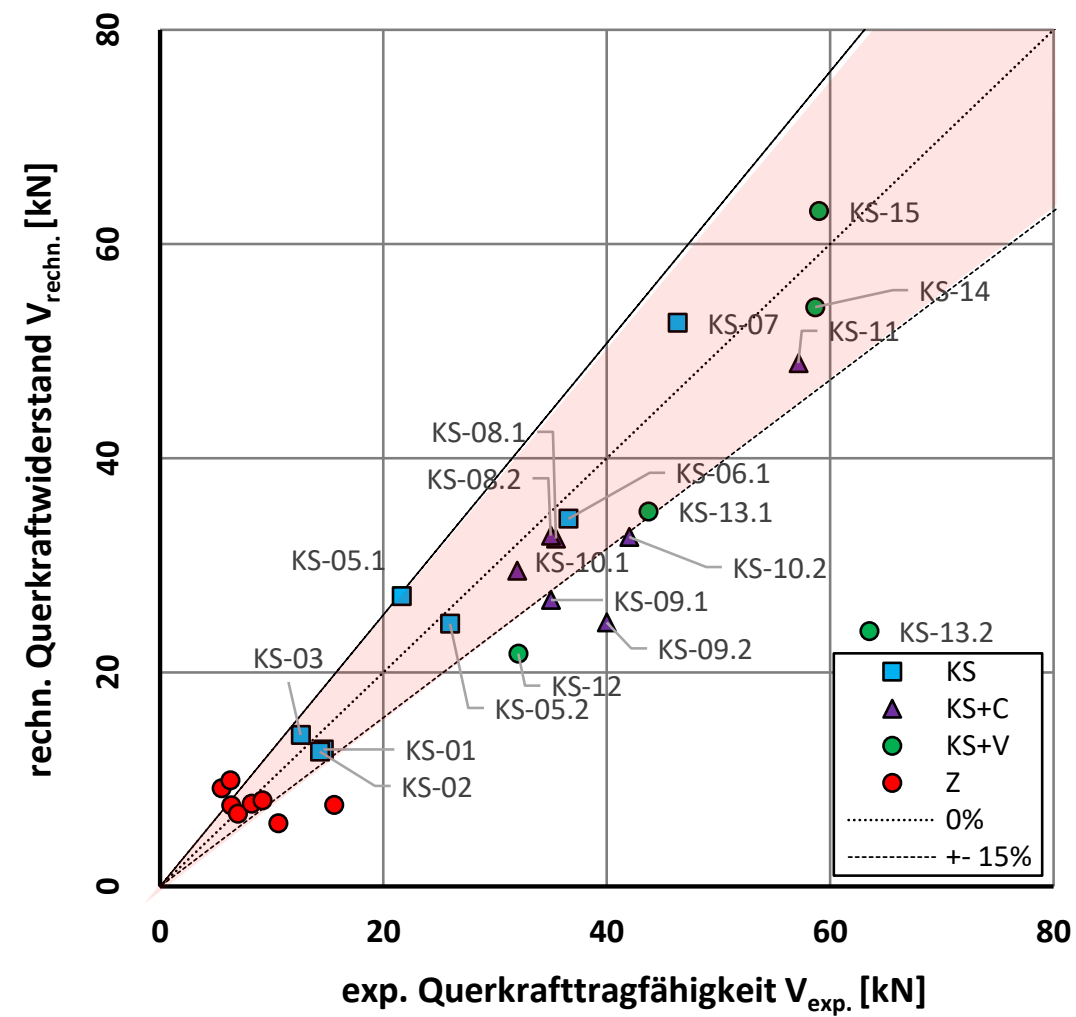

Bild 7.15 Vergleich exp. Querkrafttragfähigkeiten mit rechn. ermittelten Querkraftwiderständen im Bruchzustand von scheitrechten, schlaff bewehrten Mauerwerkbalken (KS, Z), solchen mit Ergänzungsschicht aus Beton $(\mathrm{KS}+\mathrm{C})$ und scheitrecht vorgespannten Mauerwerkbalken $(\mathrm{KS}+\mathrm{V})$

Den Umfang im Experiment untersuchter Parameter erweiternd, wurden zusätzliche FE-Analysen durchgeführt. Die FE-Rechnungen haben gezeigt, dass eine Vorspannkraft keinen signifikanten Einfluss auf die Querkrafttragfähigkeit von Mauerwerkbalken größerer Schubschlankheiten hat, wodurch nachfolgend angegebene Grenzwerte bei der Ermittlung des Druckstrebenwinkels sowohl für schlaff bewehrte als auch für vorgespannte Mauerwerkbalken zu berücksichtigen sind.

Die in diesem Abschnitt durchgeführten Vergleichsrechnungen zwischen FE-Rechnung und dem Berechnungsvorschlag haben bis zu einer Grenze des Druckstrebenwinkels von $\Theta=3\left(18,4^{\circ}\right)$ gute Übereinstimmungen gezeigt; siehe Bild 7.16. Diese Grenze entspricht dabei der geringsten Druckstrebenneigung nach EC2. Unterschreitet der Druckstrebenwinkel diesen Wert, ist der Querkraftwiderstand nach Gleichung (7.33) mit einem Abminderungsbeiwert nach Gleichung (7.44) zu multiplizieren, da die rechnerischen Ergebnisse auf der ungünstigen Seite liegen würden. Ist der Druckstrebenwinkel kleiner als $\Theta=10^{\circ}$, ist die Querkrafttragfähigkeit nur durch experimentelle Prüfung nachweisbar.

$$
\eta_{\Theta}=\frac{\Theta-7}{13}
$$




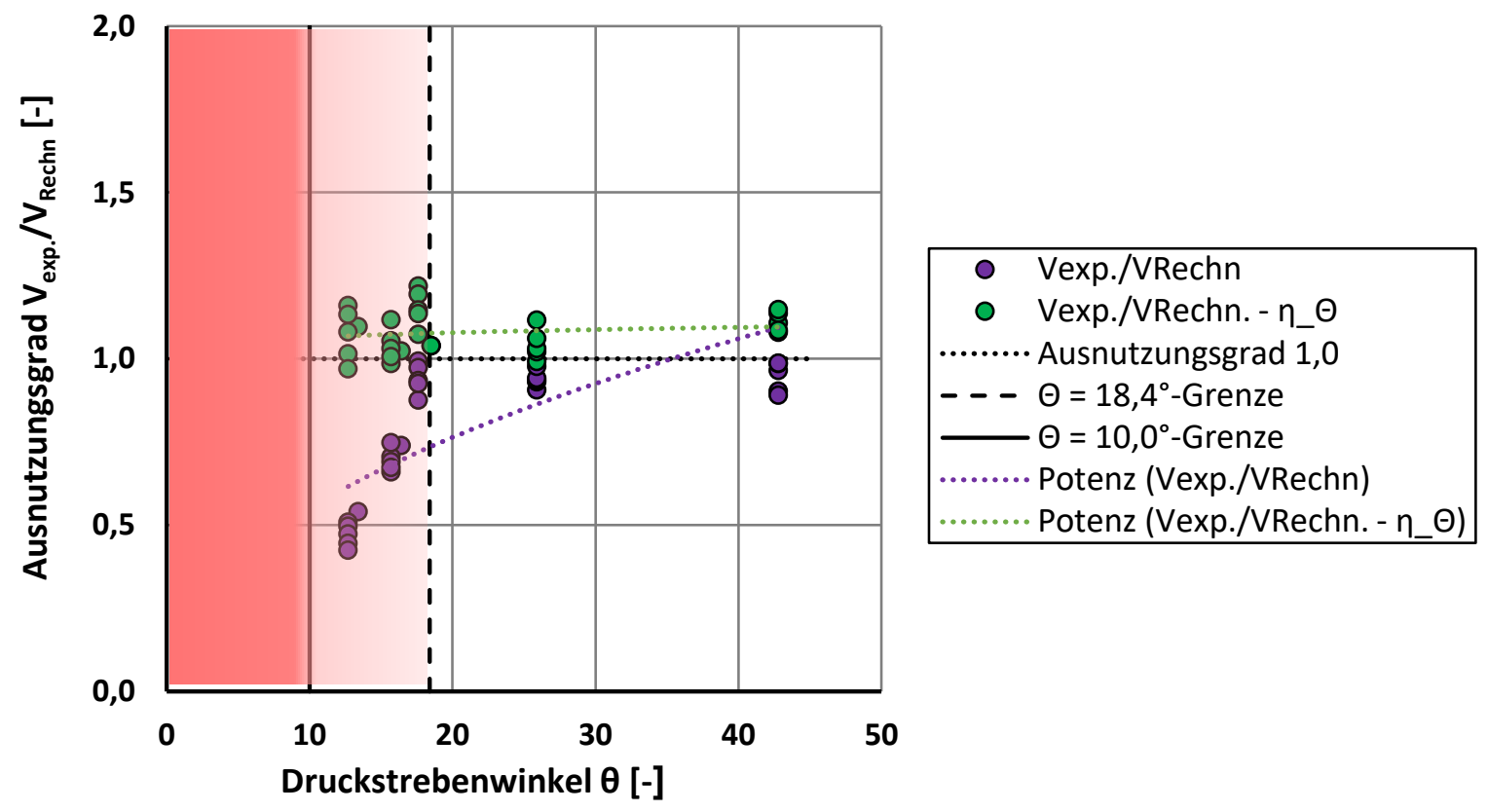

Bild 7.16 Scheitrechte MW-Balken mit und ohne Drucknormalkraft: Druckstrebenwinkel in Abhängigkeit vom Ausnutzungsgrad mit und ohne Abminderung infolge Druckstrebenneigung

Die zuvor beschriebenen numerischen Untersuchungen an exzentrisch vorgespannten Mauerwerkbalken nach Abschnitt 6.2.2 wurden in Ergänzung zu den experimentellen Untersuchungen nach Abschnitt 5.5 für die Vergleichsrechnung zwischen rechnerischen und in den FE-Untersuchungen ermittelten Querkräften verwendet. Ergänzend zur bisherigen Darstellung ist Bild 7.17 eine Vergleichsdarstellung der Wertepaare ermittelter Querkräfte zu entnehmen. Die Vergleichsdarstellung unter Einbeziehung sämtlicher, mittels FERechnung bestimmter Querkrafttragfähigkeiten exzentrisch vorgespannter Mauerwerkbalken zeigt eine gute Übereinstimmung mit einer Abweichung von $\pm 15 \%$. Die Anwendbarkeit des Berechnungsvorschlages für vorgespannte Mauerwerkbalken, unter Rücksichtnahme auf das hier durchgeführte Untersuchungsspektrum, erscheint damit gegeben. Die Darstellung wurde durch die in FERechnungen untersuchten schlaff bewehrten Mauerwerkbalken erweitert. Die Abweichung liegt ebenfalls überwiegend im Bereich von $\pm 15 \%$. Die Wertepaare befinden sich nahezu vollständig unterhalb der $45^{\circ}$ Linie und liegen damit auf der sicheren Seite. 


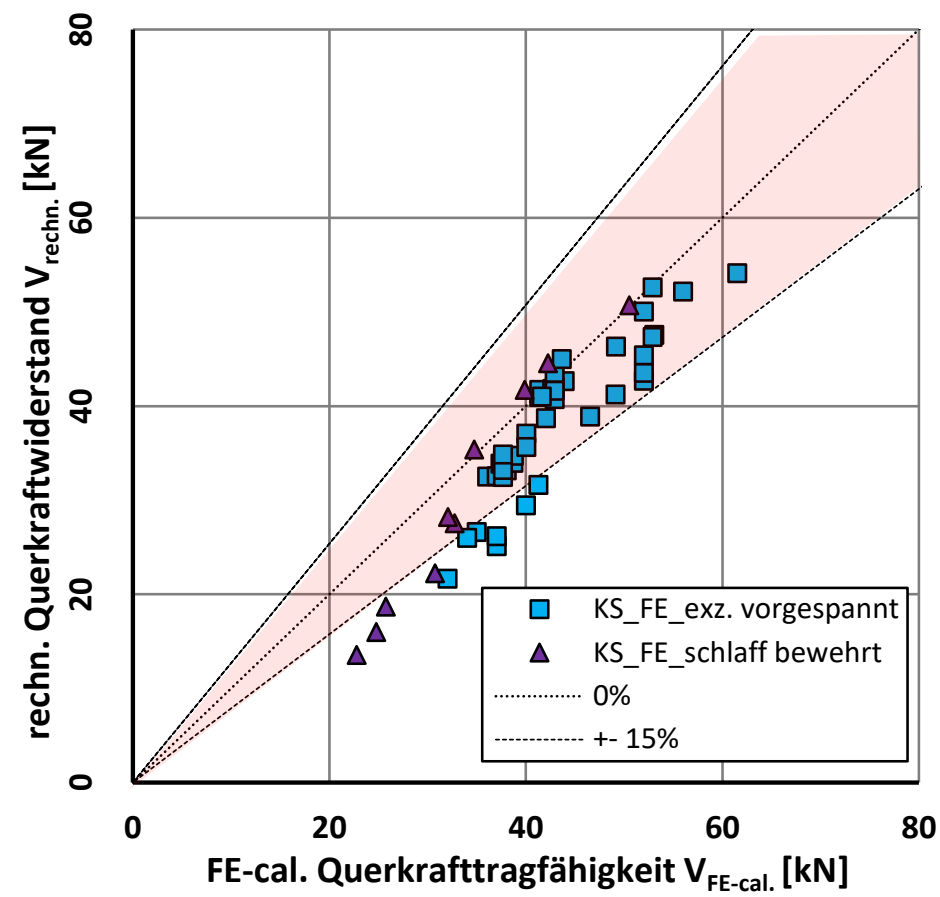

Bild 7.17 Vergleich von in FE-Rechnungen kalkulierten Querkrafttragfähigkeiten mit rechn. ermittelten Querkraftwiderständen im Bruchzustand von scheitrechten KS-Balken

Für die erweiterte Übertragbarkeit des Berechnungsvorschlages auch auf Flachstürze wird auf bereits vorhandene experimentelle Untersuchungen Bezug genommen, welche in Anlehnung an (DIN EN 8469:2016-08) durchgeführt wurden. Die Prüfungen wurden in Versuchsberichten dokumentiert und deren Ergebnisse in (Klute 2004) zusammengefasst. Wie zuvor für scheitrechte Mauerwerkbalken beschrieben, wurde für Flachstürze auf äquivalente Weise eine Vergleichsrechnung durchgeführt. Diese ist in Bild 7.18 dargestellt. Die roten Punkte stellen die Mittelwerte dar. Ausgehend von der Ideallinie, liegen die Werte überwiegend in einem Bereich von $\pm 15 \%$.

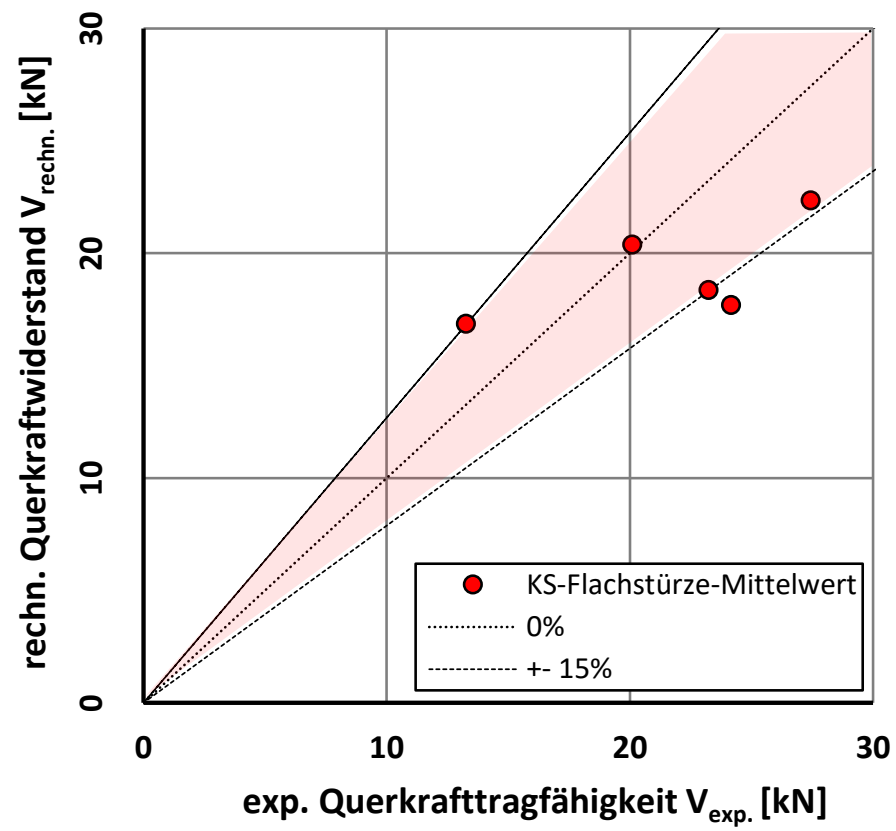

Bild 7.18 Vergleich exp. Querkrafttragfähigkeiten mit rechn. ermittelten Querkraftwiderständen im Bruchzustand von Flachstürzen aus Kalksandsteinmauerwerk

Die Vergleichsrechnungen ergänzend wurde geprüft, ob die Definition eines wandartigen Trägers nach Abschnitt 2.3 zutreffend ist und wie sich der Ausnutzungsgrad ( $V_{\mathrm{FE}-\text { Rechnung }} / V_{\text {Berechnungsvorschlag }}$ ) in 
Abhängigkeit der Trägerhöhe verändert. Hierzu wurden in Abschnitt 6.2.3 FE-Berechnungen an wandartigen Trägern unterschiedlicher Höhe mit gleichbleibender Länge durchgeführt. Angaben zu untersuchten Geometrien sind Tabelle $6.11 \mathrm{zu}$ entnehmen. Maßgebendes Versagenskriterium ist das Einsetzen eines vertikalen, teils diagonalen Risses, verlaufend zwischen Auflager und Lasteinleitung. Die Ergebnisse sind in Bild 7.19 dargestellt. Zu erkennen ist, dass bis zu einer Schubschlankheit von $\lambda>0,5$ gute Übereinstimmung zwischen den FE-Berechnungen und den Ergebnissen des hier entwickelten Berechnungsverfahrens vorliegen. Im Bereich von Schubschlankheiten $\lambda<0,5$ gilt nachweislich das typische Tragmodell für wandartige Träger; siehe Abschnitt 6.2.3. Eine Berechnung wie für Mauerwerkbalken würde die Tragfähigkeit wandartiger Träger unterschätzen. Damit wird der Anwendungsbereich des in dieser Arbeit entwickelten Berechnungsvorschlages auf eine Schubschlankheit von $\lambda \geq 0,5$ begrenzt. Die für Stahlbetonbalken getroffene Änderung in der Definition eines Balkens über das Verhältnis von $l_{\text {eff }} / h \geq 2$ auf $l_{\text {eff }} / h \geq 3$ konnte für Mauerwerk nicht bestätigt werden. Für Mauerwerkbalken gilt daher weiterhin die Grenze von $l_{\mathrm{eff}} / h \geq 2$; vgl. Bild A 5.1.

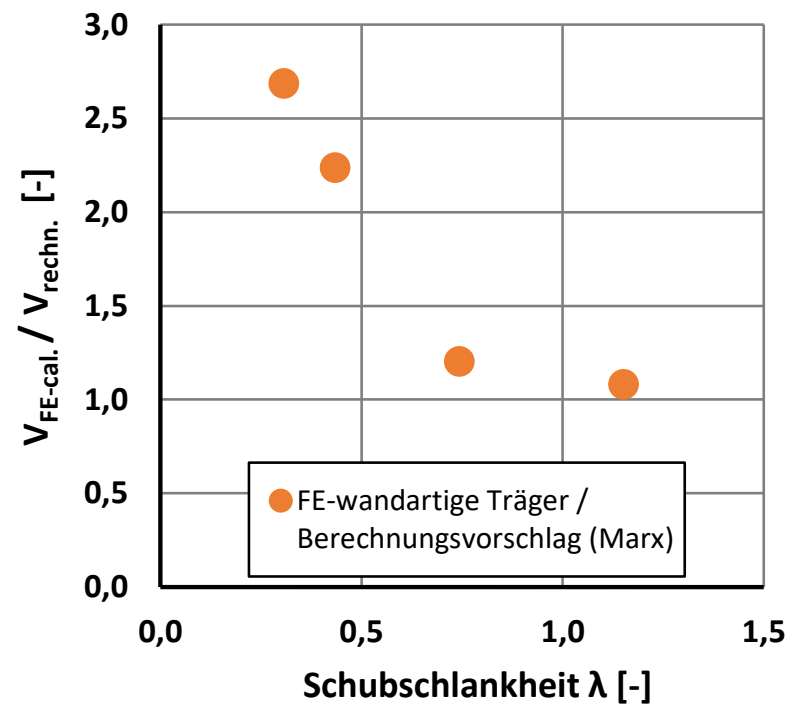

Bild 7.19 Wandartige Träger und Balken: Vergleich zwischen den Ergebnissen der FE-Berechnungen mit den Ergebnissen des Berechnungsvorschlages (Marx) in Abhängigkeit der Schubschlankheit

\subsection{Vergleich mit bestehenden Regelwerken}

Die in Abschnitt 7.3 durchgeführte Verifikation des Modellvorschlages ergab eine gute Anwendbarkeit der hergeleiteten Algorithmen zur Berechnung der Querkrafttragfähigkeit von bewehrten Mauerwerkbalken. Der Vergleich dieses Berechnungsansatzes mit Bemessungsansätzen von bauaufsichtlichen Regelwerken nach Abschnitt 2.5 ist Gegenstand dieses Abschnittes. Die Vergleichsrechnungen werden entsprechend der Gliederung nach Tabelle 7.2 getrennt für Fertigteilstürze und Flachstürze vorgenommen.

Tabelle 7.2 Gliederung der Vergleichsrechnung zwischen dem in Abschnitt 7.2 entwickelten Berechnungsvorschlag (Marx) und bauaufsichtlichen Regelwerken

\section{bewehrter Fertigteilsturz}

- Berechnungsvorschlag - Marx (siehe Abschn. 7.2)

- abZ - Fertigteilsturz (siehe Abschn. 2.5.8 dieser Arbeit)

- EC6 (siehe Abschn. 2.5.1 dieser Arbeit)

- Abschn. 6.7.3

- Anhang J (1)

- Anhang J (2)

\section{Flachsturz}

- Berechnungsvorschlag - Marx (siehe Abschn. 7.2)

- Flachsturzrichtlinie (siehe Abschn. 2.5.7 dieser Arbeit)

- EC6 (siehe Abschn. 2.5.1 dieser Arbeit)

- Abschn. 6.7.3

- Anhang J (1)

- Anhang J (2) 
Zur Ermittlung der Querkraftwiderstände wurden die Mittelwerte entsprechender Materialparameter berücksichtigt. Dabei erfolgten notwendige Umrechnungen von Bemessungswerten auf charakteristische Werte durch Anwendung des Teilsicherheitsbeiwertes $\gamma_{M}=1,5$. Die Umrechnung von charakteristischen Werten auf Mittelwerte erfolgte durch Anwendung des Faktors 0,7 für zugbeanspruchtes Mauerwerk, was eine vertretbare Näherung darstellt.

Bild 7.20 zeigt den Vergleich zwischen dem in dieser Arbeit entwickelten Berechnungsansatz (Marx) und den Regelungen nach abZ für Fertigteilstürze. Einbezogen wurden Untersuchungsergebnisse von bewehrten Mauerwerkbalken aus Abschnitt 5.3 und 5.4. Die mit dem Berechnungsverfahren dieser Arbeit berechnete Trendlinie weicht um nicht mehr als $15 \%$ von der Ideallinie ab und liegt auf der sicheren Seite. Die Berechnungsergebnisse der Querkrafttragfähigkeiten von Fertigteilstürzen nach abZ weichen hingegen deutlich von der Ideallinie ab. Sie liegen insgesamt auf der unsicheren Seite. Damit wird die Querkrafttragfähigkeit von Fertigteilstürzen durch die Regelungen der abZ oft überschätzt.

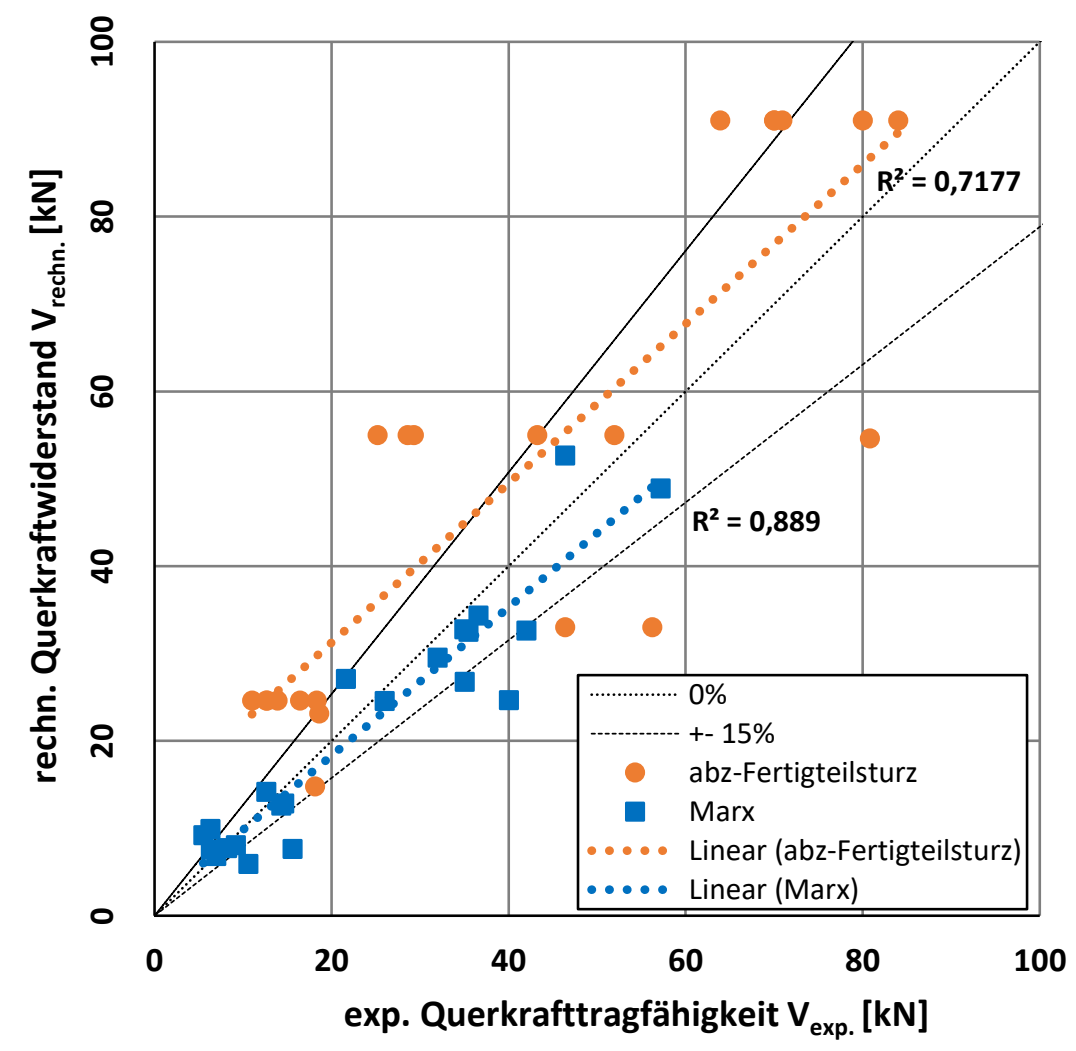

Bild 7.20 Fertigteilsturz: Vergleich zwischen dem Berechnungsvorschlag (Marx) und den Berechnungsergebnissen nach abZ für Fertigteilstürze

In Bild A 5.2 ist ein Vergleich zwischen dem in dieser Arbeit entwickelten Berechnungsvorschlag (Marx) und dem Berechnungsverfahren der DIN EN 1996-1-1 (EC6) in Kombination mit DIN EN 1996-1-1/NA zur Ermittlung der Querkrafttragfähigkeit dargestellt. Die auf der sicheren Seite liegende Berechnung nach EC6, Abschn. 6.7.3, mit der Annahme eines Schubfestigkeitswertes für unbewehrtes Mauerwerk ergibt deutlich zu geringe Querkraftwiderstände. Der im Anhang J (1) enthaltene Berechnungsvorschlag liegt geringfügig auf der unsicheren Seite. Durch die Abminderung des Schubfestigkeitswertes nach Anhang J (2) ergeben sich jedoch deutlich auf der unsicheren Seite liegende Ergebniswerte.

In Bezug auf den Maßstab werden in Bild 7.21 ausschließlich Regelungen zur Bestimmung der Querkrafttragfähigkeit von bewehrten Mauerwerkbalken miteinander verglichen. In Bild A 5.2 ist zusätzlich der Vergleich mit den Regelungen nach EC6, Abschn. 6.7.3, für unbewehrtes Mauerwerk dargestellt. 


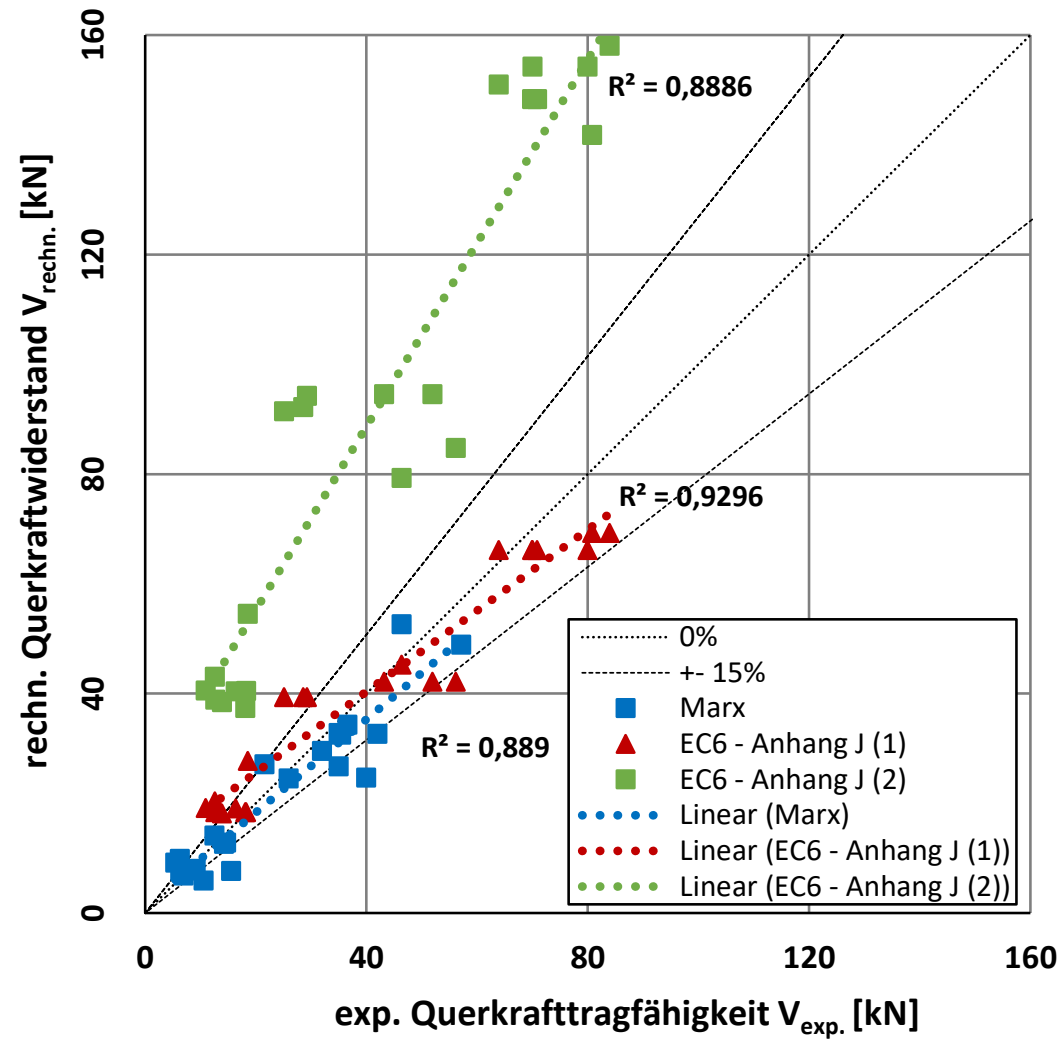

Bild 7.21 Fertigteilsturz: Vergleich zwischen dem Berechnungsvorschlag (Marx) und den Berechnungsergebnissen nach DIN EN 1996-1-1 (EC6) für bewehrtes Mauerwerk

Insgesamt liegt der in dieser Arbeit entwickelte Berechnungsvorschlag zur Bestimmung des Querkraftwiderstandes nach Abschnitt 7.2 auf der sicheren Seite. Zusätzlich wird auch die Tragfähigkeit ausreichend genau genug eingeschätzt.

Für Flachstürze ist ein Vergleich von Berechnungsverfahren in Bild 7.22 dargestellt. Für die Auswertungen wurden Ausnutzungsgrade bestimmt. Diese basieren auf der Gegenüberstellung von Querkrafttragfähigkeiten experimenteller Untersuchungen mit Querkraftwiderständen, ermittelt auf Grundlage der jeweiligen Regelwerke $\left(V_{\text {exp. }} / V_{\text {rechn. }}\right)$. Es werden ausschließlich Regelwerke zur Bestimmung der Querkrafttragfähigkeit von bewehrten Mauerwerkbalken miteinander verglichen. Die Ausnutzungsgrade wurden anhand der Prüfergebnisse von Klute (Klute 2004) in Abhängigkeit der entsprechenden Berechnungsverfahren nach Marx (Abschnitt 7.2) und nach der Flachsturzrichtlinie (Abschn. 2.5.7) sowie nach DIN EN 1996-1-1 (EC6) bestimmt.

Anhand des dargestellten Ausnutzungsgrades ist eine auf der sicheren Seite liegende, ausreichend gute Übereinstimmung zwischen dem in dieser Arbeit entwickeltem Berechnungsverfahren und den Prüfergebnissen nach Klute erkennbar. Ähnlich gute Ergebnisse liefert der Ansatz der Flachsturzrichtlinie, wobei der Tragwiderstand geringfügig unterschätzt wird. Wird die Ausnutzung nach EC6, Abschn. 6.7.3, in Kombination mit DIN EN 1996-1-1/NA zur Ermittlung des Schubfestigkeitswertes berechnet (Abschn. 2.5.1 dieser Arbeit), ergeben sich deutlich auf der sicheren Seite liegende Ausnutzungsgrade; siehe Bild A 5.3 .

Dagegen ergibt sich durch den Berechnungsansatz nach EC6, Anhang J (1), eine gute und auf der sicheren Seite liegende Genauigkeit. Die Abminderung durch Anwendung der Regelung nach EC6, Anhang J (2), liegt dagegen partiell auf der unsicheren Seite. Insbesondere betrifft dies Bereiche größerer Schubschlankheit, im Gegensatz zur Regelung nach EC6, Abschn. 6.7.3; hier kann der Schubwiderstand bis zu einer Schubschlankheit von $\lambda<6$ erhöht werden; vgl. Bild 2.26. 


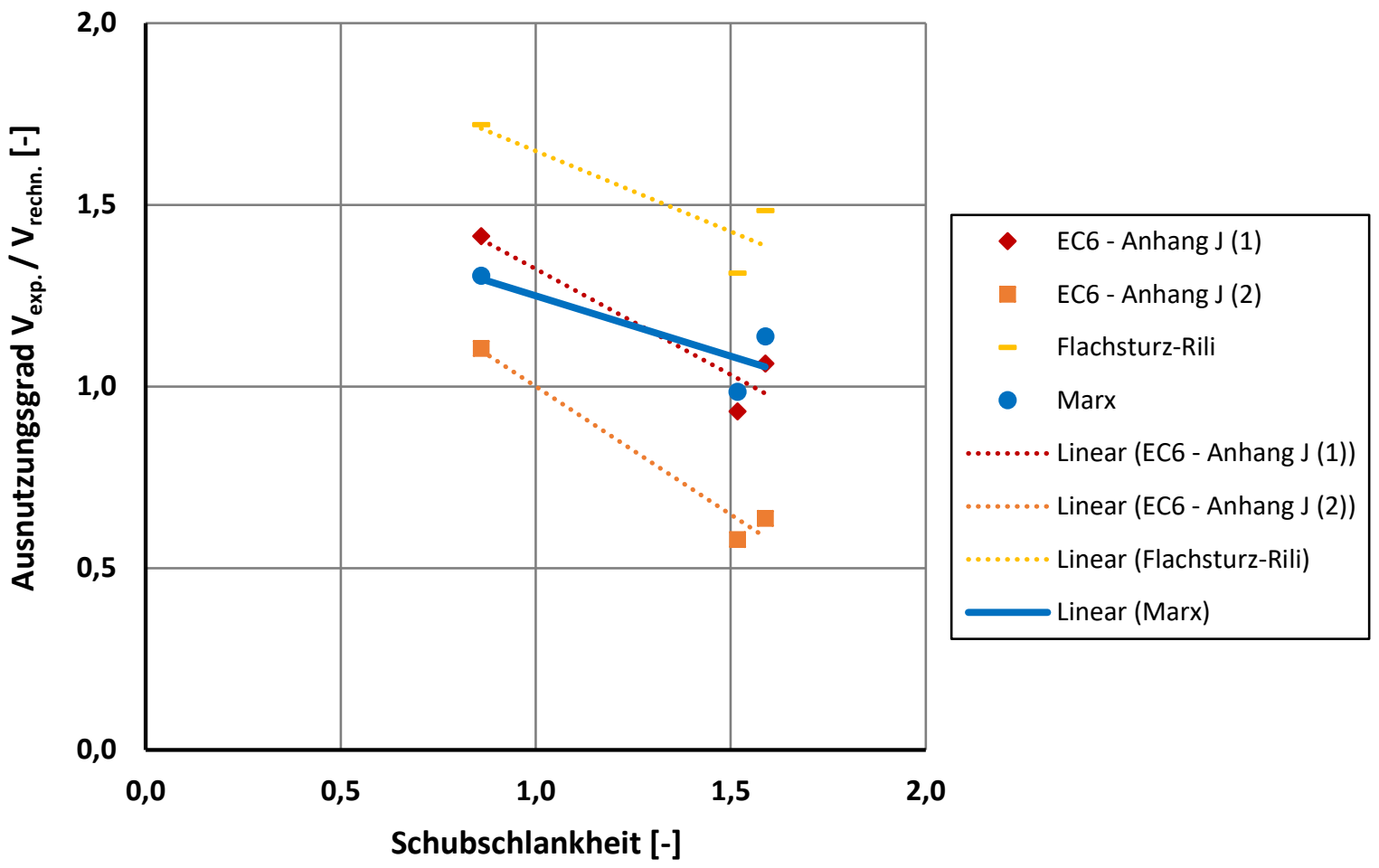

Bild 7.22 Flachsturz: Vergleich zwischen dem Berechnungsvorschlag (Marx) und den Berechnungsergebnissen nach DIN EN 1996-1-1 (EC6) für bewehrtes Mauerwerk in Abhängigkeit der Schubschlankheit

Eine Zusammenfassung der Berechnungsergebnisse ist Bild $7.23 \mathrm{zu}$ entnehmen. Dargestellt ist der Ausnutzungsgrad in Abhängigkeit der Berechnungsverfahren und der Konstruktionsarten. Die größte Übereinstimmung zwischen den Prüfergebnissen und den errechneten Schubwiderständen zeigt der in dieser Arbeit entwickelte Berechnungsvorschlag.

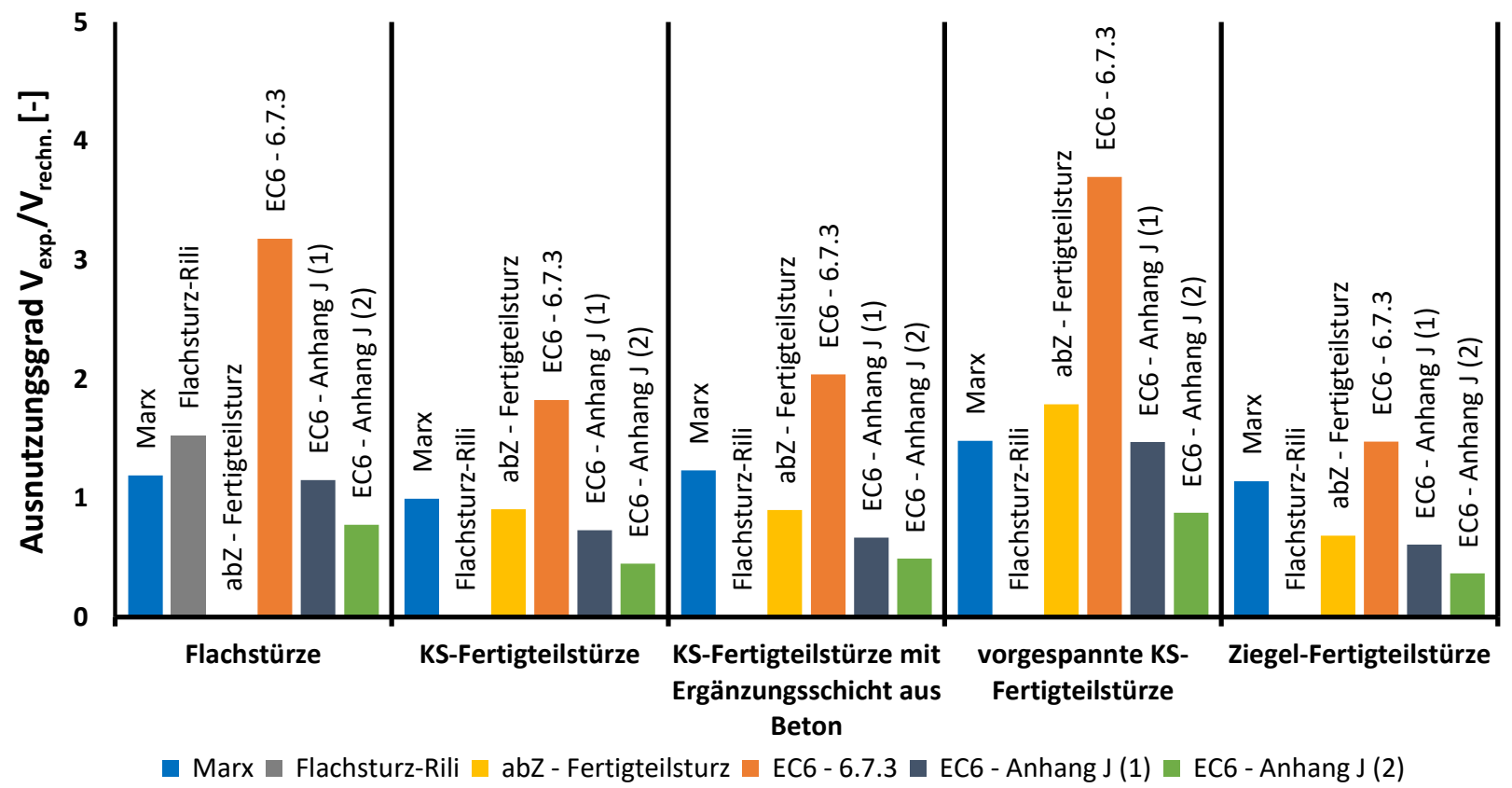

Bild 7.23 Zusammenfassende Vergleichsdarstellungen zwischen dem Berechnungsvorschlag (Marx) und den Berechnungsergebnissen nach bauaufsichtlichen Regelwerken 


\subsection{Zusammenfassung mit Bewertung der Ergebnisse}

In diesem Abschnitt wurde ein Berechnungsvorschlag für querkraftbeanspruchte Mauerwerkbalken ohne Querkraftbewehrung vorgestellt. Dabei wurde auf das aus dem Stahlbetonbau bekannte Modell der SMCFT Bezug genommen, welches im fib MC 2010 Anwendung findet. Die Berechnung erfolgte bislang weitestgehend über die Definition von Belastungsgrenzen (stress limits). Im Gegensatz dazu ermöglicht das hier vorgestellte Verfahren die Bestimmung des jeweiligen Schubtragwiderstandes durch die wirklichkeitsnahe Berücksichtigung des Deformationszustandes infolge der einwirkenden Lasten. Berücksichtigt wird dies über eine dreiecksförmige Darstellung der Längsdehnungen, in der Einflüsse aus vertikalen Auflasten, Normalkräften sowie aus Vorspannung erfasst werden; siehe Abschnitt 7.1.2. Dieses Verfahren wurde für die Berechnung von Einfeldträgern aus Stahlbeton unterschiedlicher Querschnittshöhen unter Einzellasten sowie unter Gleichstreckenlast bereits erfolgreich verifiziert und liefert gute Ergebnisse. International kommt dieses Verfahren in zahlreichen Normentexten zur Anwendung (Tue et al. 2014, S. 666). Gleichwohl ist es ein Modell aus dem Stahlbetonbau und erfasst daher die Anisotropie von Mauerwerk nicht. Aus diesem Grund wurde es durch das Werkstoffgesetz von Ganz und Mojsilović für Mauerwerk ergänzt, welches die Berücksichtigung der anisotropen Eigenschaften von auf Druck beanspruchtem Mauerwerk ermöglicht; s. Abschnitt 3.3.2.2. Eine Zusammenfassung des hier vorgestellten Berechnungsverfahrens bzw. der Algorithmen enthält Tabelle A 5.1.

Die Verifizierung des Berechnungsvorschlages erfolgte über Vergleichsrechnungen, deren Grundlage die experimentellen und rechnerischen Ergebnisse untersuchter Balkenkonstruktionen nach Abschnitt 5 und Abschnitt 6 sind. Die Ergebnisse zeigen eine zufriedenstellende Übereinstimmung zwischen Versuch und Nachrechnung.

Darüber hinaus wurden Vergleichsrechnungen mit dem hier entwickelten Berechnungsvorschlag und den Bemessungsansätzen bauaufsichtlicher Regelwerke (Abschnitt 2.5) durchgeführt. Die Auswertung ergab, dass mit dem hier entwickelten Berechnungsansatz im Vergleich zu bestehenden Regelwerken die beste Übereinstimmung zwischen Versuchsergebnis und Nachrechnung erzielt wurde. 


\section{$8 \quad$ Zusammenfassung}

Für die Berechnung der Querkrafttragfähigkeit bewehrter Mauerwerkbalken ohne Querkraftbewehrung werden in bauaufsichtlichen Regelwerken überwiegend einaxiale Festigkeitswerte unbewehrten Mauerwerks verwendet. Die Berücksichtigung mehraxialen Materialverhaltens sowie der vorhandenen Längsbewehrung erfolgt häufig nicht; Anisotropie der Mauersteine und des Mauerwerks werden vernachlässigt. Es erschien daher notwendig, einen Berechnungsvorschlag zu entwickeln, der die Querkrafttragfähigkeit von bewehrten Mauerwerkbalken ohne Querkraftbewehrung innerhalb der Schubspannungsfelder wirklichkeitsnah erfasst. Diese Anforderungen werden durch den in dieser Arbeit entwickelten Berechnungsvorschlag erfüllt.

Recherchen zu und Untersuchungen an bewehrten Mauerwerkbalken haben gezeigt, dass neben den Festigkeitseigenschaften von Mauerwerk der geometrieabhängige Einfluss der Schubschlankheit die Querkrafttragfähigkeit maßgebend beeinflusst. Dieser wurde quantifiziert und in den Berechnungsansatz implementiert. Weitere Ergebnisse der experimentellen Untersuchungen und FE-Rechnungen sind:

- Der Hebelarm der inneren Kräfte kann rechnerisch ausreichend genau bestimmt werden.

- Der Einfluss durch die Längsbewehrung auf die Querkrafttragfähigkeit steigt mit zunehmender Mauerwerkdruckfestigkeit.

- Aus dem Verlauf der das Schubfeld diagonal kreuzenden, global verlaufenden Druckstrebe wurde ein rechnerischer Ansatz zur Bestimmung des Druckstrebenwinkels abgeleitet.

- Mauerwerkbalken mit Ergänzungsschicht aus Beton (Verbundfuge $\geq 5 \mathrm{~cm}$ ) sind monolithisch.

- Die Querkrafttragfähigkeit von vorgespannten Mauerwerkbalken steigt mit kleiner werdender Schubschlankheit; bei Schubschlankheiten um $\lambda=3$ vernachlässigbar. Eine zentrische Vorspannung verstärkt den Einfluss deutlich.

- Aufgrund der Verformung und Rissbildung wird eine Vorspannung mit Verbund empfohlen.

Zur Abgrenzung des Tragmodells zwischen Mauerwerkbalken und wandartigen Trägern wurden experimentelle Untersuchungen und ergänzende FE-Berechnungen an wandartigen Trägern durchgeführt; das Tragmodell ist vergleichbar mit dem eines wandartigen Trägers aus Stahlbeton. In Übereinstimmung mit dem EC6 konnte für Mauerwerkbalken die Grenze von $l_{\text {eff }} / h \geq 2$ verifiziert werden.

Der auf Spannungsfeldern basierende, aus dem Stahlbetonbau (SMCFT) abgeleitete Berechnungsvorschlag nach Abschnitt 7.2 ermöglicht die Querkraftberechnung sowohl von bewehrten als auch vorgespannten Mauerwerkbalken unterschiedlicher Bauteilkategorie nach Tabelle 2.1. Grundlage waren die aus dem fib MC 2010 bekannten Gleichungen zur Schubbemessung von Balken ohne Querkraftbewehrung. Der Verformungszustand infolge der Einwirkungssituation wird bei der Berechnung berücksichtigt. Aufgrund anisotroper Eigenschaften von Mauerwerk unter einem variierenden Beanspruchungswinkel wurde der Ansatz durch ein Werkstoffgesetz von Ganz und Mojsilović ergänzt. Hier werden in Abhängigkeit des Beanspruchungswinkels charakteristische Bruchbedingungen von Mauerwerk berücksichtigt.

Die Verifikation des Berechnungsvorschlages zeigt eine gute Übereinstimmung mit den Ergebnissen experimentell und numerisch durchgeführter Untersuchungen und liefert die größte Übereinstimmung bei Vergleichsrechnungen mit bauaufsichtlichen Regelwerken.

Auf Grundlage dieser Arbeit ist es möglich, den Querkraftwiderstand von Mauerwerkbalken verschiedener Bauteilkategorie, die bislang teils divers zu berechnen sind, mit demselben Berechnungsansatz zu ermitteln. Die Tragfähigkeit von Mauerwerkbalken wird dabei zuverlässiger berechnet. Zusätzlich ist durch die untersuchten Mauerwerkbalken großer Schubschlankheiten eine Erweiterung bisheriger Anwendungsfelder in der Praxis vorstellbar. 




\section{Literaturverzeichnis}

A. Ghaffar; A. Javed; H. ur Rehman; K. Ahmed; M. Ilyas (2010): Development of Shear Capacity Equations for Rectangular Reinforced Concrete Beams. In: Pak. J. Engg. \& Appl. Sci (6), S. 1-8.

Adebar, Perry; Collins, Michael P. (1996): Shear strength of members without transverse reinforcement. In: Can. J. Civ. Eng. 23 (1), S. 30-41. DOI: 10.1139/196-004.

Alfes, Christoph (Hg.) (2013): Der Eurocode 6 für Deutschland. DIN EN 1996 Bemessung und Konstruktion von Mauerwerksbauten mit nationalen Anhängen ; kommentierte Fassung. Deutsche Gesellschaft für Mauerwerks- und Wohnungsbau. Berlin: Beuth [u.a.] (Kommentar : Bauwesen).

Bacht, Tobias; Stempniewski, Lothar (2013): Großformatige Biegeversuche an Balken und wandartigen Trägern aus LeichtbetonSchalungssteinen. In: Mauerwerk 17 (1), S. 27-37. DOI: 10.1002/dama.201300561.

Backes, Heinz-Peter (1985): Zum Verhalten von Mauerwerk bei Zugbeanspruchung in Richtung der Lagerfugen. Dissertation. Rheinisch-Westfälische Technische Hochschule Aachen (RWTH Aachen), Aachen. Fakultät für Bauwesen.

DIN 1045-100:2017-09: Bemessung und Konstruktion von Stahlbeton- und Spannbetontragwerken - Teil 100: Ziegeldecken. Berlin, Normenausschuss Bauwesen (NABau) im Deutschen Institut für Normung e. V., Beuth Verlag,

Bender, Michél (2019): Zum Querkrafttragverhalten von Stahlbetonbauteilen mit Kreisquerschnitt. Dissertation. Ruhr-Universität Bochum, Bochum. Fakultät für Bau- und Umweltingenieurwissenschaften.

Bentz, Evan, C.; Vecchio, Frank, J.; Collins, Michael, P (2006): Simplified Modified Compression Field Theory for Calculating Shear Strength of Reinforced Concrete Elements. In: ACI Structural Journal 2006 (103), S. 614-624.

DIN 1045:1978-12: Beton und Stahlbeton; Bemessung und Ausführung. Berlin, Normenausschuss Bauwesen (NABau) im Deutschen Institut für Normung e. V., Beuth Verlag, 1978.

DIN 488-1:2009-08: Betonstahl - Teil 1: Stahlsorten, Eigenschaften, Kennzeichnung. Berlin, Normenausschuss Bauwesen (NABau) im Deutschen Institut für Normung e. V., Beuth Verlag, 2009.

Beverly, Paul (Hg.) (2013): fib Model Code for Concrete Structures 2010. prepared by Special Activity Group 5, New Model Code. Berlin: Ernst \& Sohn.

E DIN 1053-3:2008-03: Bewehrtes Mauerwerk - Berechnung und Ausführung. Unveröffentlichtes Manuskript der Geschäftsstelle des Normenausschuss Bauwesen (NABau) im Deutschen Institut für Normung e. V., Berlin, Beuth Verlag, 2008.

Brameshuber, W.; Raupach, M. (2004): Forschungsbericht F 859. Kostengünstige Flachstürze mit übermauerter Druckzone. ibac - RWTH-Aachen. Aachen.

Brameshuber, Wolfgang (2016): Masonry Compressive Strength Parallel to the Bed Joint. TC250/SC6-WG1 Session. Dresden, 06.06.2016.

Brameshuber, Wolfgang; Jäger, Wolfram (2015): Eigenschaften von Mauersteinen, Mauermörtel, Mauerwerk und Putzen. In: Wolfram Jäger (Hg.): Mauerwerk-Kalender 2015. Berlin: Ernst \& Sohn a Wiley Company (Mauerwerk-Kalender), S. 1-34.

Budelmann, H.; Gunkler, E.; Husemann, U.; Becke, A. (2004): Rationell hergestellte Wände aus vorgespanntem großformatigen Mauerwerk mit hohem Erdbebenwiderstand - Rationell hergestellte Wände aus vorgespanntem großformatigen Mauerwerk mit hohem Erdbebenwiderstand. Abschlussbericht - AZ: Z 6-5.4-02.18 / II 13 - 800102 - 18. Forschungsbericht. Institut für Baustoffe, Massivbau und Brandschutz (iBMB) - Technische Universität Braunschweig. Braunschweig.

Carlsberg Bjælker (2013): Vorgespannte Ziegelbalken. Technische Beschreibungen. Hg. v. Randers Tegl Deutschland GmbH. Tegelbarg 9, 24576 Bad Bramstedt.

Červenka, Vladimír; Jendele, Libor; Červenka, Jan (2012): ATENA Program Documentation Part 2-1. User's Manual for ATENA 2D. Hg. v. Cervenka Consulting Ltd. Prag.

Červenka, Vladimír; Jendele, Libor; Červenka, Jan (2016): ATENA Program Documentation Part 1. Theory. Hg. v. Cervenka Consulting Ltd. Prag.

CIB Commission W023 - State of Art Report (2013): CIB Commission W023 - State of Art Report - Reinforced and Pre-stressed Masonry Beams - 1st Draft. Unter Mitarbeit von Johann Jakob Marx (M. Eng.) und Dries Beyer (M. Eng.). Hg. v. Erhard Gunkler. Detmold.

Curtin, W. G.; Shaw, G.; Beck, J. K. (1988): Design of reinforced and prestressed masonry. London, England: Thomas Telford Publishing. 
DAfStb Heft 240 (Hg.) (1991): Deutscher Ausschuss für Stahlbeton - Heft 240. Hilfsmittel zur Berechnung der Schnittgrößen und Formänderungen von Stahlbetontragwerken. 3. überarb. Aufl. nach DIN 1045, Ausg. Juli 1988. Berlin: Beuth (DAfStb-Hefte, 240).

DAfStb Heft 631 (Hg.) (2019): Deutscher Ausschuss für Stahlbeton - Heft 631. Hilfsmittel zur Schnittgrößenermittlung und zu besonderen Detailnachweisen bei Stahlbetontragwerken. 1. Auflage. Berlin: Beuth (DAfStb-Hefte, 631).

Dashkhuu, Odontsetseg (2013): Ingenieurmodell zur Tragfähigkeit ohne Verbund vorgespannter KalksandsteinMauerwerkswände. Dissertation. Technische Universität Braunschweig, Braunschweig. Fakultät Architektur, Bauingenieurwesen und Umweltwissenschaften.

Edward G. Sherwood, Evan C. Bentz and Michael P. Collins (2007): Effect of Aggregate Size on Beam-Shear Strength of Thick Slabs. In: Structural Journal 104 (2), S. 180-190. DOI: 10.14359/18530.

DIN EN 1992-1-1:2011-01: Eurocode 2: Bemessung und Konstruktion von Stahlbeton- und Spannbetontragwerken - Teil 1-1: Allgemeine Bemessungsregeln und Regeln für den Hochbau. Berlin, Normenausschuss Bauwesen (NABau) im Deutschen Institut für Normung e. V., Beuth Verlag, 2011.

DIN EN 1996-1-1:2017 (E): Eurocode 6: Bemessung und Konstruktion von Mauerwerksbauten - Teil 1-1: Allgemeine Regeln für bewehrtes und unbewehrtes Mauerwerk. Berlin, Normenausschuss Bauwesen (NABau) im Deutschen Institut für Normung e. V., Beuth Verlag, 2017.

DIN EN 1996-1-1:2013-02: Eurocode 6: Bemessung und Konstruktion von Mauerwerksbauten - Teil 1-1: Allgemeine Regeln für bewehrtes und unbewehrtes Mauerwerk. Berlin, Normenausschuss Bauwesen (NABau) im Deutschen Institut für Normung e. V., Beuth Verlag, 2013.

DIN EN 1996-2:2010-12: Eurocode 6: Bemessung und Konstruktion von Mauerwerksbauten - Teil 2: Planung, Auswahl der Baustoffe und Ausführung von Mauerwerk. Berlin, Normenausschuss Bauwesen (NABau) im Deutschen Institut für Normung e. V., Beuth Verlag, 2010.

DIN EN 845-2, 01.12.2016: Festlegungen für Ergänzungsbauteile für Mauerwerk - Teil 2: Stürze. Berlin, Normenausschuss Bauwesen (NABau) im Deutschen Institut für Normung e. V., Beuth Verlag, 2016.

Fischer, J.; König, G. (1997a): Parabel-Schrägriß-Modell für das Versagen von schubschlanken Balken (Teil 1). In: Beton- und Stahlbetonbau 92 (7), S. 173-177. DOI: 10.1002/best.199700330.

Fischer, J.; König, G. (1997b): Parabel-Schrägriß-Modell für das Versagen von schubschlanken Balken (Teil 2). In: Beton- und Stahlbetonbau 92 (8), S. 220-224. DOI: 10.1002/best.199700420.

Flachsturz-Richtlinie - Vorläufiger Schlussentwurf, 25.05.2005: Flachsturz-Richtlinie - Vorläufiger Schlussentwurf: Herstellung, Bemessung und Ausführung von Flachstürzen.

Flohrer, C.; Hilsdorf, H. K. (1984): Duktiles Mauerwerk - Alternative Bewehrungsformen. Schlussbericht. Tl.1. und Tl.2. Hg. v. Fraunhofer IRB Verlag. Universität Karlsruhe. Stuttgart.

Ganz, Hans Rudolf (1985): Mauerwerksscheiben unter Normalkraft und Schub. Dissertation. Eidgenössische Technische Hochschule Zürich, Zürich.

Graubner, Carl-Alexander (2017): Analyse der Regelungen zur Querkrafttragfähigkeit bewehrter Mauerwerkswände mit und ohne Schubbewehrung nach DIN EN 1996-1-1, Abschnitt 6.7. Forschungsbericht P 52-5-15.105-1995/16. Unter Mitarbeit von Benjamin Purkert. Hg. v. Carl-Alexander Graubner. TU Darmstadt, Institut für Massivbau. Darmstadt.

Guggisberg, Roland; Thürlimann, Bruno (1987): Versuche zur Festlegung der Rechenwerte von Mauerwerksfestigkeiten. Basel u.a.: Birkhäuser (Bericht / Institut für Baustatik und Konstruktion, ETH Zürich).

Gunkler, Erhard (1992): Zur nachträglichen Erhöhung der Biegetragfähigkeit von Mauerwerkswänden durch bewehrte Ergänzungsschichten. Dissertation. Technische Universität Braunschweig, Braunschweig. Institut für Baustoffe, Massivbau und Brandschutz (iBMB).

Gunkler, Erhard; Budelmann, Harald (Hg.) (2019): Mauerwerksbau. Bemessung und Konstruktion. 2., überarbeitete und aktualisierte Auflage. Köln: Bundesanzeiger Verlag (WIT).

Gunkler, Erhard; Marx, Johann Jakob (2016): Reinforced masonry beams under shear load - Proposals for future designs / Bewehrte schubbeanspruchte Mauerwerkbalken - Vorschläge für zukünftige Bemessungen. In: Mauerwerk 20 (3), S. 213-231. DOI: 10.1002/dama.201600694.

Gunkler, Erhard; Marx, Johann Jakob (2018): Neues Schubbemessungskonzept für bewehrtes Mauerwerk. Warum ein neues Schubbemessungskonzept für bewehrtes Mauerwerk nach EC6 benötigt wird. Hg. v. Erhard Gunkler. Hochschule OstwestfalenLippe, Institut für Baustoffe und Massivbau. Detmold. 
Gunkler, Erhard; Marx, Johann Jakob; Blum, Carsten (2017): Shear resistance of reinforced masonry beams with and without additional concrete or prestress. In: Mauerwerk 21 (3), S. 155-167. DOI: 10.1002/dama.201700002.

Gutachten Nr. G971318 (1999): Gutachten Nr. G971318. ABZ für Fertigteilstürze aus bewehrten Kalksandelementen; hier Grundlagen der Bemessung. Hg. v. H. Reeh und A. Schlundt. Hannover.

Gutachten Nr. GA 02/09 (2009): Bemessungsansätze für Fertigteilstürze aus Kalksandelementen bis 2,00 m Länge. Gu (unveröffentlicht). Hg. v. Erhard Gunkler. Detmold.

HALFEN-DEHA Vertriebsgesellschaft mbH: Halfen Konsolanker. Planungshilfe.

Hegger, Josef; König, Gert; Zilch, Konrad; Reineck, Karl-Heinz (1999): Überprüfung und Vereinheitlichung der Bemessungsansätze für querkraftbeanspruchte Stahlbeton- und Spannbetonbauteile aus normalfestem und hochfestem Beton nach DIN 1045-1“;. Deutsches Institut für Bautechnik. Berlin.

Hendry, A. W.; Sinha, B. P.; Davies, S. R. (2004): Design of masonry structures. 3 rd. United Kingdom: Taylor \& Francis.

Herbrand, Martin; Hegger, Josef (2017): Querkraftmodell für Bauteile ohne Schubbewehrung unter Druck- und Zugbeanspruchung. In: Beton- und Stahlbetonbau 112 (11), S. 704-713. DOI: 10.1002/best.201700050.

Huber, Patrick; Kollegger, Johann; Nguyen, Viet-Tue; Nguyen, Tung (2014): Mechanisch konsistentes Schubfeldmodell für Bestandsbrücken ohne bzw. mit geringer Querkraftbewehrung. Schubfeldmodell. Ein Projekt finanziert im Rahmen der Verkehrsinfrastrukturforschung_Ergebnisbericht_Schubfeldmodell_VIF_2011. Hg. v. Bundesministerium für Verkehr, Innovation und Technologie, ÖBB-Infrastruktur AG und Autobahnen- und Schnellstraßen-Finanzierungs Aktiengesellschaft. Technische Universität Wien; Technische Universität Graz.

Huber, Patrick; Schweighofer, Anton; Kollegger, Johann; Brunner, Helmut; Karigl, Walter (2012): Vergleich der rechnerischen Querkrafttragfähigkeit von Bestandsbrücken nach Eurocode 2 und fib Model Code 2010. In: Beton- und Stahlbetonbau 107 (7), S. 451-462. DOI: 10.1002/best.201200023.

Irmschler, Hans J.; Schubert, Peter (Hg.) (2000): Mauerwerk-Kalender 2000. Taschenbuch für Mauerwerk, Wandbaustoffe, Brand, Schall-, Wärme- u. Feuchtigkeitsschutz. 25. Jahrgang. Berlin: Ernst, Wilhelm \& Sohn (Mauerwerk-Kalender).

Jäger, Thomas (2007): Querkraftwiderstand und Verformungsvermögen von Stahlbetonplatten. Dissertation. Eidgenössische Technische Hochschule Zürich, Zürich.

Jäger, Wolfram; Marzahn, Gero (2010): Mauerwerk. Bemessung nach DIN 1053-100. Berlin: Ernst \& Sohn.

Kaufmann, Walter (2018): Vorlesung Stahlbeton III. 1. Einleitung. Hg. v. Walter Kaufmann. Eidgenössische Technische Hochschule Zürich. Zürich.

Klute, Jens (2004): Versuche mit KS-Stürzen nach EN 845-2 - Statistische Auswertung und Sicherheitskonzept. Projekt 3736. Klute und Klute - Ingenieurbüro für Bauwesen. Kassel.

Kohl, Matthias (2014): Tragverhalten von Stahlbetontragwerken ohne Querkraftbewehrung unter Ermüdungsbeanspruchungen. Dissertation. Technische Universität Hamburg-Harburg, Hamburg-Harburg.

König, G.; Dehn, F.; Hegger, J.; St. Görtz (2000): Der Einfluß der Rissreibung auf die Querkrafttragfähigkeit. Erkenntnisse aus experimentellen Untersuchungen an Bauteilen aus Leichtbeton und hochfestem Beton. In: Beton- und Stahlbetonbau 95 (10), S. 584-591. DOI: 10.1002/best.200001150.

König, Gert; Nguyen, Viet-Tue; Schenck, Gunter (2008): Grundlagen des Stahlbetonbaus. Einführung in die Bemessung nach DIN 1045-1. 3., aktualisierte Aufl. Wiesbaden: Vieweg + Teubner.

Korjenic, Sinan; Kolbitsch, Andreas (2012): Mauerwerksertüchtigung durch Vorspannung mit Aramidstäben. In: Wolfram Jäger (Hg.): Mauerwerk-Kalender 2012. 37. Jahrgang. Berlin: Ernst \& Sohn a Wiley Company (Mauerwerk-Kalender).

Kranzler, Thomas; Meyer, Udo; Brauer, Norbert; Ehmke, Joachim (2016): Bemessung von Ziegelmauerwerk. Nach DIN EN $1996-$ 3/NA. Vereinfachte Berechnungsmethoden. Hg. v. Arbeitsgemeinschaft Mauerziegel im Bundesverband der Deutschen Ziegelindustrie e.V. Bonn.

Lechler (2006): Bekaert Murfor - Mauerwerksbewehrung. Informationsschrift. Hg. v. LECHLER GmbH. Augsburg.

Leitl (2008): Spannbeton Ultra-Sturz, Leitl. Vital Bauen Gesund Leben. Hg. v. Martin Leitl. Eferding (Österreich).

Leitl (2015): Produktübersicht Leitl. Vital Bauen Gesund Leben. Hg. v. Martin Leitl. Eferding (Österreich).

Leonhardt, Fritz; Walther, René (1962): Schubversuche an einfeldrigen Stahlbetonbalken mit und ohne Schubbewehrung zur Ermittlung der Schubtragfähigkeit und der oberen Schubspannungsgrenze. Berlin: Ernst, Wilhelm \& Sohn (H. 151). 
Leonhatdt, Fitz; Mönnig, Eduard (1986): Sonderfälle der Bemessung im Stahlbetonbau. 3., völlig neubearb. und erw. Aufl. Berlin: Springer.

Martin, H.; Sager, H. (1986): Schubtragfähigkeit von bewehrten Mauerwerksplatten. Forschungsvorhaben IV 1-5-414/84. Hg. v. IRB Verlag. Institut Betonstahl und Stahlbetonbau e.V. München.

Marx, Johann Jakob (2018): Prüfbericht zur Durchführung experimenteller Untersuchungen_Unveröffentlicht. Grundlagen zur Entwicklung eines Schubbemessungsansatzes für schlaff bewehrte und vorgespannte Mauerwerkstürze. Hochschule OstwestfalenLippe. Detmold.

Mastumura, A. (1988): Shear Strength of Reinforced Masonry Walls. Proceedings of 9th World Conference on Earthquake Engineering. Hg. v. Department of Architecture. Kanagawa University. Yokohama Japan.

DIN 1053-3:1990-02: Mauerwerk; Bewehrtes Mauerwerk - Berechnung und Ausführung. Berlin, Normenausschuss Bauwesen (NABau) im Deutschen Institut für Normung e. V., Beuth Verlag, 1990.

DIN 1053-2:1984-07: Mauerwerk; Mauerwerk nach Eignungsprüfung; Berechnung und Ausführung. Berlin, Normenausschuss Bauwesen (NABau) im Deutschen Institut für Normung e. V., Beuth Verlag, 1984.

Michael P. Collins, Denis Mitchell Perry Adebar and Frank J. Vecchio (1996): A General Shear Design Method. In: Structural Journal 93 (1). DOI: 10.14359/9838.

Michael P. Collins, Denis Mitchell (1980): Shear and Torsion Design of Prestressed and Non-Prestressed Concrete Beams. In: PCI Journal Paper 25 (5), S. 32-100.

Mojsilović, Nebojsa (1995): Zum Tragverhalten von kombiniert beanspruchtem Mauerwerk. Eidgenössische Technische Hochschule Zürich, Zürich. Institut für Baustatik und Konstruktion.

Movila, Ioan (2012): Modelling of the Lateral Load Behavior of Unreinforced Masonry Walls using the software Atena 2D. Hg. v. 15th World Conference on Earthquake Engineering. Portugal.

Mutsuyoshi, S. V. T. Janaka Perera and Hiroshi (2013): Shear Behavior of Reinforced High-Strength Concrete Beams. In: ACI Structural Journal 110 (1). DOI: 10.14359/51684328.

Muttoni, Aurelio; Schwartz, Joseph; Thürlimann, Bruno (1997): Bemessung von Betontragwerken mit Spannungsfeldern. Basel u.a.: Birkhäuser.

DIN EN 1992-1-1/NA:2013-04: National festgelegte Parameter - Eurocode 2: Bemessung und Konstruktion von Mauerwerksbauten - Teil 1-1: Bemessung und Konstruktion von Stahlbeton- und Spannbetontragwerken - Teil 1-1: Allgemeine Bemessungsregeln und Regeln für den Hochbau. Berlin, Normenausschuss Bauwesen (NABau) im Deutschen Institut für Normung e. V., Beuth Verlag, 2013.

DIN EN 1996-1-1:2012-01/NA: Nationaler Anhang - National festgelegte Parameter - Eurocode 6: Bemessung und Konstruktion von Mauerwerksbauten - Teil 1-1: Allgemeine Regeln für bewehrtes und unbewehrtes Mauerwerk. Berlin, Normenausschuss Bauwesen (NABau) im Deutschen Institut für Normung e. V., Beuth Verlag, 2012.

Parason, D. E.; Stang, A. H.; McBurney, J. W. (1932): Shear Test of Reinforced Brick Masonary Beams. In: Bureau of Standards Journal of Research 9.

DIN EN 12390-3:2009-06: Prüfung von Festbeton - Teil 3: Druckfestigkeit von Probekörpern. Berlin, Normenausschuss Bauwesen (NABau) im Deutschen Institut für Normung e. V., Beuth Verlag, 2009.

DIN EN 12390-7:2009-07: Prüfung von Festbeton -Teil 7: Dichte von Festbeton. Berlin, Normenausschuss Bauwesen (NABau) im Deutschen Institut für Normung e. V., Beuth Verlag, 2009.

DIN EN 846-9:2016-08: Prüfverfahren für Ergänzungsbauteile für Mauerwerk - Teil 9: Bestimmung der Biegezug- und Schubfestigkeit von Stürzen. Berlin, Normenausschuss Bauwesen (NABau) im Deutschen Institut für Normung e. V., Beuth Verlag, 2016.

DIN EN 772-1:2011+A1:2015: Prüfverfahren für Mauersteine - Teil 1: Bestimmung der Druckfestigkeit. Berlin, Normenausschuss Bauwesen (NABau) im Deutschen Institut für Normung e. V., Beuth Verlag, 2015.

DIN EN 196-1:2005-05: Prüfverfahren für Zement; Teil 1: Bestimmung der Festigkeit. Berlin, Normenausschuss Bauwesen (NABau) im Deutschen Institut für Normung e. V., Beuth Verlag, 2005.

Reineck, Karl-Heinz (Hg.) (2005): Beton-Kalender 2005 (I + II). Fertigteile, Tunnelbauwerke. Modellierung der D-Bereiche von Fertigteilen. Unter Mitarbeit von Karl-Heinz Reineck. Berlin: Ernst \& Söhne. 
Roberts, J. J.; Edgell, G. J.; Rathbone, A. J. (1986): Handbook to BS 5628: BS 5628: 1985: British standard code of practice for use of masonr - Part-2. Structural Use of Reinforced and Prestressed Masonry. London, England: Taylor \& Francis Ltd.

Rombach, Günter Axel (2010): Spannbetonbau. 2. aktualisierte Aufl. Berlin: Ernst \& Sohn.

Rupf, Michael Markus (2014): Querkraftwiderstand von Stahlbeton- und Spannbetonträgern mittels Spannungsfeldern. Dissertation. École Polytechnique Fédérale de Lausanne, Lausanne (Schweiz).

Saenger, Dorothea; Brameshuber, Wolfgang (2016): Longitudinal compressive strength of masonry - Simplified calculation approach / Längsdruckfestigkeit von Mauerwerk - Vereinfachter Berechnungsansatz. In: Mauerwerk 20 (5), S. 369-380. DOI: 10.1002/dama.201600709.

Schieß1, P.; Schubert, P. (1998): Forschungsbericht F 492. Tragverhalten von Ziegel-Flachstürzen mit unvermörtelten Stoßfugen. ibac - RWTH-Aachen. Aachen.

Schlaich, J.; Schäfer, K. (Hg.) (2001): Beton-Kalender 2001. Konstruieren im Stahlbetonbau. Theoretische Grundlagen - Bemessen und Konstruieren mittels Stabwerksmodellen. 90. Jahrgang. Berlin: Ernst \& Sohn.

Schlegel, Roger (2004): Numerische Berechnung von Mauerwerksstrukturen in homogenen und diskreten Modellierungsstrategien. Dissertation. Bauhaus-Universität Weimar, Weimar. Institut für Konstruktiven Ingenieurbau.

Schmidt, Ulf; Schubert, Peter; Reeh, Helmut; Schlundt, Andreas; Duensing, Jörg (2004): Bemessung von Flachstürzen. In: Hans J. Irmschler, Wolfram Jäger und Peter Schubert (Hg.): Mauerwerk-Kalender 2004. Taschenbuch für Mauerwerk, Wandbaustoffe, Schall-, Wärme- und Feuchtigkeitsschutz. 29. Jg. Berlin: Ernst Verl. für Architektur u. techn. Wiss, S. 275-309.

Schubert, P.; Schmidt, U. (2003): Forschungsbericht F 886. Ergänzende Untersuchungen an Ziegel-Flachstürzen. ibac - RWTHAachen. Aachen.

Schubert, Peter; Graubohm, Markus (2004): Druckfestigkeit von Mauerwerk parallel zu den Lagerfugen. In: Mauerwerk 8 (5), S. 198-208. DOI: 10.1002/dama.200490074.

Schwartz, Joseph Lucien (1989): Bemessung von Mauerwerkswänden und Stahlbetonstützen unter Normalkraft. Dissertation. Eidgenössische Technische Hochschule Zürich, Zürich.

SIA 266-1:2003: SIA 266-1:2003: Mauerwerk. Schweizerischer Ingenieur und Architektenverein, Zürich, 2013.

Sigrist, Viktor; Hackbarth, Britta (2010): Querkrafttragfähigkeit von Stahlbetonträgern. In: Beton- und Stahlbetonbau 105 (11), S. 686-694. DOI: 10.1002/best.201000052.

Simon, Eric (2002): Schubtragverhalten von Mauerwerk aus großformatigen Steinen. Dissertation. Technische Universität Darmstadt, Darmstadt.

Sinha, B. P. (1982): Reinforced grouted cavity brickwork. In: Batiment international - Building research and practice (4), S. 226243.

Tue, Nguyen Viet; Theiler, Werner; Tung, Nguyen Duc (2014): Schubverhalten von Biegebauteilen ohne Querkraftbewehrung. In: Beton- und Stahlbetonbau 109 (10), S. 666-677. DOI: 10.1002/best.201400058.

Uduehi, J. (1989): A comparative study of the structural behaviour of prestressed beams of brickwork and concrete and the shear strength of brickwork. Dissertation. The University of Edinburgh, Edinburgh Schottland. Department of Civil Engineering and Building Science.

Vecchio, Frank, J. (2000): Analysis of Shear-Critical Reinforced Concrete Beams. In: ACI Structural Journal 97 (01), S. 12-21.

Vecchio, Frank, J.; Collins, Michael, P (1986): The Modified Compression Field Theory for Reinforced concrete Elements Subjected to shear. In: ACI Structural Journal, S. 219-231.

DIN EN 1520:2011-06: Vorgefertigte Bauteile aus haufwerksporigem Leichtbeton und mit statisch anrechenbarer oder nicht anrechenbarer Bewehrung. Berlin, Normenausschuss Bauwesen (NABau) im Deutschen Institut für Normung e. V., Beuth Verlag, 2011.

DIN EN 12602:2016-12, 01.10.2013: Vorgefertigte bewehrte Bauteile aus dampfgehärtetem Porenbeton. Berlin, Normenausschuss Bauwesen (NABau) im Deutschen Institut für Normung e. V., Beuth Verlag, 2016.

Walraven, Joost C. (1980): Aggregate Interlock. A theoretical and experimental analysis. Dissertation. Technische Universität Delft, Delft. 
Walraven, Joost C. (2016): XI fib Model Code 2010 - ein neues Konzept für das Entwerfen und Bemessen von Betonkonstruktionen. In: Konrad Bergmeister, Frank Fingerloos und Johann-Dietrich Wörner (Hg.): Beton-Kalender 2016. Berlin, Germany: Wilhelm Ernst \& Sohn, Verlag für Architektur und technische Wissenschaften GmbH \& Co. KG.

Weber, Marius; Stempfle, Hartwig (2013): Verformungsberechnung von Mauerwerksscheiben. Anwendung des klassischen Druckfeldmodells auf Mauerwerk. In: Mauerwerk 17 (3), S. 172-181. DOI: 10.1002/dama.201300576.

Wehr, Gunther (2001): Untersuchungen zur Querkrafttragfähigkeit querkraftbewehrter Elemente aus Porenbeton. Dissertation. Bauhaus-Universität Weimar, Weimar. Fakultät Bauingenieurwesen.

Werbegemeinschaft KS-Sturz: KS Broschüre - Kalksandsteinstürze, Technik und Anwendung. 6. Aufl.

Yang, Yuguang (2014): Shear Behaviour of Reinforced Concrete Members without Shear Reinforcement. A New Look at an Old Problem. Dissertation. Technische Universität Delft, Delft.

Z-17.1-1051 (2014): Allgemeine bauaufsichtliche Zulassung. Ytong Porenbeton Flachstürze der Typenreihe Y-1 uod v-n. Ausgestellt durch: Deutsches Institut für Bautechnik. Berlin.

Z-17.1-1065 (2017): Allgemeine bauaufsichtliche Zulassung. Vorgespannte Flachstürze "Spannton". Ausgestellt durch: Deutsches Institut für Bautechnik. Berlin.

Z-17.1-602 (2012): Allgemeine bauaufsichtliche Zulassung. ELMCO®-Ripp-Bewehrungssystem für Stürze aus bewehrtem Mauerwerk. Ausgestellt durch: Deutsches Institut für Bautechnik. Berlin.

Z-17.1-603 (2012): Allgemeine bauaufsichtliche Zulassung. MOSO-Lochband als Bewehrung für Stürze aus Mauerwerk. Ausgestellt durch: Deutsches Institut für Bautechnik. Berlin.

Z-17.1-621 (2005): Allgemeine bauaufsichtliche Zulassung. Fertigteilstürze aus Kalksandelementen. Ausgestellt durch: Deutsches Institut für Bautechnik. Berlin.

Z-17.1-957 (2017): Allgemeine bauaufsichtliche Zulassung. Vorgespannte Flachstürze "BKH". Ausgestellt durch: Deutsches Institut für Bautechnik. Berlin, zuletzt geprüft am 18.04.2018.

Z-17.1-981 (2013): Allgemeine bauaufsichtliche Zulassung. Nichttragende Flachstürze aus Zuggurten in Ziegel-Formsteinen mit oder ohne Wärmedämmung und Ziegelmauerwerk mit unvermörtelten Stoßfugen. Ausgestellt durch: Deutsches Institut für Bautechnik. Berlin.

Zedler, Thomas (2011): Zum Tragverhalten von Stahlbeton- und Spannbetonbalken unter Torsion. Dissertation. Ruhr-Universität Bochum, Bochum. Fakultät für Bau- und Umweltingenieurwissenschaften.

Zelger, C.; Schellbach, G. (1967): Vorschläge für die Schubbemessung von Ziegelstürzen. In: Die Ziegelindustrie 1967 (24), S. 767-770.

Zelger, Cölestin; Daschner, Ferdinand (1972): Die Tragfähigkeit von Stahlsteindecken. Berlin, München, Düsseldorf: Wilhelm Ernst \& Sohn (Deutscher Ausschuss für Stahlbeton, H. 219).

Zimmerli, Bruno; Schwartz, Joseph; Schwegler, Gregor (1999): Mauerwerk. Bemessung und Konstruktion. Basel u.a.: Birkhäuser.

Zink, Martin (2000): Zum Biegeschubversagen schlanker Bauteile aus Hochleistungsbeton mit und ohne Vorspannung. Zugl.: Leipzig, Univ., Diss., 1999. Stuttgart u.a.: Teubner (Forschung für die Praxis). 
Anhang

\section{A 1 Grundlagen und „Stand der Forschung“" von Mauerwerkbalken}

Tabelle A 1.1 Unterscheidungsmerkmale balkenartiger Mauerwerkkonstruktionen

\begin{tabular}{|c|c|c|}
\hline \multirow[t]{3}{*}{ Mechanik: } & Tragwerk: & $\begin{array}{ll}- & \text { Balken } \\
\text { - } & \text { Wandartige Träger }\end{array}$ \\
\hline & Tragwirkung: & $\begin{array}{l}\text { - } \quad \text { Tragend oder nicht tragend } \\
\text { - Schlaff bewehrt und/ oder vorgespannt }\end{array}$ \\
\hline & Tragmodell: & $\begin{array}{l}\text { - } \quad \text { Sprengwerk bzw. Fachwerk } \\
\text { - } \text { Bogenzugband }\end{array}$ \\
\hline \multirow[t]{8}{*}{ Konstruktion: } & Ort der Verwendung: & $\begin{array}{l}\text { - Innenwand (tragend) } \\
\text { - Außenwand } \\
\circ \text { Innenschale (tragend) } \\
\circ \quad \text { Außenschale (tragend und nicht tragend) }\end{array}$ \\
\hline & Bewehrungsart: & $\begin{array}{ll}\text { - } & \text { Betonstahl } \\
\text { - } & \text { Glasfaserverstärkter Kunststoff-Stahl } \\
\text { - } & \text { Duplexstahl } \\
\text { - } & \text { Edelstahl (Schlaff- und Spannstahl) } \\
\text { - } & \text { Nicht rostender Stahl }\end{array}$ \\
\hline & $\begin{array}{l}\text { Anordnung der } \\
\text { Bewehrung: }\end{array}$ & $\begin{array}{l}\text { Lager-/ Stoßfugen, } \\
\text { - } \quad \text { Beton- oder mörtelverfüllte } \\
\circ \text { U-Schalen aus Mauerwerk, } \\
\circ \text { Hohlräume, geformt durch Verband von Mauersteinen, } \\
\circ \text { Hohlräume, erzeugt durch Formsteine, } \\
\circ \text { Hohlräume zwischen Mauerwerkschichten. }\end{array}$ \\
\hline & Konstruktionsart: & $\begin{array}{ll}\text { - } & \text { Teilweise vorgefertigter, bauseits ergänzender Sturz } \\
& \text { (Flachsturz) } \\
\text { - } & \text { Vorgefertigter Sturz (Fertigteil) } \\
\text { - } & \text { Vorgespannte balkenartige Konstruktion } \\
\text { - } & \text { Nichttragende balkenartige Konstruktion für Vormauer- oder } \\
& \text { Verblendschale } \\
\text { - } & \text { Zusammengesetzter Sturz }\end{array}$ \\
\hline & Stoßfugenausbildung: & $\begin{array}{ll}\text { - } & \text { Vermörtelte Stoßfuge } \\
\text { - } & \text { Unvermörtelte Stoßfuge }\end{array}$ \\
\hline & Mauersteinart: & $\begin{array}{ll}\text { - } & \text { Ziegelsteine } \\
\text { - } & \text { Kalksandsteine } \\
\text { - } & \text { Hüttensteine } \\
\text { - } & \text { Porenbetonsteine } \\
\text { - } & \text { Leichtbetonsteine } \\
\text { - } & \text { Betonsteine }\end{array}$ \\
\hline & Mauerwerkart: & $\begin{array}{ll}\text { - } & \text { Einsteinmauerwerk } \\
\text { - } & \text { Verbandmauerwerk }\end{array}$ \\
\hline & $\begin{array}{l}\text { Mauerwerkverband } \\
\text { oder Steinausrichtung: }\end{array}$ & $\begin{array}{ll}\text { - } & \text { Läuferverband und weitere } \\
\text { - } & \text { Rollschicht (Binderschicht hochkant, seitlich) } \\
\text { - } & \text { Grenadierschicht (Binderschicht hochkant, oben) }\end{array}$ \\
\hline
\end{tabular}


Tabelle A 1.2 Definition von Balken und wandartigen Trägern nach (DIN EN 1992-1-1:2011-01, S. 60)

\begin{tabular}{|l|l|}
\hline Balken: & $\frac{l_{\text {eff }}}{h} \geq 3$ und $\frac{b}{h}<5$, \\
\hline Wand- bzw. scheibenartiger Träger: & $\frac{l_{\text {eff }}}{h}<3$ \\
\hline
\end{tabular}

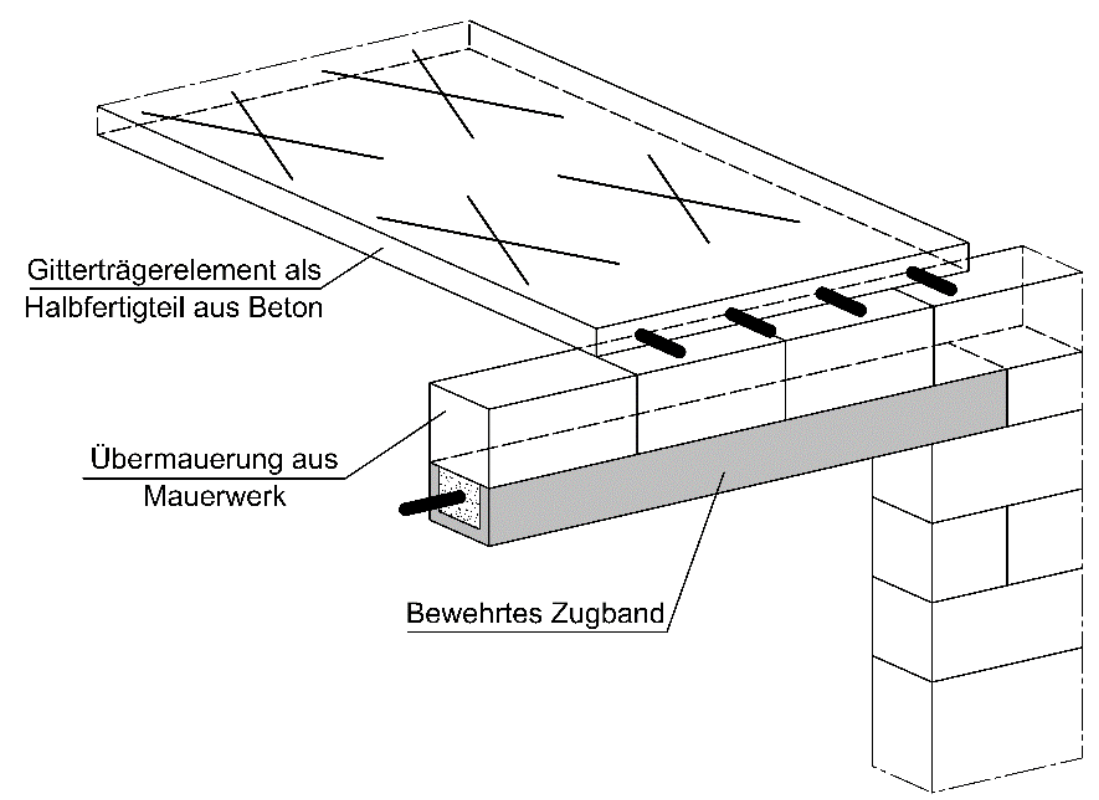

Bild A 1.1 Flachsturz mit bewehrtem Zugband, Druckzone aus Mauerwerk und einer darüber liegenden Gitterträgerelementdecke (Werbegemeinschaft KS-Sturz, S. 11)

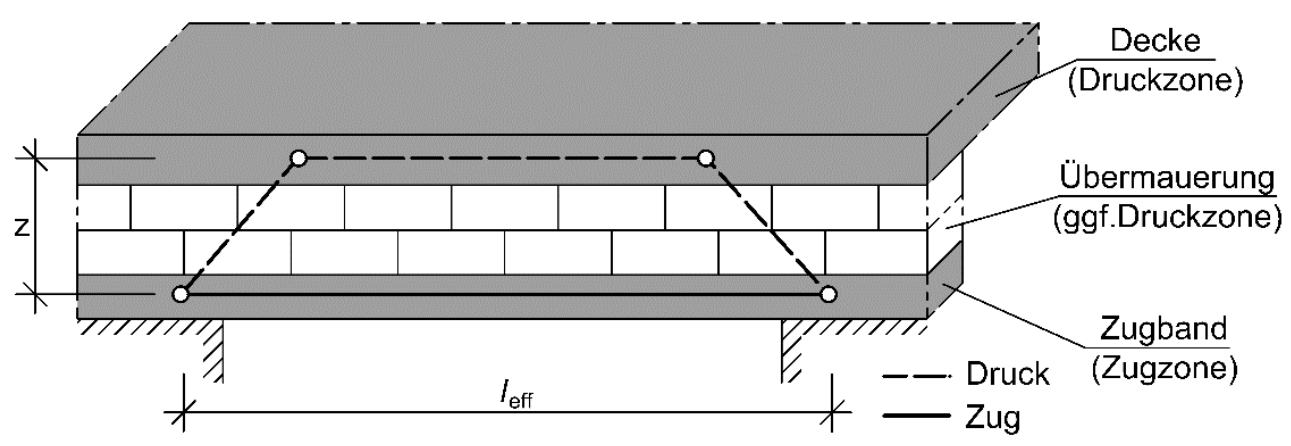

Bild A $1.2 \quad$ Flachsturz mit Druckzone aus Beton (Brameshuber und Raupach 2004, S. 2) 
Ausführungshinweis:

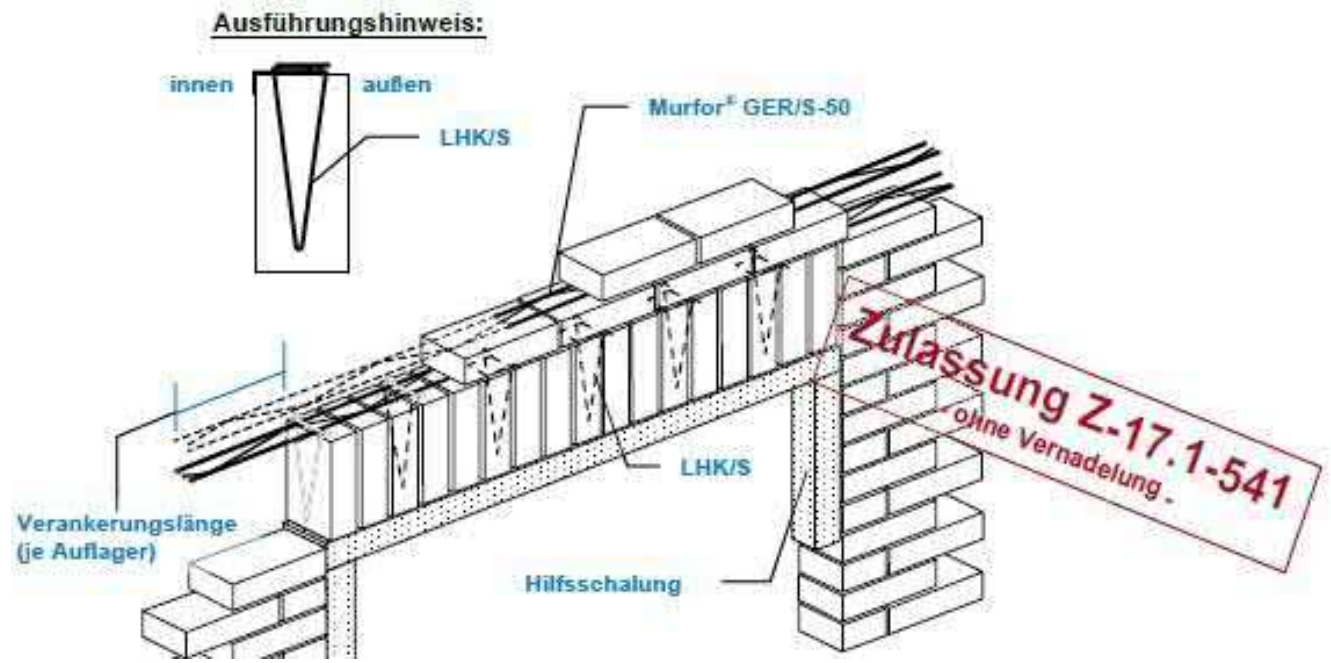

Bild A 1.3 Grenadiersturz in Verblendschale (Lechler 2006, S. 13)

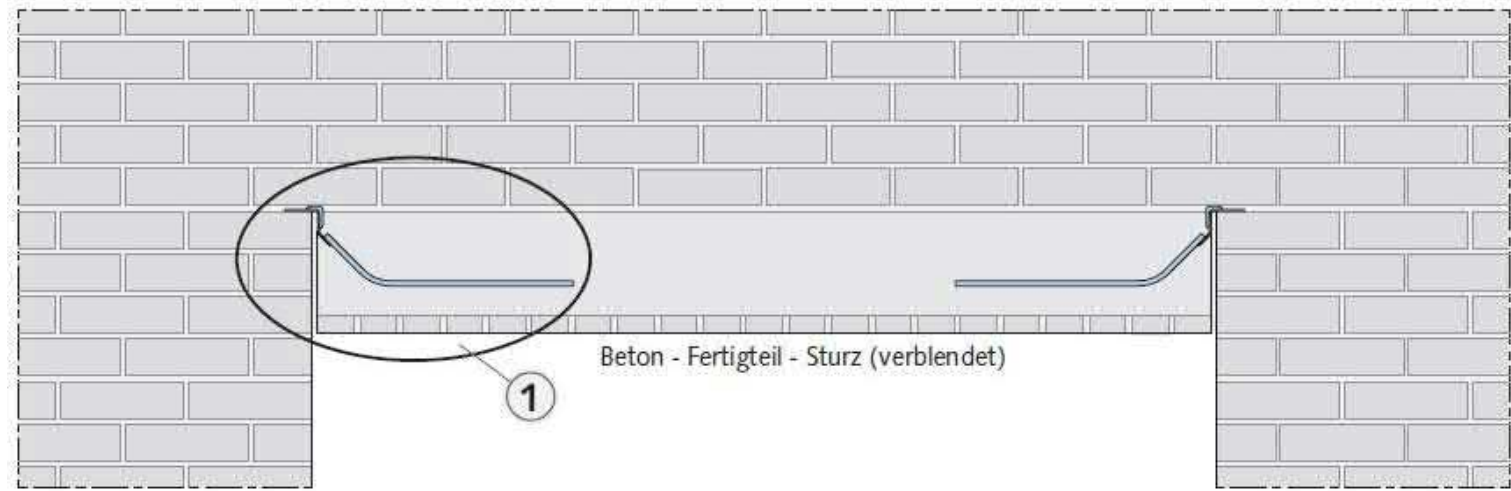

Detail 1
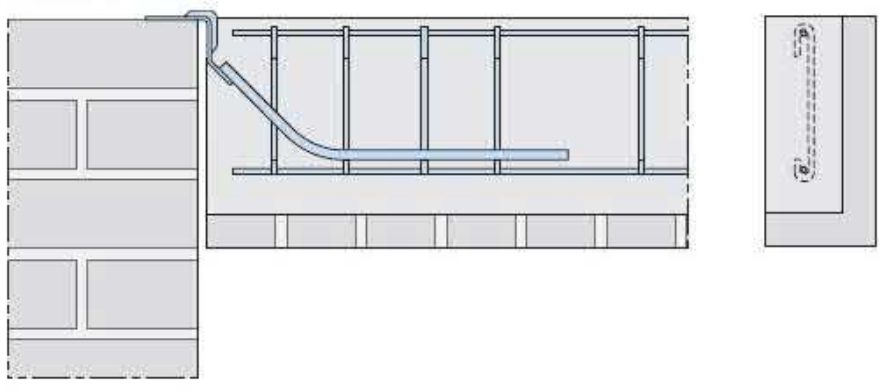

Bild A 1.4

Fertig-Verblendstürze für Fenster und Türöffnungen; Vertriebsgesellschaft mbH, S. 26)

vgl. (HALFEN-DEHA 

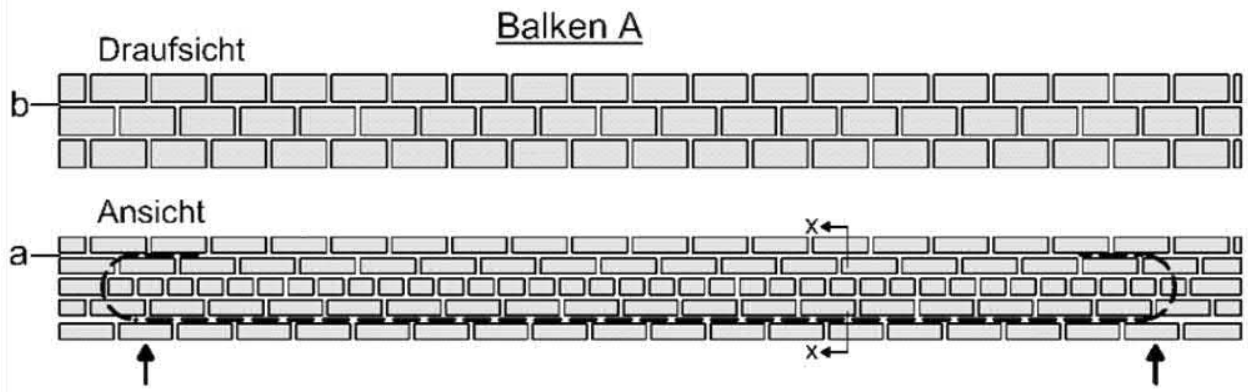

Schnitt $x-x$

b

남늠

赂响

Balken B

b-

Draufsicht

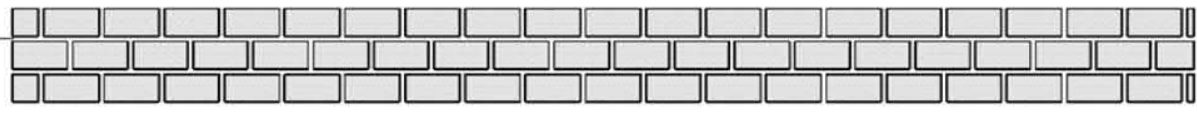

Ansicht
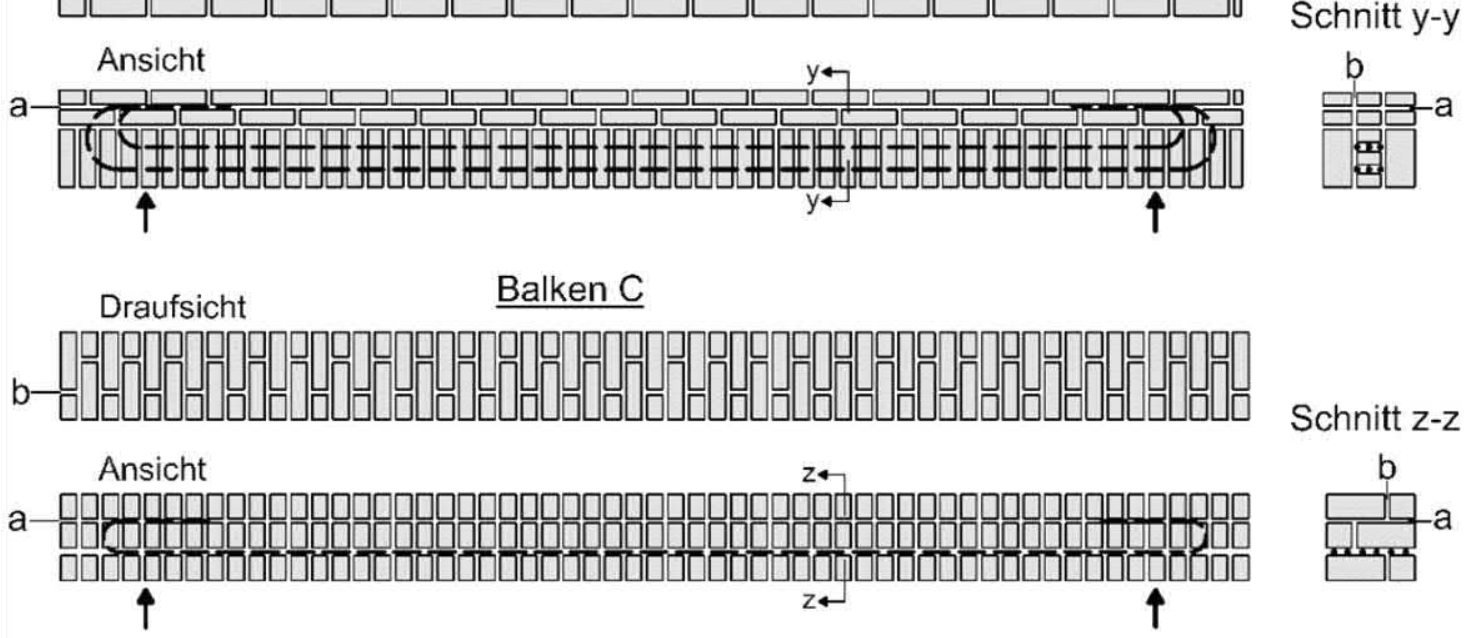

Bild A 1.5

Konstruktionsarten untersuchter Mauerwerkbalken; vgl. (Parason et al. 1932, S. 752) 


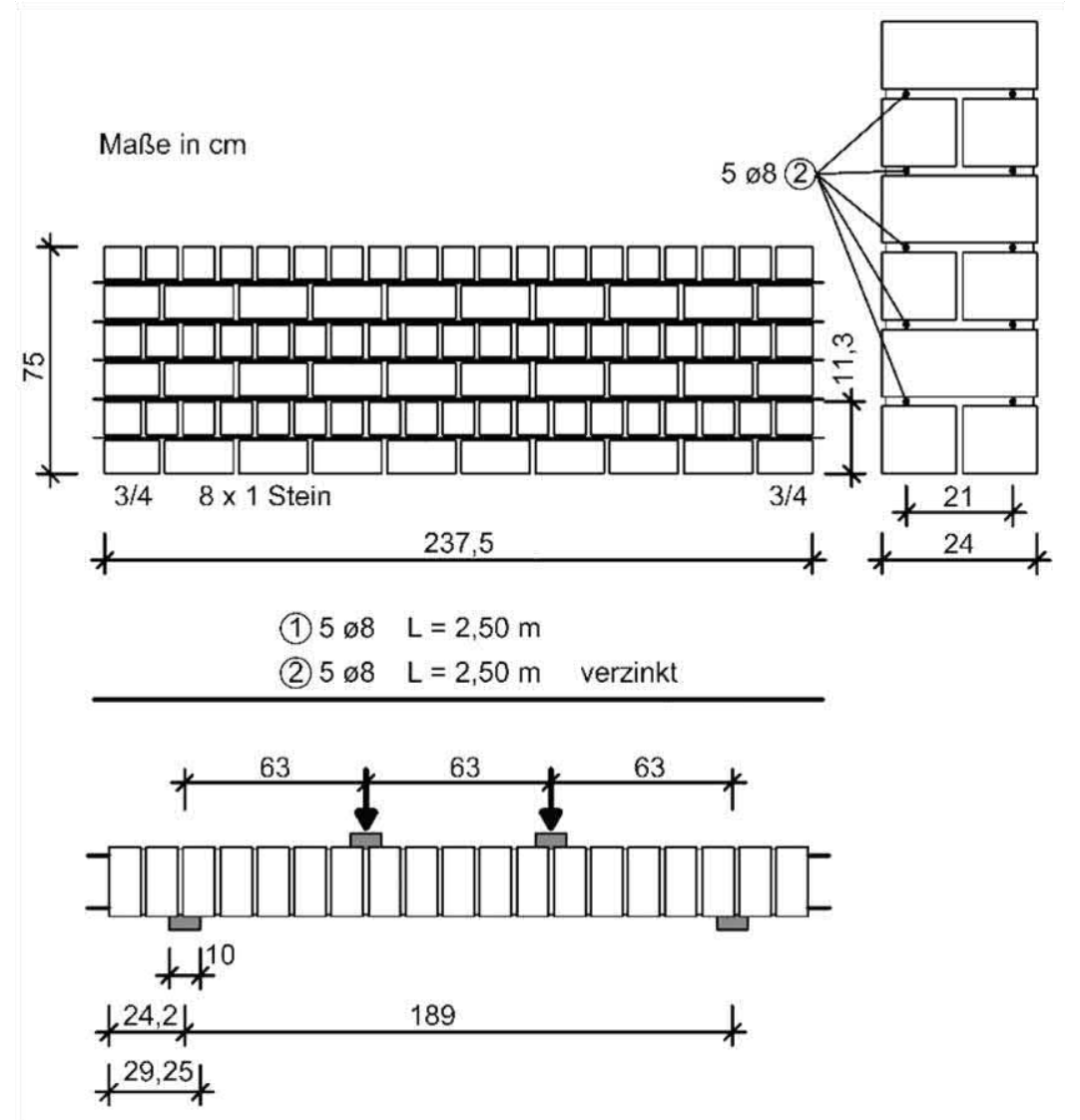

Bild A 1.6

Probekörper (oben); Versuchsaufbau (unten) (Martin und Sager 1986)

Tabelle A 1.3 Berechnung aufnehmbarer Schubspannungen $\left(\tau_{011}\right)$ nach (DIN 1053-3:1990-02) für bewehrtes Mauerwerk

Für scheibenschubbeanspruchtes Mauerwerk ist $\tau_{011}$ nach Gleichung (A 1.2) zu bestimmen. Der Nachweis darf dabei im Abstand von $0,5 \cdot d$ (d statische Höhe) von der Auflagerkante geführt werden.

$\max \tau=\frac{V}{b \cdot z} \leq \tau_{011}$

$\tau_{011}=\min \left\{\begin{array}{c}\beta_{\mathrm{Rk}}+\bar{\mu} \cdot \sigma \\ 0,45 \cdot \beta_{\mathrm{Rz}} \cdot \sqrt{1+\sigma / \beta_{\mathrm{Rz}}}\end{array}\right.$

Dabei sind:

$\beta_{\mathrm{Rk}} \quad$ Der Rechenwert der abgeminderten Kohäsion nach Tabelle 8, DIN 1053-2:1984-07,

$\bar{\mu} \quad$ der Rechenwert des abgeminderten Reibungsbeiwertes; $\bar{\mu}=0,4$,

$\beta_{\mathrm{Rz}} \quad$ der Rechenwert der Steinzugfestigkeit nach Tabelle 7, DIN 1053-2:1984-07 bzw. DIN 10533:1990, Abschnitt 4.2.2,

$\sigma \quad$ die Normalspannung rechtwinklig zur Schubkraft in der betrachteten Querschnittsebene des Bauteils,

$\max \tau$ der unter Gebrauchslasten ermittelte Rechenwert einwirkender Schubspannungen,

$\tau_{011} \quad$ der Grenzwert der aufnehmbaren Schubspannungen.

Vereinfachend darf die rechnerische Normalspannung $(\sigma)$ mit Gleichung (A 1.3) bestimmt werden. 
$\sigma=\frac{2 \cdot F_{\mathrm{A}}}{b \cdot l}$

Dabei sind:

$F_{\mathrm{A}} \quad$ Die Auflagerkraft,

$b \quad$ die Querschnittsbreite des Trägers,

$l \quad$ die Stützweite des Trägers bzw. doppelte Kragarmlänge bei Kragträgern.

Im Fall plattenschubbeanspruchten Mauerwerks wird in DIN 1053-3:1990 auf das Vorgehen von DIN 1045:1978-12, Abschnitt 17.5.5 (DIN 1045:1978-12), verwiesen. Abweichend davon sind die Grenzwerte der Schubspannungen nach Gleichung (A 1.4) zu bestimmen. Die Werte gelten ausschließlich für durchgehende Biegebewehrung; die Berücksichtigung einer Schubbewehrung ist unzulässig.

$\tau_{011}=0,015 \cdot \beta_{\mathrm{R}}$

Dabei ist:

$\beta_{\mathrm{R}}$

Der Rechenwert der Mauerwerkdruckfestigkeit nach DIN 1053-1 bzw. -2.

Tabelle A 1.4 Erläuternde Gleichungen und Zeichenerklärungen nach (E DIN 1053-3:2008-03) für bewehrtes Mauerwerk

$$
\begin{aligned}
& a_{\mathrm{v}}^{*} \leq 2 \cdot d \\
& \beta=\frac{a_{\mathrm{v}}^{*}}{2 \cdot d} \text { oder } \\
& \sigma_{\mathrm{Dd}}=\frac{2 \cdot F_{\mathrm{Ad}}}{b \cdot l}
\end{aligned}
$$

Dabei sind:

$a_{\mathrm{v}}^{*} \quad$ Der Abstand zwischen Auflagerrand und einwirkender Last,

$\sigma_{\mathrm{Dd}} \quad$ der Bemessungswert der zugehörigen Druckspannung an der Stelle der maximalen Schubspannung Im Regelfall ist entsprechend DIN 1053-100:2007 die minimale Einwirkung $F_{\mathrm{Ad}}=1,0 F_{\mathrm{Ak}, \mathrm{G}}$ maßgebend,

$b \quad$ die Querschnittsbreite des Trägers,

$l \quad$ die Stützweite des Trägers bzw. doppelte Kragarmlänge bei Kragträgern.

Tabelle A 1.5 Berechnung des Schubwiderstandes für Bauteile ohne rechnerisch erforderliche Querkraftbewehrung nach (DIN EN 12602:2016-12) für bewehrten Porenbeton

$V_{\mathrm{Rd} 1}=\max \left\{\begin{array}{c}\tau_{R D} \cdot(1-0,83 \cdot d / 1000) \cdot\left(1+240 \cdot \rho_{\mathrm{l}}\right) \cdot b_{\mathrm{w}} \cdot d \\ 0,5 \cdot \frac{f_{\mathrm{ctk} ; 0,05}}{\gamma_{\mathrm{c}}} \cdot b_{w} \cdot d\end{array}\right.$

Dabei ist:

$\tau_{\mathrm{RD}} \quad$ Der Grundwert der aufnehmbaren Schubspannung nach Gleichung (A 1.9).

$\tau_{\mathrm{RD}}=\frac{0,063 * f_{\mathrm{ck}}^{0,5}}{\gamma_{\mathrm{c}}}$

Dabei sind:

$f_{\mathrm{ck}}$

Die charakteristische Druckfestigkeit von dampfgehärtetem Porenbeton, 


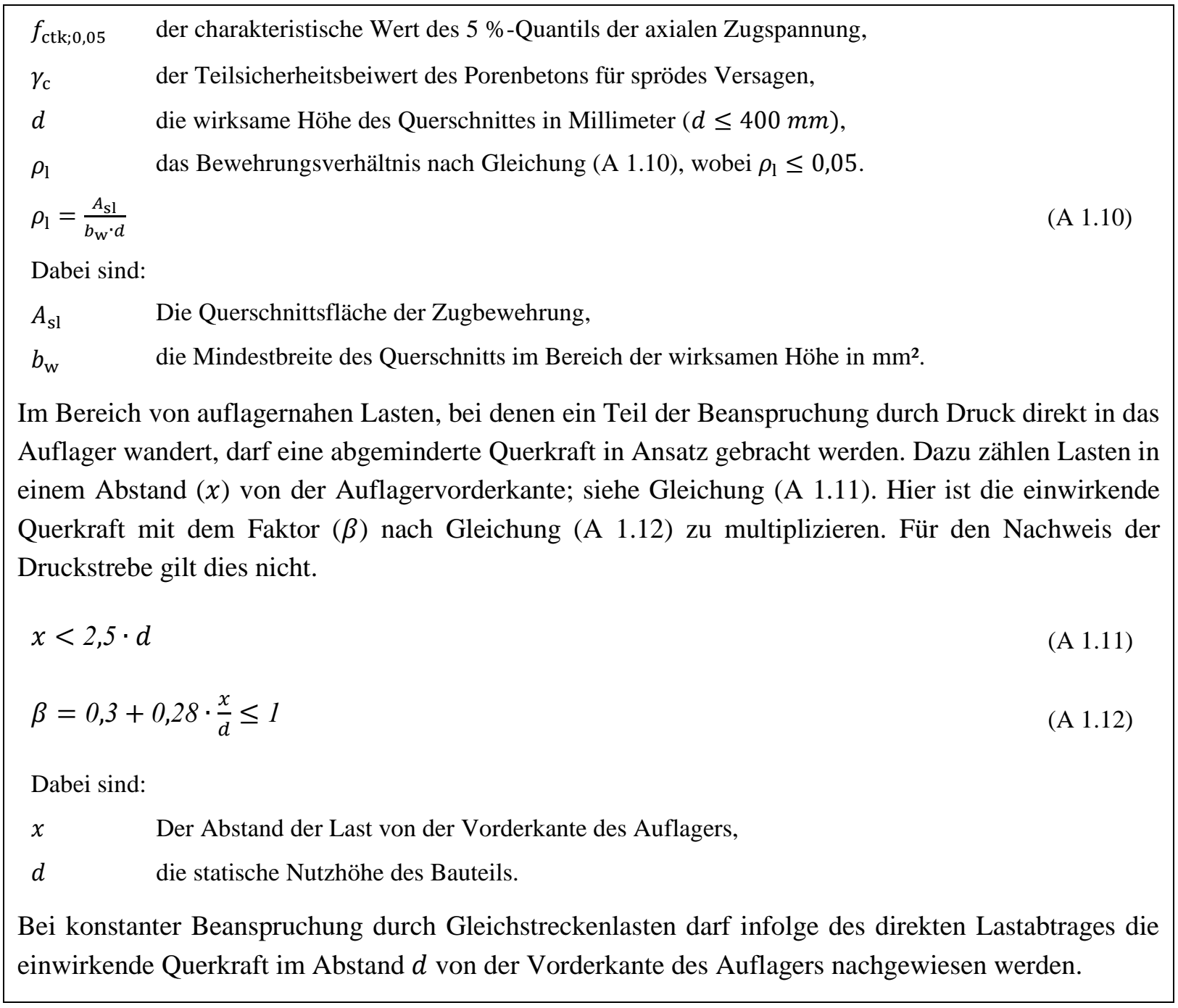

Tabelle A 1.6 Berechnung des Schubwiderstandes für Bauteile ohne rechnerisch erforderliche Querkraftbewehrung $\left(V_{\text {Rd1 }}\right)$ und der Druckstrebentragfähigkeit $\left(V_{\text {Rd2 }}\right)$ nach (DIN EN 1520:2011-06) für bewehrten Leichtbeton

$V_{\mathrm{Rd} 1}=\max \left\{\begin{array}{c}C_{\mathrm{Rd}} \cdot k \cdot \eta_{1} \cdot\left(100 \cdot \rho_{1} \cdot f_{\mathrm{ck}}\right)^{\frac{1}{3}} \cdot b_{\mathrm{w}} \cdot d \\ v_{\mathrm{mind}} \cdot b_{\mathrm{w}} \cdot d\end{array}\right.$

Dabei sind:

$C_{\mathrm{Rd}} \quad$ Ein Parameter für den Querkraftwiderstand nach Gleichung (A 1.14),

$C_{\mathrm{Rd}}=0,145 / \gamma_{\mathrm{c}}$

$k \quad$ ein Faktor für die Schubfestigkeit nach Gleichung (A 1.16),

$\eta_{1} \quad$ ein Faktor nach Gleichung (A 1.17),

$f_{\text {ck }} \quad$ die charakteristische Druckfestigkeit von LAC, in N/mm²,

$b_{\mathrm{w}} \quad$ die kleinste Breite der Querkraftübertragenden Zone in mm,

$v_{\text {mind }} \quad$ der Kleinstwert der aufnehmbaren Schubspannung von LAC in N/mm² nach Gleichung (A 1.15).

$v_{\text {mind }}=0,03 \cdot k^{\frac{3}{2}} \cdot f_{\mathrm{ck}}^{\frac{1}{2}}$

$k=1+\sqrt{200 / d} \leq 2,0$ 
$\eta_{1}=0,40+0,6 \cdot(\rho / 2200)$

Dabei sind:

$\rho \quad$ Die Trockenrohdichte von $\mathrm{LAC}$, in $\mathrm{Kg} / \mathrm{m}^{3}$,

$\rho_{1} \quad$ das Bewehrungsverhältnis nach Gleichung (A 1.10), wobei $\rho_{1} \leq 0,02$.

$V_{\mathrm{Rd} 1}=\tau_{\mathrm{Rd}} \cdot k \cdot\left(1,2+40 \cdot \rho_{1}\right) \cdot b_{\mathrm{w}} \cdot d$

Dabei sind:

$\tau_{\mathrm{Rd}} \quad$ Der Bemessungswert der aufnehmbaren Schubspannung von LAC, in N/mm², nach Gleichung (A 1.19),

$\tau_{\mathrm{Rd}}=\tau_{\mathrm{Rk}} / \gamma_{\mathrm{c}}$

$\tau_{\mathrm{Rk}} \quad$ der charakteristische Wert der aufnehmbaren Schubspannung von LAC, in N/mm², nach Gleichung (A 1.20),

$\tau_{\mathrm{Rk}}=0,125 \cdot f_{\mathrm{t}, \mathrm{flk}}$

$f_{\mathrm{t}, \mathrm{flk}} \quad$ die charakteristische Biegezugfestigkeit von LAC, nach Gleichung (A 1.21),

$f_{\mathrm{t}, \mathrm{flk}}=0,42 \cdot f_{\mathrm{ck}}^{\frac{2}{3}} \cdot \eta_{1}$

$k \quad$ ein Faktor für die Schubfestigkeit, nach Gleichung (A 1.22).

$k=1,6-(d / 1000) \geq 1,0$

$V_{\mathrm{Rd} 2}=0,5 \cdot \eta_{1} \cdot b_{\mathrm{w}} \cdot z \cdot v \cdot f_{\mathrm{cd}}$

Dabei sind:

z Der Hebelarm der inneren Kräfte,

$v \quad$ der Wirksamkeitsbeiwert zur Berücksichtigung der verminderten Druckfestigkeit $f_{\text {ck }}$ in der die Querkraft übertragenden Zone des Bauteils, definiert mit $v=0,6$,

$f_{\text {cd }} \quad$ der Bemessungswert der Druckfestigkeit des Porenbetons, nach Gleichung (A 1.24).

$f_{\mathrm{cd}}=f_{\mathrm{ck}} / \gamma_{\mathrm{c}}$

Der Nachweis der einwirkenden Querkraft kann in einem Abstand (x) vom Auflagerrand nach Gleichung (A 1.25) entfallen. Eine Abminderung infolge auflagernaher Einzellasten wird als Anwendungsvoraussetzung ausgeschlossen.

$x<\mathrm{d} / 2$

Tabelle A 1.7 Bemessungswert der aufnehmbaren Querkrafttragfähigkeit nach (DIN 1045-100:2017-09) für Ziegeldecken

$V_{\mathrm{Rd}}=\tau_{\mathrm{Rd}} \cdot b_{\mathrm{w}} \cdot d$

Dabei sind:

$b \quad$ Die kleinste Querschnittsbreite innerhalb der Zugzone des Querschnitts,

d die statische Nutzhöhe im betrachteten Querschnitt, 
$\tau_{\mathrm{Rd}} \quad$ der Bemessungswert der aufnehmbaren Schubspannungen nach Tabelle 1 (DIN $1045-$ 100:2017-09, S. 8).

Tabelle A 1.8 Bemessungswert der aufnehmbaren Querkrafttragfähigkeit nach (Flachsturz-Richtlinie Vorläufiger Schlussentwurf)

$V_{\mathrm{Rd}}=f_{\mathrm{vdf}} \cdot b \cdot d \cdot \frac{\lambda+0,4}{\lambda-0,4}$

Dabei sind:

$f_{\text {vdf }} \quad$ Der Bemessungswert der Schubfestigkeit von Flachstürzen: 0,14 N/mm²; (Flachsturz-Richtlinie Vorläufiger Schlussentwurf, S. 10),

$d \quad$ die Nutzhöhe des Bauteils mit einem Grenzwert von $d \leq \frac{l_{\mathrm{ef}}}{2,4}$,

$\lambda \quad$ die Schubschlankheit nach Gleichung mit einem Grenzwert von $\lambda \geq 0,6$.

Tabelle A 1.9 Berechnung des Schubwiderstandes nach (Gutachten Nr. GA 02/09 2009; Gutachten Nr. G971318 1999) für Fertigteilbalken aus KS-Mauerwerk

Widerstand der Vertikalfuge - Reibung:

$V_{\mathrm{Rd}, \mathrm{Fuge}}=\frac{f_{\mathrm{vk} 0}}{\gamma_{\mathrm{M}}} \cdot \frac{1}{1-\mu \cdot \lambda_{\mathrm{s}}} \cdot b \cdot d$

Dabei sind:

$f_{\mathrm{vk} 0} \quad$ Die Haftscherfestigkeit,

$\mu \quad$ der Reibungsbeiwert: $\mu=0,6$,

$\lambda_{\mathrm{s}} \quad$ die Schubschlankheit nach Gleichung (A 1.29).

$\lambda_{\mathrm{s}}=\frac{a}{0,85 \cdot d}$

Widerstand gegen Steinzugversagen:

$V_{\mathrm{Rd}, \text { Stein }}=2 \cdot \frac{f_{\mathrm{bz}}}{\gamma_{\mathrm{M}}} \cdot \frac{1}{\sqrt{1+\lambda_{\mathrm{s}}^{2}}} \cdot b \cdot d$

Dabei ist im Weiteren:

$f_{\mathrm{bz}} \quad$ Die Steinzugfestigkeit. 


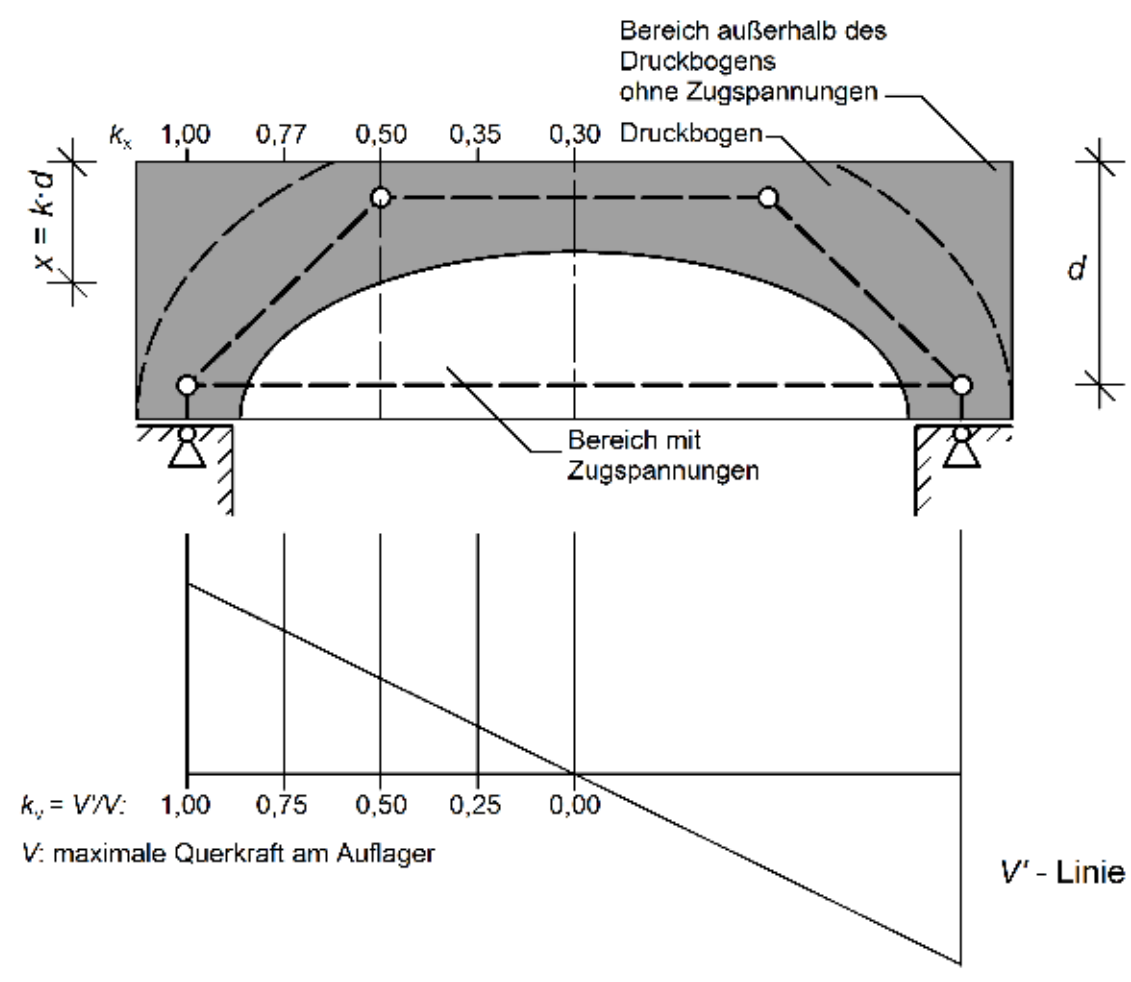

Bild A 1.7 Verhältnisdarstellung zwischen abnehmender Querkraft und geringerer Druckzone in Höhe der ersten Mauerwerkfuge vgl. (Gutachten Nr. GA 02/09 2009, S. 20) 


\section{A 2 Analytische Grundlagen zu Spannungsfeldern für bewehrtes Mauerwerk}

Tabelle A 2.1 Schubtragmodelle für Bauteile ohne Querkraftbewehrung (Bender 2019, S. 14)

\begin{tabular}{|l|||l||l||}
\hline Modell & Lastabtrag & Literatur (AusZug) \\
\hline Bogenmodelle & KANI (1969) \\
KoTSOVOS (1993) \\
Zahnmodelle
\end{tabular}
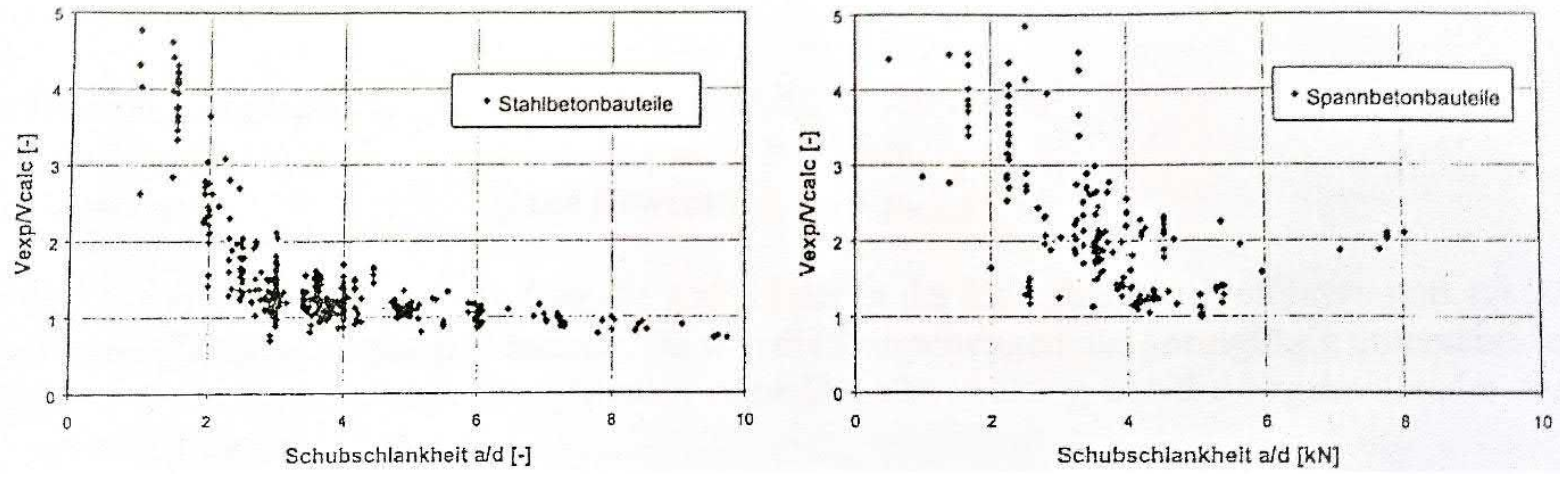

Bild A 2.1 Zunahme des Sicherheitsniveaus im Bereich abnehmender Schubschlankheiten; Stahlbetonbauteile links, Spannbetonbauteile rechts (Hegger et al. 1999, S. 4)

Tabelle A 2.2 Ermittlung von Spaltzugkräften und Randzugkräften für eine exzentrisch wirkende Vorspannkraft (DAfStb Heft 631 2019, S. 90)

$$
\begin{aligned}
& F_{\mathrm{S}}=0,25 \cdot F \cdot\left(1-\frac{h_{1}}{h_{\mathrm{S}}}\right) \\
& F_{\mathrm{R}}=F \cdot\left(\frac{e}{h}-\frac{1}{6}\right) \geq 0
\end{aligned}
$$


Dabei sind:

$F_{\mathrm{S}} \quad$ Die Resultierende Spaltzugkraft,

$F_{\mathrm{S} 2} \quad$ die resultierende Zugkraft,

$F_{\mathrm{R}} \quad$ die resultierende Randzugkraft,

$h_{1} \quad$ die Seitenlänge der Teilfläche,

$h_{\mathrm{s}} \quad$ die Seitenlänge der Verteilungsfläche,

F die orthogonal, zentrisch auf die Teilfläche und ausmittig auf die Gesamtfläche wirkende Druckkraft,

$e \quad$ der Abstand des ausmittigen Lastangriffspunktes von der Mittellinie der Gesamtfläche $(e \geq 1 / 6$. $h)$,

h die Seitenlänge der Gesamtfläche.

\section{A 3 Werkstoffbeschreibende Ausgangsgrößen}

Tabelle A 3.1 Druckfestigkeiten verwendeter Mauersteine senkrecht zur Lagerfuge

\begin{tabular}{|c|c|c|c|c|c|}
\hline Kennzeichnung & $\begin{array}{c}\text { Mittlere } \\
\text { Druck- } \\
\text { festigkeit } \\
\beta_{\mathrm{D}, \mathrm{St}, \perp} \\
{\left[\mathbf{N} / \mathbf{m m}^{2}\right]^{1}}\end{array}$ & $\begin{array}{c}\text { Form- } \\
\text { faktor } \\
D^{1}\end{array}$ & $\begin{array}{c}\text { Normierte } \\
\text { Druck- } \\
\text { festigkeit } \\
\beta_{\mathbf{b}, \perp} \\
{\left[\mathbf{N} / \mathbf{m m}^{2}\right]^{1}}\end{array}$ & $\begin{array}{c}\text { Steindruck- } \\
\text { festigkeitsklasse } \\
f_{\mathbf{b k}}{ }^{2}\end{array}$ & $\begin{array}{c}\text { Mittlere Mindest- } \\
\text { druckfestigkeit } \\
f_{\text {st }} \\
{\left[\mathbf{N} / \mathbf{m m}^{2}\right]^{2}}\end{array}$ \\
\hline HLZ B $-8 \mathrm{DF}-12-0,8$ & 10,4 & 1,42 & 14,8 & 10 & 12,5 \\
\hline HLZ B - 6 DFA $-12-0,8$ & 9,1 & 1,40 & 12,7 & 10 & 12,5 \\
\hline HLZ B - 5 DFE $-12-0,8$ & 8,9 & 1,40 & 12,5 & 10 & 12,5 \\
\hline $\mathrm{KS}-6 \mathrm{DF}-12-1,4$ & 10,6 & 1,42 & 15 & 12 & 15,0 \\
\hline KS XL-QU $20-2,0$ & $24,9^{3}$ & 1,00 & 24,9 & 16 & 20,0 \\
\hline KS 6DF 20-2,0 & 27,2 & 1,30 & 35,2 & 28 & 35,0 \\
\hline PPW $-4-0,5$ & 3,9 & 3,90 & 3,9 & 2 & 2,5 \\
\hline \multicolumn{6}{|c|}{${ }^{1}$ nach DIN EN 772-1 (DIN EN 772-1:2011+A1:2015) ${ }^{2}$ nach DIN EN 1996-1-1 (DIN EN 1996-1-1:2013-02) ${ }^{3}$} \\
\hline
\end{tabular}

Tabelle A 3.2 Zugfestigkeiten verwendeter Mauersteine senkrecht zur Lagerfuge

\begin{tabular}{|c|c|c|}
\hline Kennzeichnung & Verhältniswerte ${ }^{1}$ & $\begin{array}{c}\text { Zugfestigkeit nach } \boldsymbol{\beta}_{\mathrm{z}, \mathrm{I}} \\
{\left[\mathrm{N} / \mathbf{m m}^{2}\right]}\end{array}$ \\
\hline HLZ B $-8 \mathrm{DF}-12-0,8$ & $0,013 \ldots 0,041$ & $0,192 \ldots 0,607$ \\
\hline HLZ B - 6 DFA $-12-0,8$ & $0,013 \ldots 0,041$ & $0,165 \ldots 0,521$ \\
\hline HLZ B - 5 DFE - $12-0,8$ & $0,013 \ldots 0,041$ & $0,163 \ldots 0,513$ \\
\hline $\mathrm{KS}-6 \mathrm{DF}-12-1,4$ & $0,027 \ldots 0,065$ & $0,405 \ldots 0,975$ \\
\hline KS XL-QU $20-2,0$ & $0,027 \ldots 0,065$ & $0,667 \ldots 1,606$ \\
\hline KS 6DF 20-2,0 & $0,039 \ldots 0,081$ & $1,373 \ldots 2,851$ \\
\hline PPW $-4-0,5$ & $0,09 \ldots 0,13$ & $0,351 \ldots 0,507$ \\
\hline
\end{tabular}


Tabelle A 3.3 Biegezug- und Drucktragfähigkeit verwendeter Mauermörtel

\begin{tabular}{|c|c|c|c|c|}
\hline Mauersteinart & Mauermörtel & $\begin{array}{c}\text { Rohdichte }^{1} \\
\rho_{\mathbf{m}} \\
{\left[\mathbf{k g} / \mathbf{d m}^{3}\right]}\end{array}$ & $\begin{array}{c}\text { Biegezugtragfähigkeit }{ }^{1} \\
\beta_{\mathrm{bt}, \mathrm{b}} \\
{\left[\mathbf{N} / \mathbf{m m}^{2}\right]}\end{array}$ & $\begin{array}{c}\text { Drucktragfähigkeit }^{1} \\
\boldsymbol{\beta}_{\mathbf{m}} \\
{\left[\mathbf{N} / \mathbf{m m}^{2}\right]}\end{array}$ \\
\hline $\mathrm{Z}$ & DM & 1,60 & 3,73 & 11,94 \\
\hline KS & DM & 1,79 & 3,40 & 12,40 \\
\hline PP & DM & 1,26 & 2,30 & 9,90 \\
\hline
\end{tabular}

Tabelle A 3.4 Haftscherfestigkeit und Reibungswinkel der Stein-Mörtelkombinationen

\begin{tabular}{|c|c|c|c|c|}
\hline \multirow[t]{2}{*}{ Art der Mauersteine } & \multicolumn{3}{|c|}{$\begin{array}{c}\text { Haftscherfestigkeit } \beta_{\mathrm{HS}}{ }^{1} \\
{\left[\mathrm{~N} / \mathbf{m m}^{2}\right]}\end{array}$} & \multirow[t]{2}{*}{$\begin{array}{c}\text { Reibungsbeiwert } \mu^{2} \\
{[-]}\end{array}$} \\
\hline & $\bar{x}$ & $\min x$ & $\max x$ & \\
\hline Ziegel & 0,43 & 0,18 & 0,93 & \multirow{3}{*}{$\begin{array}{c}\text { 0,4 (Scheibenschub) } \\
\text { 0,6 (Plattenschub) }\end{array}$} \\
\hline Kalksandstein & 0,94 & 0,37 & 1,68 & \\
\hline Porenbeton & 0,75 & 0,41 & 1,28 & \\
\hline
\end{tabular}

${ }^{1}$ nach Literatur (Brameshuber und Jäger 2015, S. 10-11) ${ }^{2}$ nach DIN EN 1996-1-1/NA (DIN EN 1996-1-1:201201/NA, S. 17)

Tabelle A 3.5 Haftzugfestigkeiten der Stein-Mörtelkombinationen

\begin{tabular}{|c|c|c|c|}
\hline \multirow[t]{2}{*}{ Art der Mauersteine } & \multicolumn{3}{|c|}{$\begin{array}{c}\text { Haftzugfestigkeit }{ }^{1} \beta_{\mathrm{HZ}} \\
{\left[\mathrm{N} / \mathrm{mm}^{2}\right] 1}\end{array}$} \\
\hline & $\overline{\mathbf{x}}$ & $\min x$ & $\max x$ \\
\hline Ziegel & 0,19 & 0,10 & 0,32 \\
\hline Kalksandstein & 0,42 & 0,24 & 0,82 \\
\hline Porenbeton & 0,37 & 0,25 & 0,50 \\
\hline
\end{tabular}

${ }^{1}$ nach Literatur (Brameshuber und Jäger 2015, S. 12-

13).

Tabelle A 3.6 Drucktragfähigkeit des verwendeten Ziegelmauerwerks senkrecht zur Lagerfuge nach Zulassung

\begin{tabular}{|c|c|c|c|c|c|}
\hline Kennzeichnung & Mauerstein & Mauermörtel & $\begin{array}{c}\begin{array}{c}\text { Steindruck- } \\
\text { festigkeitsklasse }\end{array} \\
f_{\mathrm{bk}}\end{array}$ & $\begin{array}{c}\text { Charakteristische } \\
\text { Mauerwerk- } \\
\text { druckfestigkeit } \\
f_{\mathrm{k}} \\
{\left[\mathrm{N} / \mathbf{m m}^{2}\right]}\end{array}$ & $\begin{array}{c}\text { Mittlere } \\
\text { Mauerwerk- } \\
\text { druckfestigkeit } \\
\boldsymbol{\beta}_{\mathrm{D}, \mathbf{m w}, \perp} \\
{\left[\mathbf{N} / \mathbf{m m}^{2}\right]}\end{array}$ \\
\hline $\begin{array}{c}\text { HLZ B }-8 \mathrm{DF}- \\
12-0,8\end{array}$ & \multirow{3}{*}{ HLZ B } & \multirow{3}{*}{ DM } & \multirow{3}{*}{10} & \multirow{3}{*}{$4,2^{1}$} & \multirow{3}{*}{$5,25^{2}$} \\
\hline $\begin{array}{c}\text { HLZ B - } 6 \text { DFA } \\
-12-0,8\end{array}$ & & & & & \\
\hline $\begin{array}{l}\text { HLZ B - } 5 \text { DFE } \\
\quad-12-0,8\end{array}$ & & & & & \\
\hline
\end{tabular}


Tabelle A 3.7 Drucktragfähigkeit des verwendeten Kalksandsteinmauerwerks senkrecht zur Lagerfuge

\begin{tabular}{|c|c|c|c|c|c|c|c|c|}
\hline $\begin{array}{c}\text { Kenn- } \\
\text { zeichnung }\end{array}$ & $\begin{array}{c}\text { Mauer- } \\
\text { stein }\end{array}$ & $\begin{array}{c}\text { Mauer- } \\
\text { mörtel }\end{array}$ & \multicolumn{2}{|c|}{ Konstante } & $\begin{array}{c}\text { Normierte } \\
\text { Druck- } \\
\text { festigkeit } \\
\boldsymbol{f}_{\mathbf{b}, \mathbf{S t}} \\
{\left[\mathbf{N} / \mathbf{m m}^{2}\right]}\end{array}$ & $\begin{array}{c}\text { Drucktrag- } \\
\text { fähigkeit } \\
\boldsymbol{f}_{\mathbf{m}} \\
{\left[\mathbf{N} / \mathbf{m m}^{2}\right]}\end{array}$ & $\begin{array}{c}\text { Charakt. } \\
\text { Druck- } \\
\text { festigkeit } \\
\boldsymbol{f}_{\mathrm{k}} \\
{\left[\mathrm{N} / \mathrm{mm}^{2}\right]}\end{array}$ & $\begin{array}{c}\text { Mittlere } \\
\text { Mauerwerks- } \\
\text { druckfestigkeit } \\
\beta_{\mathrm{D}, \mathrm{mw}, \perp} \\
{\left[\mathrm{N} / \mathbf{m m}^{2}\right]}\end{array}$ \\
\hline \multirow{3}{*}{$\begin{array}{l}\mathrm{KS}-6 \mathrm{DF} \\
-12-1,4\end{array}$} & \multirow{3}{*}{ KS-Planstein } & \multirow{3}{*}{$\mathrm{DM}$} & $K$ & 1,15 & \multirow{3}{*}{15} & \multirow{3}{*}{-} & \multirow{3}{*}{5,61} & \multirow{3}{*}{$7,01^{1}$} \\
\hline & & & $\alpha$ & 0,585 & & & & \\
\hline & & & $\beta$ & - & & & & \\
\hline \multirow{3}{*}{$\begin{array}{c}\text { KS XL- } \\
\text { QU 20- } \\
2,0\end{array}$} & \multirow{3}{*}{$\begin{array}{l}\text { KS- } \\
\text { Ergänzungs- } \\
\text { element }\end{array}$} & \multirow{3}{*}{$\mathrm{DM}$} & $K$ & 0,8 & \multirow{3}{*}{24,9} & \multirow{3}{*}{-} & \multirow{3}{*}{10,47} & \multirow{3}{*}{$13,09^{1}$} \\
\hline & & & $\alpha$ & 0,8 & & & & \\
\hline & & & $\beta$ & - & & & & \\
\hline \multirow{3}{*}{$\begin{array}{c}\mathrm{KS} 6 \mathrm{DF} \\
20-2,0\end{array}$} & \multirow{3}{*}{ KS-Planstein } & \multirow{3}{*}{$\mathrm{DM}$} & $K$ & 0,8 & \multirow{3}{*}{35,2} & \multirow{3}{*}{-} & \multirow{3}{*}{13,81} & \multirow{3}{*}{$17,26^{1}$} \\
\hline & & & $\alpha$ & 0,8 & & & & \\
\hline & & & $\beta$ & - & & & & \\
\hline
\end{tabular}

Tabelle A 3.8 Drucktragfähigkeit des verwendeten Porenbetonmauerwerks senkrecht zur Lagerfuge

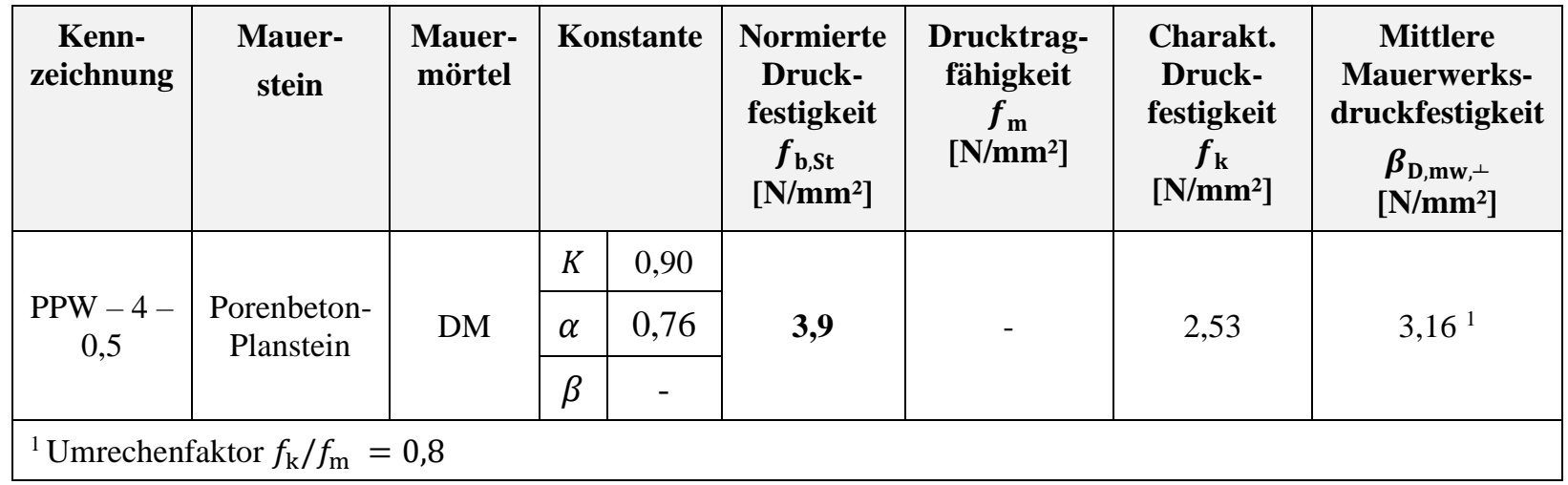

Tabelle A 3.9 Druck-Elastizitätsmodul der verwendeten Mauerwerke anhand charakteristischer Mauerwerkdruckfestigkeit

\begin{tabular}{|c|c|c|c|c|}
\hline Kennzeichnung & Mauerwerkart & $\begin{array}{c}\text { Kennzahl } \\
K_{\mathrm{E}}{ }^{1}\end{array}$ & $\begin{array}{c}\text { Charakteristische } \\
\text { Druckfestigkeit } f_{\mathrm{k}} \\
{\left[\mathrm{N} / \mathrm{mm}^{2}\right]}\end{array}$ & $\begin{array}{c}\text { Druck- } \\
\text { Elastizitätsmodul } E \\
{\left[\mathrm{~N} / \mathbf{m m}^{2}\right]}\end{array}$ \\
\hline HLZ B $-8 \mathrm{DF}-12-0,8$ & \multirow{3}{*}{ Ziegel } & \multirow{3}{*}{1100} & \multirow{3}{*}{4,2} & \multirow{3}{*}{4620} \\
\hline HLZ B - 6 DFA - $12-0,8$ & & & & \\
\hline HLZ B - 5 DFE $-12-0,8$ & & & & \\
\hline $\mathrm{KS}-6 \mathrm{DF}-12-1,4$ & \multirow{3}{*}{ Kalksandstein } & \multirow{3}{*}{950} & 5,61 & 5330 \\
\hline KS XL-QU $20-2,0$ & & & 10,47 & 9948 \\
\hline KS 6DF 20-2,0 & & & 13,81 & 13215 \\
\hline PP & Porenbeton & 550 & 2,53 & 1392 \\
\hline
\end{tabular}


Tabelle A 3.10 Querdehnungszahlen $\left(\mu_{\mathrm{D}}\right)$ und Dehnungen bei Höchstspannung $\left(\varepsilon_{\mathrm{u}, \mathrm{D}}\right)$ verwendeter Mauerwerke

\begin{tabular}{|c|c|c|c|}
\hline Kennzeichnung & Mauerwerkart & $\begin{array}{c}\text { Querdehnungszahl }{ }^{1} \\
\text { (Rechenwert) }^{1} \\
{[-]}\end{array}$ & $\begin{array}{c}\text { Dehnung bei } \\
\text { Höchstspannung }{ }^{1} \\
\text { (Rechenwert) } \\
{[\mathrm{mm} / \mathrm{m}]}\end{array}$ \\
\hline HLZ B $-8 \mathrm{DF}-12-0,8$ & \multirow{3}{*}{ Ziegel } & \multirow{3}{*}{$\begin{array}{c}0,05 \ldots 0,23 \\
(0,1)\end{array}$} & \multirow{3}{*}{$\begin{array}{c}1,0 \ldots 2,6 \\
(1,8)\end{array}$} \\
\hline HLZ B - 6 DFA - $12-0,8$ & & & \\
\hline HLZ B - 5 DFE $-12-0,8$ & & & \\
\hline $\mathrm{KS}-6 \mathrm{DF}-12-1,4$ & \multirow{3}{*}{ Kalksandstein } & \multirow{3}{*}{$\begin{array}{c}0,07 \ldots 0,12 \\
(0,1)\end{array}$} & \multirow{3}{*}{$\begin{array}{c}1,3 \ldots 3,9 \\
(2,5)\end{array}$} \\
\hline KS XL-QU $20-2,0$ & & & \\
\hline KS 6DF 20-2,0 & & & \\
\hline PP & Porenbeton & $\begin{array}{c}0,17 \ldots 0,32 \\
(0,25)\end{array}$ & $\begin{array}{c}1,4 \ldots 3,7 \\
(2,0)\end{array}$ \\
\hline
\end{tabular}

Tabelle A 3.11 Fugendruckfestigkeiten in Abhängigkeit des Mörtels vgl. (Brameshuber 2016, S. 7)

\begin{tabular}{|l|l|l|l|}
\hline Mörtelart & Mörtelklasse & $\boldsymbol{f}_{\mathbf{m}}\left[\mathbf{N} / \mathbf{m m}^{2}\right]$ & $\boldsymbol{f}_{\mathbf{m}, \text { joint }}\left[\mathbf{N} / \mathbf{m m}^{2}\right]$ \\
\hline \multirow{4}{*}{ Normalmörtel } & M 2,5 & 2.5 & $1.75 \ldots 3.25$ \\
\cline { 2 - 4 } & M 5 & 5.0 & $3.50 \ldots 6.50$ \\
\cline { 2 - 4 } & M 10 & 10.0 & $7.00 \ldots 13.00$ \\
\cline { 2 - 4 } & M 20 & 20.0 & $14.00 \ldots 26.00$ \\
\hline Dünnbettmörtel & M10 & 10.0 & $7.00 \ldots 13.00$ \\
\hline
\end{tabular}

Tabelle A 3.12 Empirischer Verhältnisfaktor zur Umrechnung auf Steindruckfestigkeit parallel zur Lagerfuge vgl. (Brameshuber 2016, S. 9)

\begin{tabular}{|l|l|l|}
\hline \multicolumn{2}{|l|}{ Mauersteinart } & $\boldsymbol{a}_{\mathrm{b}}[-]$ \\
\hline \multirow{4}{*}{ Vollsteine } & Ziegelsteine & $0.6(0.8)^{2}$ \\
\cline { 2 - 3 } & Leichtbetonsteine & 0.3 \\
\cline { 2 - 3 } & Porenbetonsteine & $0.6(0.8)^{2}$ \\
\cline { 2 - 3 } & Kalksandsteine & $0.3(0.6)^{2}$ \\
\hline \multirow{3}{*}{ Lochsteine (bezogene Lochfläche $\leq 50 \%)$} & Ziegelsteine & $* 1$ \\
\cline { 2 - 3 } & Leichtbetonsteine & 0.3 \\
\cline { 2 - 3 } & Kalksandsteine & 0.3 \\
\hline keine Angabe & & \\
\hline
\end{tabular}


Tabelle A 3.13 Drucktragfähigkeit des verwendeten Mauerwerks parallel zur Lagerfuge

\begin{tabular}{|c|c|c|}
\hline Kennzeichnung & $\begin{array}{c}\text { Druckfestigkeit } \\
\boldsymbol{\beta}_{\mathbf{D}, \mathbf{m w}, \boldsymbol{l l}} \\
{\left[\mathbf{N} / \mathbf{m m}^{2}\right]^{1}}\end{array}$ & $\begin{array}{c}\text { Verhältnis von } \\
\boldsymbol{\beta}_{\mathbf{D}, \mathbf{m w}, \boldsymbol{l l}}\end{array}$ \\
\hline $\boldsymbol{\beta}_{\mathbf{D}, \mathbf{m w}, \perp}$
\end{tabular}

Tabelle A 3.14 Versagenskriterien infolge Scheibenschub nach (DIN EN 1996-1-1:2012-01/NA, S. 17) in Anlehnung an Mann/Müller

Für die Ermittlung der charakteristischen Schubfestigkeit $\left(f_{\mathrm{vk}}\right)$ nach DIN EN 1996-1-1/NA (DIN EN 1996-1-1:2012-01/NA, S. 17) ist für in seiner Ebene beanspruchtes Mauerwerk der kleinere der beiden Grenzwerte aus $f_{\mathrm{vlt1}}$ und $f_{\mathrm{vlt2}}$ maßgebend.

In Anlehnung an Mann/Müller sind folgende Versagenskriterien zu unterscheiden:

a. Schubversagen infolge Überschreiten der Haftzugfestigkeit

Für Mauersteine mit einem Längen-Höhen-Verhältnis $l_{\mathrm{u}} / h_{\mathrm{u}} \leq 1$ wird die Nachweisgleichung für Reibungsversagen (b) maßgebend. Aus diesem Grund wird normativ auf eine Gleichung zur Berücksichtigung dieses Lastfalls verzichtet (Jäger und Marzahn 2010, S. 169). Bei Elementmauerwerk mit unvermörtelten Stoßfugen mit einem Verhältnis $l_{\mathrm{u}} / h_{\mathrm{u}}>1$ gilt die Gleichung NA.23, nach DIN EN 1996-1-1/NA (DIN EN 1996-1-1:2012-01/NA, S. 67).

b. Schubversagen infolge Überschreiten der Haftscherfestigkeit (Reibungsversagen)

Gemäß DIN EN 1996-1-1/NA ist zur Bestimmung des Schubwiderstands infolge Reibung der Grenzwert $\left(f_{\text {vlt1 }}\right)$ nach Gleichung (A 3.1) zu bestimmen.

$f_{\mathrm{vlt} 1}=f_{\mathrm{vk} 0}+\mu \cdot \sigma_{\mathrm{Dd}}$

Dabei sind:

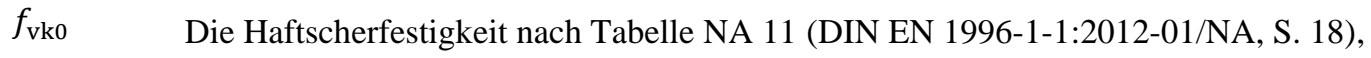

$\mu \quad$ der Reibungsbeiwert für Scheibenschubbeanspruchung mit $\mu=0,4$ (unvermörtelte Stoßfugen); $\mu=0,6$ (vermörtelte Stoßfugen),

$\sigma_{\mathrm{Dd}} \quad$ die Vertikalspannung nach Gleichung (A 3.2) bzw. Gleichung (A 3.3).

Zur Berechnung von $f_{\text {vlt1 } 1}$ ist der in der Lagerfuge wirkende Bemessungswert der Mauerwerkdruckspannung $\left(\sigma_{\mathrm{Dd}}\right)$ bei direkt aufgelagerten Balken vereinfachend mit der Auflagerkraft 
$\left(F_{\text {Ad }}\right)$ nach Gleichung (A 3.2) abzuschätzen. Für Rechteckquerschnitte gilt in allen anderen Fällen Gleichung (A 3.3).

$$
\sigma_{\mathrm{Dd}}=\frac{2 \cdot F_{\mathrm{Ad}}}{t \cdot l_{\mathrm{eff}}}
$$

Dabei sind:

$$
\begin{aligned}
& \sigma_{\mathrm{Dd}} \quad \text { Der Bemessungswert der zugehörigen Druckspannung an der Stelle der maximalen } \\
& \text { Schubspannung, } \\
& t \quad \text { die Mauerwerkdicke, } \\
& l_{\text {eff }} \quad \text { die Stützweite des Balkens bzw. Sturzes, } \\
& N_{\mathrm{Ed}} \quad \text { der Bemessungswert der einwirkenden Normalkraft senkrecht zur Lagerfuge } N_{\mathrm{Ed}}=\gamma_{\mathrm{G}} \cdot N_{\mathrm{Gk}} \text { mit } \\
& \gamma_{\mathrm{G}}=1,0 \text {, } \\
& \text { A die überdrückte Querschnittsfläche. } \\
& \sigma_{\mathrm{Dd}}=N_{\mathrm{Ed}} / A
\end{aligned}
$$

Mit steigender Auflastspannung wird der Reibungswiderstand so groß, dass „Steinzugversagen“ einsetzt. Hierfür ist der Grenzwert ( $f_{\text {vlt2 }}$ ) nach Gleichung (A 3.3) zu bestimmen.

$$
f_{\mathrm{vlt} 2}=0,45 \cdot f_{\mathrm{bt}, \mathrm{cal}} \cdot \sqrt{1+\frac{\sigma_{\mathrm{Dd}}}{f_{\mathrm{bt}, \mathrm{cal}}}}
$$

Dabei ist:

$$
\begin{aligned}
& f_{\mathrm{bt}, \mathrm{cal}} \text { Die Steinzugfestigkeit nach NPD 3.6.2 (3) (DIN EN 1996-1-1:2012-01/NA, S. 17). } \\
& \text { d. Schubversagen durch Überschreiten der Mauerwerkdruckfestigkeit }
\end{aligned}
$$

Damit dieser Versagenslastfall eintritt, muss das Mauerwerk durch hohe Normaldruckspannungen beansprucht werden. Für diese Art der Beanspruchung ist i.d.R. die Steinzugfestigkeit maßgebend, weshalb in DIN EN 1996-1-1/NA kein gesonderter Nachweis für das Schub-Druckversagen enthalten ist. Ausgenommen davon ist Elementmauerwerk mit einem Überbindemaß $l_{\mathrm{ol}} / h_{\mathrm{u}}<0,4$; hier ist der Nachweis nach Gleichung NA.21 der DIN EN 1996-1-1/NA durchzuführen (DIN EN 1996-1-1:201201/NA, S. 67).

Tabelle A 3.15 Biegezug- und Drucktragfähigkeit verwendeter Injektionsmörtel ${ }^{1}$

\begin{tabular}{|c|c|c|c|}
\hline Mauersteinart & $\begin{array}{c}\text { Rohdichte }^{\mathbf{1}} \boldsymbol{\rho}_{\mathbf{m}} \\
{\left[\mathbf{k g} / \mathbf{d m}^{\mathbf{3}}\right]}\end{array}$ & $\begin{array}{c}\text { Biegezugtragfähigkeit }{ }^{\mathbf{1}} \boldsymbol{\beta}_{\mathbf{b t , b}} \\
{\left[\mathbf{N} / \mathbf{m m}^{\mathbf{2}} \mathbf{l}\right.}\end{array}$ & $\begin{array}{c}\text { Drucktragfähigkeit }^{\mathbf{1}} \boldsymbol{\beta}_{\mathbf{m}} \\
{\left[\mathbf{N} / \mathbf{m m}^{\mathbf{2}}\right]}\end{array}$ \\
\hline Z & 1,42 & 7,10 & 39,5 \\
\hline KS & 2,12 & 7,40 & 50,3 \\
\hline \multicolumn{2}{|l}{ nach DIN EN 196-1 (DIN EN 196-1:2005-05) } \\
\hline
\end{tabular}

Tabelle A 3.16 Drucktragfähigkeit verwendeten Aufbetons

\begin{tabular}{|c|c|}
\hline $\begin{array}{c}\text { Rohdichte }^{\mathbf{1}} \boldsymbol{\rho}_{\mathbf{m}} \\
{\left[\mathbf{k g} / \mathbf{d m}^{3}\right]}\end{array}$ & $\begin{array}{c}\text { Drucktragfähigkeit } \\
{ }^{2} \boldsymbol{\beta}_{\text {cm,dry }} \\
{\left[\mathbf{N} / \mathbf{m m}^{2}\right]}\end{array}$ \\
\hline 2,03 & 39,1 \\
\hline \multicolumn{2}{|c|}{${ }^{2}$ nach DIN EN 12390-7 (DIN EN 12390-7:2009-07); ${ }^{2}$ nach DIN EN 12390-3 (DIN EN 12390-3:2009-06) } \\
\hline
\end{tabular}


Tabelle A 3.17 Mechanische Eigenschaften von Bewehrungsstahl für bewehrtes Mauerwerk

\begin{tabular}{|c|c|c|c|c|c|}
\hline Art der Bewehrung & $\begin{array}{c}\text { E- Modul } \\
E_{\mathrm{s}} \\
\left(\mathrm{N} / \mathbf{m m}^{2}\right)\end{array}$ & $\begin{array}{c}\text { Streckgrenze }^{1} \\
f_{\mathbf{y}} \\
\left(\mathbf{N} / \mathbf{m m}^{2}\right)\end{array}$ & $\begin{array}{c}\text { char. } \\
\text { Festigkeit }^{1} \\
f_{\text {yk }} \\
\left(\mathrm{N} / \mathbf{m m}^{2}\right)\end{array}$ & $\begin{array}{c}\text { Streckgrenzen- } \\
\text { dehnung } \\
f_{\mathrm{y}} / E_{\mathrm{s}} \\
{[\% \mathrm{o}]}\end{array}$ & $\begin{array}{c}\text { Bruchdehnung }{ }^{2} \\
\varepsilon_{\mathrm{uk}} \\
{[\% \mathrm{o}]}\end{array}$ \\
\hline B500 & 200000 & 500 & 435 & 2,5 & 25 \\
\hline
\end{tabular}

Tabelle A 3.18 Mechanische Eigenschaften von Spannstahl für bewehrtes Mauerwerk

\begin{tabular}{|c|c|c|c|c|c|}
\hline Art der Bewehrung & $\begin{array}{c}\text { E- Modul } \\
\boldsymbol{E}_{\mathbf{S}} \\
\left(\mathbf{N} / \mathbf{m m}^{\mathbf{2}}\right)\end{array}$ & $\begin{array}{c}\text { Nennfestigkeit } \\
\boldsymbol{R}_{\mathbf{p 0 , 2}} \\
\left(\mathbf{N} / \mathbf{m m}^{\mathbf{2}}\right)\end{array}$ & $\begin{array}{c}\text { Zugfestigkeit }^{\mathbf{1}} \\
\boldsymbol{R}_{\mathbf{m}} \\
\left(\mathbf{N} / \mathbf{m m}^{\mathbf{2}}\right)\end{array}$ & Dehngrenze $^{\mathbf{1}}$ & $\begin{array}{c}\text { Bruchdehnung }^{\mathbf{1}} \\
\boldsymbol{A}\end{array}$ \\
\hline S 670/800 & 195600 & 716 & 839 & 2,0 & 12,9 \\
\hline${ }^{1}$ nach Prüfbericht (Marx 2018)
\end{tabular}

\section{A 4 Experimentelle Untersuchungen}

\section{A 4.1 Flachstürze - Ia}

\section{A 4.1.1 Systemskizze}

PP-01 bis PP-04

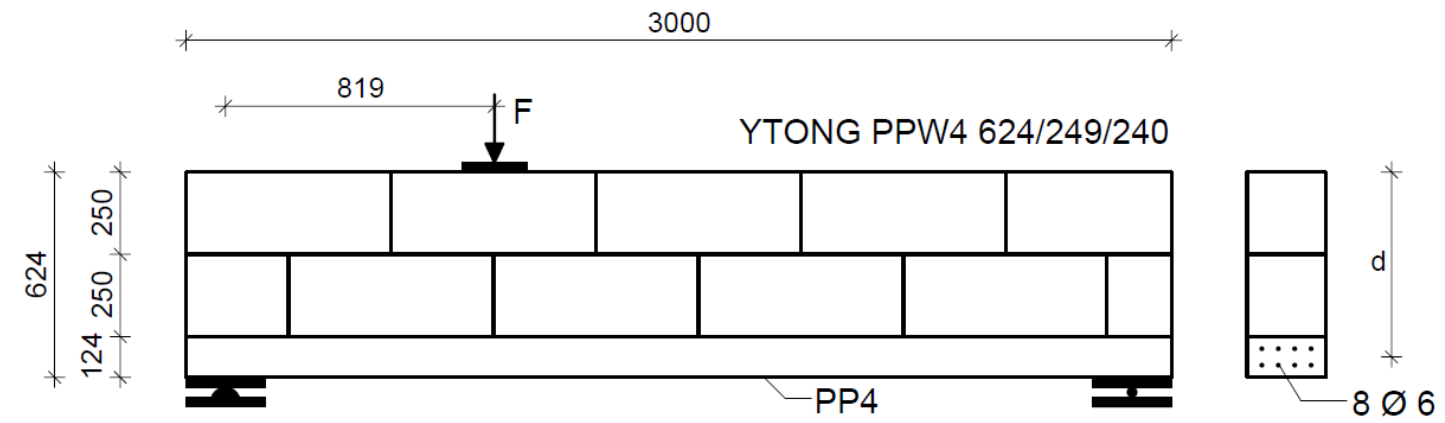

Bild A 4.1 Systemskizze der Porenbeton-Flachstürze - PP-01 bis PP-04 


\section{A 4.1.2 Messstellenplan}

PP-01 bis PP-04

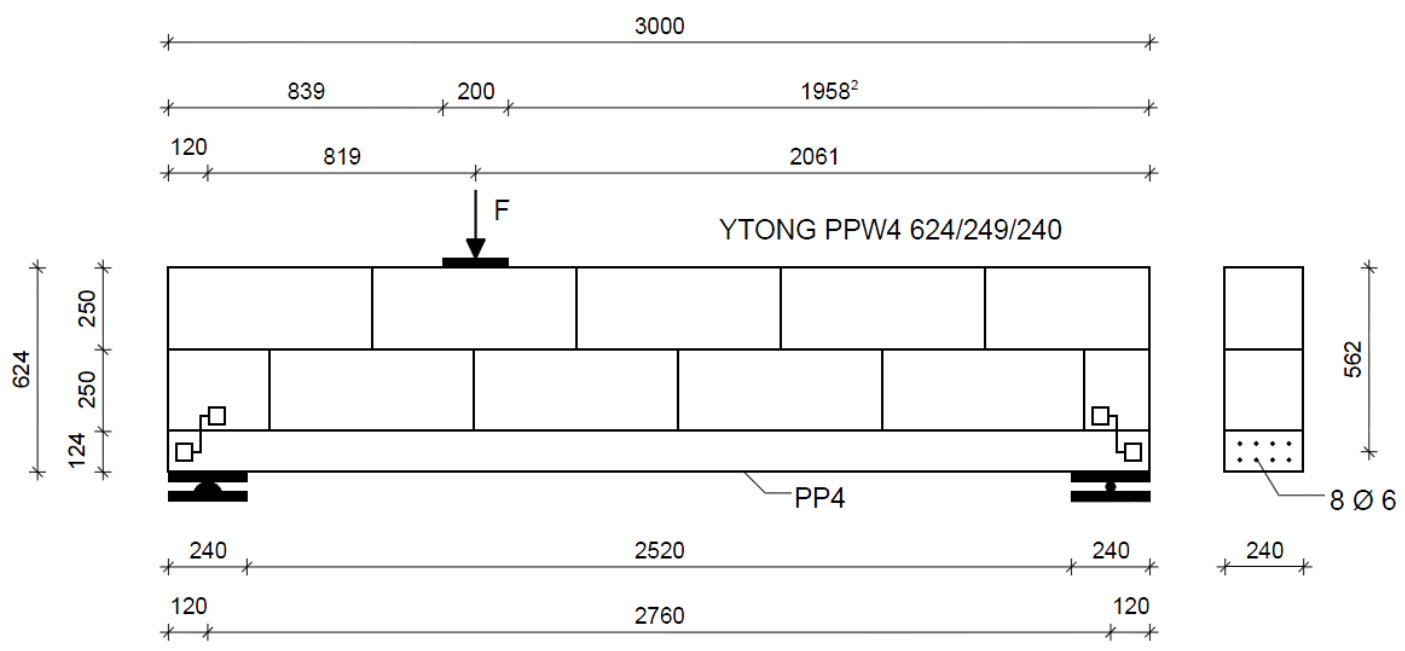

Bild A 4.2 Messstellenplan der Porenbeton-Flachstürze- PP-01 bis PP-04

\section{A 4.1.3 Rissbilder}

PP-01

3000

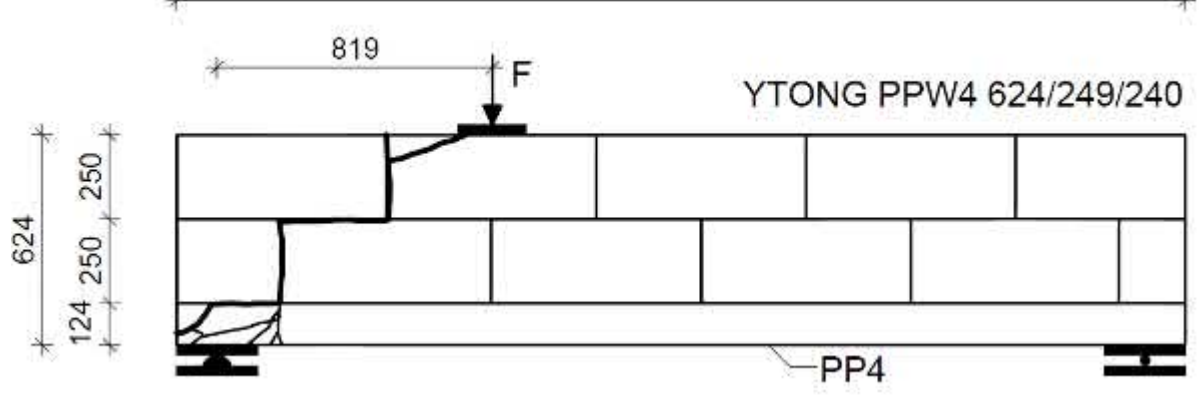

PP-02

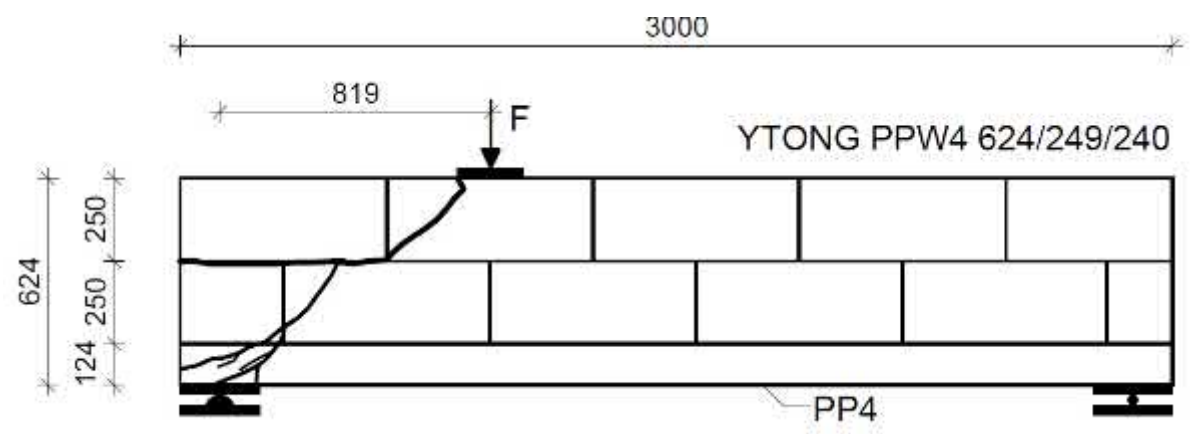


PP-03

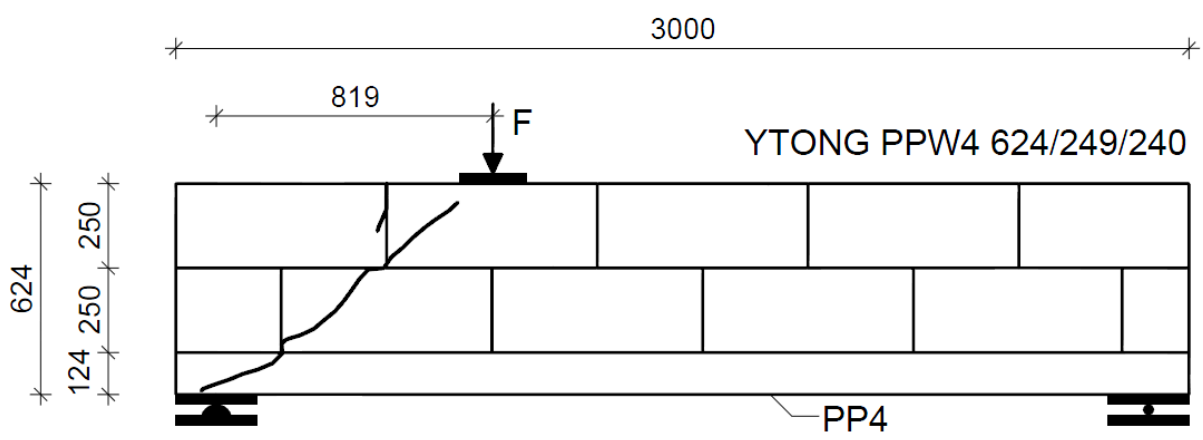

PP-04

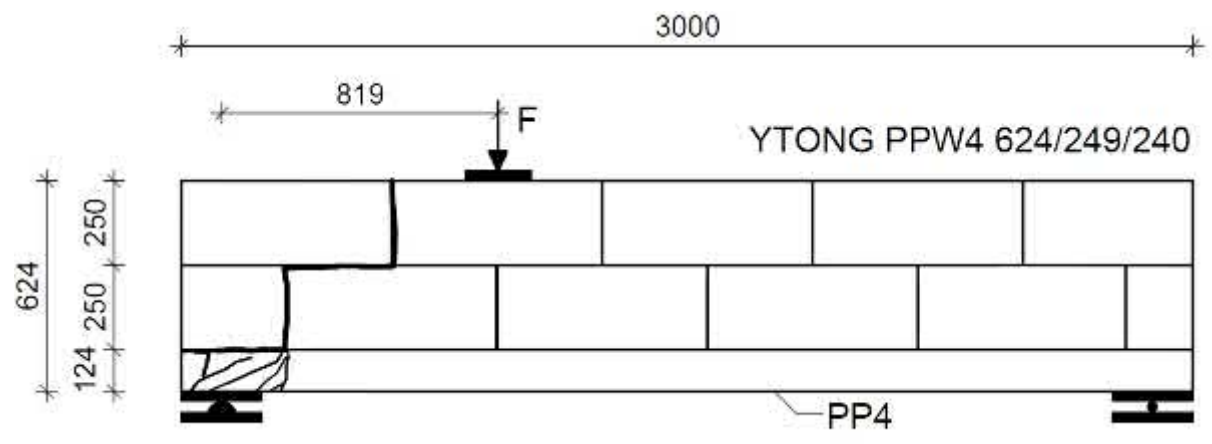

Bild A 4.3 Rissbilder der Porenbeton-Flachstürze - PP-01 bis PP-04 
A 4.1.4 Lastdurchbiegungslinien und flächenhafte Darstellung der Verschiebung in horizontaler und vertikaler Richtung sowie Hauptformänderungen

PP-01

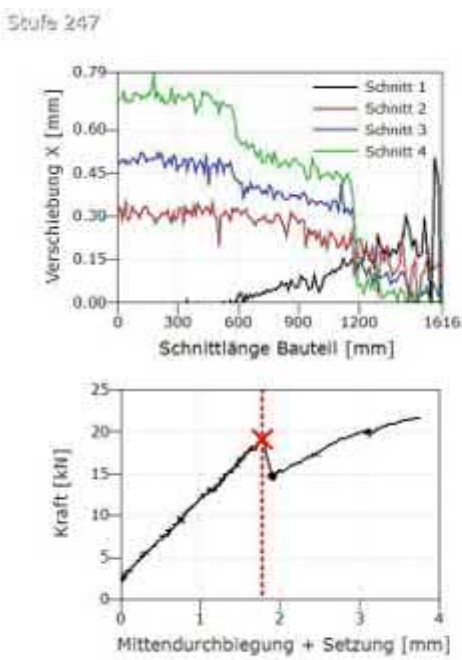

Hochschule Ostwestfalen-Lippe University of Applied Sciences
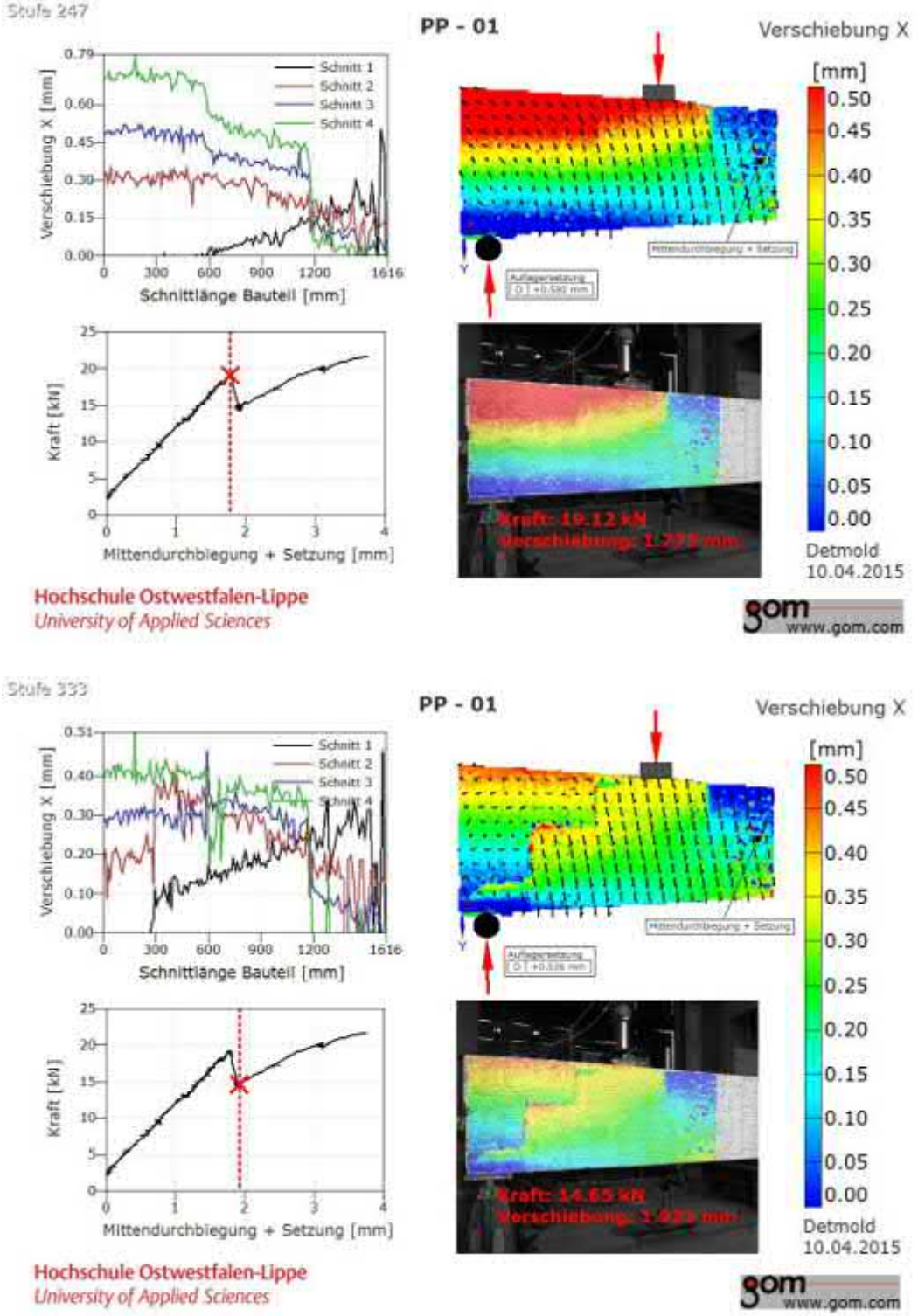

Hochschule Ostwestfalen-Lippe 


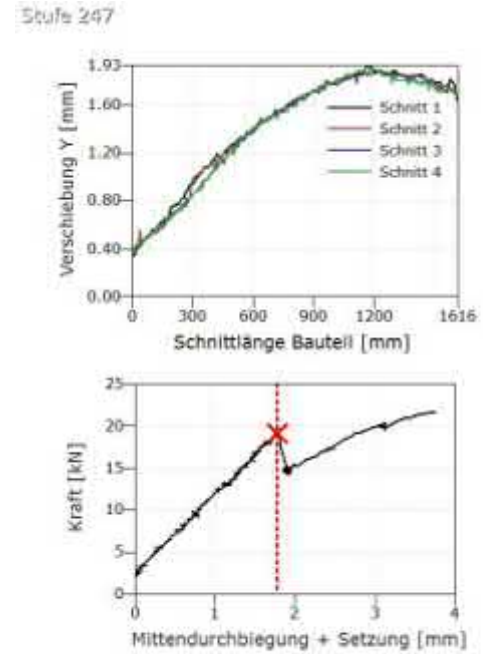

Hochschule Ostwestfalen-Lippe University of Applied Sciences

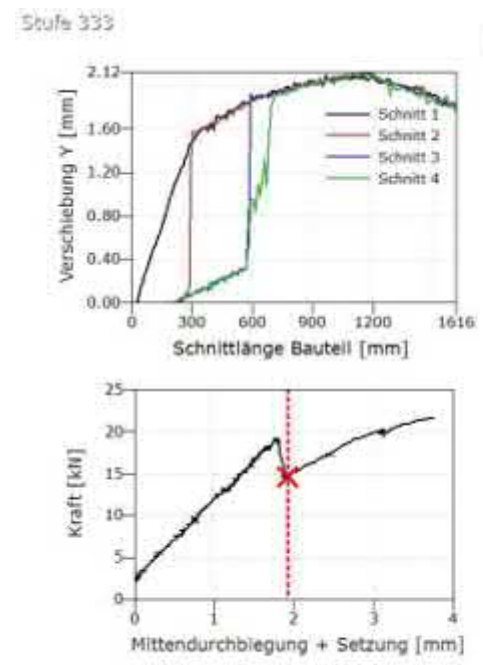

Hochschule Ostwestfalen-Lippe University of Applied Sciences
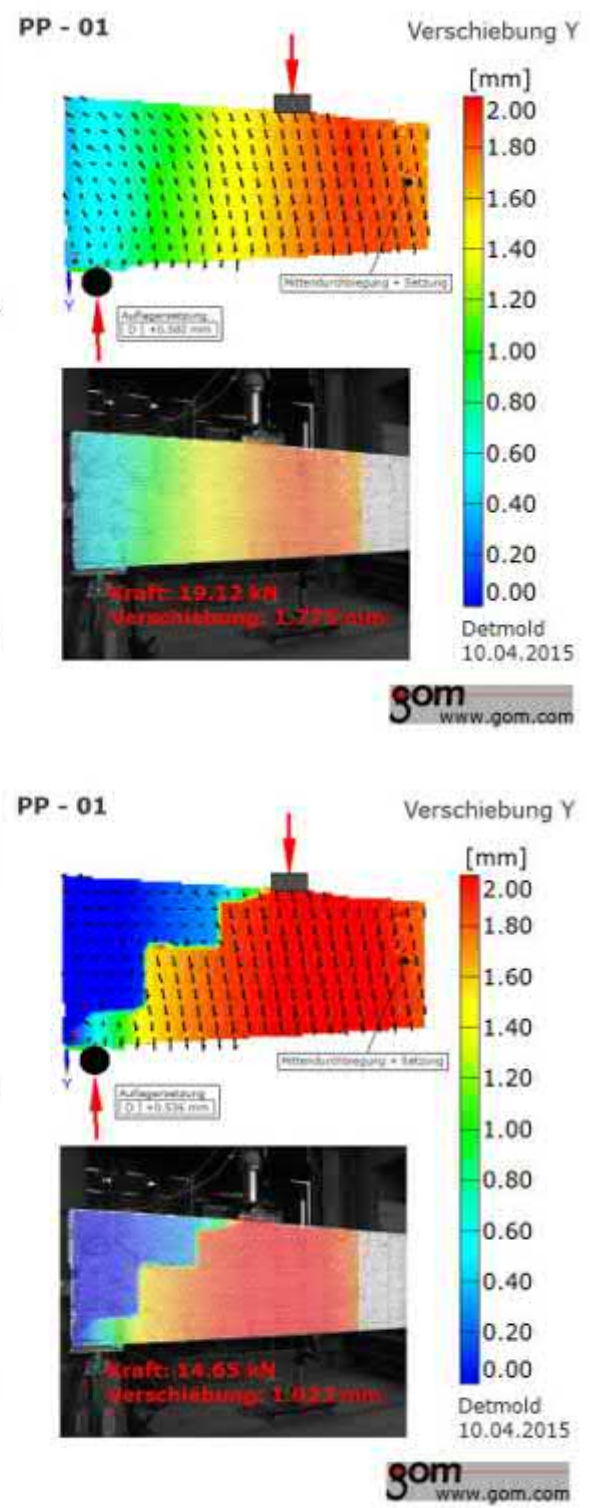

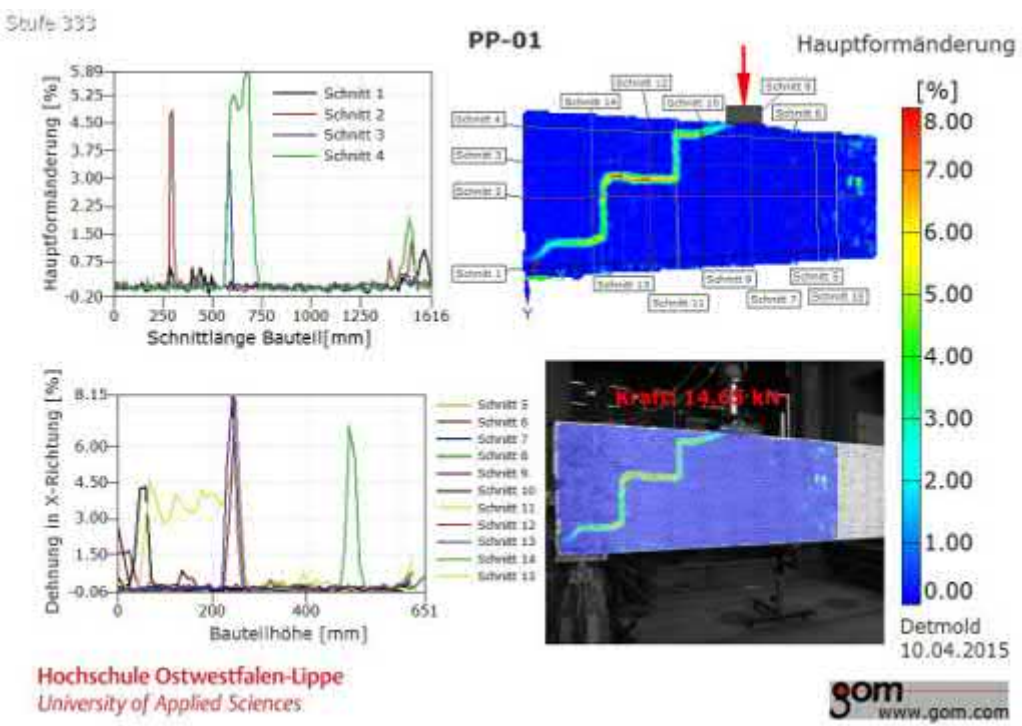




\section{PP-02}
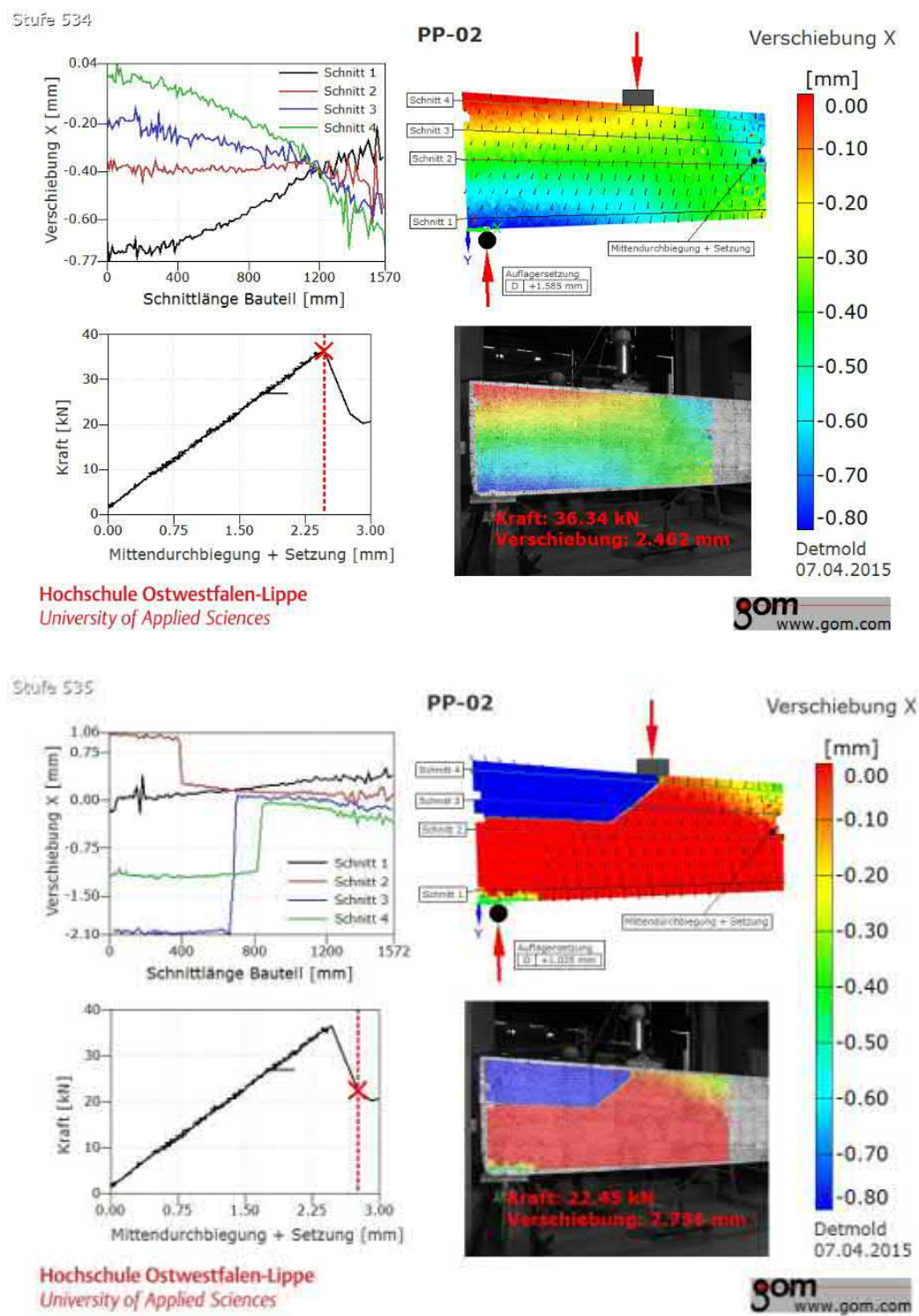

Hochschule Ostwestfalen-Lippe University of Applied Sciences

30m
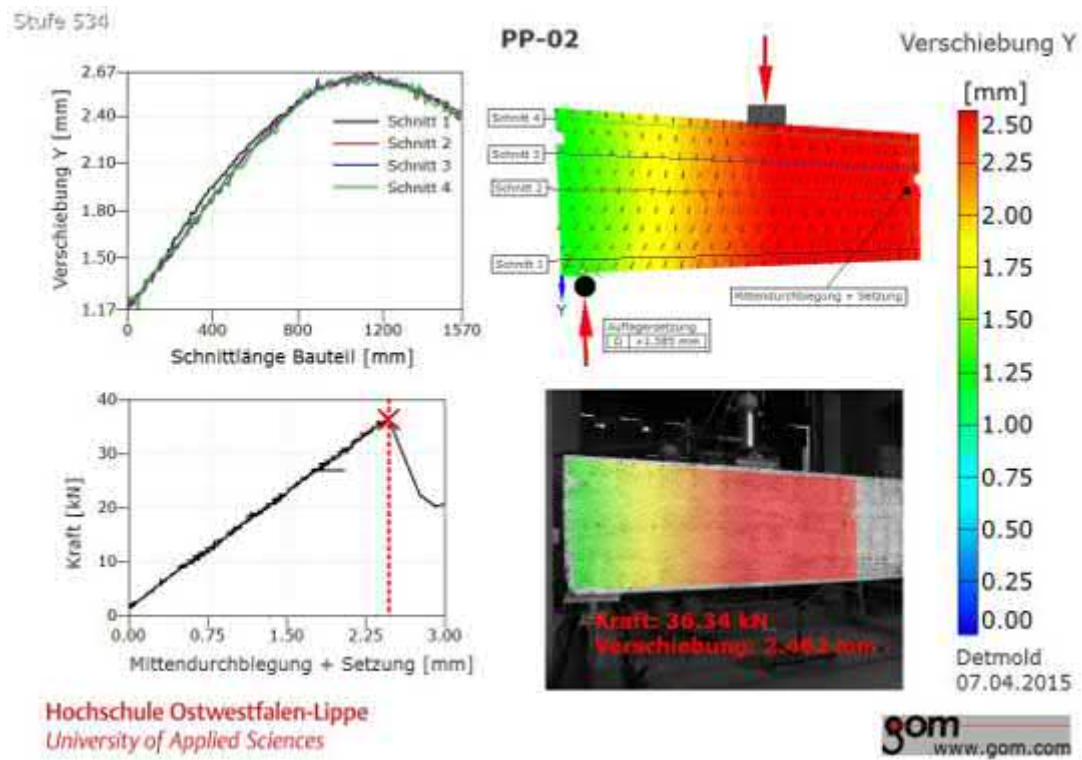

Hochschule Ostwestfalen-Lippe University of Applied Sciences 

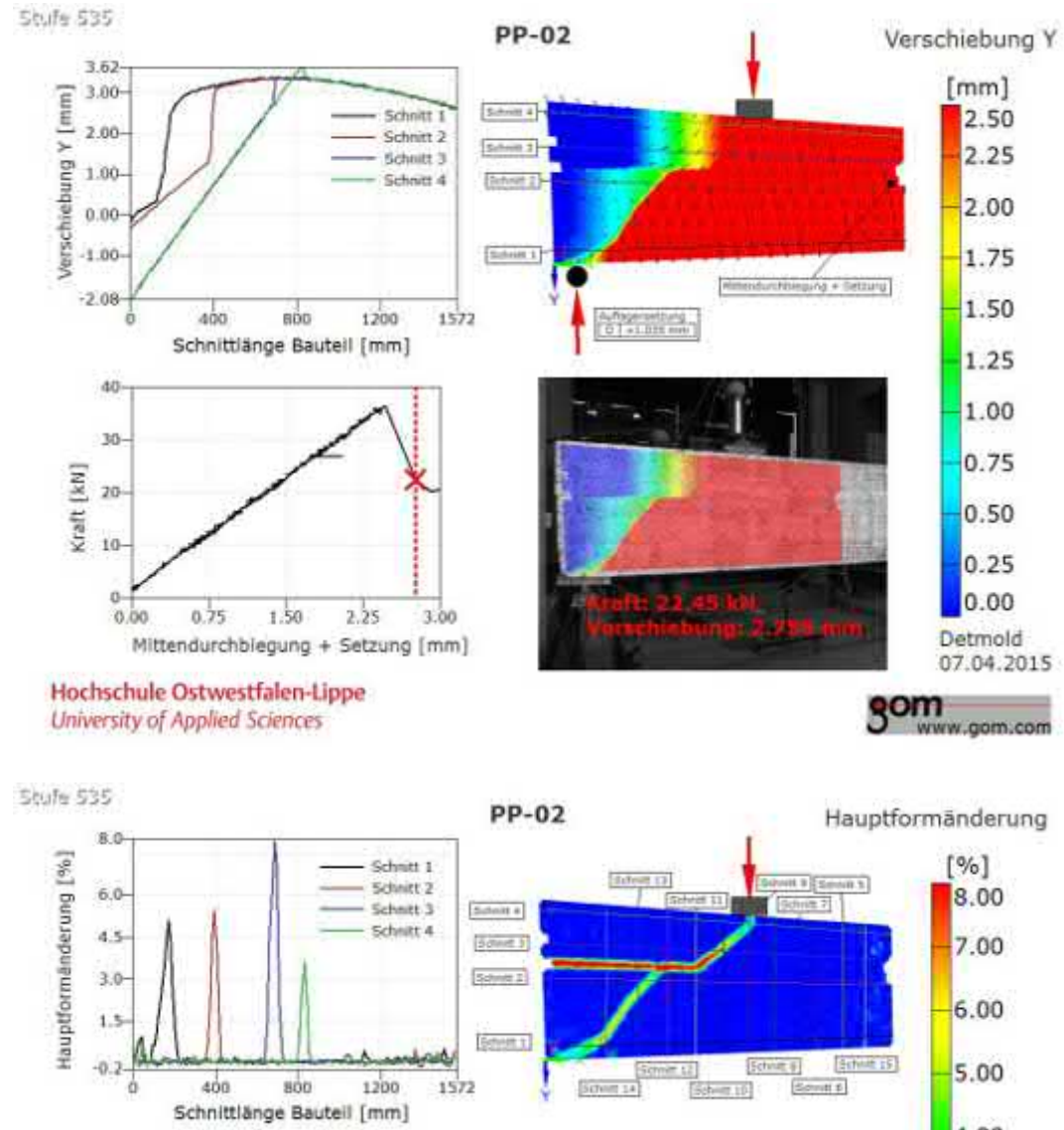

Hauptformānderung

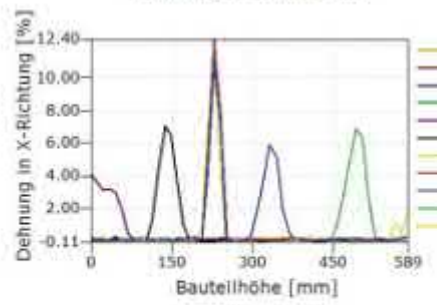

Hochschule Ostwestfalen-Lippe University of Applied Sciences

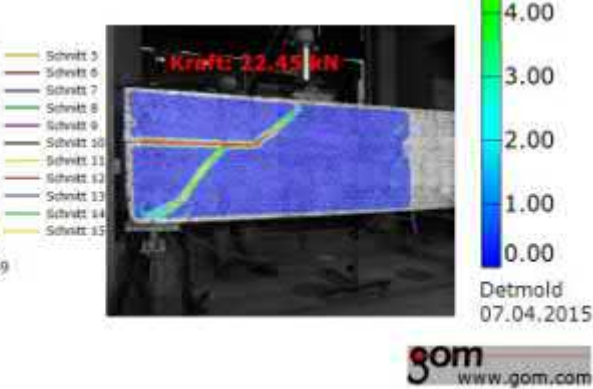

\section{PP-03}
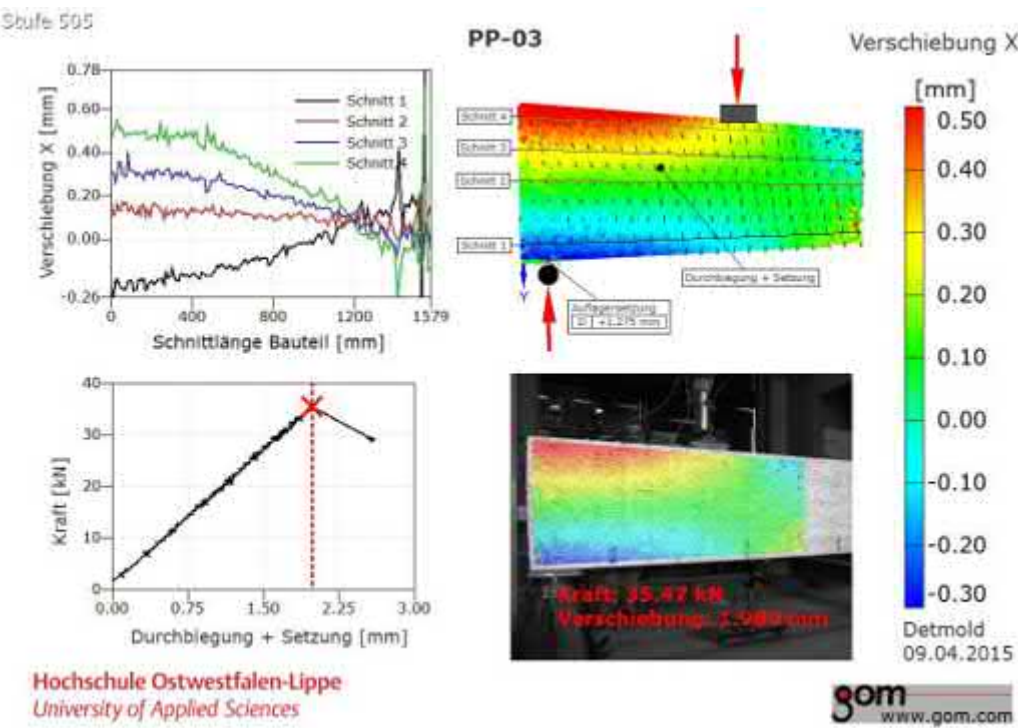

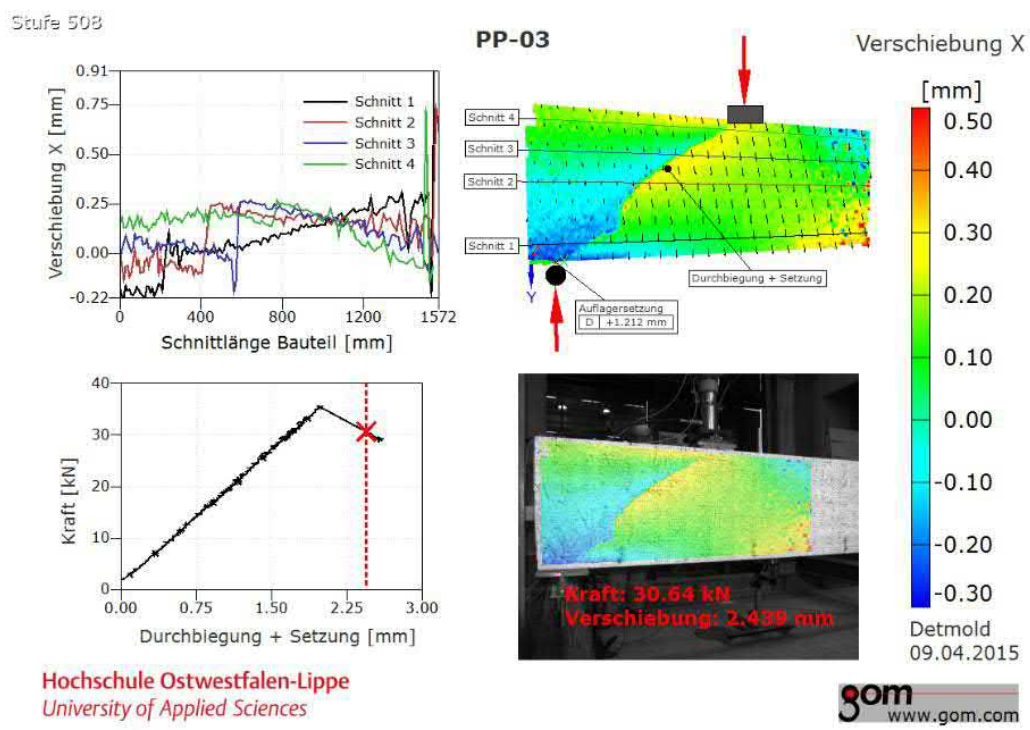

Hochschule Ostwestfalen-Lippe University of Applied Sciences

SOm www.gom.com
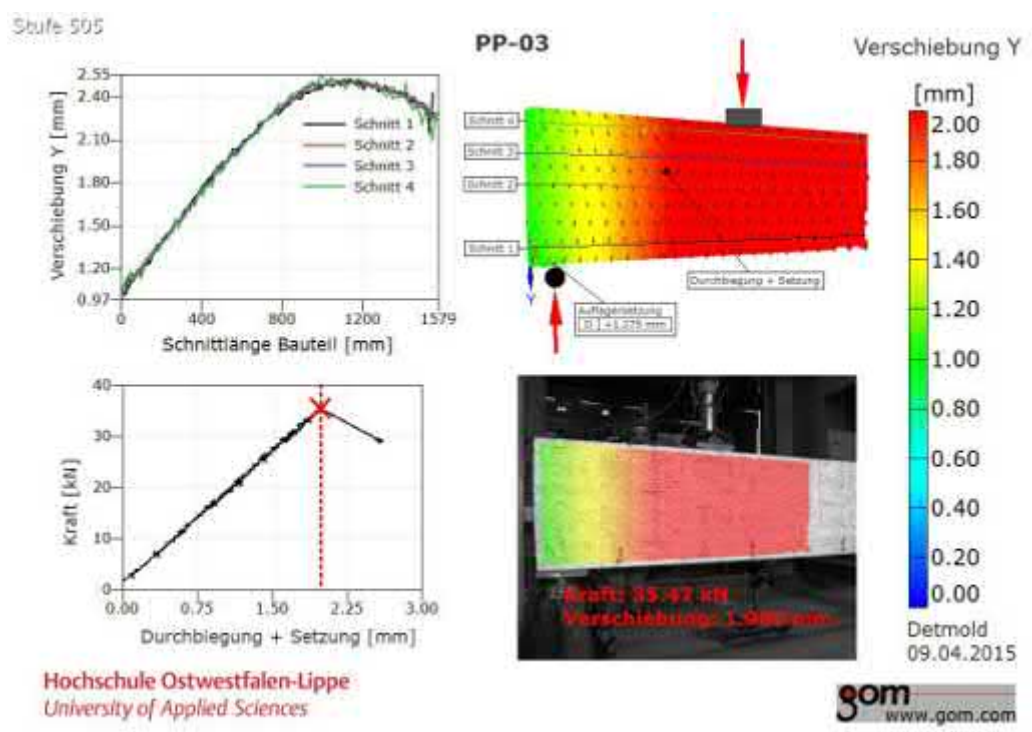

Hochschule Ostwestfalen-Lippe University of Applied Sciences

Stute 5us
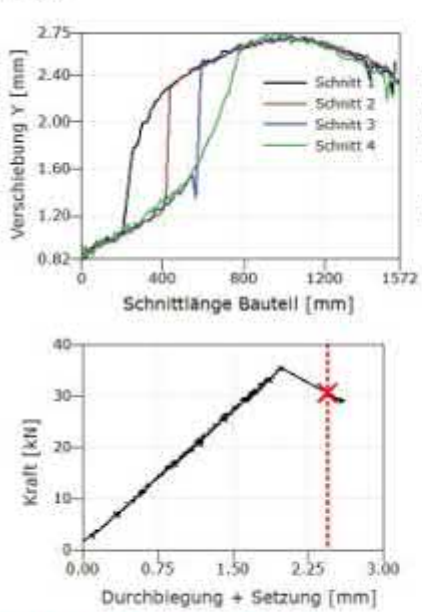

Hochschule Ostwestfalen-Lippe University of Applied Science:

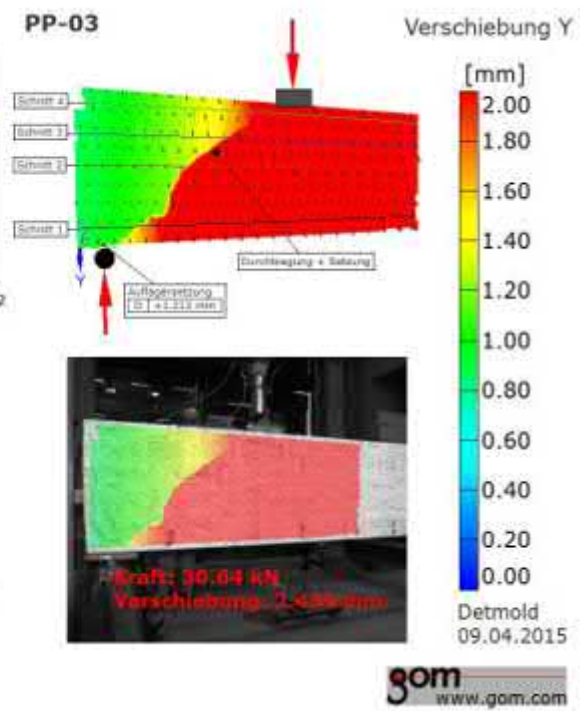




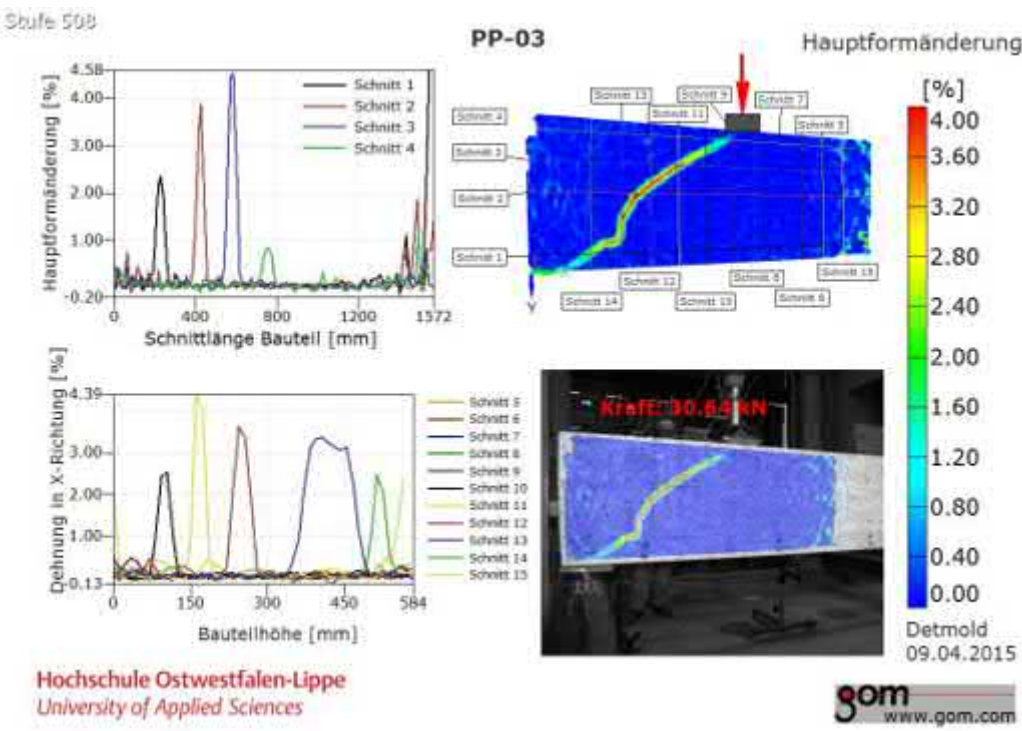

\section{PP-04}
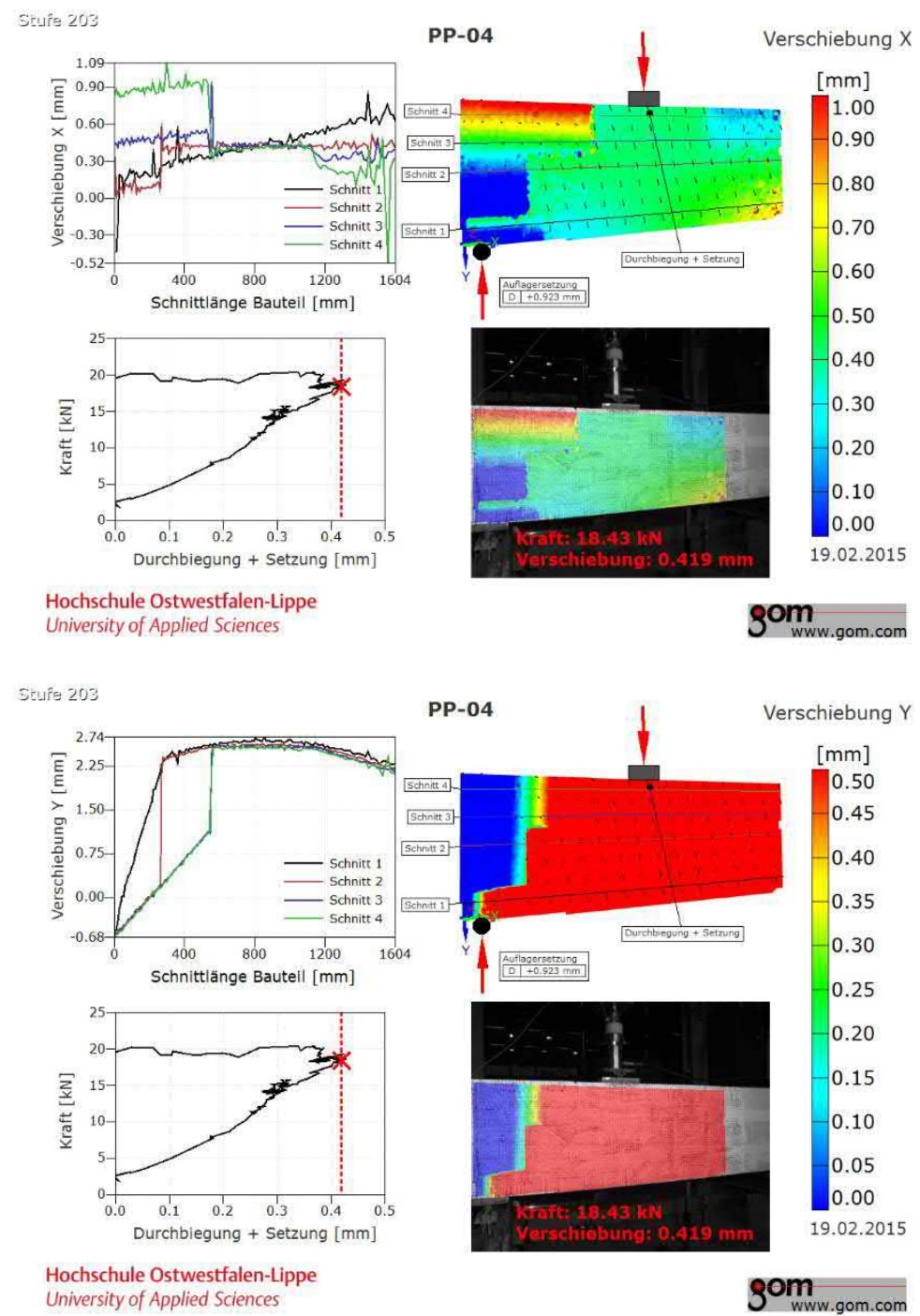


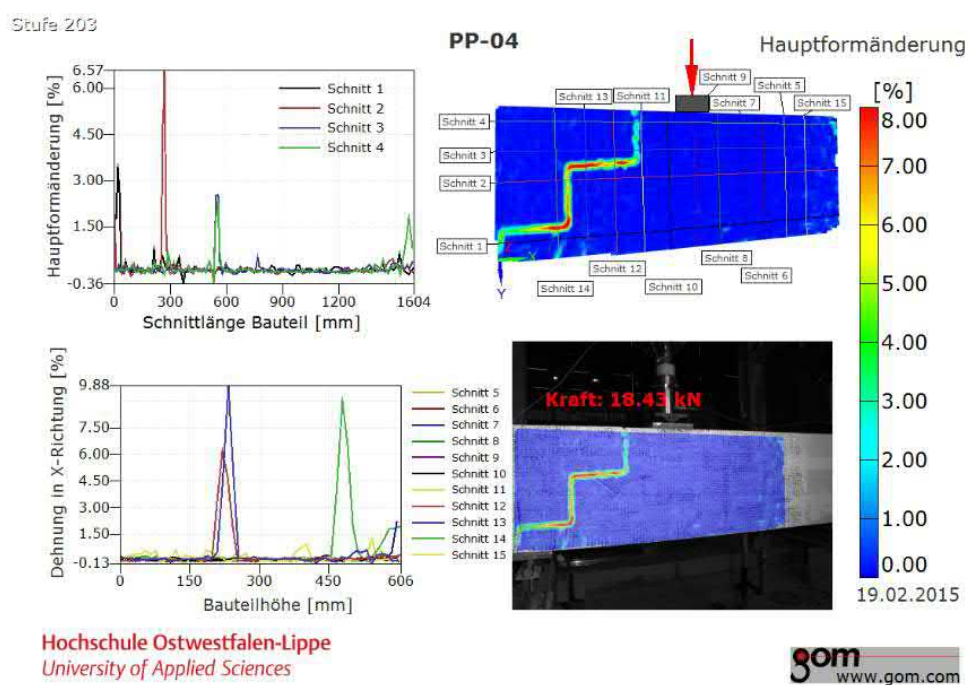

Bild A 4.4 Auswertung der Horizontal- und Vertikalverschiebung sowie der Hauptformänderung der Porenbeton-Flachstürze - PP-01 bis PP-04 
A 4.2 Scheitrechte Ziegelbalken - IIa

A 4.2.1 Systemskizzen der bewehrten scheitrechten Ziegel-Mauerwerkbalken A 4.2.2 ZI-01

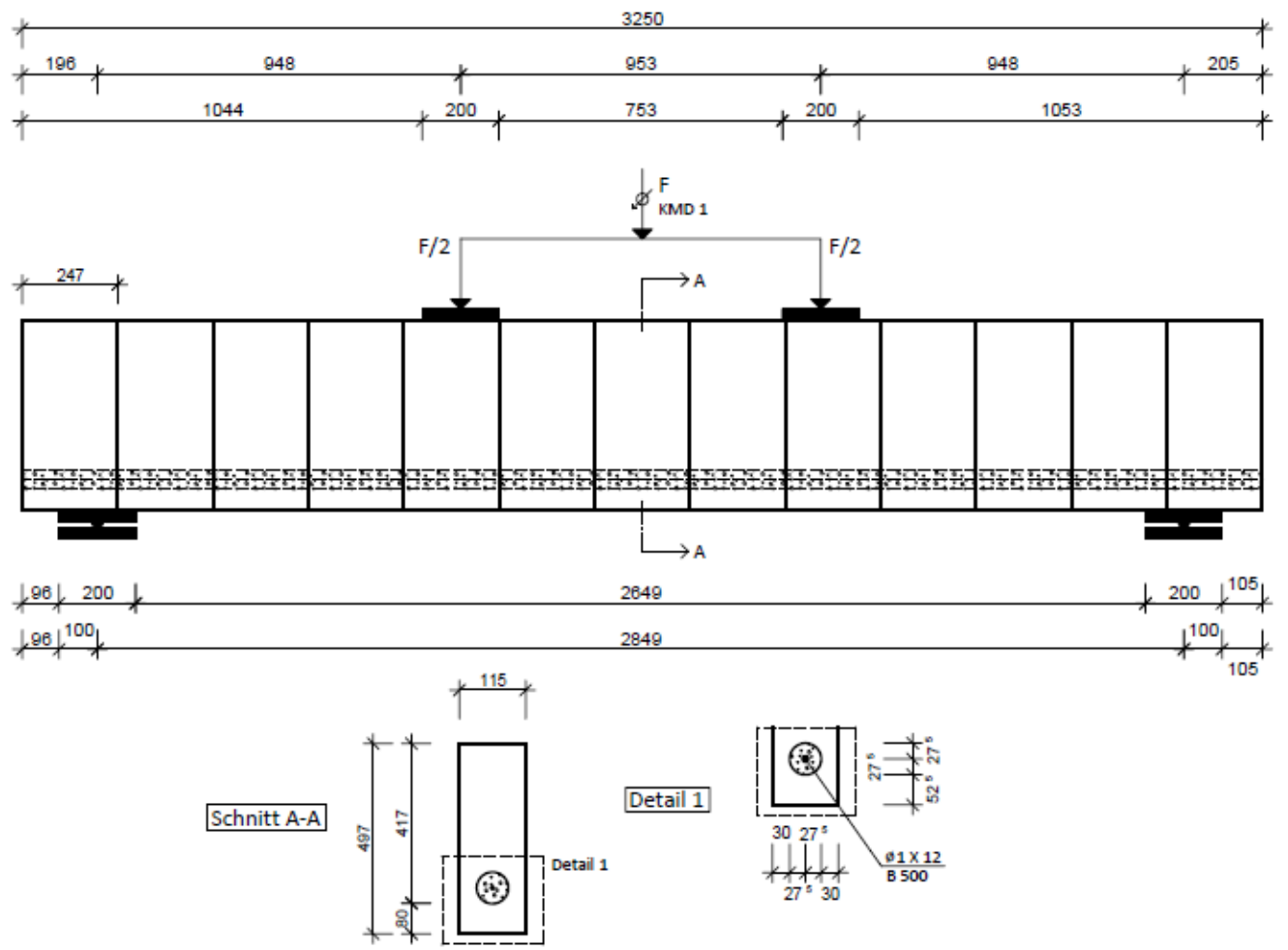

ZI-02
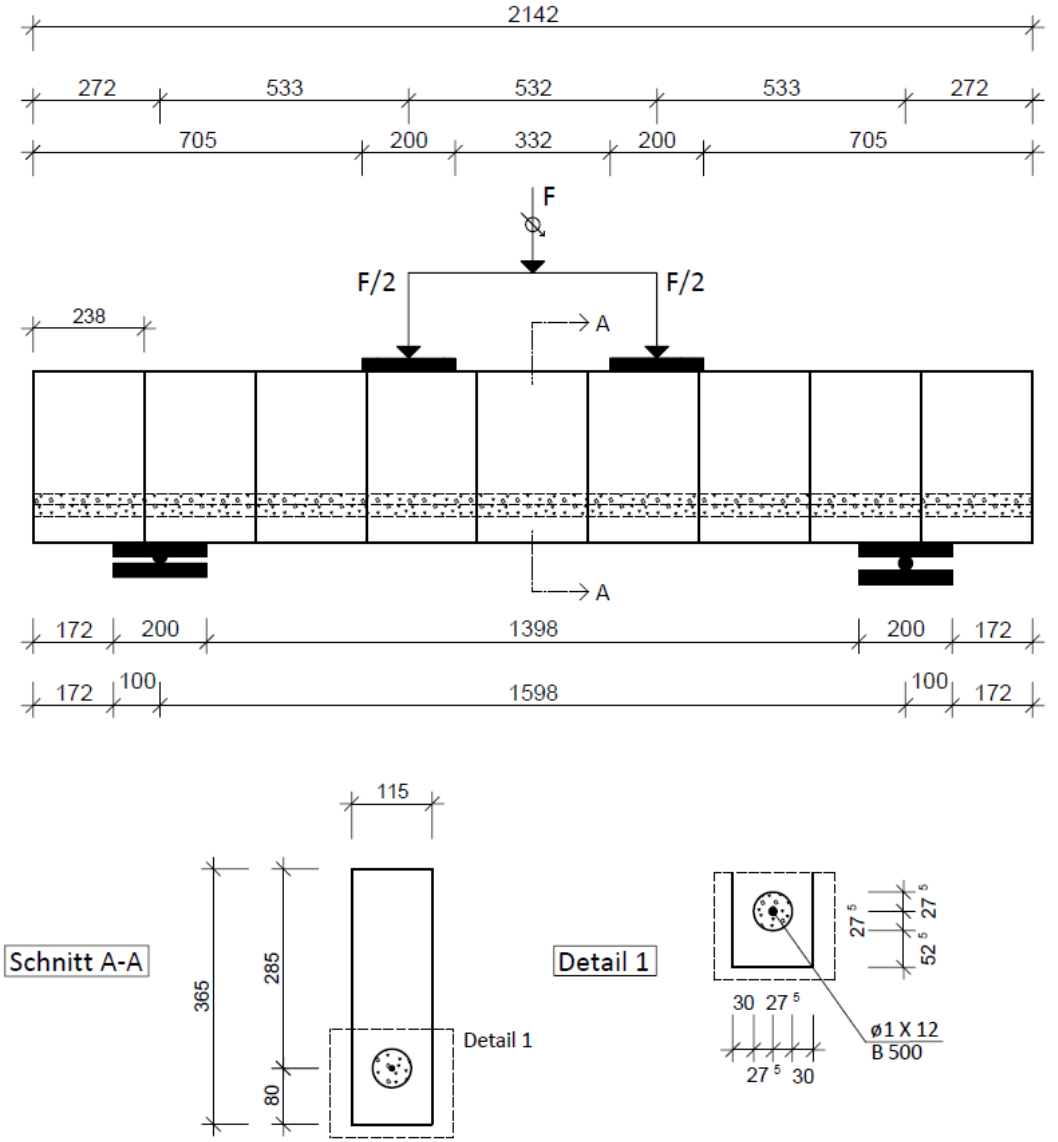
ZI-03
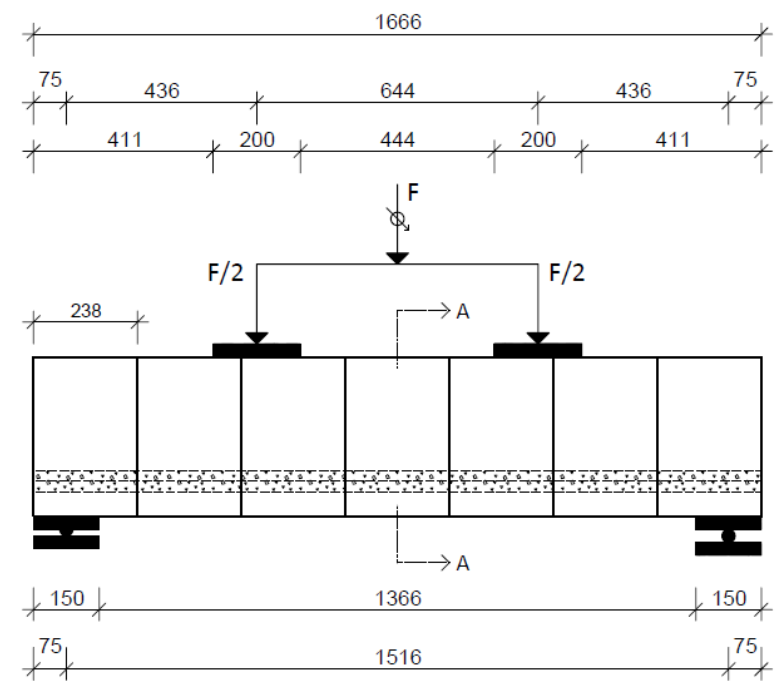

Schnitt A-A

ZI-04
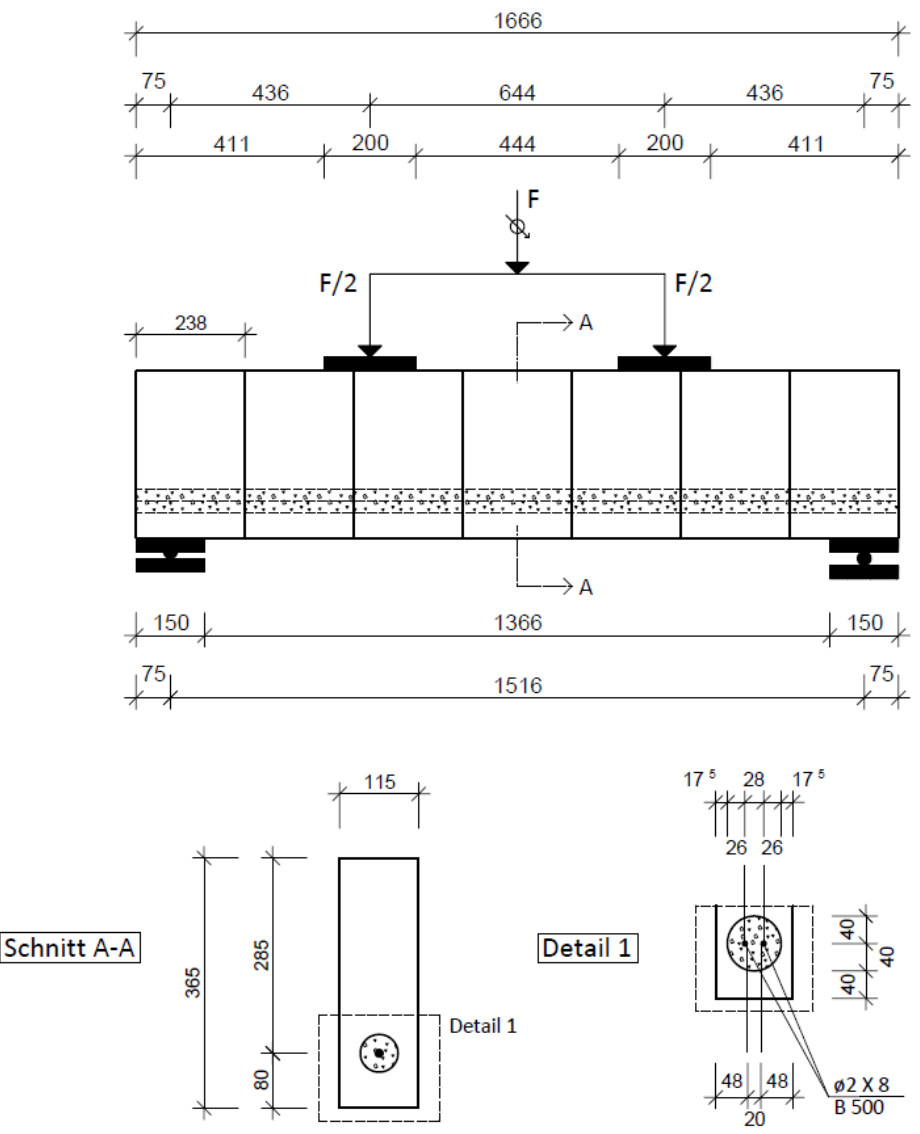
ZI-05
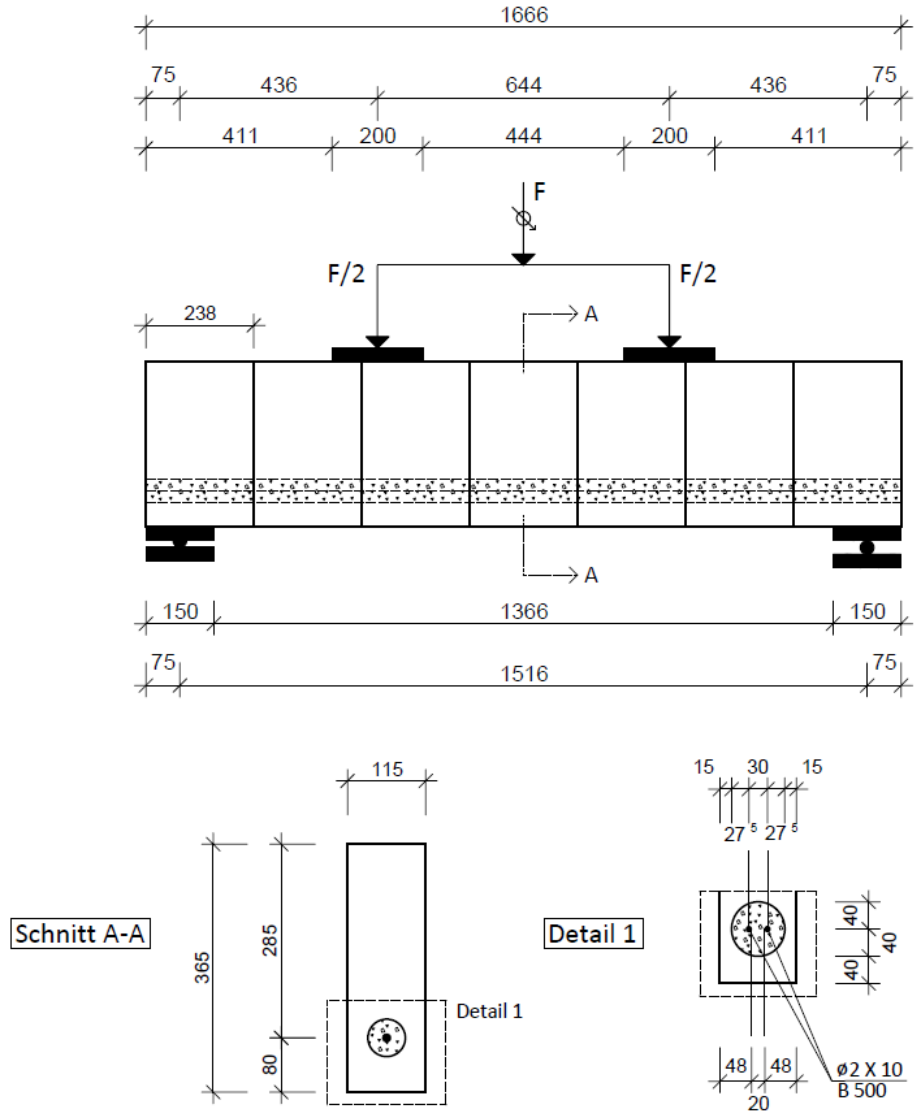

ZI-06
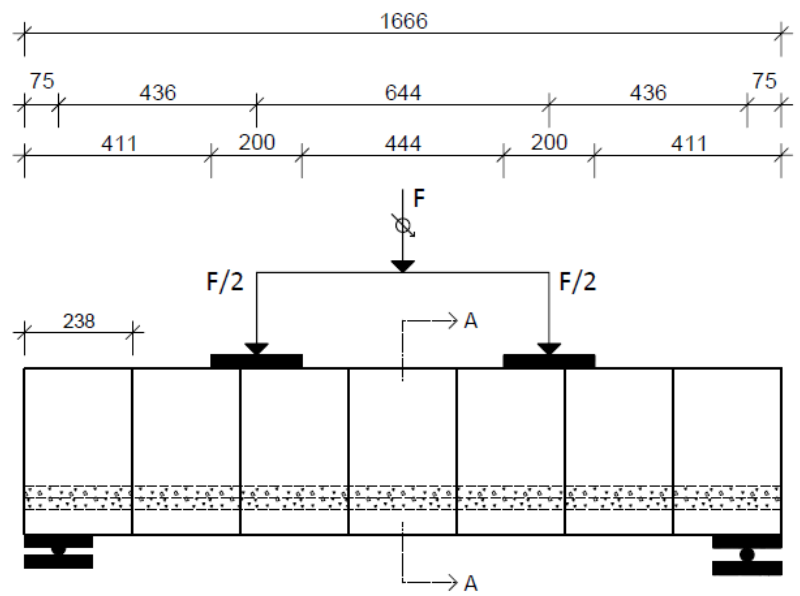

+150

1366

$+150\}$

$+^{75}$

1516

$x^{75}+$

Schnitt A-A

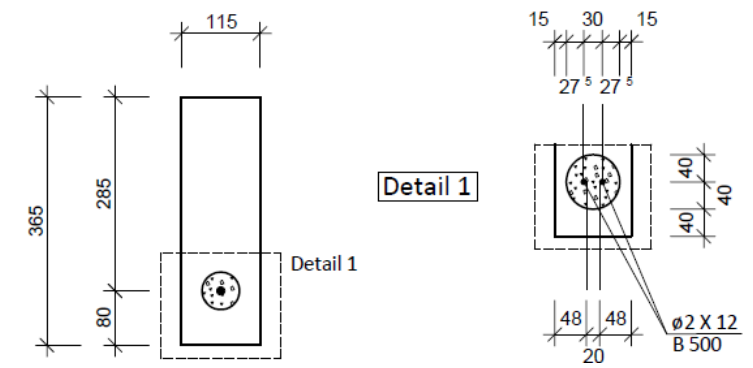


ZI-07
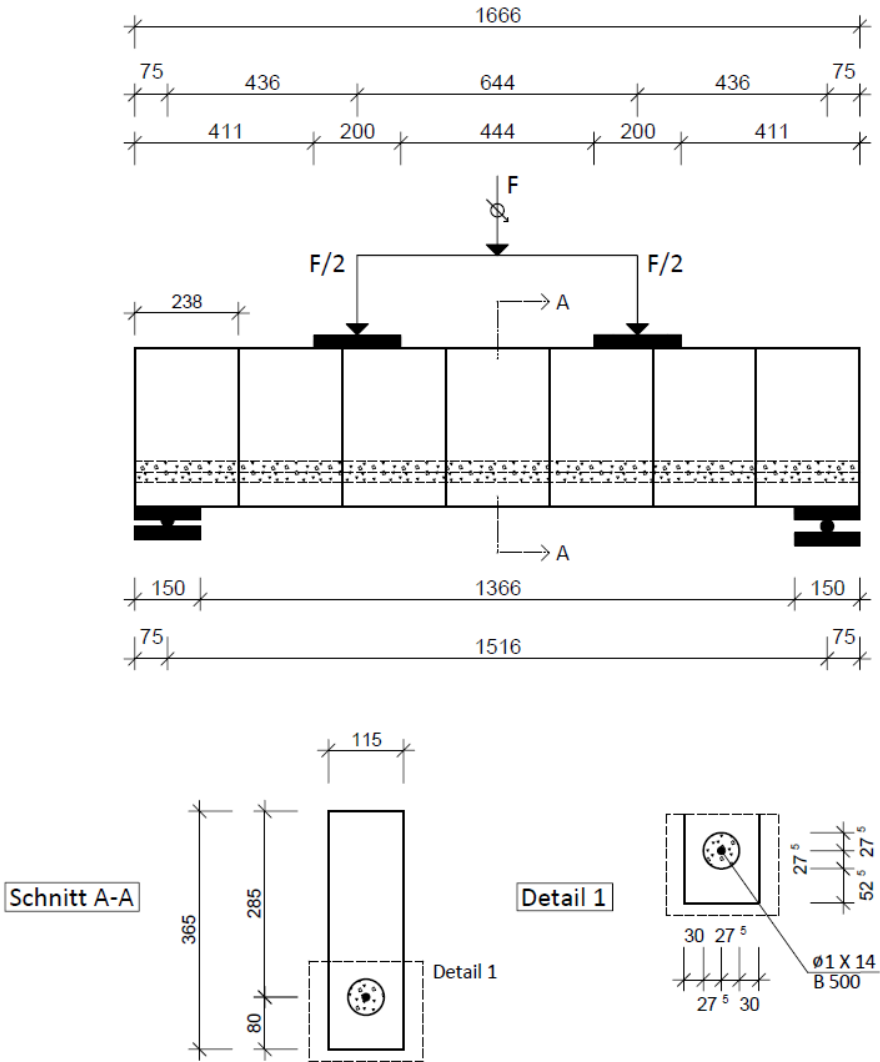

ZI-08
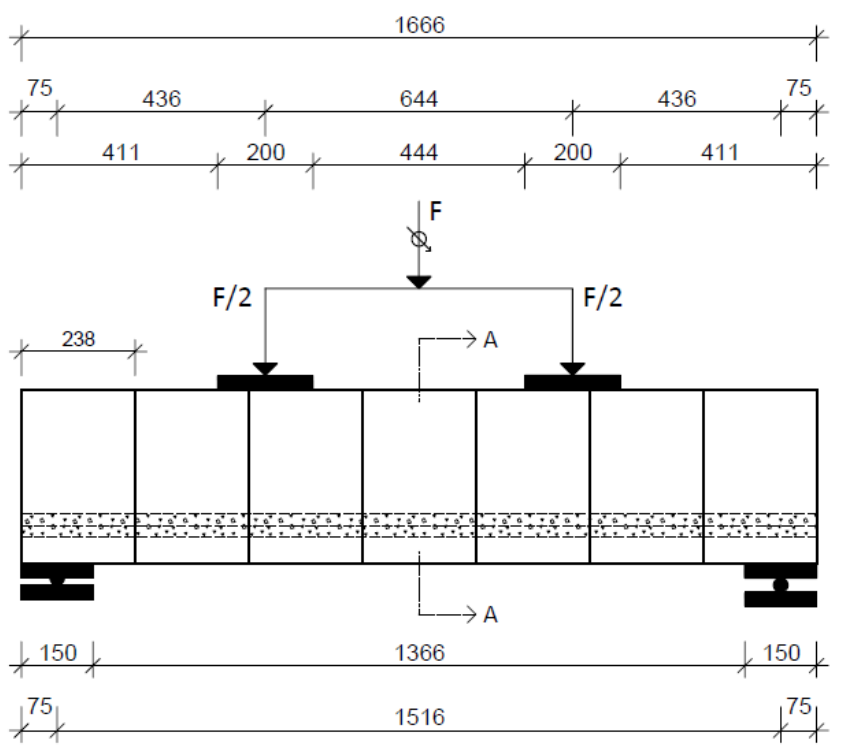

Schnitt A-A 


\section{ZI-09}
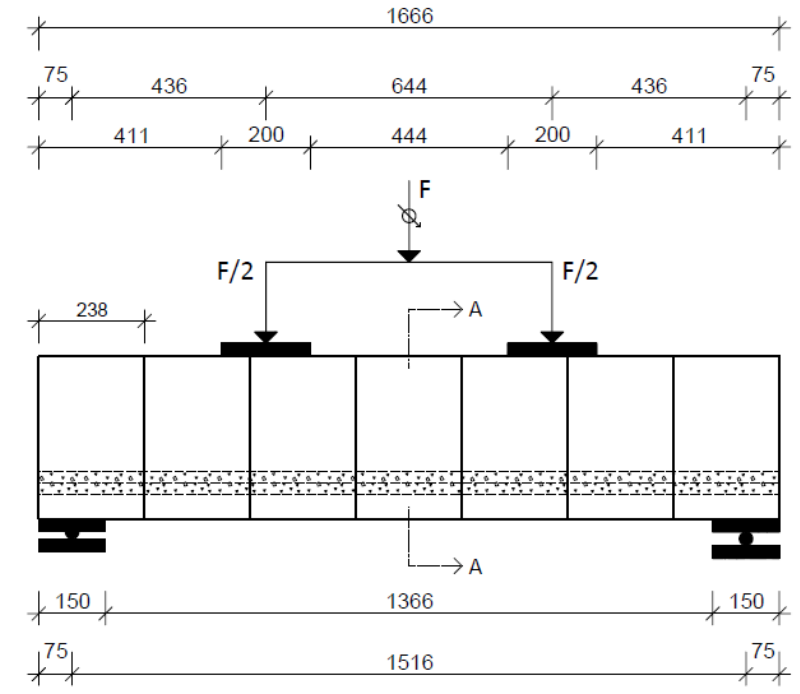

Schnitt A-A

ZI-10
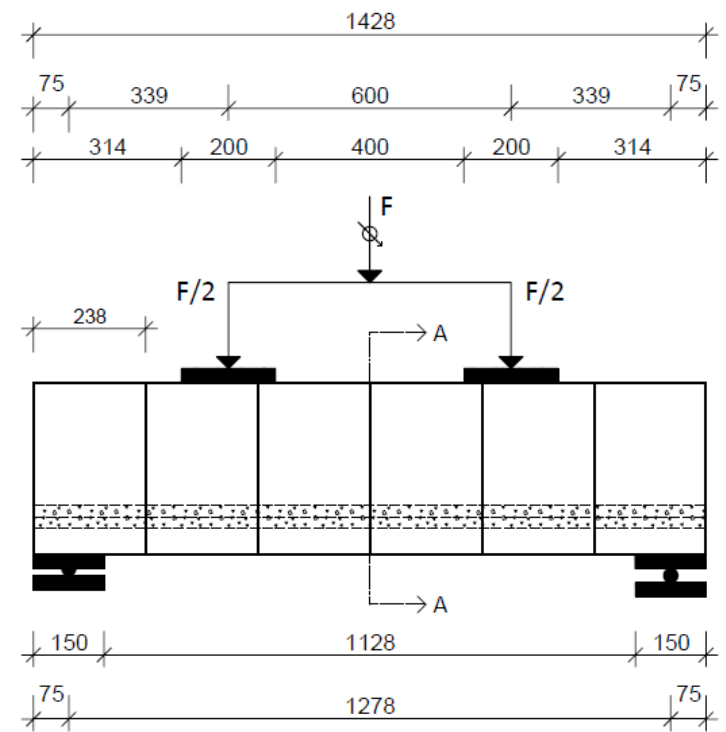

Schnitt A-A 
ZI-11
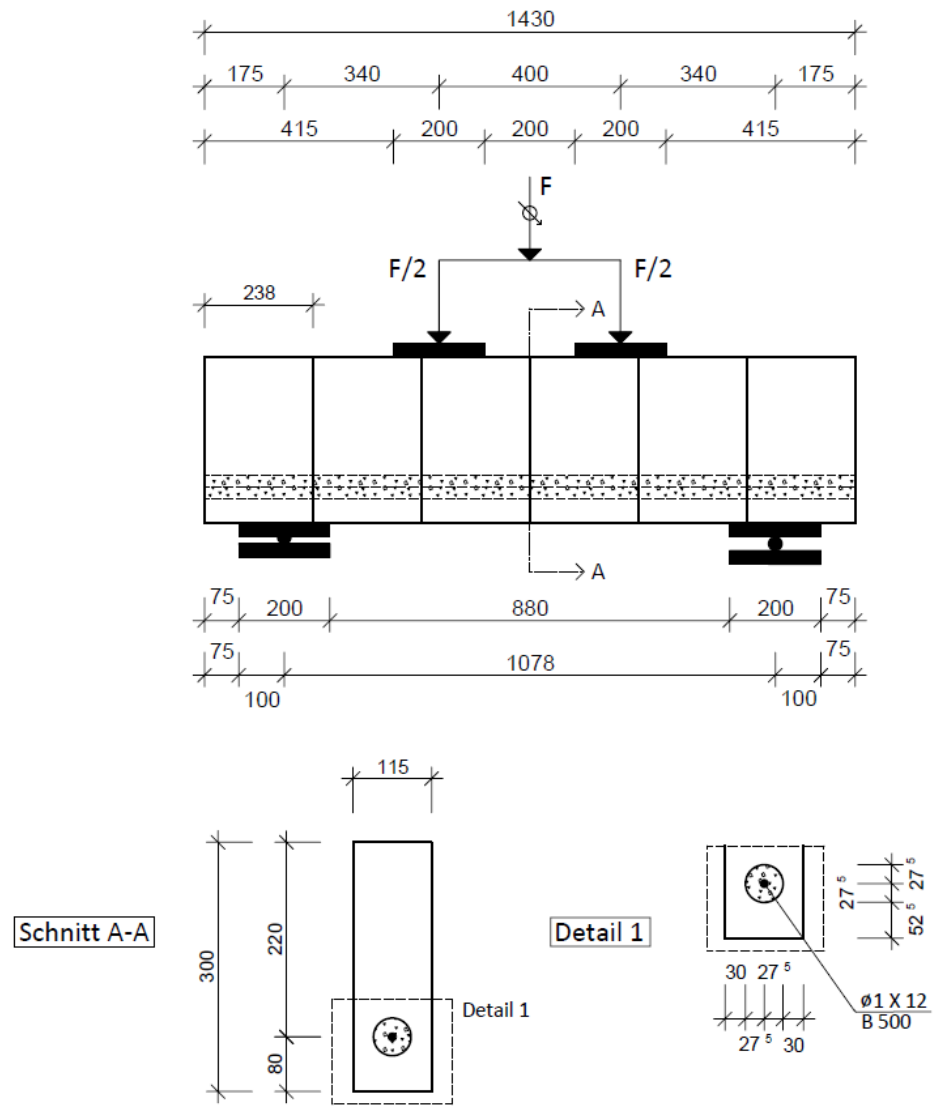

ZI-12
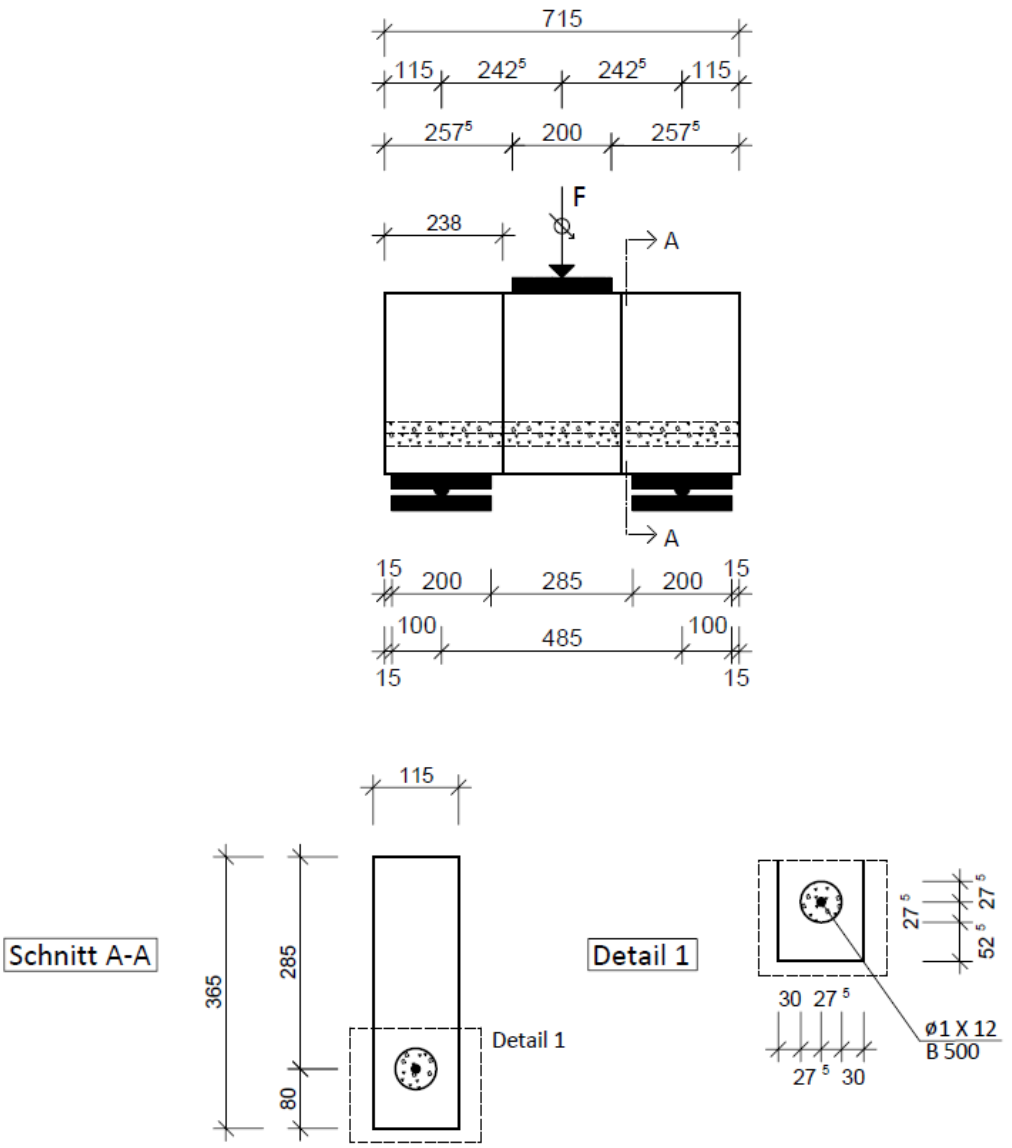


\section{ZI-13}
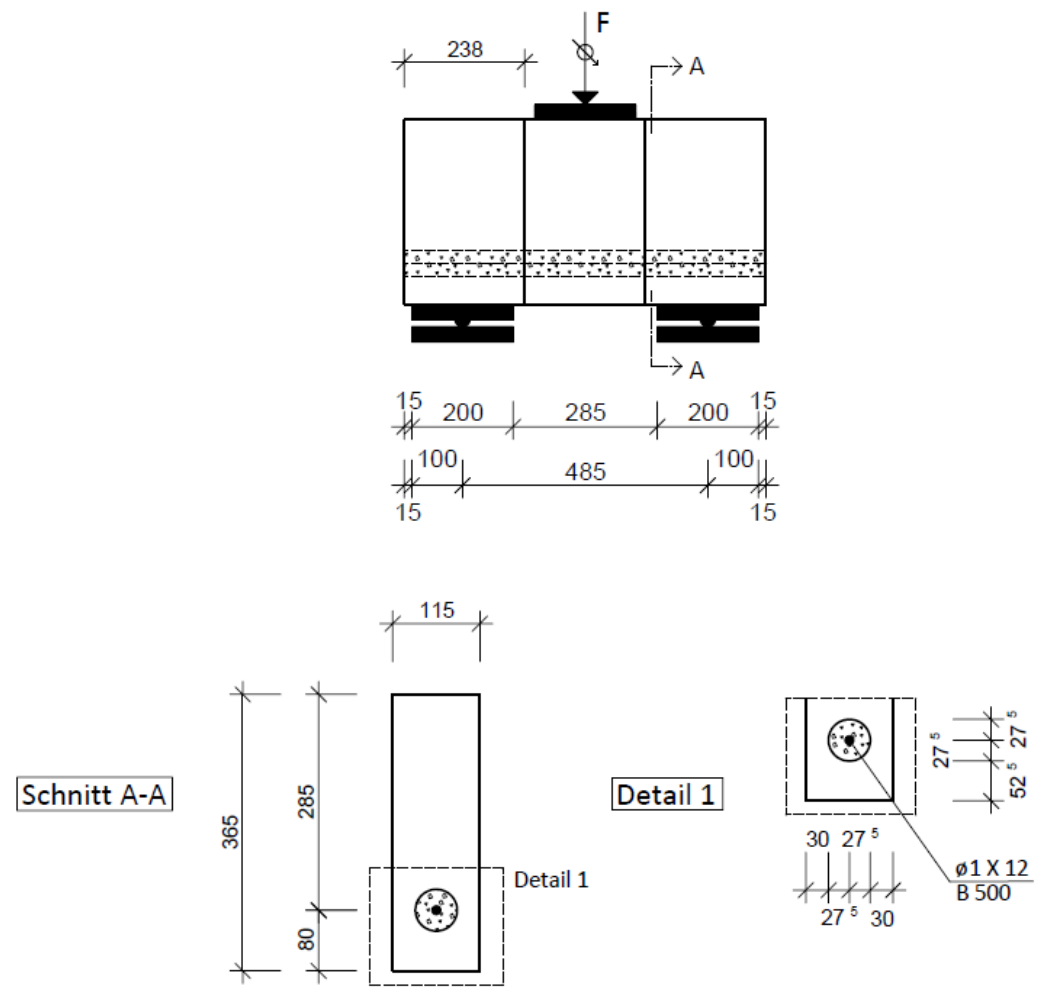

Bild A 4.5 Systemskizzen der bewehrten scheitrechten Ziegel-Mauerwerkbalken - ZI-01 bis ZI-13 
A 4.2.3 Messstellenpläne der bewehrten scheitrechten Ziegel-Mauerwerkbalken ZI-01

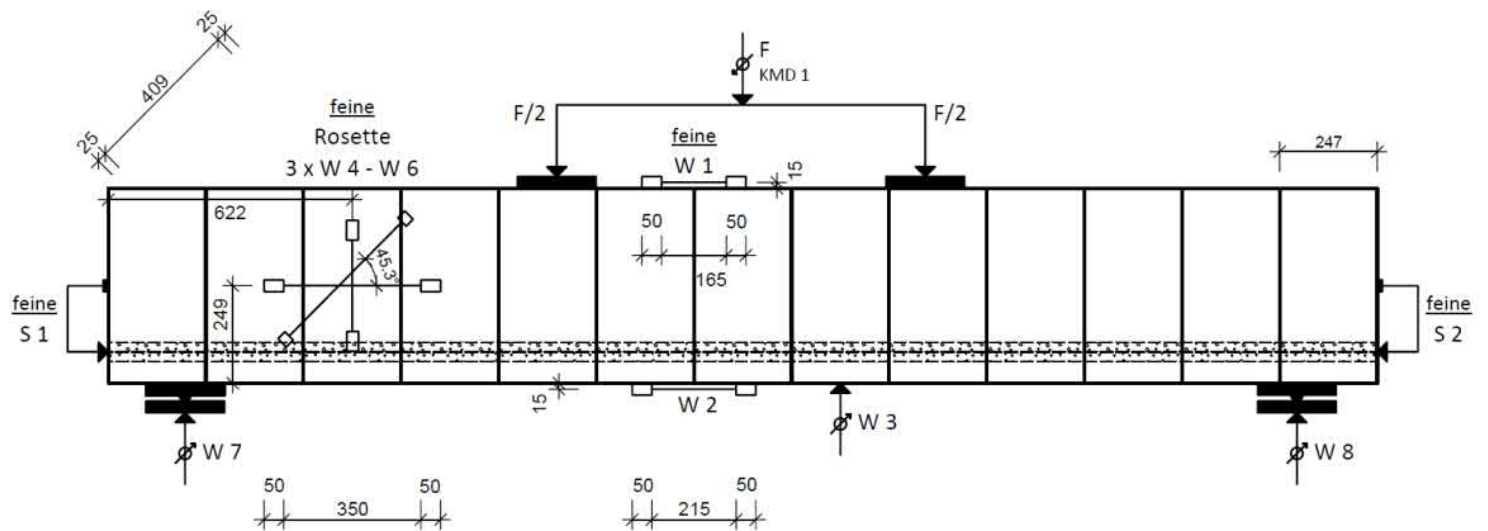

ZI-02

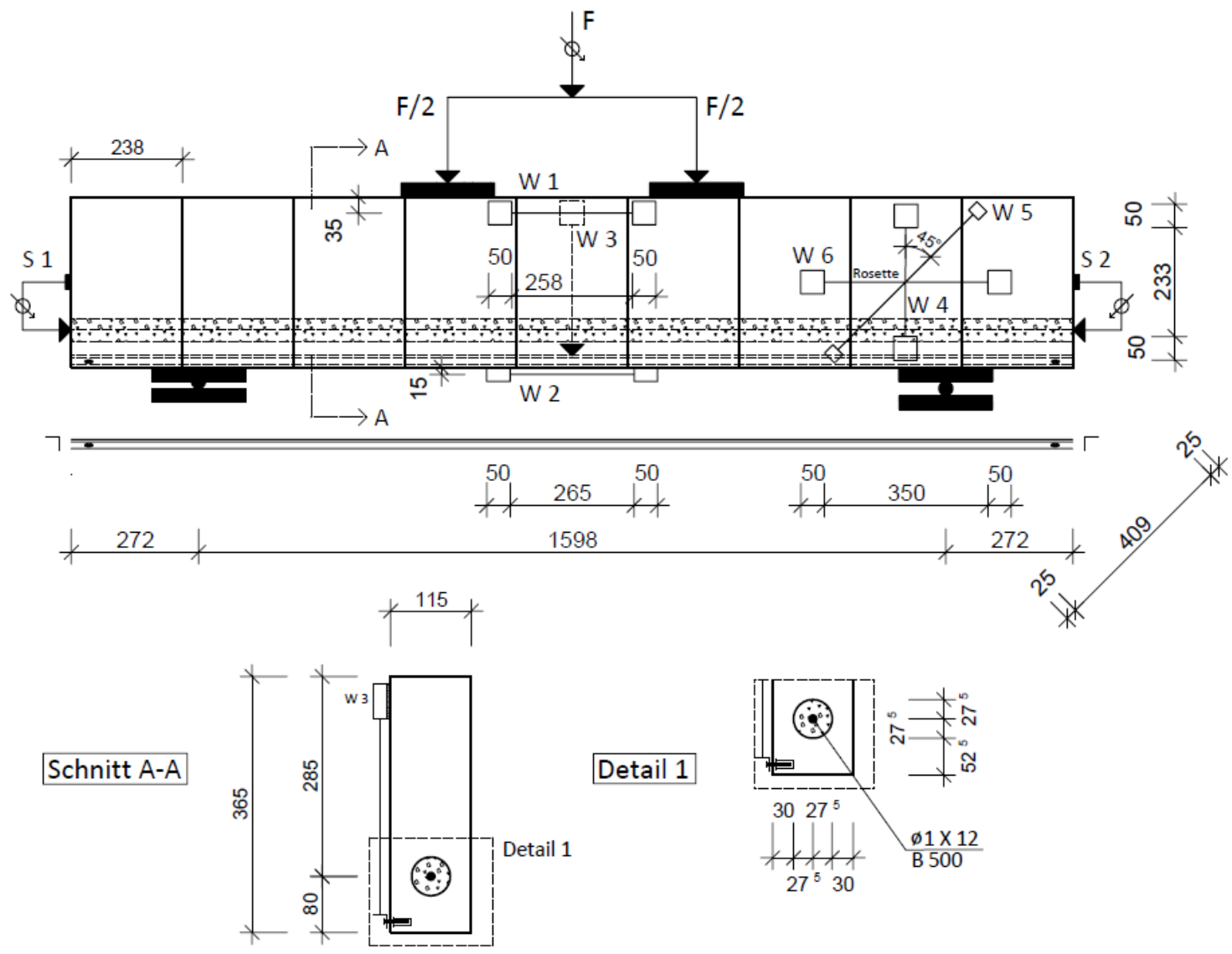


ZI-03
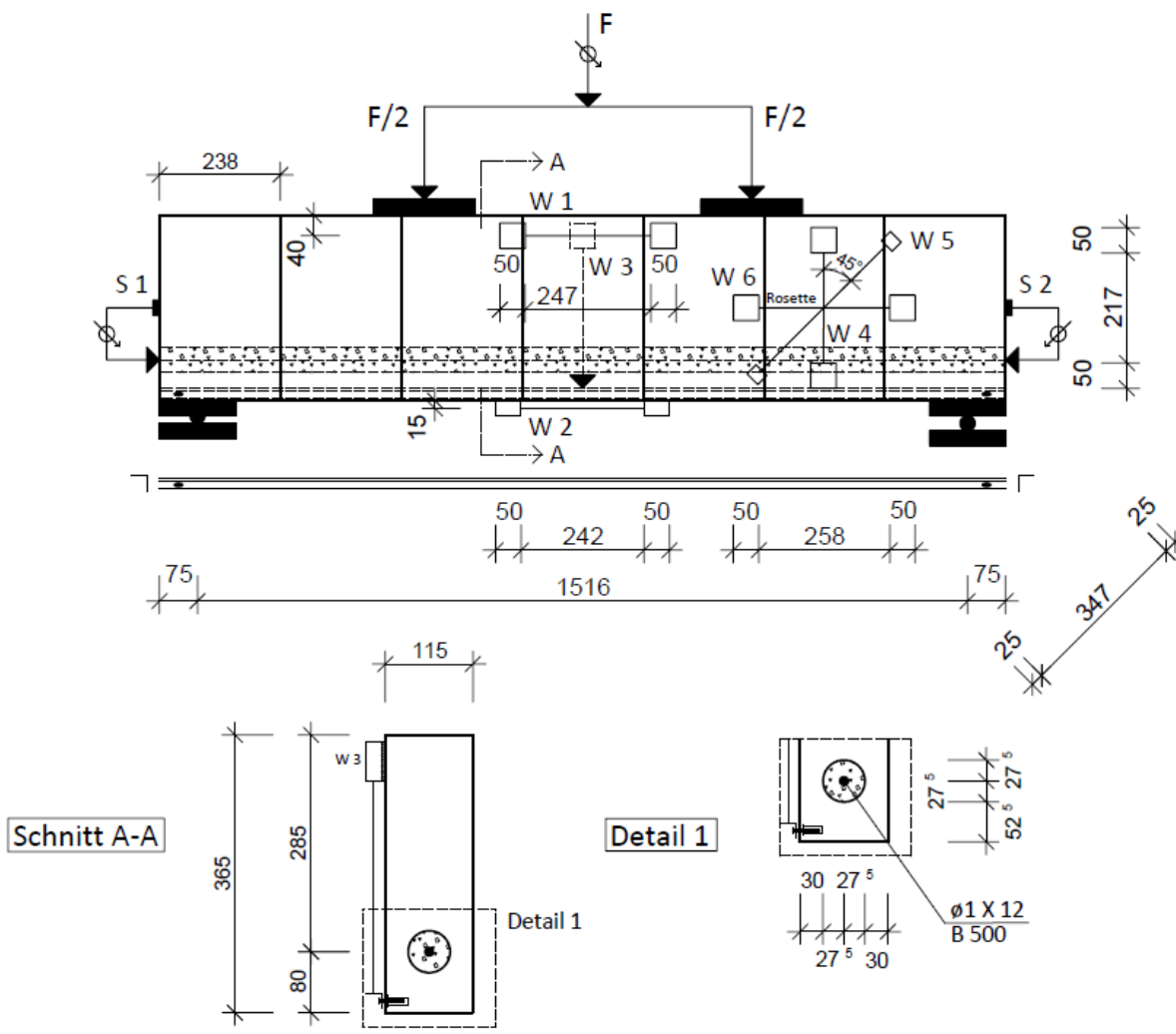

ZI-04

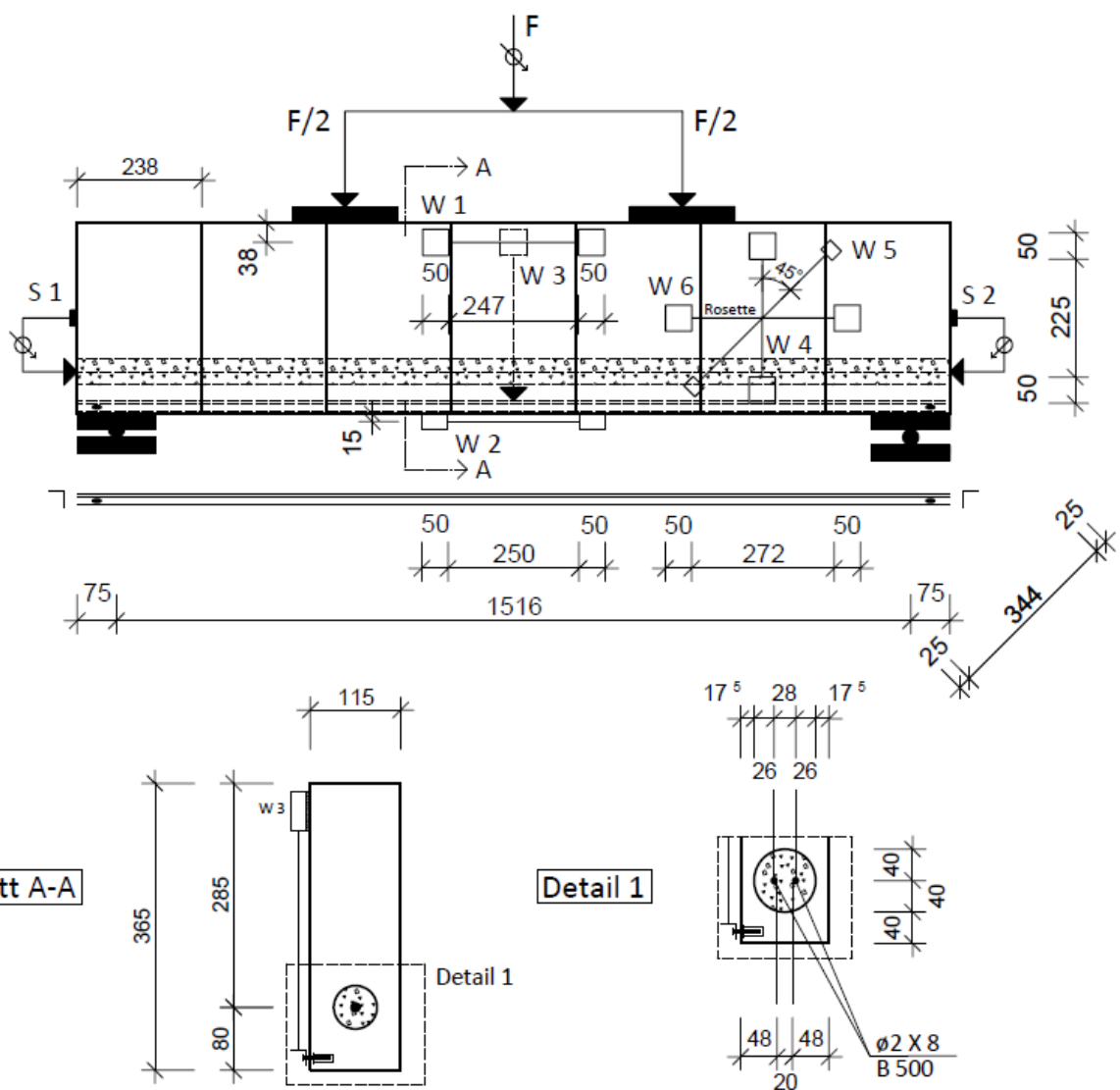


ZI-05
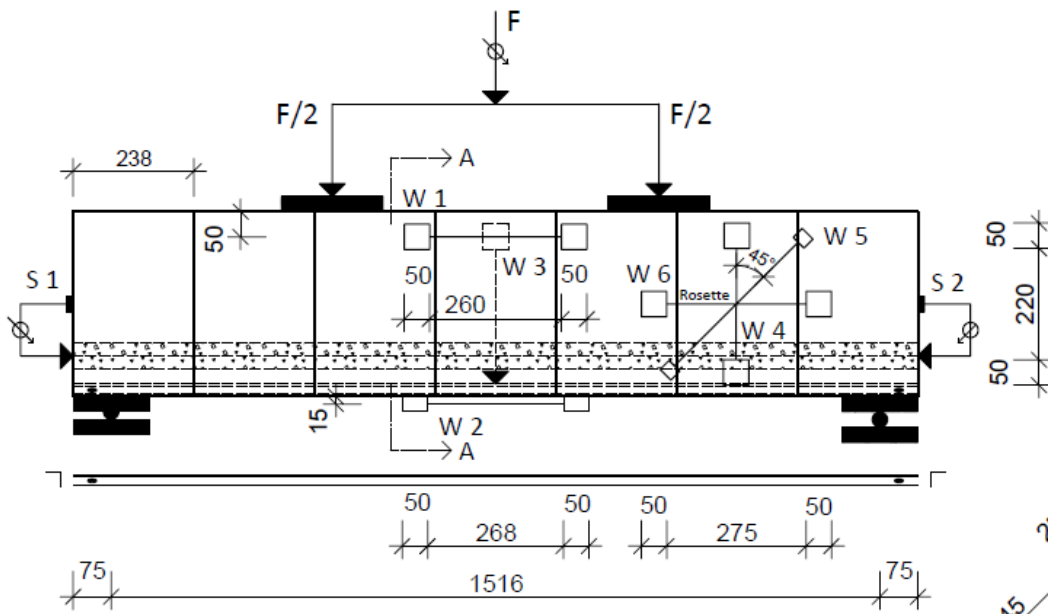

Schnitt A-A
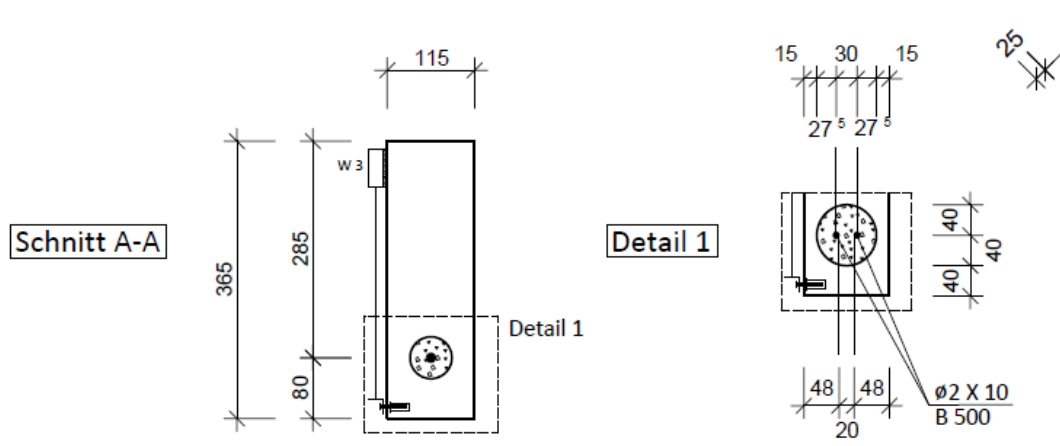

ZI-06

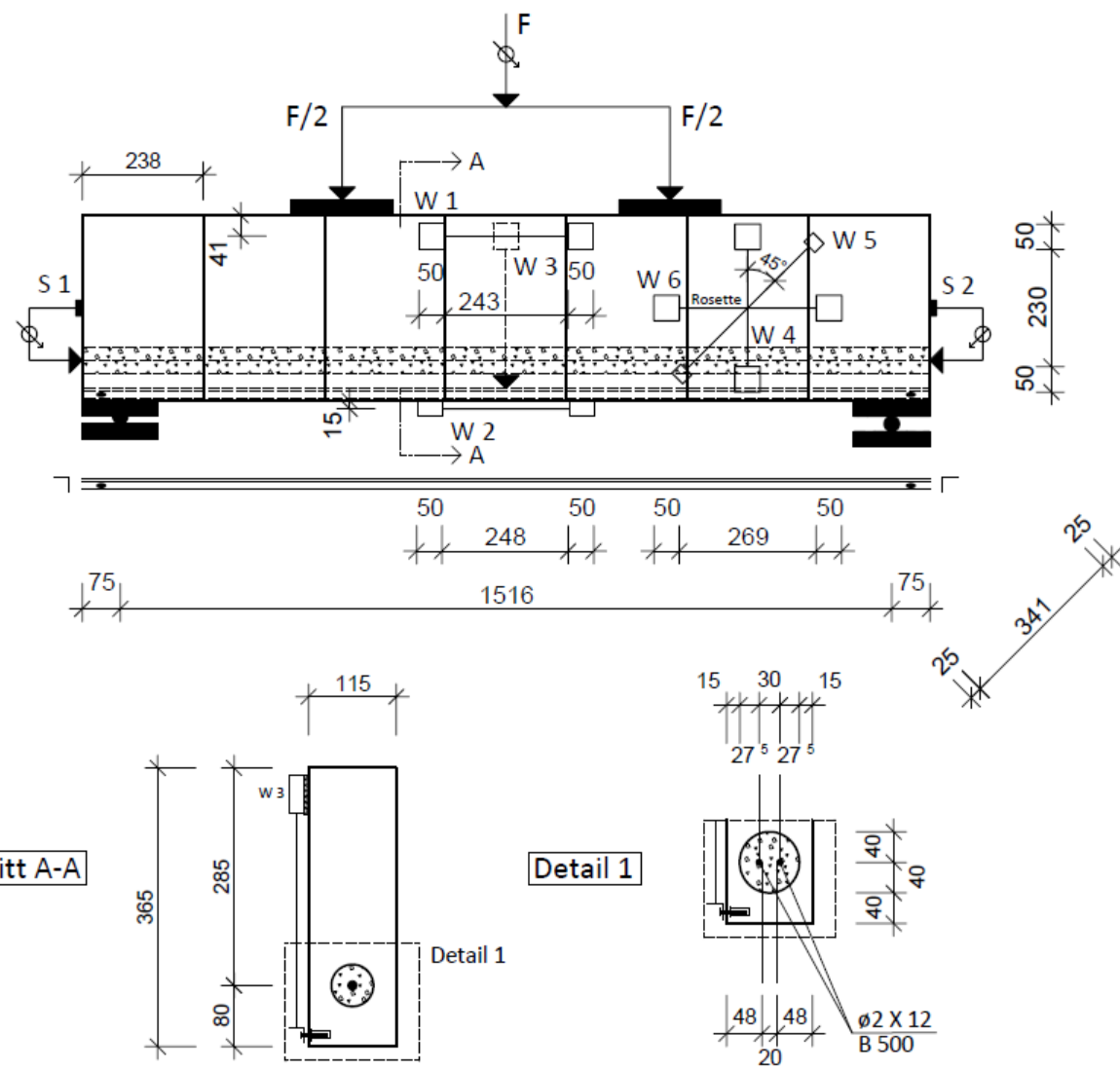


ZI-07

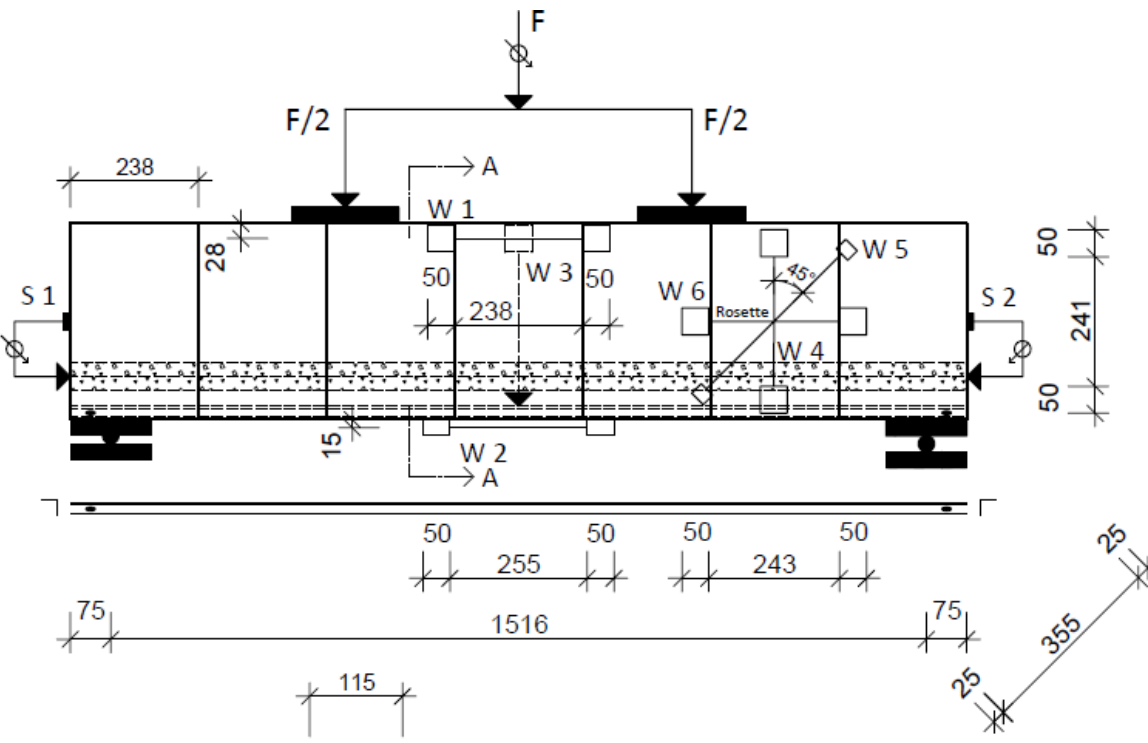

Schnitt A-A

\section{ZI-08}
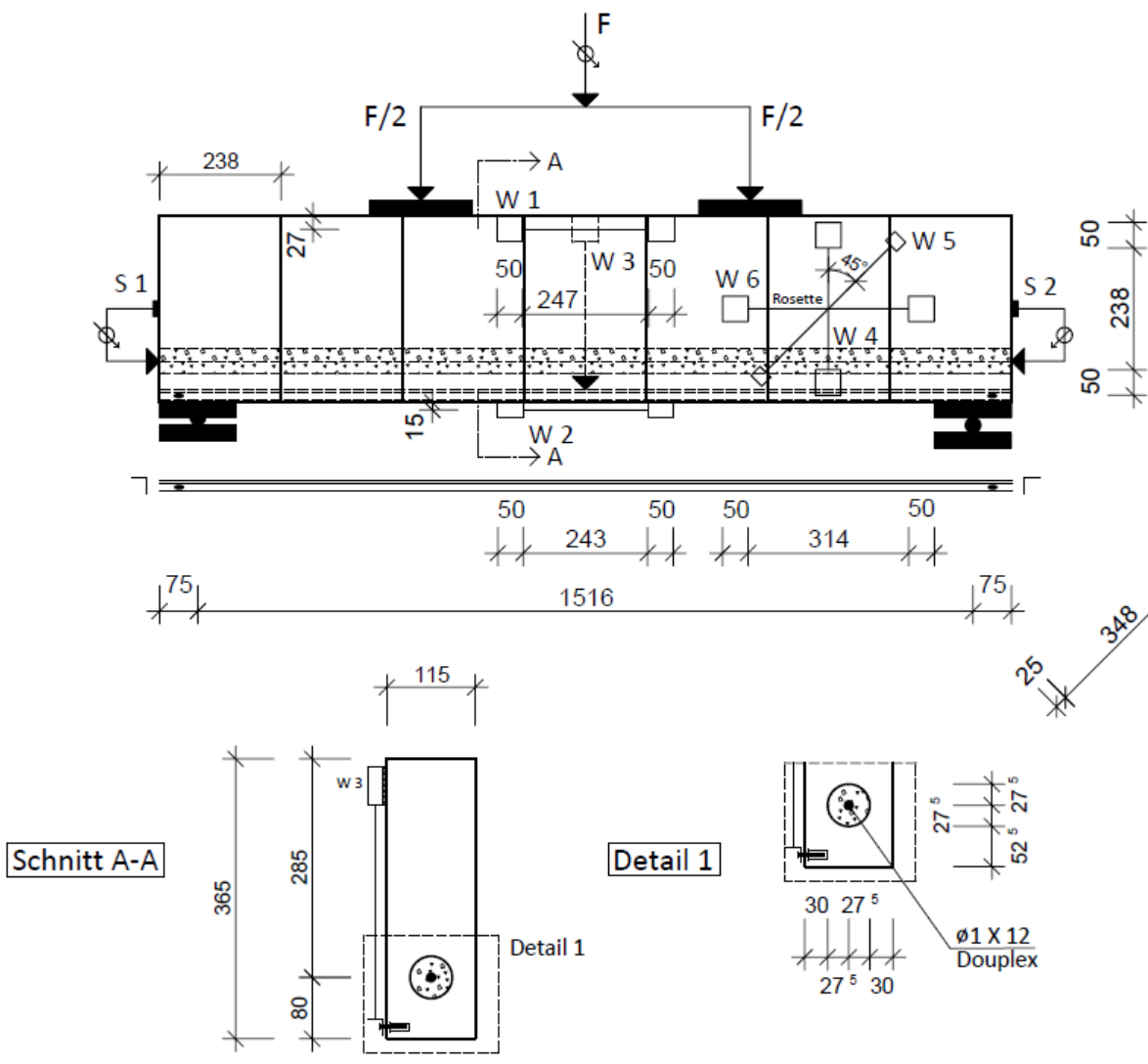
ZI-09
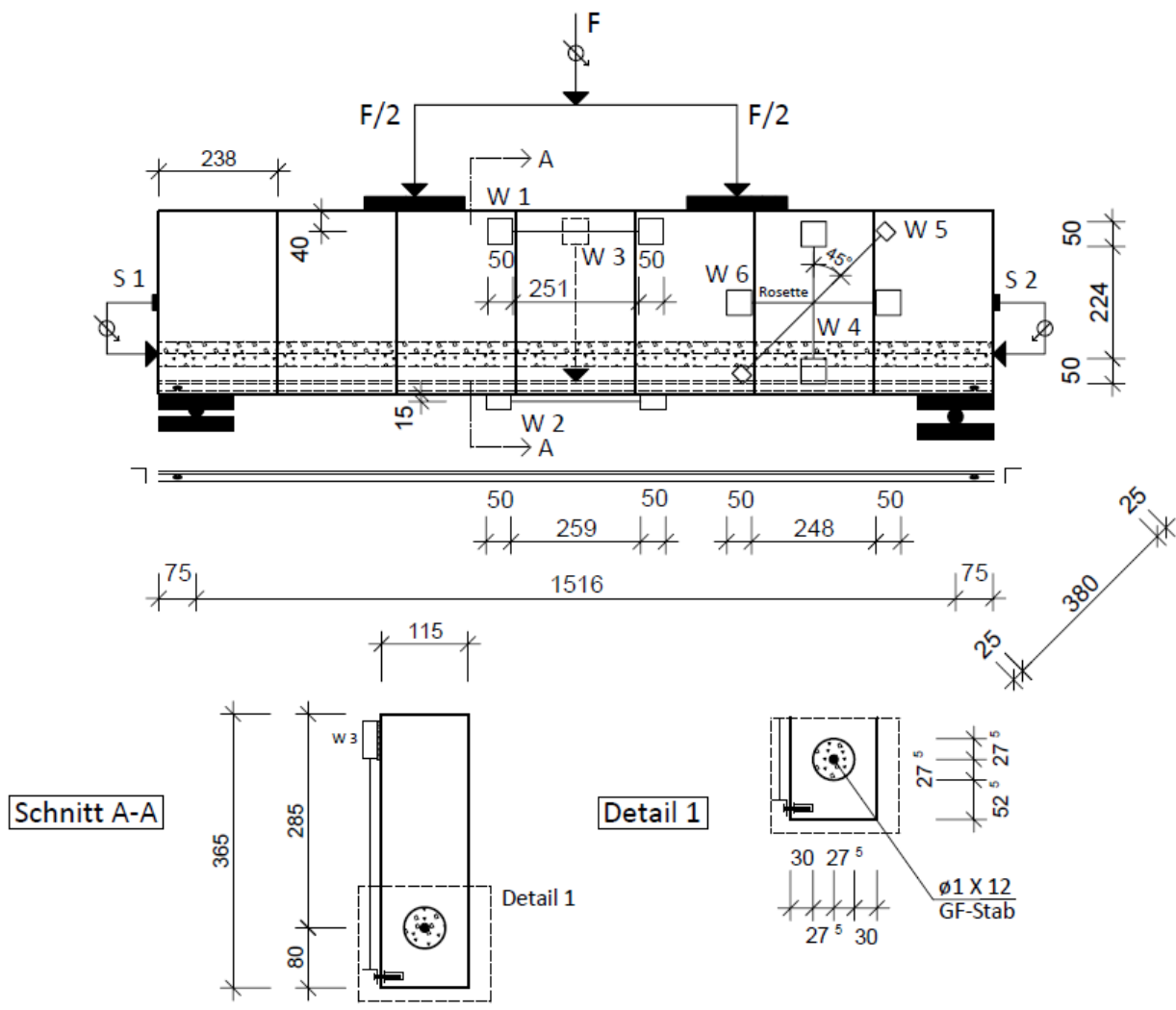

ZI-10
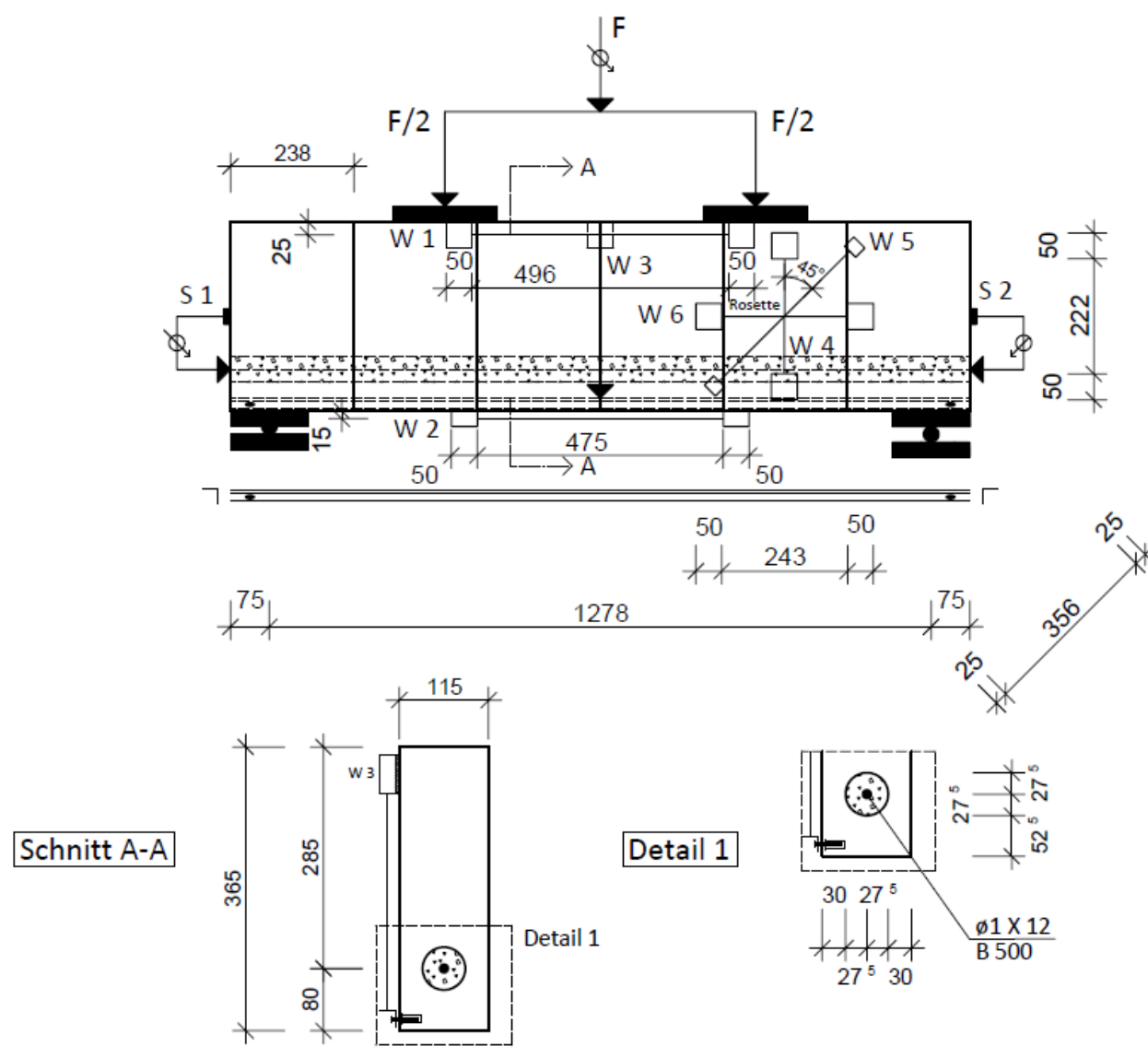
ZI-11
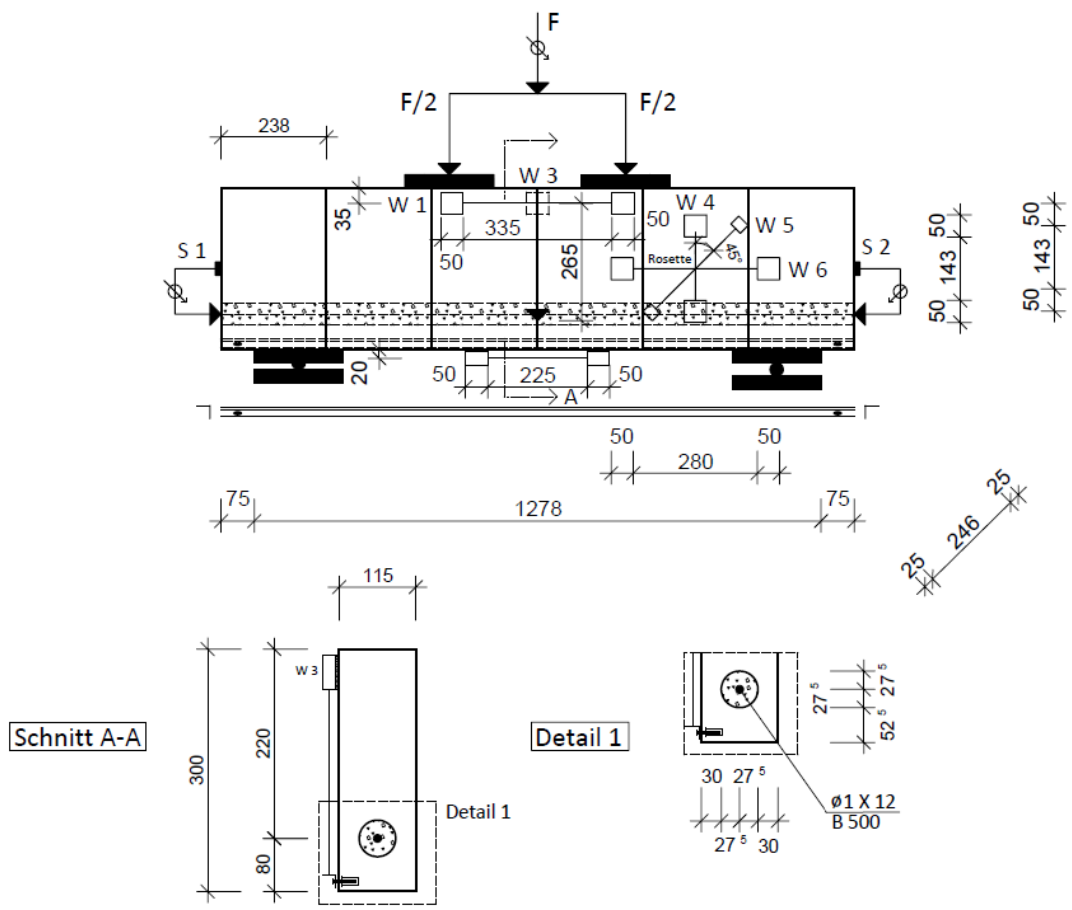

ZI-12
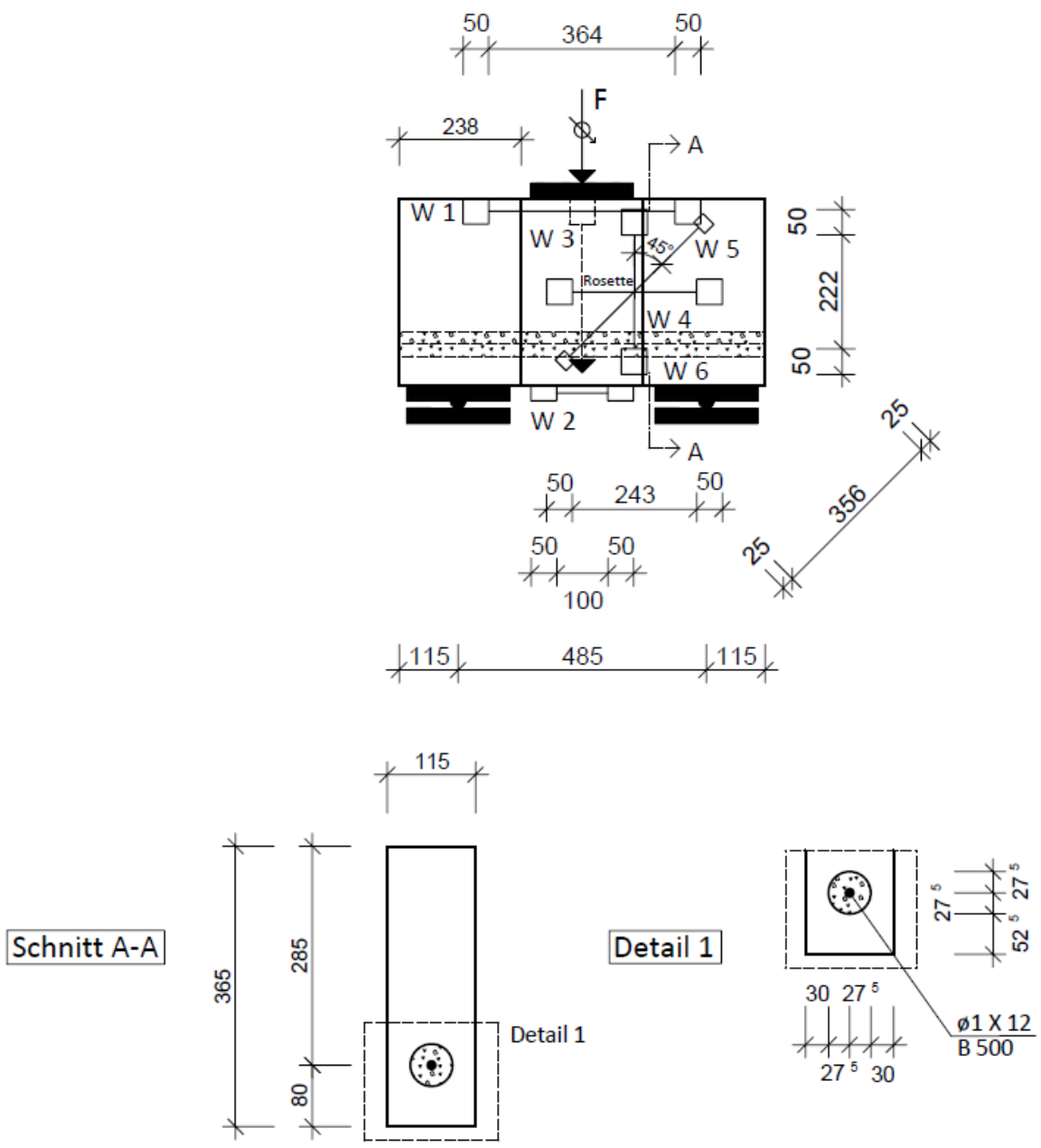
ZI-13
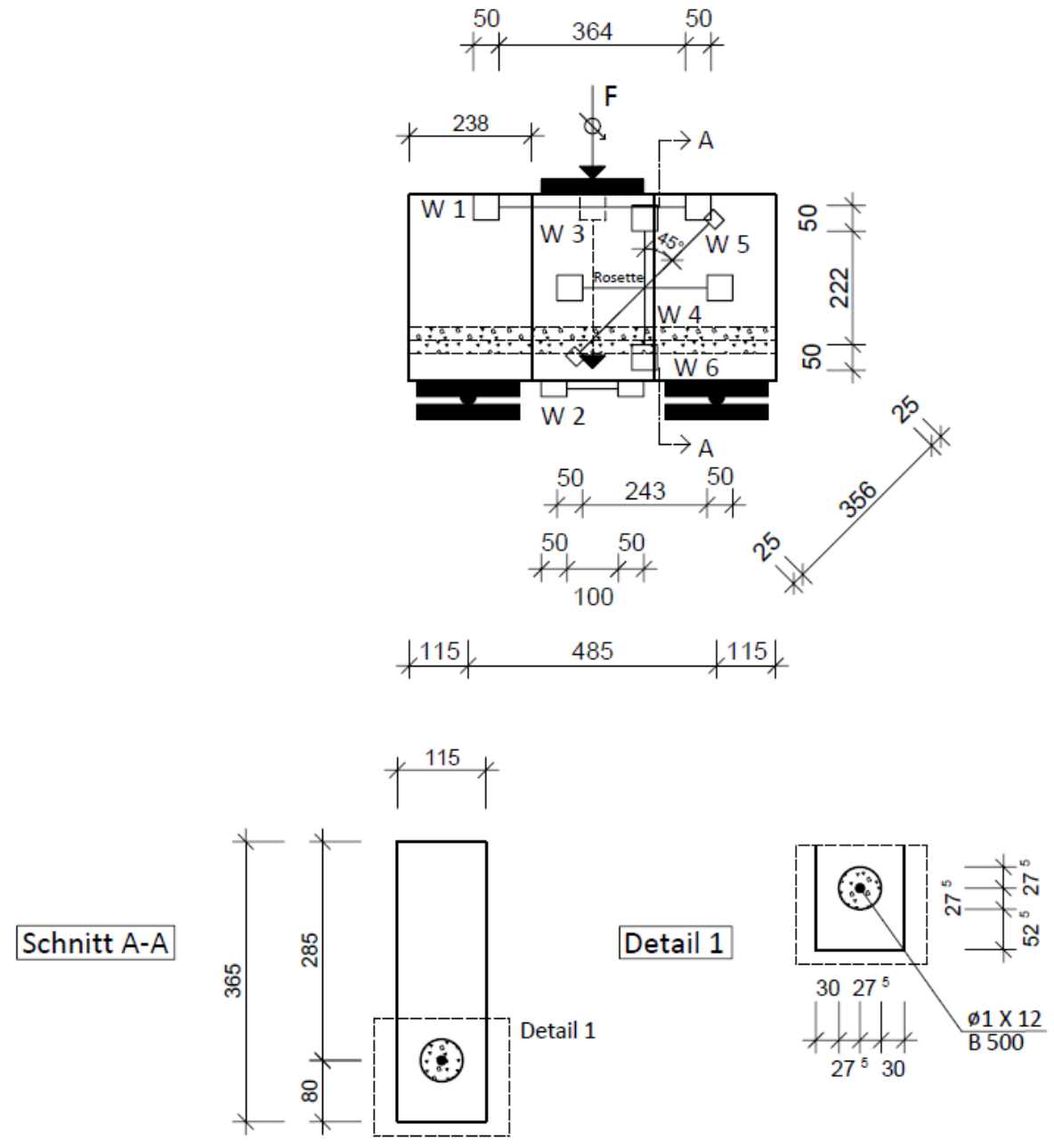

Bild A 4.6

Messstellenpläne der bewehrten scheitrechten Ziegel-Mauerwerkbalken - ZI-01 bis ZI-13 
A 4.2.4 Rissbilder der bewehrten scheitrechten Ziegel-Mauerwerkbalken ZI-01
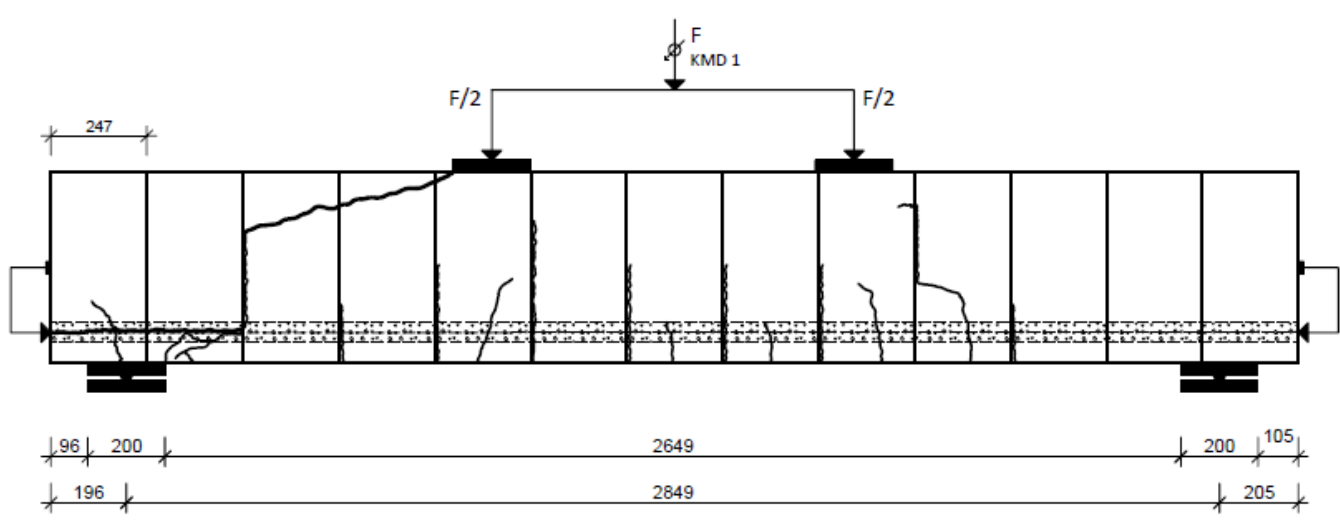

ZI-02
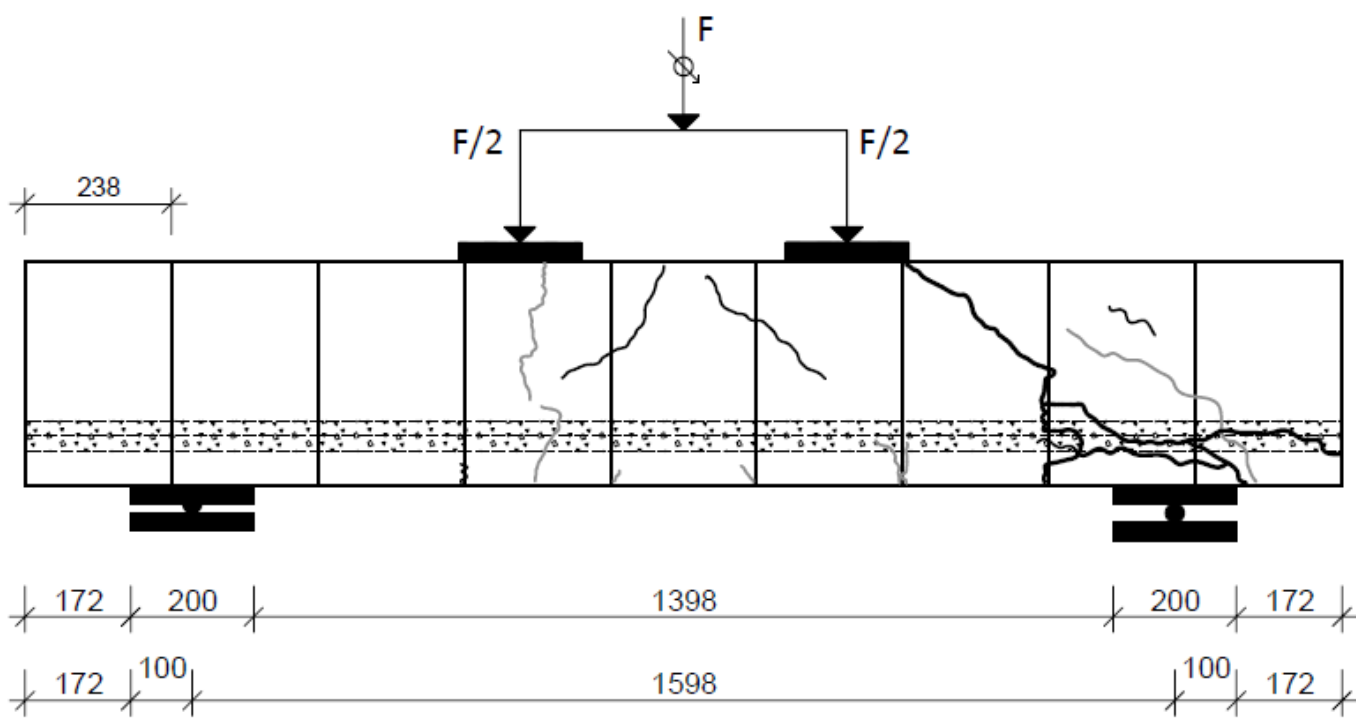

ZI-03
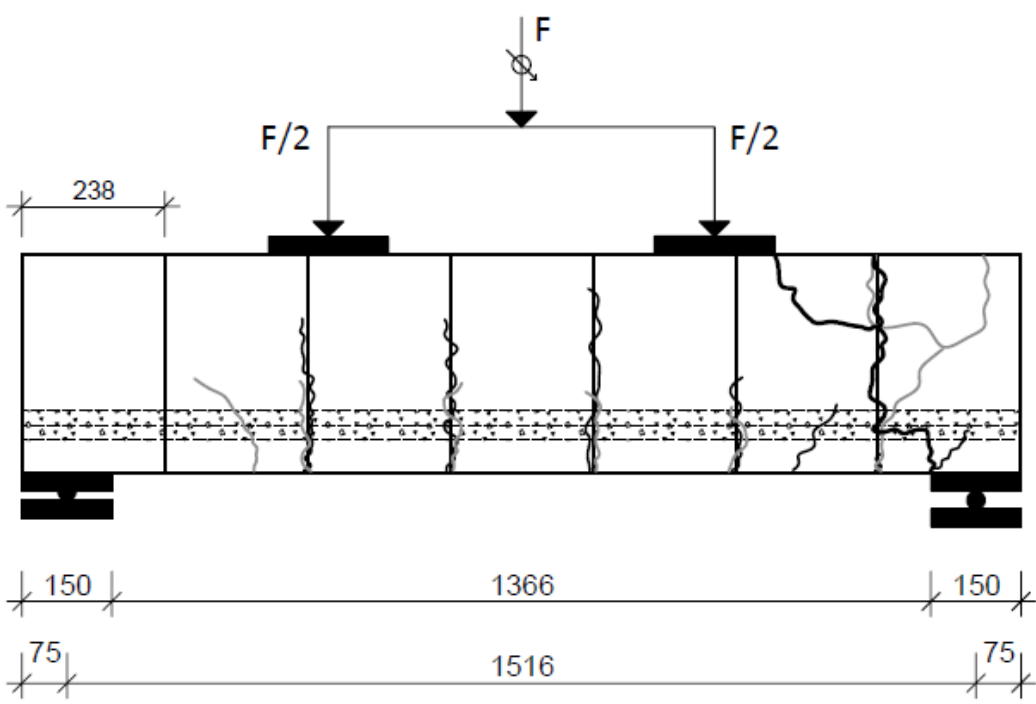


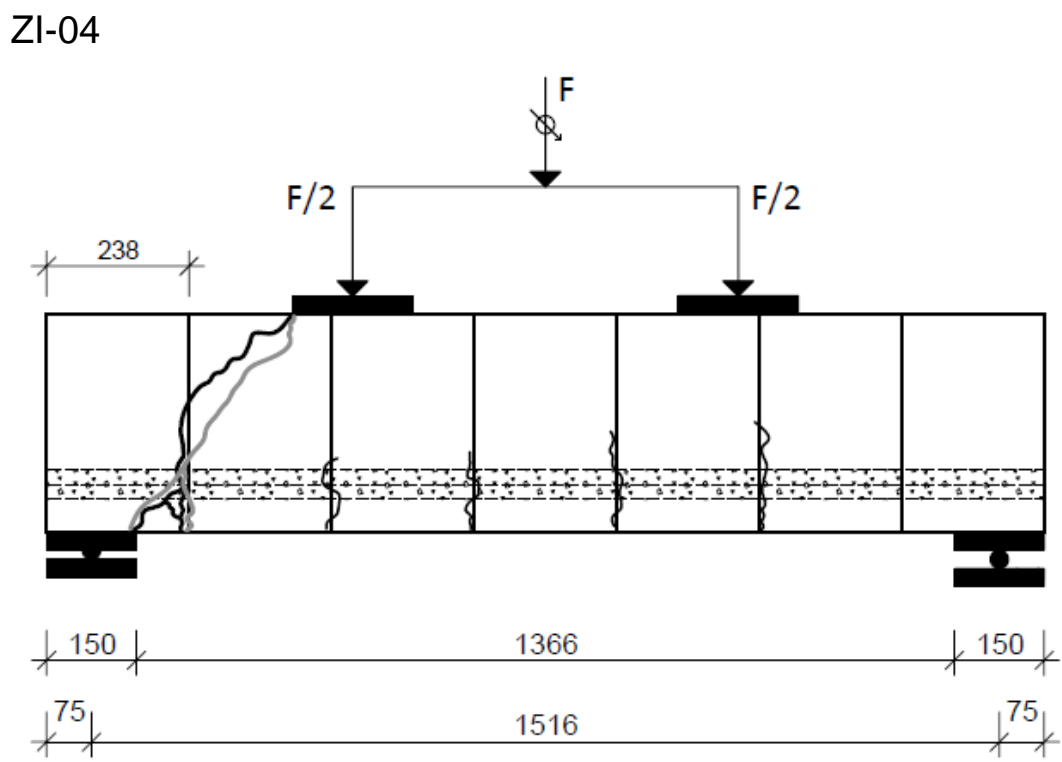

ZI-05
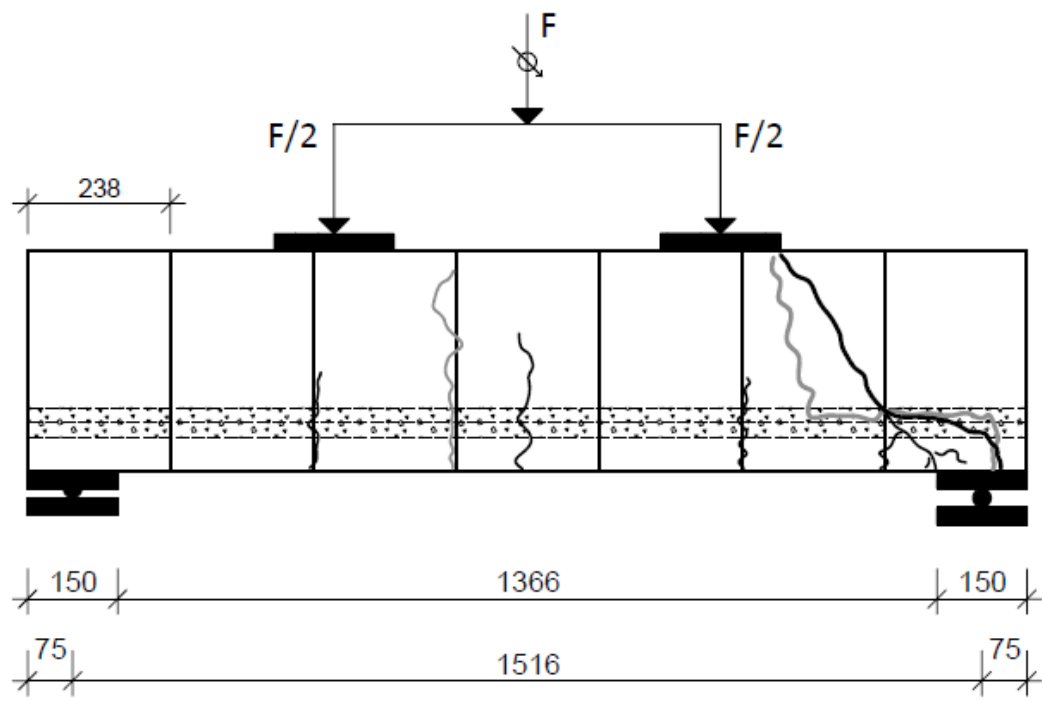

ZI-06

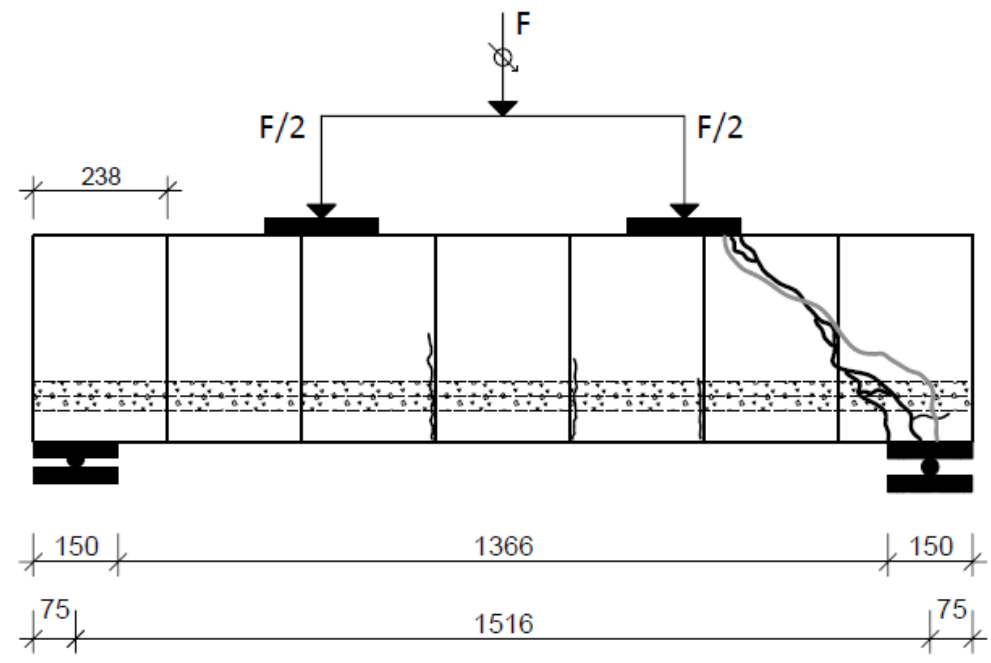


ZI-07
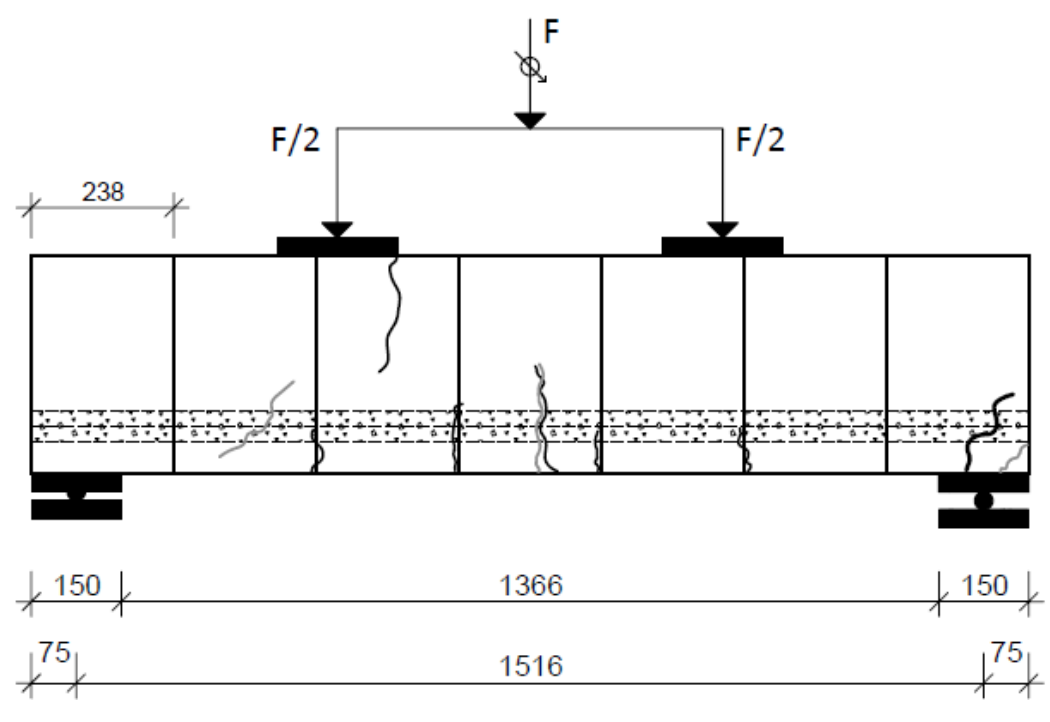

ZI-08
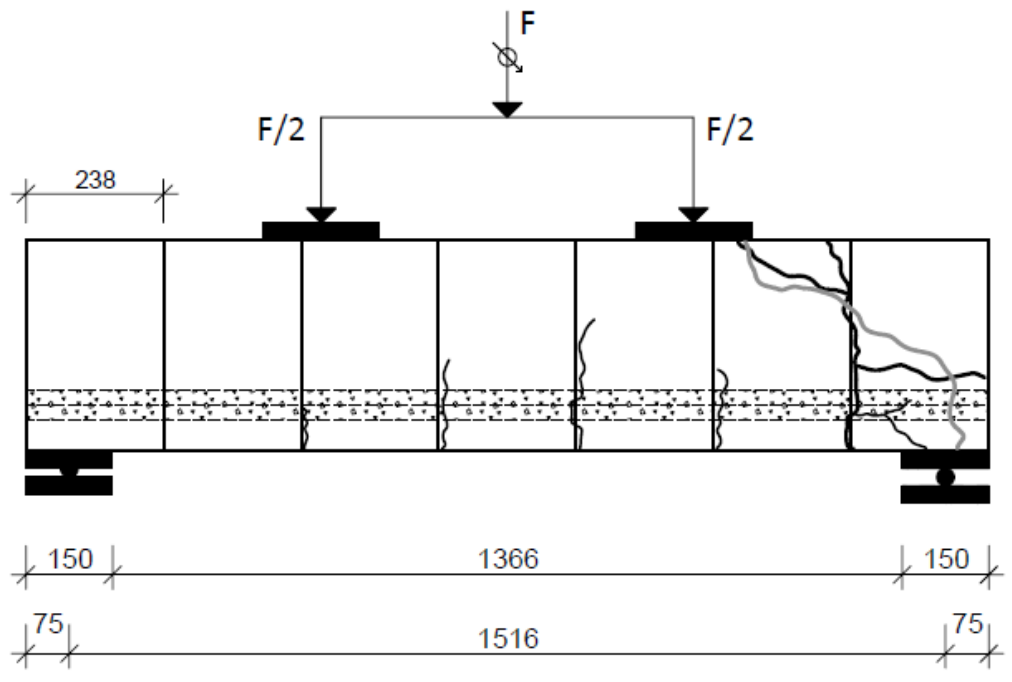

ZI-09

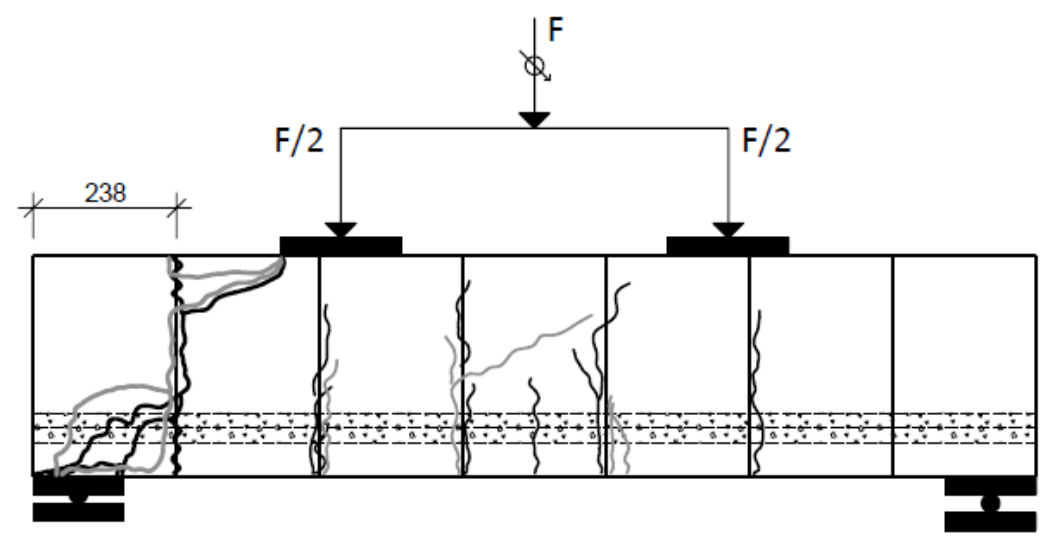

$\begin{array}{rrr}\nmid 150 \nmid & 1366 & 150 \nmid \\ \mathfrak{x}^{75} \nmid & 1516 & \downarrow^{75} \nmid\end{array}$




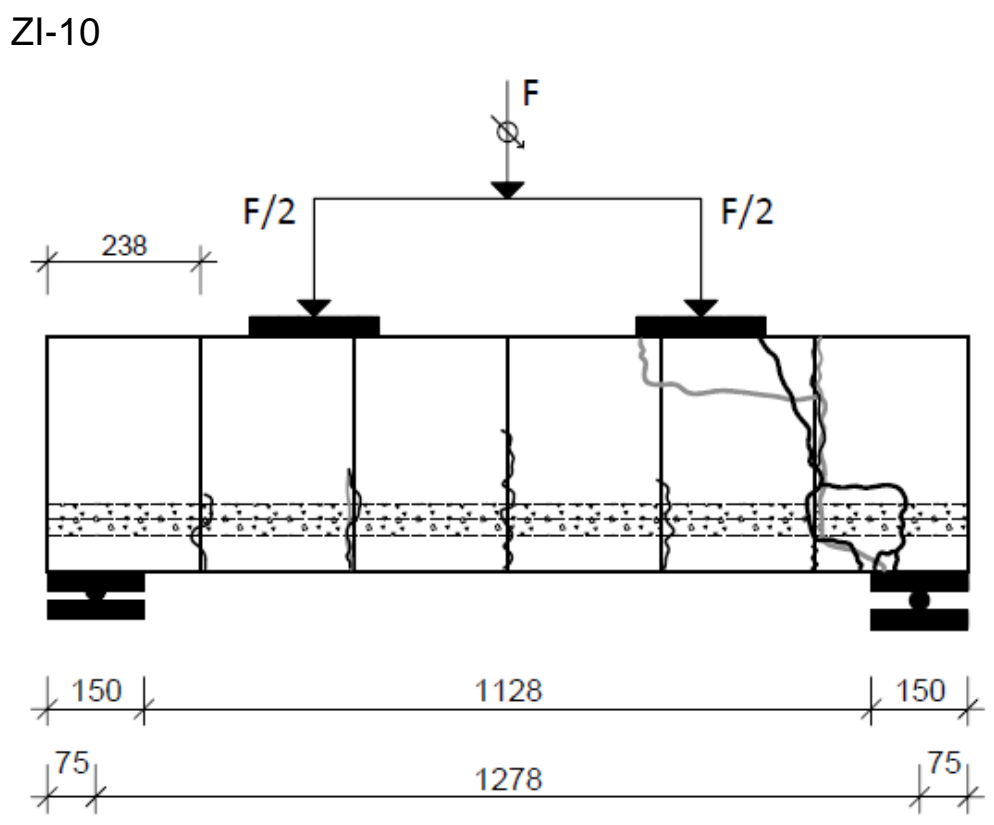

ZI-11
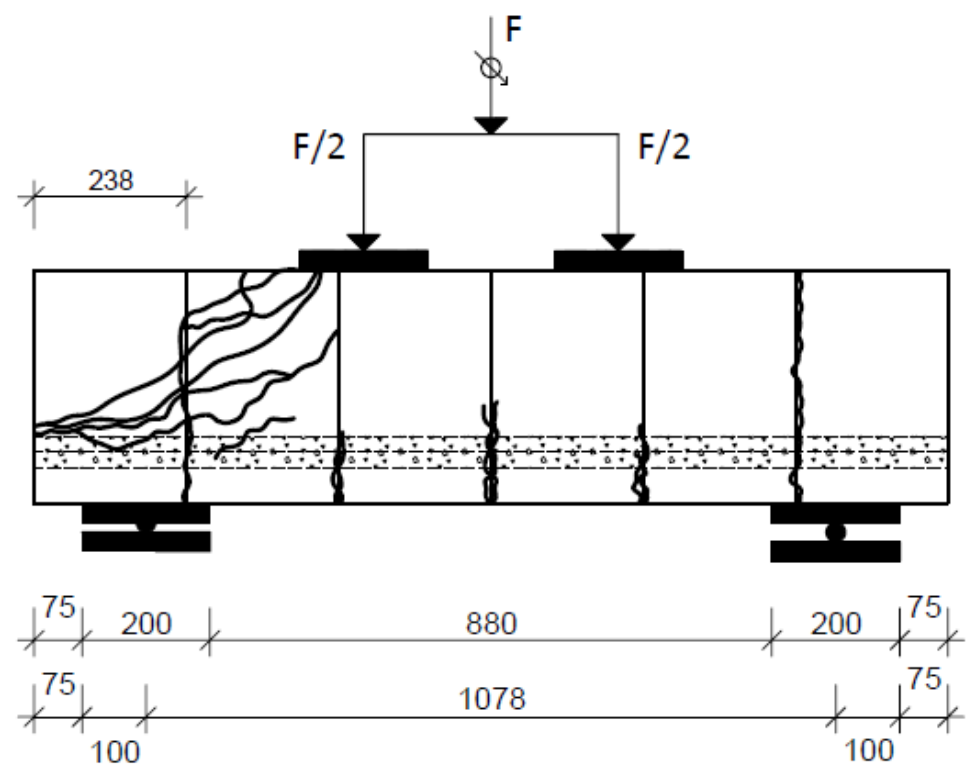
$\mathrm{ZI}-12$
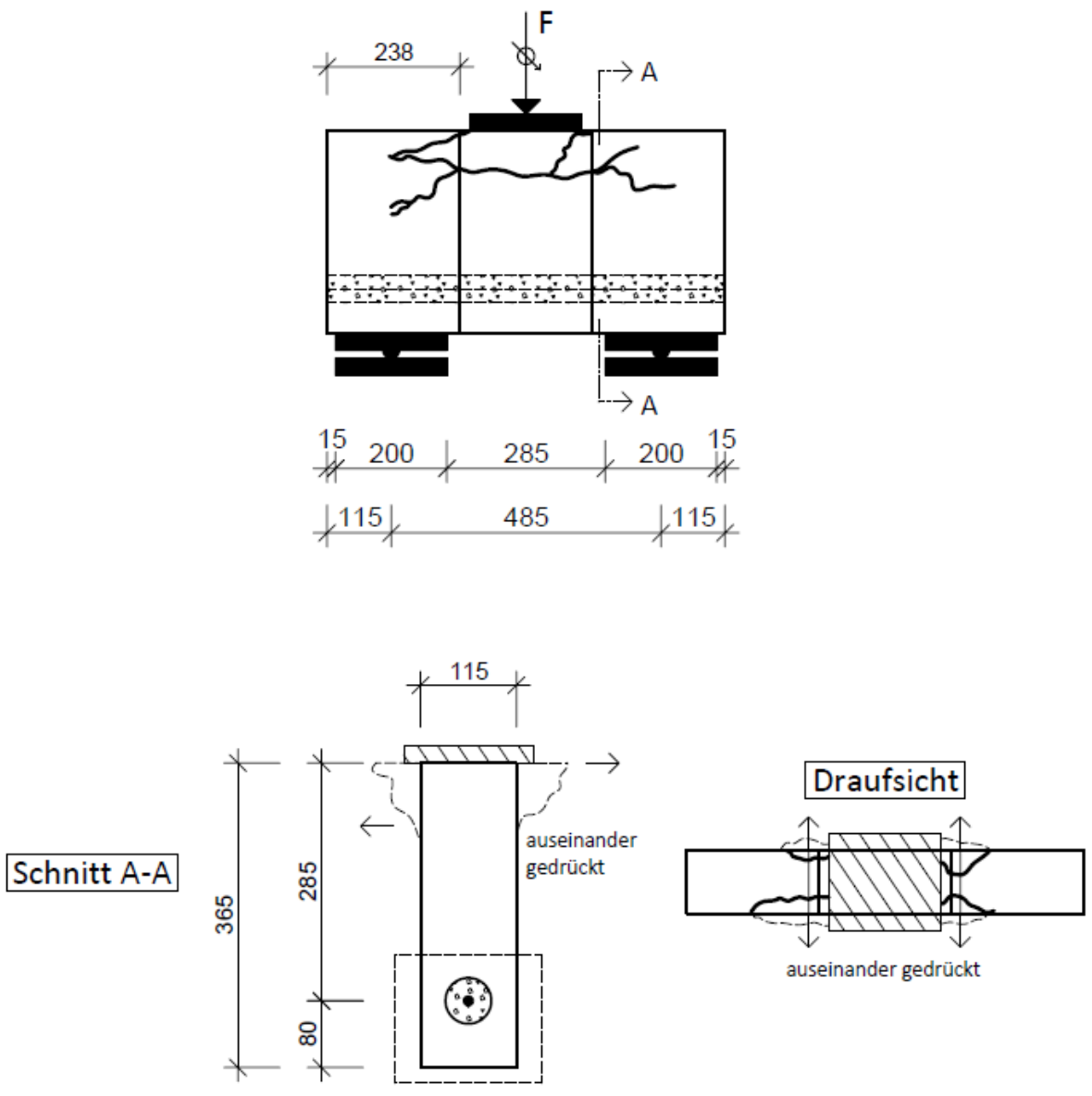

ZI-13
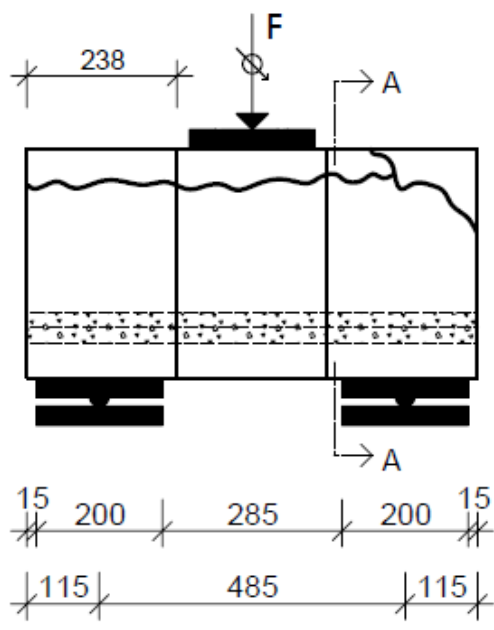

Bild A 4.7

Rissbilder der bewehrten scheitrechten Ziegel-Mauerwerkbalken - ZI-01 bis ZI-13 


\section{A 4.2.5 Lastdurchbiegungslinien}

ZI-01

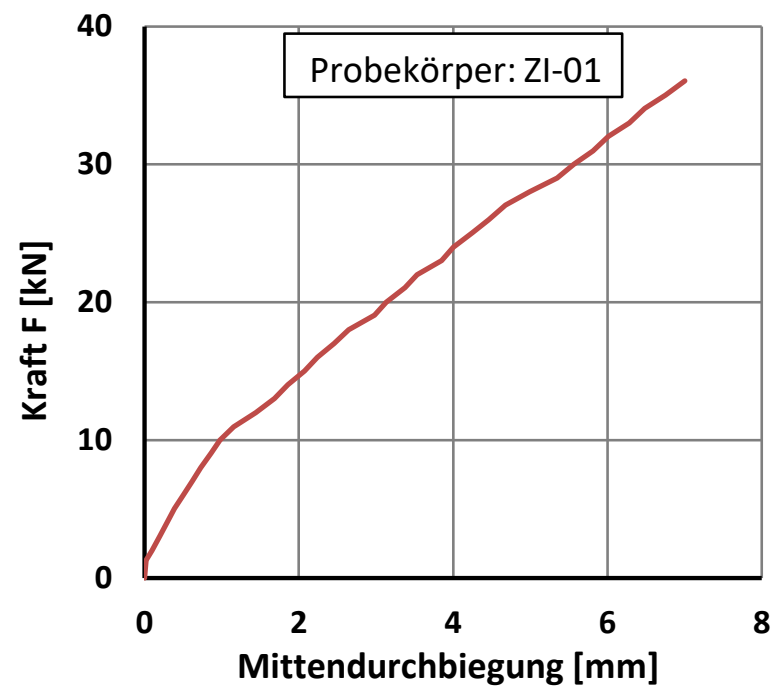

ZI-02
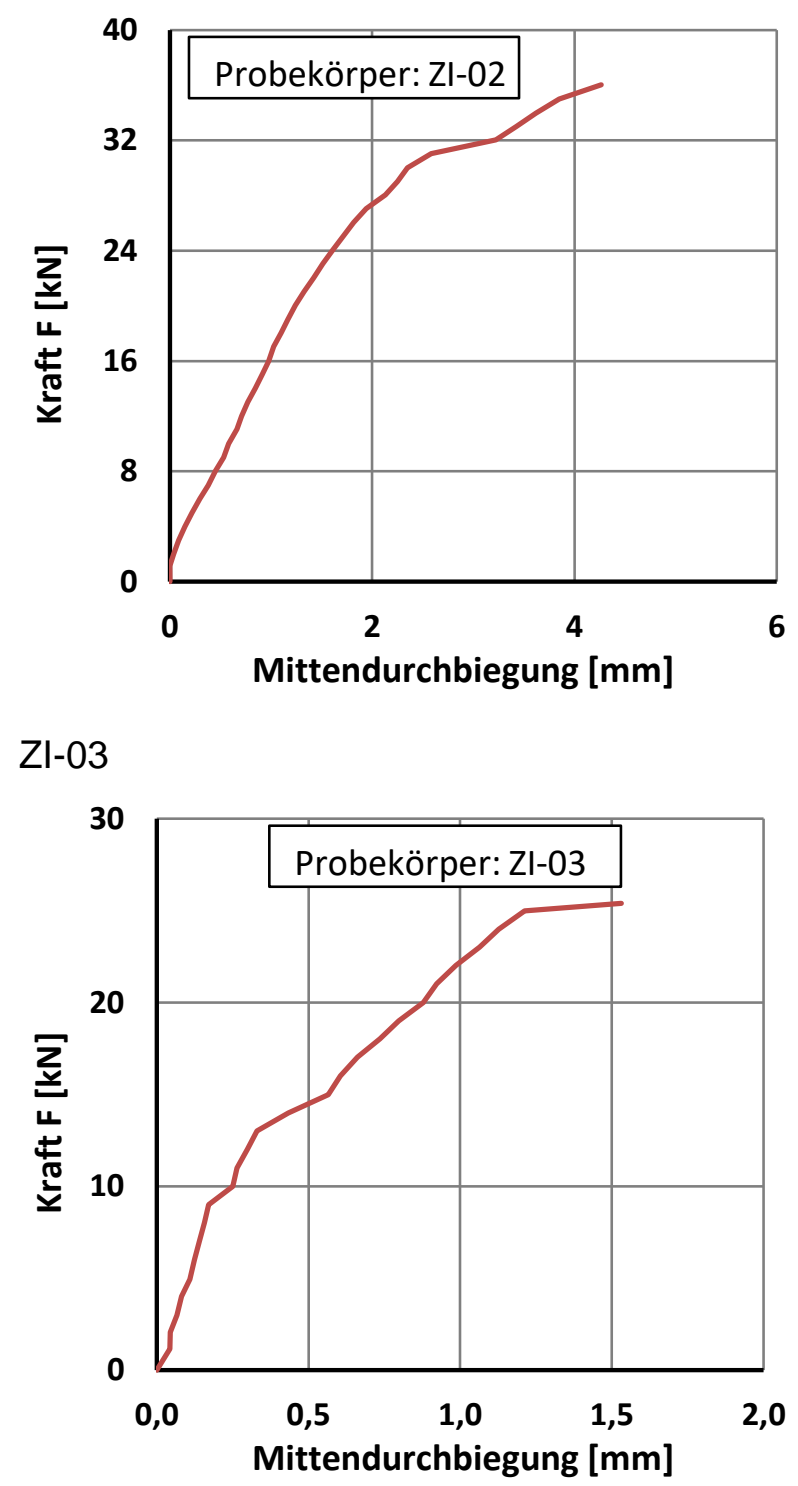
ZI-04

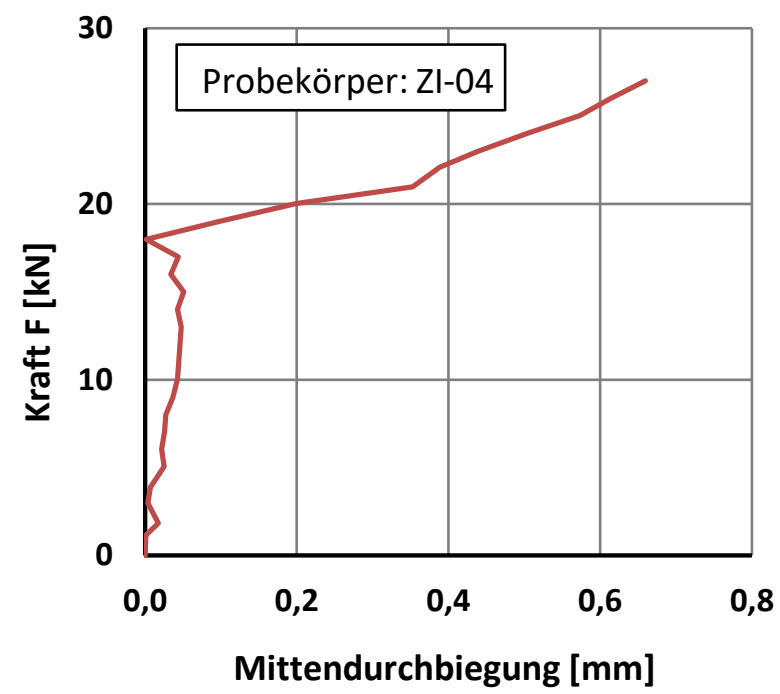

ZI-05

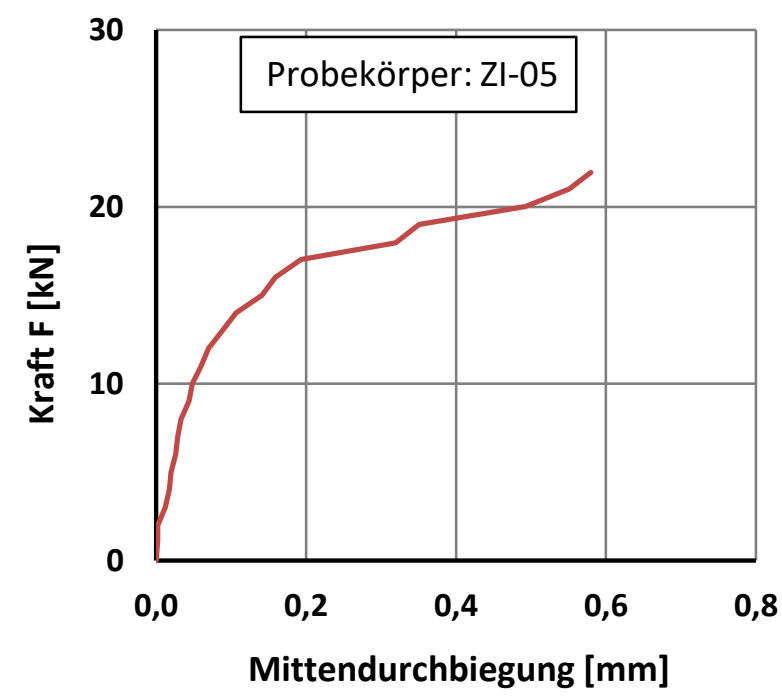

ZI-06

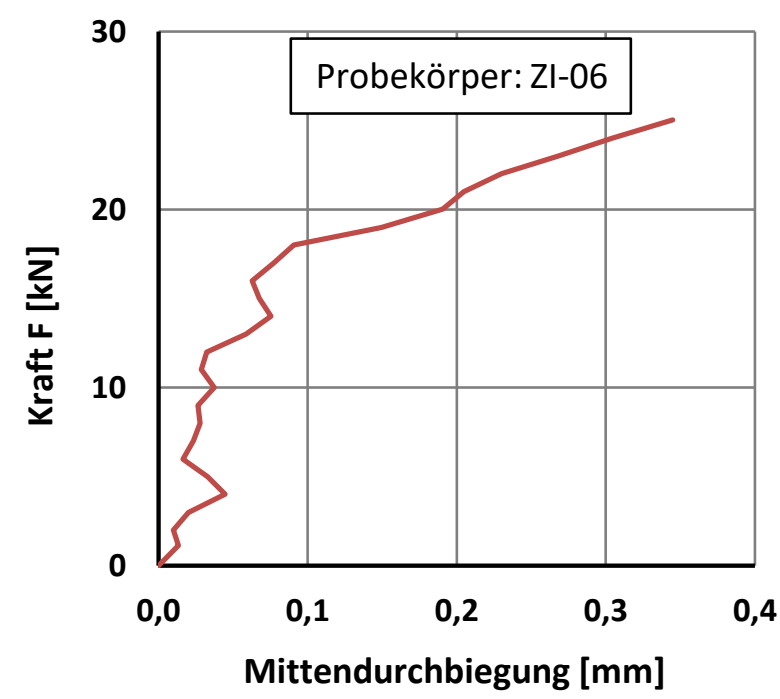



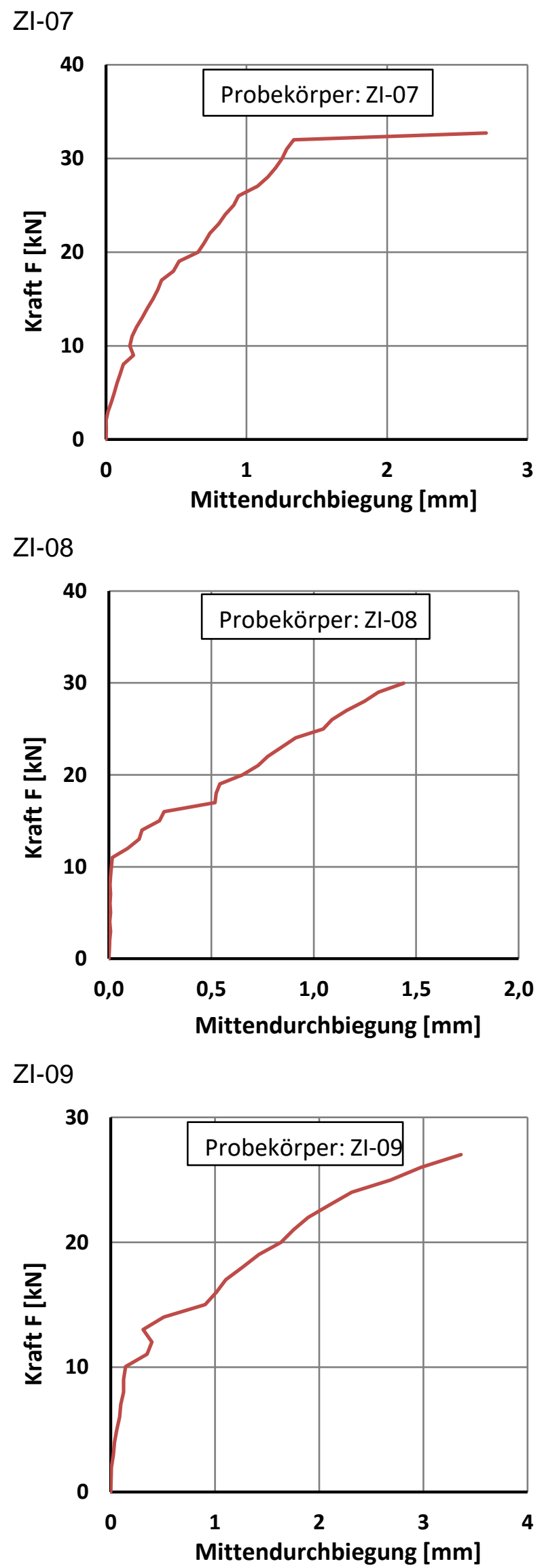


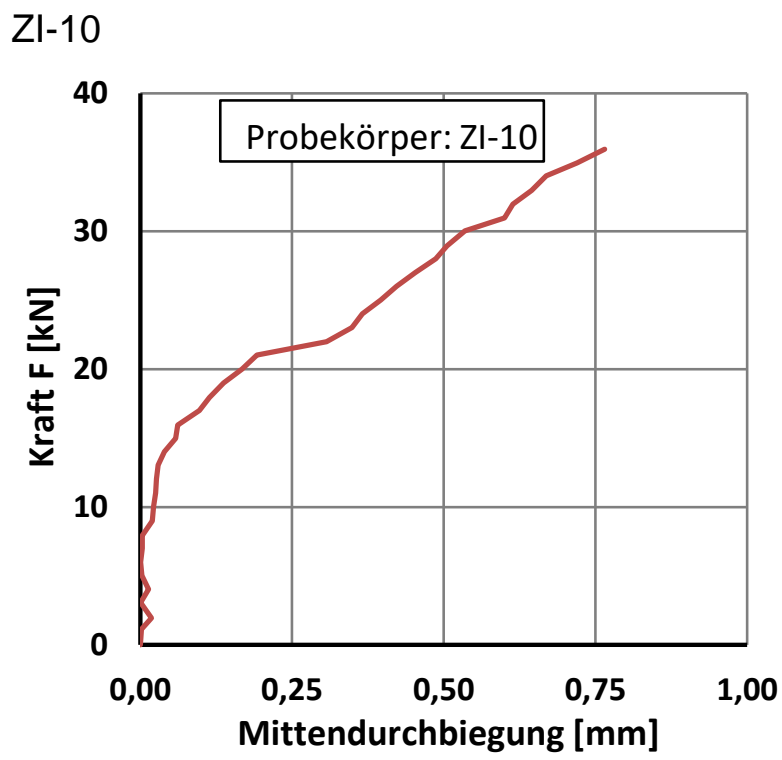

ZI-11

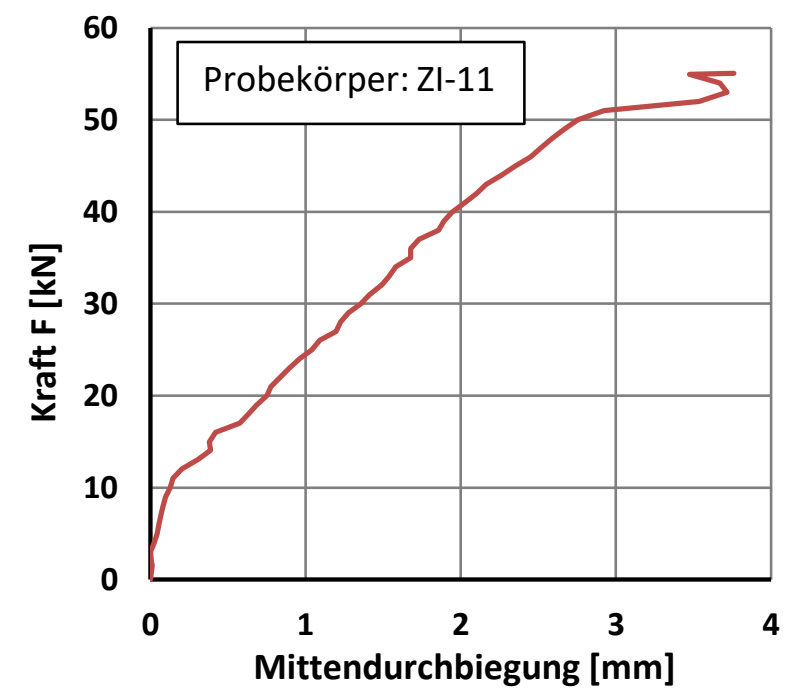

ZI-12

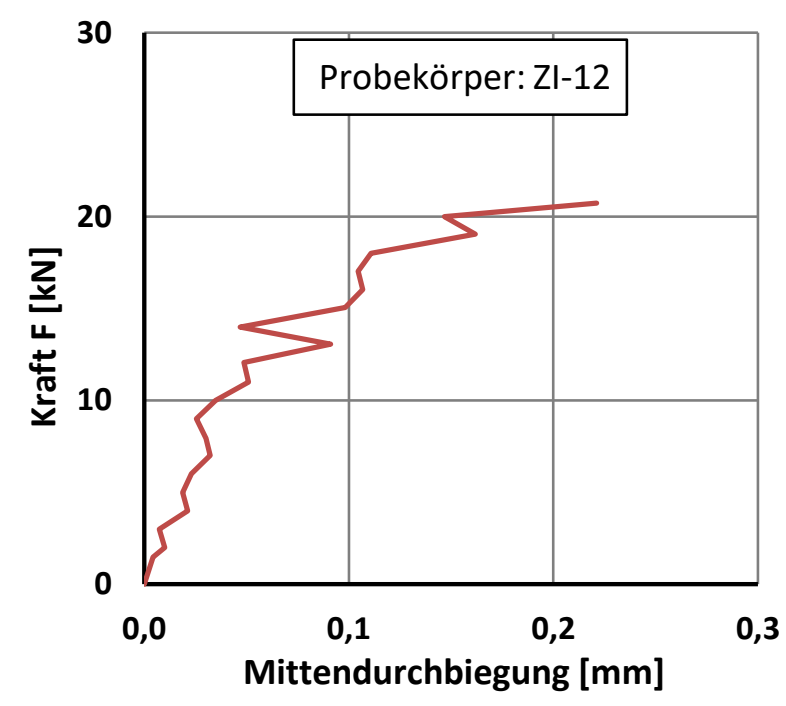




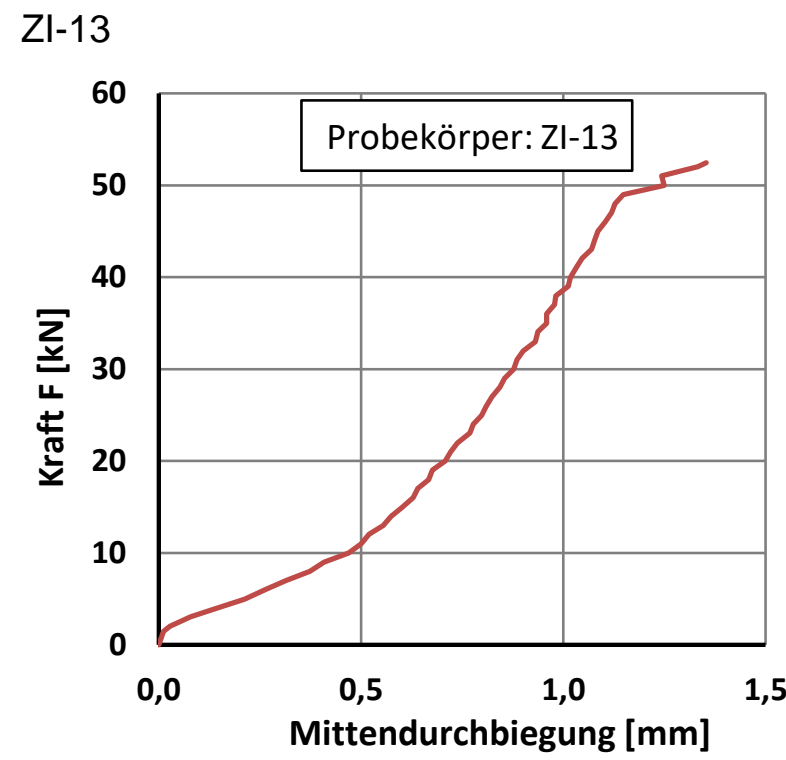

Bild A 4.8 Lastdurchbiegungslinien der bewehrten scheitrechten Ziegel-Mauerwerkbalken - ZI-01 bis ZI-13 


\section{A 4.2.6 Rissbilder}

Tabelle A 4.1 Rissbilder exp. untersuchter Mauerwerkbalken

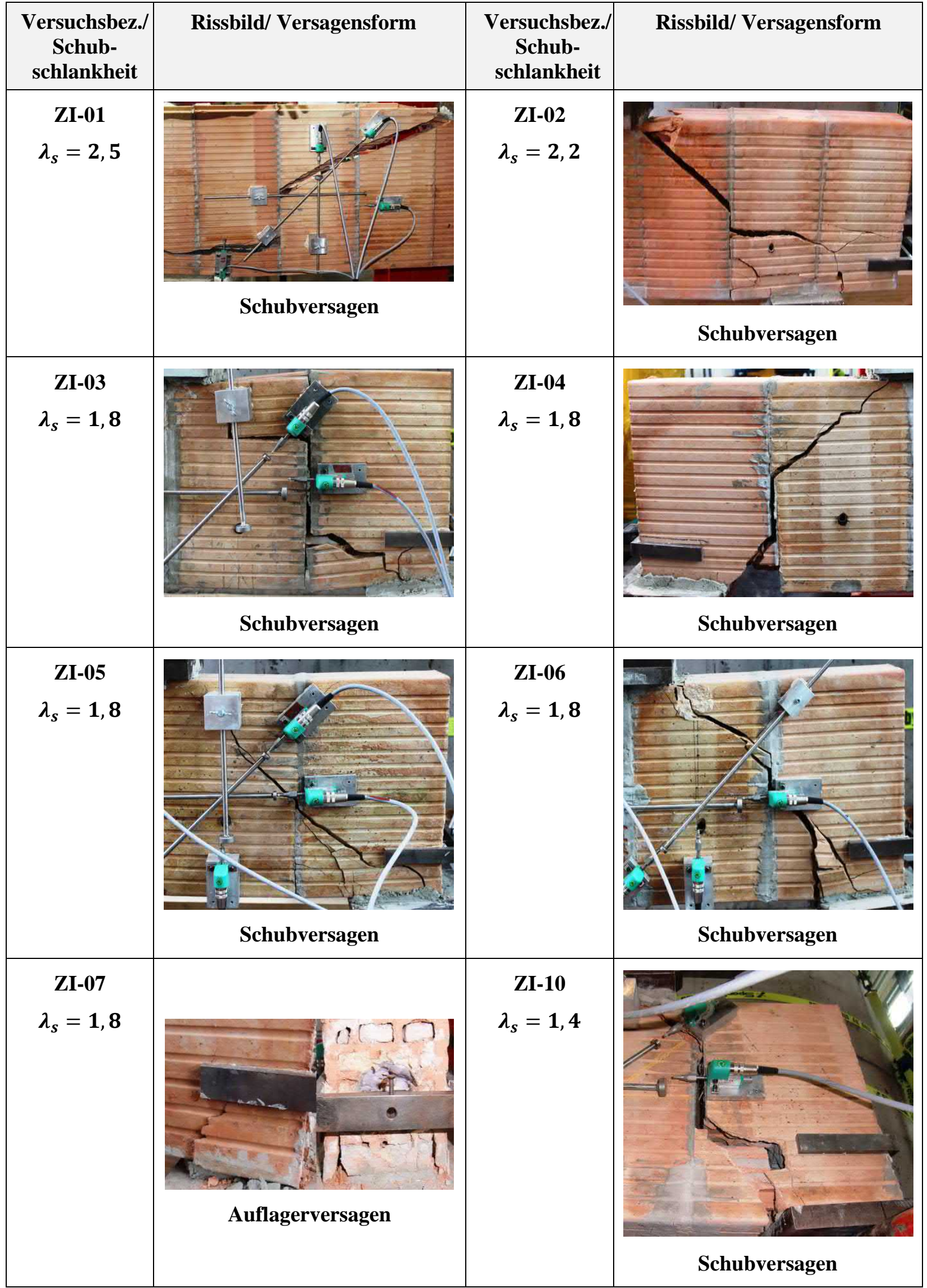




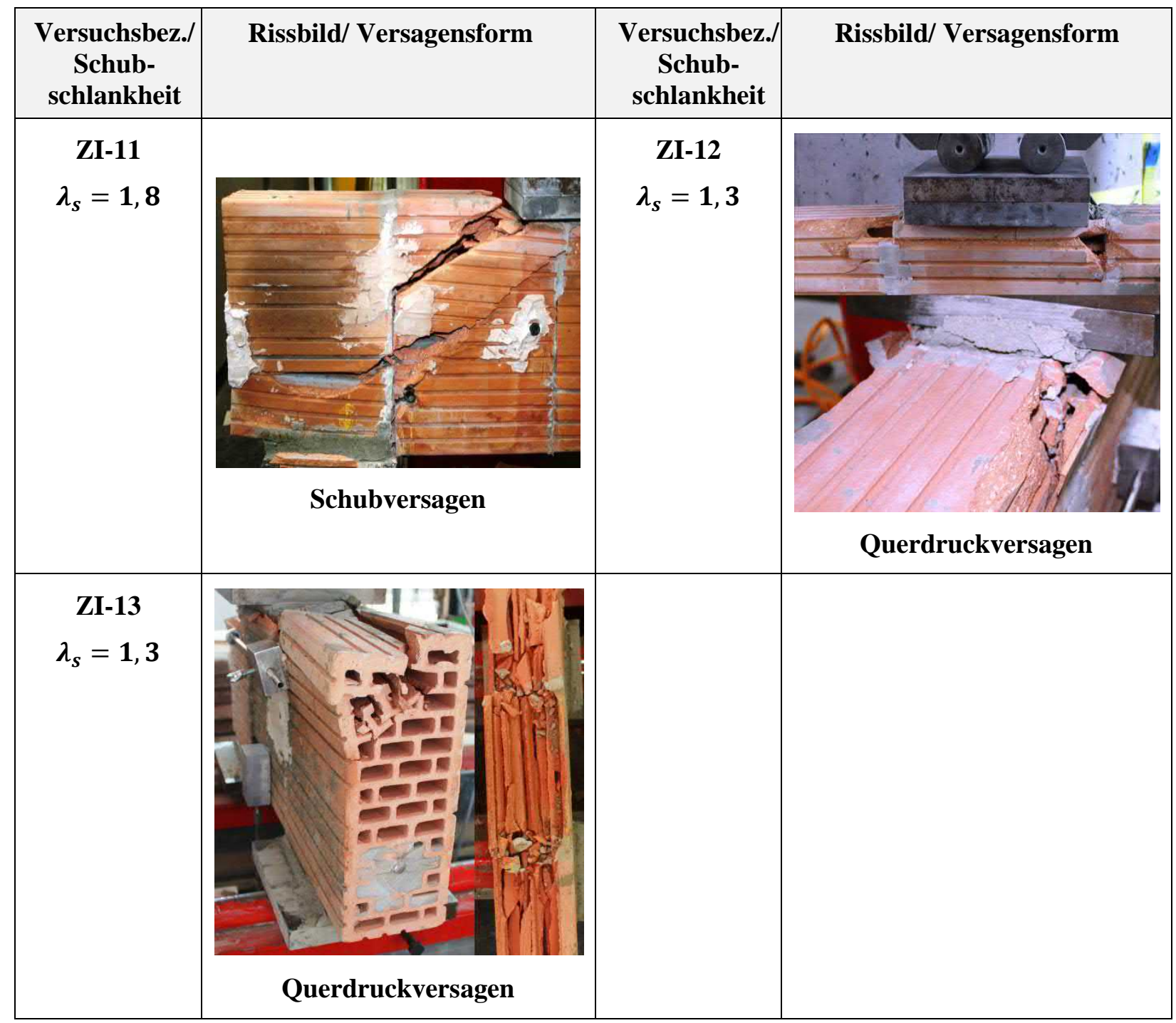


A 4.3 Scheitrechte Kalksandsteinbalken - IIa

A 4.3.1 Systemskizzen

KS-01

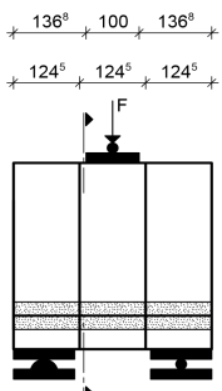

* $115+143^{5} \times 115$,

$57^{5}, 258^{5} \quad 57^{5}$
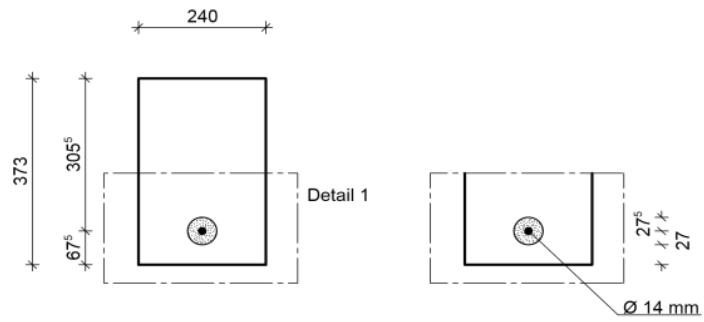

Schnitt A-A

Detail 1

KS-02
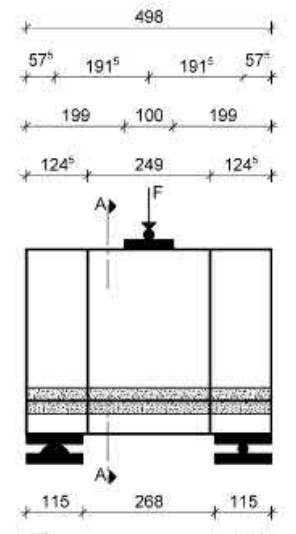

$57^{\circ}, \quad 383 \quad 57^{\circ}$.

$\times 240$ ×
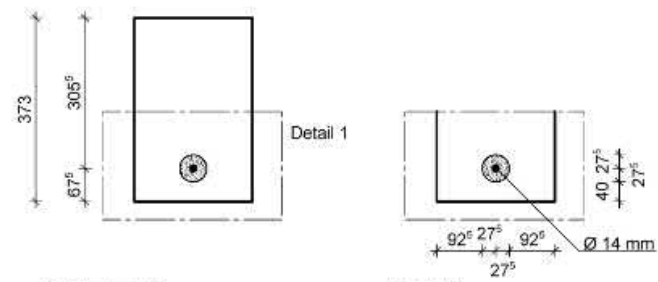

Schnitt A-A

Detail 1 
KS-03
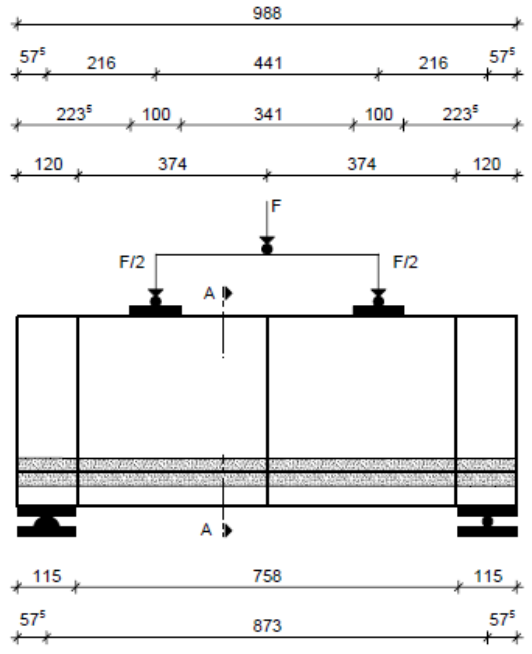

$+240$

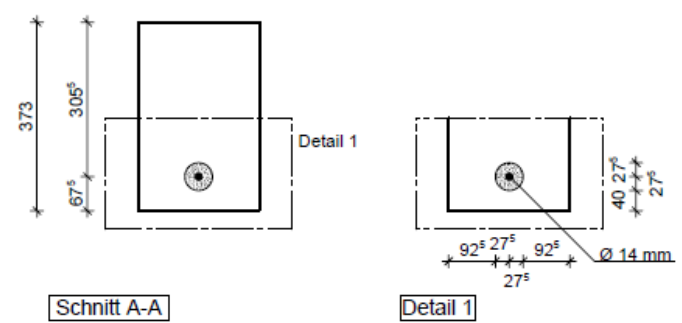

KS-05.1
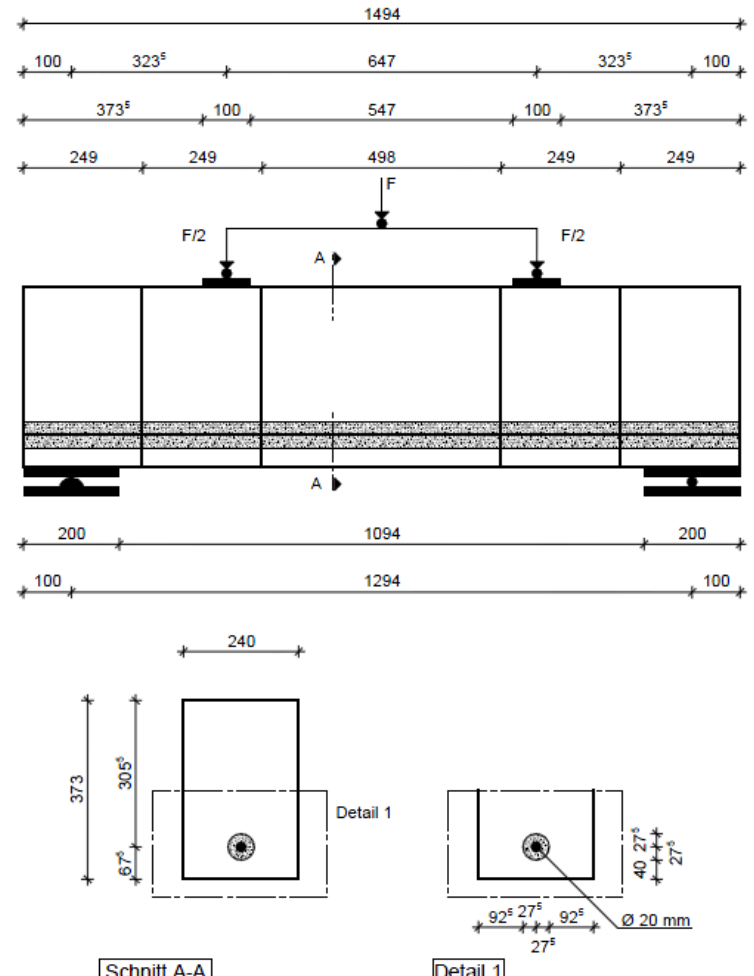

Schnitt A-A

Detail 1 
KS-05.2
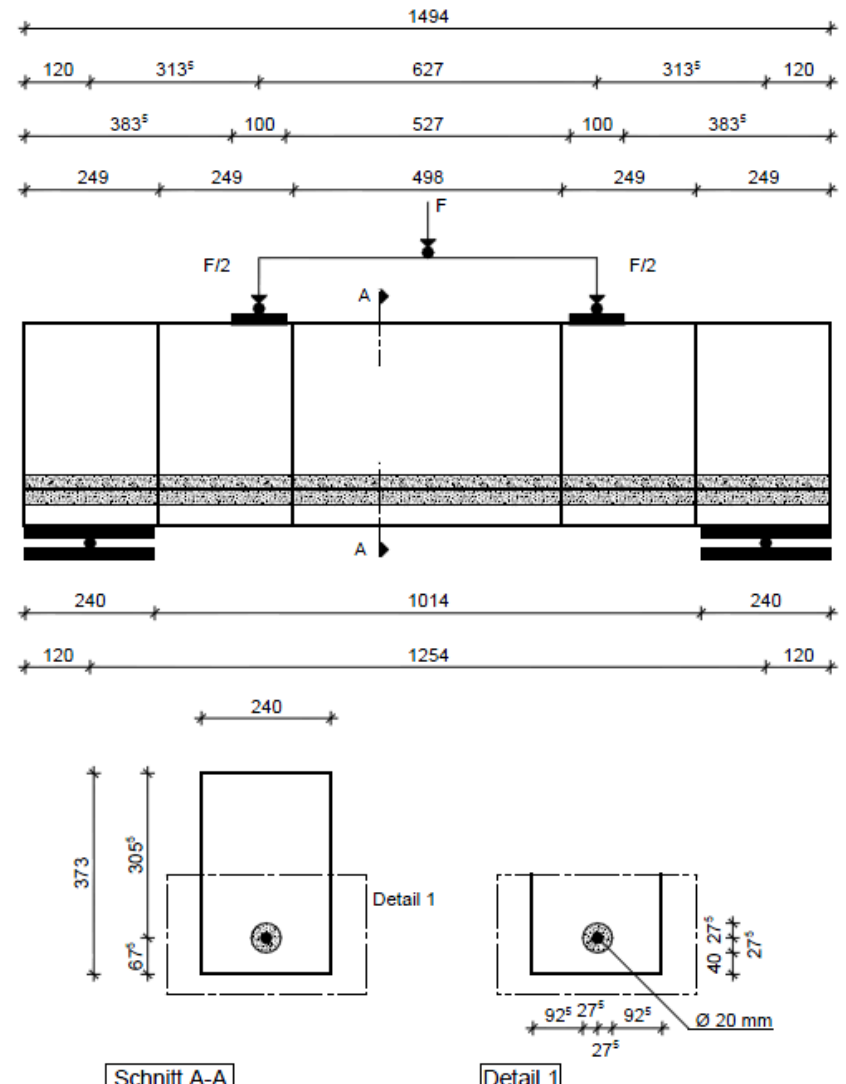

Schnitt A-A Detail 1

KS-06.1

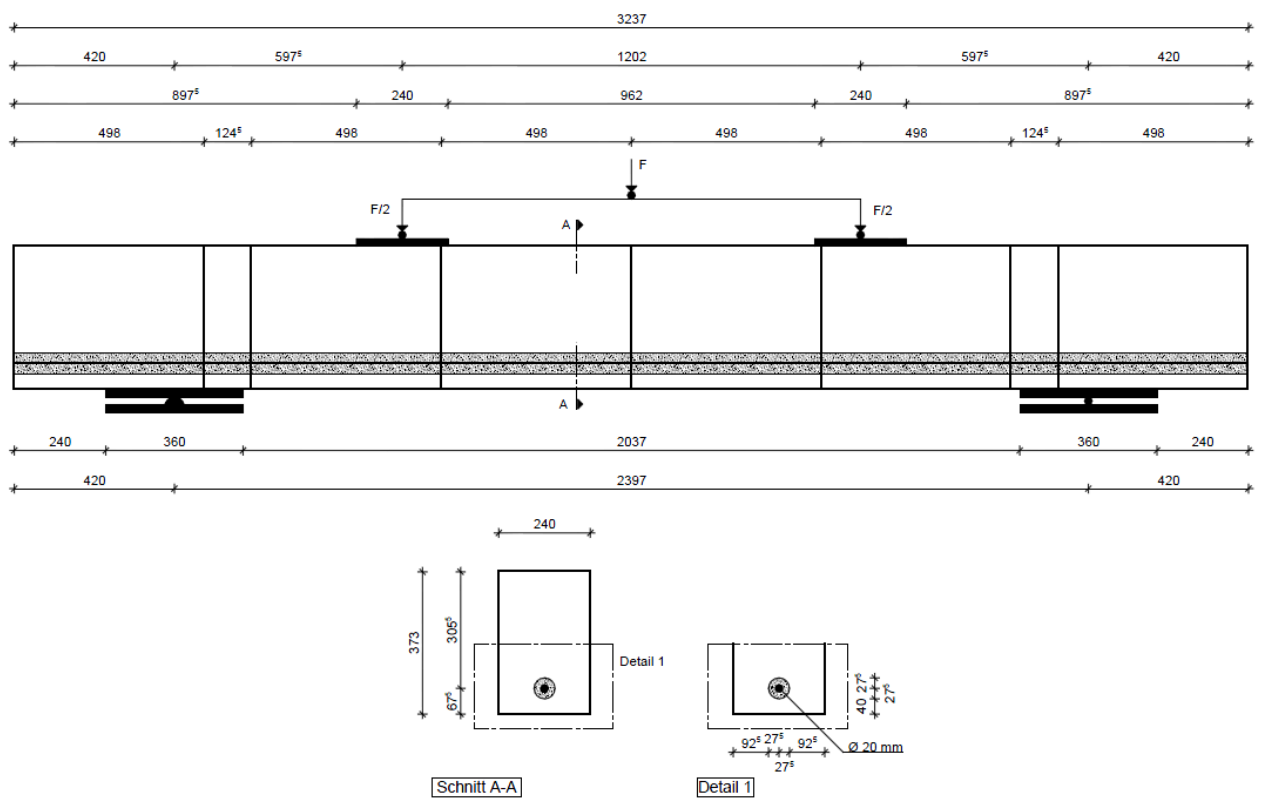


KS-07
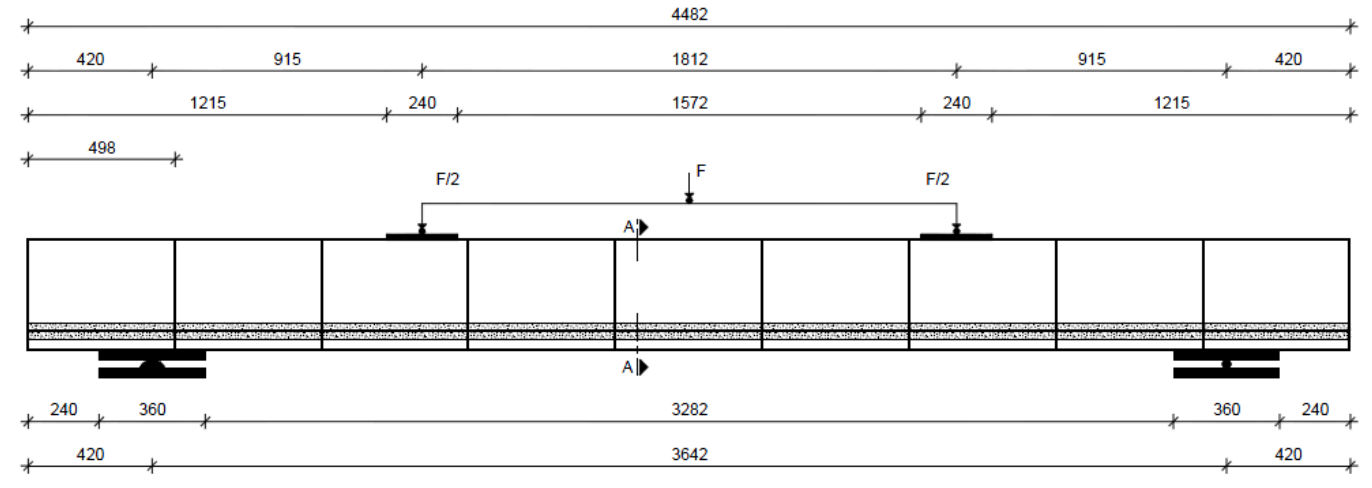

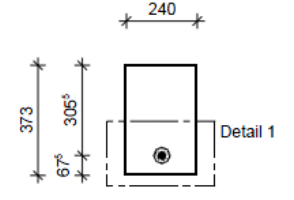

Schnitt A-A

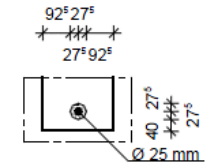

Detail 1

Bild A 4.9 Systemskizzen der bewehrten scheitrechten Kalksandstein-Mauerwerkbalken ohne Aufbeton - KS-01 bis KS-07 


\section{A 4.3.2 Messstellenpläne}

KS-03
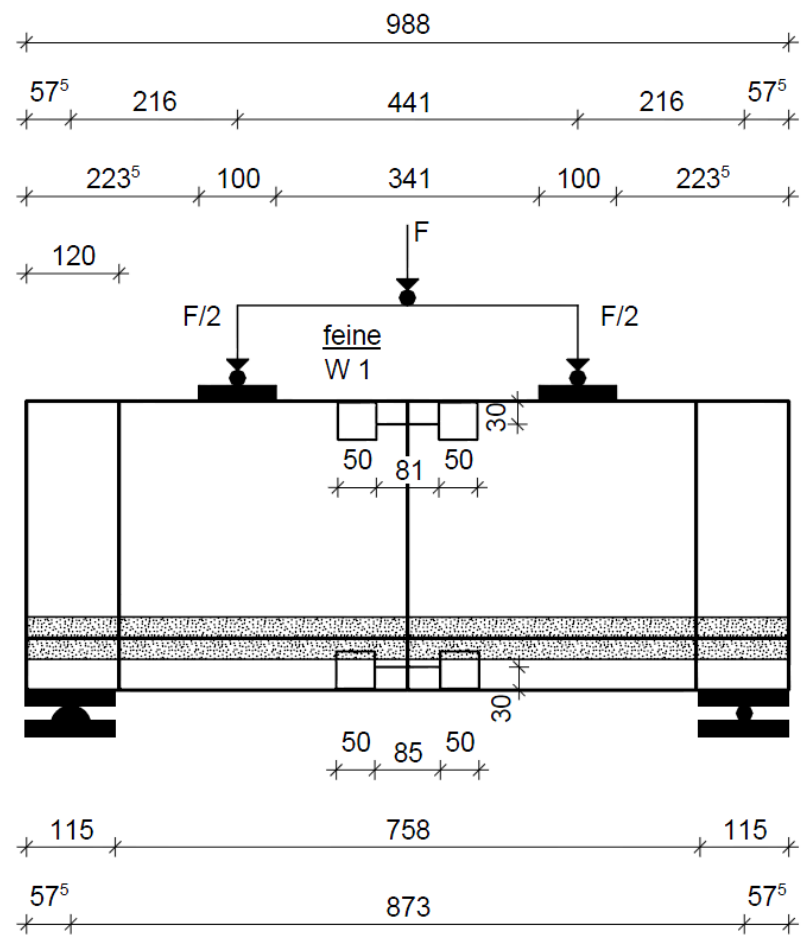

KS-05.2

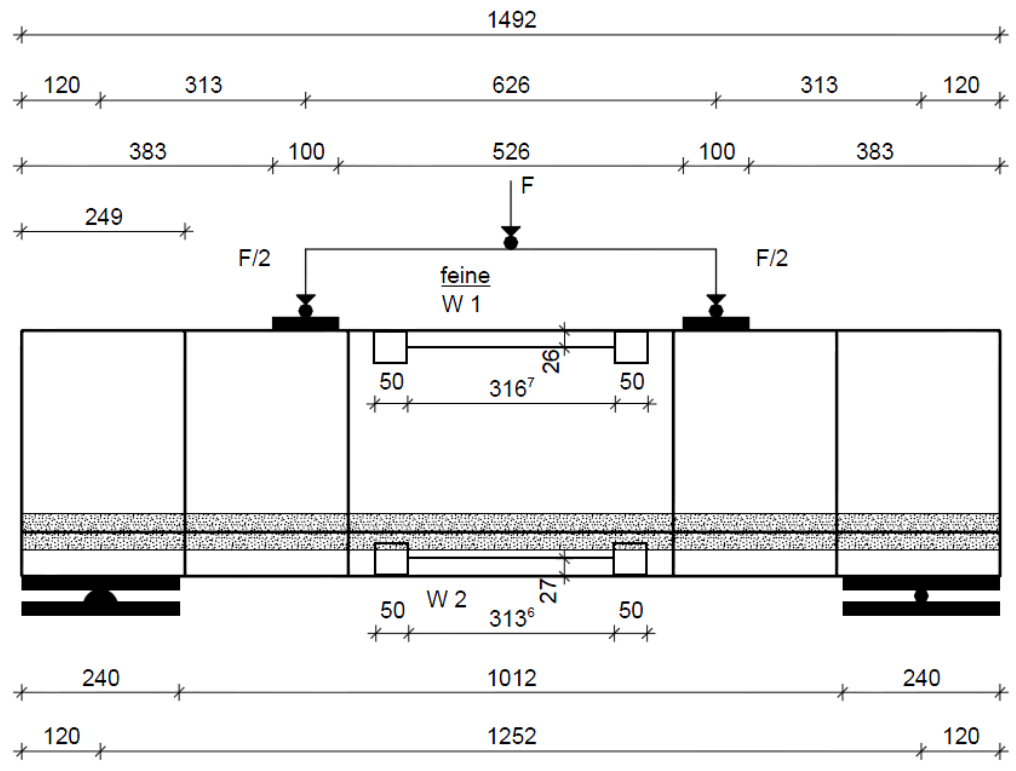


KS-06.1

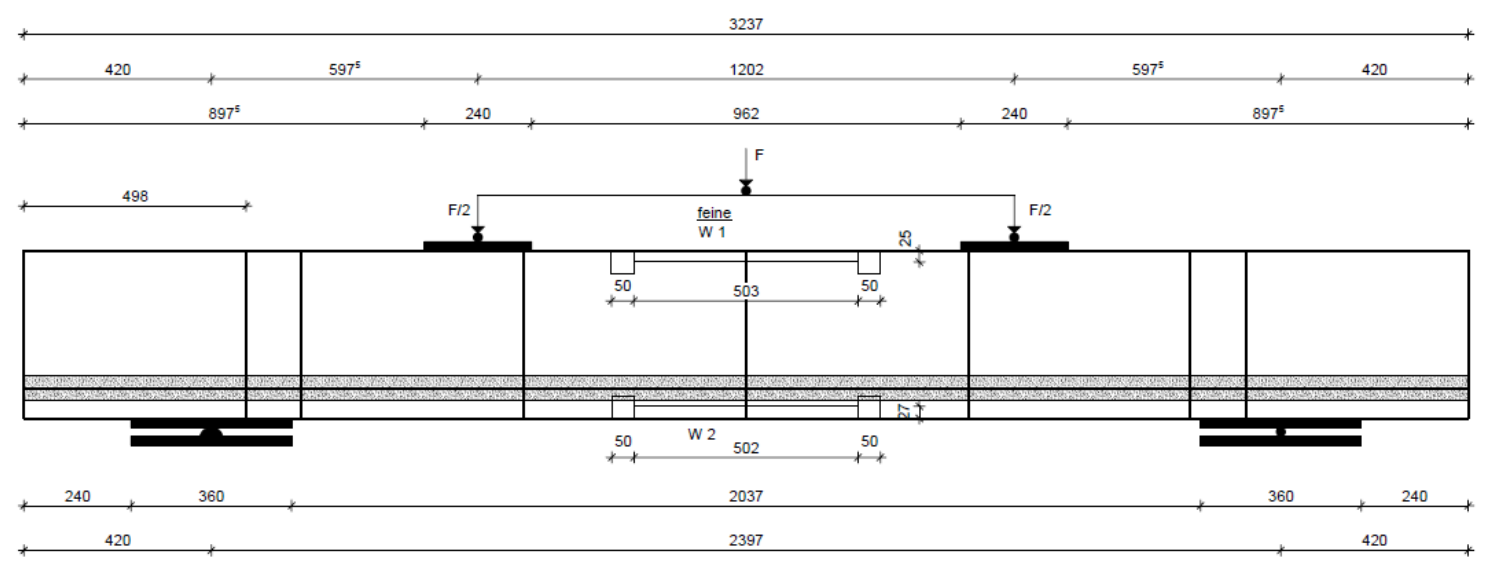

KS-07

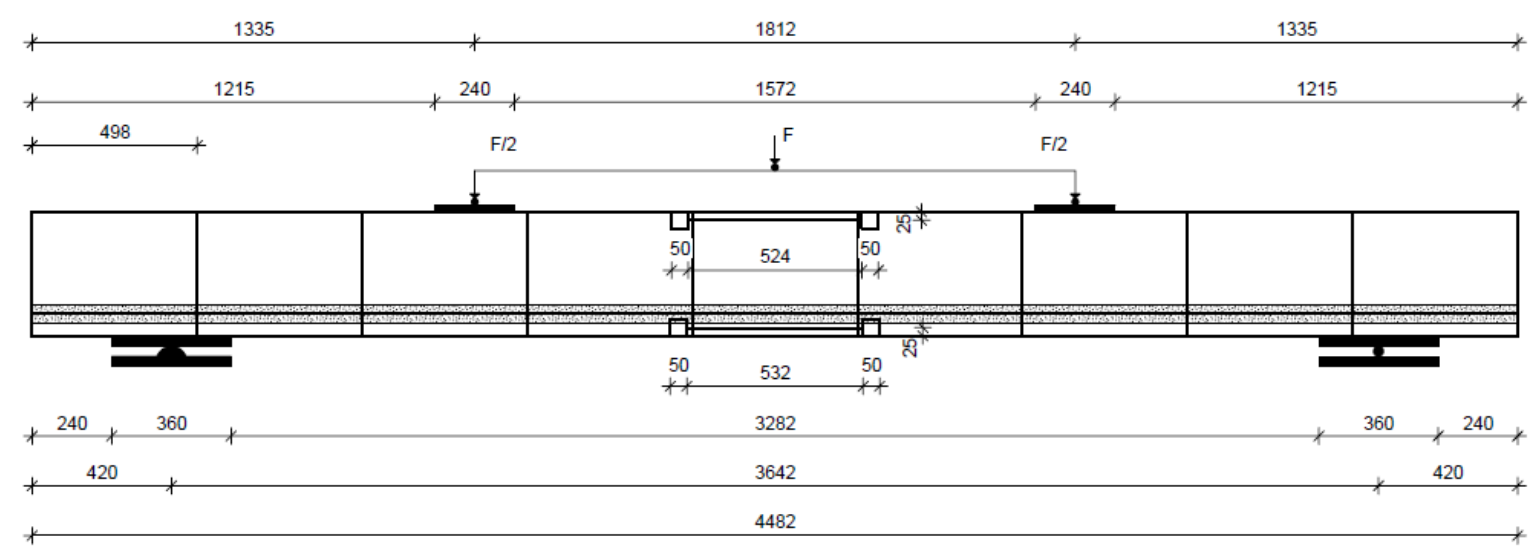

Bild A 4.10 Messstellenpläne der bewehrten scheitrechten Kalksandstein-Mauerwerkbalken ohne Aufbeton - KS-03 bis KS-07 


\section{A 4.3.3 Rissbilder}

KS-01

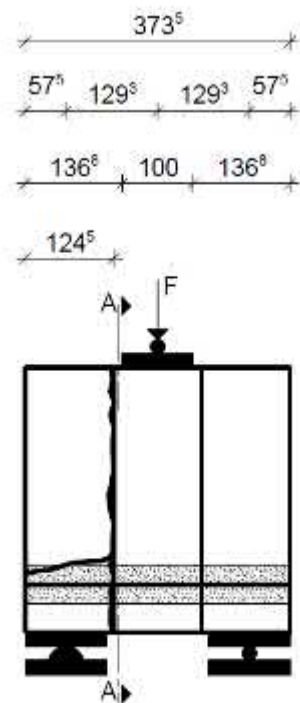

$+115 \times 143^{5}, 115$

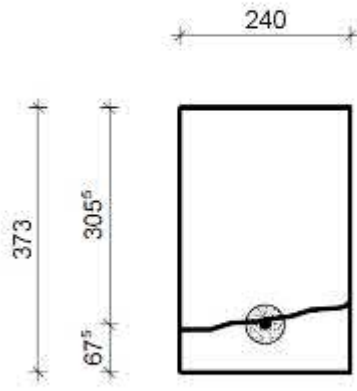

Schnitt A-A

$57^{5}, \quad 258^{5} \quad 57^{5}$

KS-02

489
$+57^{5} 187 \times 187+57^{\circ}$
$+194^{5} \times 100,194^{5}$

$+120$
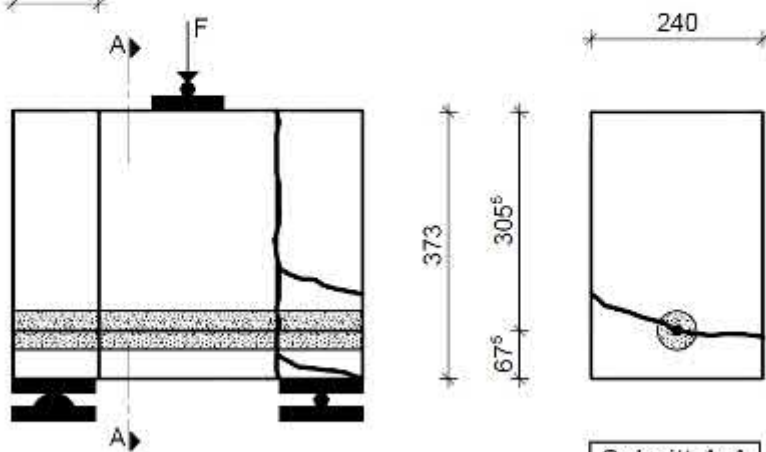

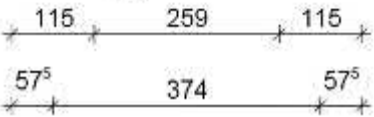

Schnitt A-A 
KS-03

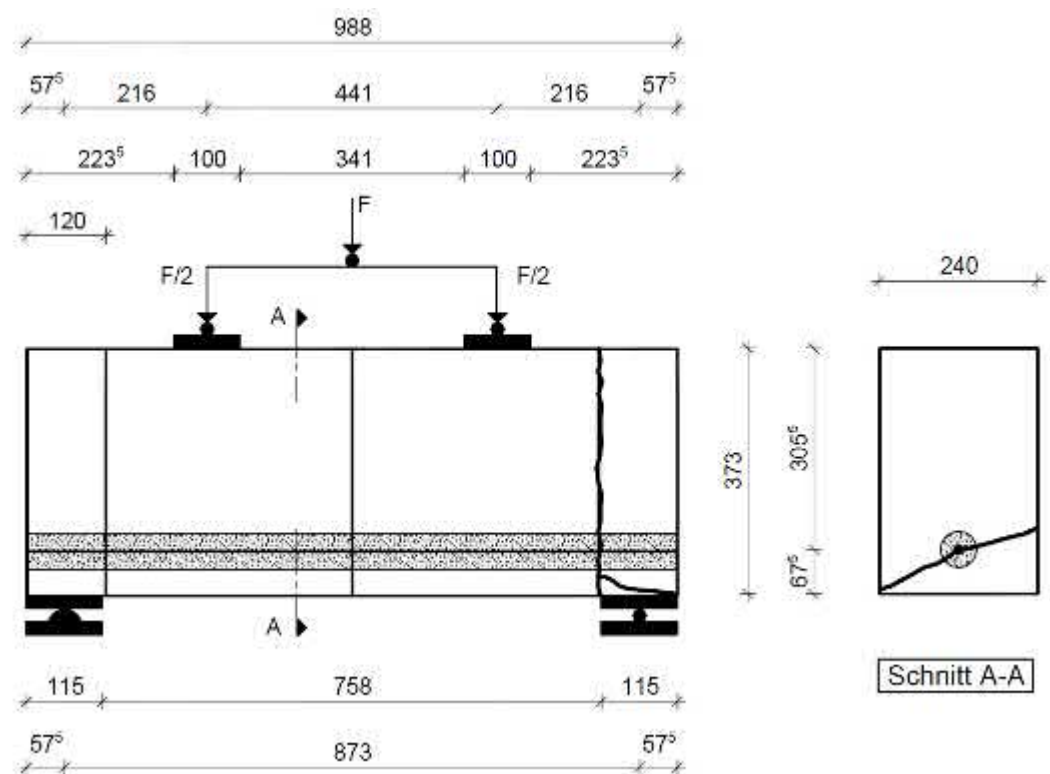

KS-05.1

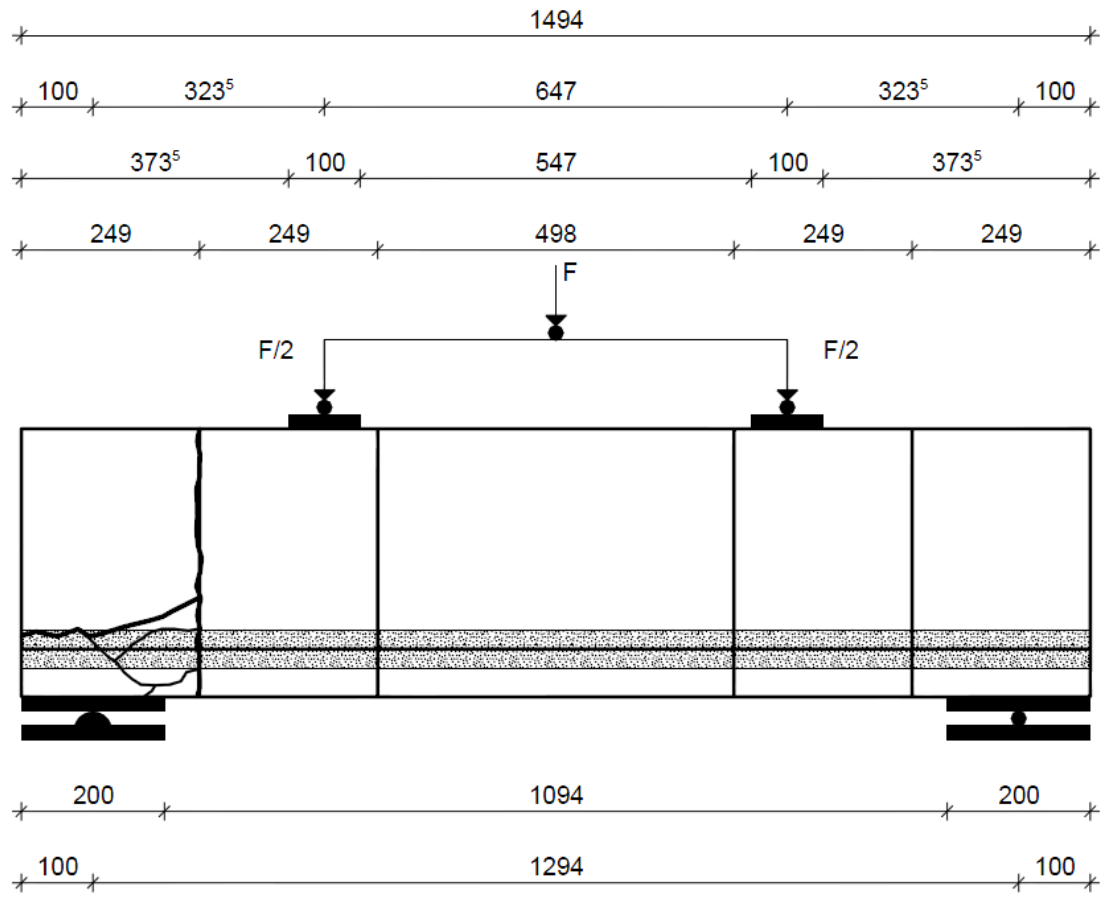


KS-05.2

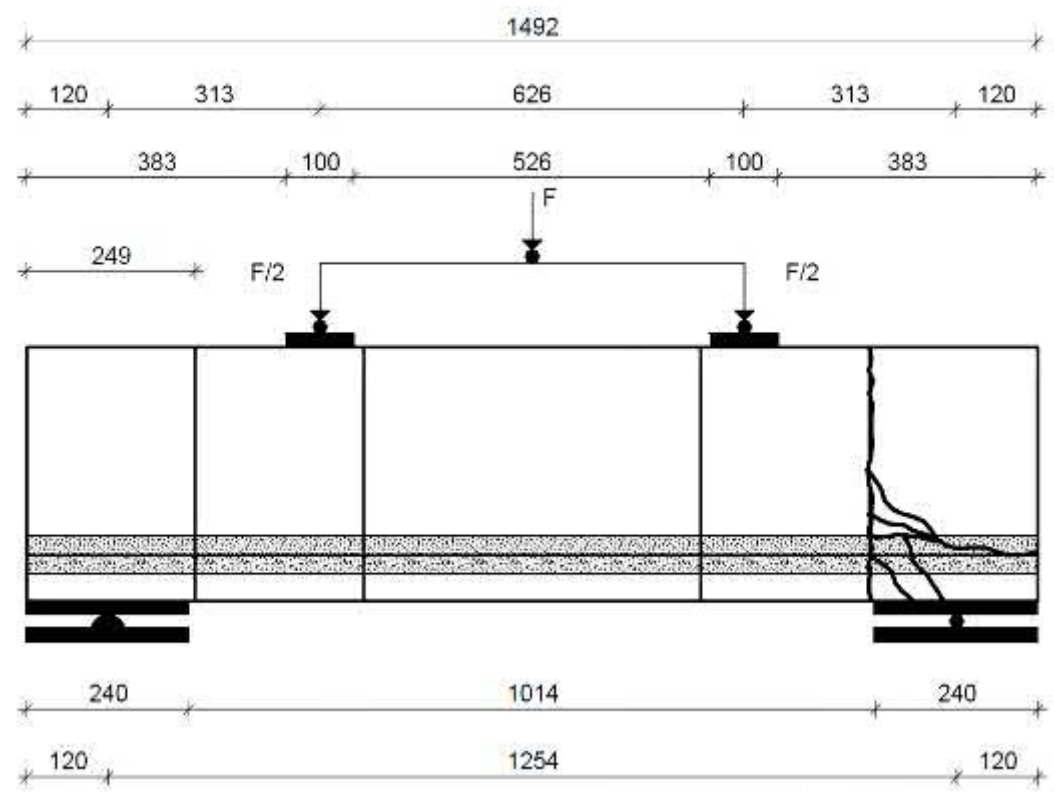

KS-06.1

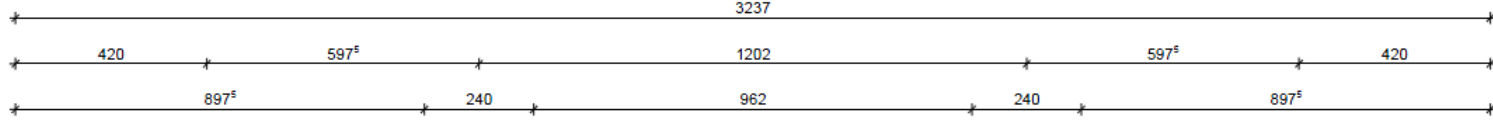

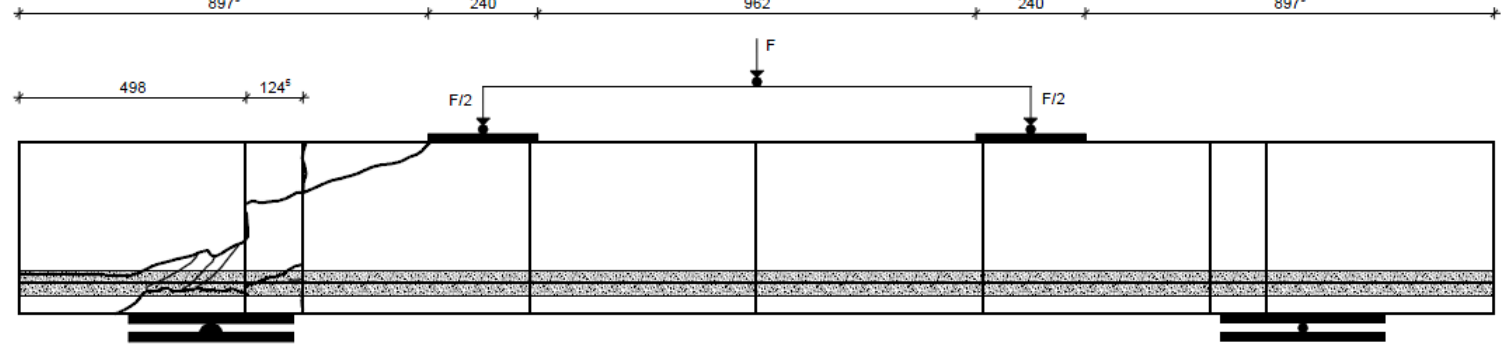

* 240 * $360 \quad 2037$

$360 \ldots 240 *$

KS-07
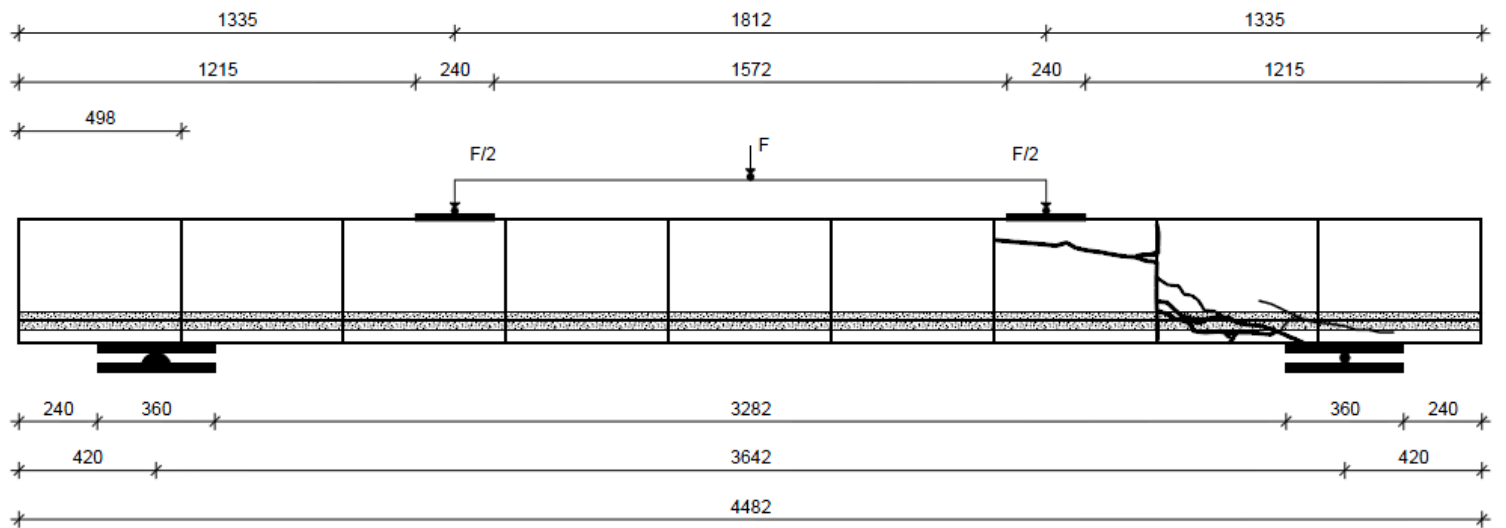

Bild A 4.11

Rissbilder der bewehrten scheitrechten Kalksandstein-Mauerwerkbalken ohne AufbetonKS-01 bis KS-07 
A 4.3.4 Lastdurchbiegungslinien und flächenhafte Darstellung der Verschiebung in horizontaler und vertikaler Richtung

KS-01

Sture 594
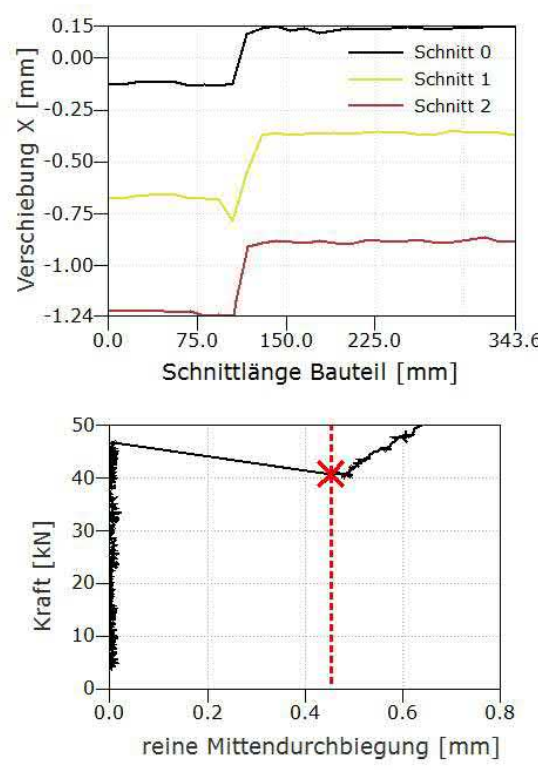

Hochschule Ostwestfalen-Lippe

University of Applied Sciences

\section{Stufe 69!}
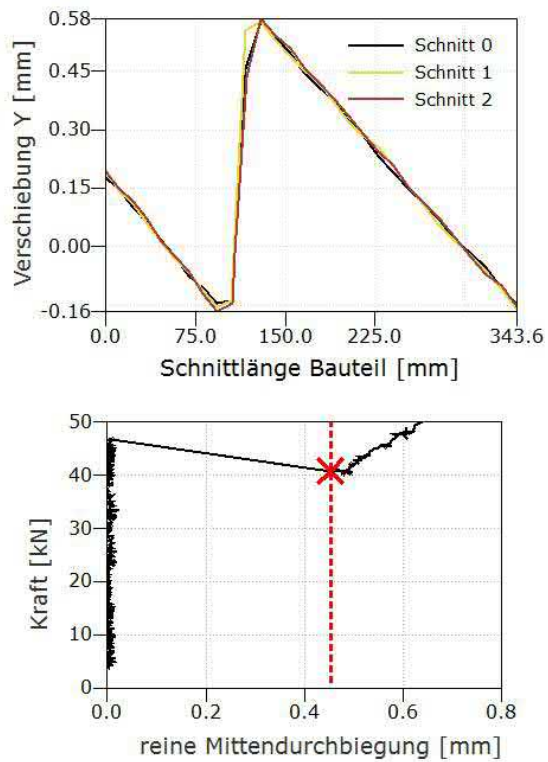

Hochschule Ostwestfalen-Lippe University of Applied Sciences
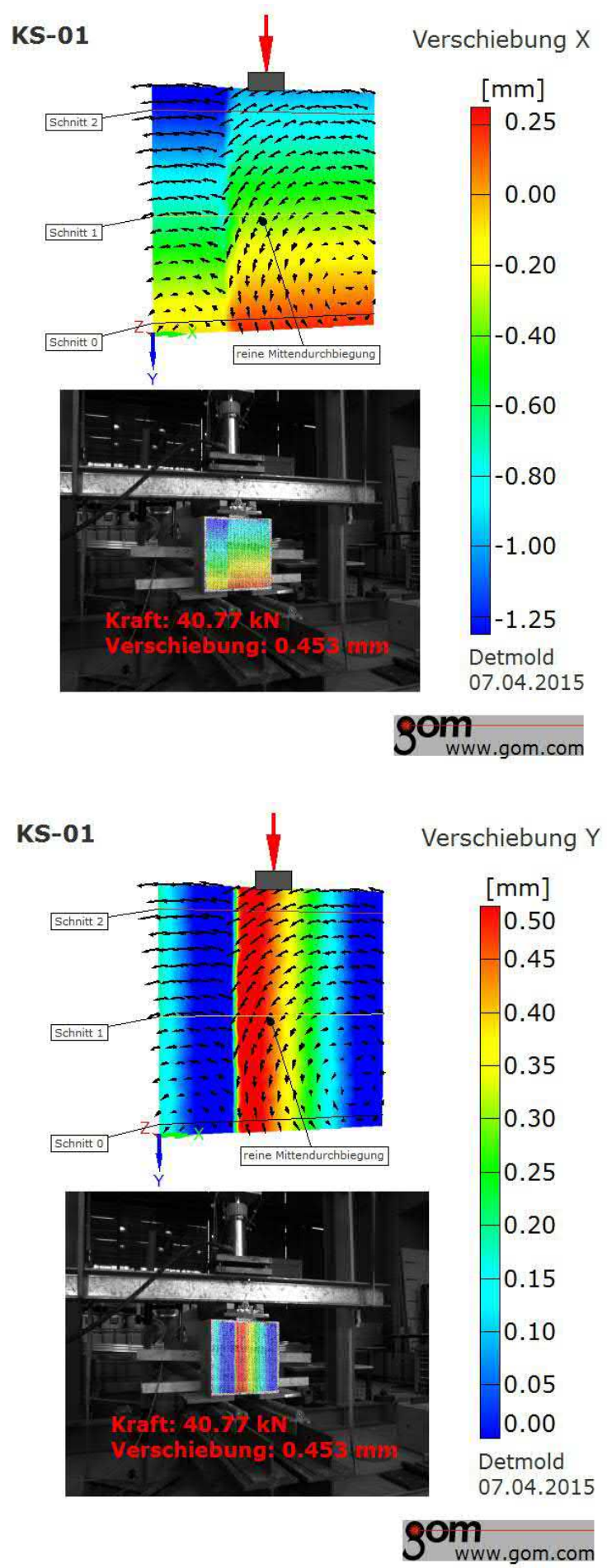
KS-02

Stuif 455
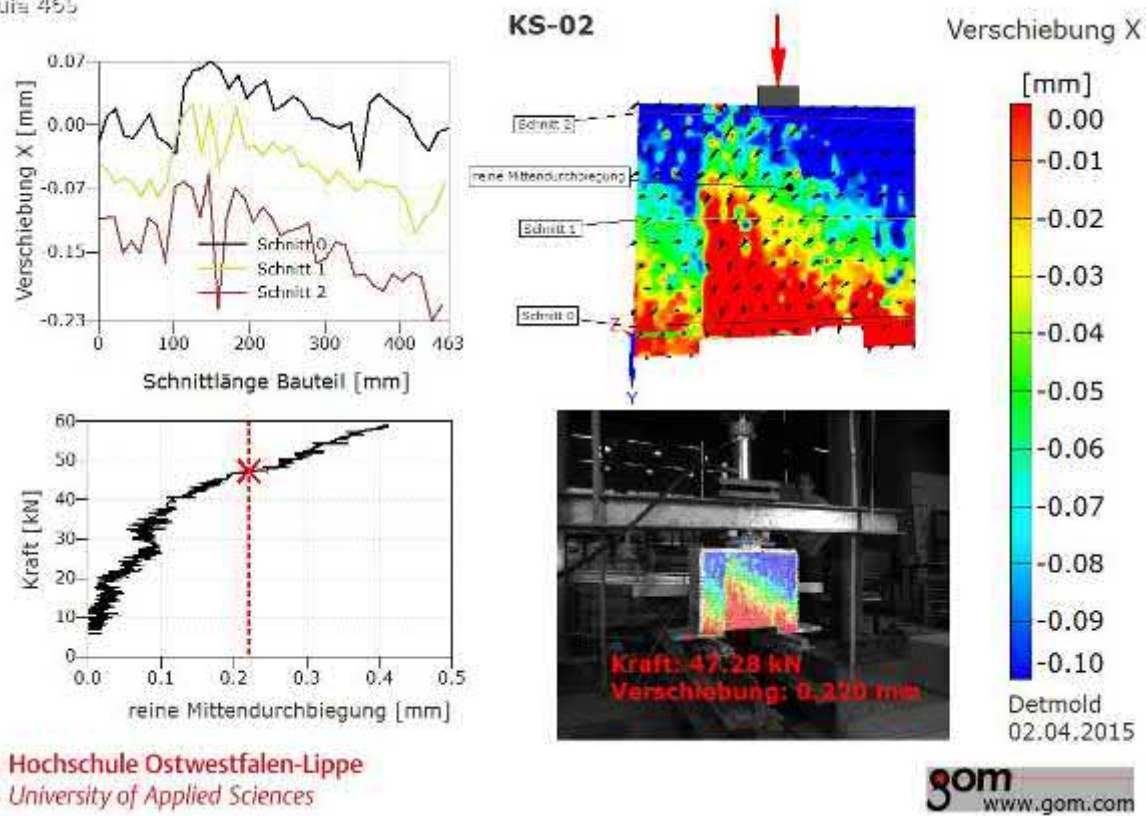

Hochschule Ostwestfalen-Lippe University of Applied Sciences

30m

Gtữ 5.1
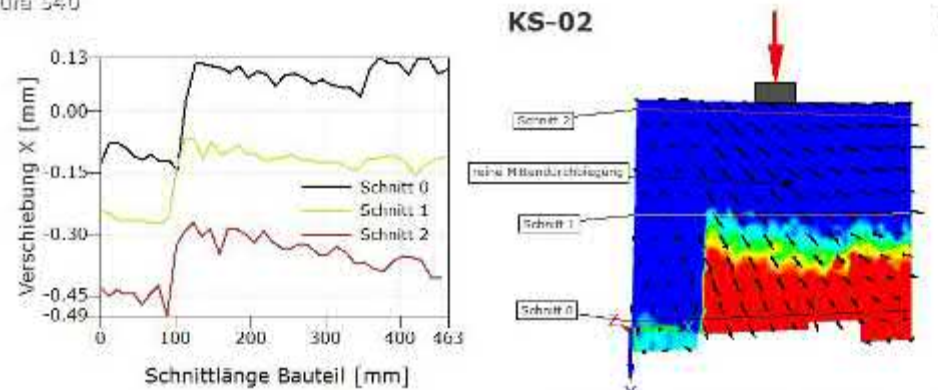

Verschiebung $X$
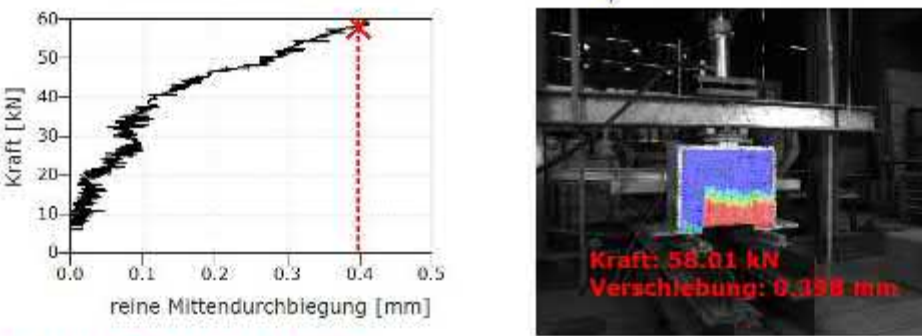

$$
\begin{gathered}
{[\mathrm{mm}]} \\
0.00 \\
-0.01 \\
-0.02 \\
-0.03 \\
-0.04 \\
-0.05 \\
-0.06 \\
-0.07 \\
-0.08 \\
-0.09 \\
-0.10
\end{gathered}
$$

Detmold

02.04 .2015

Hochschule Ostwestfalen-Lippe

University of Applied Sciences 
Litupis= 4.8:S
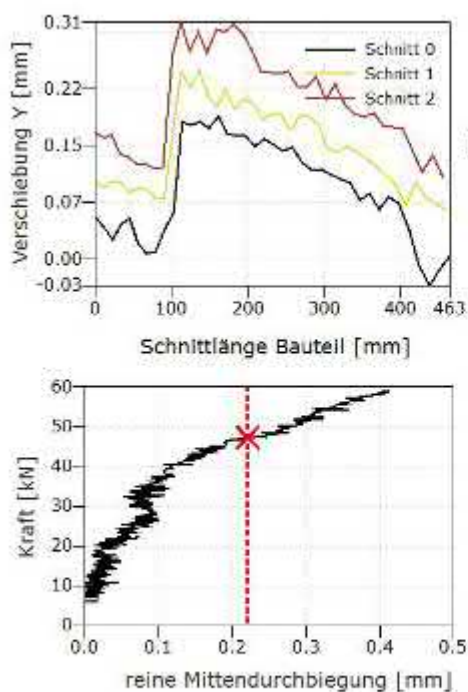

Hochischule Ostwestfalen-Lippe University of Applied Sciences

Stuí: sit!
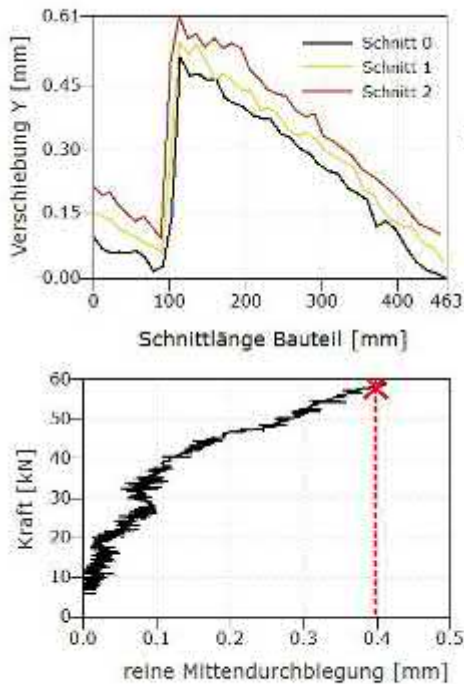

Hochschule Ostwestfalen-Lippe University of Applied Sciences
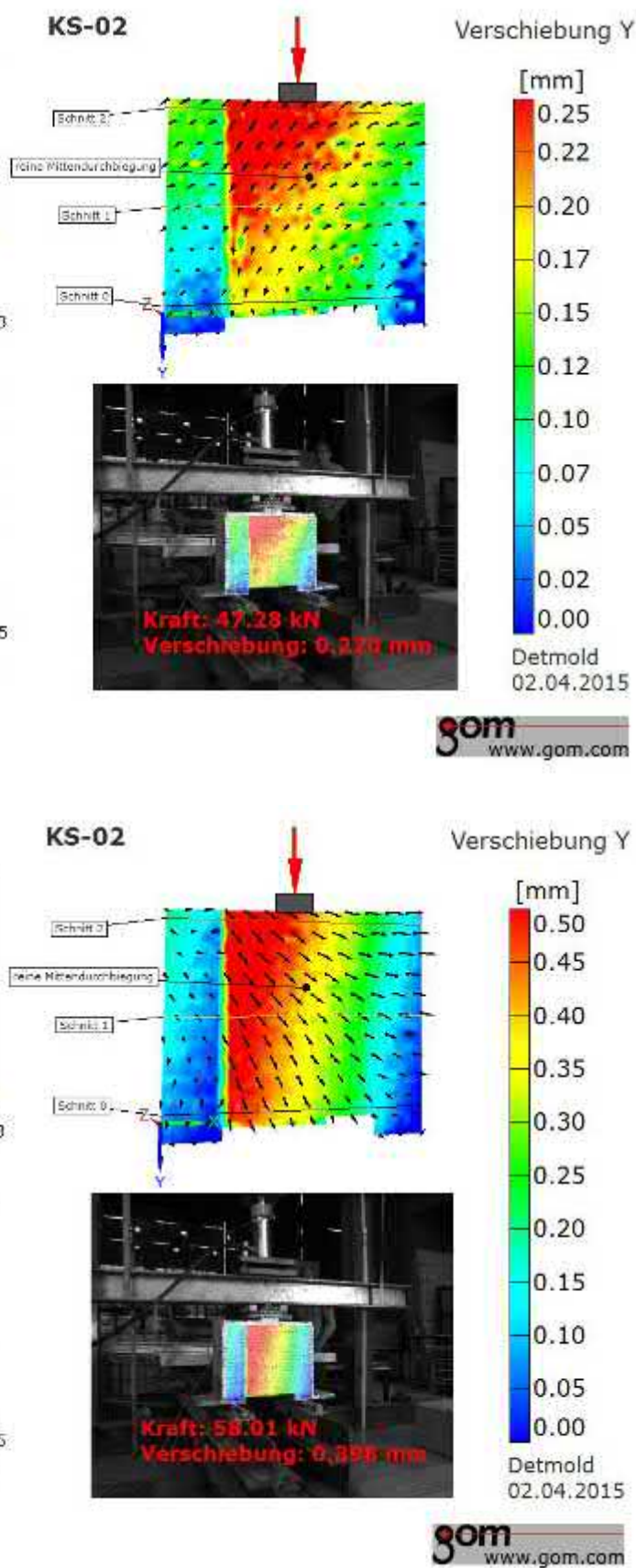


\section{KS-03}

Stute 456
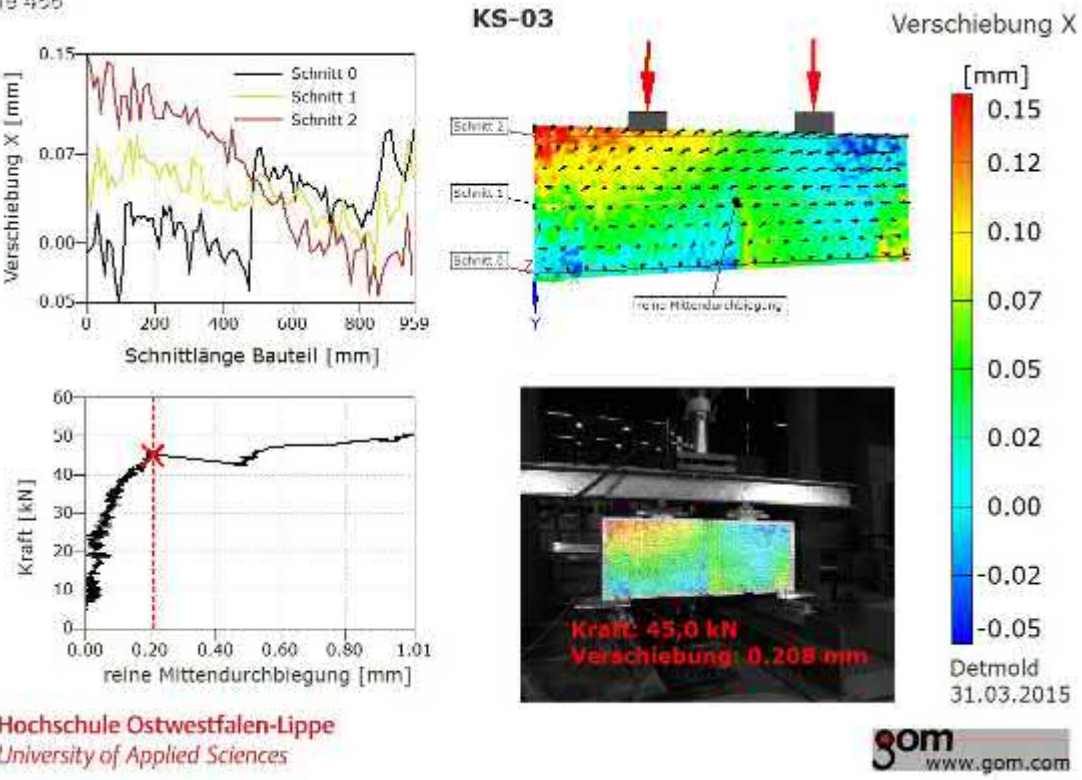

Hochschule Ostwestfalen-Lippe

University of Applied Sciences

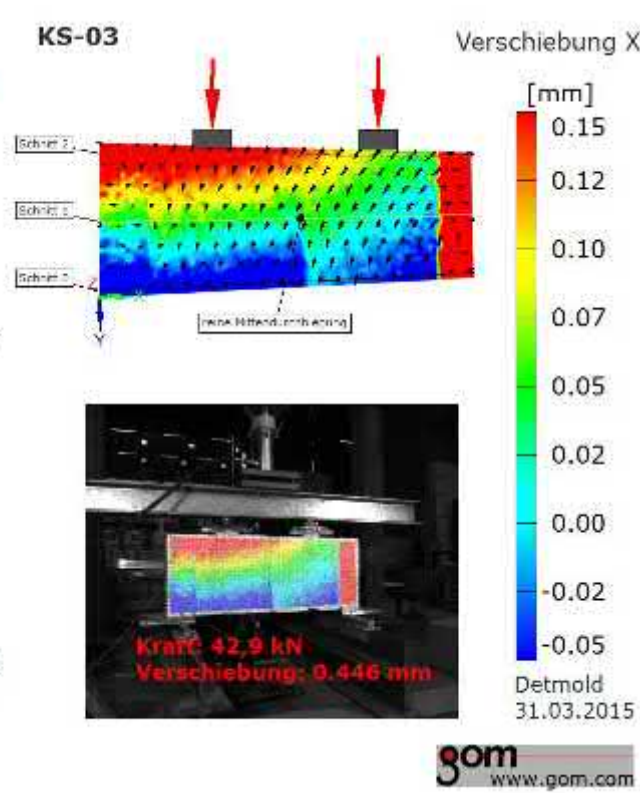

Hochschule Ostwestfalen-Lippe

University of Applied Sciences

jom 


\section{stif. 456}

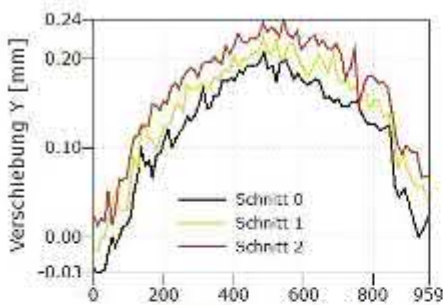

Schnittlănge Bauteil [mm]

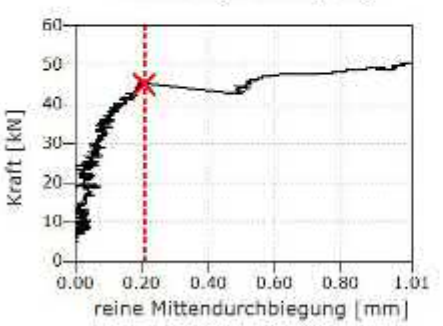

Hochschule Ostwestfalen-Lippe University of Applied Sciences

\section{Sto. $48:$}
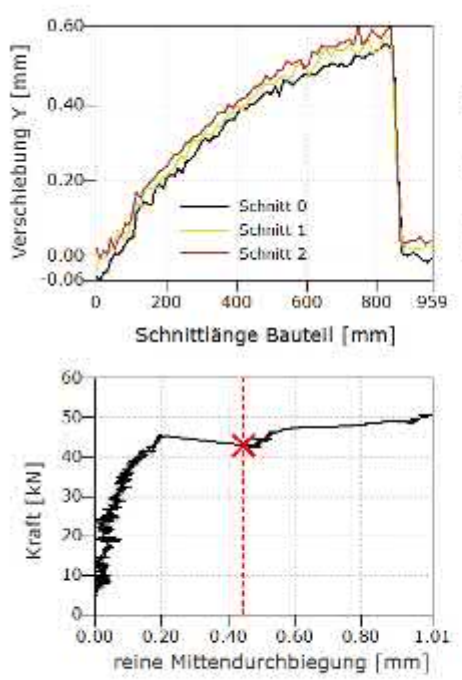

Hochschule Ostwestfalen-Lippe University of Applied Sciences
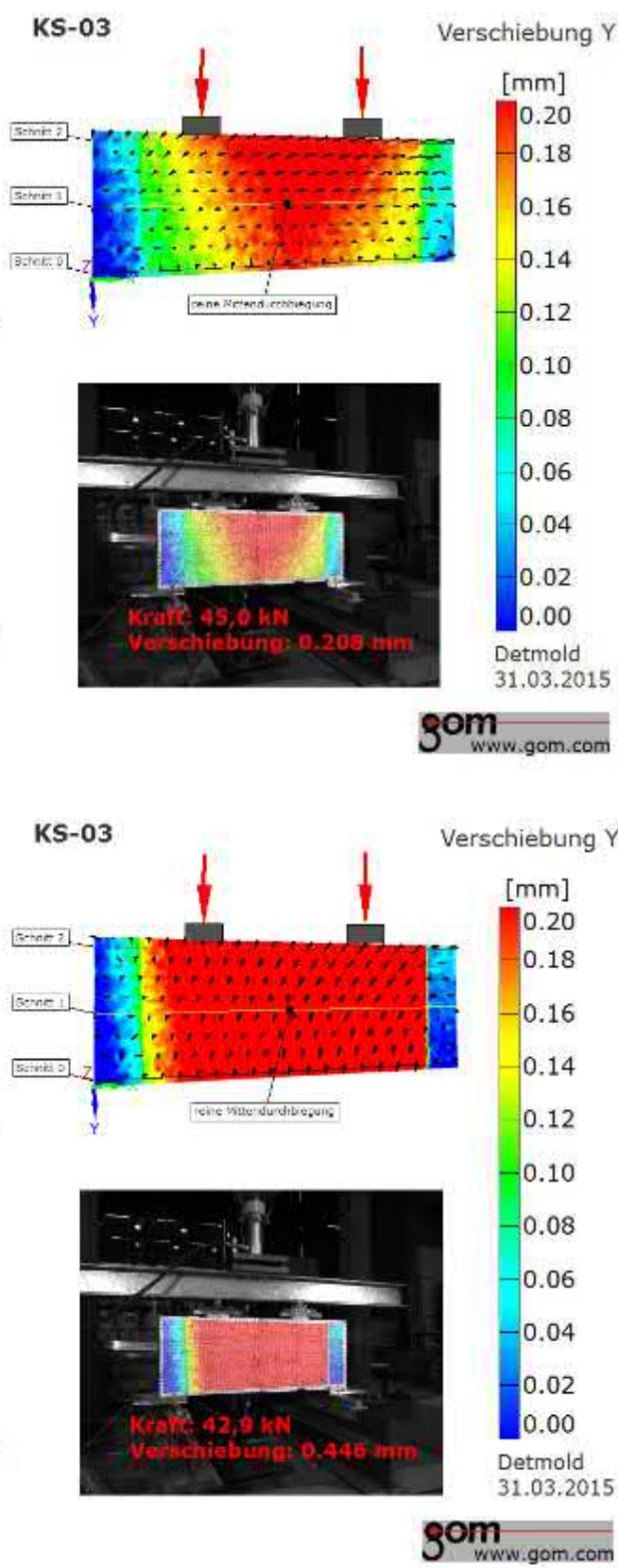
KS-05.1

Stufs 730
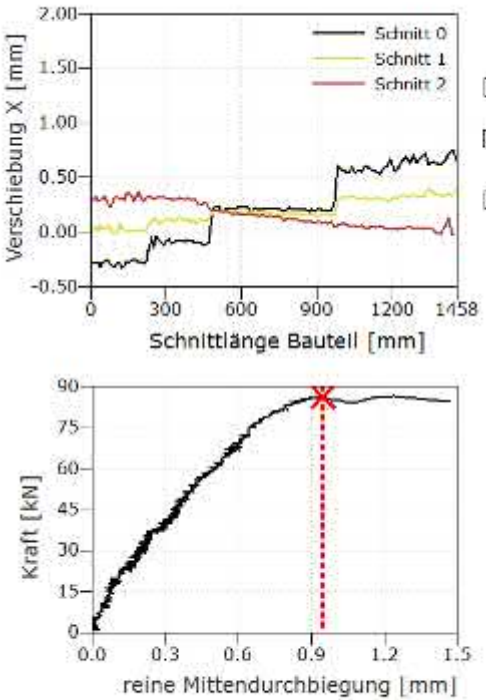

Hochschule Ostwestfalen-Lippe University of Applied Sciences

उrufs 748
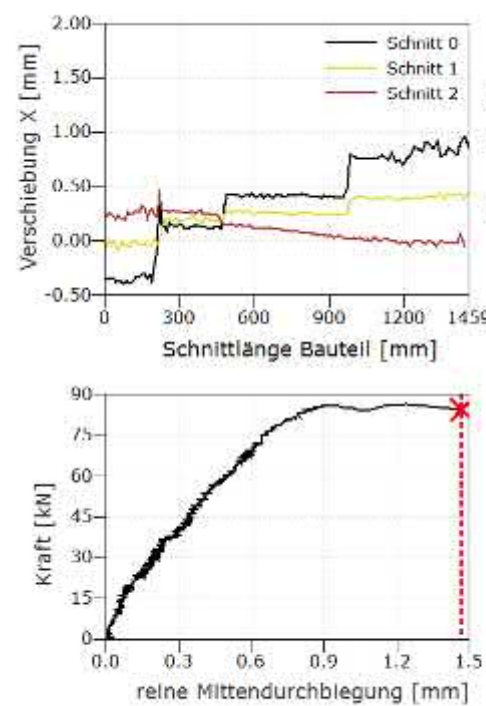

Hochschule Ostwestfalen-Lippe University of Applied Sciences
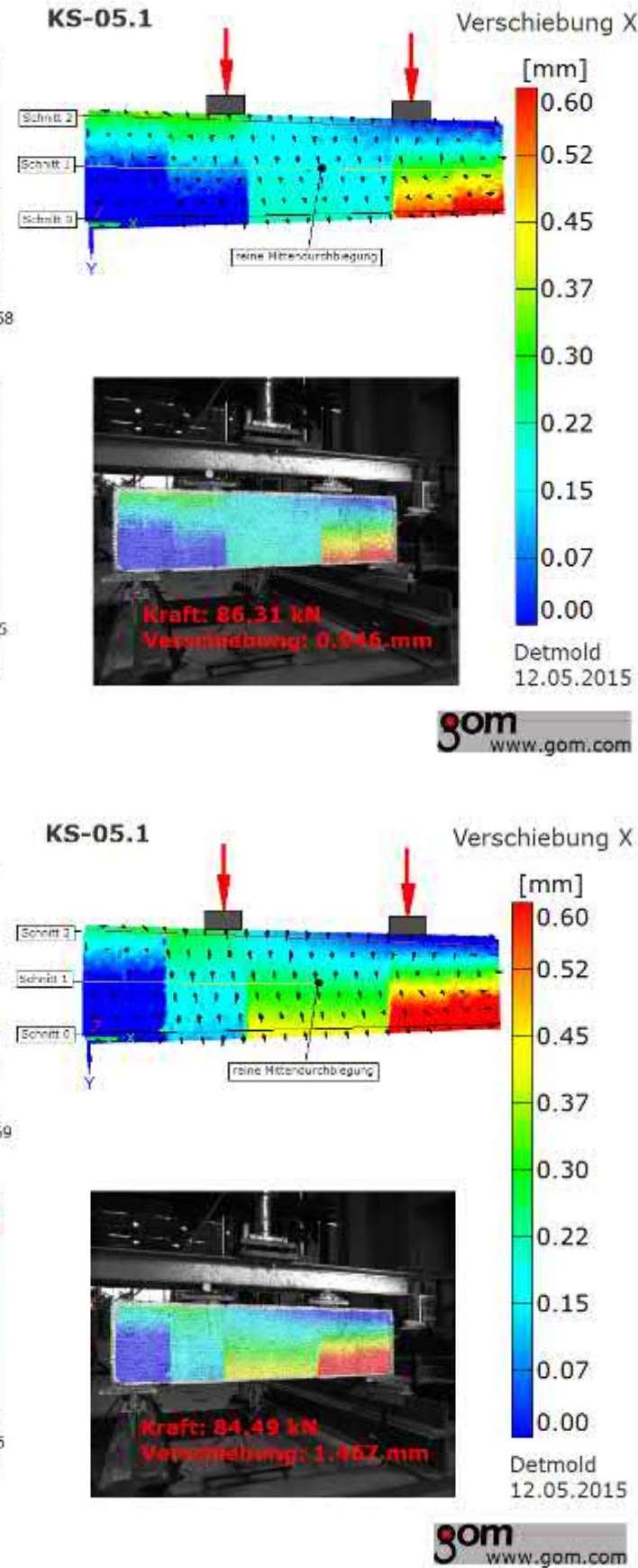
Bitus= 730

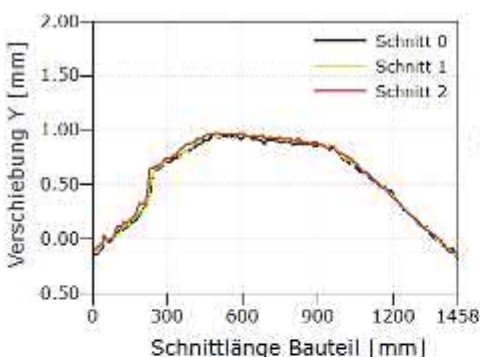

Schnittlänge Bauteil [mm]

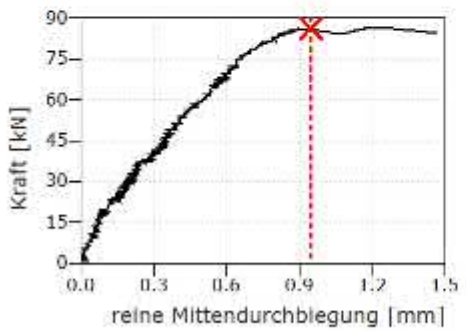

Hochschule Ostwestfalen-Lippe University of Applied Sciences

stup $/ 4.5$
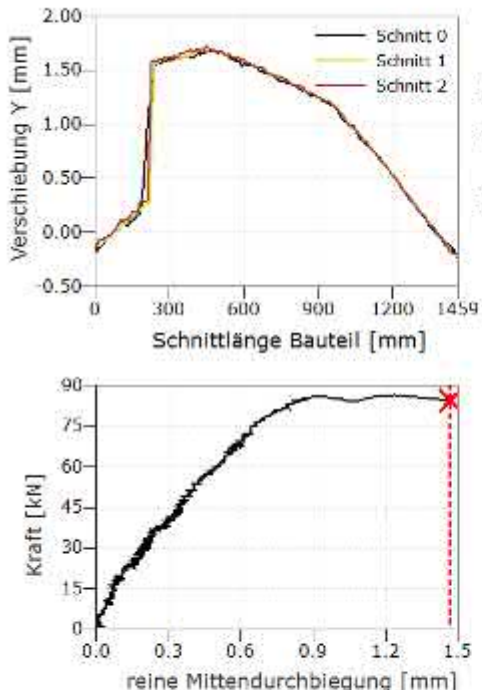

Hochschule Ostwestfalen-Lippe University of Applied Sciences
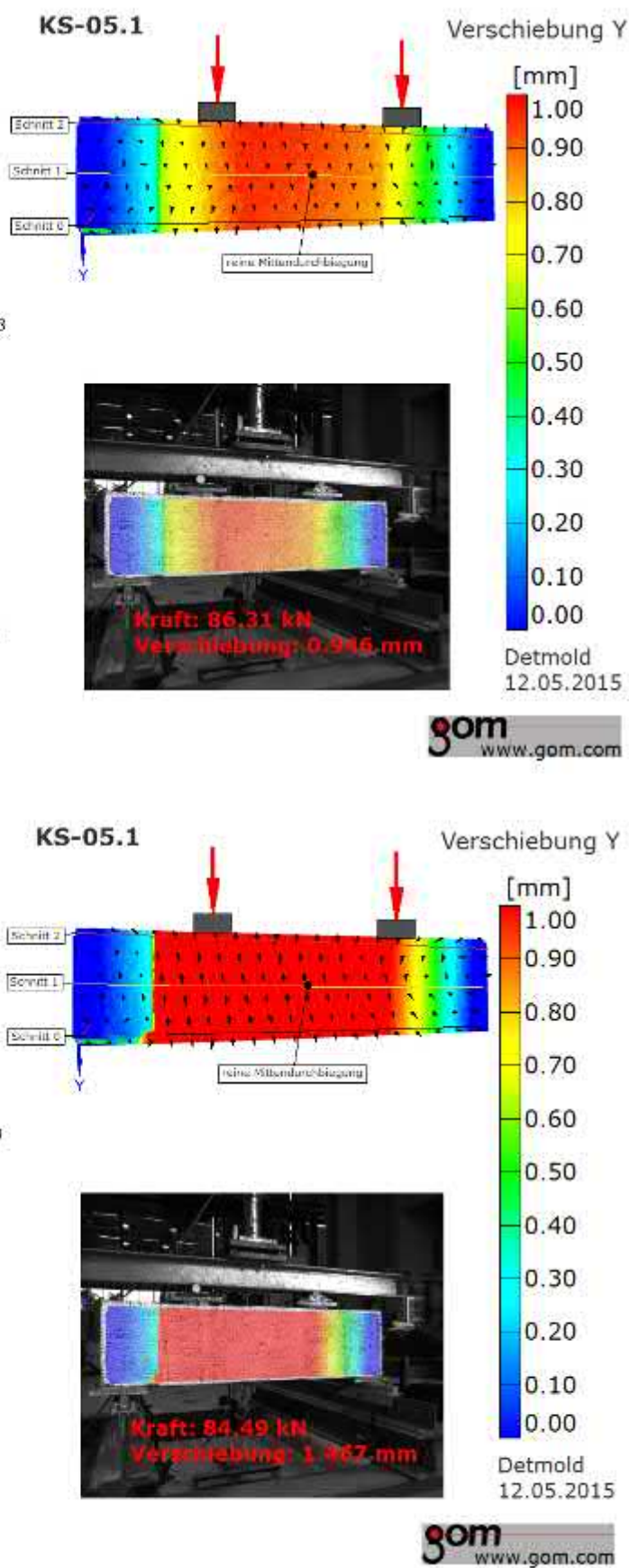


\section{KS-05.2}

Sirif 115
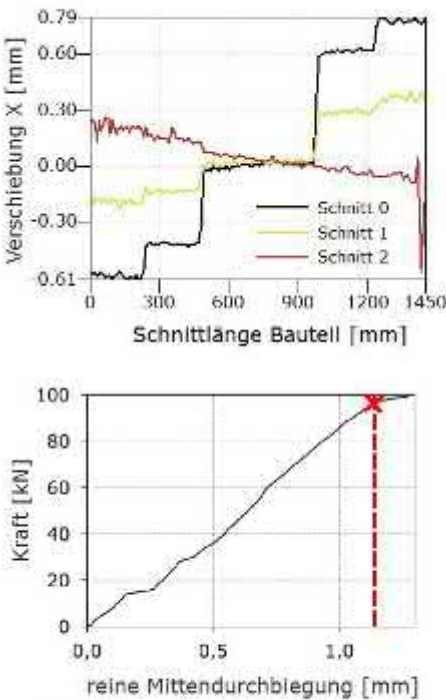

Hochschule Ostwestfalen-Lippe University of Applied Sciences

$5 x+17=185$
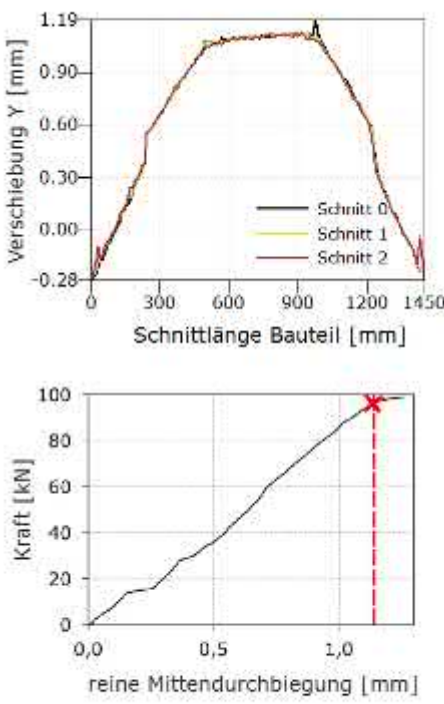

Hochschule Ostwestfalen-Lippe University of Applied Sciences
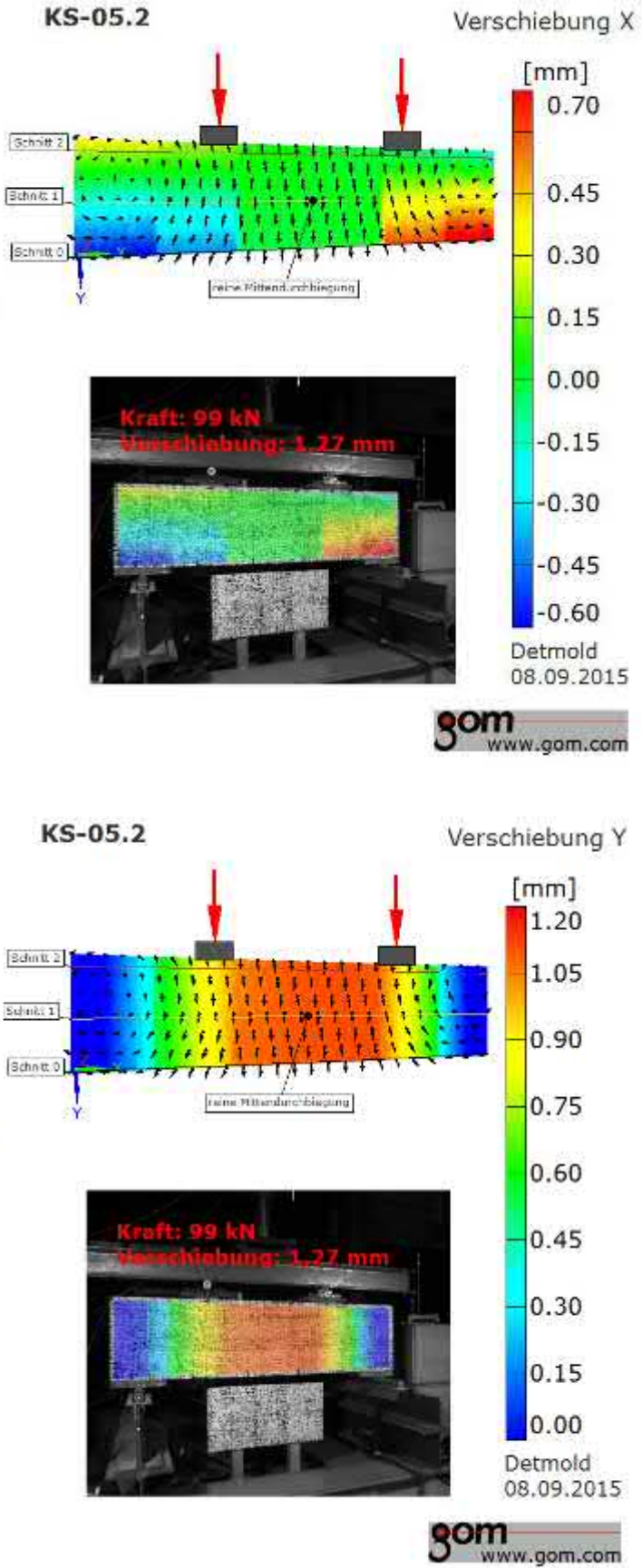
KS-06.1

Stufre 104
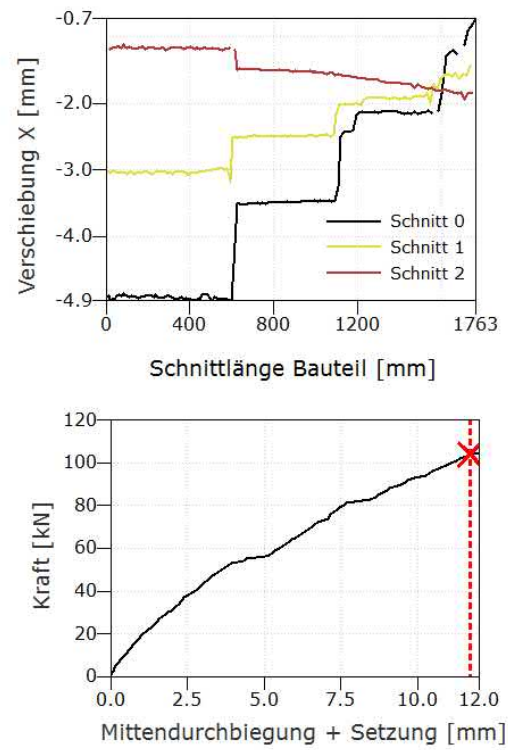

Hochschule Ostwestfalen-Lippe University of Applied Sciences

Stufre 104
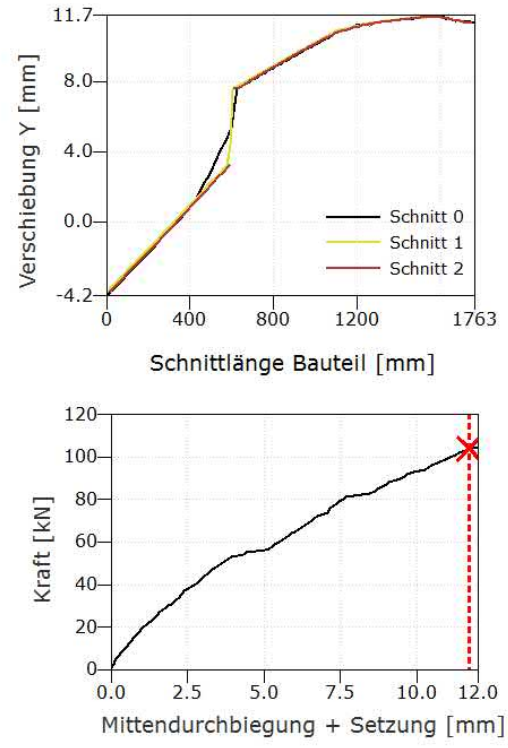

Hochschule Ostwestfalen-Lippe

University of Applied Sciences
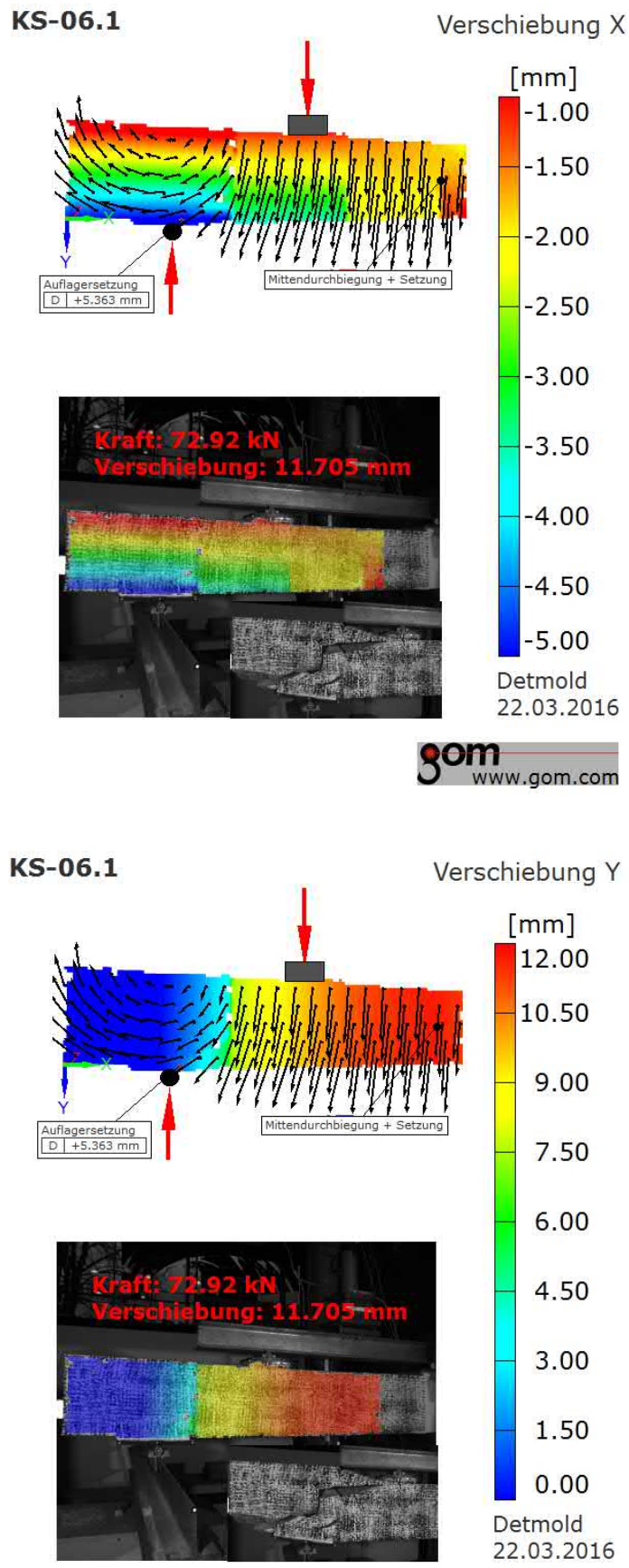

Verschiebung $Y$

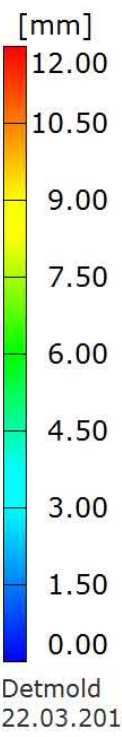

22.03.2016

som 
KS-07

Stuife 33
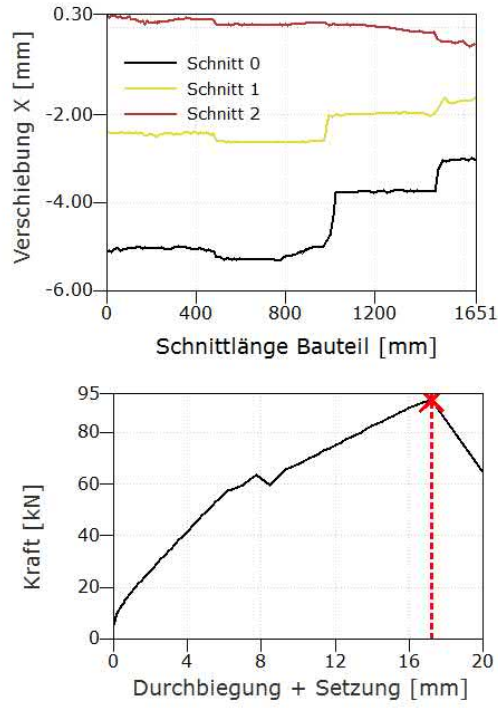

Hochschule Ostwestfalen-Lippe University of Applied Sciences

Sture 33
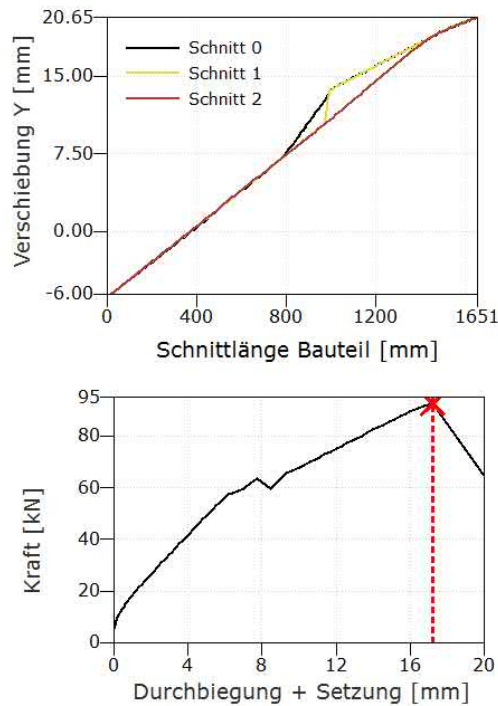

Hochschule Ostwestfalen-Lippe University of Applied Sciences

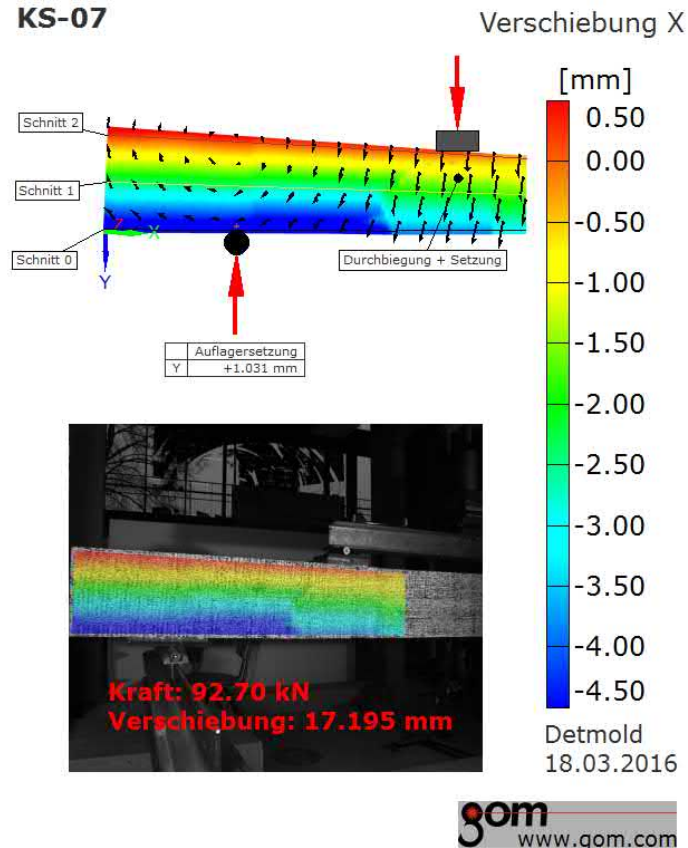

KS-07 Verschiebung $Y$

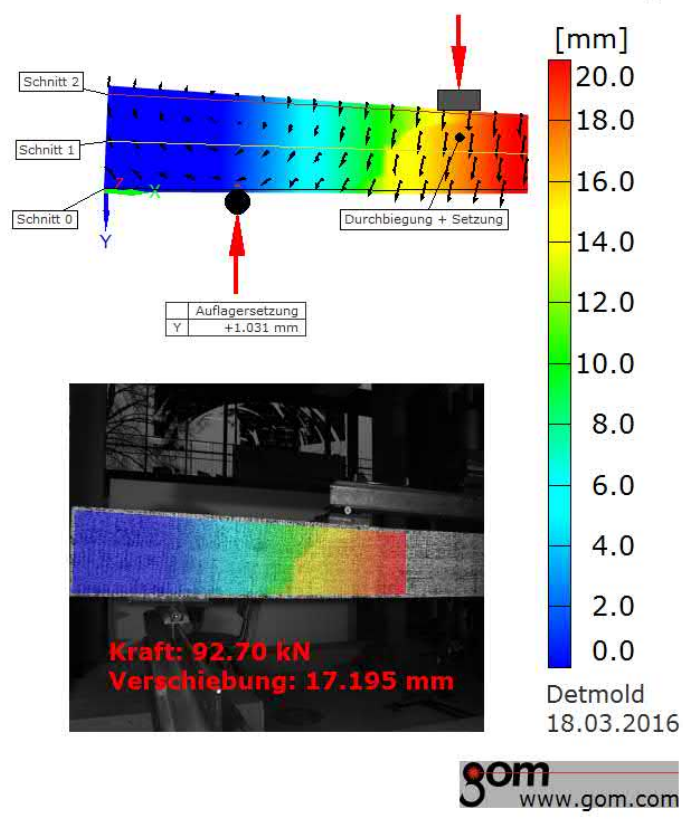

Bild A 4.12 Auswertung der Horizontal- und Vertikalverschiebung der bewehrten scheitrechten Mauerwerkbalken ohne Aufbeton - KS-01 bis KS-07 
A 4.4 Scheitrechte Kalksandsteinbalken mit Ergänzungsschicht aus Beton - IIa

A 4.4.1 Systemskizzen

KS-08.1
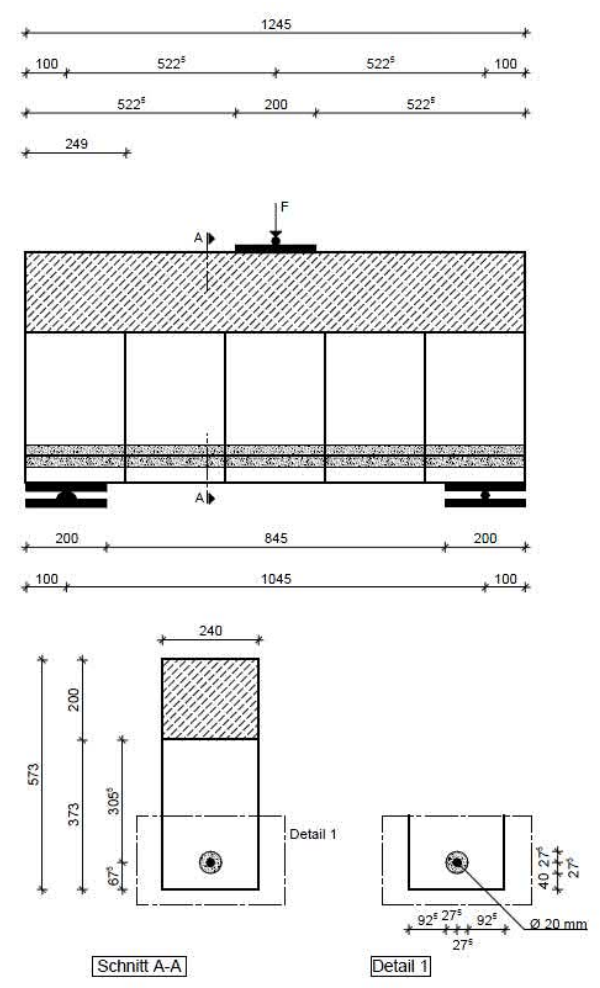

KS-08.2
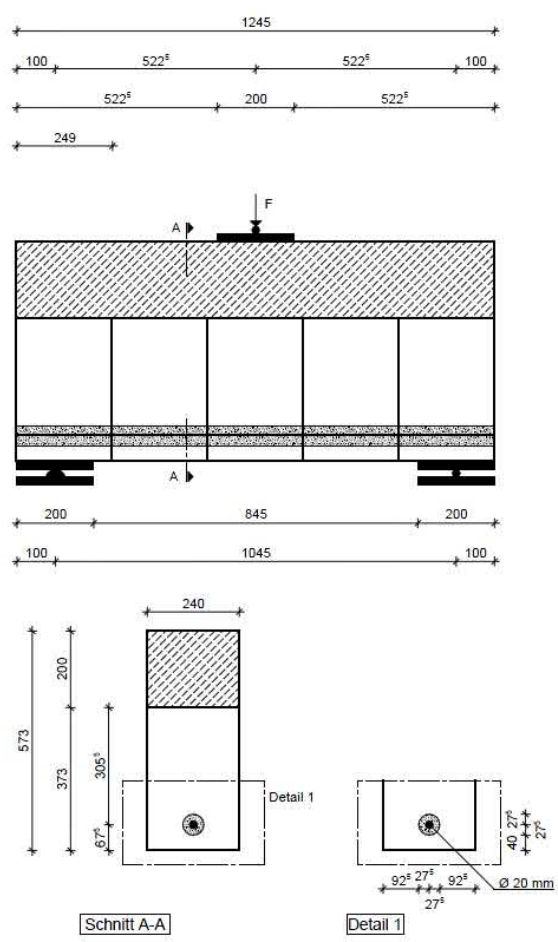
KS-09.1
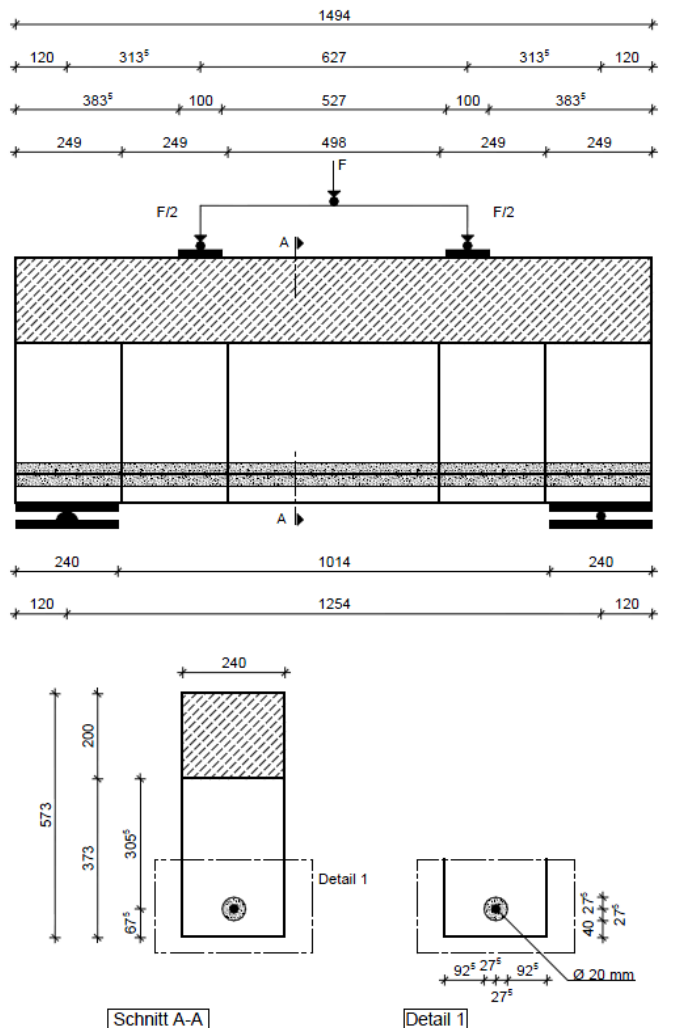

KS-09.2
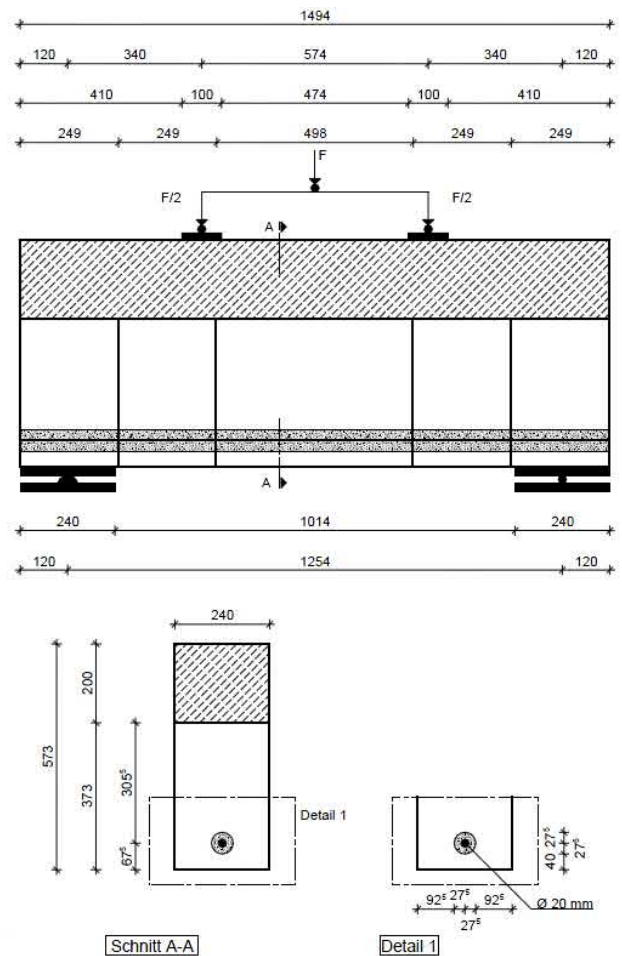

Schnitt A-A Detail 1 
KS-10.1
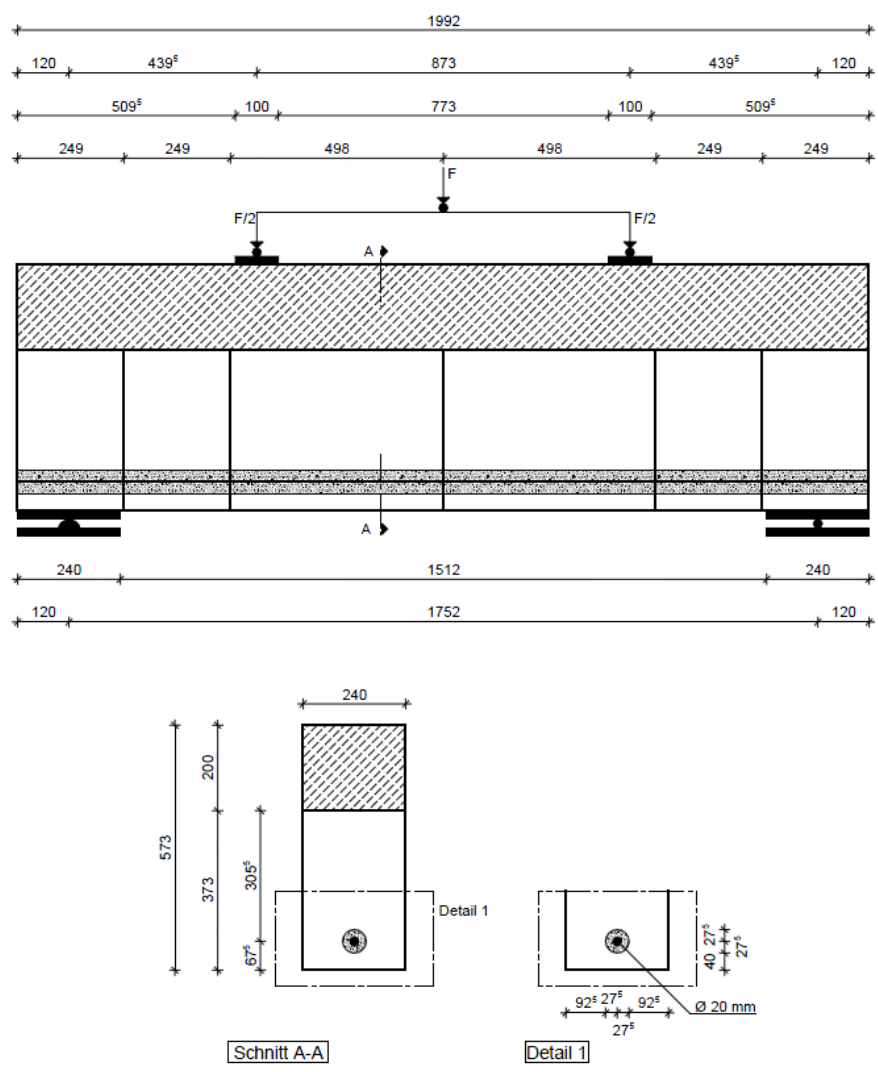

KS-10.2
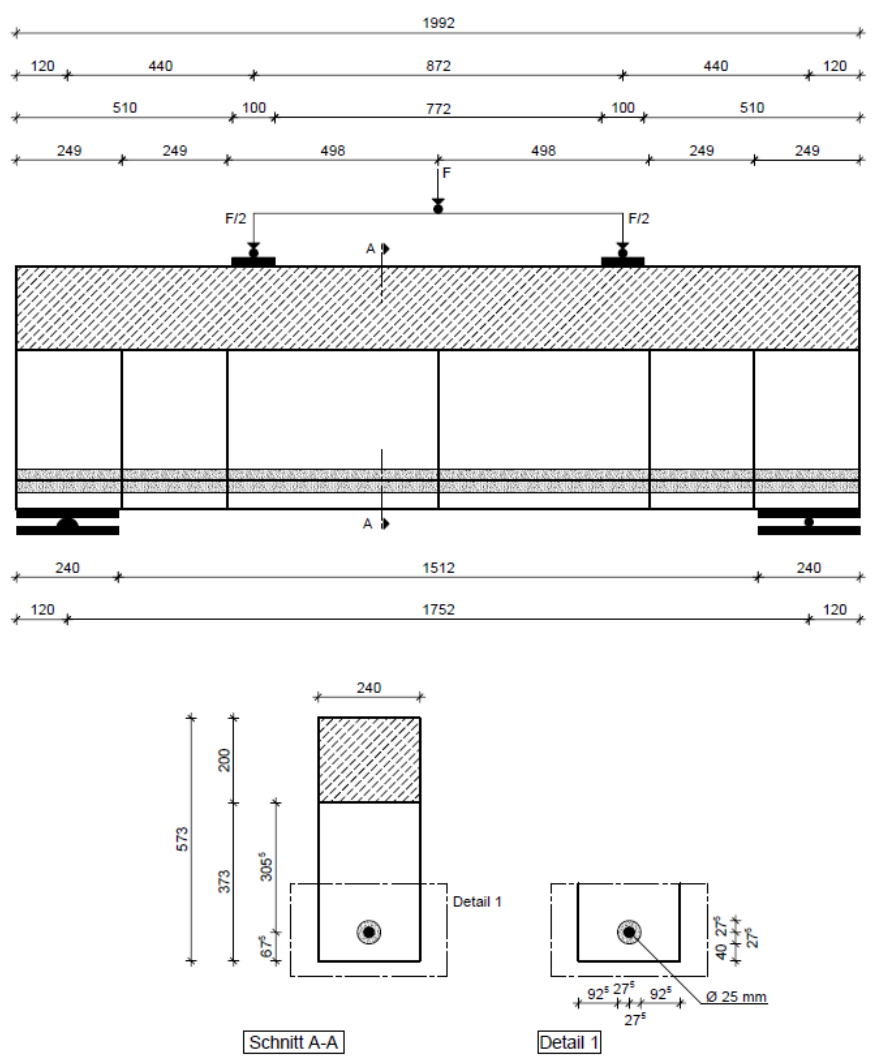
KS-11
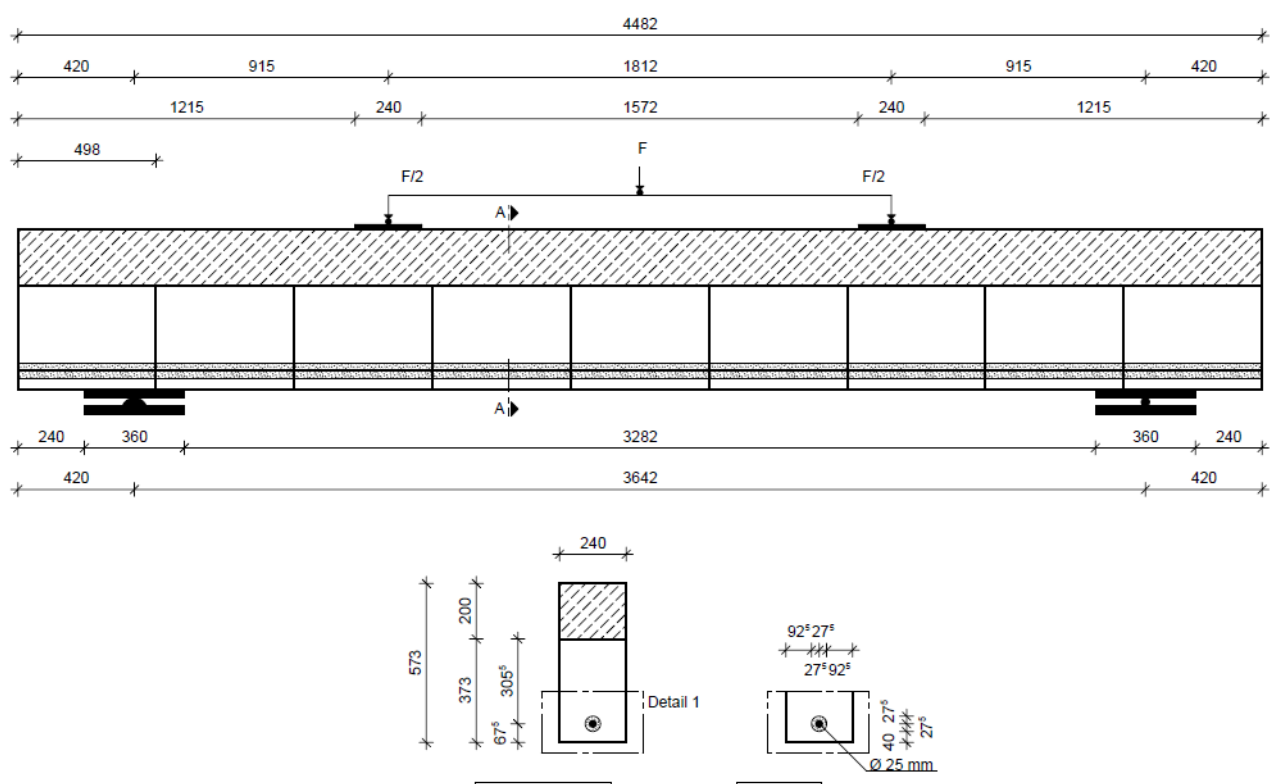

\begin{tabular}{|l|l|}
\hline Schnitt A-A & Detail 1 \\
\hline
\end{tabular}

KS-16 F.1

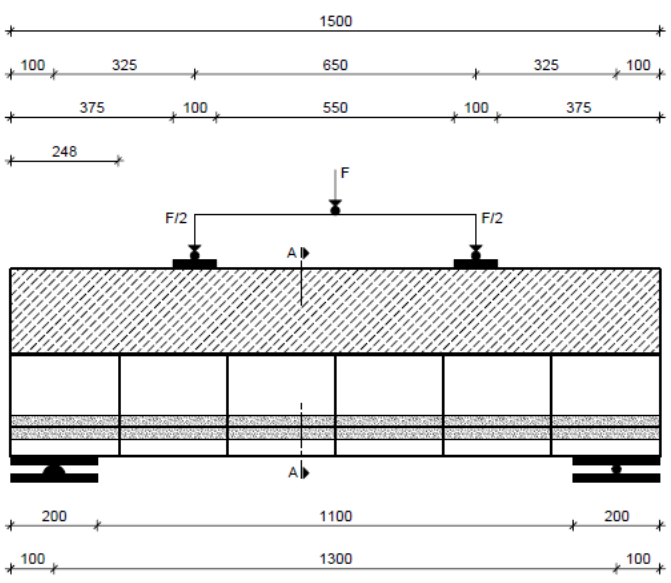

$+\underset{+\infty}{+}+\frac{175}{+}$

Schnitt A-A

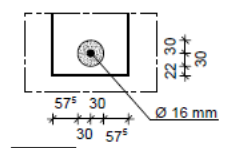

Detail 1 
KS-16 F.2
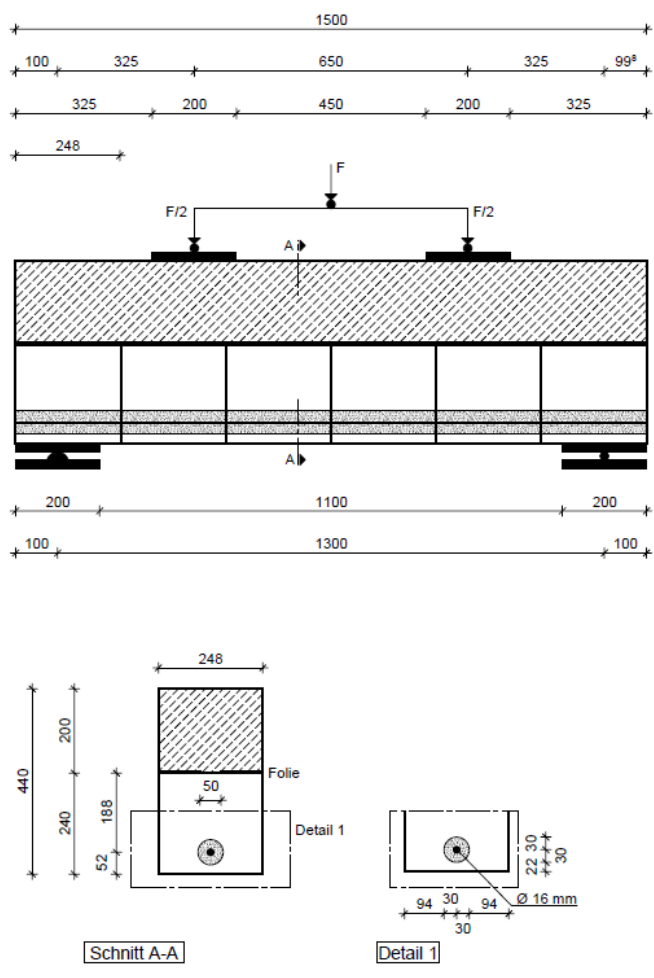

KS-17 F

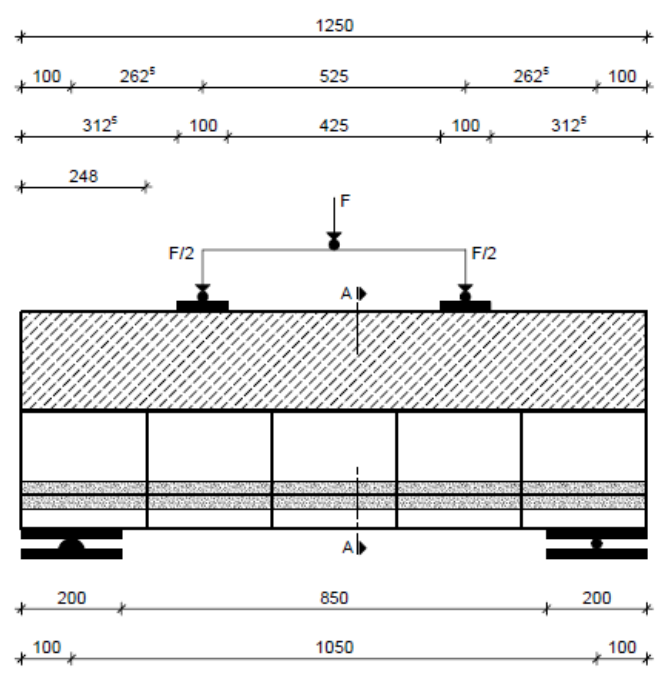

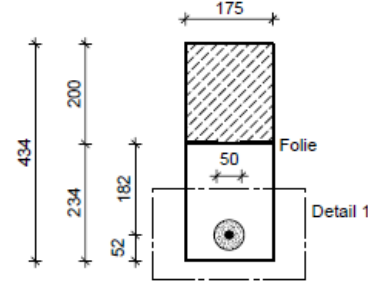

Schnitt A-A

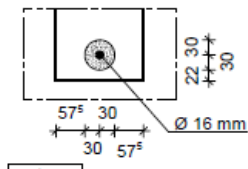

Detail 1

KS-18 F. 1 

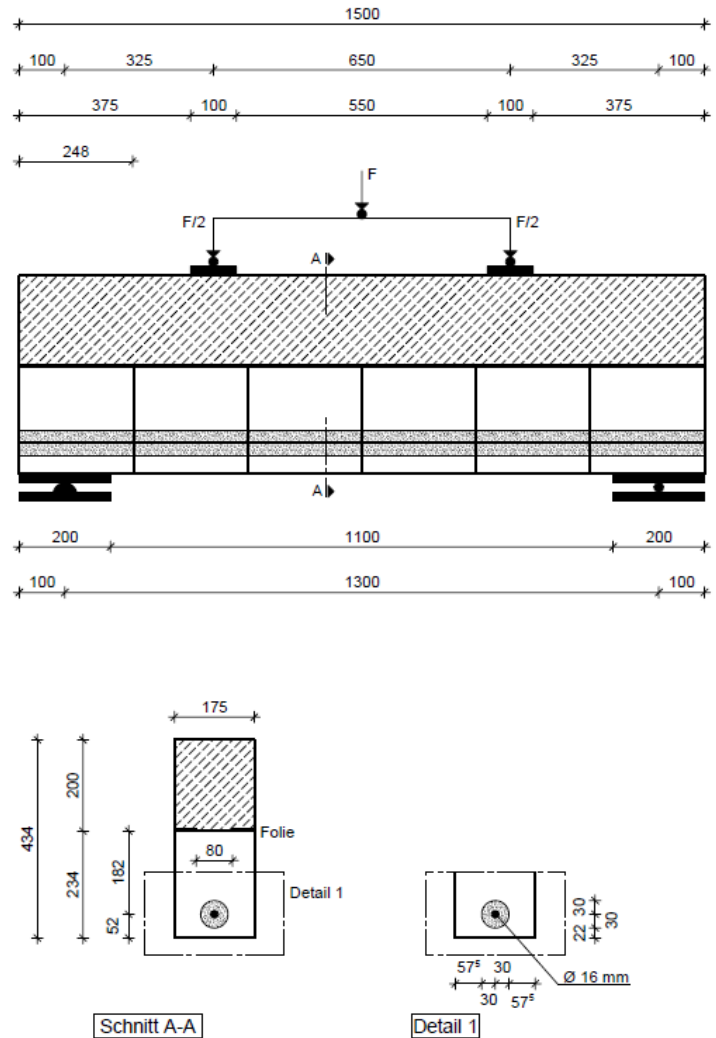

KS-18 F.2
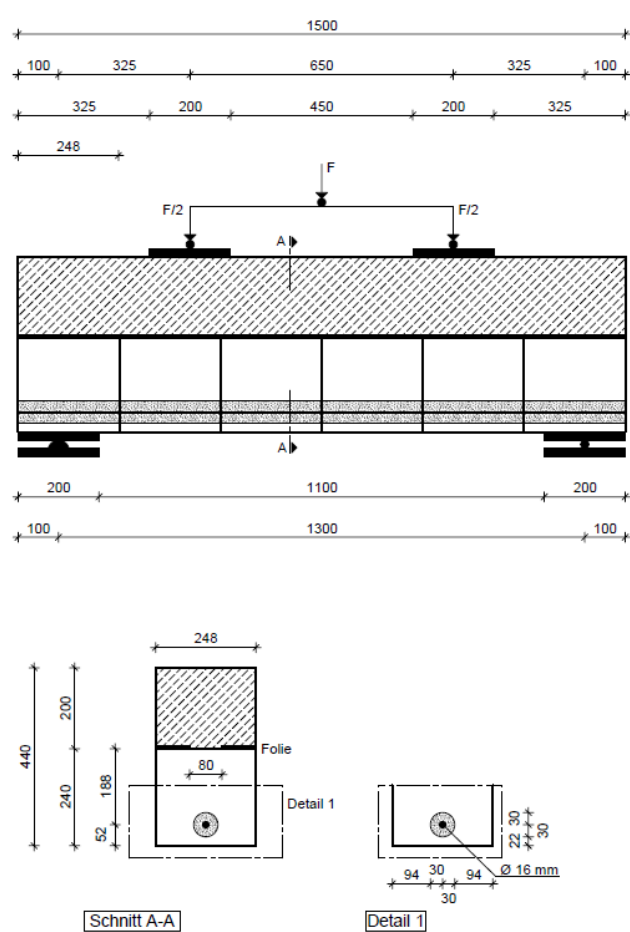

Bild A 4.13 Systemskizzen der bewehrten scheitrechten Kalksandstein-Mauerwerkbalken mit Aufbeton - KS-08.1 bis KS-11 sowie KS-16 F.1 bis KS-18 F.2 


\section{A 4.4.2 Messstellenpläne}

KS-08.1

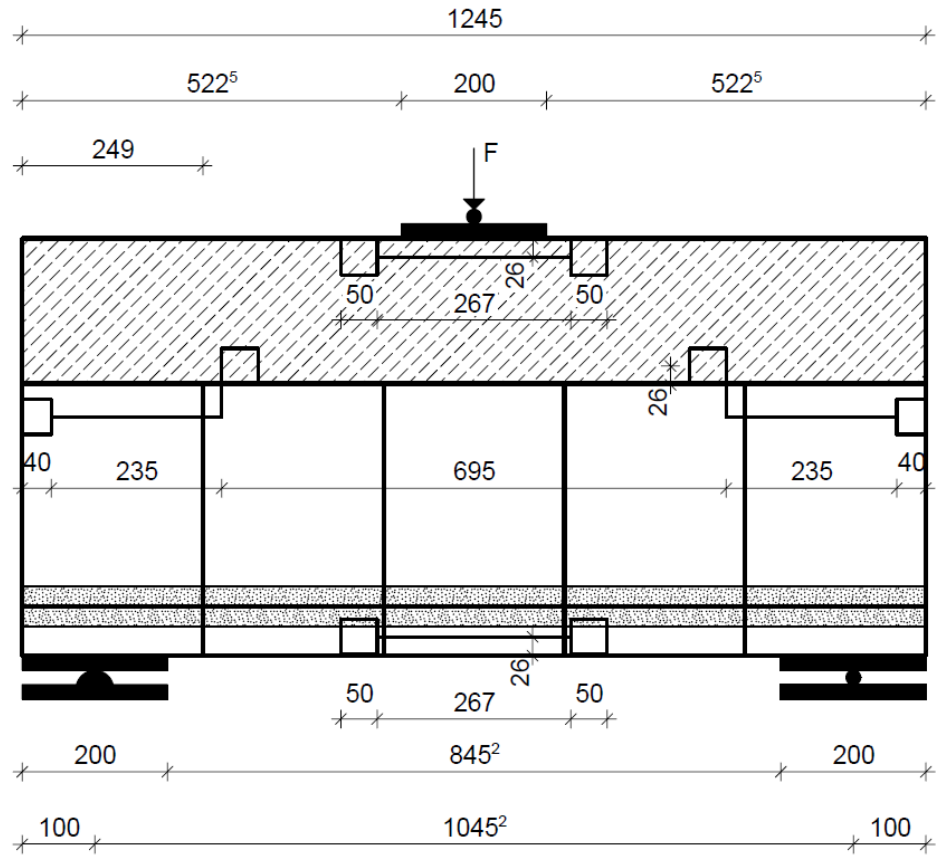

KS-08.2

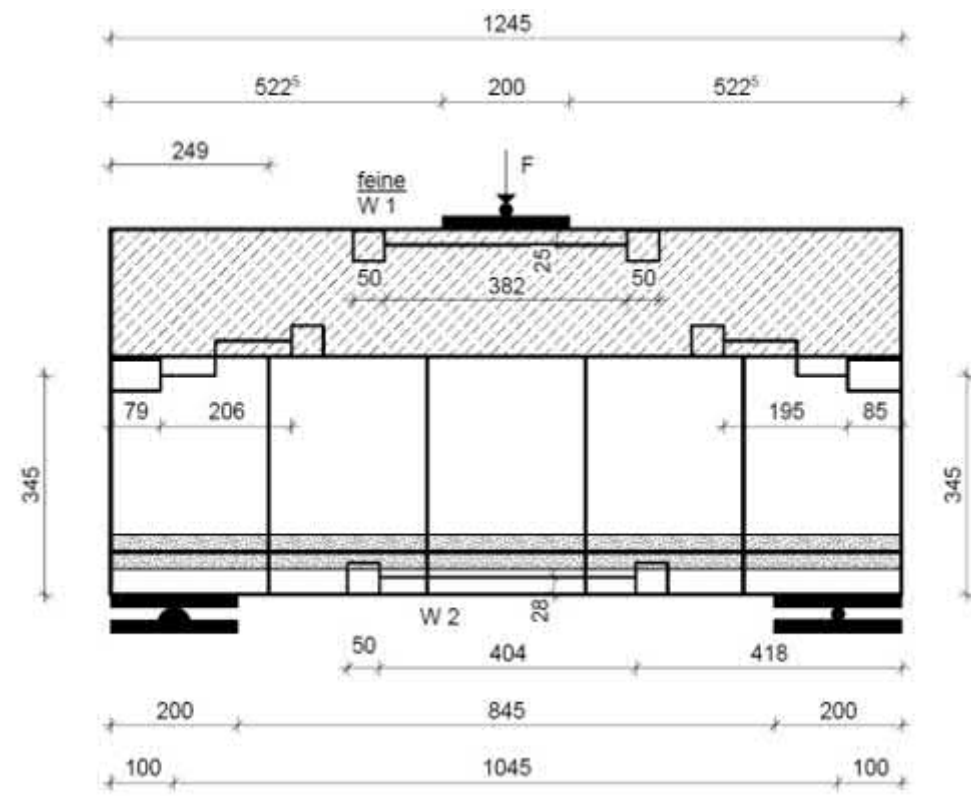


KS-09.1

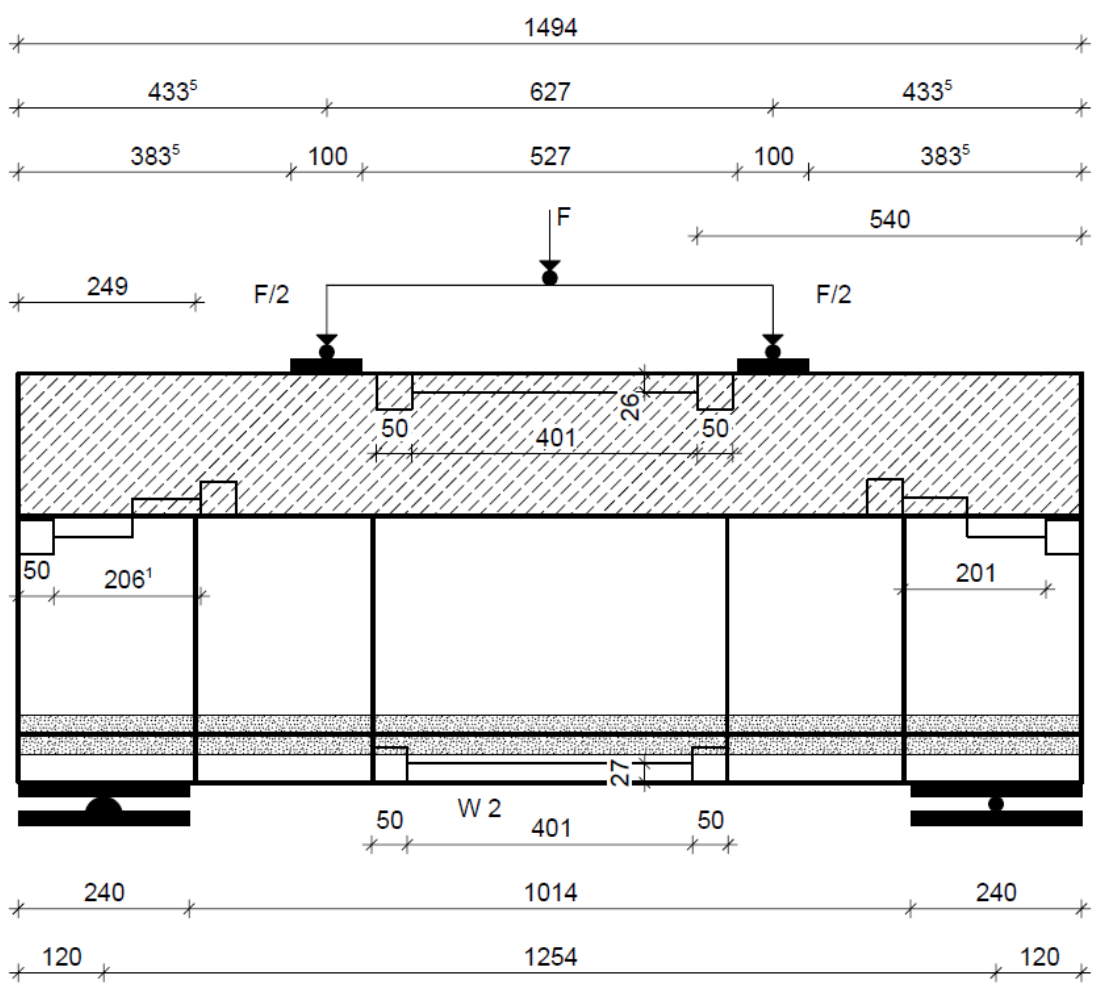

KS-09.2

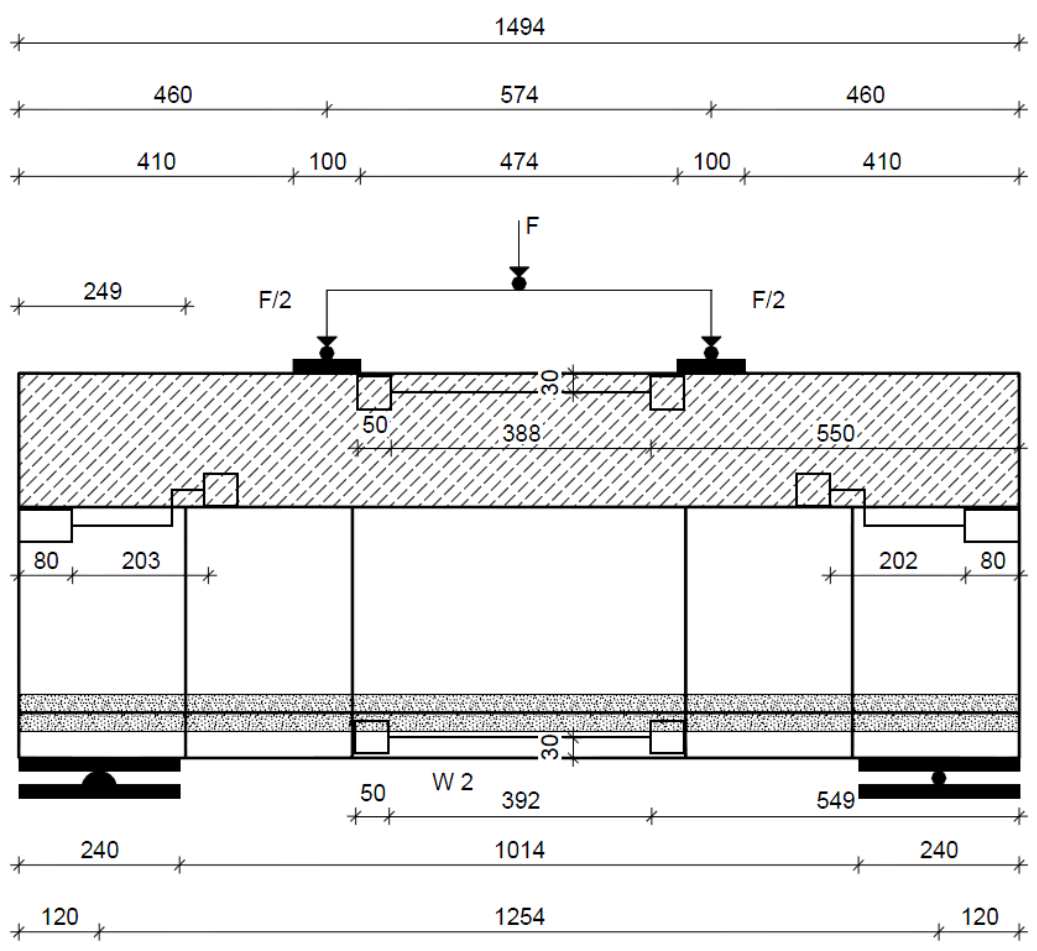


KS-10.1

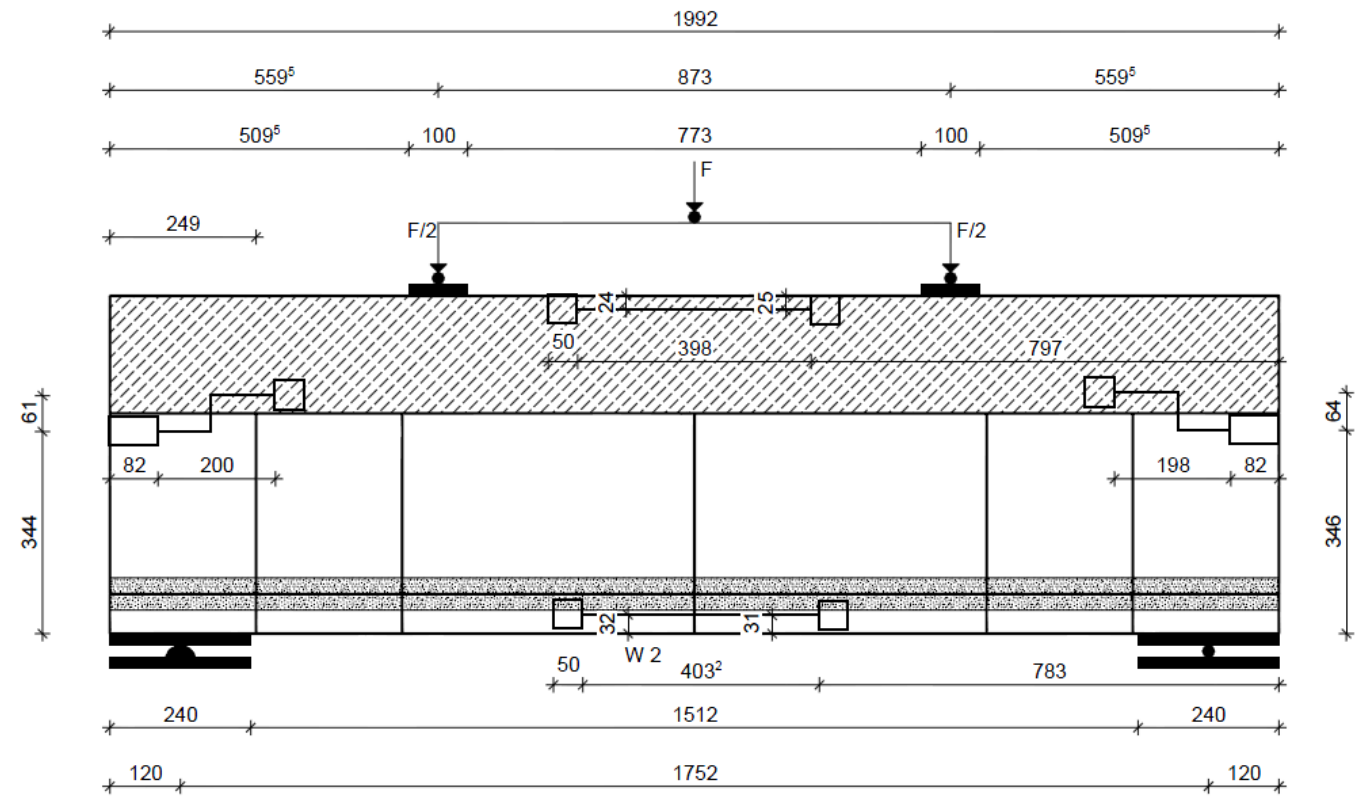

KS-10.2

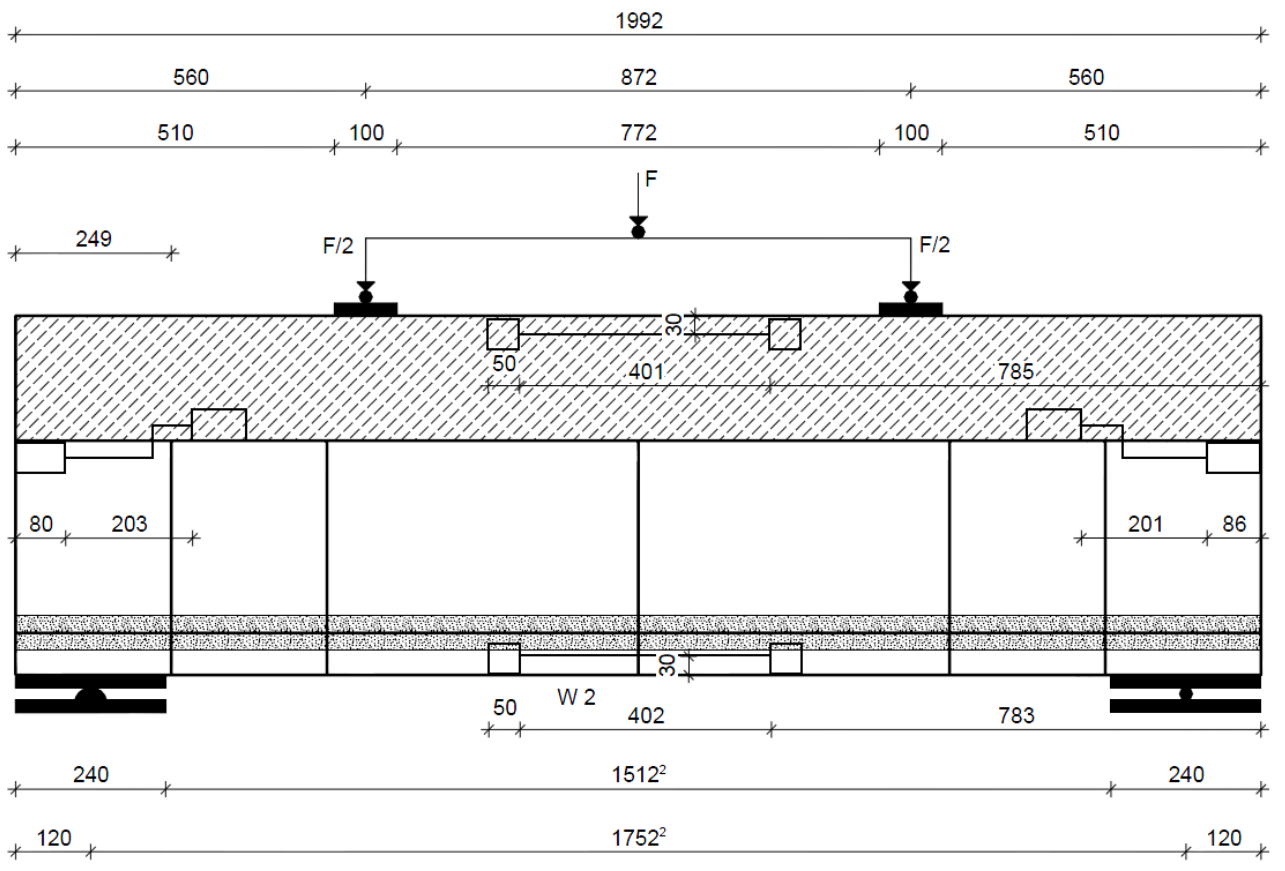


KS-11

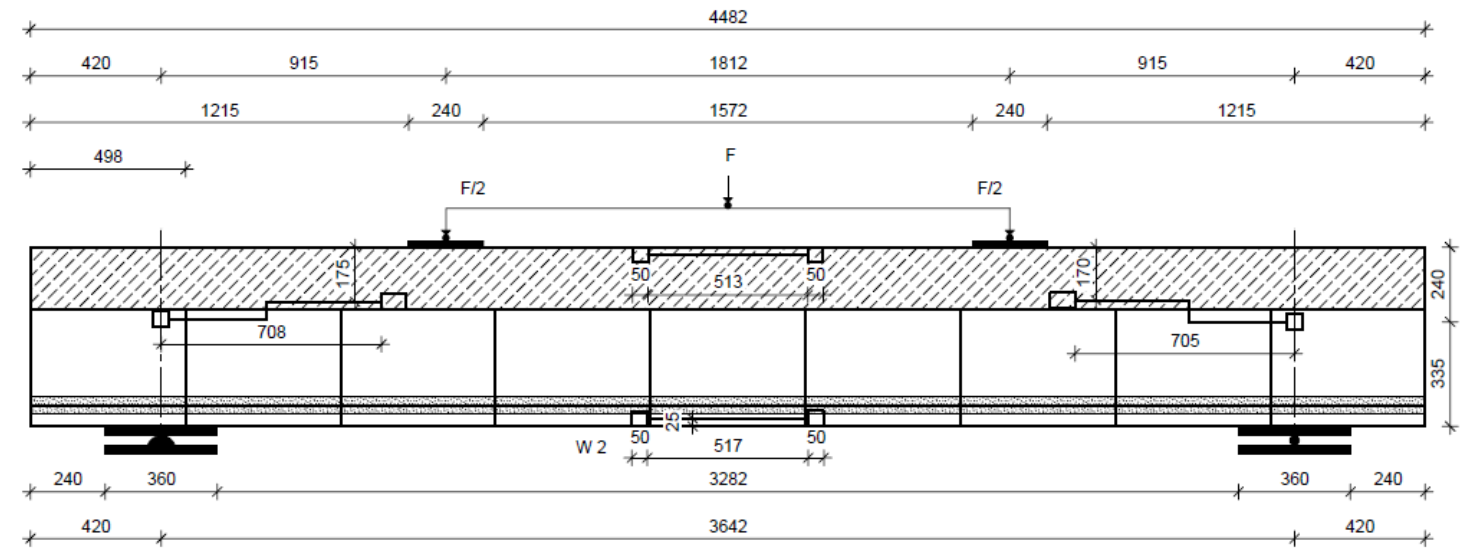

\section{KS-16 F.1}

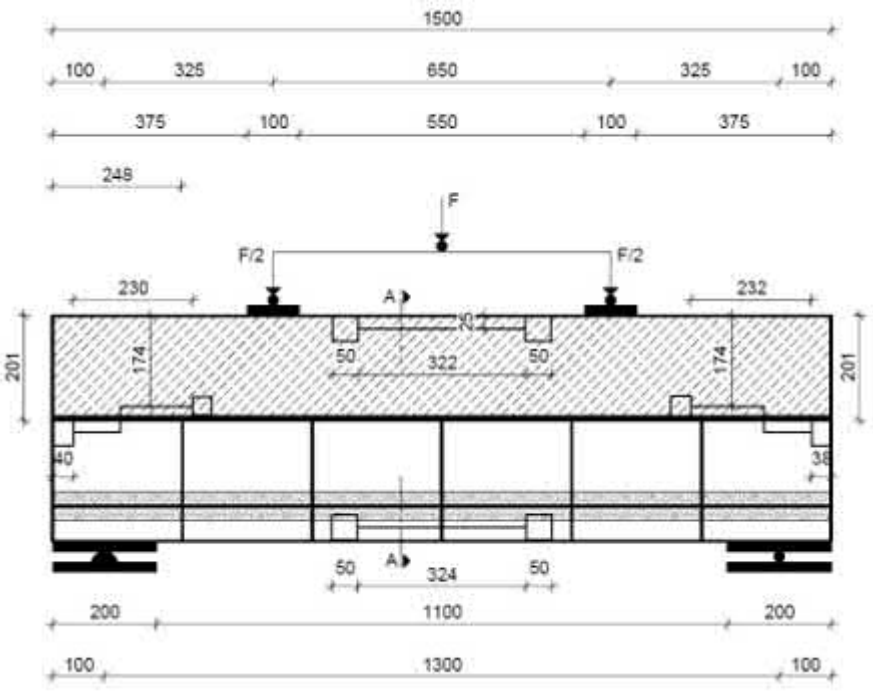

KS-16 F.2 vorne

\begin{tabular}{|c|c|c|c|c|c|}
\hline \multicolumn{6}{|c|}{1500} \\
\hline 100 & 325 & 650 & & & 100 \\
\hline 325 & 200 & 450 & 200 & 325 & \\
\hline
\end{tabular}

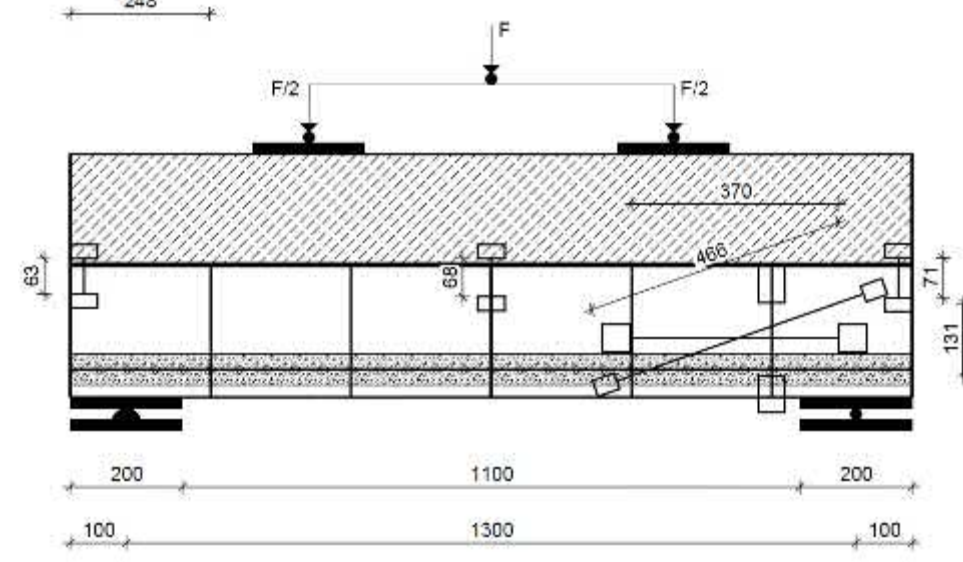


KS-16 F.2 hinten

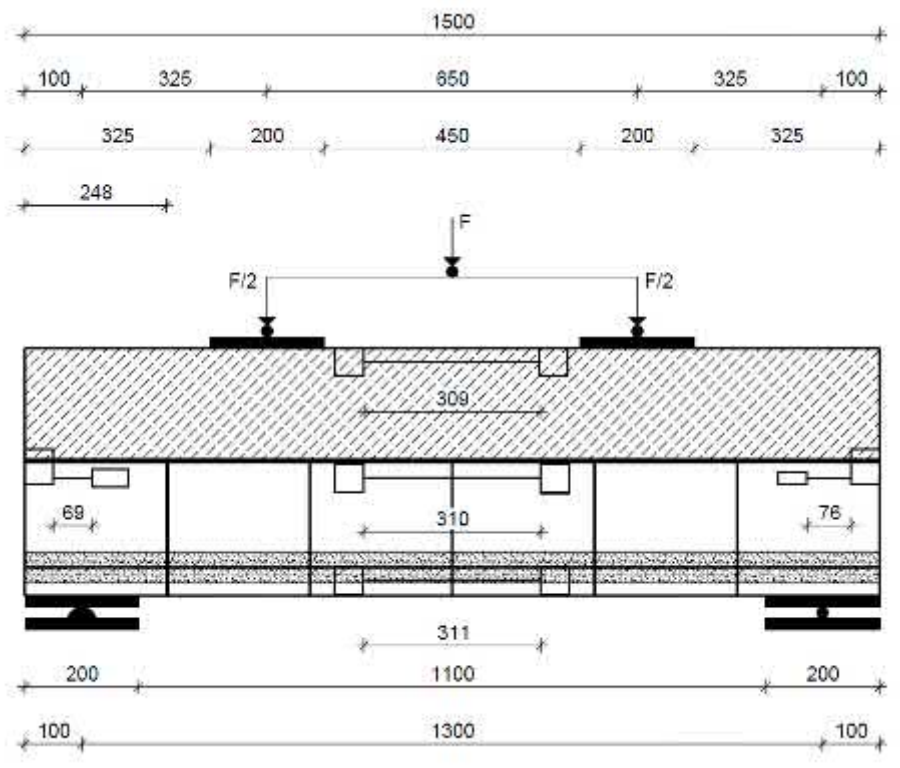

KS-17 F

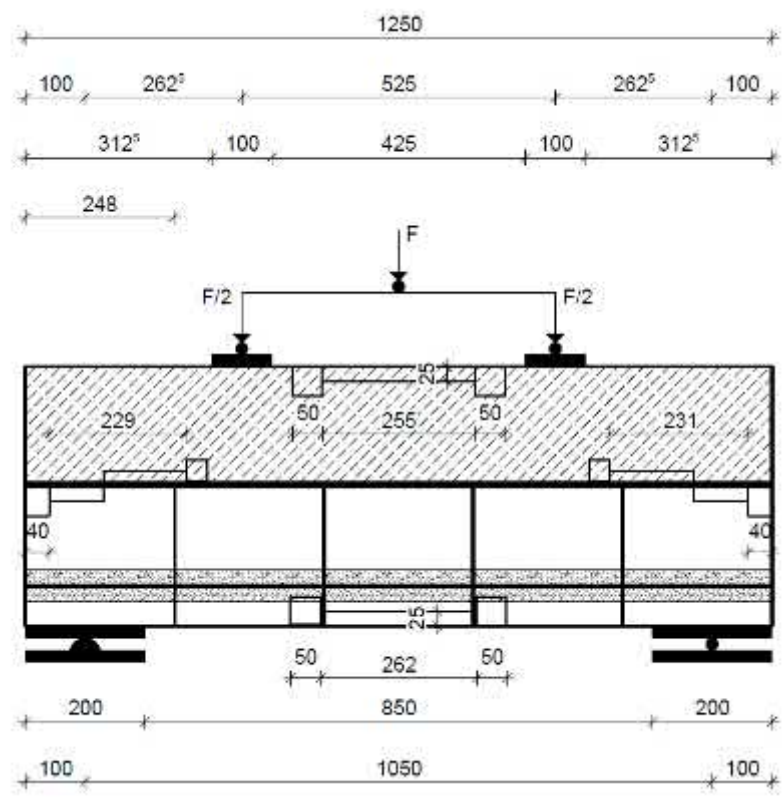


KS-18 F.1

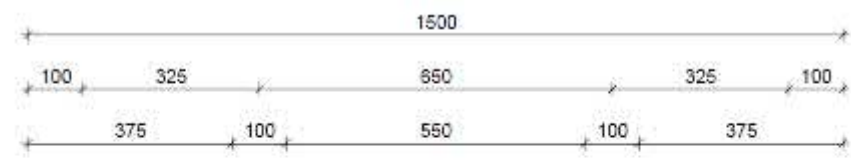

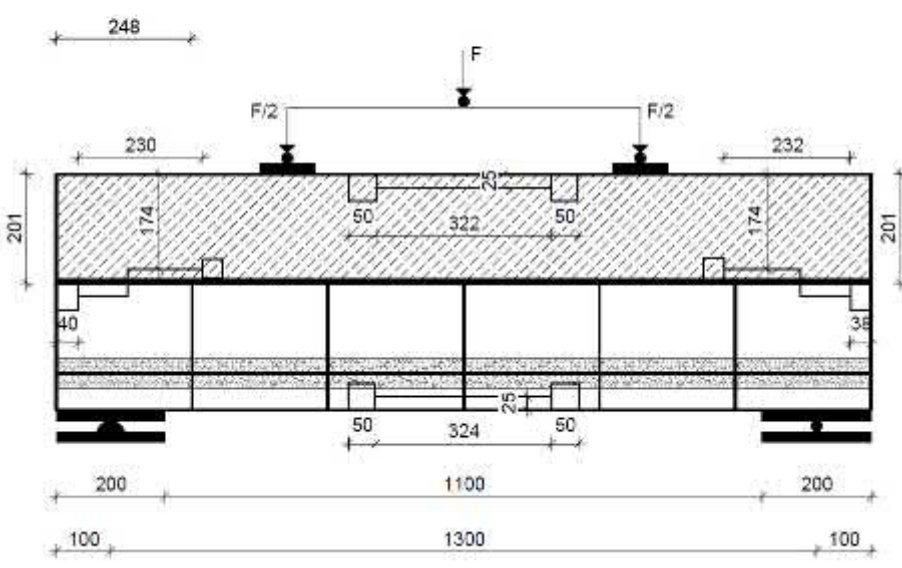

KS-18 F.2 vorne

$\begin{array}{lll}4 & 1500 \\ +100,325, & 650 & 325,100 \\ +325, & 400, & 450,200, \\ +\end{array}$

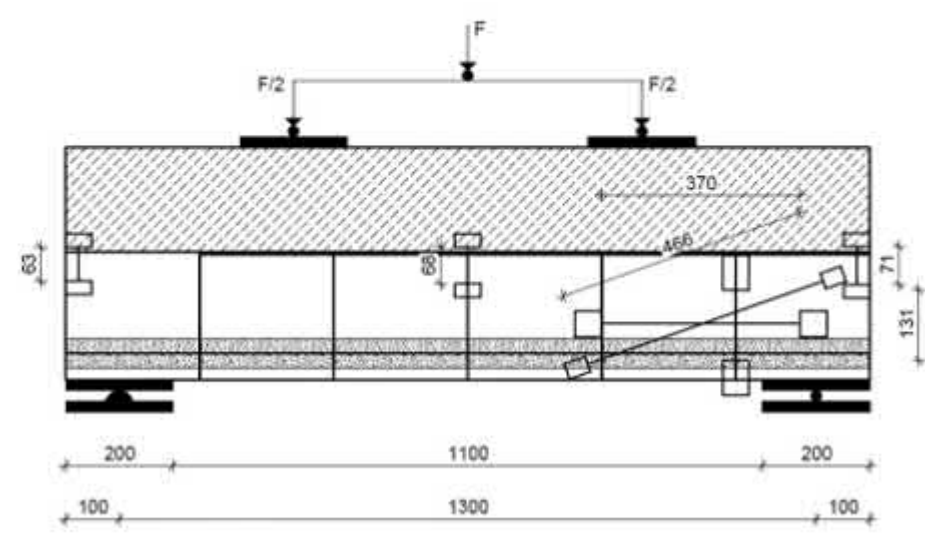


KS-18 F.2 hinten

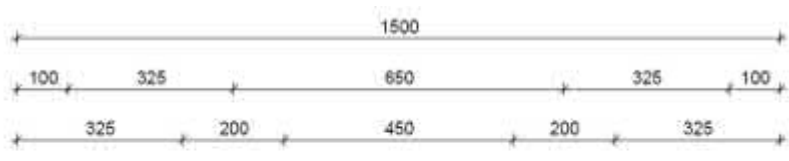

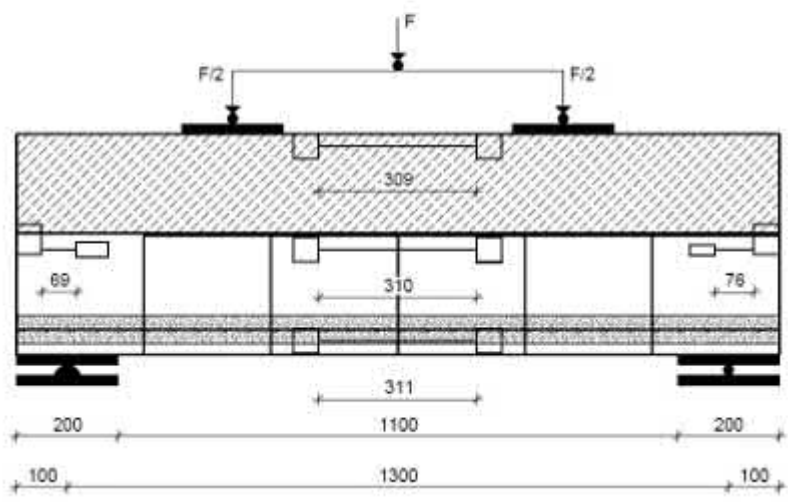

Bild A 4.14 Messstellenpläne der bewehrten scheitrechten Kalksandstein-Mauerwerkbalken mit Aufbeton - KS-08.1 bis KS-11 sowie KS-16 F.1 bis KS-18 F.2 
A 4.4.3 Rissbilder

KS-08.1

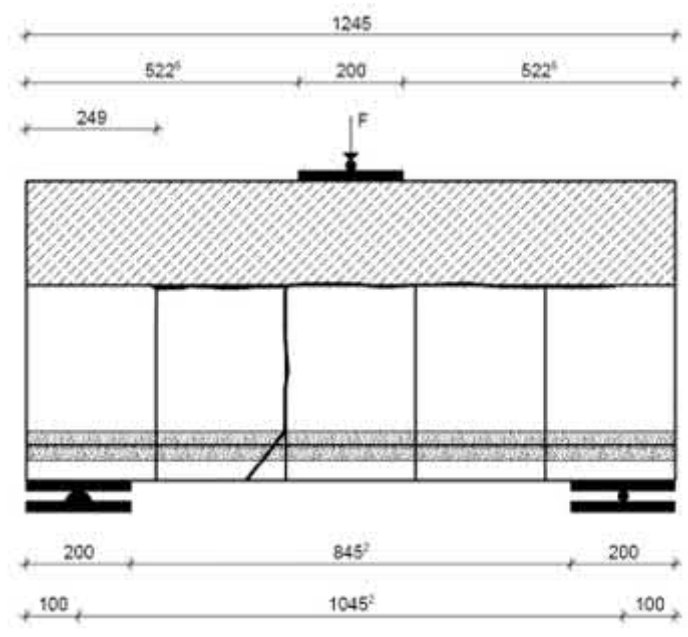

KS-08.2

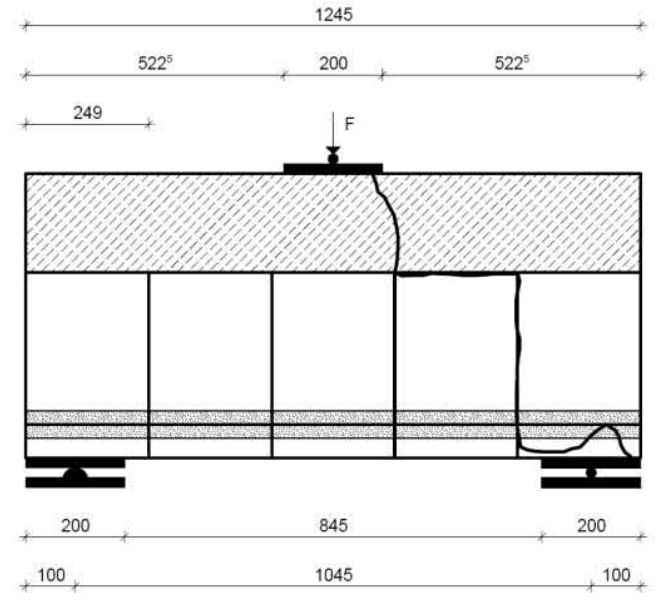

KS-09.1

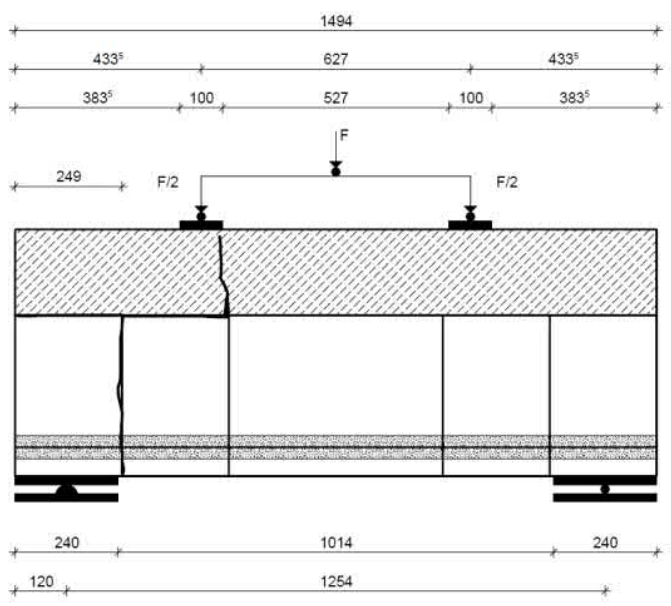


KS-09.2

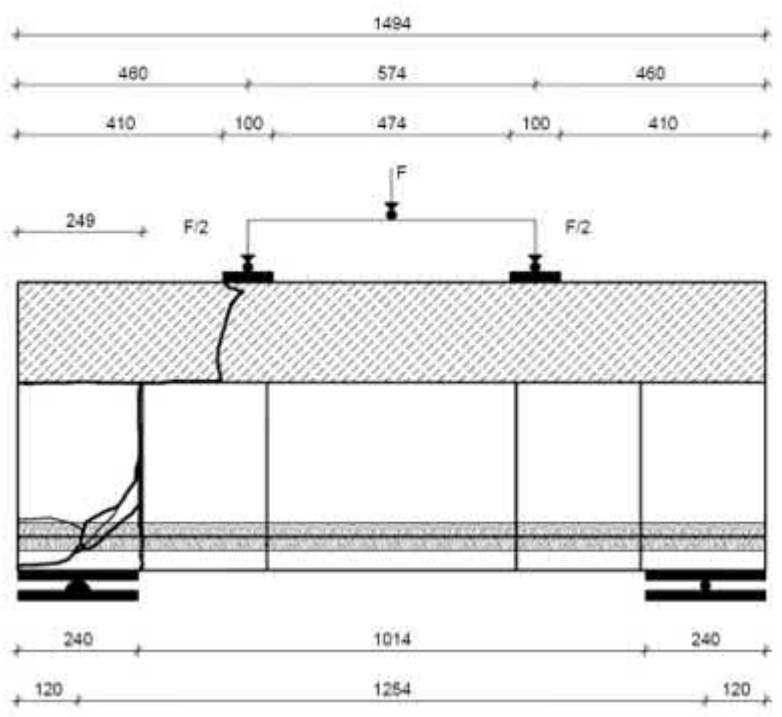

KS-10.1

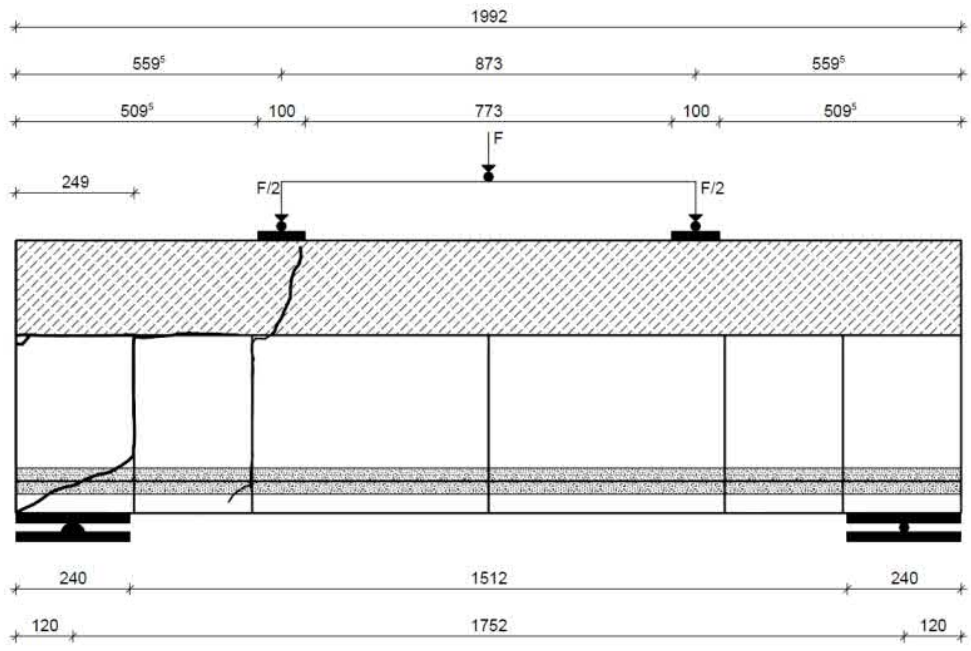


KS-10.2
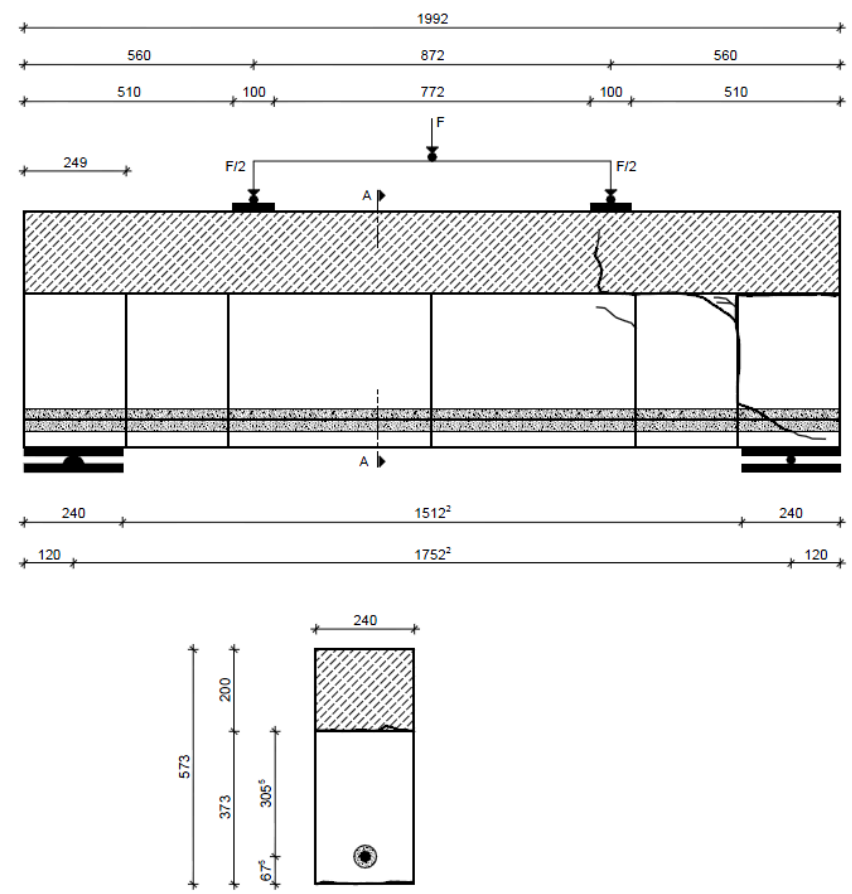

Schnitt A-A

KS-11

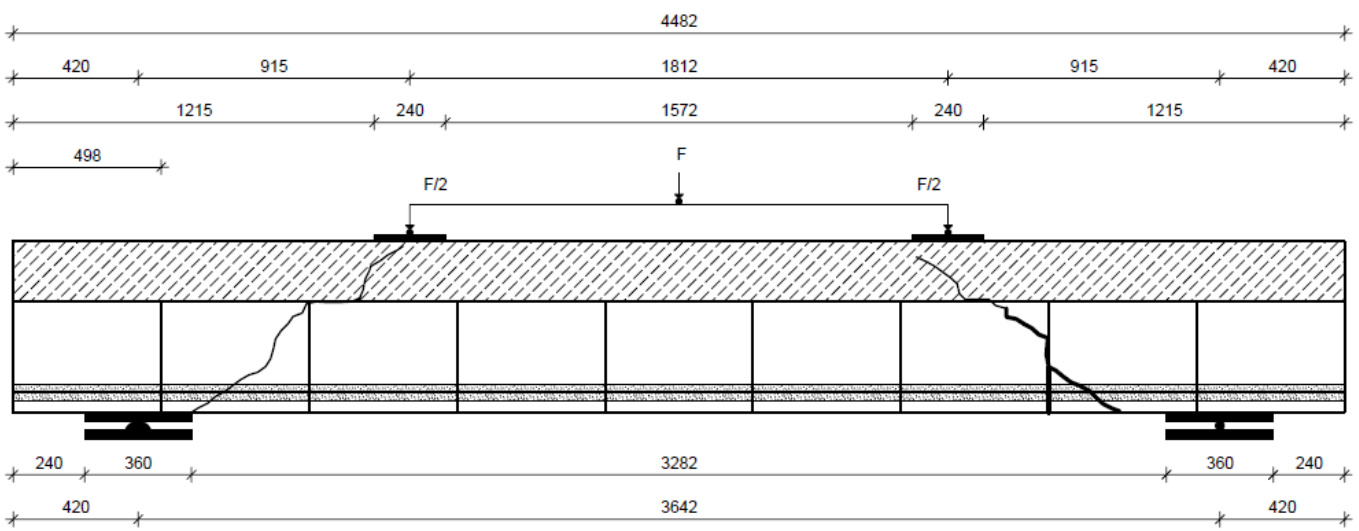


KS-16 F.1

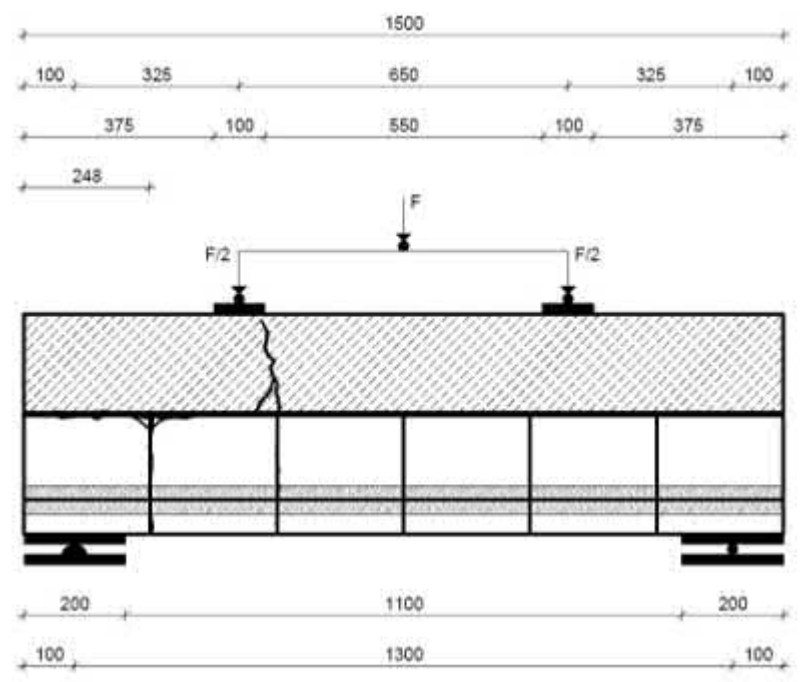

KS-16 F.2

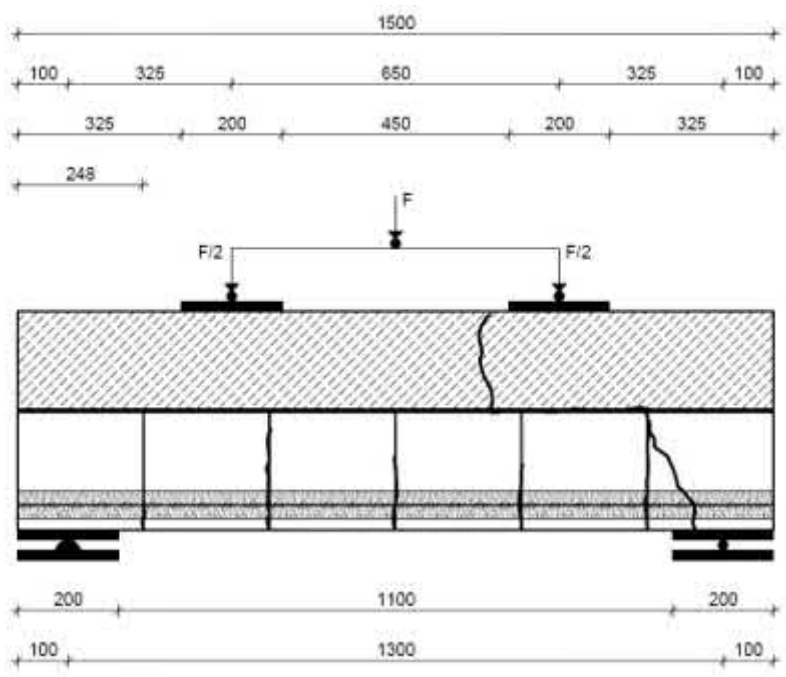

KS-17 F

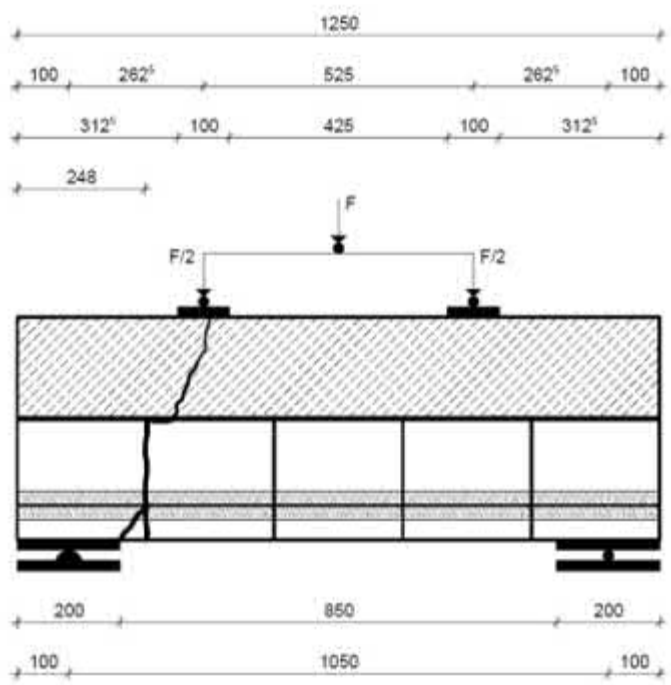


KS-18 F.1

\begin{tabular}{|c|c|c|c|c|c|}
\hline \multicolumn{6}{|c|}{1500} \\
\hline 100 & 325 & & 650 & 325 & 100 \\
\hline & & 100 & 550 & 100 & \\
\hline
\end{tabular}

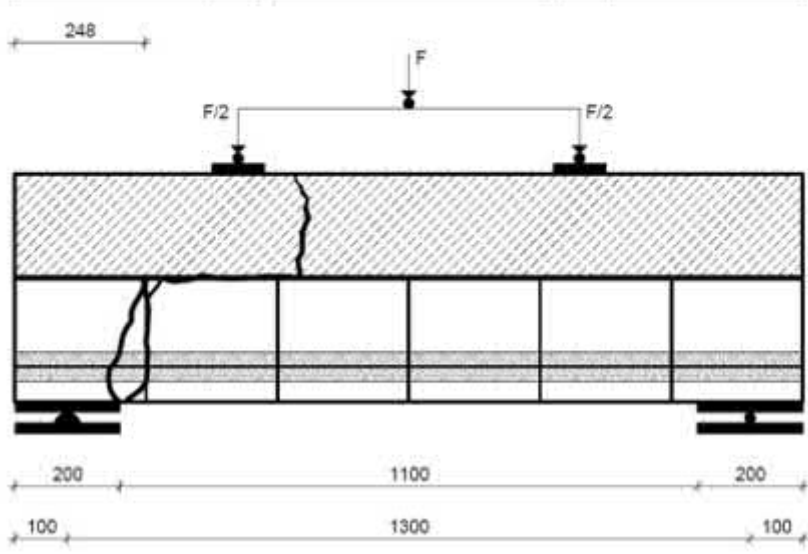

KS-18 F.2

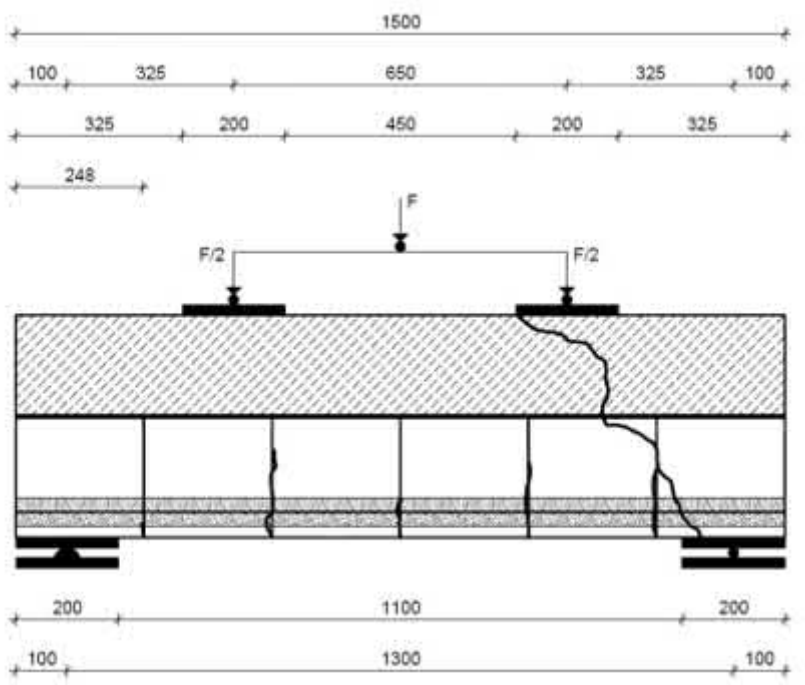

Bild A 4.15 Rissbilder der bewehrten scheitrechten Kalksandstein-Mauerwerkbalken mit Aufbeton KS-08.1 bis KS-11 sowie KS-16 F.1 bis KS-18 F.2 
A 4.4.4 Lastdurchbiegungslinien und flächenhafte Darstellung der Verschiebung in horizontaler und vertikaler Richtung sowie Hauptformänderungen

KS-08.1
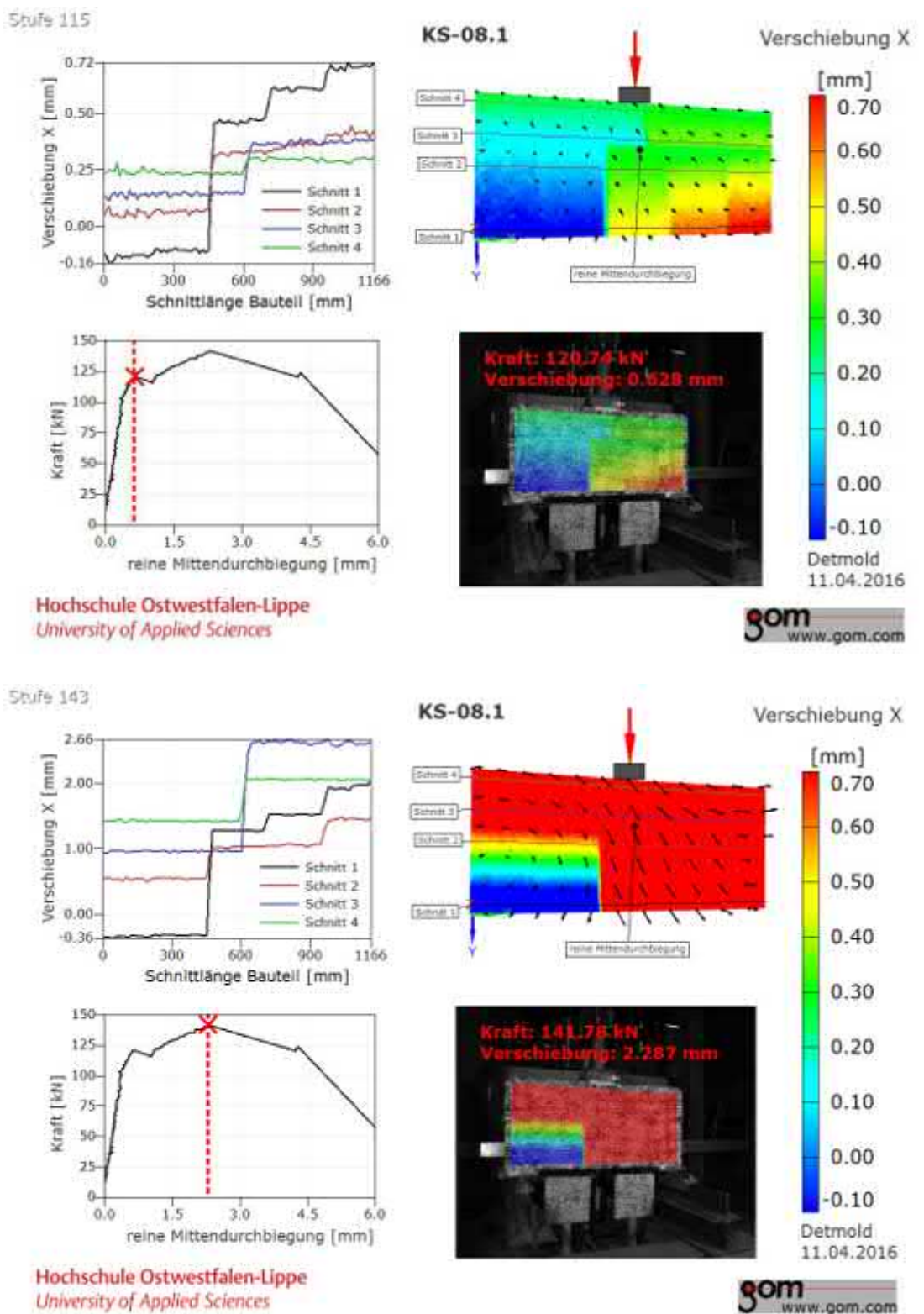

Hochschule Ostwestfalen-Lippe University of Applied Sciences 

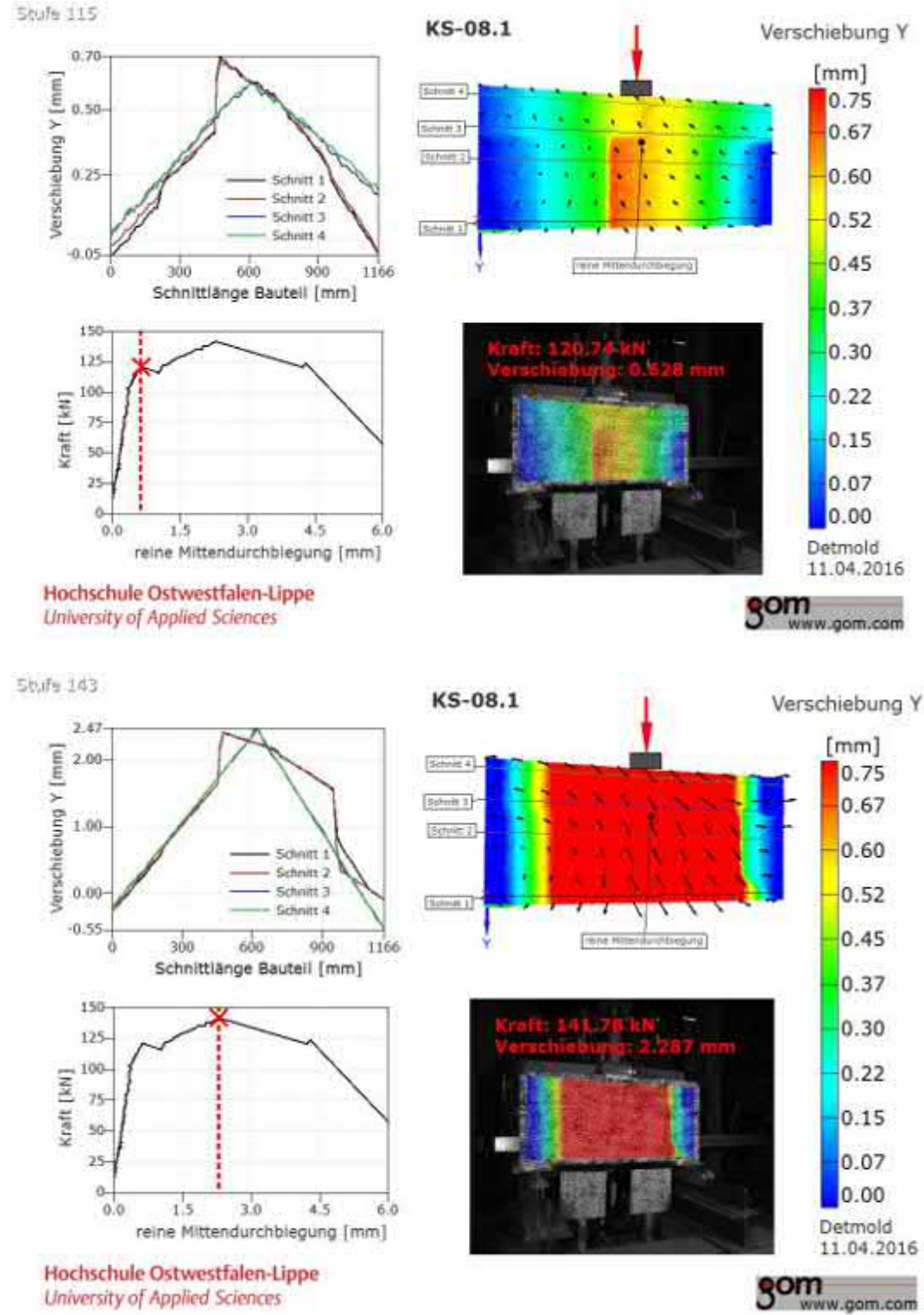

Hochschule Ostwestfalen-Lippe University of Applied Sciences

Seufe 143
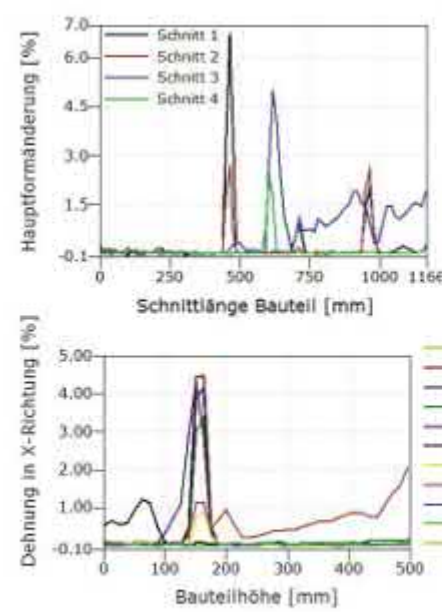

Hochschule Ostwestfalen-Lippe University of Applied Sciences
KS-08.1 Hauptformānderung

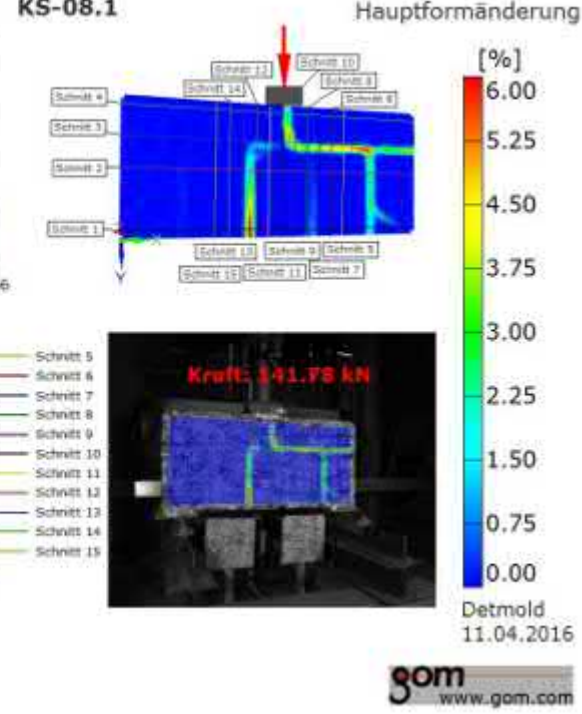


KS-08.2
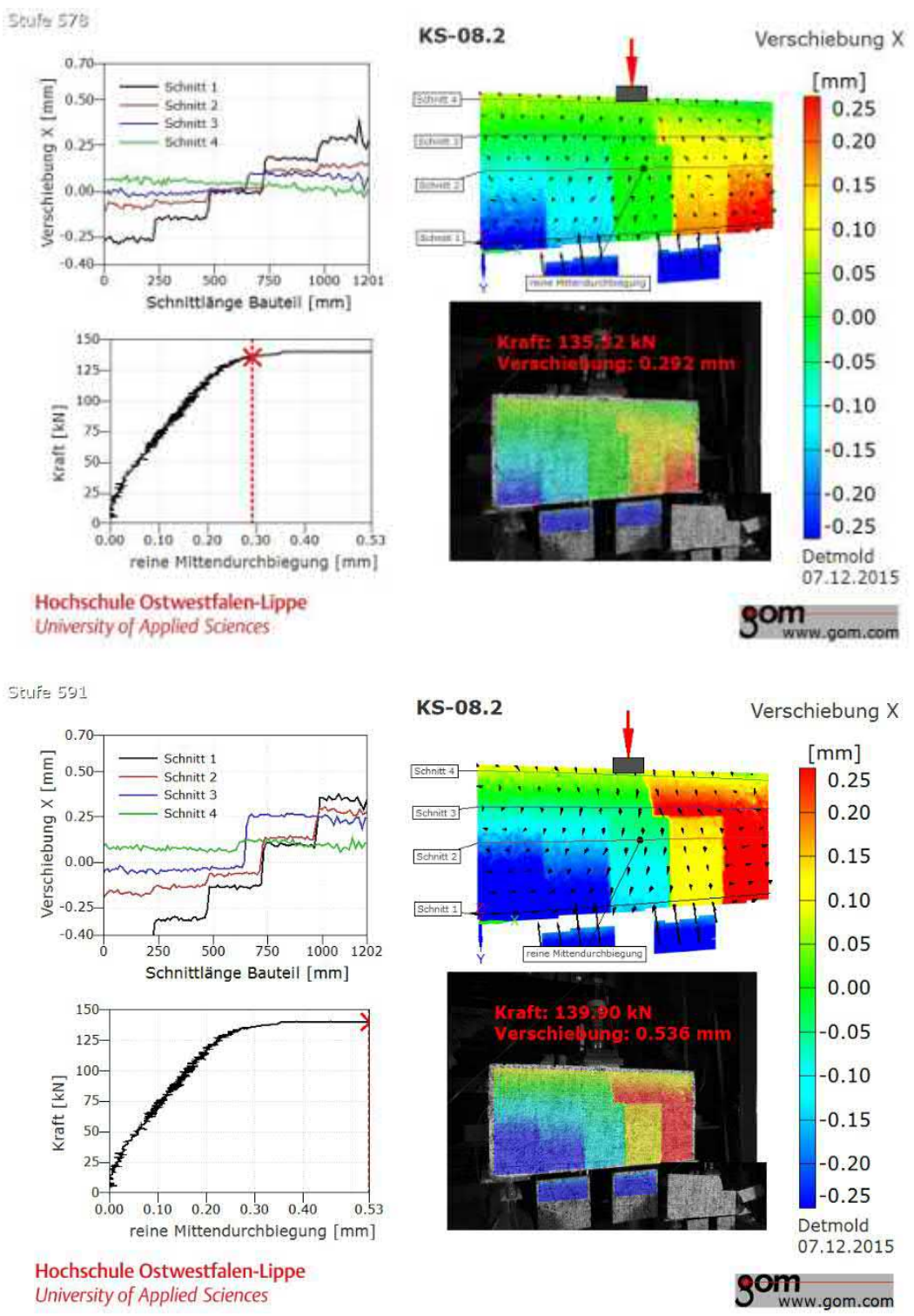

Hochschule Ostwestfalen-Lippe University of Applied Sciences

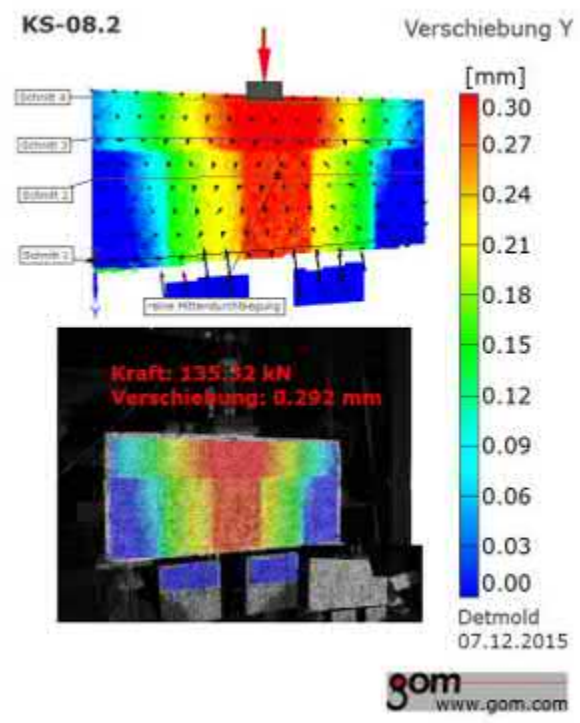



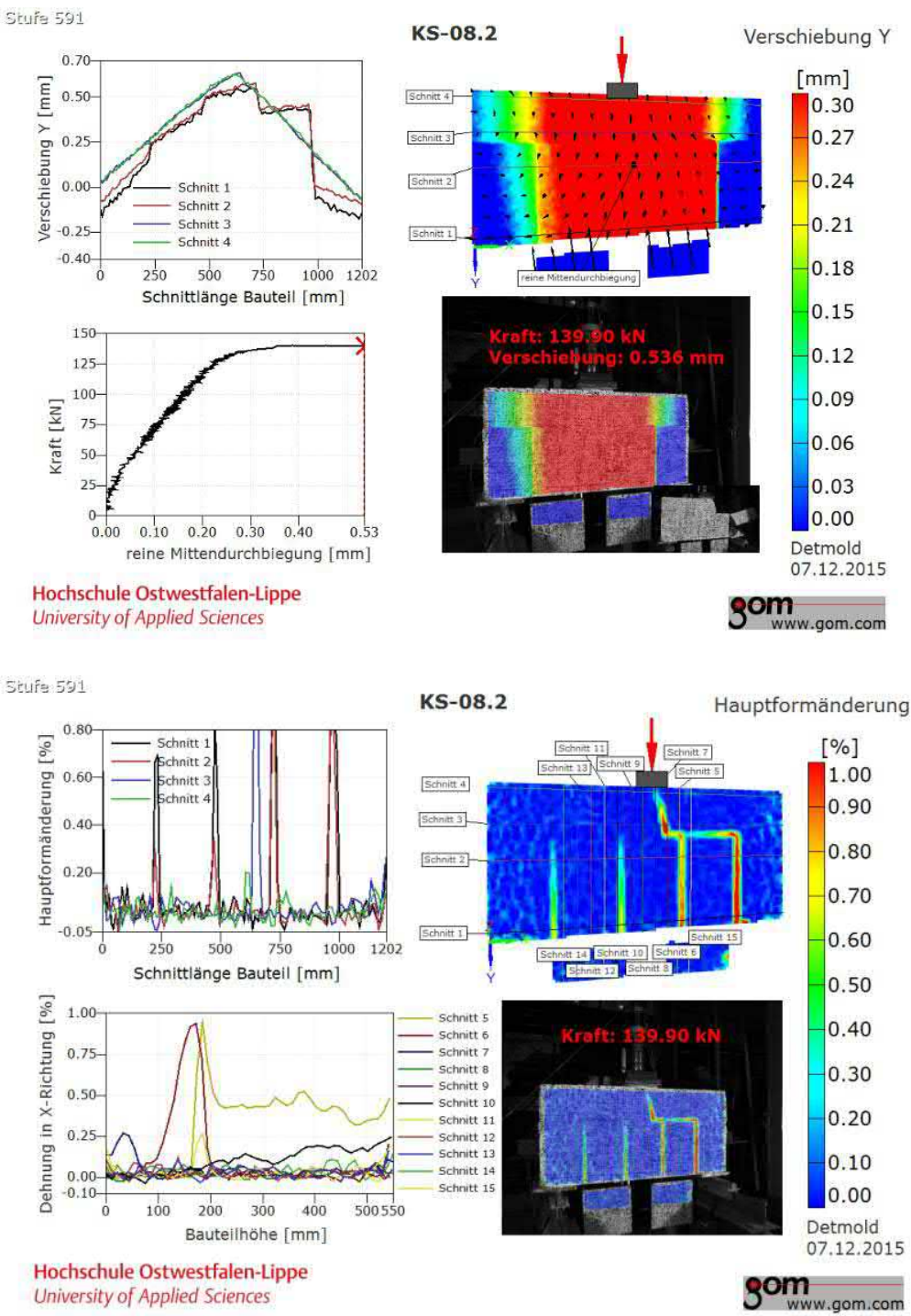

KS-09.1

Sture 456

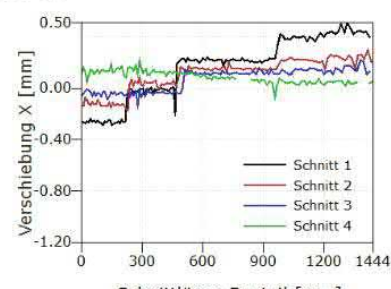

Schnittlänge Bautell [mm]

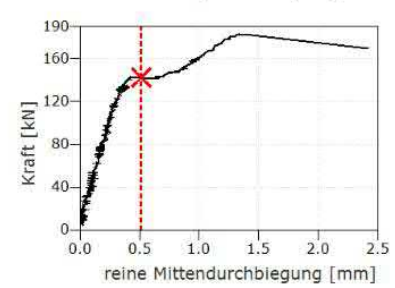

Hochschule Ostwestfalen-Lippe University of Applied Sciences

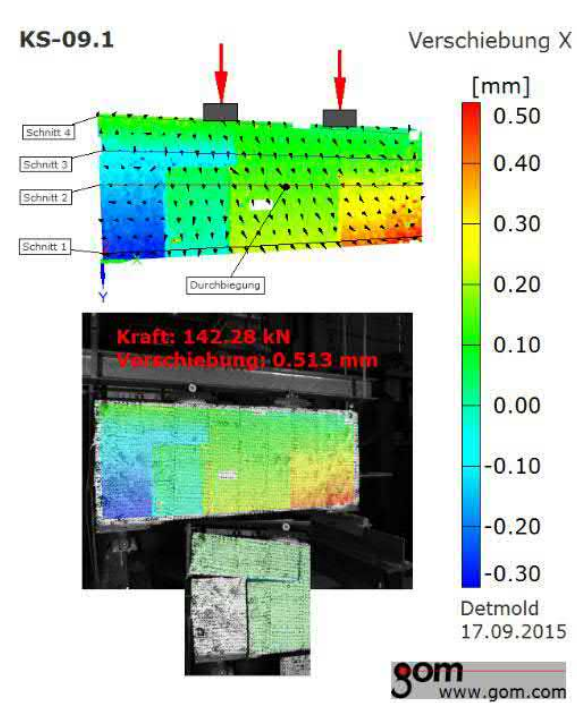




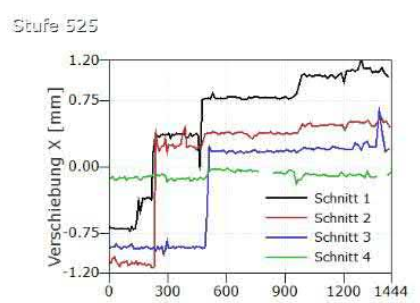

Schnittlänge Bautell [mm]

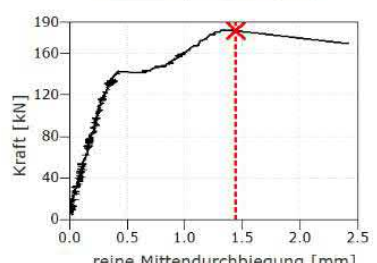

reine Mittendurchbiegung [mm]

Hochschule Ostwestfalen-Lippe University of Applied Sciences
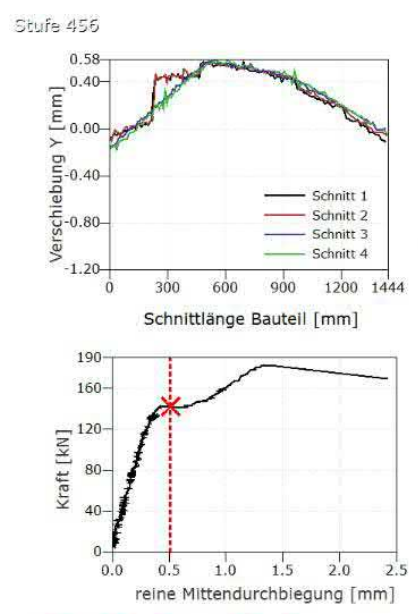

Hochschule Ostwestfalen-Lippe University of Applied Sciences

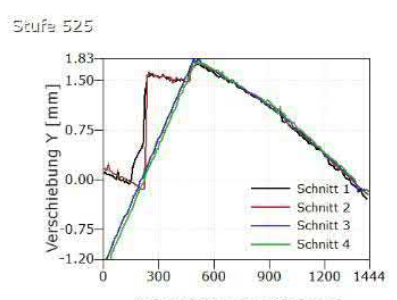
Schnittlänge Bauteil [mm]

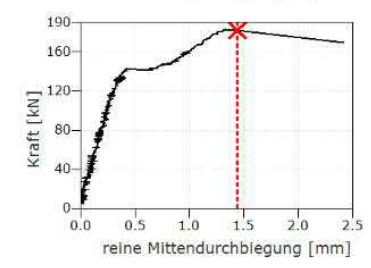

Hochschule Ostwestfalen-Lippe University of Applied Sciences
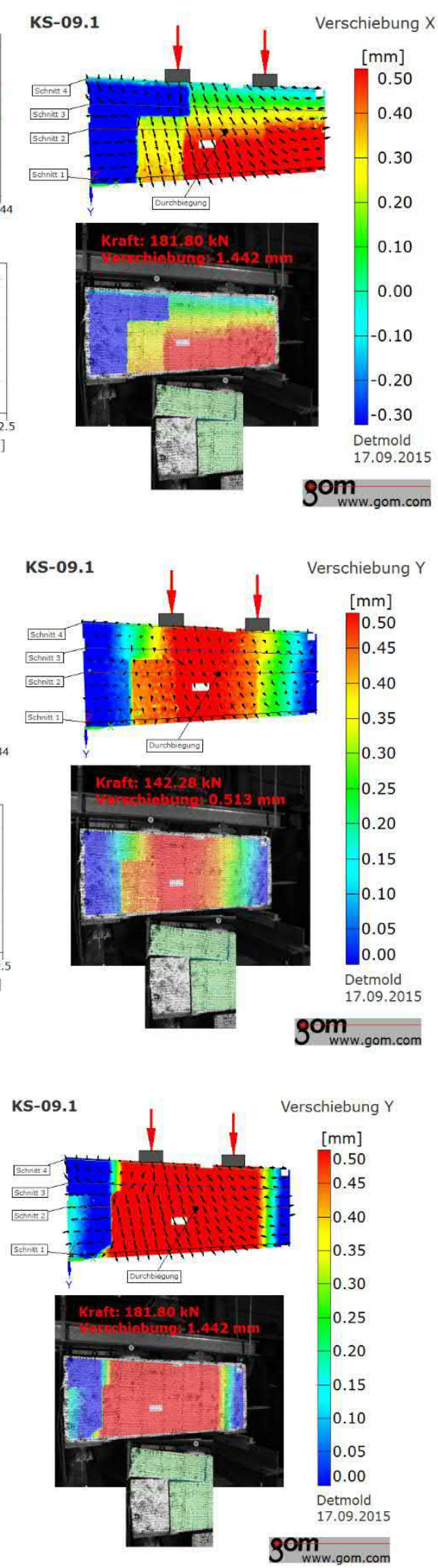


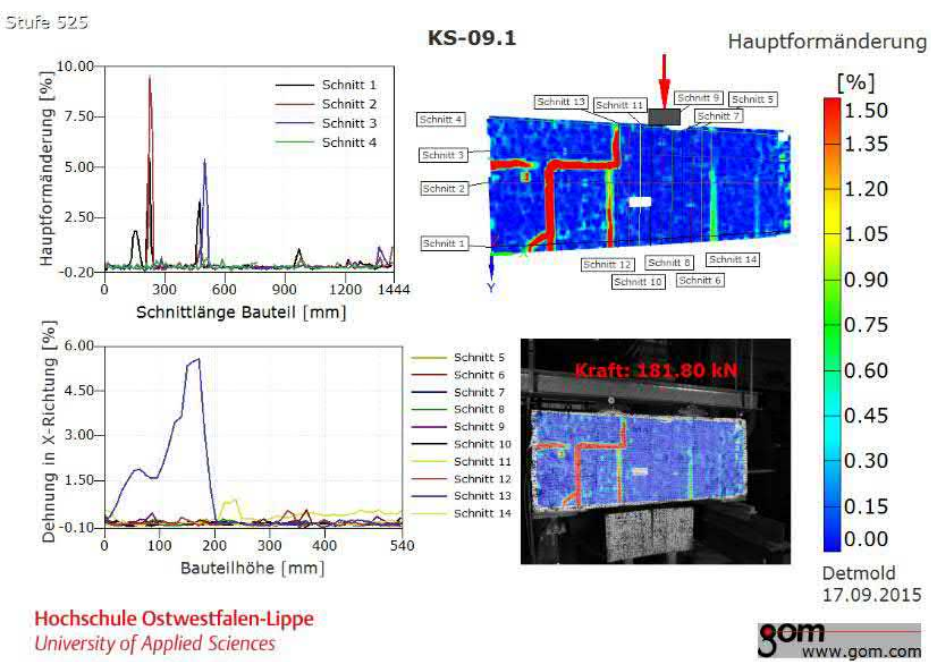

KS-09.2

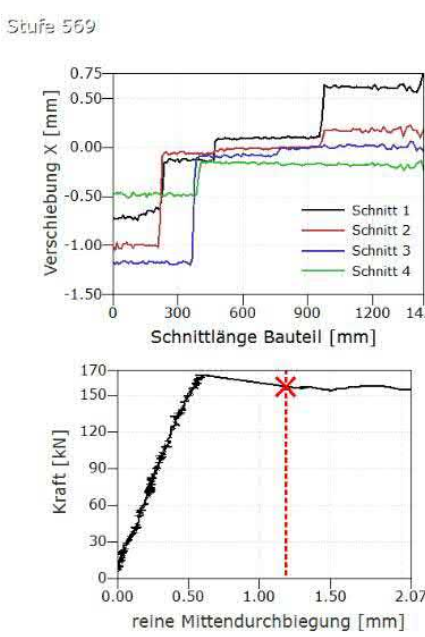

Hochschule Ostwestfalen-Lippe University of Applied Sciences

Seate 506
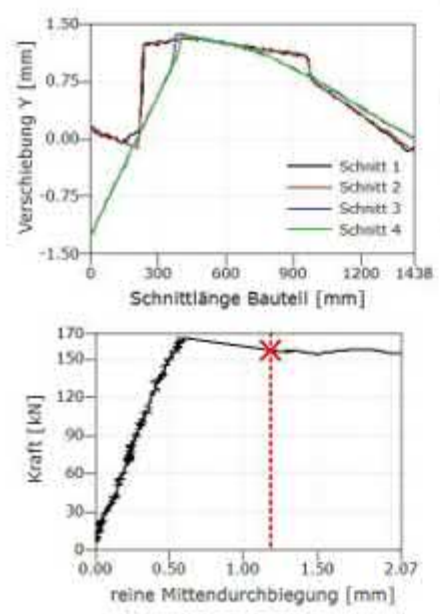

Hochschule Ostwestfalen-Lippe University of Applied Sciences
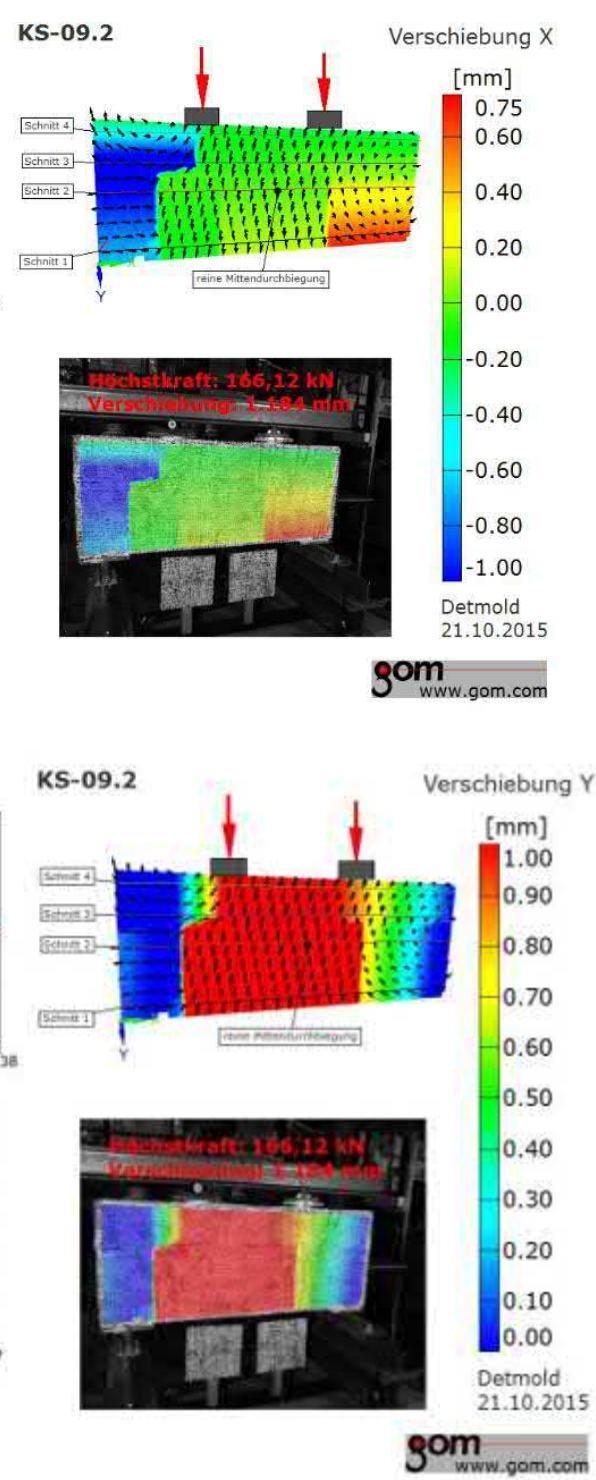


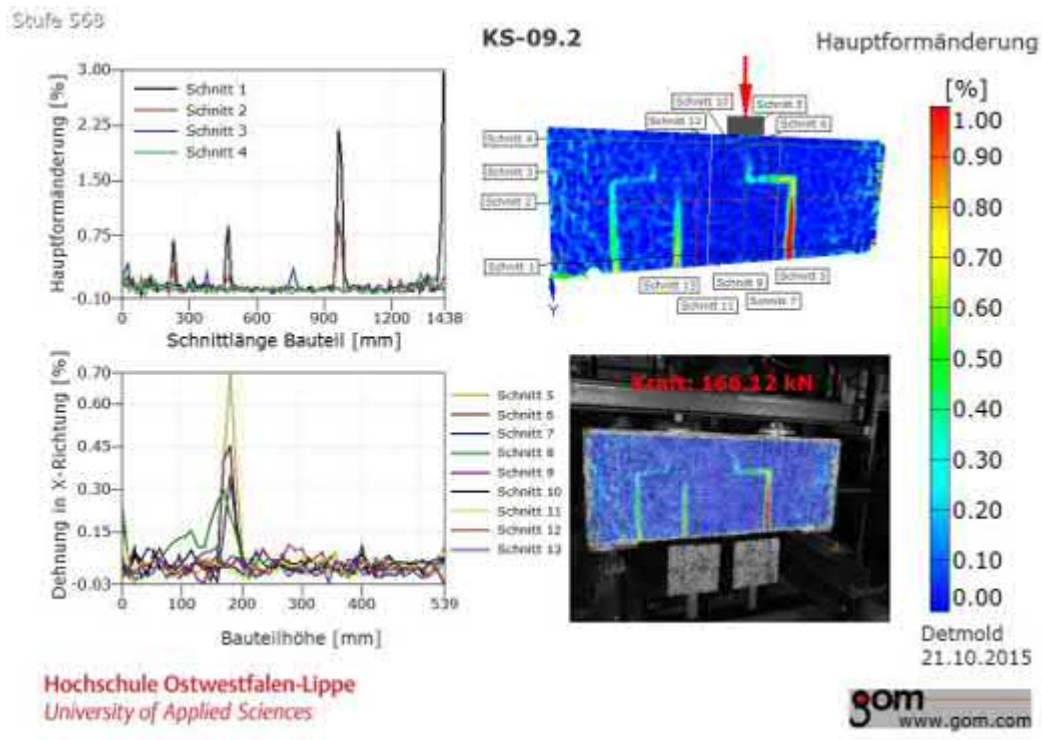

KS-10.1

Seife 230
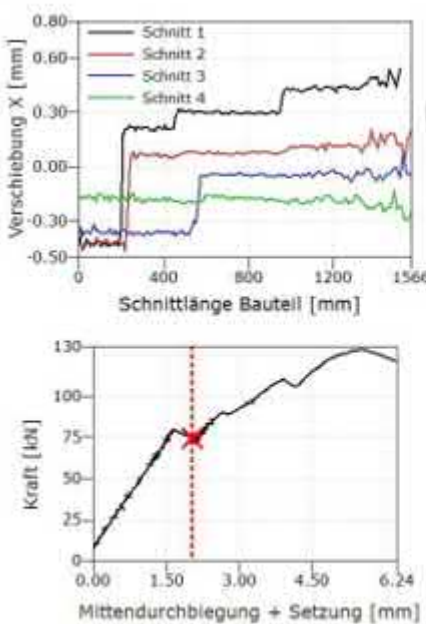

Hochischule Ostwestfalen-Lippe University of Applied Sciences

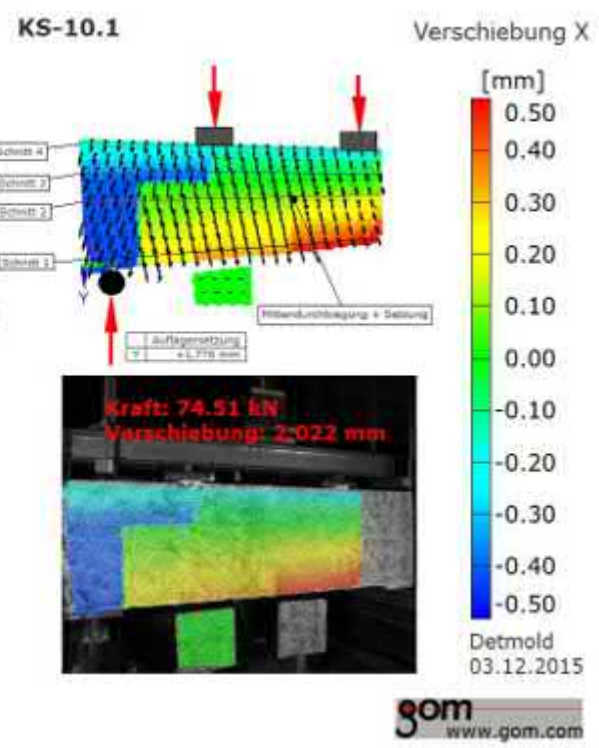

KS-10.1

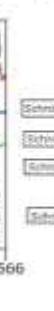

Sant

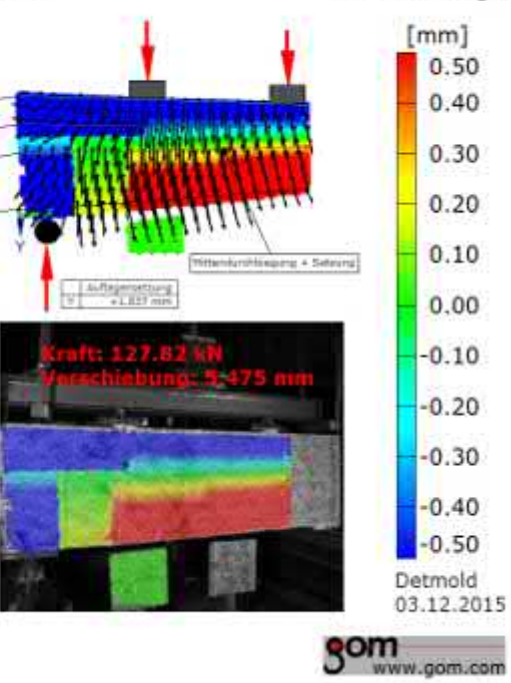


5 cute 230
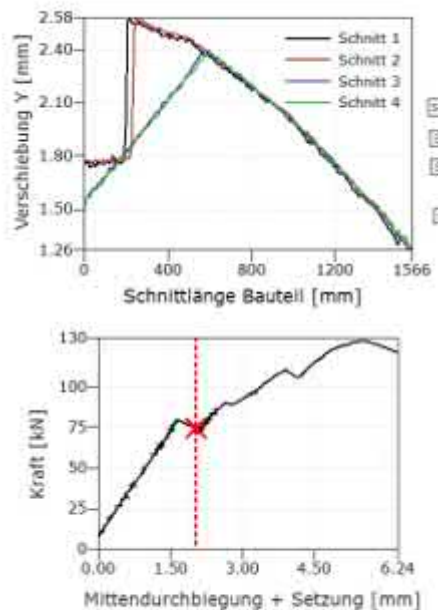

Hochschule Ostwestfalen-Lippe University of Applied Sciences
KS-10.1 Verschiebung $Y$

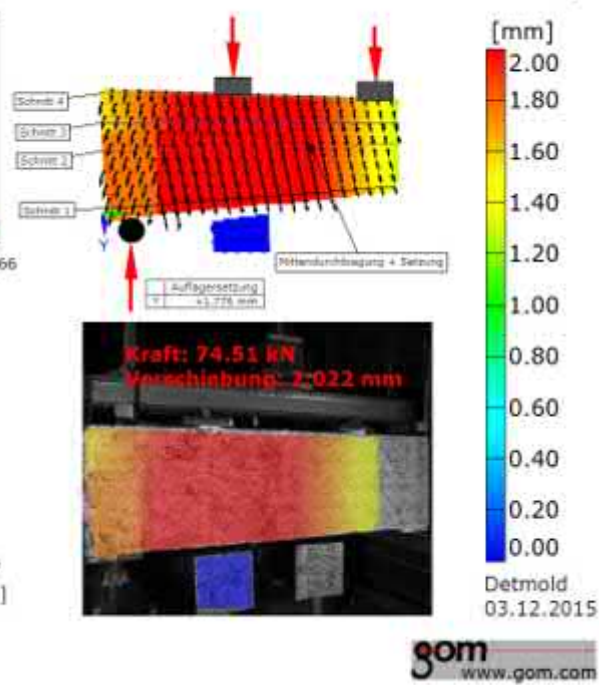

KS-10.1 Verschiebung $Y$

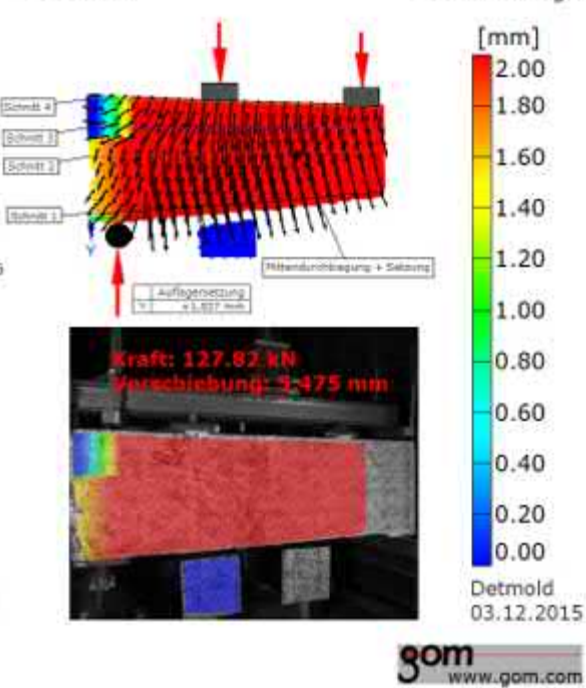

KS-10.1 Hauptformänderung

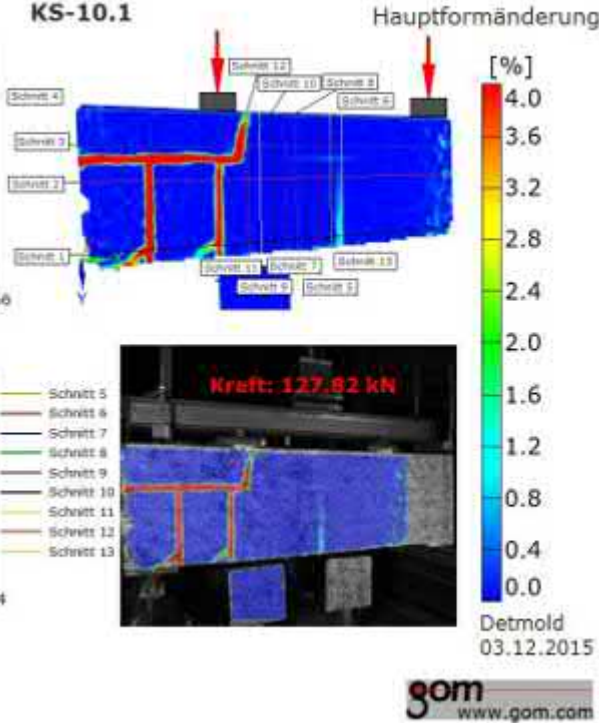


KS-10.2

Sture 5e9
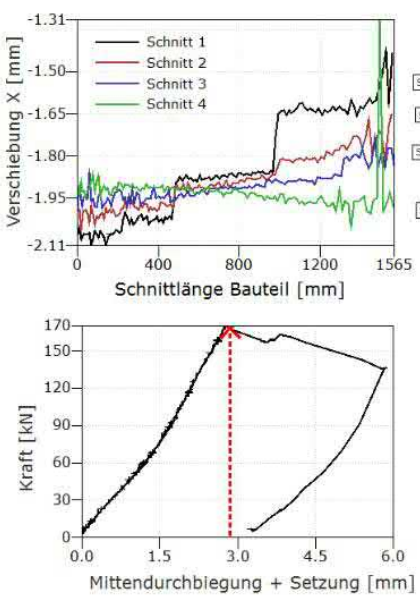

Hochschule Ostwestfalen-Lippe University of Applied Sciences

Sture 529
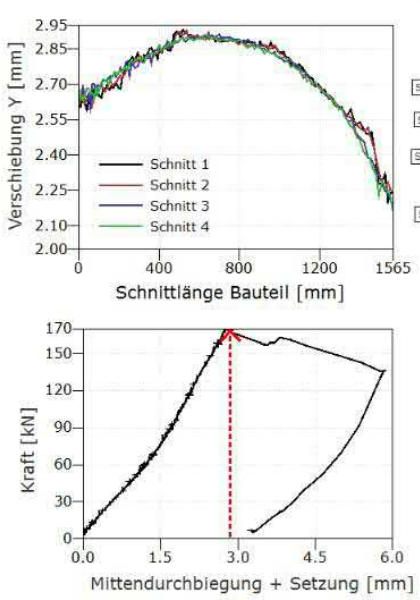

Hochschule Ostwestfalen-Lippe University of Applied Sciences

Sture 513
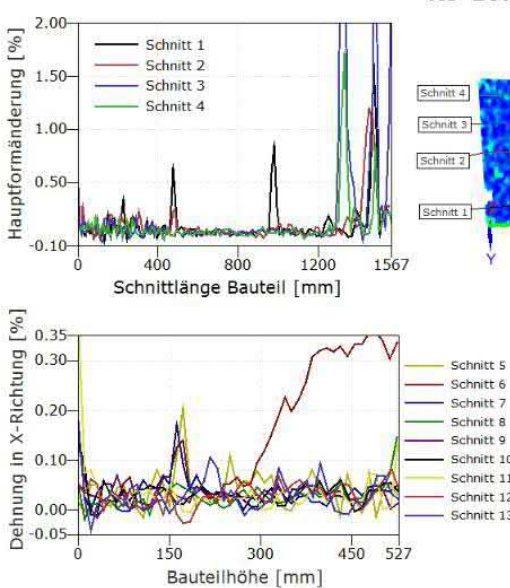

Hochschule Ostwestfalen-Lippe University of Applied Sciences
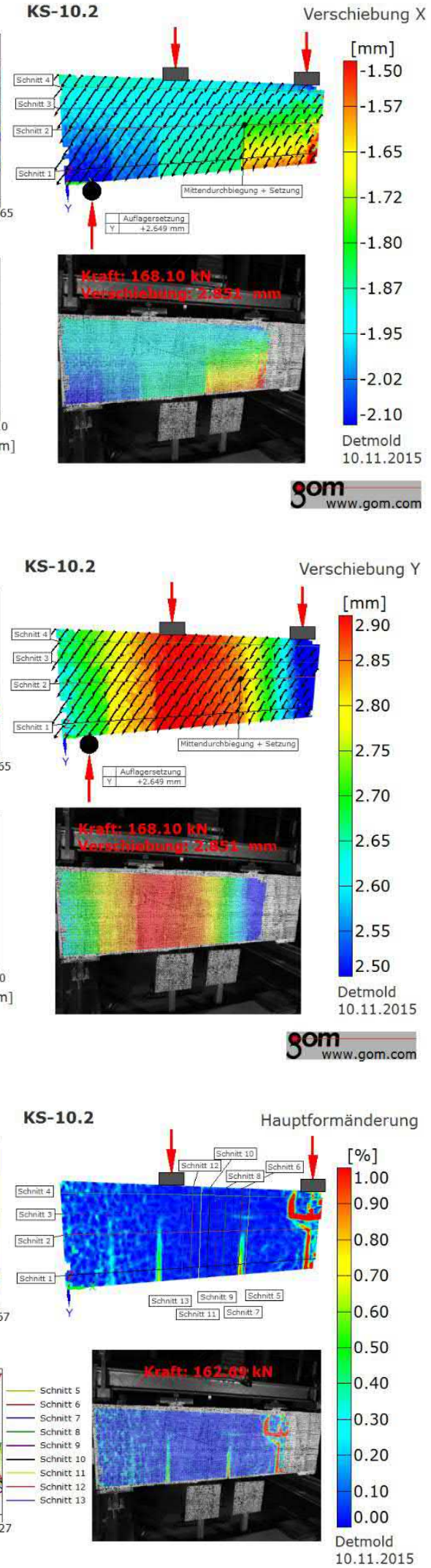

8Om 
KS-11
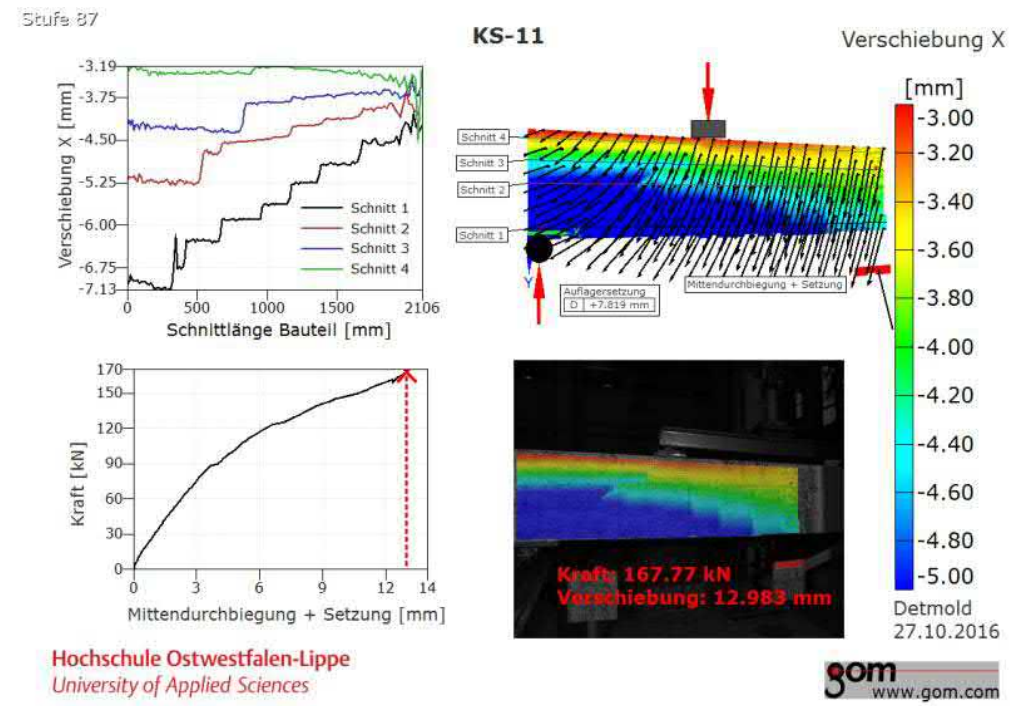

Hochschule Ostwestfalen-Lippe University of Applied Sciences

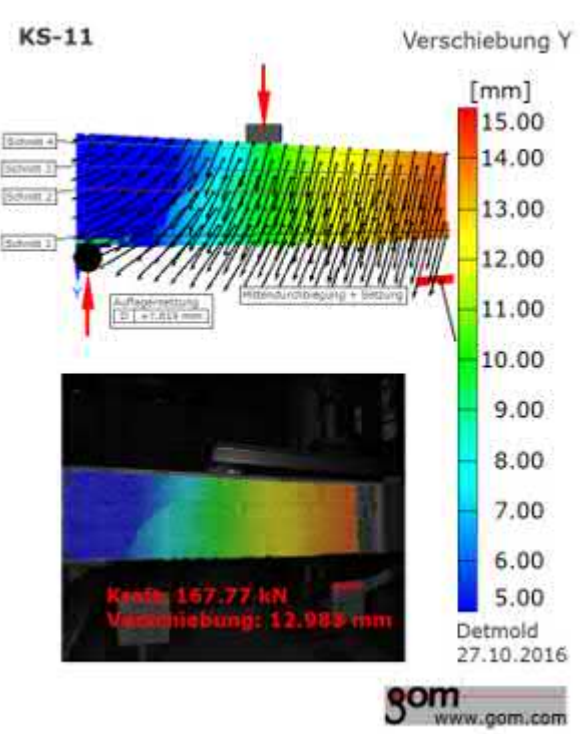

Hochschule Ostwestfalen-Lippe University of Applied Sciences

KS-11

Hauptformānderung
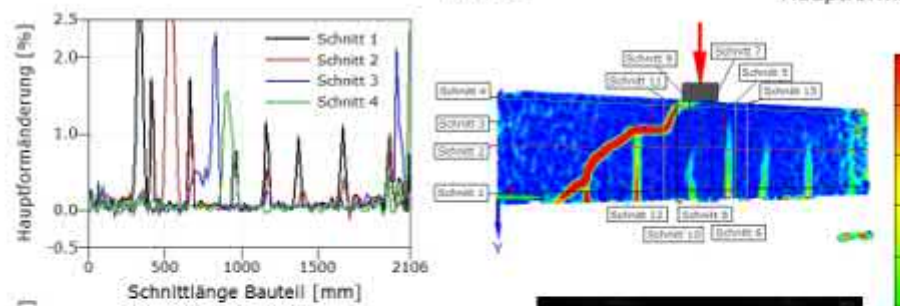

$\%$ ]

1.50

1.35

1.20
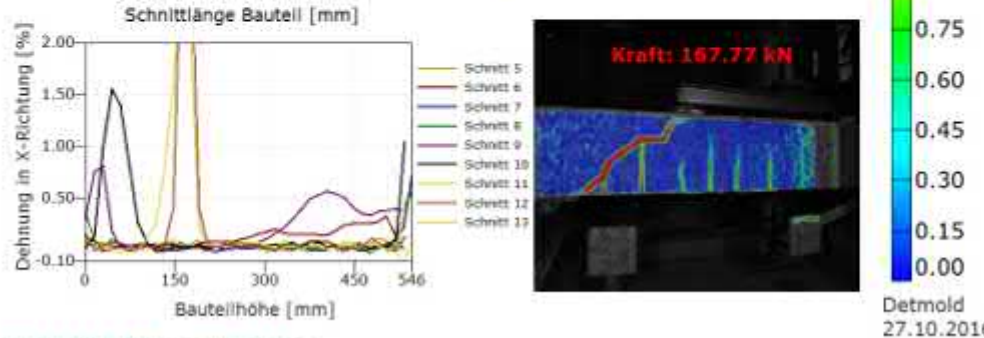

Hochschule Ostwestfalen-Lippe University of Applied Sciences 
KS-16 F.1

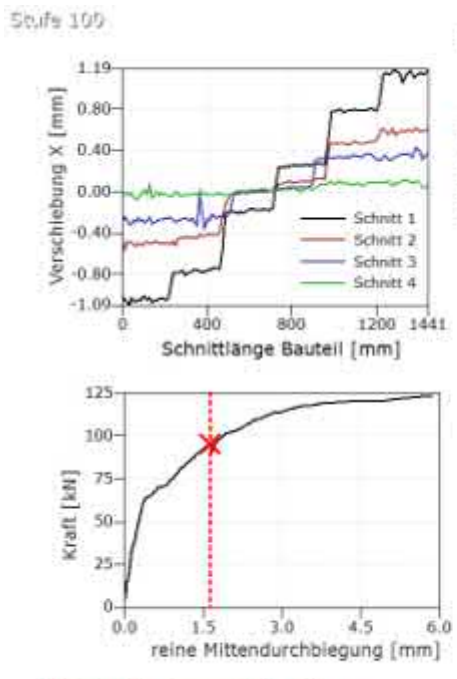

Hochschule Ostwestfalen-Lippe University of Applied Sciences
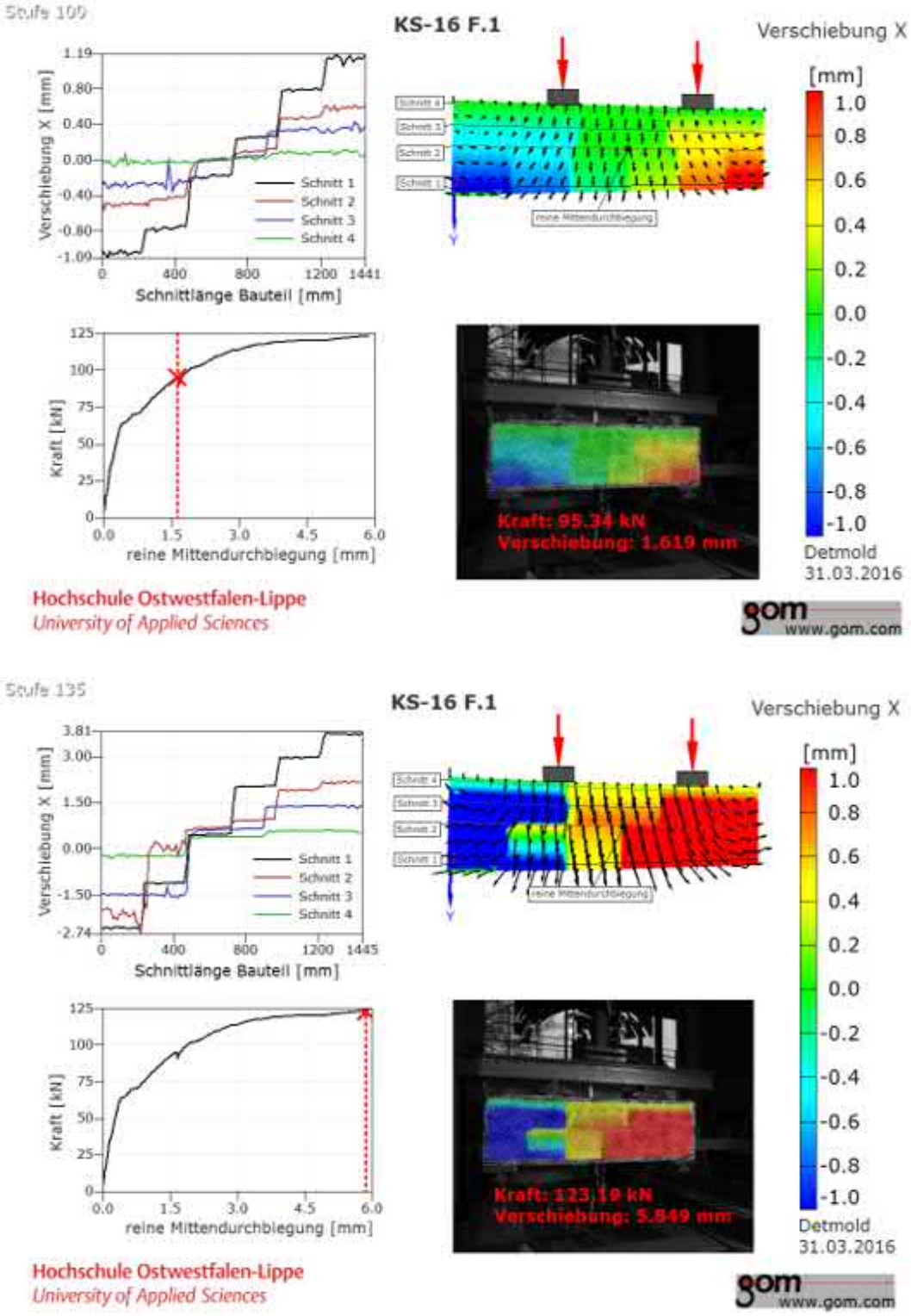

Hochschule Ostwestfalen-Lippe University of Applied Sciences

gom www.gom.com
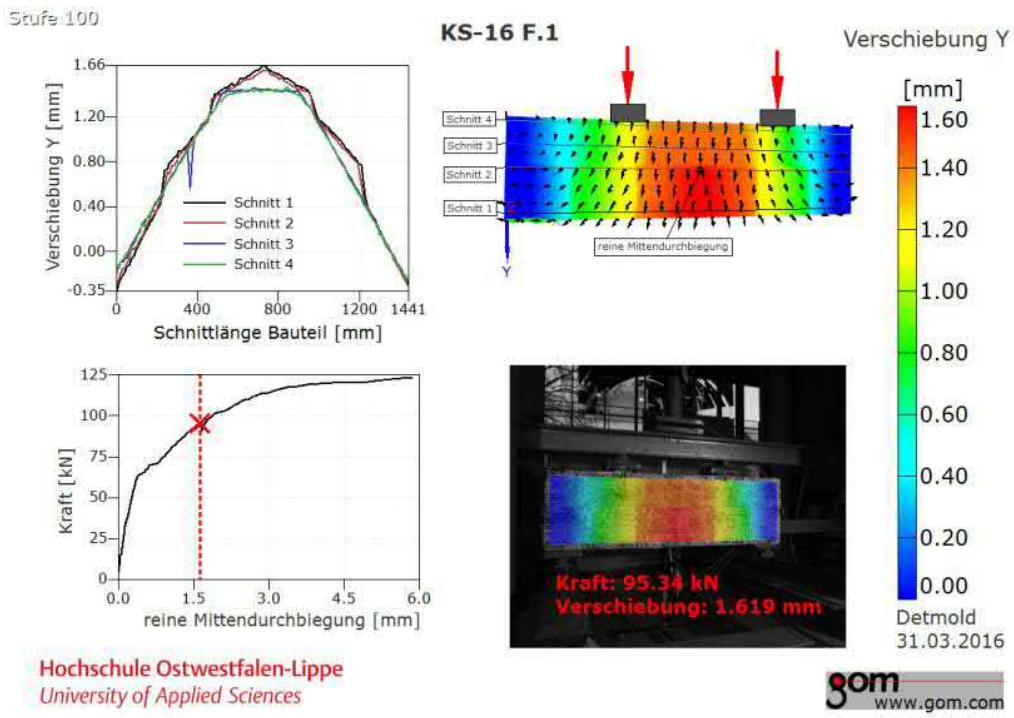

Hochschule Ostwestfalen-Lippe University of Applied Sciences 

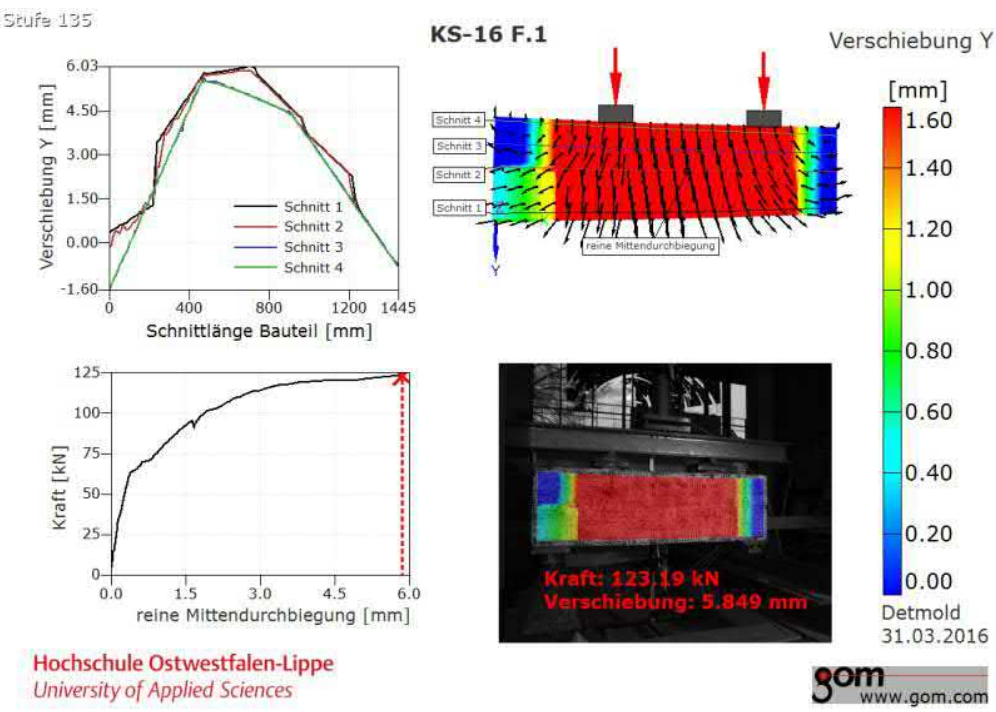

Hochschule Ostwestfalen-Lipp

University of Applied Sciences
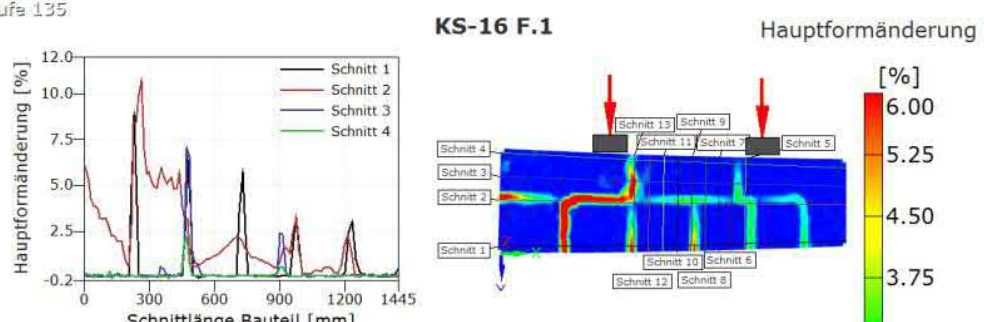

KS-16 F.1 Hauptformänderung
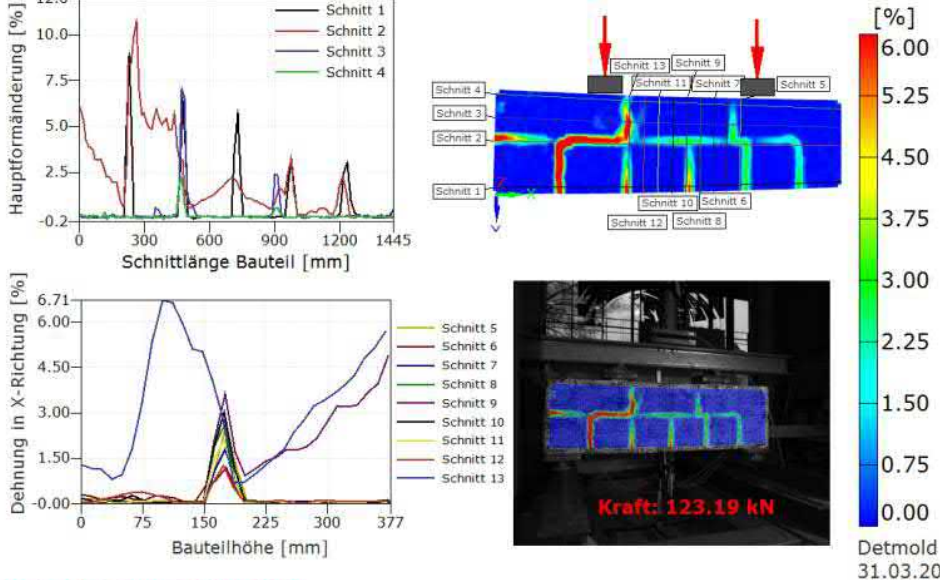

Hochschule Ostwestfalen-Lipp

University of Applied Sciences

80m www.gom.com

\section{KS-17 F}

5nits 134
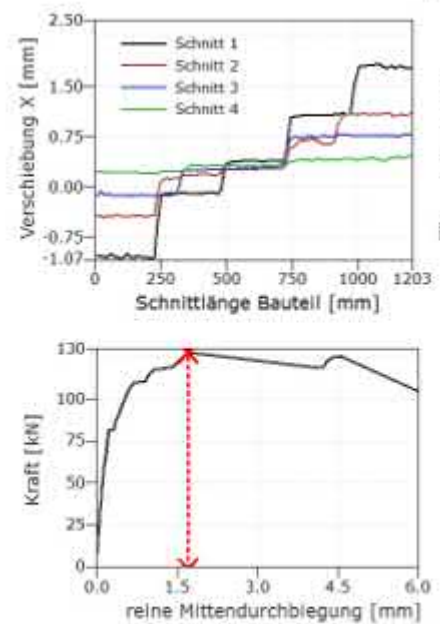

Hochschule Ostwestfalen-Lippe University of Applied Sciences
KS-17 F Verschiebung $X$

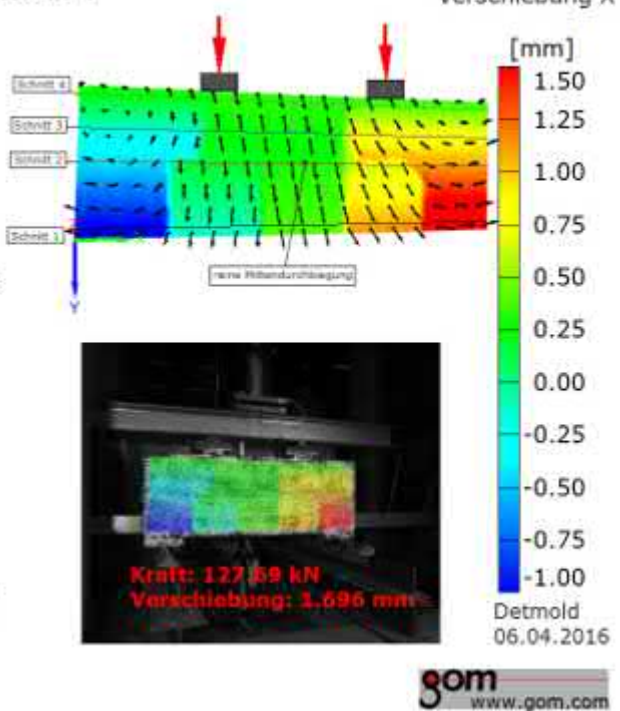




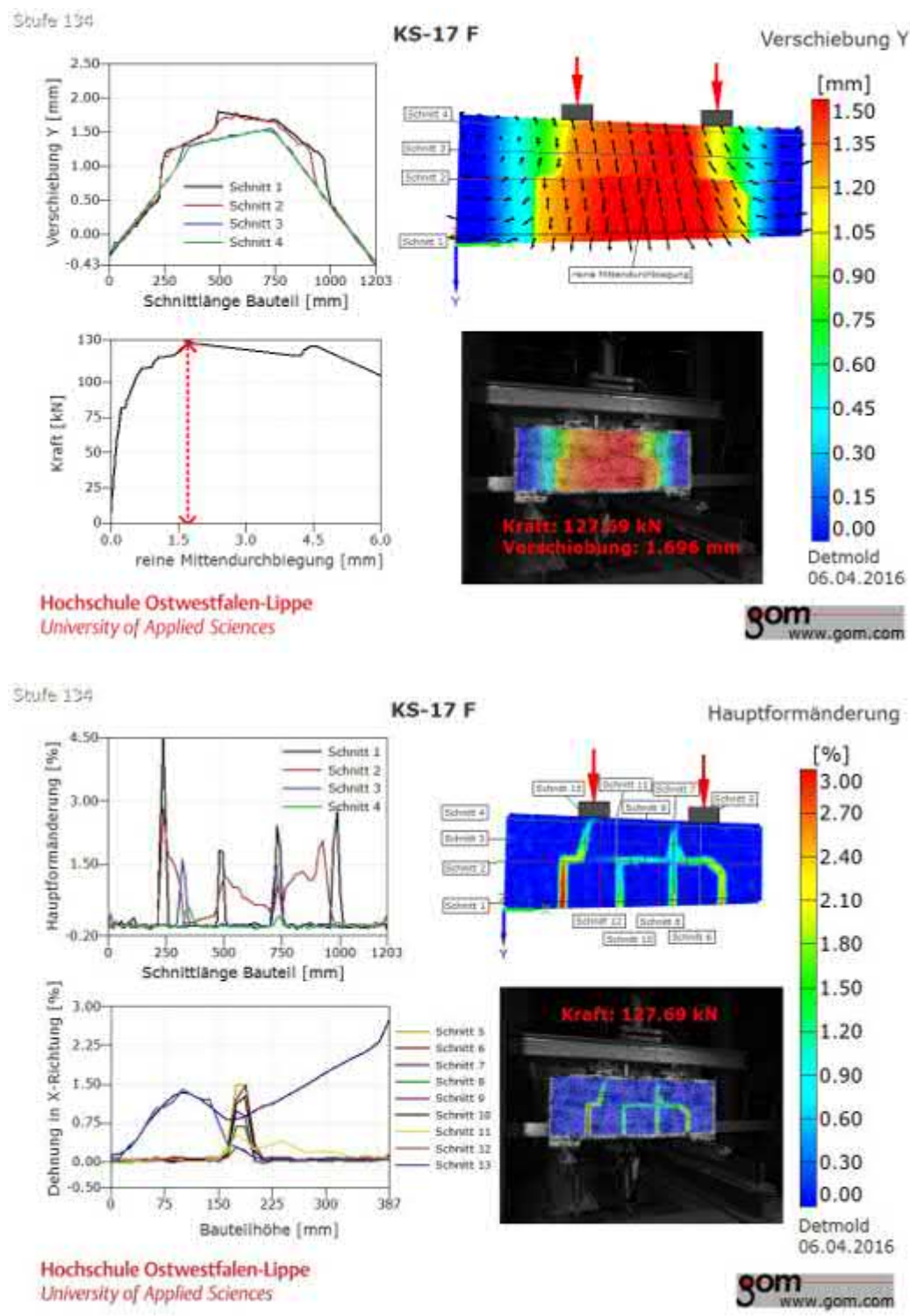

\section{KS-18 F.1}

Strate 122
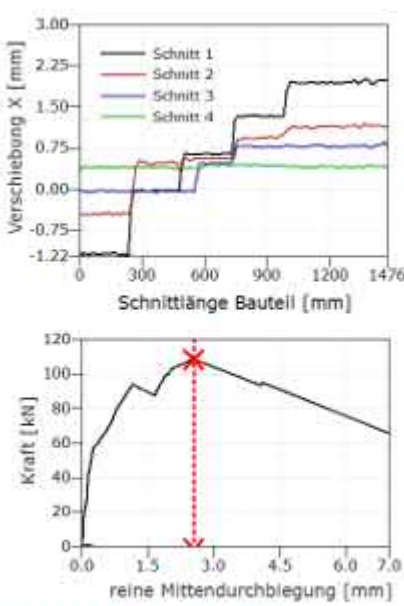

Hochschule Ostwestfalen-Lippe University of Applied Sciences
KS-18 F.1 Verschiebung $X$
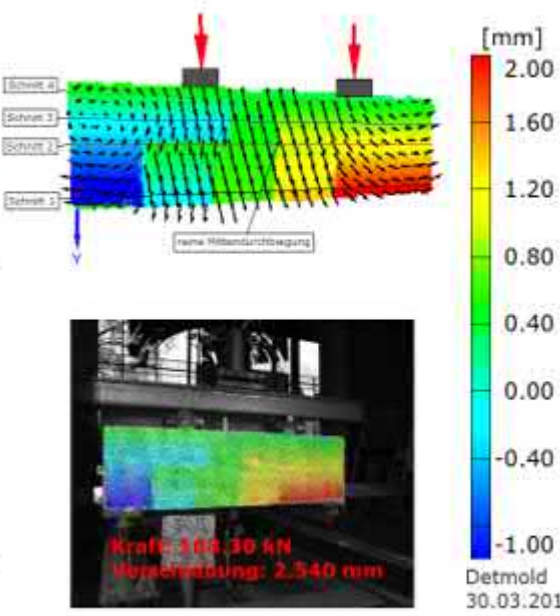

Detmold

gom 


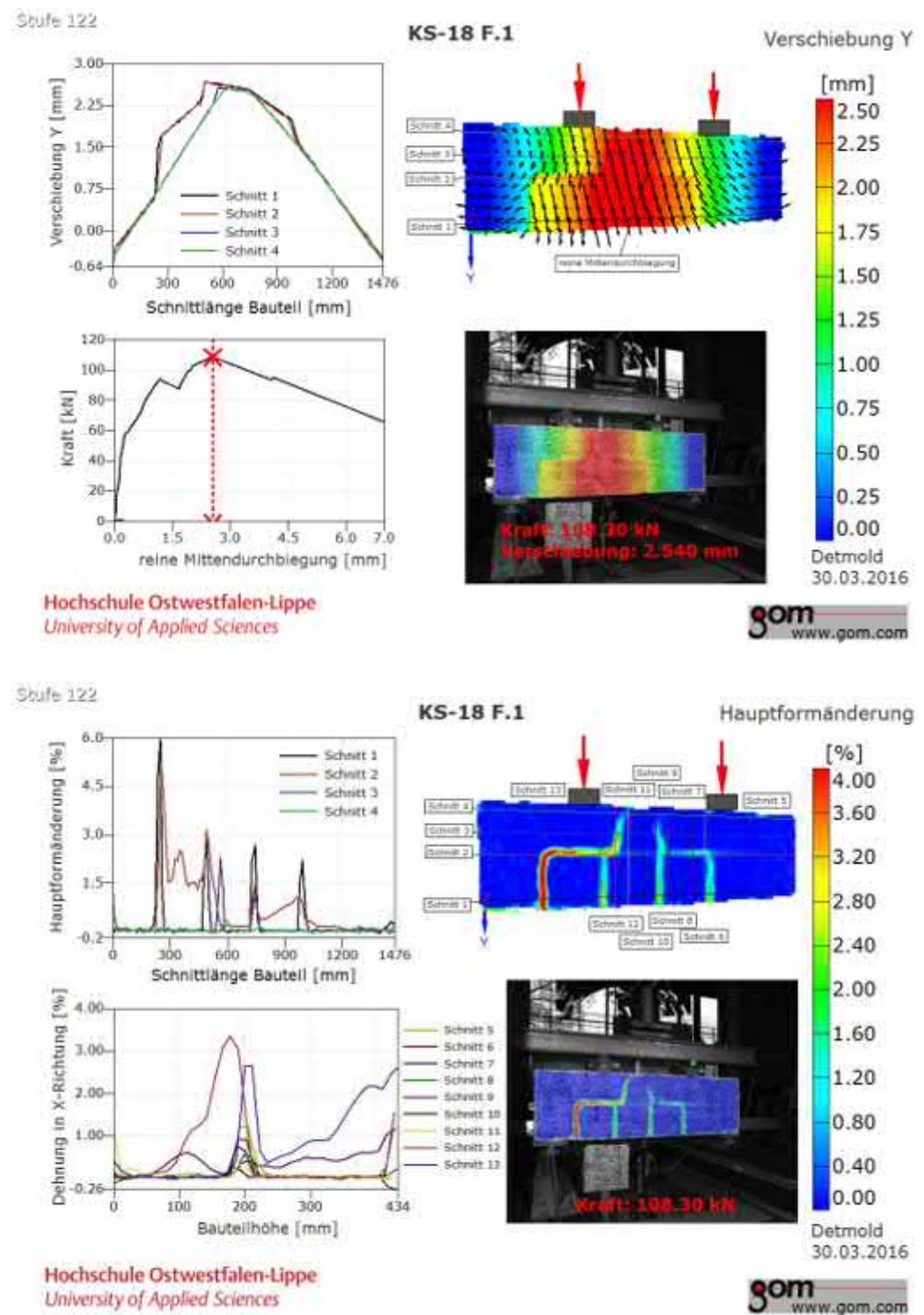

Bild A 4.16 Auswertung der Horizontal- und Vertikalverschiebung sowie der Hauptformänderung der bewehrten scheitrechten Mauerwerkbalken mit Aufbeton - KS-08.1 bis KS-11 sowie KS-16 F.1 bis KS-18 F.1 
A 4.5 Scheitrechte Mauerwerkbalken unter Vorspannung - IIbIII

A 4.5.1 Systemskizzen

KS-12
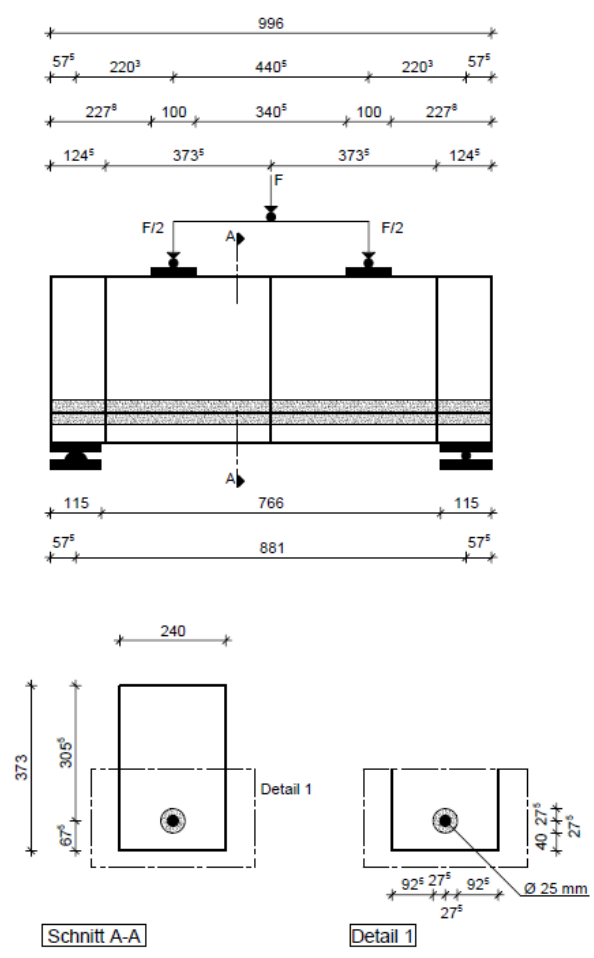

KS-13.1
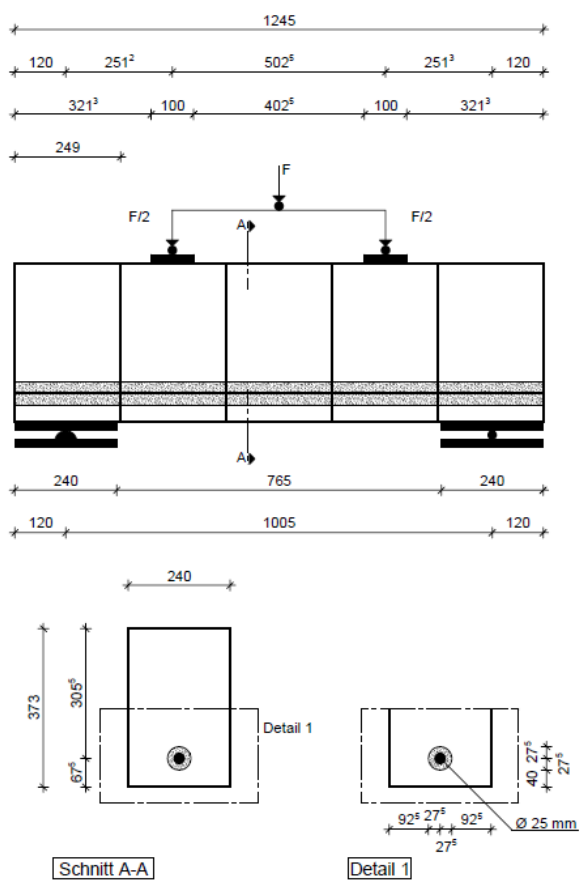
KS-13.2

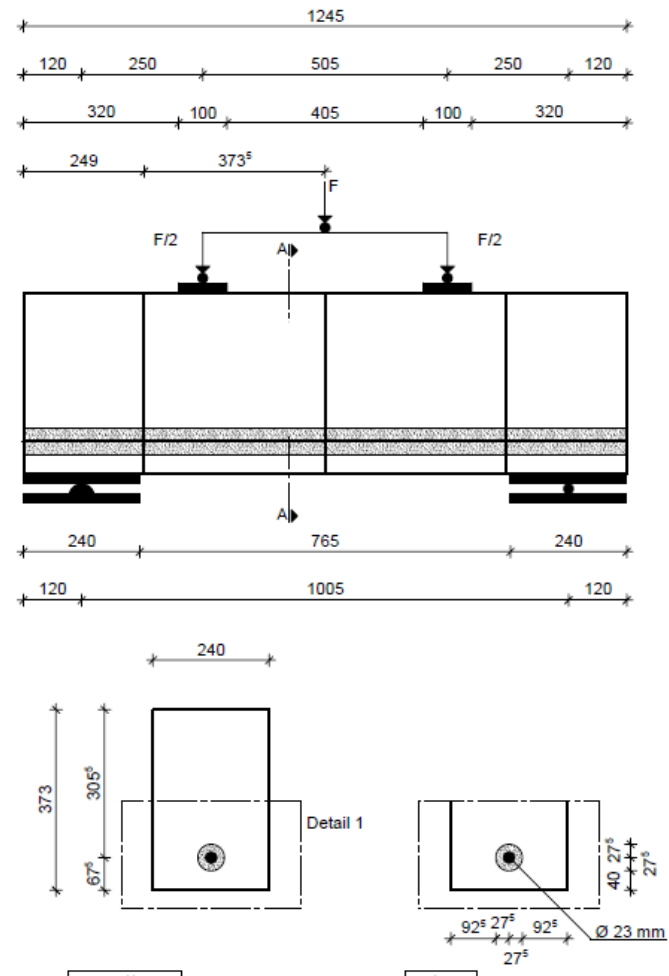

Schnitt A-A Detail 1

KS-14

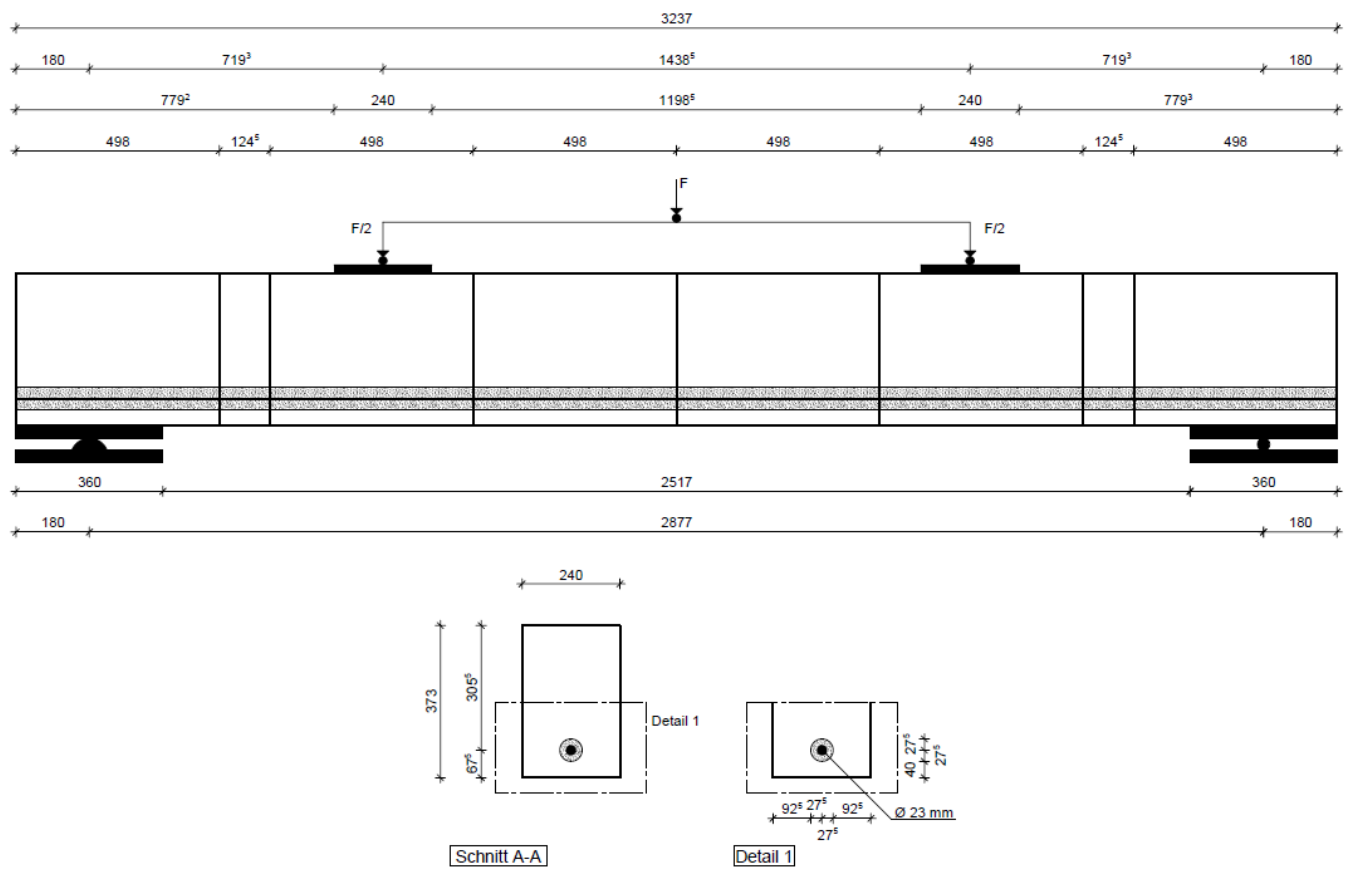


KS-15
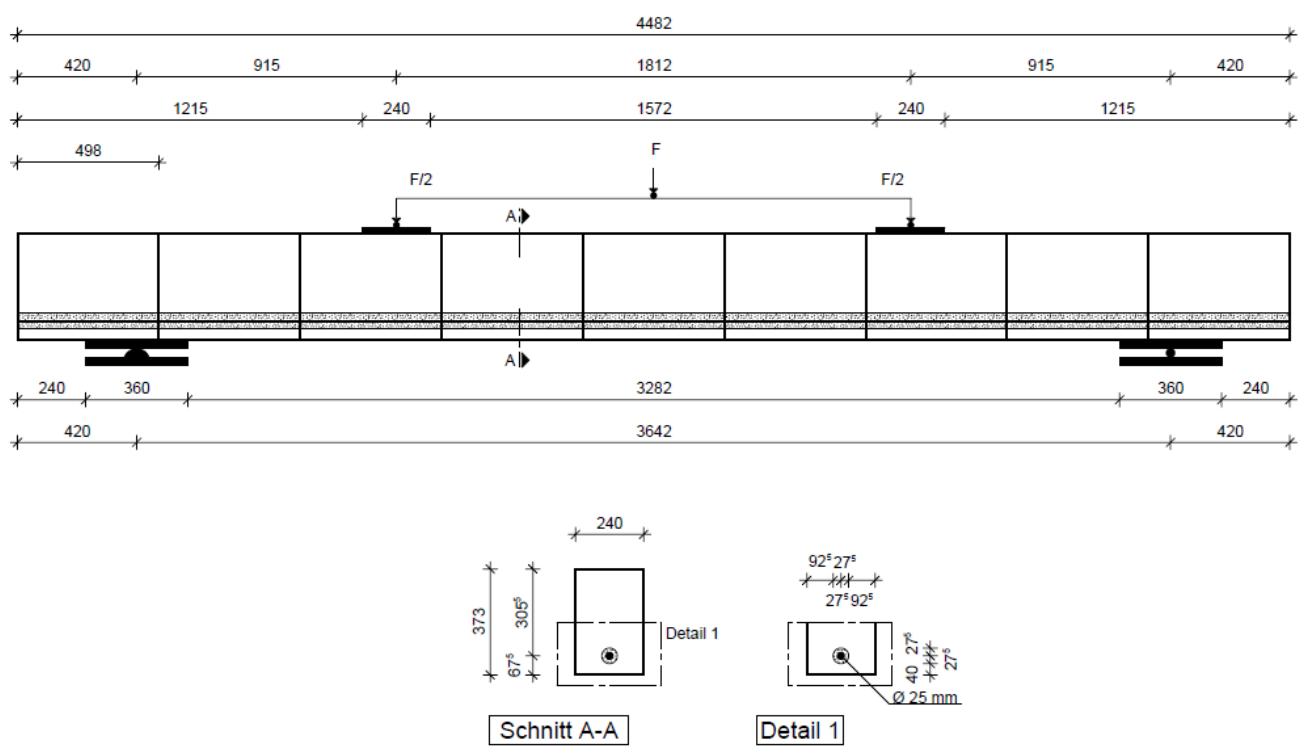

Bild A 4.17 Systemskizzen der vorgespannten scheitrechten Kalksandstein-Mauerwerkbalken - KS-12 bis KS-15 


\section{A 4.5.2 Messstellenpläne}

KS-12

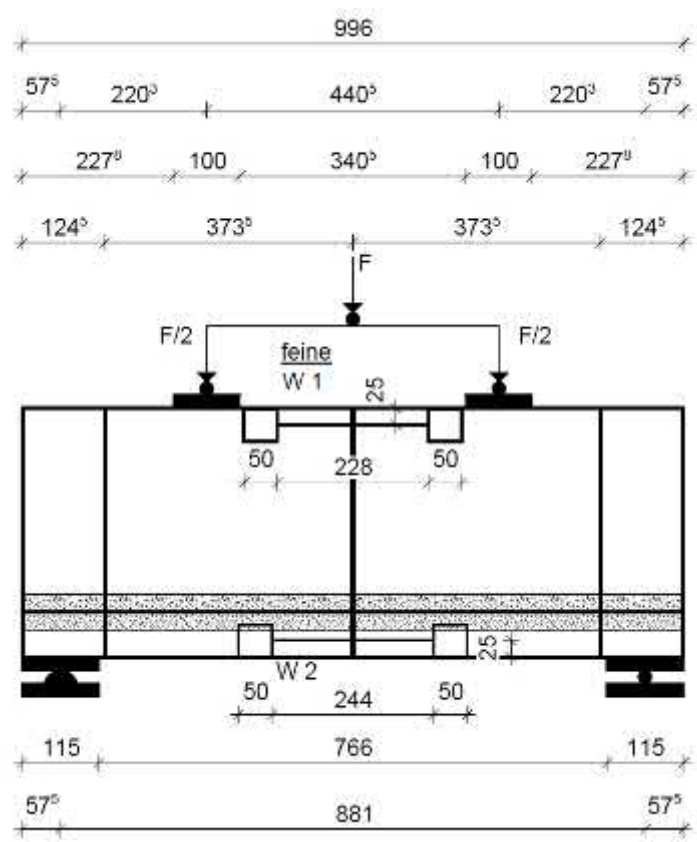

KS-13.1

1245
$+120+251^{2}+502^{5}$
$+321^{3}, 100 \times 251^{3} \times 120$

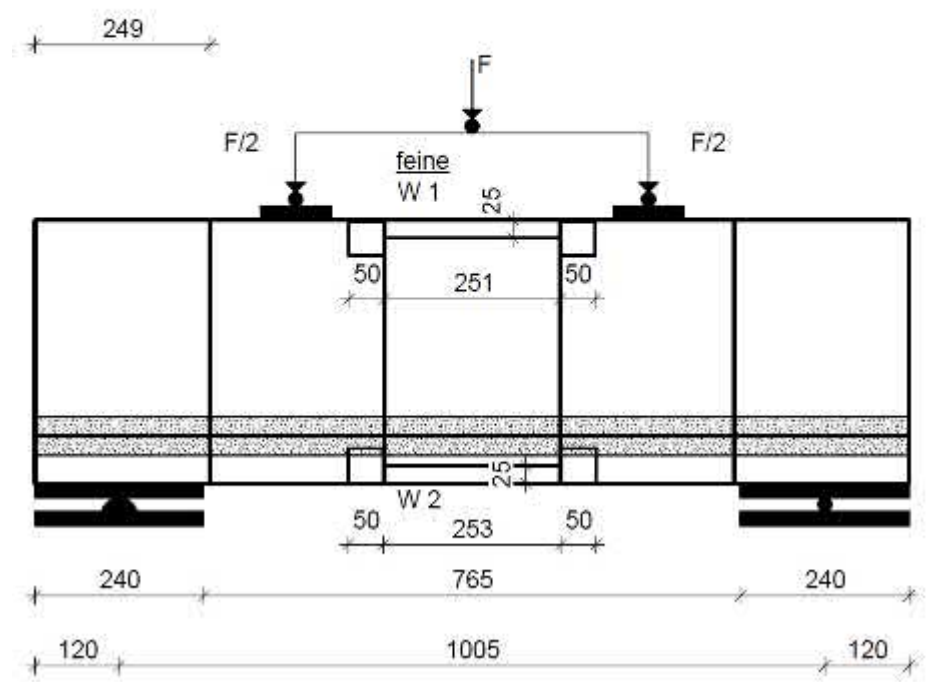


KS-13.2

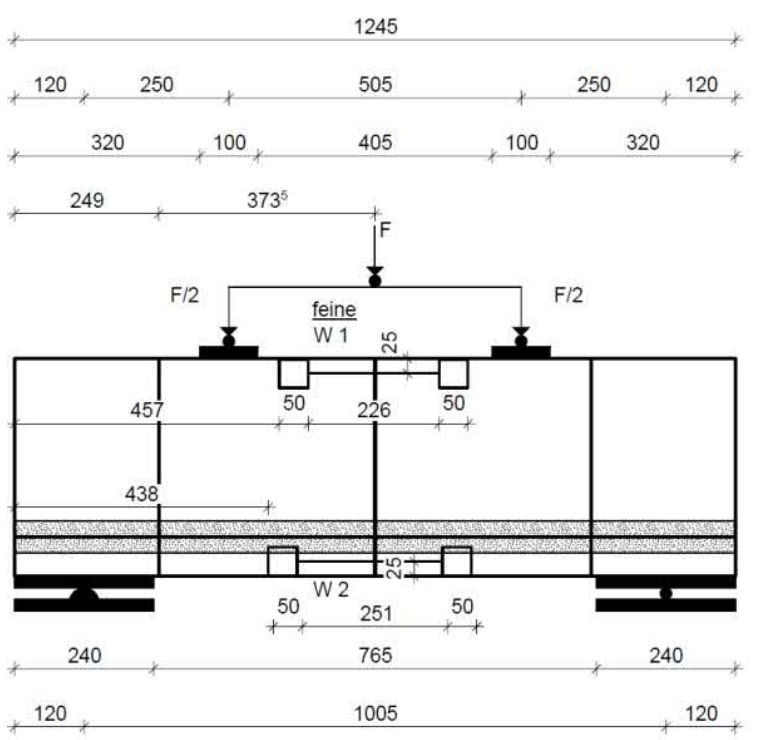

KS-14
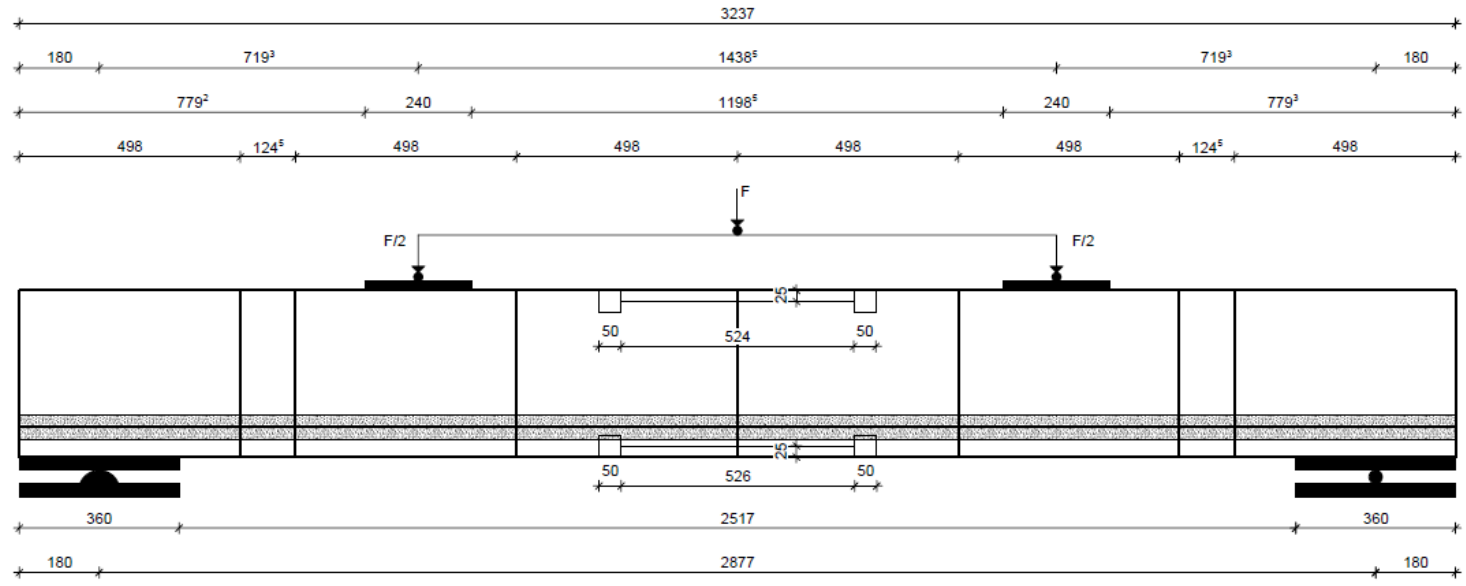

KS-15
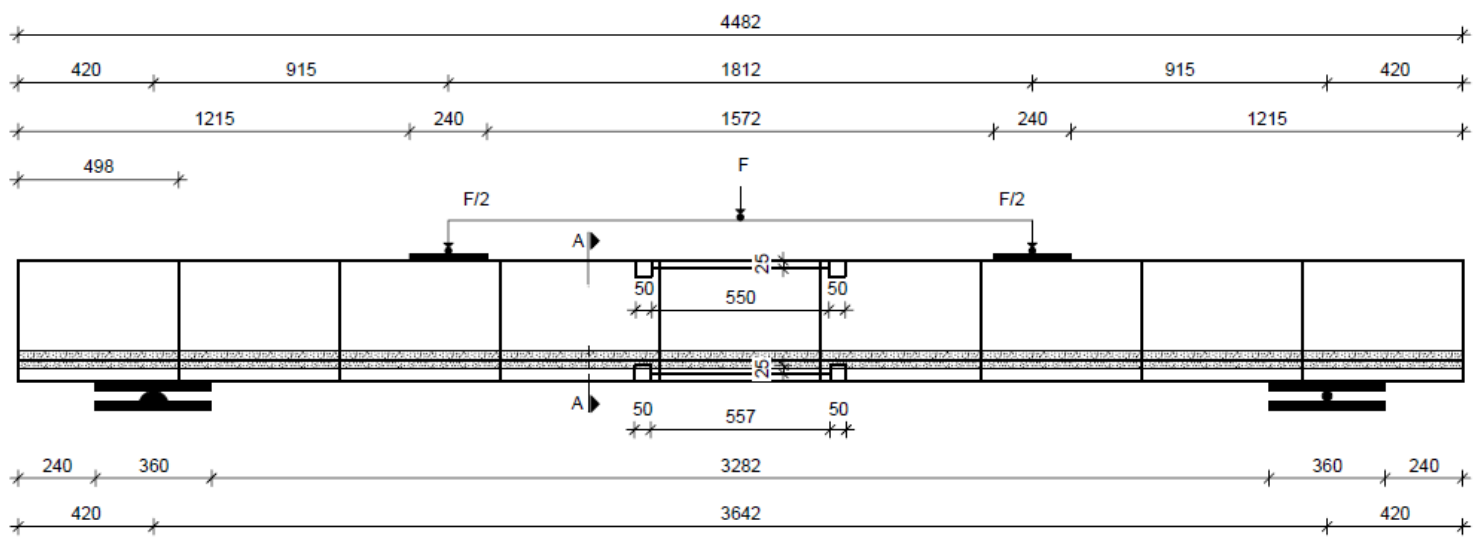

Bild A 4.18 Messstellenpläne der vorgespannten scheitrechten Kalksandstein-Mauerwerkbalken - KS12 bis KS-15 
A 4.5.3 Rissbilder

KS-12

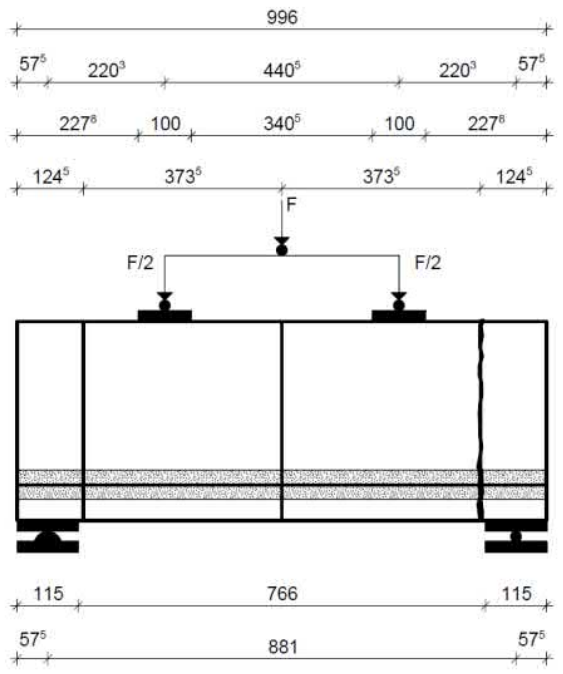

KS-13.1

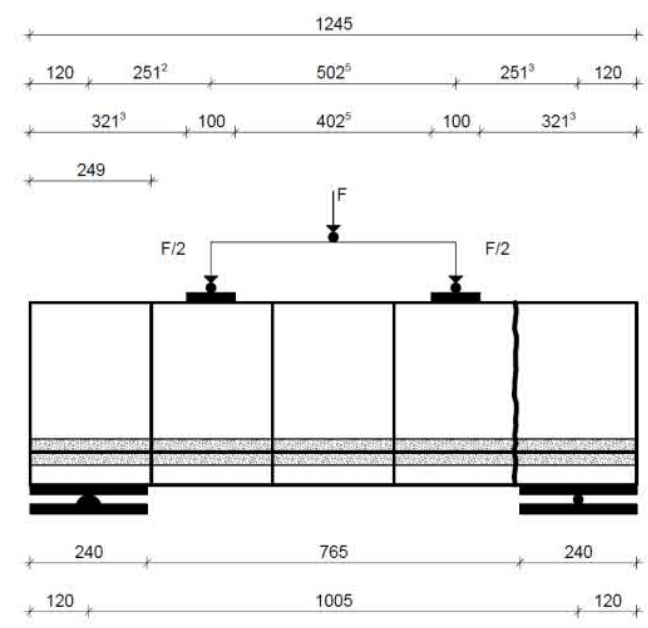

KS-13.2

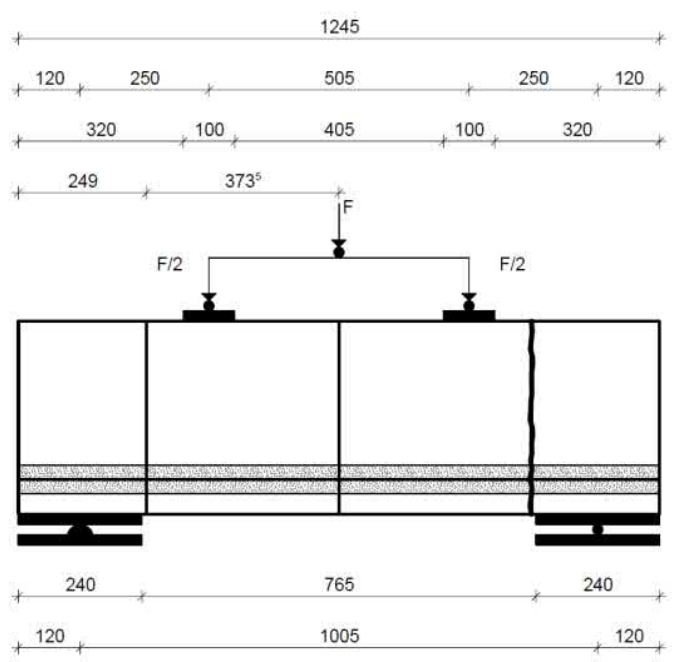


KS-14

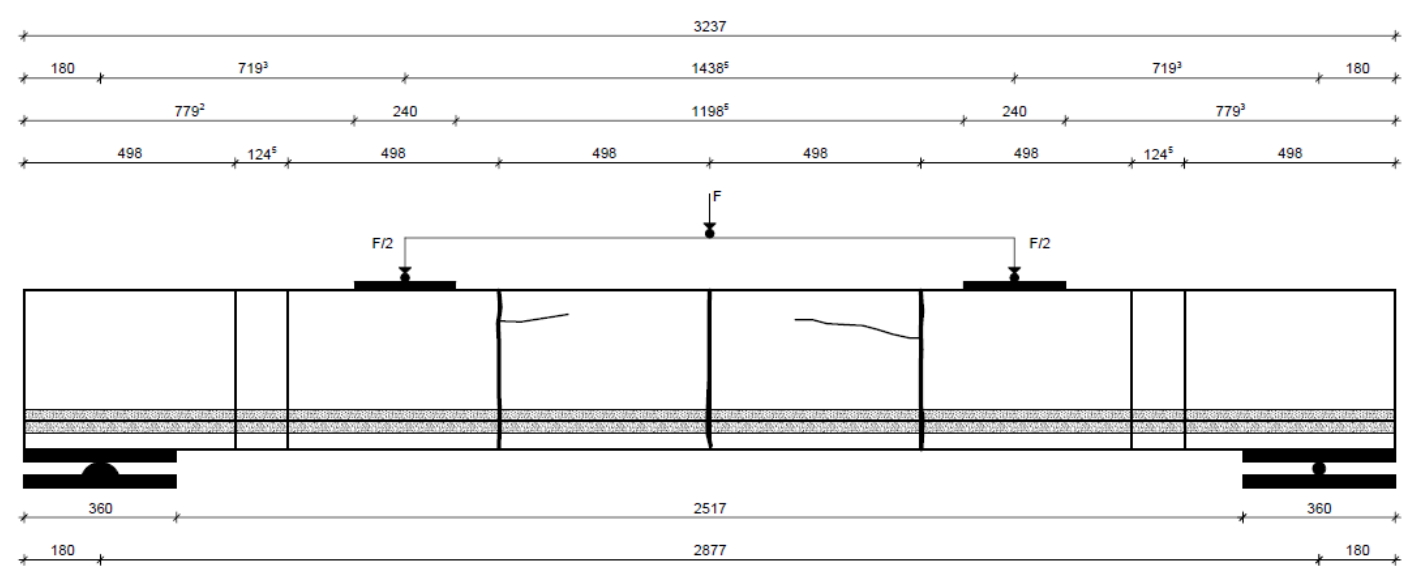

KS-15

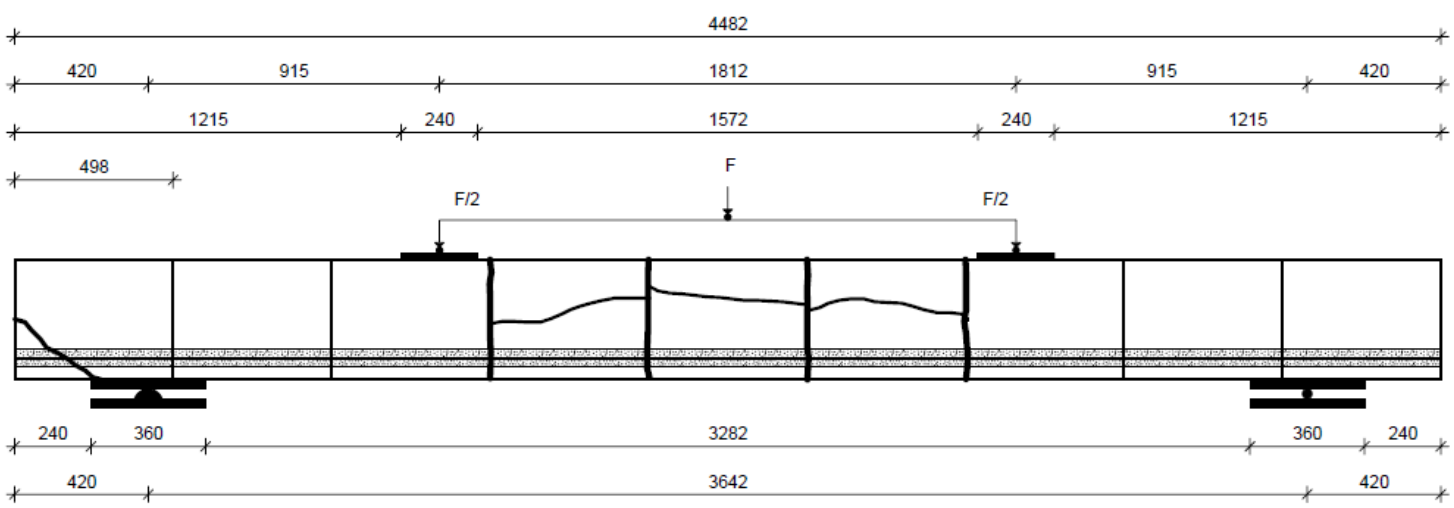

Bild A 4.19 Rissbilder der vorgespannten scheitrechten Kalksandstein-Mauerwerkbalken - KS-12 bis KS-15 
A 4.5.4 Lastdurchbiegungslinien und flächenhafte Darstellung der Verschiebung in horizontaler und vertikaler Richtung

KS-12

Stufe 48
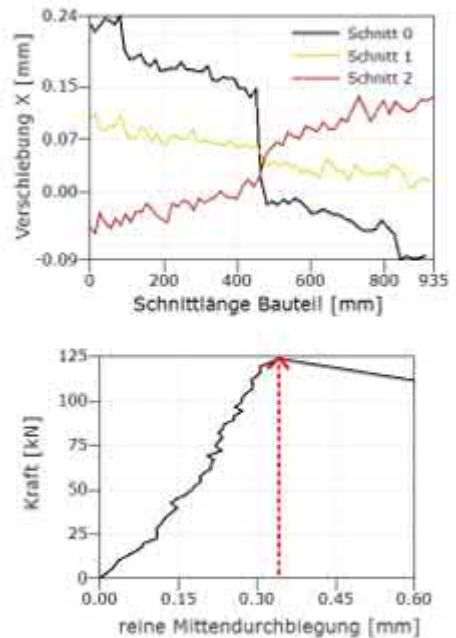

Hochschule Ostwestfalen-Lippe

University of Applied Sciences
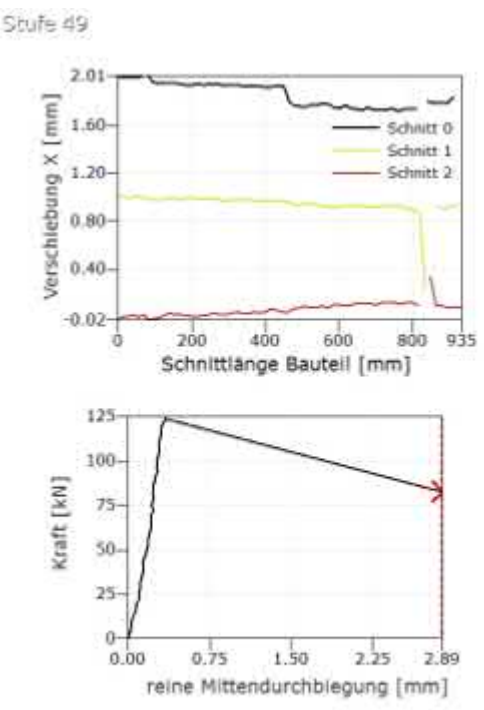

Hochschule Ostwestfalen-Lippe University of Applied Sciences
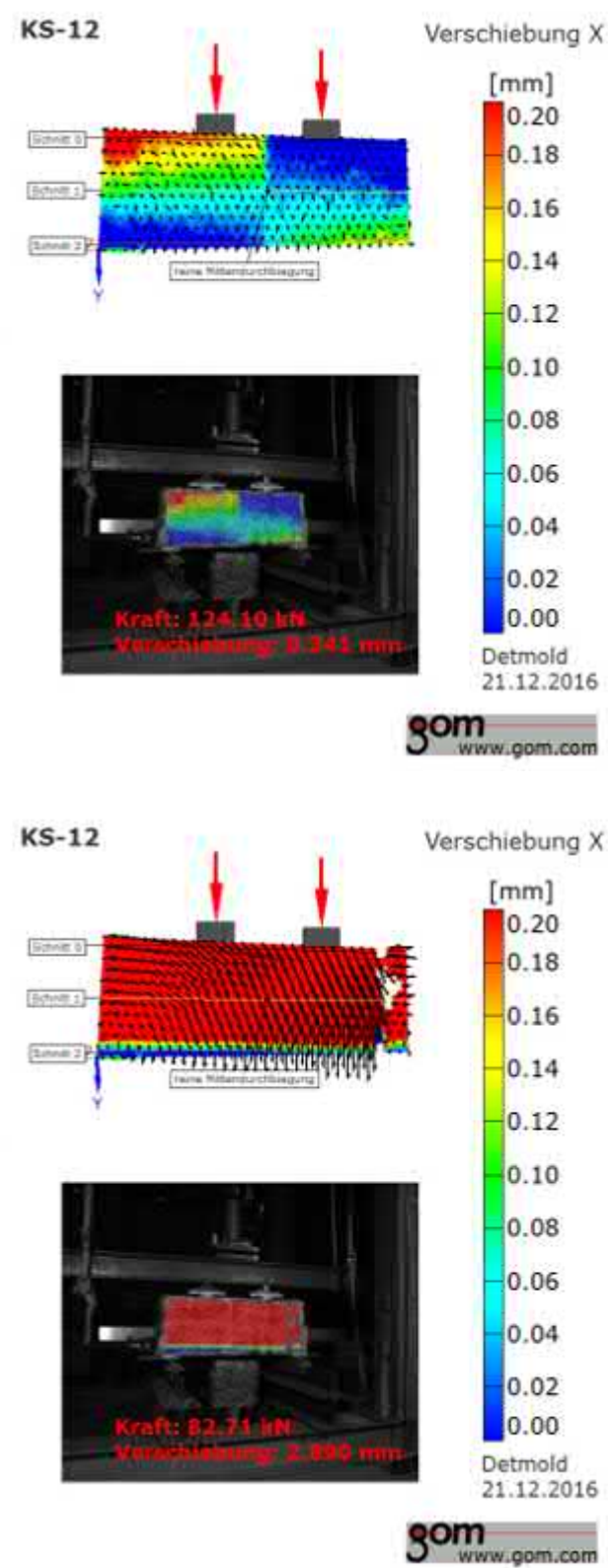
S.uit 43
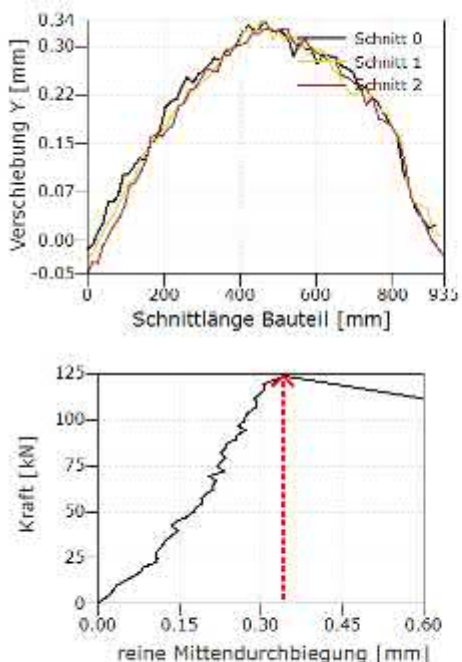

Hochschule Ostwestfalen-Lippe University of Applied Sciences

Stufe 49
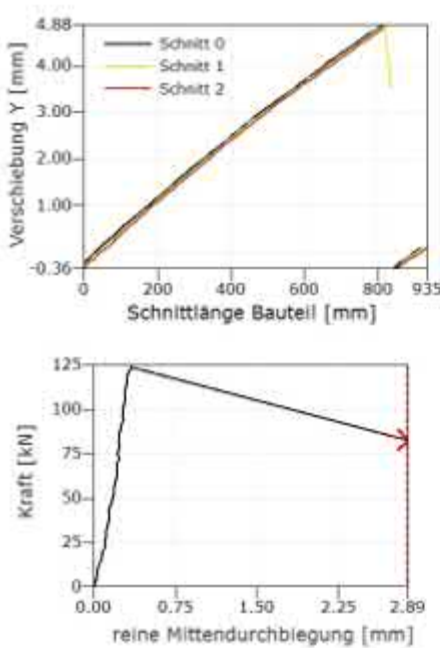

Hochschule Ostwestfalen-Lippe University of Applied Sciences
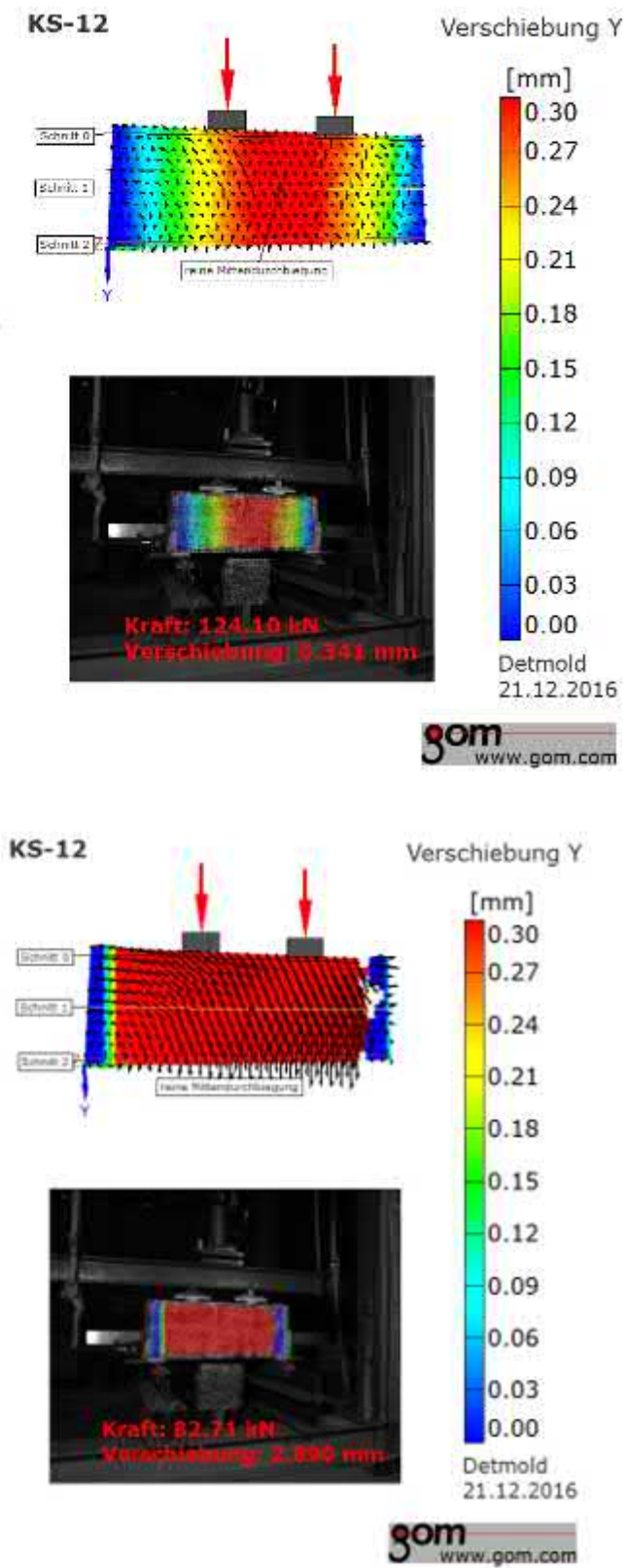
KS-13.1
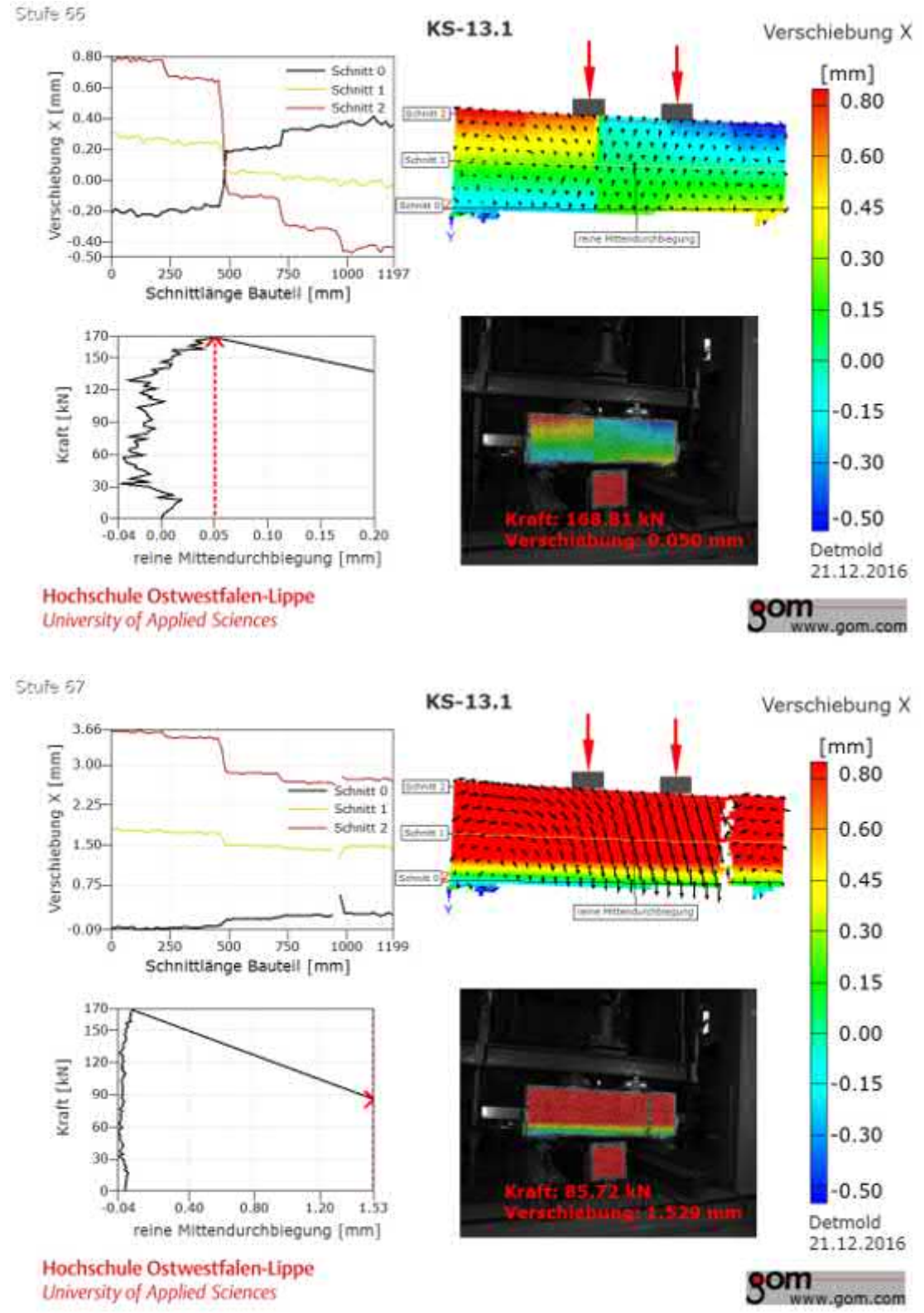

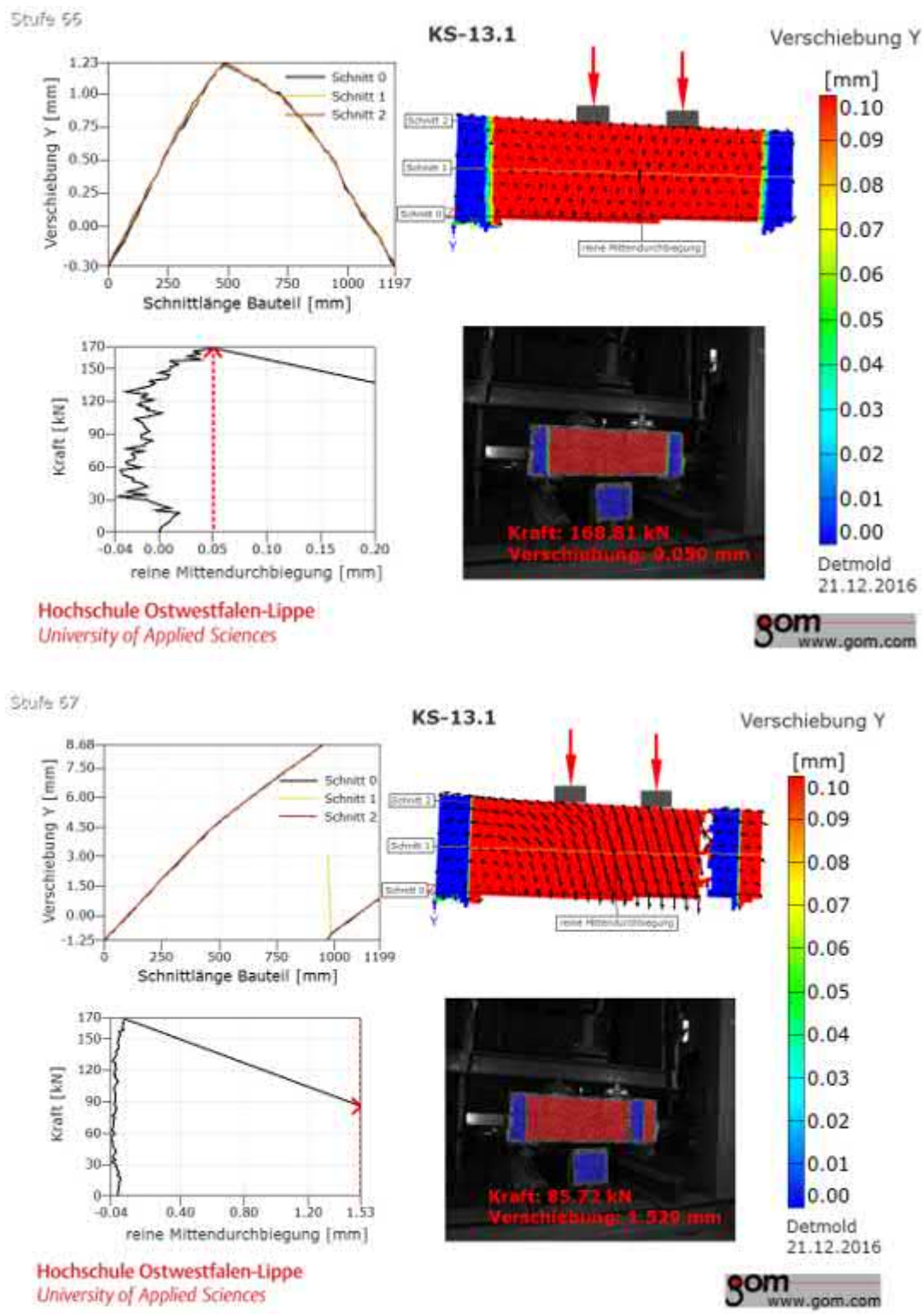

KS-13.2

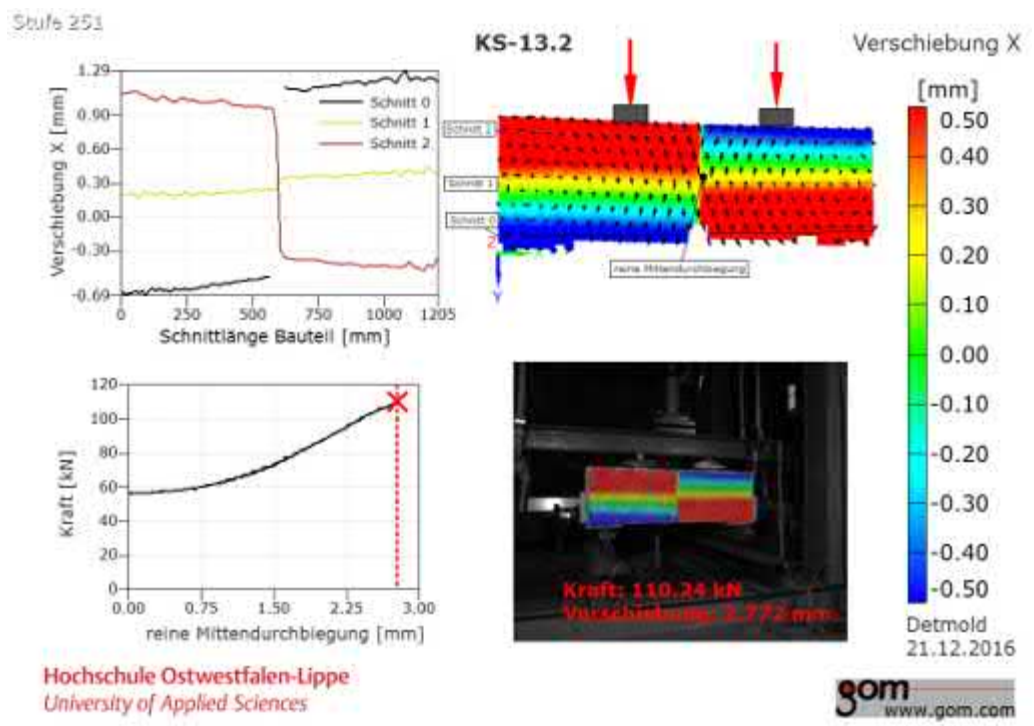




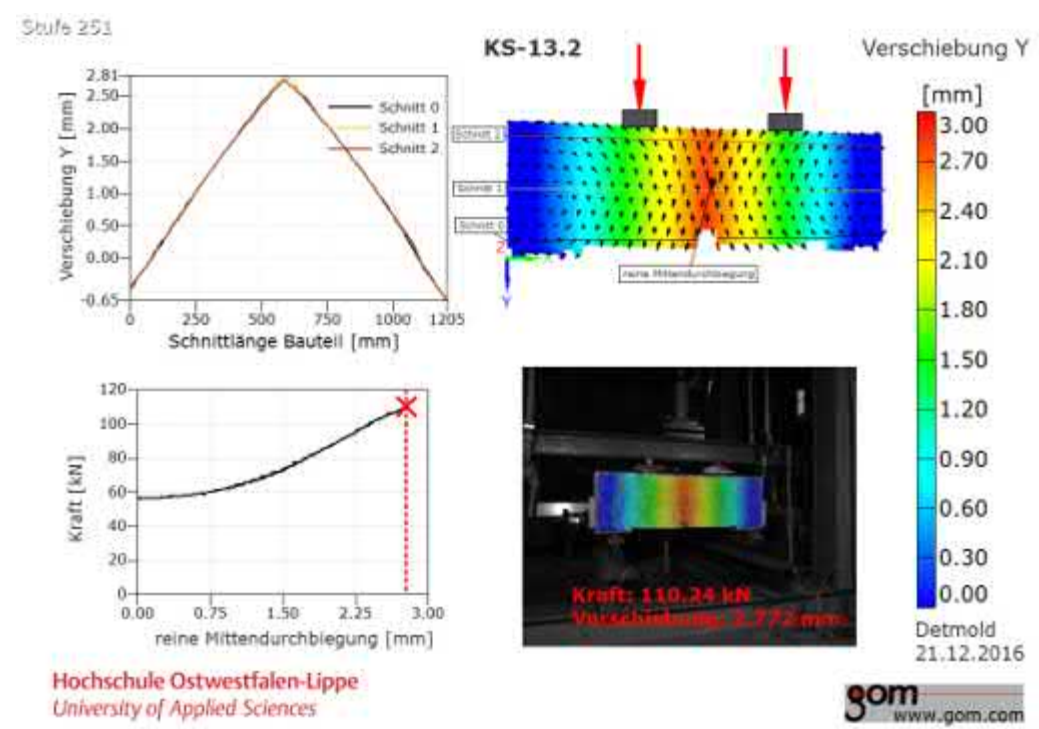

KS-14
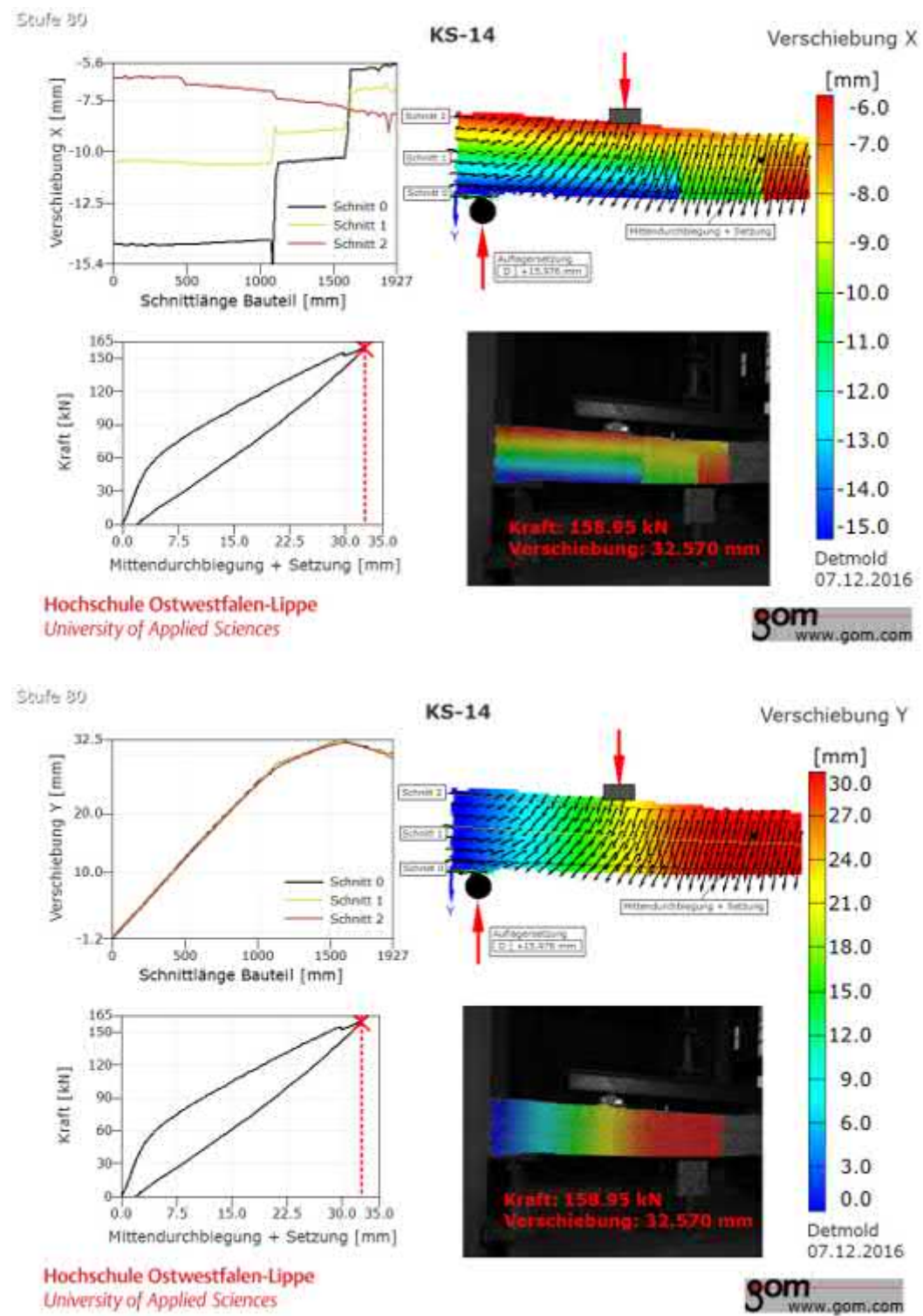
KS-15

Stuits 59
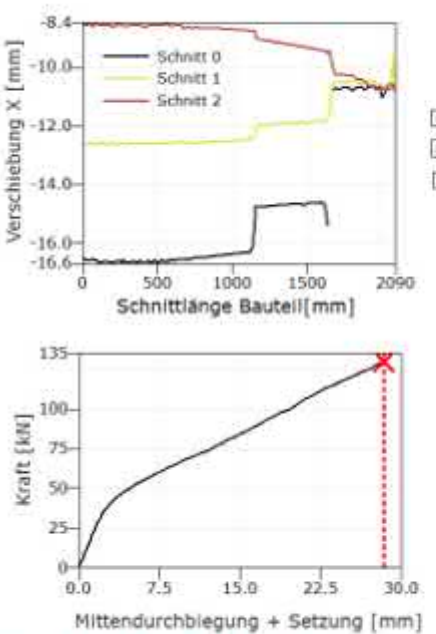

Hochschule Ostwestfalen-Lippe

University of Applied Sciences

Shifts 59
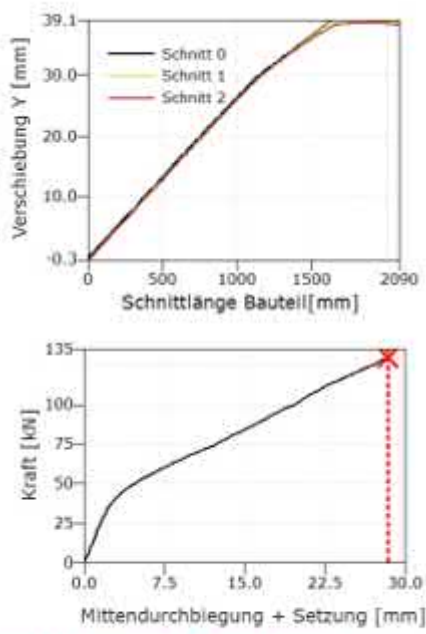

Hochschule Ostwestfalen-Lippe University of Applied Sciences
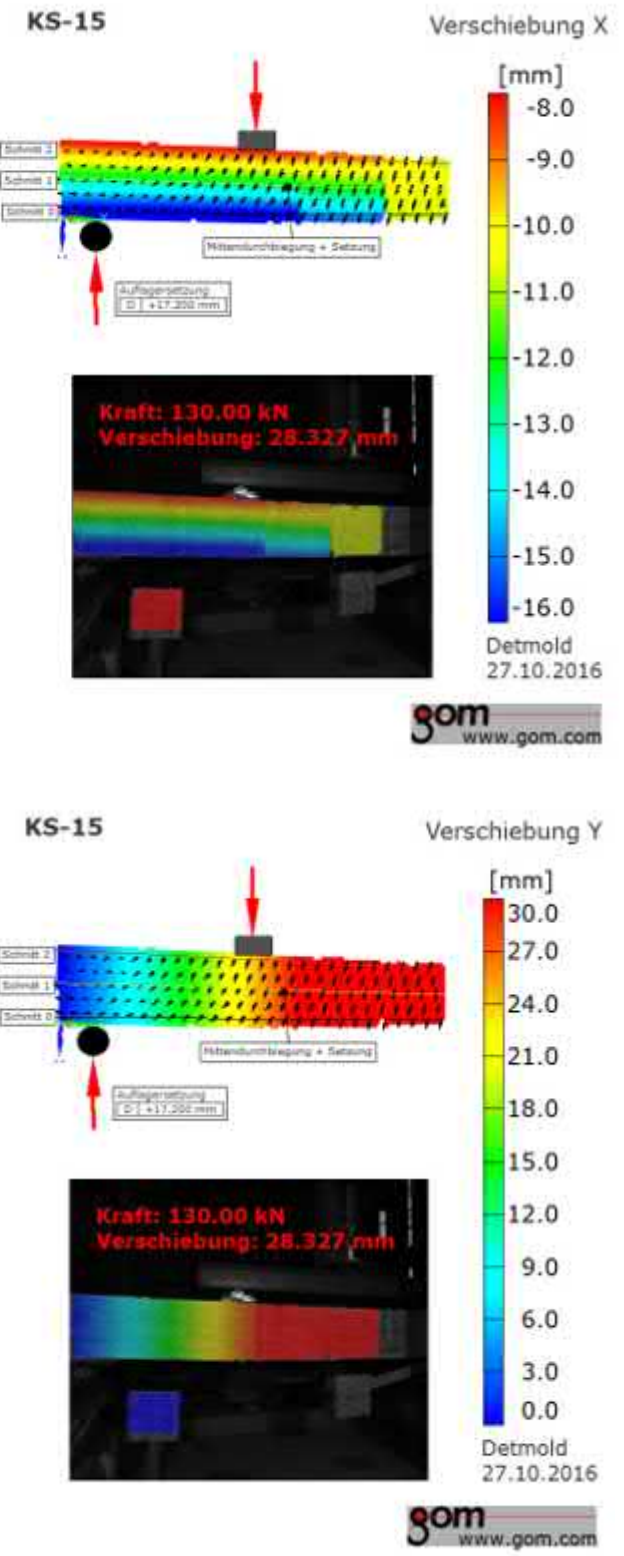

Bild A 4.20

Auswertung der Horizontal- und Vertikalverschiebung der vorgespannten scheitrechten Mauerwerkbalken - KS-12 bis KS-15 
A $5 \quad$ Vergleichsrechnung in Bezug auf den Berechnungsvorschlag

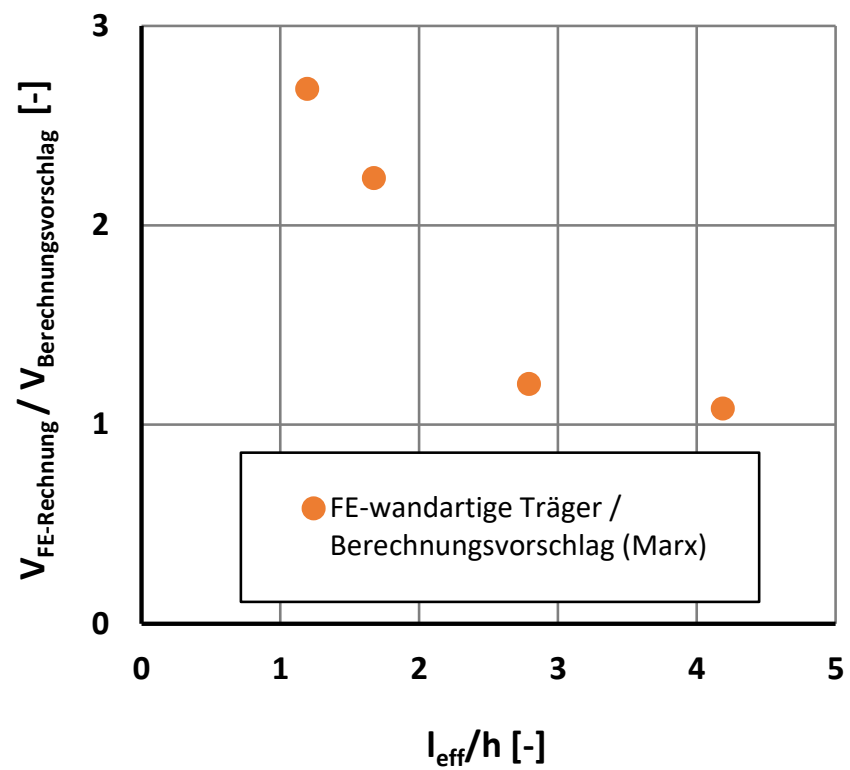

Bild A 5.1 Wandartige Träger bzw. Balken: Vergleich zwischen den Ergebnissen der FEBerechnungen mit den Ergebnissen des Berechnungsvorschlages (Marx) in Abhängigkeit zu $l_{\text {eff }} / \mathbf{h}$

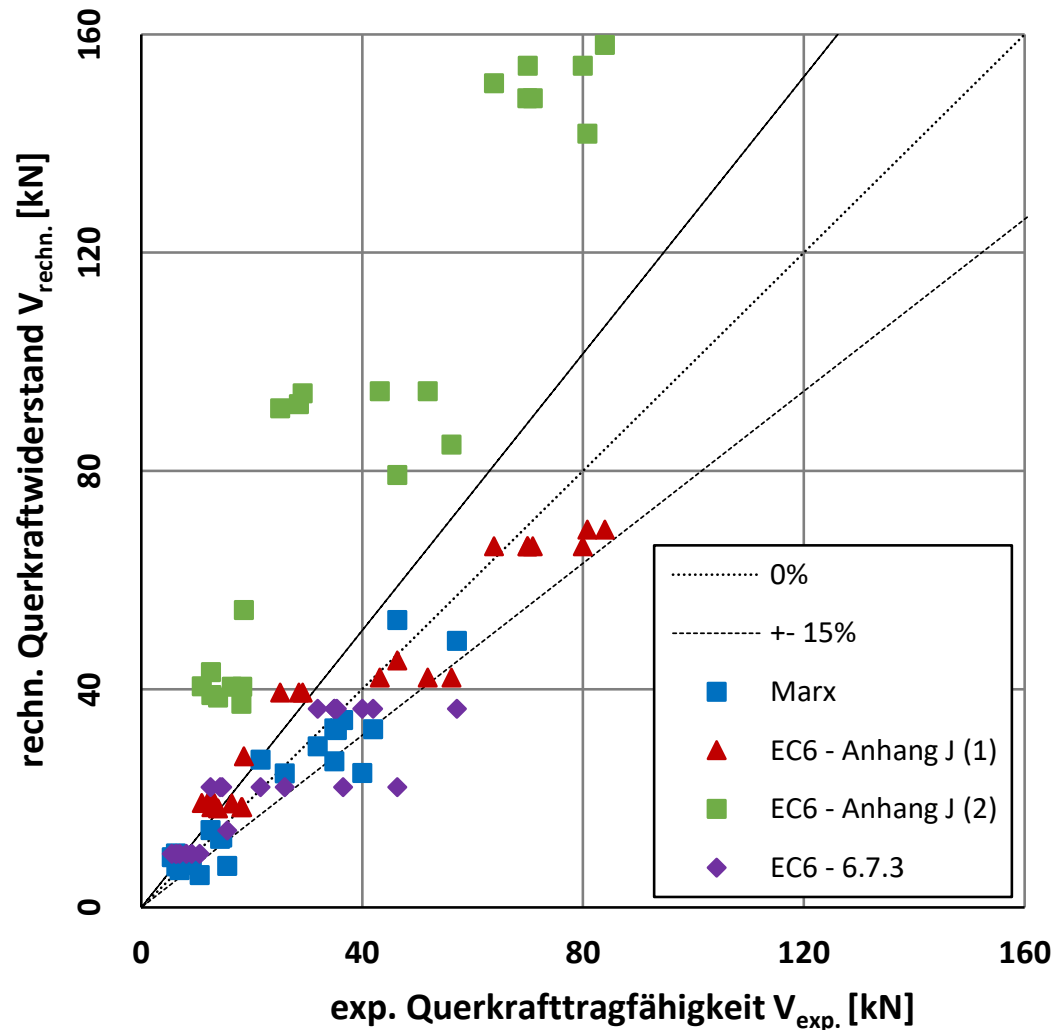

Bild A 5.2 Fertigteilsturz: $\quad$ Vergleich zwischen dem in Abschnitt 7.2 entwickelten Berechnungsvorschlag (Marx) und den Berechnungsergebnissen nach DIN EN 1996-1-1 (EC6) 


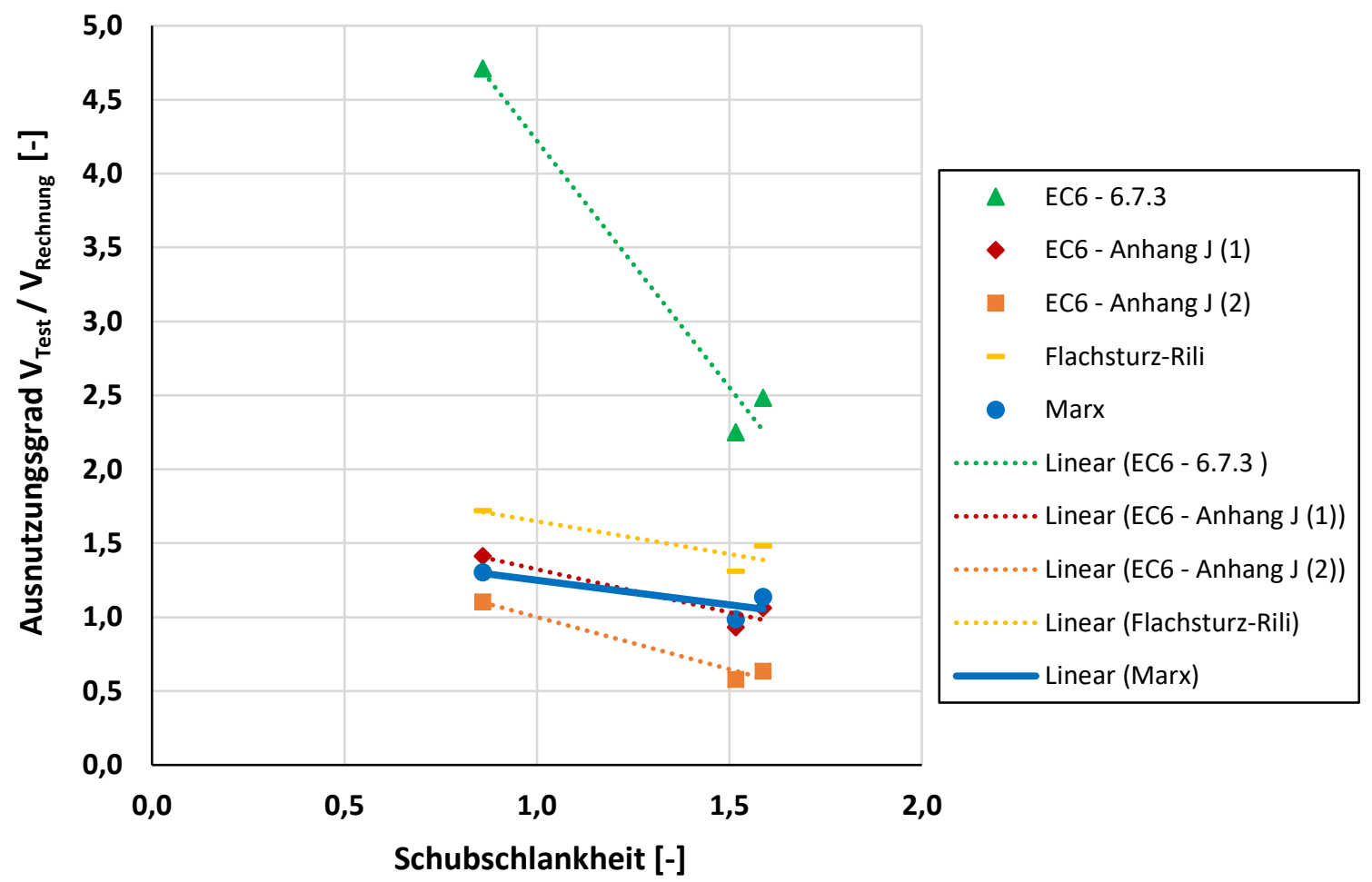

Bild A 5.3 Flachsturz: Vergleich zwischen dem in Abschnitt 7.2 entwickelten Berechnungsvorschlag (Marx) und den Berechnungsergebnissen nach DIN EN 1996-1-1 (EC6) in Abhängigkeit der Schubschlankheit 
Tabelle A 5.1 Zusammenfassung des Berechnungsvorschlages

\begin{tabular}{|c|c|c|c|c|}
\hline \multicolumn{2}{|c|}{ Mauerwerkbalken } & \multicolumn{2}{|c|}{$V_{\mathrm{R}}=\boldsymbol{f}_{\alpha} \cdot \boldsymbol{k}_{\mathrm{v}} \cdot \boldsymbol{z} \cdot \boldsymbol{b}_{\mathrm{w}}$} & s. $(7.33)$ \\
\hline \multicolumn{2}{|c|}{ Mauerwerkbalken mit Ergänzungsschicht aus Beton } & \multicolumn{2}{|c|}{$V_{\mathrm{R}}=k_{\mathrm{v}} \cdot\left(f_{\alpha} \cdot \frac{d-h_{\mathrm{c}}}{d}+\sqrt[3]{f_{\mathrm{cm}}} \cdot \frac{h_{\mathrm{c}}}{d}\right) \cdot z \cdot b_{\mathrm{w}}$} & s. (7.37) \\
\hline$k_{\mathrm{v}}$ & \multicolumn{3}{|l|}{$k_{\mathrm{v}}=\frac{0,4}{1+1500 \cdot \varepsilon_{\mathrm{x}}} \cdot \frac{1300}{1000+k_{\mathrm{dg}} \cdot z}$} & s. $(7.28)$ \\
\hline \multirow{2}{*}{$Z$} & Mauerwerk & \multicolumn{2}{|c|}{$z_{\mathrm{MW}}=0,85 \cdot d$} & s. (7.35) \\
\hline & Mauerwerk mit Ergänzungsschicht & \multicolumn{2}{|c|}{$z_{\mathrm{MW}+\mathrm{C}}=0,9 \cdot d$} & s. $(7.36)$ \\
\hline \multirow[b]{2}{*}{$k_{\mathrm{dg}}$} & $D_{\max } \leq 16 \mathrm{~mm}$ & \multicolumn{2}{|l|}{$k_{\mathrm{dg}}=2$} & \\
\hline & $D_{\max }>16 m m\left(d_{g} \hat{=} D_{\max }\right)$ & \multicolumn{2}{|c|}{$k_{\mathrm{dg}}=\frac{32}{16+d_{\mathrm{g}}} \geq 0,75$} & s. (7.32) \\
\hline \multirow[b]{2}{*}{$\varepsilon_{\mathrm{X}}$} & ohne Vorspannung & \multicolumn{2}{|c|}{$\varepsilon_{\mathrm{X}}=\frac{1}{2 \cdot E_{\mathrm{S}} \cdot A_{\mathrm{s}}} \cdot\left(\frac{M_{\mathrm{Ed}}}{z}+V_{\mathrm{Ed}}+N_{\mathrm{Ed}} \cdot\left(\frac{1}{2} \pm \frac{\Delta e}{z}\right)\right)}$, & s. (7.29) \\
\hline & mit Vorspannung & \multicolumn{2}{|c|}{$\varepsilon_{x}=\frac{\left(\frac{M_{\mathrm{Ed}}}{z}\right)+V_{\mathrm{Ed}}+N_{\mathrm{Ed}} \cdot\left(\frac{z_{\mathrm{p}}-e_{\mathrm{p}}}{z}\right)}{\left(\frac{z_{\mathrm{S}}}{z} \cdot E_{\mathrm{s}} \cdot A_{\mathrm{s}}+\frac{z_{\mathrm{p}}}{z} \cdot E_{\mathrm{p}} \cdot A_{\mathrm{p}}\right)}}$, & s. $(7.30)$ \\
\hline \multirow{5}{*}{$f_{\alpha}$} & \multicolumn{3}{|c|}{$\begin{array}{l}\text { Mauerwerkspezifisch zu ermitteln; siehe Bild 7.14: } \\
\text { Die richtungs- und vom Belastungswinkel }(\alpha) \text { abhängige Mauerwerkdruckfestigkeit. }\end{array}$} & $\begin{array}{l}\text { s. Abschn. } \\
7.3\end{array}$ \\
\hline & \multirow{4}{*}{$\begin{array}{l}\text { Näherung: } \\
\begin{aligned}- & f_{\mathrm{mx}} \\
- & f_{\mathrm{my}}=0,6 \cdot f_{\mathrm{mx}} \\
- & c=0,04 \cdot f_{\mathrm{my}} \\
- & c_{\mathrm{b}}=0,25 \cdot f_{\mathrm{my}} \\
- & \varphi_{\mathrm{b}}\left(\varphi=\varphi_{\mathrm{b}}=\tan ^{-1}(0,75)\right)\end{aligned}\end{array}$} & $A-B:$ & $f_{\alpha}=f_{\mathrm{my}}=\eta_{\mathrm{fmy}} \cdot f_{\mathrm{mx}}$ & s. $(7.40)$ \\
\hline & & $\mathrm{B}-\mathrm{C}$ : & $f_{\alpha}=\frac{c_{\mathrm{b}}}{2 \cdot \sin ^{2} \alpha \cdot\left(\tan \varphi_{\mathrm{b}}-\cot \alpha\right)}$ & s. $(7.41)$ \\
\hline & & $C-D$ & $f_{\alpha}=\frac{c}{\cos ^{2} \alpha \cdot(\tan \varphi-\tan \alpha)}$ & s. $(7.42)$ \\
\hline & & $\mathrm{D}-\mathrm{E}$ & $f_{\alpha}=\frac{2 \cdot c \cdot \cos \varphi}{1-\sin \varphi}$ & s. $(7.43)$ \\
\hline \multirow{2}{*}{$\alpha$} & Scheitrechter Balken & \multicolumn{2}{|c|}{$=\arctan \left(\frac{\max V_{\mathrm{Ed}} \cdot d}{\max M_{\mathrm{Ed}}}\right)=\arctan \left(\frac{d}{a}\right)$} & s. $(5.2)$ \\
\hline & Flachsturz & \multicolumn{2}{|c|}{$\alpha=\arctan \left(\frac{a}{d}\right)$} & s. (7.34) \\
\hline
\end{tabular}

